\title{
INFORMALIDAD URBANA EN EL PARTIDO DE LA PLATA
}

ANALISIS DEL PROCESO DE OCUPACION Y APROPIACION TERRITORIAL.
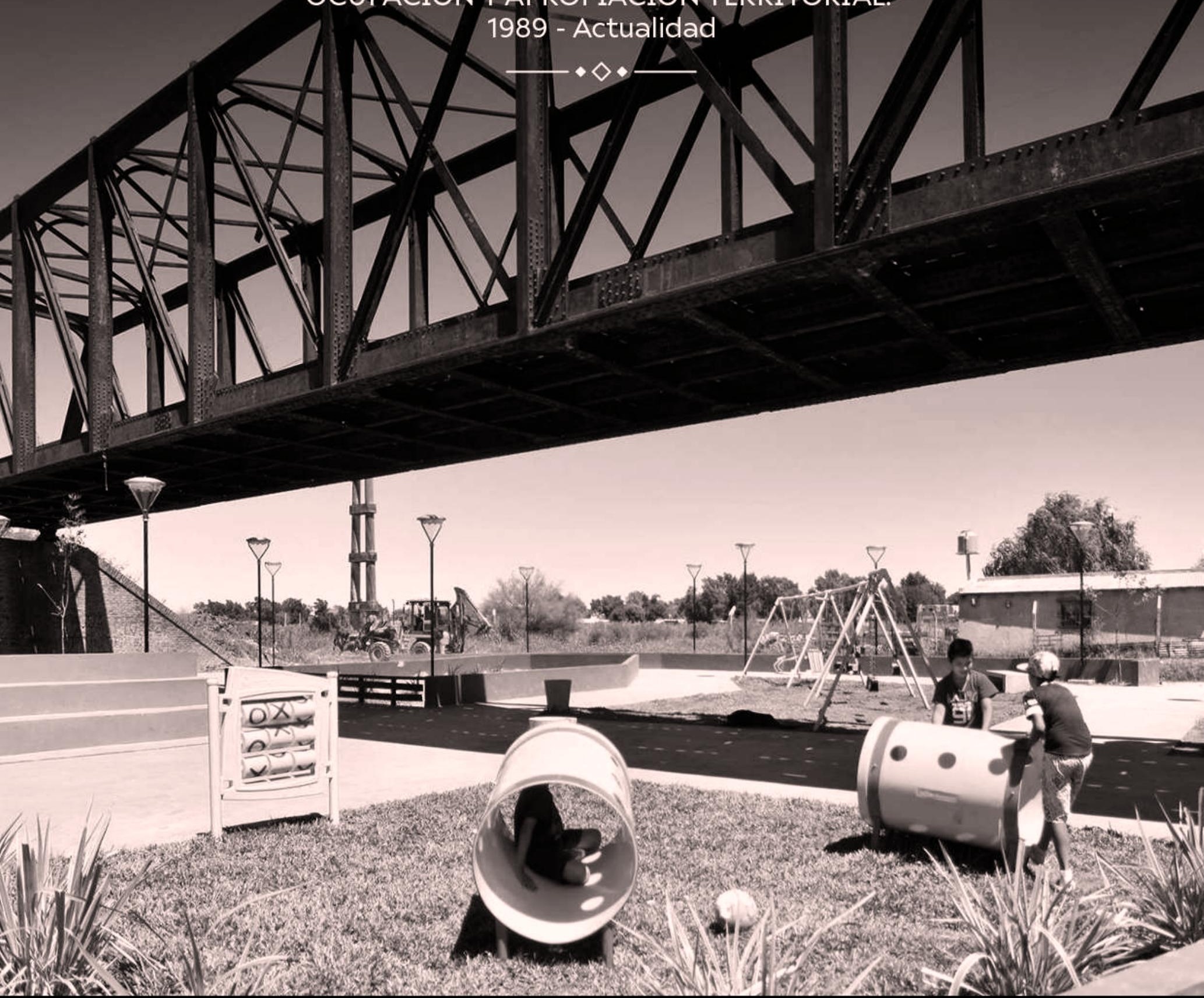

Tesista I Arq. Rocio Rodriguez Tarducci

Director Dr. Horacio Bozzano I Co directora Dra Julieta Frediani 


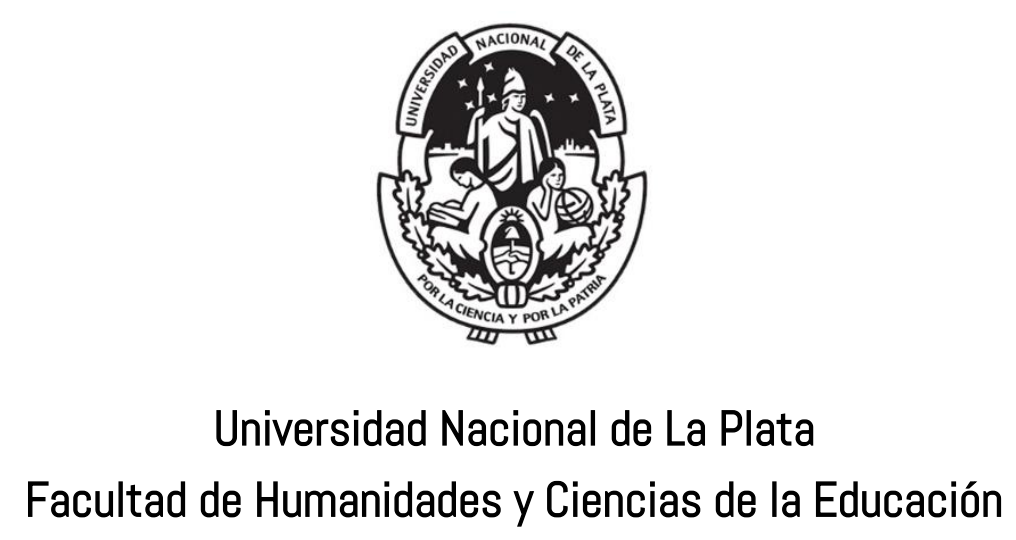

Tesis Doctoral en Geografía

\title{
INFORMALIDAD URBANA EN EL PARTIDO DE LA PLATA
}

Análisis del proceso de ocupación y apropiación territorial, 1989 - Actualidad

\author{
Autora: Arq. Rocío Rodríguez Tarducci \\ Director: Dr. Horacio Bozzano \\ Co-directora: Dra. Julieta Frediani
}

La Plata, Buenos Aires Argentina

2019 


\section{GRACIAS}

En primer lugar, quisiera agradecer al Consejo Nacional de Investigaciones Científicas y Técnicas (CONICET), por brindarme la oportunidad de formarme en investigación mediante el otorgamiento de una beca doctoral en el transcurso de estos cinco años que resultaron intensos y de gran aprendizaje.

... A la Universidad Nacional de La Plata, especialmente a la Facultad de Arquitectura y Urbanismo (FAU), por haber sido casa de mis estudios de grado, y actualmente mi lugar de trabajo de todos los días. Agradecer especialmente a la Facultad de Humanidades y Ciencias de la Educación, por brindarme la oportunidad de realizar mis estudios de posgrado en una institución pública y de calidad.

... A mis directores, por acompañarme en todo este trayecto recorrido, mi director, Horacio por compartir las visitas con el equipo al barrio Puente de Fierro, donde trabajamos y forjamos lazos junto a los vecinos durante 4 años, siempre buscando el intercambio y la transformación. A mi codirectora, Julieta quien fue mi mentora desde el primer momento, quien me presentó este maravilloso mundo de la investigación al cual me enorgullece pertenecer y el cual defenderé eternamente. Gracias a sus enseñanzas y consejos he podido transitar este camino y llegar finalmente a la instancia de presentación de tesis. Gracias por la paciencia, por el tiempo compartido y por confiar en mí como su becaria.

...Al Instituto de Investigaciones y Políticas del Ambiente Construido (IIPAC-UNLPCONICET) por permitirme contar con un lugar de trabajo en donde desarrollar mi investigación. A mis compañeras y compañeros del IIPAC por su calidez humana y por los buenos momentos entre trabajo, mates y almuerzos que hemos compartido, crecimos juntos como personas y profesionales.

... A todas las personas que de alguna u otra manera colaboraron con la realización de esta tesis, un agradecimiento muy especial para todos los vecinos del barrio Puente de Fierro, por abrirme las puertas de su casa y dejarme formar parte de su mundo. Seguiremos trabajando codo a codo.

Por último, quiero agradecer a todos mis afectos, familia y amigos, en especial a mi mamá y a mi papá, por darme la oportunidad de estudiar y enseñarme desde muy chica el valor del esfuerzo. A Kalita, por hacerme compañía durante el proceso de escritura, y a toda mi familia, amigos y amigas incondicionales, los de siempre, los de la vida, y los que me regalo el mundo académico. A todos, quiero agradecerles por darme ánimos y acompañarme, siempre con su buena energía, consejos y palabras de aliento. 


\section{RESUMEN}

La presente tesis doctoral realiza un aporte al campo temático de la informalidad urbana al concentrarse en el análisis del proceso de ocupación y apropiación territorial en el Partido de La Plata-Buenos Aires, Argentina, durante el período 1989-Actualidad. El enfoque adoptado, así como sus derivaciones metodológicas necesarias para el abordaje integral del objeto de estudio resulta de interés central para el correcto planteamiento del problema y su abordaje, por lo que la problemática de estudio de esta tesis se fundamenta, principalmente, en la generación de conocimiento desde la especificidad disciplinar de la geografía y el urbanismo con una mirada crítica sobre la misma.

El objetivo general que se persigue consiste en contribuir a la producción de conocimiento acerca de la problemática de la informalidad urbana en el Partido de La Plata, ofreciendo aportes teórico-metodológicos para el análisis crítico de sus dimensiones territoriales e implicancias simbólicas en el proceso de ocupación y apropiación territorial en urbanizaciones informales, en el período comprendido entre el año 1989 y la actualidad. Se busca aportar herramientas para la generación de conocimiento que contribuya a la mejora de las prácticas empíricas de intervención en el territorio dentro de un campo de interés multidisciplinar, principalmente de carácter social con poder de transformación.

La estrategia propuesta para el abordaje del objeto de estudio rescata los aportes de la triangulación metodológica, incorporando al mismo tiempo elementos cuantitativos que contribuyen al análisis de la problemática de la informalidad urbana dentro de un planteamiento general que responde a un abordaje mayormente cualitativo.

Palabras Clave: Informalidad urbana - Ocupación y apropiación territorial Partido de La Plata 


\section{INDICE}

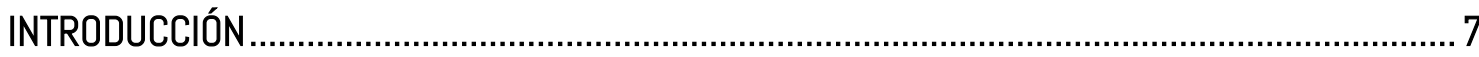

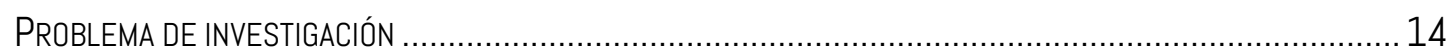

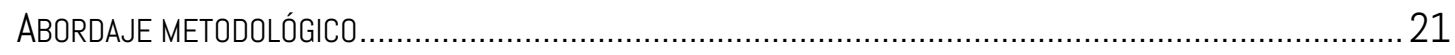

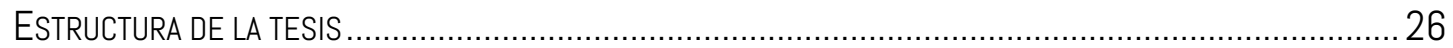

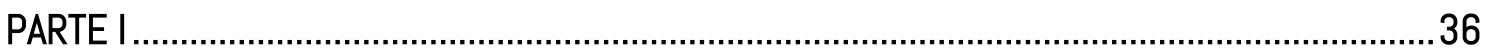

CAPÍTULO 1: APROXIMACIONES TEÓRICO CONCEPTUALES........................................................

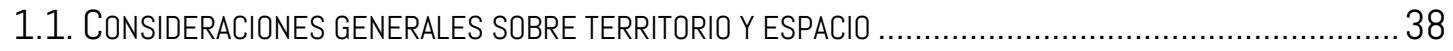

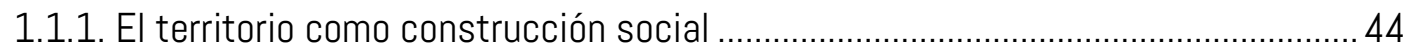

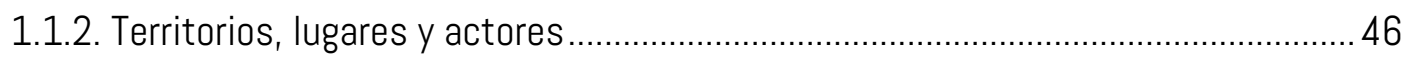

1.1.3. Ocupación y apropiación del territorio en la conformación del lugar ....................... 48

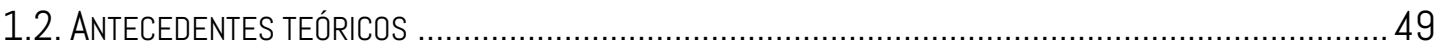

1.2.1. Ocupación, apropiación e informalidad urbana...........................................................5 50

1.2.2. Debates sobre la informalidad urbana y el acceso al suelo en América Latina..... 53

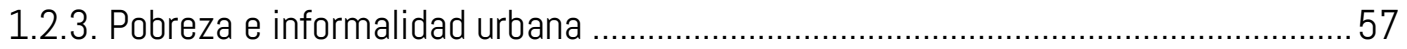

CAPÍTULO 2: LA URBANIZACIÓN CAPITALISTA EN AMÉRICA LATINA...........................................62

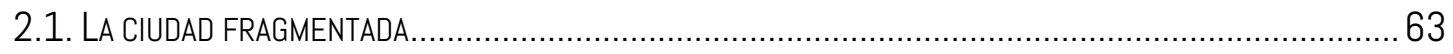

2.2. LA PRODUCCIÓN DEL TERRITORIO EN LA CIUDAD CAPITALISTA DE AMÉRICA LATINA .............................67

2.3. LA OCUPACIÓN INFORMAL DE TERRITORIO COMO ESTRATEGIA DE ACCESO AL SUELO EN AMÉRICA LATINA . 71

2.4. EL MERCADO DE SUELO COMO ELEMENTO DETERMINANTE DE LA PRODUCCIÓN URBANA EN AMÉRICA LATINA

2.5. El DERECHO A LA CIUDAD EN AMÉRICA LATINA: LA DISPUTA POR EL TERRITORIO _............................... 79

CAPÍTULO 3: LA PROBLEMÁTICA DE LA INFORMALIDAD URBANA EN ARGENTINA, CON REFERENCIA AL AREA METROPOLITANA DE BUENOS AIRES...................................................82

3.1. REVISIÓN HISTÓRICA: LOS CAMBIOS SOCIO-TERRITORIALES EN EL AMBA........................................ 84

3.2. INFORMALIDAD URBANA EL AMBA: MERCADO DE TIERRA Y ACCESO AL SUELO ….............................. 92

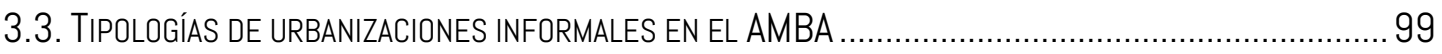

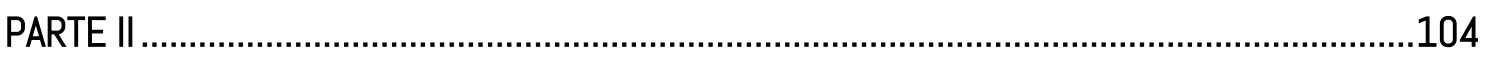

CAPÍTULO 4: LA PROBLEMÁTICA DE LA INFORMALIDAD URBANA EN EL PARTIDO DE LA PLATA,

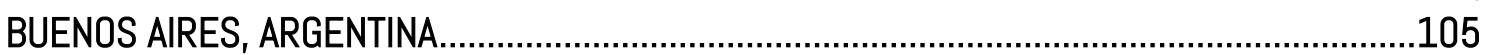

4.1. EXPANSIÓN URBANA Y OCUPACIÓN DEL TERRITORIO EN LA PERIFERIA DEL PARTIDO dE LA PLATA .........107

4.2. URBANIZACIONES INFORMALES DEL PARTIDO DE LA PLATA ...................................................119

4.2.1. Tipologías de urbanizaciones informales en el Partido de La Plata.......................125

CAPÍTULO 5: OCUPACIÓN TERRITORIAL EN LA MESO ESCALA: LAS URBANIZACIONES INFORMALES DEL PARTIDO DE LA PLATA ......................................................................129

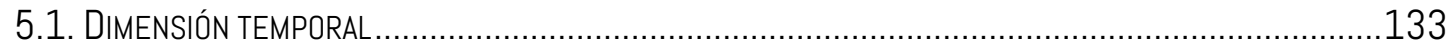

5.1.1. Primer Período: Urbanizaciones informales anteriores a 1990 .........................139

5.1.2. Segundo Período: Urbanizaciones informales entre 1990 y 2001 ......................143 
5.1.3. Tercer Período: Urbanizaciones anteriores a los años entre 2001 y 2015 .........146

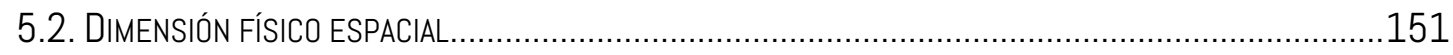

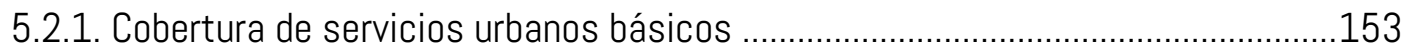

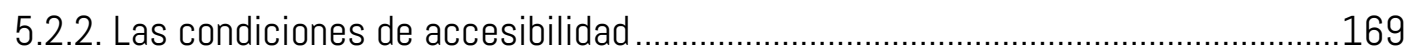

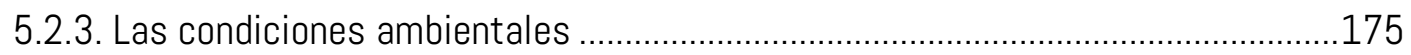

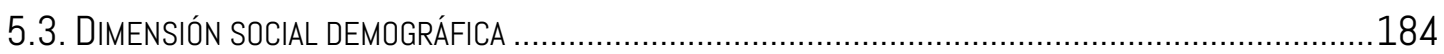

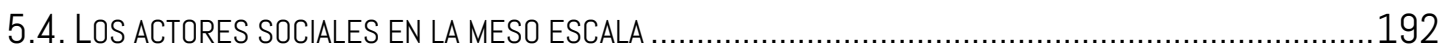

CAPÍTULO 6: OCUPACIÓN Y APROPIACIÓN TERRITORIAL EN LA MICRO ESCALA: EL CASO DEL

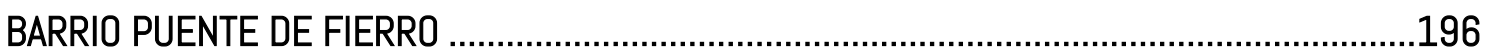

6.1. EL PROCESO HISTÓRICO DEL BARRIO PUENTE DE FIERRO Y LA OCUPACIÓN DEL TERRITORIO ................199

6.1.2. Puente de Fierro: Patrimonio histórico y lugar de significado ..............................206

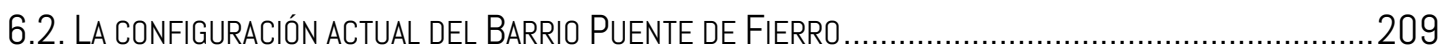

6.2.1. El acceso a los servicios urbanos básicos en la micro escala ............................217

6.2.2. Las condiciones de accesibilidad en la micro escala............................................221

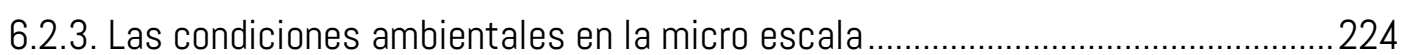

6.3. El SENTIDO DE LUGAR: LA EXPERIENCIA DE HABITAR PUENTE DE FIERRO …..................................... 229

6.4. LA DIALÉCTICA ENTRE LA OCUPACIÓN Y LA APROPIACIÓN TERRITORIAL EN LA MICRO ESCALA ..................232

6.4.1. Primera dimensión de análisis: Apego al lugar (componente simbólica).............242

6.4.2. Segunda dimensión de análisis: Identificación (componente simbólica)............244

6.4.3. Tercera dimensión de análisis: Las acciones.......................................................246

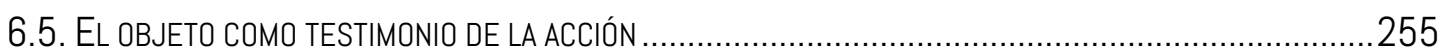

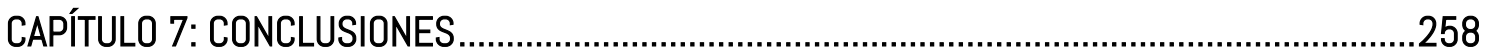

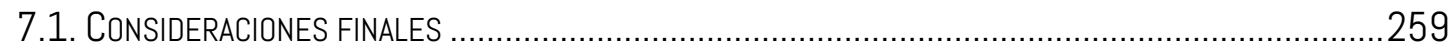

7.1.1. El proceso de ocupación y apropiación territorial en urbanizaciones informales

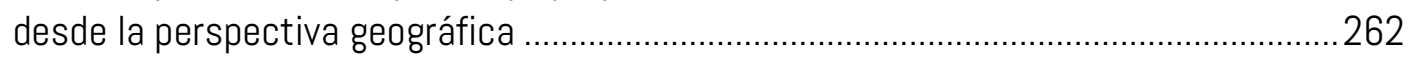

7.1.2. Aspectos referidos al abordaje del objeto de estudio ............................................261

7.1.3. Ocupación y apropiación del territorio y la comunidad: Los vecinos de Puente de

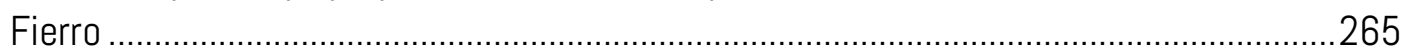

7.1.4. La ocupación y apropiación territorial en relación con la comunidad, la ciencia y el

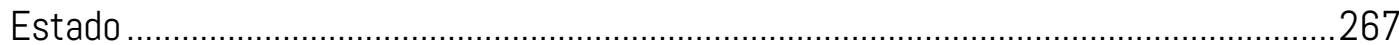

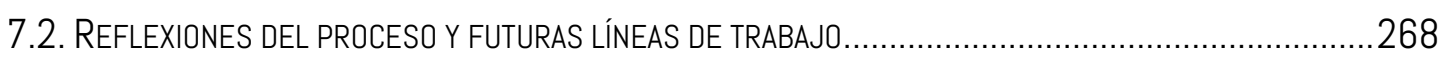

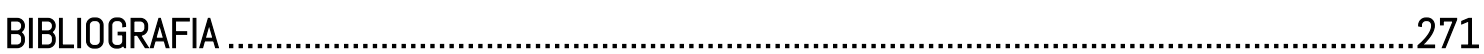

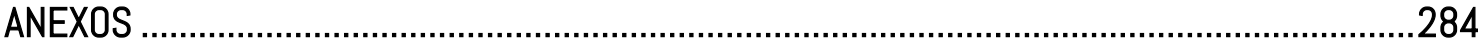

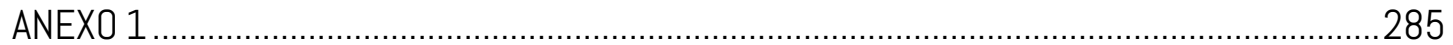

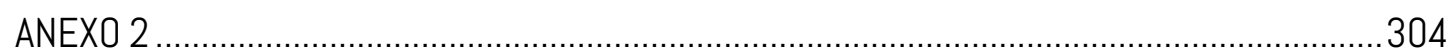

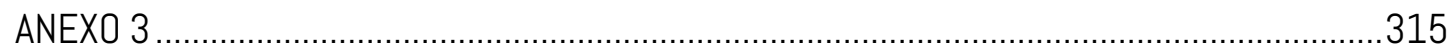

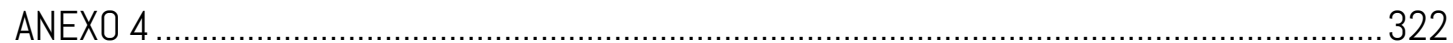




\section{FIGURAS}

Figura 1. La ciudad fragmentada en Latinoamérica, contrastes y polarización.........................65

Figura 2. Ejemplo polarización: La villa 31 de Buenos Aires y zona de Puerto Madero. ...........69

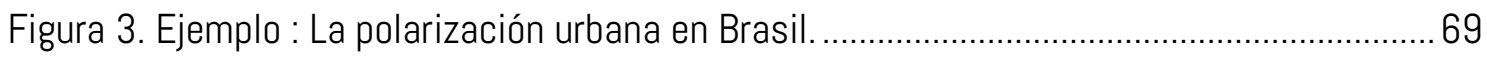

Figura 4. Viviendas autoconstruidas en Colombia y México ..................................................... 74

Figura 5. La villa 1-11-14 de Buenos Aires parte del tejido del centro urbano y la Villa 31 de

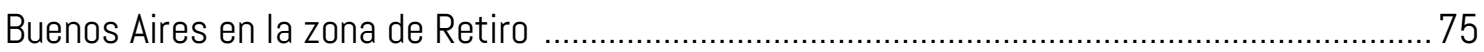

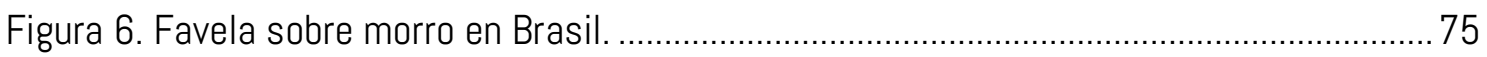

Figura 7. Crecimiento de la mancha urbana Metropolitana de Buenos Aires 1782-2001....... 91

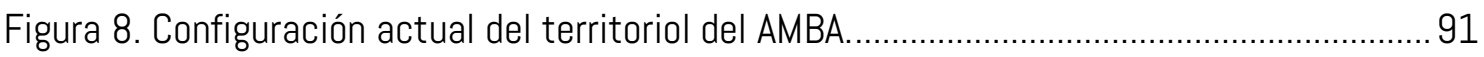

Figura 9. Localización de las urbanizaciones informales del AMBA, 2013.............................96

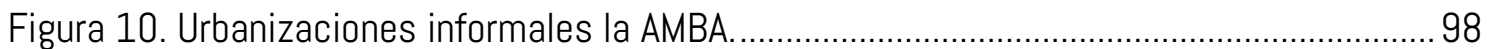

Figura 11. Tipologías de urbanizaciones informales en Argentina.............................................. 102

Figura 12. Localización geográfica del Partido de La Plata Fuente. Elaboración propia, 2017.

108

Figura 13. El Gran La Plata y la conexión con el Area Metropolitana de Buenos Aires (AMBA) 109

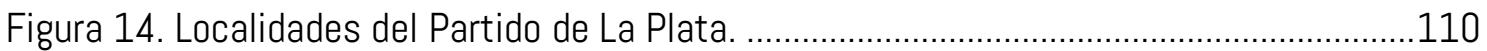

Figura 15. Densidad de población Partido de La Plata 2010................................................113

Figura 16. Crecimiento del área urbana del Partido de La Plata 1990, 2000 y 2010............117

Figura 17. Usos del suelo Partido de La Plata 2016 ..........................................................118

Figura 18. Urbanizaciones informales del Partido de La Plata: Distribución por localidades 120

Figura 19. Concentración de Urbanizaciones del Partido de La Plata....................................123

Figura 20. Tipologías de urbanizaciones informales Partido de La Plata. ................................125

Figura 21. Villas en las localidades de Los Hornos y Tolosa.............................................128

Figura 22. Expansión del área urbana del Partido de La Plata (1990, 2001 y 2015)...........134

Figura 23. Expansión del área urbana y urbanizaciones informales en la zona sur; sureste y

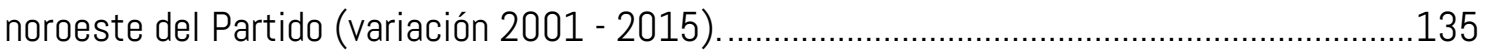

Figura 24. Síntesis del análisis temporal urbanizaciones informales del Partido de La Plata.

Figura 25. Urbanizaciones informales en el primer período de análisis temporal. .................139

Figura 26. Primer Período: Tipologías de urbanizaciones informales....................................141

Figura 27. "El Mercadito" y "La Favelita" surgidas en el período y consolidadas en la

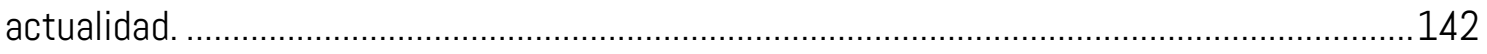

Figura 28. Urbanizaciones informales en el segundo período de análisis temporal. .............143

Figura 29. Segundo Período: Tipologías de urbanizaciones informales. ................................145

Figura 30. Urbanizaciones informales en el tercer período de análisis temporal. .................147

Figura 31. Tercer Período de análisis: Tipologías de urbanizaciones informales...................148

Figura 32. Síntesis de los tres períodos y el área urbana actual. ..........................................150

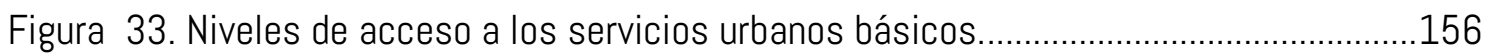

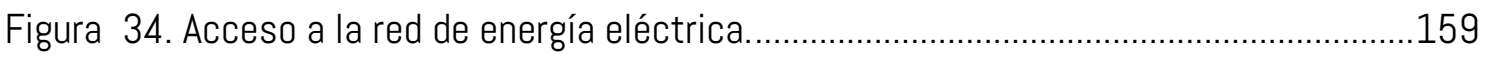

Figura 35. Conexiones clandestinas en dos barrios informales del Partido de La Plata en la localidad de Altos de San Lorenzo y en la localidad de Los Hornos ..........................................160

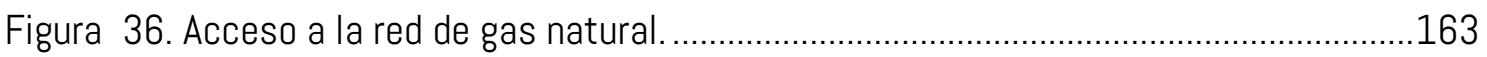


Figura 37. Acceso a la red de agua corriente 166

Figura 38. Acceso a la red cloacal. 169

Figura 39.Jerarquización de vías y prinicpales conexiones en La Pata y su área periférica.171 Figura 40. Urbanizaciones informales y acceso al casco urbano Partido de La Plata. 173

Figura 41. Tipologías de urbanizaciones informales y accesibilidad en el Partido de La Plata.

Figura 42. Pavimentación de calles en urbanizaciones informales del Partido de La Plata. 175

Figura 43. Cuencas y arroyos del Partido de La Plata, 2016. 177

Figura 44. Niveles de peligrosidad hídrica en urbanizaciones informales Partido de La Plata.

Figura 45. Asentamiento de Villa Elvira sobre el arroyo Maldonado....................................180

Figura 46. Basural a cielo abierto en la localidad de Altos de San Lorenzo y Los Hornos. ..180

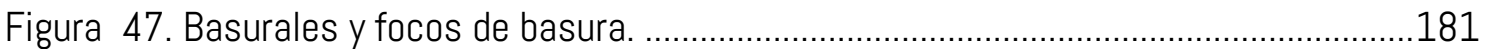

Figura 48. Cavas y urbanizaciones informales en el Partido de La Plata. ..............................183

Figura 49. Urbanizaciones informales cercanas a cavas y canteras en el Partido. ...............183

Figura 50. Tamaño urbanizacion informales según cantidad de familias. ..............................188

Figura 51. Índice NBI en el Partido de La Plata y urbanizaciones informales.........................189

Figura 52. Localización del barrio Puente de Fierro en la Localidad de Altos de San Lorenzo,

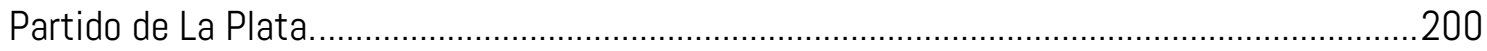

Figura 53. Puente de Fierro en 1990, antes de la creación del asentamiento......................201

Figura 54. Fotografías aéreas del emplazamiento actual de Puente de Fierro 1966-1972-

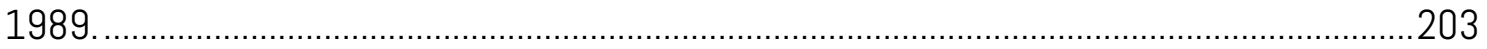

Figura 55. Consolidación del barrio Puente de Fierro entre los años 2004-2019 ................205

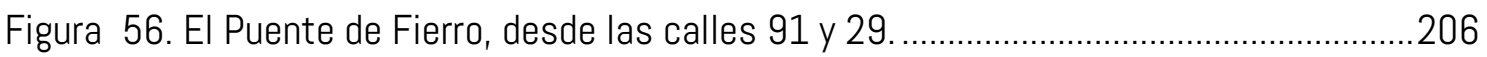

Figura 57. El puente de fierro, símbolo recordatorio de "Memoria verdad y justicia" ............207

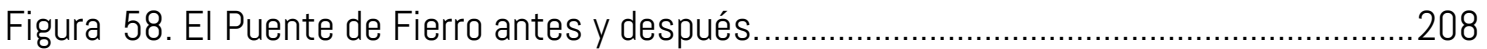

Figura 59. Delimitación espacial del barrio Puente de Fierro ...................................................210

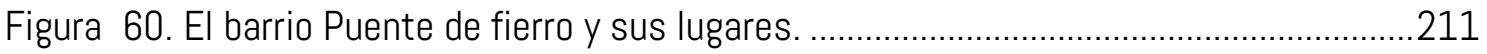

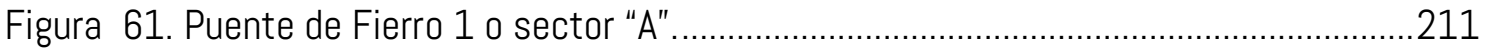

Figura 62. Tipología asentamiento informal dentro de Puente de Fierro ................................212

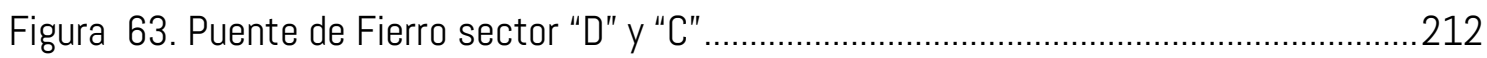

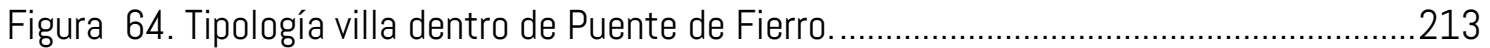

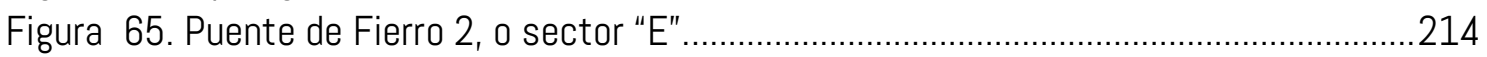

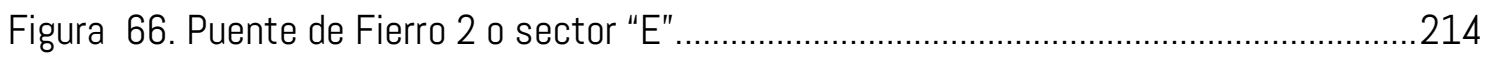

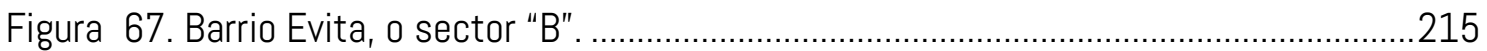

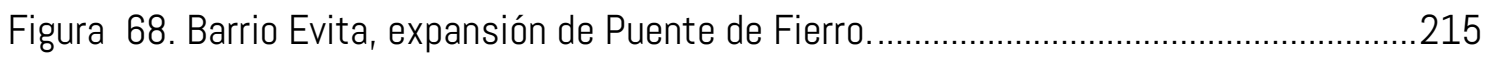

Figura 69. Abastecimiento de servicios básicos en el barrio Puente de Fierro.....................218

Figura 70. Conexiones precarias en distintos sectores del barrio y restos de una vivienda

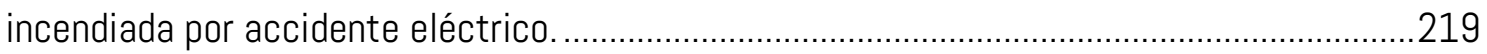

Figura 71. Grafiti en el barrio reclama "Agua potable para Puente de Fierro" .........................220

Figura 72. Imágenes de conexiones informales al desagüe................................................221

Figura 73.Principales vías de conexión entre Altos de San Lorenzo y el casco urbano. ........222

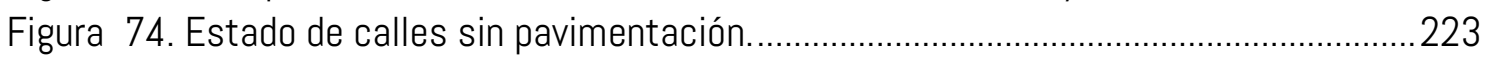

Figura 75. Puente de Fierro en la Cuenca del arroyo Maldonado. .............................................224

Figura 76. Niveles de peligrosidad hidrica en Puente de Fierro..............................................22 
Figura 77. Análisis de crecimiento en relaciona los niveles de peligrosidad .........................226

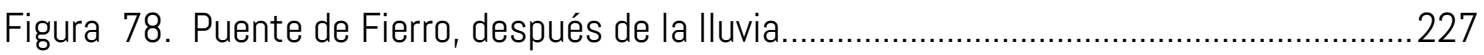

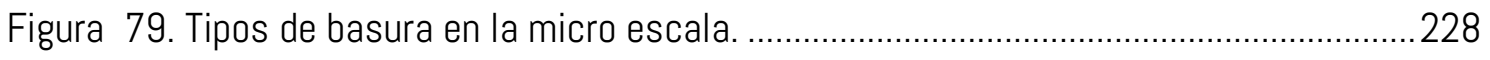

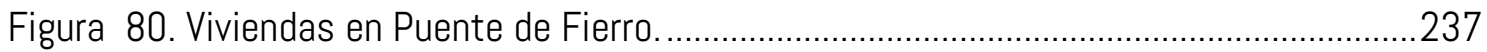

Figura 81. Símbolos y prácticas que se mantienen en Puente de Fierro. .............................238

Figura 82. El barrio Puente de Fierro, y el símbolo, el Puente original de hierro...................240

Figura 83. Manifestaciones de la identificación barrial con murales en Puente de Fierro...245

Figura 84. Algunas acciones cotidianas en el barrio......................................................248

Figura 85. Comedores, copas de leche y merenderos en Puente de Fierro ...........................248

Figura 86. La placita y la canchita de Puente de Fierro, dos espacios diarios de recreación.

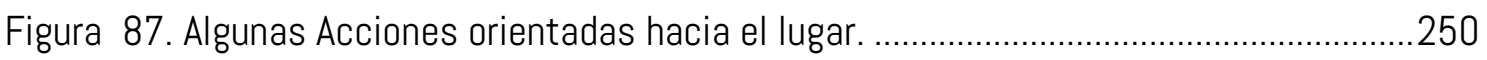

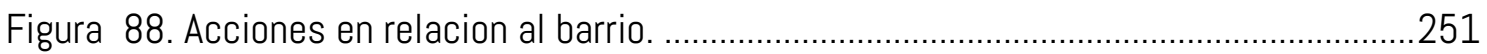

Figura 89. Las Mesas de Trabajo Permanente en Puente de Fierro ........................................252

Figura 90. La revista de Puente y temario planteado en mesas de trabajo ..........................253

Figura 91. La placita de Puente de Fierro, uno de los primeros logros del barrio...................255

Figura 92. La canchita de Puente de Fierro como lugar de recreacion y encuentro...............256

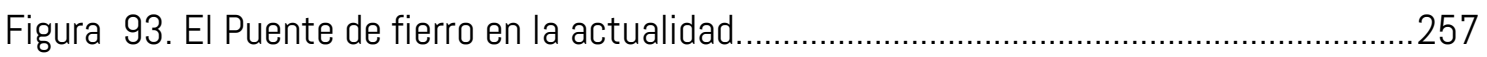

\section{GRÁFICOS}

Gráfico 1. Variación intercensal de la población en el Partido de La Plata.............................111

Gráfico 2. Crecimiento del área urbana, suburbana y rural en el Partido de La Plata .............115

Gráfico 3. Acceso a los servicios urbanos básicos por localidad y porcentaje.......................157

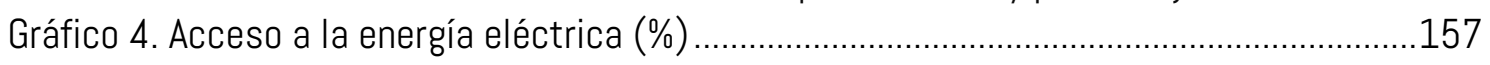

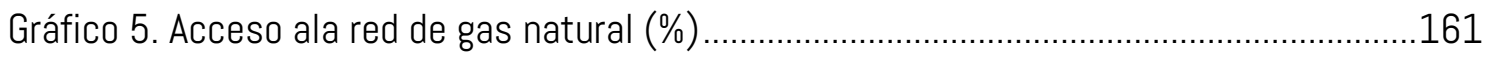

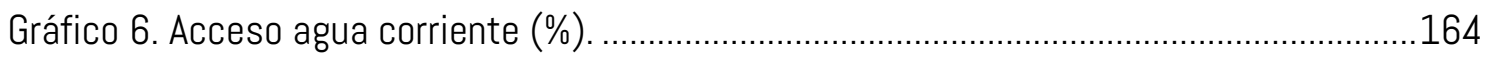

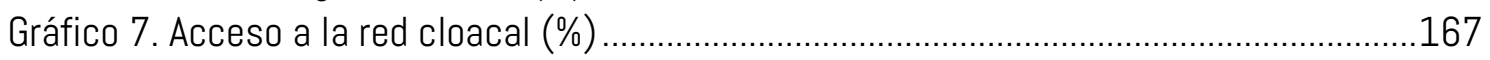

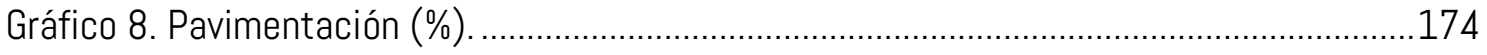

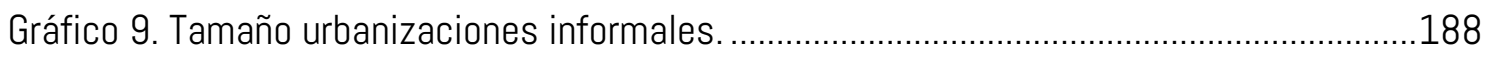

\section{TABLAS}

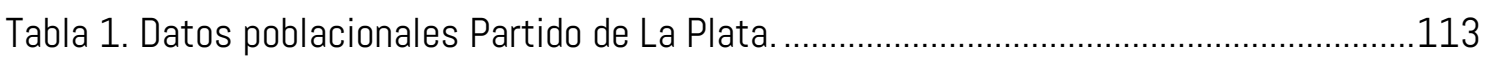

Tabla 2. Crecimiento área construida urbana, suburbana y rural Partido La Plata. ................114

Tabla 3. Precios promedio del suelo urbano residencial (en U\$S/m2) según oferta parcela < 1000 de m2 por ejes de crecimiento, Partido de La Plata 1999-2001 y 2012-2013 ...........115

Tabla 4. Urbanizaciones informales por localidad (\%) y la ocupación en hectáreas (\%).......122

Tabla 5. Tipologías de urbanizaciones informales, por localidad en el Partido de La Plata...127

Tabla 6. Matríz de dimensiones, variables e indicadores de análisis......................................132

Tabla 7. Tipologías y cortes temporales en el Partido de La Plata............................................138 


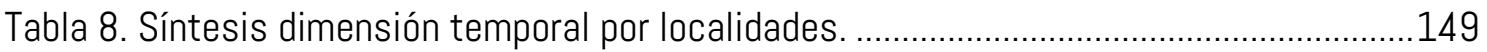

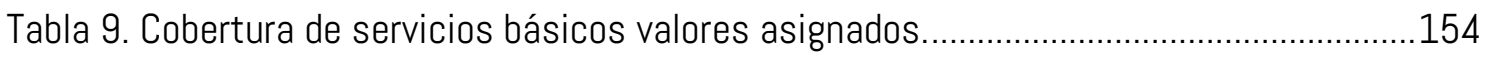

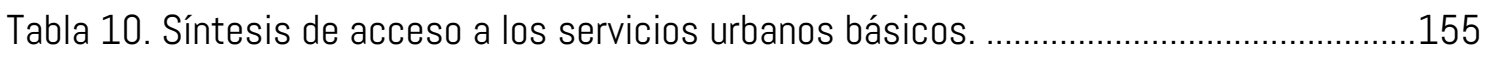

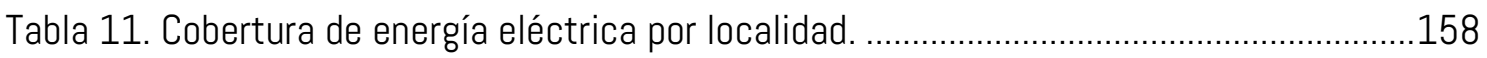

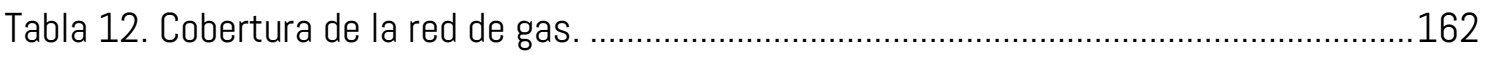

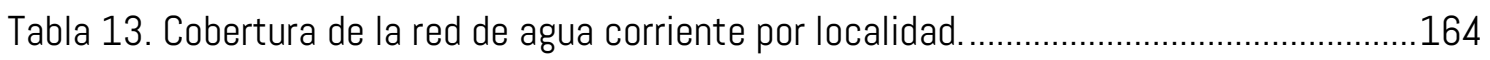

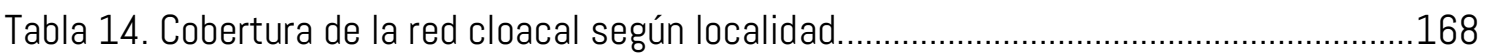

Tabla 15. Cuencas y urbanizaciones informales del Partido de La Plata................................178

Tabla 16. Tamaño de las urbanizaciones informales en el Partido de La Plata. ......................186

Tabla 17. Tamaño de las urbanizaciones informales en el Partido de La Plata ......................187

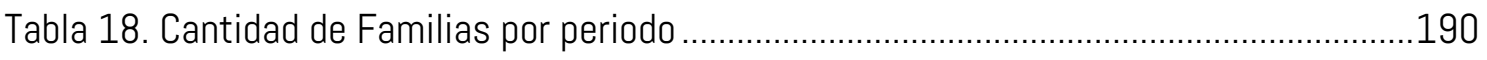

Tabla 19. Niveles de peligrosidad hídrica en Puente de Fierro................................................225

Tabla 20. Dimensiones y variables de la apropiación territorial en la micro escala...............241

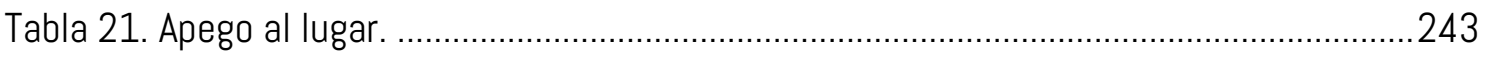

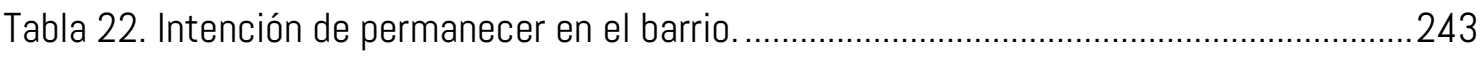

\section{ESQUEMAS}

Esquema 1. La dialéctica del proceso de ocupación y apropiación territorial. ......................... 11

Esquema 2. Causas de la informalidad urbana en América Latina. .......................................... 17

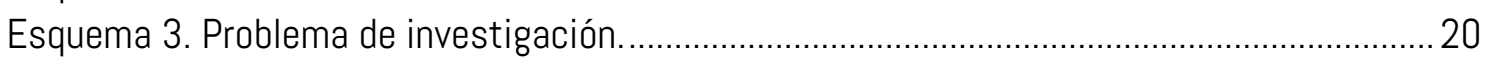

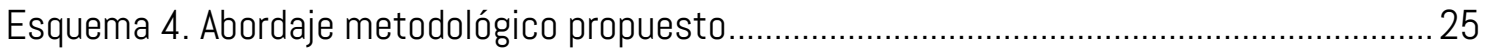

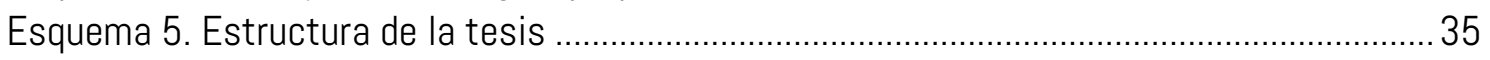

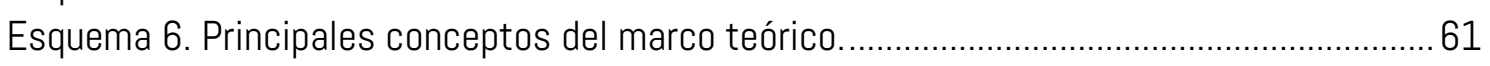

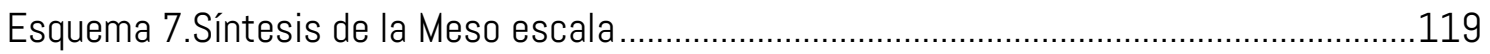

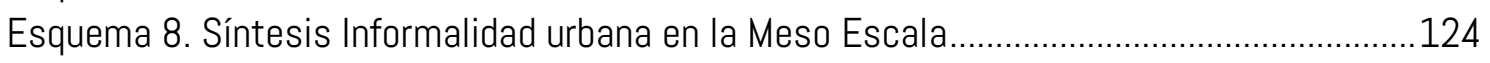

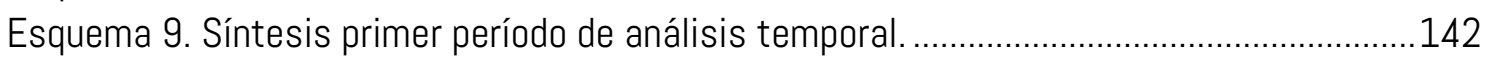

Esquema 10. Síntesis segundo período de análisis temporal. ............................................146

Esquema 11. Síntesis del Proceso de ocupación territorial en la meso escala.....................191

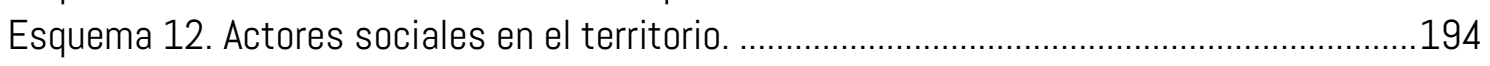

Esquema 13. Los actores sociales en el proceso de ocupación ............................................195

Esquema 14. Operacionalización de la apropiación territorial en la micro escala..................234

Esquema 15. La dialéctica entre los objetos y las acciones, la ocupación y la apropiación. 235 


\section{Introducción}

La elaboración de la presente tesis constituye la culminación del doctorado en Geografía de la Facultad de Humanidades y Ciencias de la Educación de la Universidad Nacional de La Plata, desarrollado a través de una Beca Doctoral del Consejo Nacional de Investigaciones Científicas y Técnicas (CONICET). La presentación de esta tesis resulta una instancia significativa dentro del proceso de formación académica y en investigación, donde se capitalizaron los conocimientos adquiridos hasta el momento, acerca del territorio y sus problemáticas, con el fin de lograr una visión integradora de su complejidad, organización, configuración y ordenamiento.

El tema propuesto para esta tesis doctoral se vincula con las problemáticas abordadas y las orientaciones relacionadas con trabajos realizados en instancias anteriores de investigación. Asimismo, se relaciona con aquellas cuestiones enmarcadas dentro del campo de interés de los trabajos de investigación realizados en el Instituto de Investigación de Políticas del Ambiente Construido IIPAC- de la Facultad de Arquitectura y Urbanismo de la Universidad Nacional de La Plata, lugar donde se desarrolla la investigación y casa de formación del equipo de trabajo y de quien escribe, como profesional de la arquitectura y el urbanismo.

En este contexto, y debido al interés por el estudio del territorio y su complejidad, y en relación con la línea de investigación desarrollada y explorada durante los últimos años junto con el equipo de trabajo, en la presente tesis se analiza la ocupación y apropiación territorial en las urbanizaciones informales del Partido de La Plata, como resultado del proceso de expansión urbana, durante el período comprendido entre el año 1989 y la actualidad. La elección de este período se encuentra en relación con los cambios a nivel político, económico y social que se produjeron en Argentina, y sus repercusiones a nivel territorial en el Área Metropolitana de Buenos Aires, y del Partido de La Plata particularmente. 
Cabe mencionar que dentro del período abordado es posible identificar tres etapas fundamentales que permiten explicar las transformaciones territoriales que consolidaron la informalidad urbana como una problemática actual y en crecimiento en Argentina. Esas etapas se vinculan, en parte, con hechos de carácter económico como fue el paso a las políticas neoliberales durante la década de los años 1990; la crisis socioeconómica que sufrió la población argentina en el año 2001, y el período postcrisis entre los años 2001 y 2015. En este contexto, y para el desarrollo esta tesis, resulta importante aclarar que se considera a la problemática de la informalidad urbana como una de las cuestiones sobre las cuales más se ha reflexionado durante los últimos años en los países de América Latina, y acerca de la cual es posible encontrar múltiples enfoques que varían con cada disciplina.

En este sentido, el enfoque adoptado se enmarca en una mirada desde la geografía, el urbanismo y la sociología urbana, por lo que el tratamiento de conceptos tales como la informalidad urbana y la ocupación y apropiación territorial representan cuestiones centrales en el planteamiento del problema y su abordaje. La problemática de estudio se fundamenta principalmente en el interés disciplinar que guía toda la investigación y que trata de desarrollar un conocimiento que, desde la especificidad de la geografía y el urbanismo, aporta herramientas para posteriores trabajos de carácter pluridisciplinar, orientados a la planificación, intervención y transformación territorial. De este modo se contribuye al desarrollo de una disciplina geográfica que, nutriéndose de diversas tradiciones de conocimiento y comprometiéndose con la transformación, forma parte de una nueva ciencia social emancipatoria (Wright, Erik Olin 2010). El propósito consiste en contribuir al conocimiento acerca de la problemática de la informalidad urbana, estrechamente vinculada con procesos de carácter socio territorial en el marco de la configuración de las periferias de las ciudades medias latinoamericanas, más específicamente, el área periférica del Partido de La Plata.

Se propone para ello, el análisis de la ocupación y apropiación territorial en urbanizaciones informales, entendiendo que constituye un proceso dialéctico donde la ocupación y la apropiación se producen simultáneamente. Este proceso 
forma parte constituyente en la configuración y organización del territorio de la informalidad urbana en un escenario estructural de insuficientes políticas públicas de hábitat para los sectores más vulnerables. Se plantea el abordaje en términos de proceso, comprendiendo que la ocupación y apropiación se producen en un contexto en donde la lógica de la urbanización capitalista es la que termina por definir el desarrollo de la ciudad. Por lo tanto, el presente análisis se desarrolla desde una perspectiva territorial, proveniente de la geografía crítica, con especial énfasis en los procesos de configuración territorial, la conformación de los lugares y la transformación del territorio.

El recorte espacial se delimita dentro del área que incluye la expansión urbana residencial de la periferia del Partido de La Plata, Buenos Aires Argentina. Para la delimitación se tuvo en cuenta la posibilidad de participación de los diferentes actores involucrados, quienes adoptan distintas estrategias relevantes en el análisis del proceso de ocupación y apropiación del territorio, de acuerdo a sus respectivas lógicas e intereses. Se incluyen en este análisis, principalmente actores provenientes de sectores de la población de bajos recursos económicos, que encuentran dificultades en el acceso a la tierra a través del mercado formal. Esta situación conduce a la ocupación del territorio a través de la toma de tierra (privada o fiscal) como estrategia principal de producción del suelo urbano, guiada por la lógica de la necesidad ${ }^{1}$. En este sentido, autores como Pírez (1995) explican que dentro de la lógica de la necesidad, la producción de la urbanización informal puede realizarse de cuatro maneras fundamentales: a) Por acciones individuales $o$ colectivas directas; b) A través de la organización comunitaria, de base solidaria para la producción directa; c) A través de organización de movimientos reivindicativos frente a los actores gubernamentales; y d) Por la orientación hacia relaciones clientelares, conformándose en clientela de algunos actores

\footnotetext{
${ }^{1}$ Existen actores que se determinan en razón de lo que podemos denominar la lógica de la necesidad. Esta se muestra relevante en tanto que se desarrolla fuera (total o parcialmente) del mercado y de las políticas públicas (Actores sociales y gestión de la ciudad, Pírez 1995).
} 
gubernamentales o políticos. Esas formas no son excluyentes y pueden combinarse en un mismo momento o sucesivamente.

Al producirse la ocupación informal del territorio comienza simultáneamente (dialécticamente) el proceso de apropiación, en tanto que los "ocupantes" se empiezan a vincular entre ellos generando redes y con el territorio ocupado. De este modo, los actores se organizan para lograr transformar el territorio ocupado y hacerlo propio, tanto material como simbólicamente (convertirlo en un lugar). Es posible determinar entonces que el proceso de ocupación y apropiación en urbanizaciones informales comienza durante la toma de la tierra, y se manifiesta a través de los mecanismos de producción del territorio, tales como la auto producción de la vivienda y los diversos procesos de consolidación. De este modo la tierra antes vacante, luego ocupada y apropiada adquiere un significado y características propias, transformándose en un lugar. En este sentido y a partir de lo expuesto, surgen algunos interrogantes que permiten pensar en un análisis con una mayor profundidad y complejidad, y al mismo tiempo orientan el proceso de investigación contribuyendo al abordaje y delimitación del objeto de estudio de esta tesis:

1. ¿De qué manera y bajo que estrategias de investigación sería posible analizar el proceso de ocupación y apropiación territorial en contextos de informalidad urbana? ¿Qué dimensiones del análisis resultan necesarias para el abordaje de la informalidad urbana? más concretamente, ¿qué se debe mirar (observar) cuando se analiza el proceso de ocupación y apropiación en un territorio?

2. ¿En qué contextos (históricos) y bajo qué circunstancias (políticas, económicas, sociales) se produjo y se produce actualmente la ocupación y apropiación informal del territorio en América Latina, en Argentina y en particular, en el área periférica del Partido de La Plata? ¿Qué circunstancias impulsan dicho proceso? ¿Cuáles son las características que permiten identificar el proceso en cada momento histórico? 
3. ¿Quiénes son los actores que llevan adelante el proceso de ocupación y apropiación territorial?; ¿A través de qué mecanismos se produce la ocupación y apropiación del territorio? ¿Quiénes (actores) y de qué manera (estrategias) producen y re producen las lógicas que configuran los territorios de la informalidad urbana en el Partido de La Plata?

A efectos operativos resulta importante mencionar que para dar respuesta a estos interrogantes, en principio muy abstractos pero que al mismo tiempo complejizan el pensamiento para adentrarse en el conocimiento y análisis de la problemática desde todas sus aristas, se pone especial énfasis en el trabajo de campo, empírico y con los actores, de manera de llegar a reconocer las huellas (marcas) e improntas (prácticas, símbolos) que ponen de manifiesto el vínculo que se genera entre los actores sociales y el territorio, así como la identificación de algunas de las instancias dominantes desde el origen simultáneo de la ocupación (objetos, materialidades) y de la apropiación (acciones, prácticas) (Bozzano, 2009).

Esquema 1. La dialéctica del proceso de ocupación y apropiación territorial.

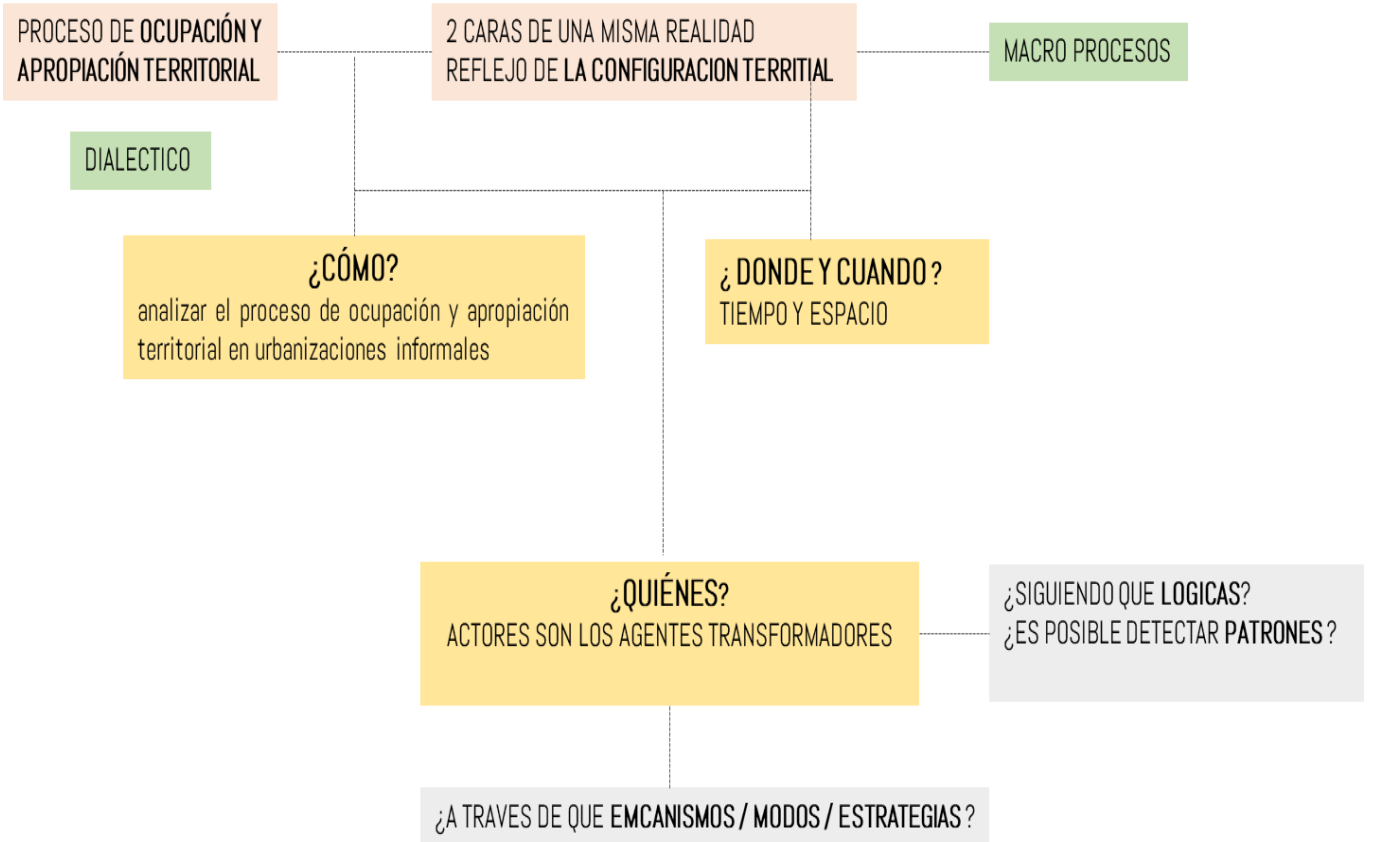

Fuente: Elaboración propia, 2018. 
En este marco, el objetivo principal que persigue esta investigación consiste en contribuir a la producción de conocimiento acerca de la problemática de la informalidad urbana en el Partido de La Plata, ofreciendo aportes teóricometodológicos para el análisis crítico de las dimensiones territoriales y sus implicancias simbólicas en el proceso de ocupación y apropiación territorial en urbanizaciones informales, durante el período comprendido entre el año 1989 y la actualidad. Como planteo general del trabajo, se adopta una postura teórica y epistemológica de base que guía todo el desarrollo de la tesis, que permite profundizar en el estudio de la problemática de la informalidad urbana y la caracterización de las urbanizaciones informales del Partido de La Plata. Se focaliza en el análisis particularizado sobre una urbanización informal del Partido denominada Puente de Fierro en la localidad de Altos de San Lorenzo, a través de la cual se busca introducir un nivel de abordaje de mayor detalle y acercamiento, centrado en el análisis empírico del proceso de ocupación y apropiación territorial en un lugar concreto de la micro escala.

En tanto, los objetivos específicos de la investigación son:

1- Profundizar en el conocimiento acerca de la problemática de la informalidad urbana en América Latina, como resultado de la expansión urbana sin planificación territorial con baja intervención Estatal, y la dificultad en el acceso al suelo, dentro del contexto del modelo de la ciudad capitalista latinoamericana actual.

2- Comprender la incidencia de los cambios económicos, políticos y sociales producto del sistema dominante actual, su expresión en la configuración del territorio, la urbanización informal y las tipologías más extendidas en Argentina con especial énfasis en el Área Metropolitana de Buenos Aires (AMBA).

3- Analizar la problemática de la informalidad urbana en la meso escala (Partido de La Plata) como parte del proceso de expansión de la periferia urbana, identificando tipologías y patrones comunes producto de la ocupación informal del territorio. 
4- Identificar los actores sociales que intervienen en el proceso de ocupación y apropiación territorial en las urbanizaciones informales correspondientes con la meso escala (Partido de La Plata), a partir de la comprensión y análisis de sus lógicas e intereses.

5- Analizar el proceso de ocupación y apropiación territorial en la micro escala (Barrio Puente de Fierro) a partir de a partir del reconocimiento de los atributos físicos del espacio y los relatos de los actores sociales acerca de la historia del barrio y la conformación del lugar.

6- Explicar la dialéctica subyacente en el proceso de ocupación y apropiación territorial, a partir del establecimiento de una relación conceptual y empírica entre la ocupación y la apropiación territorial con la creación del sentido de lugar, definido como el resultado entre las acciones, las concepciones simbólicas y los atributos físicos del espacio.

Los primeros dos objetivos específicos se relacionan con el nivel superior de análisis y abordaje teórico, planteado en grados de abstracción que parten del entendimiento de los conceptos macro interpretativos acerca de procesos territoriales, en corresponden con los capítulos 1, 2 y 3 de esta tesis. A partir del tercer objetivo, se introduce al lector en el análisis de la informalidad urbana en un nivel medio de abordaje y análisis, marcando el inicio de la segunda parte de la tesis. Los objetivos 3 y 4, reflejados en los capítulos 4 y 5 profundizan en el análisis de la problemática de la informalidad urbana en la meso escala, correspondiente con la escala geográfica de la periferia del Partido de La Plata. En este nivel se busca caracterizar la totalidad de las urbanizaciones informales del Partido, así como reconocer e identificar ciertos patrones comunes derivados de la ocupación informal del territorio. Los objetivos 5 y 6 se abordan particularmente en el desarrollo del capítulo 6 y refieren al caso concreto de estudio en la micro escala, en un nivel de abordaje y análisis inferior, con un mayor detalle. En este nivel se focaliza en el análisis del proceso de ocupación y apropiación territorial a través del trabajo empírico en el barrio Puente de Fierro. 
Entre los aportes originales de esta tesis, en primer lugar se destaca la producción de conocimiento acerca de la problemática de la informalidad urbana, a través de la comprensión de la organización y configuración del territorio en el contexto de la urbanización capitalista. En segundo lugar, la contribución al análisis y comprensión del proceso de ocupación y apropiación territorial en las urbanizaciones informales del Partido de La Plata a través de la construcción de fundamentos teóricos y metodológicos, factibles de replicar en otros casos, que parten de la combinación de teorías geográficas, sociales y urbanas. Por último, esta tesis aporta los elementos descriptivos, interpretativos y explicativos acerca de las particularidades del proceso de ocupación y apropiación territorial en un caso concreto, el Barrio Puente de Fierro en la localidad de Altos de San Lorenzo en la periferia urbana del Partido de La Plata.

En síntesis, el análisis de la ocupación y apropiación territorial en urbanizaciones informales se articula e interrelaciona con el análisis de procesos, contextos políticos, económicos y aspectos físico espaciales, poniendo particular énfasis en la dinámica social. Por lo antes expuesto, esta tesis contribuye en el ámbito de la producción de conocimiento científico y académico, mediante la utilización de diferentes métodos y técnicas, a la interrelación de las principales dimensiones que estructuran el territorio, permitiendo así dar cuenta de la complejidad que caracteriza a estos espacios periféricos.

\section{Problema de investigación}

La informalidad urbana es una problemática que afecta a una gran cantidad de habitantes, a nivel mundial puede estimarse que alrededor de un cuarto de la población urbana vive en barrios en condiciones de informalidad, sin infraestructura de servicios urbanos básicos y sin seguridad de tenencia del suelo (ONU-hábitat, 2015). En este sentido, las ciudades de América Latina se encuentran entre las más desiguales del mundo, y aun habiendo descendido la población urbana que vive en la pobreza desde un 41,4\% en 1990 a un 23,2\% en el 
2013 (CEPAL y ONU-Hábitat, 2016), no necesariamente esto ha implicado una disminución de la desigualdad.

La desigualdad determina condiciones de vulnerabilidad para la población urbana, especialmente para los sectores de menores recursos y se expresa espacialmente en la forma de segregación socioeconómica, informalidad urbana, desafíos persistentes en accesibilidad económica a la vivienda y al suelo urbano, y se asocia, además, con altos niveles de violencia y criminalidad (CEPAL y ONUHábitat, 2016). De acuerdo al índice Gini², la desigualdad urbana a nivel regional alcanza a 0,42 comparado al promedio urbano de la OCDE un poco mayor de 0,3 puntos. Aunque existen variaciones por país y ciudad, ningún país presenta un índice de menos de 0,4 puntos, y las ciudades en el análisis caso por caso, presentan niveles preocupantes de desigualdad de ingresos.

En las ciudades latinoamericanas la denominada "ciudad informal" (por fuera de la ciudad formal) conforma una gran parte del suelo urbano, habiéndose incrementando de manera significativa en las últimas décadas y convertido así en la forma principal de desarrollo de las ciudades y sus áreas periféricas (Smolka; Mullahy, 2010). En América Latina, donde la regularización de la vivienda informal contribuyó de forma histórica a plantear soluciones a los problemas habitacionales, las urbanizaciones informales constituyen hoy en día, una característica fundamental de las áreas urbanas y suburbanas. Se estima que el 24 \% de la población urbana de la región vive en áreas informales, debido a las dificultades para obtener el acceso legal al suelo urbano. Esta cifra podría crecer rápidamente si no se toman medidas efectivas para revertir este proceso (ONUHábitat, 2015).

\footnotetext{
${ }^{2}$ El índice de Gini o coeficiente de Gini es una medida económica que sirve para calcular la desigualdad de ingresos que existe entre los ciudadanos de un territorio, normalmente de un país. El valor del índice de Gini se encuentra entre 0 y 1 . Siendo cero la máxima igualdad (todos los ciudadanos tienen los mismos ingresos) y 1 la máxima desigualdad (todos los ingresos los tiene un solo ciudadano)
} 
La urbanización informal es llevada adelante, en parte, por aquellos que no cuentan con la posibilidad de comprar una vivienda o adquirir una renta a través del mercado formal ni son beneficiarios de políticas habitacionales públicas, es decir, personas que se encuentran impedidas de habitar la ciudad por la vía formal. Si bien existen otros tipos de informalidad urbana que no se relacionan con la capacidad de adquirir bienes, en este trabajo se focaliza en aquellas urbanizaciones informales producto de problemáticas en relación con sectores con bajos recursos económicos de la población que, como se mencionara anteriormente, encuentran dificultad en el acceso al suelo.

En relación a los procesos de expansión y ocupación del territorio, es posible reconocer en América Latina, según diversos autores, algunas características comunes que adoptan las urbanizaciones informales y que tienen que ver con los motivos por los cuales éstas surgen, los objetivos que persiguen sus habitantes, las áreas donde se localizan y las características físicas de la ocupación, entre otras.

Entre los principales factores que permitirían explicar el proceso de urbanización informal en América Latina pueden reconocerse, por un lado, el elevado precio del suelo urbano residencial en el mercado formal, que deja excluidos a los sectores de menores ingresos, quienes sólo pueden acceder a la tierra en condiciones informales. Por el otro lado la escasez de políticas públicas en materia de hábitat para los sectores más vulnerables constituye un factor de peso que permite explicar esta crítica situación. La ausencia de obras de urbanización formalmente requeridas, la baja calidad y dificultad en el acceso a la tierra y, fundamentalmente la falta de seguridad jurídica hace que los precios en el mercado informal sean relativamente menores que en el mercado formal. Por estos motivos es que la informalidad urbana suele ser característica de las áreas de residencia de los sectores sociales más excluidos (Frediani, 2010).

En Argentina, las formas de urbanización informal más extendidas en el territorio son las villas, los asentamientos informales, los loteos irregulares y los loteos clandestinos, entre otros. Cabe mencionar que, durante las últimas décadas, 
se ha intensificado de manera exponencial la aparición de urbanizaciones informales de distintos tipos con características particulares en las periferias de las principales ciudades del país caracterizadas, en su mayoría, por tratarse de invasiones masivas y tomas de tierras vacantes (fiscales y/o particulares desocupados) como estrategia de acceso al suelo (Clichevsky, 2000).

Esquema 2.Causas de la informalidad urbana en América Latina.

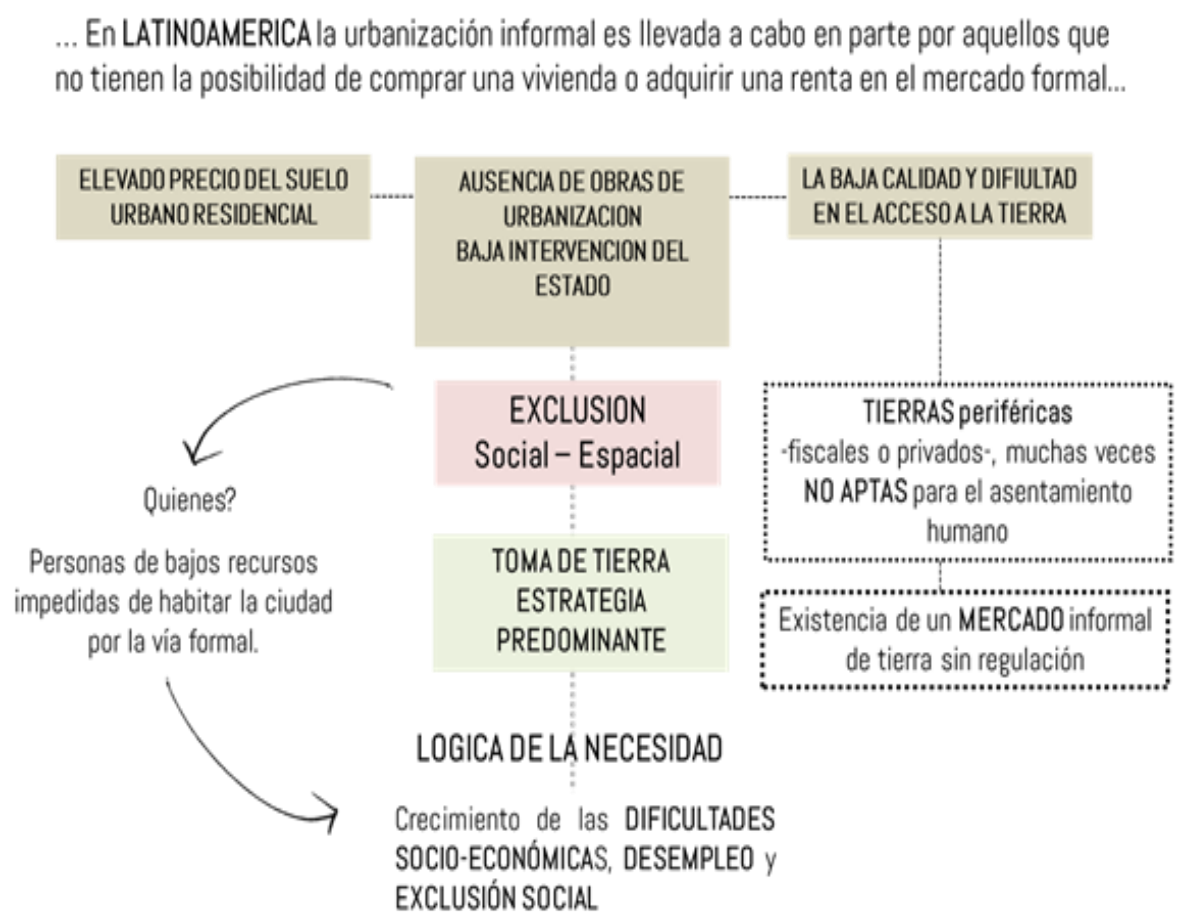

Fuente: Elaboración propia, 2018.

El análisis de la informalidad urbana permite visualizar la relevancia actual de la problemática de la falta de acceso al suelo para amplios sectores de la población. Sólo en la Provincia de Buenos Aires, según los datos difundidos por el Registro Público Provincial de Villas y Asentamientos Precarios (en adelante RPPVAP) existen 1.585 barrios caracterizados como informales, en donde residen alrededor de 419.000 familias, y de los cuales más de un cuarto se encuentran ubicados en localidades del interior bonaerense. En el Partido de La Plata existen 128 urbanizaciones informales según el informe del RPPVAP, ésto representa más de 20.000 familias, colocándolo como el segundo municipio (después de La Matanza) de la Provincia de Buenos Aires con mayor cantidad de urbanizaciones informales. 
Los datos presentados no sólo invitan a la reflexión acerca de la problemática de la informalidad urbana, sino que también ponen de manifiesto la necesidad de analizar este fenómeno desde sus orígenes y su evolución, abarcando todas sus aristas.

Como se mencionó, esta investigación hace hincapié en el análisis de la ocupación y apropiación territorial en contextos de informalidad urbana, desde el origen de la toma de la tierra, y a través de los distintos mecanismos de producción (autoproducción) de la vivienda y los diversos procesos de consolidación del barrio. En este sentido, para Chombart de Lauwe (1979) la apropiación viene dada, en parte, por el derecho al espacio y su entorno donde se presentan las mayores transformaciones territoriales por parte de los actores dadas las acciones que en ellos llevan adelante en un tiempo y espacio determinados. La vivienda, en este sentido, representa un claro ejemplo del primer mecanismo de autoproducción de este tipo de urbanizaciones, así como el proceso de conformación y consolidación del barrio.

El desafío que se plantea en este trabajo consiste en articular una doble lectura, de carácter dialéctico, acerca de la informalidad urbana; la primera desde la ocupación informal del territorio, por fuera de la norma existente y lo que implica; y la otra desde la apropiación y el valor simbólico que constituye. Interpretando a Coraggio (1994) el proceso de ocupación y apropiación del territorio puede explicarse en el contexto de las relaciones sociales capitalistas, es por esto que resulta necesario para este trabajo constituir un primer nivel de abordaje partiendo del entendimiento de la dinámica de la ciudad capitalista latinoamericana, para luego focalizar en los procesos particulares.

En cuanto al recorte temporal de esta tesis se toma como punto de partida el año 1989, debido a que representa un año que marca un punto de inflexión dentro de las transformaciones territoriales que se produjeron en Argentina y en particular, en relación con los procesos de urbanización del Área metropolitana de Buenos Aires y en el área de estudio propiamente dicha, el Partido de La Plata. 
Cabe mencionar que aquellos cambios que se produjeron a nivel económico, político y social en Argentina, entre los que cabe destacar la implementación de la Ley de Reforma del Estado y de Emergencia Económica de 1989 y al Plan de Convertibilidad puesto en marcha desde 1991, marcaron el inicio de la reactivación de la industria de la construcción y el mercado inmobiliario contribuyendo a generar nuevos espacios urbanos periféricos (Frediani, 2010).

En este contexto histórico, la flexibilización de las normas urbanísticas y de ordenamiento territorial, junto con el debilitamiento del Estado frente al protagonismo de agentes inmobiliarios privados nacionales e internacionales, generó una alteración en los patrones de urbanización, un replanteo de la planificación urbana y de las modalidades de gestión. La crisis socioeconómica que sufrió el país desde mediados de la década del '90 impactó significativamente en los sectores medios y bajos de la población, producto de una distribución regresiva del ingreso. Como consecuencia, la exclusión del modelo adoptó formas territoriales como la segregación forzada de un amplio contingente de excluidos, que se reflejó en un fuerte crecimiento de las urbanizaciones informales ubicadas en la periferia de las ciudades, contribuyendo así a la expansión de periferias social y territorialmente fragmentadas.

La delimitación del área de estudio, como se mencionó anteriormente, dentro del sudeste metropolitano de la provincia de Buenos Aires, focaliza en el área periférica del Partido de La Plata. Este recorte se debe a un interés particular por profundizar en conocimientos adquiridos durante los últimos años, a partir de trabajos de investigación cuyos temas se centraron sobre el estudio de diversas problemáticas en la periferia de mencionado Partido. De este modo el recorte espacio-temporal se fundamenta a partir de considerar que las transformaciones socio territoriales producidas en la periferia del Partido de La Plata fundamentalmente desde finales de los años 80 y comienzos de los años 90, contribuyeron a un notable cambio en la morfología de la ciudad originalmente planificada, dando lugar a un territorio periférico fragmentado y disperso. En este marco, las hipótesis que guían esta investigación sostienen que: 
H1- Las transformaciones socioterritoriales producidas en la periferia del Partido de La Plata desde fines de los años 80 y comienzos de los años 90, sumado al alto costo de la tierra, han contribuido al avance del proceso de expansión residencial sin planificación dando como resultado el incremento de la informalidad urbana.

H2- La ocupación informal del territorio a partir de la toma de tierras como estrategia de acceso al suelo, por parte de sectores de la población de bajos recursos, se produce simultáneamente (de manera dialéctica) con la apropiación del territorio, manifestándose espacial y simbólicamente en la conformación lugar.

Esquema 3. Problema de investigación.

PROBLEMADE INVESTIGACION

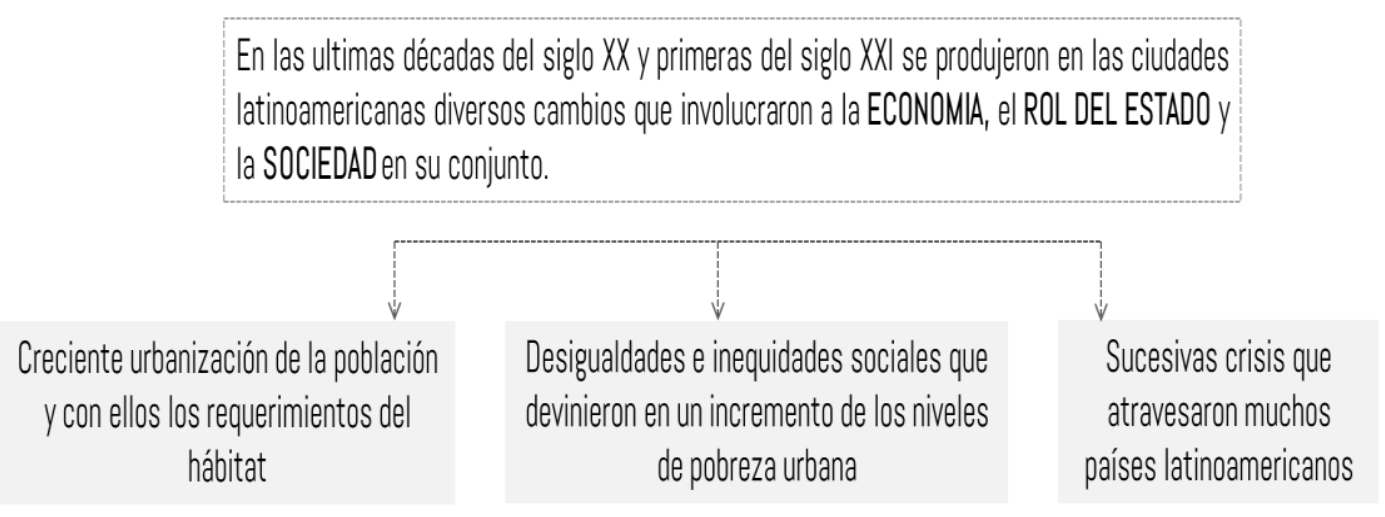

La necesidad de espacios urbanos para el hábitat, en el marco del MODELO NEOL IBERAL, ha significado que un importante sector de la población vea restringidas sus posibilidades de acceso a esos espacios por la vía formal.

La INFORMALIDADENEL ACCESO AL SUELOURBANO se convirtió en un fenómeno creciente en América Latina, siendo la modalidad predominante del crecimiento de las ciudades.

Fuente. Elaboración propia, 2019. 


\section{Abordaje metodológico}

El abordaje metodológico, necesario para cumplir con los objetivos propuestos para este trabajo de tesis en términos prácticos, aplica una estrategia compuesta por una serie de decisiones, procedimientos y técnicas, cuya selección se vincula con el objeto de estudio, sus circunstancias y los objetivos planteados. En este sentido, resulta adecuado hablar, en principio, de criterios metodológicos abiertos a diversas formas de instrumentalización que tratan de propiciar la apertura del pensamiento para captar las diferentes modalidades a través de las cuales la realidad se concreta (Frediani, 2010).

La metodología adoptada en la presente tesis doctoral parte por considerar al territorio como un "sistema complejo", y por "sistema complejo" se refiere a una representación de un recorte de la realidad, conceptualizado como una totalidad organizada en la cual sus elementos no son "separables" y por lo tanto, no pueden ser estudiados aisladamente (García, 2006). En este sentido, se trata de sistemas constituidos por un proceso determinado o por la confluencia de múltiples factores que interactúan de tal manera que no pueden ser analizados por separado, en definitiva, este abordaje implica lograr una síntesis integradora de la problemática original. De este modo, se plantea el abordaje desde una visión sistémica y compleja en función del objeto estudiado. Al tratarse de un fenómeno multidimensional, como lo representa la ocupación y apropiación territorial en urbanizaciones informales, se asume la denominada triangulación metodológica como procedimiento de investigación. La misma puede definirse como la combinación de múltiples métodos en un estudio del mismo objeto o evento para abordar mejor el fenómeno que se investiga (Cowman, 1993).

La articulación de diversos métodos permite construir una visión integral que contribuye en la mejor comprensión de la problemática. El abordaje metodológico que se adopta confronta el cuerpo teórico y la realidad, revalorizando el abordaje dialéctico. En este sentido, la relación entre el conocimiento y la realidad supone un proceso donde el valor reside en la 
problematización tanto teórica como empírica de lo que se pretende indagar. Por lo antes dicho, se trabaja con el método del estudio de caso como una de las herramientas fundamentales de investigación dentro de la instancia empírica y de aplicación en un caso concreto. Este método contribuye en la vinculación de la teoría con la empiria, permitiendo indagar detalladamente tanto en las causas como en los procesos en un caso concreto. Se propone entonces un esquema metodológico que contempla tres niveles de abordaje y análisis:

El primer nivel, denominado Nivel superior de abordaje $\mathbf{y}$ análisis se relaciona con la adopción del enfoque acerca cuestión teórica y los conceptos de territorio, ocupación y apropiación, por un lado, como conceptos abstractos y fundamentales para este trabajo. Por el otro lado, la informalidad urbana en el contexto de las ciudades capitalistas latinoamericanas, el acceso al suelo y la configuración del territorio. Este nivel se lleva adelante con base en los macro conceptos, los macro procesos y las teorías que los explican, haciendo referencia a los principales autores en cada tema. La escala territorial es múltiple ya que dependerá de los requerimientos del macro proceso / concepto que se esté analizando. Se trata de abstraer el análisis para poder comprender la complejidad del problema de investigación, pudiendo en los siguientes niveles, focalizar en las particularidades que hacen al objeto de estudio más concretamente.

El segundo nivel de abordaje, es el Nivel medio de abordaje y análisis y se relaciona con un enfoque centrado en el análisis de la totalidad de las urbanizaciones informales, tomando como escala territorial la denominada meso escala que representa el Partido de La Plata. En este nivel se articulan y operacionalizan aquellas dimensiones y variables desde donde pueden analizarse las cuestiones principales vinculadas con el proceso de ocupación del territorio. Este análisis tiene por objetivo presentar una caracterización general de las urbanizaciones informales del Partido de La Plata, explicando la ocupación como consecuencia de los macro procesos con incidencia en la configuración territorial, tales como la expansión urbana, la insuficiencia de políticas de intervención y planificación urbana, el precio de suelo urbano y rol del mercado de tierra. 
El tercer y último nivel de abordaje propuesto se denomina Nivel inferior de abordaje y análisis, y se vincula con el análisis territorial en la micro escala. En este nivel se focaliza en un caso de estudio en particular (Barrio Puente de Fierro), donde se analiza el proceso de ocupación y apropiación territorial en términos de sistemas de objetos y sistemas de acciones (Santos, 1996. Este análisis se lleva acabo principalmente teniendo en cuenta el relato de referentes, sus acciones y prácticas visibles en el territorio. En este sentido, se busca lograr la operacionalización del análisis en el territorio a partir de la aplicación de la teoría en la empiria en un caso concreto de la realidad. Para ello, por un lado, se analizan los sistemas de objetos (fijos) en el territorio, es decir la componente material, físicos y construidos que hacen a la historia y creación del barrio y se relacionan directamente con el proceso de ocupación. Por otro lado, los sistemas de acciones (los flujos), interpretados a partir de las transformaciones producidas en el barrio desde el momento en que se produce la ocupación y la componente simbólica, a partir del análisis de los sentidos de pertenencia y el apego al lugar manifestados por los propios habitantes y reflejados en sus acciones hacia el barrio.

Los métodos, técnicas y herramientas que se emplean en cada nivel del análisis, se definen en relación con la complejidad requerida en cada caso. En el nivel superior de análisis se parte del conocimiento de la bibliografía temática específica y diversos trabajos en relación a los macro conceptos, como los de territorio y espacio, que contribuyen a definir la postura epistemológica que guía toda la investigación. Los conceptos de ocupación y apropiación territorial, son trabajados desde el primer nivel de abordaje según el enfoque de las diversas disciplinas y autores. Por último, para el análisis de la informalidad urbana, entendida como una problemática actual de las ciudades latinoamericanas, resulta de suma de relevancia el conocimiento acerca de aquellos trabajos antecedentes especializados en el tema, mayormente desde el ámbito local.

El segundo nivel requiere de un análisis que contemple tanto aspectos cualitativos como cuantitativos, que explican el proceso de ocupación y apropiación en la meso escala. Se requiere la utilización y confección de cartografía 
temática con información primaria y secundaria, y la aplicación de la herramienta $\mathrm{SIG}^{3}$ (Sistemas de Información Geográfica) para la confección de mapas. En este nivel también se recurre a la foto lectura histórica, como técnica para determinar el proceso de crecimiento de la mancha urbana y las áreas de localización de las urbanizaciones informales vinculadas con proceso históricos reflejados en la configuración territorial.

Para llevar adelante el análisis en la micro escala se requiere de la combinación de métodos tanto cualitativos como cuantitativos. Por un lado, el análisis del proceso de ocupación del territorio se relaciona, principalmente, con la confección de cartografía específica partir de la recolección de datos mediante la observación directa y la toma de fotografías en las visitas al campo. Asimismo, se trabaja a partir del análisis de imágenes satelitales y fotografías aéreas históricas, así como el procesamiento de datos censales e información proporcionada por diversos actores. Para el análisis de la apropiación territorial en la micro escala se pone especial atención a las acciones llevadas adelante por los actores en el territorio. Para ello resultan fundamentales las entrevistas con los vecinos del barrio, algunos de ellos fundadores de primera, segunda o tercera generación, vecinos que habitan el barrio hace relativamente pocos años y otros que se encuentran participando activamente en cuestiones de mejoramiento del barrio a través de la pertenencia a distintas organizaciones sociales. El Esquema 4, presenta una síntesis de la metodología propuesta para el abordaje del objeto de estudio en este trabajo de tesis doctoral.

\footnotetext{
${ }^{3}$ Los Sistema de Información Geográfica (también conocido con los acrónimos SIG en español o GIS en inglés) representan un conjunto de herramientas que integran y relacionas diversos componentes (usuarios, hardware, software, procesos) que permiten la organización, almacenamiento, manipulación, análisis y modelización de grandes cantidades de datos procedentes del mundo real que están vinculados a una referencia espacial, facilitando la incorporación de aspectos sociales-culturales, económicos y ambientales que conducen a la toma de decisiones de una manera más eficaz.
} 
Esquema 4. Abordaje metodológico propuesto.

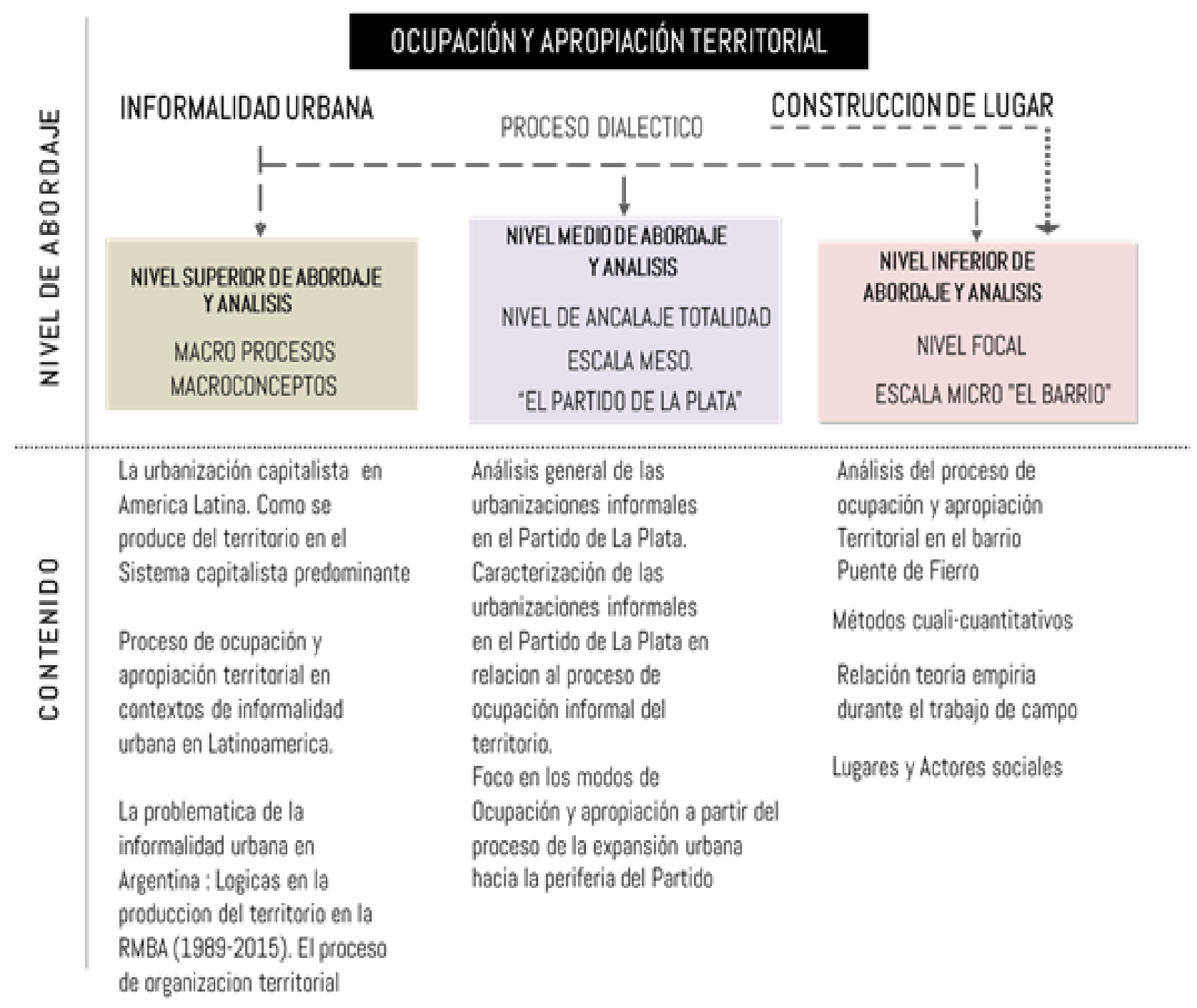

Fuente. Elaboración propia,2018. 


\section{Estructura de la tesis}

En este apartado, se presenta brevemente la estructura que organiza los apartados que componen este trabajo, con el objetivo de facilitar la lectura del mismo. En tal sentido, esta tesis se organiza a partir de dos grandes apartados y contiene un total de 7 capítulos.

La PARTE I de esta tesis doctoral contiene un total de tres capítulos que presentan aquellas aproximaciones al marco teórico metodológico y los antecedentes acerca de los conceptos principales a través de los cuales es posible comprender el proceso de ocupación y apropiación territorial en urbanizaciones informales. En los capítulos de la primera parte se busca introducir en el análisis de los macro procesos y los macro conceptos, como los de territorio, espacio y lugar, que constituyen el marco de referencia teórico que delimita el objeto de estudio y que fundamentan la postura epistemológica que se adopta desde un nivel de abstracción superior. En este sentido, las concepciones teóricas del enfoque territorial propuesto se construyen con aportes provenientes de la teoría social crítica del espacio, que en palabras de Santos (1998) refiere a la teoría desde la cual se pueda recrear el mundo a partir del lugar.

Otro autor dentro de la teoría social crítica del espacio, en el que esta tesis se apoya es Harvey, a partir de la teoría de la utilización y renta del suelo y de su valor de uso y de cambio, como una forma de analizar el espacio urbano en la ciudad capitalista contemporánea. En el análisis de Harvey el espacio es interpretado como un producto social, y se busca comprender su significado simbólico y sus complejas influencias sobre el comportamiento social (Harvey 1998). Las teorizaciones de Soja sobre el espacio, por su parte, señalan que la organización del mismo es un producto social que surge de la práctica social útil, y que las relaciones de poder están registradas en la aparente espacialidad inocente de la vida social.

Las concepciones teóricas sobre espacio, territorio y lugar son las que resultan fundamentales en la elaboración de esta tesis, y se abordan durante los primeros 
capítulos. Del mismo modo, en esta instancia se analizan aquellos antecedentes más significativos a partir de los cuales, se encuadra el enfoque adoptado y se justifica la vacancia teórica donde esta tesis se inserta. Finalmente, el análisis en la primera parte se lleva a cabo desde una perspectiva histórica y crítica que contribuye a explicar y comprender la problemática en términos de proceso en el territorio. Metodológicamente, como se detalló en el apartado anterior, los primeros tres capítulos se incluyen dentro nivel superior de análisis y abordaje, focalizado en los macro procesos y contextos globales que configuran el territorio de la denominada ciudad capitalista latinoamericana.

El CAPITULO 1 de esta tesis corresponde con el nivel de abordaje y análisis superior, por lo que requiere una mayor abstracción teórica. El objetivo central es el de presentar los conceptos principales, justificando la postura teórica y epistemológica adoptada en el marco del doctorado en geografía. El capítulo uno se divide en dos apartados; el primero toma en consideración las concepciones teóricas fundamentales que guían todo el trabajo. En este sentido, se presentan aquí los conceptos y categorías teóricas que se utilizan a lo largo de toda la tesis para abordar y comprender el objeto de estudio. En este sentido, el capítulo inicia con una aproximación teórica a los conceptos de territorio y espacio, confrontando diversos autores que adoptan distintos enfoques disciplinares en diferentes momentos históricos. Aquí se establecen aquellas teorizaciones más relevantes para este trabajo acerca del territorio como construcción social, focalizando en el vínculo que se crea entre los actores sociales y el territorio. A lo largo del capítulo se recurre al análisis de autores como Bourdieu, Santos y Haesbert entre otros.

El segundo apartado se concentra fundamentalmente en los antecedentes teóricos sobre el estado de la cuestión en relación con otros trabajos de investigación que estudian problemáticas similares, con el objetivo de justificar la relevancia de la problemática objeto de estudio en esta tesis. 
Se focaliza en la relación entre el territorio, los actores y los lugares, a partir de la comprensión de que en él se articulan las relaciones sociales y se gestiona el poder de forma dialéctica y dinámica, de modo que la construcción de lugares, ocupados y apropiados, obedece a las interacciones y relaciones sociales entre los actores sociales. El tercer apartado, denominado Ocupación y apropiación del territorio en la conformación del lugar, constituye una síntesis en donde se integra y explica la relación entre los actores sociales, quienes definen sus lógicas en el territorio y su participación en la creación de los lugares, y el proceso de ocupación y apropiación territorial, entendido como un proceso dialéctico en clave de sistemas de objetos(fijos) y sistemas de acciones (flujos) (Santos, 1996).

La segunda parte del primer capítulo presenta los principales antecedentes teóricos acerca de la problemática que hacen al estado de la cuestión. La misma se estructura a partir de tres ejes. El primer eje toma en cuenta trabajos acerca de la ocupación, apropiación territorial y la informalidad urbana. En este sentido se busca evidenciar la vacancia temática que se produce al encontrar antecedentes que abordan dichos conceptos de manera desagregada. Este eje pone de manifiesto el carácter de originalidad de esta tesis, al proponer una mirada integral sobre la problemática en cuestión. El segundo eje se concentra en los debates acerca de la problemática de la informalidad urbana y el acceso al suelo en América Latina, delimitando espacial y temporalmente al objeto de estudio, en sincronía con los principales referentes que trabajaron en el tema en el ámbito local. El tercer eje profundiza sobre la relación entre la pobreza y la informalidad urbana, un tema que ha sido objeto de estudio antecedente a esta investigación y sobre el cual se debatió durante las últimas décadas, por lo que en este trabajo se considera relevante de análisis.

Este tipo de investigaciones representan un antecedente valioso para comprender el territorio desde la mirada del actor, como principal hacedor y creador de lugares, haciendo referencia a la importancia de los movimientos sociales y a los sentidos de pertenencia que se generan entorno a la creación de un lugar. La ocupación y la apropiación del territorio y la informalidad urbana fueron 
estudiadas según la óptica de distintos referentes en todo el mundo y con énfasis hacia diversos objetos de estudio en múltiples universos teóricos. Resulta una vacancia temática la existencia de trabajos que relacionen al proceso de ocupación y apropiación territorial, con la problemática de la informalidad urbana en América Latina de la forma que se pretende demostrar en este trabajo de investigación.

La mayor parte de los trabajos de investigación antecedentes a esta tesis doctoral se especializan en el estudio de la apropiación de un espacio determinado, o en el establecimiento de modos o patrones de ocupación territorial, o bien en el estudio de la informalidad urbana y el acceso al suelo como procesos históricos y sociales de manera desagregada. El desafío de este trabajo consiste en realizar un aporte original de carácter teórico metodológico, desde un enfoque integrador con el objetivo de explicar la ocupación y apropiación territorial en urbanizaciones informales como un proceso dialéctico en el que se conjugan los objetos, las acciones, los acontecimientos y los actores en un territorio y en un momento dando como resultado la conformación de un lugar.

En el CAPITULO 2 se analiza la problemática de la informalidad urbana en el contexto de la ciudad capitalista latinoamericana. Este capítulo se centra en el análisis de los macro procesos relacionados con la organización y configuración del territorio de las principales ciudades de América Latina, interpretando a autores como David Harvey, Jaramillo y Topalov. Del mismo modo se hace referencia a la importancia del derecho a la ciudad en relación con las disputas por el espacio urbano, llevadas a cabo por distintos grupos sociales en gran parte de las ciudades de América Latina (Lefebvre, 1968; Harvey, 2012). Se pretende hacer gráficas estas nociones mediante la presentación de ejemplos que expliquen el modelo territorial capitalista en algunas de las ciudades más importantes de la región. Para ello se hace especial hincapié en aquellas particularidades comunes que comparten algunas de las ciudades latinoamericanas más importantes, producto de la lógica capitalistas de producción de suelo urbano, la ocupación informal del territorio, el funcionamiento del mercado de suelo y el derecho a la ciudad. 
El CAPITUlo 3, representa el último de la primera parte de esta tesis que mantiene el abordaje dentro de un nivel superior de análisis, modificando la escala geográfica para focalizar en la problemática de la informalidad urbana en Argentina, haciendo hincapié en aquellos procesos de carácter económico, social y político que permiten explicar la producción informal del suelo desde finales de los años '80 e inicio de los '90 hasta la actualidad. Este capítulo incluye una revisión histórica a partir de diversas fuentes y autores. El objetivo es el de comprender y explicar de qué manera incidieron en el territorio los cambios que se produjeron a nivel económico, político y social en la Argentina, poniendo especial énfasis en el Área Metropolitana de Buenos Aires (AMBA), durante el período 1989-actualidad. De este modo, se busca comprender la relación entre problemática de las urbanizaciones informales, el mercado de tierra y el acceso al suelo y así explicar la ocupación informal del territorio y las tipologías de urbanizaciones informales que surgen. Finalmente, este capítulo constituye el nexo entre la primera y segunda parte de la tesis y da paso a al nivel medio de abordaje y análisis en la meso escala.

La PARTE II de esta tesis se compone de un total de 4 capítulos en los que se profundiza el análisis en la meso y micro escala dentro de los niveles de abordaje y análisis medio e inferior respectivamente. Al interior de los capítulos se busca evidenciar empíricamente lo analizado de forma abstracta durante la primera parte, ya que resulta de gran importancia para este trabajo el contrastar los aspectos teóricos con la realidad en el territorio. El fin es poner de manifiesto en un caso concreto la dialéctica existente entre la teoría y la empiria y así materializar la postura teórica y metodológica que guía, estructura y le da coherencia a todo el trabajo. En este sentido, y con fines metodológicos, el estudio de caso resulta particularmente útil como herramienta de investigación empírica dentro del análisis de un fenómeno contemporáneo en su contexto situado y real.

El CAPITULO 4 se denomina La problemática de las Urbanizaciones informales en el Partido de La Plata, y corresponde con el análisis de la totalidad de las urbanizaciones informales de la periferia del Partido de La Plata (entendida metodológicamente como la meso escala). En primer lugar, se analiza la 
configuración territorial de la periferia del Partido de La Plata, explicando las causas y consecuencias de la expansión urbana residencial. En el análisis hace hincapié en las formas de ocupación del suelo urbano residencial, se buscar poner de manifiesto la heterogeneidad que caracteriza al área periferia del Partido de La Plata, y así dimensionar la problemática de la informalidad urbana. La caracterización de las urbanizaciones informales en el Partido de La Plata se realiza con el fin de visibilizar la magnitud de la problemática a nivel social y territorial, al mismo tiempo que se establecen las categorías de análisis y las principales tipologías de urbanización informal presentes en el territorio de la meso escala.

El CAPITULO 5 titulado, La ocupación territorial en la meso escala: Urbanizaciones informales en el Partido de La Plata, es resultado directo de la caracterización general de las urbanizaciones informales del Partido presentada en el capítulo 4. Este capítulo tiene como objetivo el análisis de la ocupación territorial en la meso escala, a partir del establecimiento dimensiones de análisis. La primera dimensión de análisis corresponde con la temporalidad del proceso, y en este sentido plantean tres cortes temporales que permiten explicar el proceso de ocupación desde una mirada contextual. La segunda dimensión de análisis tiene que ver con el reconocimiento y análisis de los atributos físicos del espacio, las condiciones de infraestructura, de accesibilidad y ambientales. Estas tres variables dentro de la dimensión físico espacial son las que materializan la problemática de la informalidad urbana y contribuyen a visibilizarla a través de los datos.

La tercera dimensión encierra las cuestiones vinculadas con las condiciones sociales en las urbanizaciones informales en la meso escala. Se analizan datos poblacionales a partir de la cantidad de familias, el tamaño de la urbanización y las condiciones de la población en relación al índice de necesidades básicas insatisfechas. Cabe mencionar que la cuestión social está presente y atraviesa todas las dimensiones del análisis, pero particularmente en esta dimensión, se pone de manifiesto la magnitud de la problemática con el cruce entre los resultados del análisis de las demás dimensiones. 
En el final del capítulo a partir de diversas fuentes se analizan los roles de los actores sociales en la meso escala, la lógica del Estado, del mercado y de la ciudadanía poniendo énfasis en la participación de cada actor en el proceso de ocupación y apropiación informal del territorio. El objetivo es comenzar a comprender la relación entre los objetos en el territorio y las acciones llevadas a cabo por los actores sociales. Se busca poner de manifiesto que esta relación no se da por separado, sino que son las acciones las que determinan las transformaciones territoriales y viceversa.

El CAPITULO 6 se titula Ocupación y apropiación territorial en la micro escala: El caso del Barrio Puente de Fierro. En este capítulo se procede al nivel de análisis y abordaje en la micro escala, por lo que todo lo analizado en capítulos previos se aplica de manera empírica en el caso particular de una urbanización informal del Partido de La Plata denominada Puente de Fierro. Este capítulo se divide en cinco apartados, el primero se encuentra en correlación con la metodología aplicada en capítulos anteriores y focaliza en el análisis del proceso histórico y la ocupación del territorio en el emplazamiento donde se localiza el caso de estudio. En tal sentido, el análisis del proceso histórico y contextual refiere a la creación y consolidación del barrio a partir de los relatos de los residentes y creadores. Al mismo tiempo, se pone en evidencia el valor simbólico del objeto, el puente de fierro propiamente dicho, como patrimonio histórico y cultural para la localidad de Altos de San Lorenzo y su importancia en la identidad del barrio.

En el segundo apartado se pone especial atención al análisis de la configuración actual del barrio en relación a las tres variables que constituyen los atributos físicos del espacio, tales como el acceso a los servicios básicos, las condiciones de accesibilidad y las condiciones ambientales. Este análisis, se presenta con una estructura similar al capítulo 5 en la meso escala, la diferencia radica en la profundidad del mismo, ya que en este apartado se focaliza en el caso de estudio, puntualizando en las particularidades de cada variable en Puente de Fierro. 
A partir del tercer apartado se analizan los roles de los actores sociales que participaron durante la conformación del barrio. Este análisis incluye entrevistas a actores vinculados directa o indirectamente con el proceso de ocupación y apropiación territorial en Puente de Fierro. En este sentido, se toman en cuenta las acciones llevadas adelante en el barrio, los sentidos de pertenencia, aspectos simbólicos y redes sociales comunitarias. Resulta fundamental la percepción de los actores acerca del proceso de ocupación y apropiación territorial en el barrio a través de sus relatos y las huellas y marcas visibles en el territorio. El objetivo es analizar la dialéctica que subyace en el proceso de ocupación y apropiación del territorio, que pone de manifiesto que al mismo tiempo que un territorio se ocupa, los actores sociales comienzan a apropiarse de él, es decir cargan significados dejando sus huellas, marcas, e improntas y definiendo ese lugar según sus lógicas e intereses.

En el proceso de ocupación y apropiación del territorio surgen, principalmente, dos categorías trabajadas por Santos (1996) los sistemas de objetos y los sistemas de acciones, asociadas con la configuración y con las relaciones sociales. En este sentido, la dialéctica del proceso de ocupación y apropiación en la micro escala parte del análisis tanto de los fijos en el territorio, como de los flujos, es decir aquellas relaciones y acciones llevadas adelante por los actores, en este caso del Barrio Puente de Fierro. A partir de los daros se busca reconocer las marcas e improntas en el territorio, así como aquellas prácticas y símbolos que hacen referencia a los acontecimientos en proceso, dando cuenta así de la ocupación y apropiación territorial en la micro escala.

Metodológicamente se trabaja con dos categorías de análisis que operacionalizan dicho concepto, la acción-transformación y la identificación simbólica. Para ello se llevan a cabo distintas técnicas de recolección de información como encuestas, entrevistas a informantes clave (creadores y habitantes del barrio, miembros de ONG y organizaciones sociales barriales); análisis de fotografías (foto lectura histórica), observación directa, etc. Cabe destacar la importancia de este capítulo dentro de esta tesis doctoral, ya que es el 
capítulo donde se sintetiza todo el trabajo realizado relacionando la teoría con la empiria y los distintos niveles de abordaje adoptados. A partir de comprender la importancia y magnitud de la problemática de la informalidad urbana en América Latina y en la meso escala, se pone el foco en el caso de estudio y las principales características que lo definen y diferencian de otros casos, con el análisis de los atributos físicos del barrio caso de estudio y la historia del mismo. De este modo, a partir del relato de los actores y el trabajo de campo, es posible profundizar en el análisis del proceso de ocupación y apropiación en la micro escala y la dialéctica subyacente en él, articulando con la postura teórica y epistemológica planteada.

En el CAPITULO 7 se sintetiza todo el trabajo realizado y se arriba a las consideraciones finales, reflexiones $y$ perspectivas que demuestran el cumplimiento de los objetivos planteados al inicio. En este sentido, todo el trabajo es revisado y reconstruido a la luz de los avances teóricos y empíricos producto de la investigación, con el fin de llegar a nuevos interrogantes. Se trata, en definitiva, de articular de manera lógica todos los capítulos de la tesis para finalmente posibilitar al lector una mirada integral acerca de la problemática en cuestión. A modo de síntesis, y para un mejor entendimiento, se presenta un esquema que representa la estructura y organización de esta tesis con las partes y capítulos que la componen (Esquema 5). 
Esquema 5. Estructura de la tesis

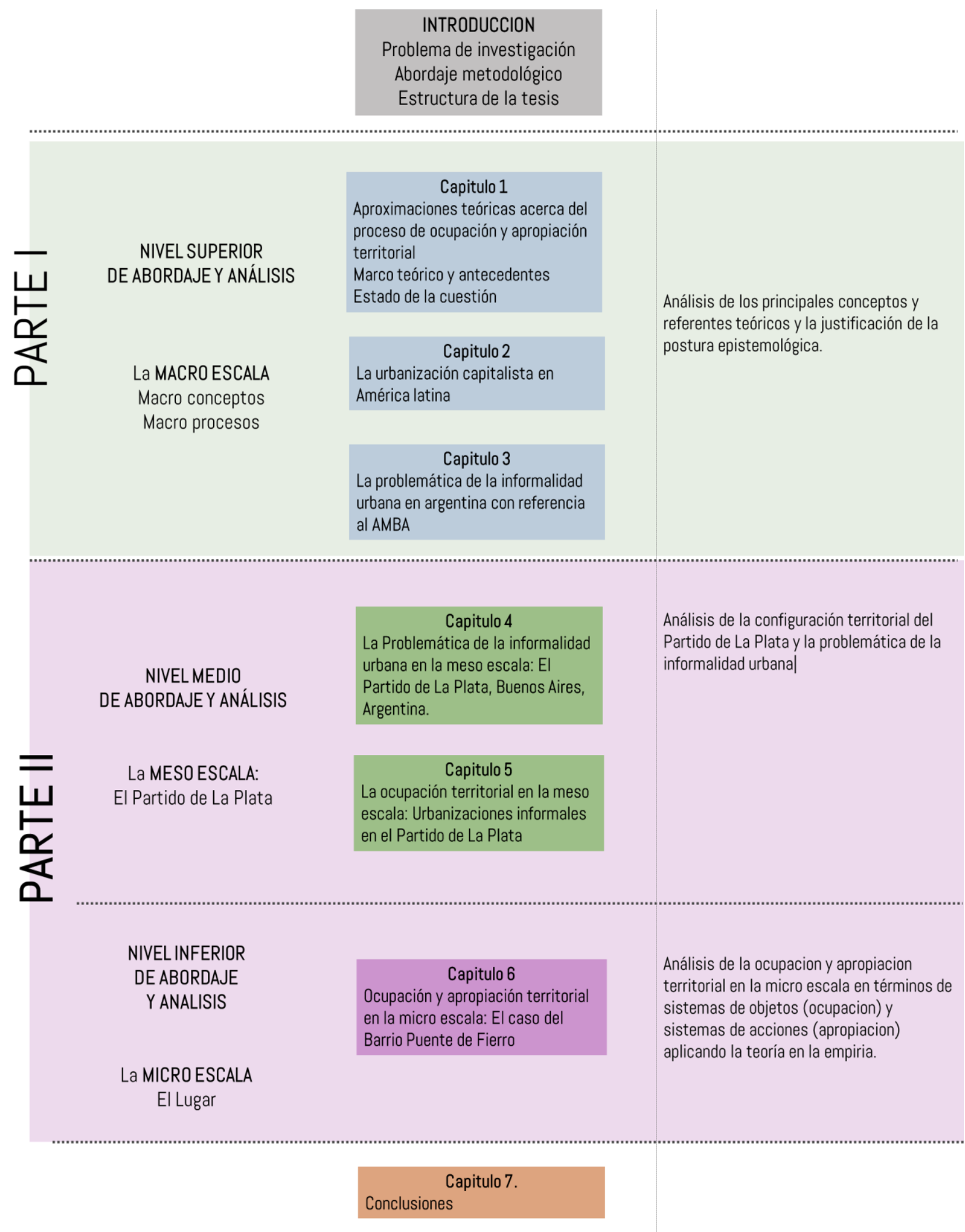

Fuente. Elaboración propia, 2019. 


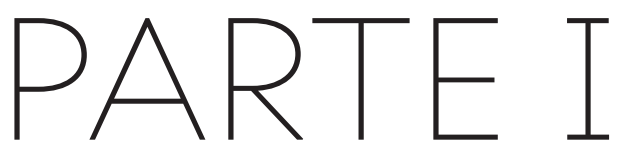

«El territorio no es apenas el resultado de la superposición de un conjunto de sistemas naturales y un conjunto de sistemas de cosas creadas por el hombre. El territorio es la tierra más la población, es decir, una identidad, el hecho y el sentimiento de pertenecer a aquello que nos pertenece. El territorio es la base del trabajo, de la residencia, de los intercambios materiales y espirituales y de la vida, sobre los cuales él influye. Cuando se trata sobre territorio se debe, pues, desde luego, entender que se está hablando sobre el territorio usado, utilizado por una población dada»

Santos, 2000 


\section{Capítulo 1}

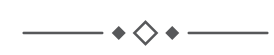

\section{Aproximaciones teórico conceptuales}

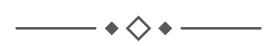

«El método de Marx y Engels consiste, precisamente en la búsqueda del vínculo que existe entre lo que los hombres piensan, desean, dicen y creen por si mismos, y lo que son, lo que hacen»

Lefebvre, 1976 


\subsection{Consideraciones generales sobre territorio y espacio}

El primer capítulo de esta tesis tiene como objetivo presentar al lector las principales concepciones teóricas y los antecedentes que representan las bases sobre las que se elabora este trabajo. En pos de la organización del capítulo, se lo divide en dos apartados, el primero presenta las consideraciones generales que marcan la postura acerca de los distintos conceptos que guían todo el trabajo. Se presentan los conceptos de espacio y territorio, a través de los cuales se fundamenta y explica la adopción de la postura teórica y epistemológica en relación con la tesis en el marco del doctorado en geografía. El segundo apartado por su parte, se concentra en el reconocimiento de los antecedentes más significativos para esta tesis, es decir, aquellos trabajos que han abordado la problemática desde distintas corrientes teóricas y enfoques disciplinares, teniendo en cuenta múltiples aristas.

En primer lugar, cabe mencionar que los conceptos de espacio y territorio se encuentran estrechamente vinculados, pero suelen generar algunas confusiones acerca de la lo que cada uno abarca y representa. En este sentido, es pertinente la distinción entre ellos ya que no resulta indistinto un término u otro, aunque muchas veces se utilicen como sinónimos. Tradicionalmente en las ciencias sociales se entiende al territorio como un macro - objeto de estudio, de una manera subordinada al espacio, constituyendo un concepto referido a una porción del espacio caracterizada por su uso y ocupación social. Desde esta perspectiva territorial son concebidos con un contenido similar el espacio social de Bourdieu o el espacio geográfico de Santos, por citar algunos ejemplos. La característica común que comparten estos conceptos radica precisamente en que el pasaje del espacio al territorio se encuentra dado por la mediación social. Al respecto Raffestín (1993) sostiene que el territorio se forma a partir del espacio, por una acción de apropiación concreta o simbólica por parte de un actor (Cirio, 2016). 
En lo que respecta a la concepción del espacio, en primer lugar y a efectos del abordaje del objeto de estudio de este trabajo de tesis, se rescata la postura epistemológica de Lefebvre (1976) y su teoría acerca de la producción del espacio con base en el materialismo histórico ${ }^{4}$, asegurando que las relaciones sociales se proyectan en el espacio, se inscriben a sí mismas en él a medida que se producen, siendo que, de otra manera quedarían en una pura abstracción. En este sentido, el autor identifica tres tipos ideales de espacio, el espacio percibido, concepto que engloba aspectos materiales de la vida cotidiana de producción y reproducción social; el espacio concebido, que refiere a representaciones del espacio, discursos socialmente construidos que resignifican los aspectos instrumentales; y, por último, el espacio vivido, que resulta de la interacción entre los dos espacios antes mencionados. Esta concepción se produce de igual manera sea a través de su asociación con imágenes y símbolos, como el espacio de los actores, o como la generación de contra espacios o espacios de resistencia al orden dominante, donde otros espacios materiales y simbólicos son imaginados y disputados.

La concepción del espacio de Lefebvre es interpretada como lo que algunos geógrafos, como Harvey (1998) denominaron materialismo histórico geográfico, haciendo referencia a la consideración conjunta del espacio social y del tiempo histórico en tanto productos sociales. De este modo, el espacio y la espacialidad se convierten en productor y producto de lo social (Soja, 1985). Por su parte Santos (1996) en su teoría social critica conceptualiza al espacio como un híbrido que forma parte tanto de la condición de lo social como de lo físico. Desde esta

\footnotetext{
${ }^{4}$ La concepción materialista de la historia es un término acuñado por Plejánov, que alude al marco conceptual identificado por Marx y usado originalmente por él y Engels para comprender la historia humana. El materialismo histórico investiga la sociedad humana, tratando de hacerlo sin presupuestos ideológicos, partiendo de los individuos empíricos y las relaciones que establecen entre ellos. A diferencia de los enfoques que muestran al capitalismo como un sistema estático o como el producto de una evolución "natural" del ser humano, la investigación históricomaterialista revela su carácter histórico y por lo tanto transitorio en el desarrollo de la humanidad.
} 
perspectiva los objetos y las acciones, materialidad y acontecimiento, resultan inseparables y constituyen la naturaleza social, histórica y dinámica del espacio.

Bourdieu (2000) por su parte, se aproxima a las concepciones de Santos sobre el espacio al concebirlo como uno de los lugares donde se afirma y ejerce el poder. Este autor profundiza su idea en la misma línea que afirma que en una sociedad jerárquica no hay espacio que no esté jerarquizado y no exprese las distancias sociales. Sin embargo, la diferencia entre autores radica en el hecho de que Bourdieu hace una diferenciación entre un espacio de carácter físico y un espacio de carácter social, en contraste con la propuesta por Santos que refiere a híbridos indisolubles. El espacio para Bourdieu se presenta como la distribución en el espacio físico de diferentes especies de bienes y servicios, y también de agentes individuales y grupos localizados físicamente provistos de oportunidades de apropiación de esos bienes y servicios (Bourdieu, 2000; en Cirio, 2016). De este modo, las disposiciones de lo que él denomina habitus ${ }^{5}$ son precisamente los mecanismos de posesión y posición en el espacio que producen territorio. En este sentido, los actores sociales no se consideran aislados, sino que son producto de la historia, esto es de la historia de todo el campo social y de la experiencia acumulada en el curso de una trayectoria determinada en el sub campo que se considere.

De este modo se define el espacio social, en donde se da lugar a valorizaciones diferenciales en función de la posesión de diversos tipos de capitales en un contexto de lucha por la apropiación. En este sentido, este trabajo de tesis adhiere firmemente a la concepción propuesta por Bourdieu (2000) al definir un espacio social y siendo que coincide en este punto, en parte, con la teoría de Santos (1996) al establecer la necesidad de distinguir las relaciones de poder en torno a los conceptos de apropiación y ocupación diferencial del espacio. En la misma

\footnotetext{
${ }^{5}$ Habitar para Bourdieu (2000) es significar y apropiarse del espacio. El hábitus hace que personas de un entorno social homogéneo tiendan a compartir estilos de vida parecidos, pues sus recursos, estrategias y formas de evaluar el mundo son parecidas.
} 
línea, Castells (1974), afirma que " desde el punto de vista social, no hay espacio, magnitud física, entidad abstracta en cuanto práctica, sino espacio-tiempo históricamente definidos, espacialmente construidos, trabajados y practicados por las relaciones sociales ".

Retomando el concepto de territorio, se entiende que el mismo puede considerarse como un producto y al mismo tiempo como un proceso de las relaciones sociales, recuperando la dialéctica espacial y siendo contenedor de procesos políticos, pero al mismo tiempo presentando singularidades que afectan activamente a dichos procesos (Di Virgilio, 2011). De este modo el territorio se presenta como un concepto un tanto más operativo que el de espacio en el campo de la geografía, que se ha expandido a diversas ciencias sociales que se ocuparon de los procesos de producción del espacio (Schneider; Tartaruga, 2008).

En este trabajo de tesis particularmente, para adoptar la definición de territorio, se identificaron dos corrientes teóricas que guían la adopción de la postura teórica y epistemológica: una de carácter más hegemónico, en donde se insiste con la concepción de soporte de las relaciones sociales, en su mayoría centradas en estudios locales, sin hacer referencia a los procesos que los generan; y otra línea surgida como fuerte respuesta problematizando el concepto, preguntándose cómo las diferencias de la producción espacial y territorial son organizadas y reproducidas, y por qué tipos de relaciones de poder. Es a esta segunda línea, de carácter crítico, a la que este trabajo suscribe y desde donde se decide problematizar y darle enfoque al objeto de estudio.

Entre los aportes que incluyen al territorio como un concepto crítico y explicativo de la realidad, resulta importante destacar a autores como Sack (1996) y Raffestín (1993). Por su parte Raffestín define al territorio como una manifestación espacial del poder, fundamentada en relaciones sociales que son determinadas en diferentes grados por la presencia de energía (acciones y estructuras concretas) y de información (acciones y estructuras simbólicas), y hace hincapié en la multi dimensionalidad del poder, rompiendo la asociación al 
poder del Estado, y por lo tanto, la concepción clásica del territorio que lo asociaba estrictamente con su delimitación jurídico-política-administrativa.

Por su parte Sack (1996) le otorga al territorio un carácter socio-histórico ya que, para este autor, el mismo se encuentra en constante disputa y movimiento. En este sentido, un área puede ser utilizada como un territorio en un momento o período cualquiera y perder esta calidad en otro. En sus palabras, "un área para ser territorio necesita de un esfuerzo constante para mantener las estrategias para influenciar y controlar el acceso a través de sus límites, y cuando estos cesan el atributo territorial también lo hace” (Sack, 1996). Estos autores dieron inicio a la ruptura ideológica con las acepciones tradicionales del concepto de territorio, que como se mencionó anteriormente, se encontraban sujetas sólo al carácter jurídico administrativo, al proponer el estudio del territorio basado en su historia, en su conformación y en su conflicto, no sólo entre naciones, sino también entre clases. En este sentido, se consolido un campo donde lo territorial comenzó a ser problematizado al entenderlo como el resultado del uso que hacen del espacio los seres humanos. Es decir, el territorio tomado como objeto de análisis social en tanto construcción humana, un espacio socialmente apropiado (Santos, 2000).

El caso de Oliveira (2001) resulta interesante de introducir en el análisis teórico, ya que ha problematizado la relación entre espacio y territorio afirmando que "es fundamental comprender que el espacio es una propiedad que el territorio posee y desenvuelve y por eso, es anterior al territorio". En este sentido, el territorio es a su vez es un espacio transformado por el trabajo y, por lo tanto, una producción humana, espacio de lucha de clases o fracciones de clase siendo, en consecuencia, el lugar de lucha cotidiana de la sociedad para su devenir (Oliveira, 2001). Si bien el autor no toma la concepción de Lefebvre o Santos acerca del espacio, sí resalta de esta conceptualización que el concepto de territorio gana en operatividad y, por lo tanto, permite enfatizar la disputa y la lucha por su apropiación, dominación y delimitación. En ese sentido, este trabajo 
de tesis también suscribe a dicha forma de entender y abordar los conceptos de espacio y el territorio.

Por su parte Haesbaert (2013) marca una doble connotación sobre el concepto de territorio, en tanto material y simbólica. Por un lado, el concepto aparece asociado a la dominación de la tierra, y por otro inspira una identificación (positiva) y una apropiación simbólica. De igual modo para López de Souza (1995), el territorio es entendido como "el espacio determinado y delimitado por y a partir de relaciones de poder que define así, un límite y que opera sobre un sustrato referencial". En este sentido, el territorio se define a partir de las relaciones sociales y de poder, pudiendo estar vinculado hacia diferentes escalas de análisis y atravesado por diversos procesos económicos, políticos y/o culturales.

Haesbaert (2013) logra una aproximación a partir de la distinción realizada por Lefebvre (1981) entre espacios dominados y apropiados, entiende que por dominación se refiere al sentido más funcional y concreto asociado al valor de cambio, mientras que la apropiación es un proceso de carácter más simbólico, en el que se cargan las marcas de lo vivido y en el que predomina el valor de uso. El primero tiende a comprender una visión más unifuncional de territorio único, y el segundo es siempre múltiple, diverso y complejo (Gonzalez, 2010). Por último, cabe destacar que, etimológicamente, la palabra territorio proviene de las palabras latinas terra y torium, que significan la tierra que pertenece a alguien (Lobato Correa, 1997, en G. Montañez Gómez, 2001). Por lo tanto, se entiende que tierra y alguien, "tierra" entendida como un lugar del planeta cualquiera sea su escala y "alguien" como un actor, un grupo social, un sector social o una sociedad, determinan al territorio como concepto que nace de manera dialéctica.

A modo de síntesis, y luego del análisis conceptual expuesto, al referirse al territorio se está refiriendo a un lugar de variada escala donde actores del Estado, del mercado y de la ciudadanía, ponen en interacción sistemas de acciones y sistemas de objetos, constituidos éstos por un sinnúmero de técnicas, híbridos 
naturales y artificiales, identificables según particulares acontecimientos, en tiempo-espacio, y con diversos grados de inserción en la relación local-mesoglobal (Bozzano, 2009).

Se desprende de lo anterior, que el territorio no es solo la sociedad en acción, tampoco solo es la naturaleza ni el sustrato físico natural y/o construido. En sentido amplio es soporte natural y sociedad en interacción dialéctica, en constante cambio y transformación. Lo presentado hasta el momento representa, en este trabajo de tesis, un recorrido teórico para poder llegar a un entendimiento acerca del territorio que no es único ni absoluto, sino que se nutre de lo expuesto por los autores mencionados hasta el momento.

\subsubsection{El territorio como construcción social}

Del análisis presentado se desprende el territorio como un lugar de variada escala, micro, meso o macro, donde los actores públicos y privados ponen en marcha procesos complejos de interacciones complementarias, contradictorias, conflictivas y/o cooperativas entre los sistemas de acciones y los sistemas de objetos, constituidos por un sinnúmero de técnicas, híbridos naturales y artificiales, e identificables según instancias de un proceso de organización territorial en particulares acontecimientos en tiempo-espacio, y con diversos grados de inserción en la relación local-meso-global (Bozzano, 2009). En la misma línea y teniendo en cuenta que el territorio siempre se re define, en el presente apartado surge un interrogante sobre cómo se articulan en entonces la sociedad y el territorio en una unidad indisoluble en la que se pueden identificar procesos, lugares y actores.

Para dar respuesta, se introduce al concepto de territorialidad, definido en un espacio concreto, en un momento dado y con límites precisos. La territorialidad es socialmente construida (Sánchez, 1991 en Laurín, op cit) y forma parte del proceso de producción del espacio al entrar en interacción la sociedad con un territorio determinado que se transforma producto de esa interacción. Este 
proceso de transformación es considerado como de territorialización, ya que involucra la afirmación de la influencia o el control sobre un área determinada geográficamente, por parte de una organización o un individuo (Sack, 1980).

En este sentido, Haesbaert (2013) considera al territorio como "el resultado de un proceso de territorialización que implica un dominio (aspecto económicopolítico) y una apropiación (aspecto simbólico-cultural) de los espacios por los grupos humanos" (Gómez, 2006). Por lo tanto, el territorio implica posesión, uso y control, límites y soberanía y la territorialidad por su parte funciona como una estrategia espacial, donde los sistemas de objetos y los sistemas de acciones (Santos, 1996) se ven vinculados a través de normas que regulan y controlan el acceso y la apropiación de recursos. Las normas, dentro de esta concepción, cumplen la función de constituir la base de toda organización territorial al articular la territorialidad en un espacio y tiempo determinados. Su función es organizar y regular el uso del territorio y constituyen entonces el nexo entre los sistemas de objetos y sistemas de acciones, es decir que tienen carácter arbitrario y remiten a la territorialidad y la acción del Estado.

El territorio como espacio/tiempo divisible y transitorio de la ocupación y apropiación implica una específica estructura social y particulares relaciones de poder espacializadas, expresando una construcción social activa y compleja (Rodríguez, 2008). Al mismo tiempo el territorio se ve atravesado por la historia, la cultura, los procesos ambientales y naturales, los procesos políticos y de corte estructural, pero también lo atraviesa una dinámica que corresponde a los actores sociales, con intereses que interactúan entre sí, muchas veces con interés trasformador. Es en este espacio social-territorial donde los actores participan de campos sociales específicos, donde se configuran las condiciones sociales y materiales de accesibilidad a recursos estratégicos, equipamiento, infraestructuras, determinadas leyes e ilegalismos, usos, costumbres, representaciones, etc. En definitiva, donde se dan las condiciones de producción, de apropiación y de re significación de aquellos capitales sociales, económicos, culturales y simbólicos que están en juego (Bourdieu; Wacquant, 1986). 
Un entendimiento adecuado del territorio implica reconocer la lucha y negociación entre múltiples actores con distintas lógicas por la gestión del mismo y la generación de transformaciones como un fenómeno multi escalar y complejo del que se puede dar cuenta atendiendo a las interacciones concretas de los individuos, grupos y organizaciones sociales que luchan para definir y defender sus propios espacios sociales, fronteras culturales y posiciones dentro de un campo de poder más amplio (Long, 2007).

\subsubsection{Territorios, lugares y actores}

A partir de reconocer al territorio como una construcción social, se pone de manifiesto la importancia que tiene el actor en la definición del mismo. Autores como Hiernaux, Lindón y Noyola (2000) hacen referencia al concepto de construcción social del territorio al incorporar la voz de los actores para comprender el entramado de sentidos y las interacciones concretas con los que éstos construyen y reconstruyen un territorio en un proceso incesante de construcción de un conocimiento compartido que "incluye referentes territoriales, formas de identificar el territorio, de apropiarse de él, hacerlo un lugar o muchos lugares, es decir, cargarlo de códigos simbólicos" (Hiernaux; Lindón y Noyola, op cit:20-21).

Surge entonces el concepto de lugar, que para Bourdie (2000) representa un espacio de lucha entre actores sociales con intereses diversos, y para explicarlo resulta necesario adoptar una perspectiva multidimensional. Se entiende por actor (sujeto) al ser humano representativo de un colectivo, agrupación u organización política, económica o ciudadana de tamaño diverso que desarrolla al menos cuatro capacidades: desarrolla intereses, acumula recursos cognitivos y materiales, satisface necesidades y tracciona hechos (Bozzano, 2005). Se entiende que un lugar también representa un híbrido, entre formas de ocupación y formas de apropiación, mientras el primero se relaciona en mayor medida con sistemas de objetos, la apropiación está ligada a los sistemas de acciones (Santos, 1996). Es por esto que, en un lugar, los sistemas de objetos y sistemas de acciones, los fijos 
y flujos, el trabajo vivo y trabajo muerto, la forma y la función, la configuración territorial y relaciones sociales, todos ellos son inseparables, funcionan dialécticamente y no existe uno sin el otro. Autores como Oakes (1997) parten del supuesto que establece que el lugar puede ser definido como el local de la actividad (acción) inmediata del actor, lo que muestra la diferencia entre lugar y región ya que, en la región, el sentido de identidad es una abstracción para los individuos y es también el local de identidades significativas.

Como se ha mencionado los lugares no existen sin los actores que los hacen, trabajan, disfrutan y padecen. En este sentido, las categorías objeto y acción, materialidad y acontecimiento, deberían ser tratadas de forma unitaria. En cada momento hay una relación entre el valor de la acción y el valor del lugar donde se realiza. Por ello, el valor del espacio no es independiente de las acciones que es susceptible de acoger (Santos, 2000). Santos (Santos; 2000:85) afirma "Estamos empapados de siglos de inducción y deducción, de análisis y más análisis y no tenemos ejercicio suficiente de pensamiento dialéctico. Debido a que la realización concreta de la historia no separa lo natural y lo artificial, lo natural y lo político, debemos proponer otro modo de ver la realidad, opuesto a este trabajo secular de purificación, que está basado en dos polos distintos". Latour (1991) en la misma línea se pregunta ¿Por qué en la construcción epistemológica, no es preferible partir de los híbridos en vez de partir de la idea de conceptos puros? Dando respuesta, Hagerstrand (1991) propone tratar de forma simultánea el mundo de la materia y el mundo del significado humano. En el mismo sentido que Godelier (1966) explica que todo sistema y toda estructura deben ser abordados como realidades mixtas y contradictorias de objetos y de relaciones que no pueden existir separadamente.

A modo de síntesis, se entiende que en un territorio se articulan relaciones sociales y se gestiona el poder de forma dialéctica y dinámica, cuando se produce la disputa por un territorio es entonces la disputa en torno a determinadas representaciones y formas de relaciones sociales enfrentadas (González, 2010). De este modo la construcción de territorios y sus lugares obedece a las 
interacciones y experiencias sociales que permitan su control, en el primer caso, y su apropiación subjetiva, en el segundo.

\subsubsection{Ocupación y apropiación del territorio en la conformación del lugar}

En apartados anteriores y siguiendo a Santos (1996) se presentó y analizó el concepto de territorio, entendido como un híbrido entre formas de ocupación y modos de apropiación, mientras que los modos de ocupación se relacionan en mayor medida con sistemas de objetos, las formas de apropiación están ligadas a los sistemas de acciones en la conformación de lugares.

En relación con la apropiación y la conformación de lugares, la propuesta de Lefebvre (1991), que también ha sido utilizada por Haesbaert (1997; 2004; 2013), utiliza dos categorías analíticas. Las mismas señalan, por un lado, al desarrollo de la sociedad capitalista y del espacio socialmente construido como un factor determinante en la producción del territorio, y por el otro la categoría de los espacios dominados y la de los espacios apropiados. En este sentido, resulta necesario aclarar que Lefebvre no utiliza la palabra territorio, él solamente remite al espacio, como se ha mencionado, a pesar de estar en ese momento hablando de relaciones de poder. En ese sentido, los territorios apropiados serían aquellos utilizados para cubrir las necesidades y las posibilidades de un grupo determinado. De este modo los espacios se convertirían en lugares de apropiación simbólica y de identidad, además de funcional, por lo tanto, la apropiación sólo puede tener inicio en el lugar de cada individuo. Por su parte, los territorios dominados serían aquellos espacios transformados y también dominados (Schneider ;Tartaruga, 2006).

En su análisis, Bourdieu (1999) apunta a un espacio social entendido como la materialización de las relaciones de poder y las interacciones entre los actores, donde despliegan sus capitales estructurando las diferencias con una dialéctica de conflicto y en una continua proyección de sus representaciones sociales. En Bourdieu las disposiciones del habitus son los mecanismos de posesión y 
posición sobre/en el espacio los que producen territorio (Bourdieu, 1999). Resulta interesante adentrarse en las relaciones complejas y variadas que se establece entre los actores y el territorio, al transformar el espacio a medida que se establece el proceso de ocupación, apropiación, junto con la dotación de sentido, involucrando relaciones identitarias que finalmente pueden ser analizadas a través de la categoría de lugar. En este sentido, para el análisis del proceso de ocupación y apropiación territorial y la construcción de los lugares, posiblemente sean los recuerdos referenciales en espacios concretos donde los actores experimentaron una historia de vida los que marquen el hilo conductor de cómo es llevado a cabo dicho proceso.

\subsection{Antecedentes teóricos}

En el presente apartado se analizan los principales antecedentes teóricos, que terminan de definir la postura teórica y metodológica adoptada. El apartado se divide en tres, en un primer momento, se abordan antecedentes en relación con trabajos de investigación que incluyen los conceptos de ocupación, apropiación e informalidad urbana, ya que éstos son los principales que se elaboran para el desarrollo de esta tesis. La segunda parte presenta los aspectos relacionados con los debates acerca de la problemática de la informalidad urbana y el acceso al suelo en América Latina. Resulta necesario identificar qué tipos de trabajos abordan la problemática dentro del nivel superior de abordaje y análisis en el ámbito latinoamericano, ya que son muchos los estudios sobre el tema, y si bien no es específicamente el objeto de estudio de esta tesis, es una de las aristas del análisis. Por último, la tercera parte retoma un punto que resulta interesante para el análisis de la ocupación y apropiación territorial en urbanizaciones informales, y es la relación entre la pobreza y la informalidad urbana. En este sentido, existen posturas que relacionan directamente ambas cuestiones y otros que, por su parte, marcan una diferencia conceptual que resulta de suma importancia tomar en cuenta para un abordaje integral. 


\subsubsection{Ocupación, apropiación e informalidad urbana}

La relación y los procesos inherentes a la interacción entre el ser humano y el territorio han sido objeto de estudio durante décadas de diversas disciplinas como la geografía, la sociología urbana, la psicología ambiental, etc. Problemáticas como la informalidad urbana, la ocupación y apropiación del territorio, han sido trabajadas por distintos referentes en todo el mundo y con énfasis hacia diversos objetos de estudio en múltiples universos teóricos. Resulta una vacancia temática la existencia de trabajos que relacionen al proceso de ocupación y apropiación territorial, con la problemática de la informalidad urbana en América Latina, entendiendo que es a partir del proceso de ocupación y apropiación territorial que se construyen y se les da sentido los lugares. La mayoría de los trabajos antecedentes a esta tesis doctoral se especializan en el estudio de la apropiación de un espacio determinado, en el establecimiento de modos o patrones de ocupación territorial o en el estudio de la informalidad urbana y el acceso al suelo como procesos históricos y sociales de manera desagregada.

El desafío de este trabajo consiste en el enfoque integrador propuesto, a partir del cual surge el objetivo de analizar la ocupación y apropiación territorial como un único proceso en el cual se conjugan los objetos, las acciones, los acontecimientos y los actores en un territorio y en un momento dado, y que por resultado tiene la conformación de lugares. Principalmente, el estudio del estado de la cuestión da cuenta de la vacancia de investigaciones de carácter integral acerca del proceso de ocupación y apropiación territorial. Dicha vacancia se acrecienta aún más si se observa este proceso referido al contexto de la informalidad urbana, una problemática muy estudiada y sobre la cual es posible encontrar gran cantidad de investigaciones y debates, principalmente aplicados en países de América Latina.

La mayor parte de los trabajos de investigación que analizan los procesos de ocupación del territorio suelen tener distintos tipos de objetos de estudio en 
relación al tipo de ocupación. Es posible reconocer aquellos trabajos que se dedican al estudio de los procesos de ocupación del territorio de manera formal, es decir aquellos procesos que se desarrollan conforme la planificación urbana y las legislaciones existentes, y por otro lado aquellos estudios que se dedican a los procesos en un marco de informalidad, ilegalidad o irregularidad como es el caso de Cravino (2006, 2008) y Clichevsky (2000), dos autoras latinoamericanas cuyo trabajo se construye sobre esta línea temática. En este sentido, la presente tesis doctoral hace especial referencia al análisis de aquellos procesos de ocupación territorial (en la meso y micro escala) que encuentran explicación en procesos informales en relación a los modos de acceso al suelo.

Un primer enfoque tiene que ver con antecedentes teóricos sobre de los modos de acceder al suelo, ya que distintas formas y estrategias determinan diversos patrones y lógicas de ocupación, así como modos de apropiación. En este sentido, los aportes de autores tales como McDonald (1998) y Smolka (2003) evidenciaron que, a lo largo de la década de 1990, en pleno auge de las reformas estructurales, la informalidad en el acceso al suelo y la ocupación del mismo en las ciudades latinoamericanas pasó de ser excepcional a ser generalizada. Estos autores señalan que este proceso se debió a varios factores, tales como la creciente necesidad de espacios urbanos para el hábitat, la preeminencia del mercado en el modelo neoliberal y un Estado con intervención mínima para regular el funcionamiento del mercado de suelo. Estos factores sumandos a la expansión de las ciudades sin planificación, generaron que una parte importante del suelo para el asentamiento de la población de menores ingresos se provea a través de transacciones comerciales irregulares o no comerciales (Mac Donald, 1998).

La modalidad de acceso y ocupación informal del territorio aparece entonces como la única opción para muchas familias imposibilitadas de acceder al suelo urbano por la vía formal y genera repercusiones negativas, tanto sociales como económicas, legales, políticas, etc., no solo para las familias habitantes, sino también para los gobiernos de las ciudades y la población urbana en general 
(Fernández y Smolka 2004). En el caso de la utilización del concepto de apropiación, uno de los principales antecedentes para esta tesis acerca de los estudios sobre la apropiación del espacio es llevado a cabo por Lefebvre (1974), cuyo pensamiento es considerado uno de los más sugerentes de la sociología urbana moderna y que ha influido en muchas otras disciplinas como la geografía social y la geografía social crítica. Las investigaciones realizadas por Lefebvre, contienen numerosas referencias a la apropiación del espacio y aunque su anclaje teórico es muy anterior a este trabajo de tesis, suele aparecer en sus enunciados sobre el materialismo dialéctico y en sus tesis sobre la cotidianidad, como una crítica en su reflexión acerca de la sociedad urbana. Este aporte es posiblemente una de las contribuciones más significativas al propósito del urbanismo y del estudio de la articulación entre el espacio, la configuración urbana y la vida social.

Esta perspectiva sobre el habitar y la apropiación del espacio complementa y amplia las investigaciones sobre la producción del mismo, y se encuentra ligada estrechamente a su crítica de la cotidianidad y al proyecto de reconstrucción del materialismo dialéctico. A partir de estas concepciones es posible abordar una visión global de la teoría urbana de Lefebvre sobre la complejidad de la ciudad, de la vida social y de la configuración urbana. La apropiación del espacio para Lefebvre designa básicamente el conjunto de prácticas sociales que confieren a un espacio determinado las cualidades de un lugar; la apropiación, por lo tanto, exige en todo momento una producción, la necesidad y el deseo de hacer. Para esta tesis doctoral los aportes de este autor resultan un insumo valioso en tanto antecedente al objeto de estudio, en particular aquellas reflexiones relativas al habitar y a la apropiación del espacio, enmarcándolas en su perspectiva teórica y perfilando sus implicaciones de ser operacionalizadas y de poder transformador de la realidad siempre compleja, en relación con los designios que desde el poder pretenden dominar el proceso de producción del territorio y fijar las prácticas de sus habitantes.

Otro aporte a destacar en relación al concepto de apropiación que data del año 2005 (muy posterior al trabajo de Lefebvre) es el llevado a cabo por Tomeu 
Vidal Moranta \& Enric Pol Urrútia, cuyo interés parte de disciplinas como la psicología social y ambiental. En este sentido el trabajo llevado a cabo por los autores consiste en una propuesta teórica para comprender la vinculación entre las personas y los lugares. Resulta interesante el abordaje del concepto de la apropiación del espacio, basado en los vínculos entre las personas y los espacios, entendidos como construcción social de lugares, donde se destacan el espacio simbólico, la identidad y el apego al lugar como principales conceptos categorías de análisis de la apropiación. Al mismo tiempo, este trabajo hace referencia a que dichos conceptos pueden ser explicados desde la apropiación, hipótesis que ha sido contrastada en este tipo de trabajos de manera empírica.

La línea de trabajo llevada adelante por Vidal y Pol, se interesa en las peculiares formas de construir las relaciones de los actores y el territorio, poniendo cierto énfasis en la dimensión psicosocial, donde la cuestión de la exclusión o la inclusión es otra clave en la forma de generar significados y vínculos con los entornos. En este sentido, para estos autores y del mismo modo para esta tesis, se trata de investigar la relación entre las experiencias cotidianas y las nociones de lugar que construyen los actores, enfatizándose las acciones que se llevan a cabo en un lugar y tiempo determinado y las emociones, pautas y nociones que de éstas se derivan de forma conjunta y complementaria.

\subsubsection{Debates sobre la informalidad urbana y el acceso al suelo en América Latina}

En este apartado interesa particularmente destacar aquellos antecedentes acerca de la problemática de la informalidad urbana desde abordajes en los cuales se prioriza una perspectiva teórica y empírica que focaliza en trabajos sobre América Latina en general, y en Argentina en particular. En este sentido, resulta fundamental mencionar que la problemática de la informalidad urbana se ha convertido durante los últimos años, en uno de los temas más discutidos en la reflexión acerca de los procesos urbanos, en América Latina y el en el resto mundo también. Resulta muy extensa la lista de los autores que han reflexionado 
acerca de este fenómeno en el campo internacional y de las metrópolis latinoamericanas específicamente bajo el análisis de distintas disciplinas. Sin embargo, en este apartado no se pretende compendiar dicha lista de autores, sino interpretar aquellas reflexiones que existen hasta el momento sobre la problemática de la informalidad urbana en relación con el proceso de ocupación y apropiación territorial.

En primera medida y para lograr un entendimiento del problema, es preciso mencionar que existen diferentes y múltiples interpretaciones acerca del fenómeno de la informalidad urbana, por lo que la reflexión se realiza en torno a los distintos tipos de enfoques ideológicos, disciplinares, regionales, etc. Comprender y tener en cuenta las diversas interpretaciones resulta fundamental en este trabajo de tesis para afrontar un análisis original. En este sentido, es importante tener en cuenta que el concepto de informalidad, inicialmente, se originó haciendo referencia al modo en que históricamente se resolvió la relación entre el capital y el trabajo entre sectores que no lograban insertarse en la economía moderna. Este fenómeno se dio principalmente en las ciudades latinoamericanas que crecieron y se densificaron en virtud de él.

El pasaje de entender la informalidad solamente como la relación capitaltrabajo a los posteriores debates de carácter territorial sobre la informalidad en el modo de acceso al suelo y a la vivienda se debe, en principio, a que los procesos asociados a la informalidad provocaron un cambio en la estructura socio espacial de las ciudades y en la forma en la que los actores sociales se insertan informalmente en el mercado de trabajo y el modo en que resuelven su acceso al mercado de tierra y vivienda. En ese marco, la noción de informalidad supera las problemáticas asociadas al mercado de trabajo y se hace extensiva para caracterizar, también, a la forma en la que se resuelve la relación con el mercado de tierra y vivienda y con el sistema de propiedad (Herzer, 2006). De esta manera el concepto de informalidad es re significado, desde el campo económico donde tuvo su origen, hacia temas referidos a las problemáticas socio territoriales como el proceso de urbanización capitalista y el acceso al suelo. 
Durante las últimas décadas, los debates latinoamericanos acerca de la informalidad urbana giraron fundamentalmente en torno al mercado de tierra y el acceso al suelo (o la dificultad en) y como estos configuran el denominado hábitat informal, entendido como una realidad socio-espacial compleja y como producción de suelo urbano que busca consolidarse y ser parte de la ciudad. En este sentido algunos autores como Clichevsky (1975) y Jaramillo (1982) referentes en Latinoamérica y otros referentes extranjeros como es el caso de Smolka (1981), representan algunos de los principales exponentes que abordaron la problemática de la informalidad urbana en América Latina desde la perspectiva del acceso al suelo y los mercados en torno a la tierra.

Este tipo de debates en América Latina comenzaron a producirse a partir de la década de 1990, tanto a nivel académico como de políticas nacionales e internacionales de intervención en urbanizaciones informales. En ese marco comenzaron a plantearse las primeras controversias acerca de la utilización de términos como legalidad-ilegalidad, formalidad-informalidad y/o regularidadirregularidad en torno a la problemática del acceso al suelo en América Latina. El uso de un término $\mathrm{u}$ otro en muchos casos hace referencia a distintas perspectivas sobre el tema y para comprenderlas, es necesario establecer un dialogo entre perspectivas tales como la jurídica, económica, política y social, debido a la complejidad que presentan conceptos tales como ilegalidad; informalidad o irregularidad al referirse a las formas de acceder al suelo por parte de sectores sociales de escasos recursos.

En este sentido, una de las primeras cuestiones que aparece en la literatura tiene que ver con la utilización de los términos, y esto remite a dos grandes posibilidades de abordaje y reflexión. Por un lado, a qué se refiere cuando se utilizan categorías como ilegal-informal-irregular; y por otro, en qué consisten dichos conceptos. Sobre el concepto de ilegalidad un primero autor, Calderón (1999) reflexiona "añadir al mercado de tierras el adjetivo de informal e ilegal agrega un elemento al acto en sí de una transacción económica, que es la que se viola o contraviene el ordenamiento jurídico. Conceptual y teóricamente, la 
dimensión jurídica resulta intrínseca al fenómeno de estudio" (Calderón 1999). Sin embargo, el autor considera que en la investigación urbana en Latinoamérica generalmente, se utilizan indistintamente cuatro términos que aparecen como sinónimos intercambiables: informal, ilegal, irregular y clandestino. En su discurso, Calderón denomina ilegal a la acción que realiza tanto un propietario como un promotor inmobiliario que no se ajusta a las normas jurídicas existentes. Por su parte la calidad de informal aparece por tratarse de acciones que no se enmarcan en las reglas establecidas y que desarrollan actividades que generan ingresos y beneficios por fuera de las regulaciones estatales. Esta diferenciación apunta a distinguir al interior de lo ilegal las actividades consideradas criminosas, de aquellas vinculadas a las actividades económicas como lo informal (Portes, 1995 en Calderón, 1999).

Otro autor que reflexiona sobre la problemática es Duhau (2002) quien utiliza los conceptos de irregular o informal indistintamente, al referirse tanto a la forma de calificar determinado espacio urbano como a las formas de apropiación existentes en el mismo: En términos del no cumplimiento de normas jurídicas que regulan las relaciones de propiedad o las formas de producción del espacio urbano aplicables en cada caso, es decir, que las prácticas predominantes de acceso al suelo se hacen extensivas a un territorio, nominándolo de igual manera.

Queda claro que la perspectiva adoptada por Calderón y Duhau sostiene una postura en donde el foco se pone en la relación entre el conflicto legal y los modos de acceso al suelo. En este trabajo de tesis no basta solamente con incluir el debate sobre la perspectiva legal, sino que para sostener un análisis integral de la problemática de la informalidad urbana resulta necesario ampliar la mirada hacia otros campos y autores con distintos enfoques. En este sentido surge la propuesta de Clichevsky (2000) quien amplia el debate apartándolo de lo exclusivamente jurídico (legal) al introducir el concepto de informalidad en el acceso al suelo desde una doble perspectiva: (I) tanto urbano- ambiental - ocupación de tierras con problemas de inundaciones, sin infraestructura, con difícil acceso al lugar de trabajo, educación, servicios primarios de salud, con napas contaminadas, etc. 
Ocupación de inmuebles abandonados por diferentes razones; (II) como legal, ocupación de tierra pública o privada, loteos clandestinos e irregulares; venta de lotes rurales como propiedades indivisas; etc. Del mismo modo se distingue al interior de esta segunda dimensión un gradiente de situaciones que varían de acuerdo a la magnitud del fenómeno.

Sumado al aporte de Clichevsky, los debates y perspectivas se amplían aún más al incorporarse algunas de carácter integral como es el caso de Smolka y Damasio (2005 en Viana, 2007) quienes hacen referencia a la informalidad definida como un fenómeno multidimensional que involucra problemas vinculados a la propiedad del suelo urbano, las normas y regulaciones vigentes, el número y la calidad de los servicios provistos, la calidad ambiental del área en que tiene lugar el asentamiento y el proceso de ocupación en sí mismo.

En relación con lo expuesto frente a los diversos debates teóricos, en esta tesis se optó por la denomina urbanizaciones informales a todo tipo de asentamiento cuyas formas de ocupación del suelo no se ajustan a las normas urbanísticamente establecidas, ni a parámetros ambientales y cuyas características físicas del entorno revisten cierto grado de precariedad. Esta concepción de la informalidad pretende integrar tanto aspectos jurídicos (legales) como formales, entendiendo que la informalidad urbana puede darse tanto en las formas de acceso al suelo en su proceso mercantil, así como en los modos de ocupación del territorio y asentamiento, generalmente sobre áreas degradadas, frágiles ambientalmente y no aptas para el asentamiento humano.

\subsubsection{Pobreza e informalidad urbana}

Son varios los antecedentes que históricamente vinculan la informalidad urbana y los procesos de ocupación informal del territorio con la problemática de la pobreza en América Latina. Sobre finales de la década del '50 y principios de la década del '60 muchos académicos comenzaron a poner atención sobre la relación entre las dinámicas sociales y las connotaciones espaciales y territoriales 
del proceso de urbanización informal en las ciudades latinoamericanas. Esto se debió principalmente a que, durante estos años, las tradicionales estructuras del trazado colonial de las principales ciudades comenzaron a ser desbordadas por nuevos barrios que no habían sido planificados. Una de las principales características territoriales de estos desbordes consistió en la aparición de urbanizaciones informales, en muchos casos localizadas en áreas de riesgo ambiental y sitios urbanos no aptos para el asentamiento humano. En la mayoría de los casos, las urbanizaciones informales se localizaron cercanas a los lugares de trabajo, medios de transporte y vías principales de comunicación, con el fin de mejorar la movilidad de los habitantes de este tipo asentamientos. En cuanto al acceso al suelo urbano, se ocuparon intersticios de tierras vacantes siguiendo una modalidad de estructura habitacional que iba desde la agrupación de viviendas de carácter precario por agregación, hasta loteos pirata en grandes parcelas, generalmente como extensiones de la traza urbana existente. Este proceso en pocos años significó la transformación de las ciudades y generó un profundo impacto a nivel político y social, a tal punto que comenzó a ser problematizado durante los años '60 como un nuevo fenómeno social y urbano.

Una de las disciplinas académicas que primero reflexionó acerca del fenómeno de la pobreza urbana y las urbanizaciones informales fueron la antropología y la sociología urbana, partiendo de la idea de que la pobreza urbana es una forma de exclusión multidimensional económica, social y cultural. En este sentido, el estudio de Lewis (1959) analizando el caso de cinco familias pobres en la ciudad de México utilizó el concepto de cultura de la pobreza ${ }^{6}$, es decir, del círculo donde la mala alimentación, la imposibilidad de alcanzar una mejor educación, y las deficientes condiciones de vida empeoran el ambiente donde se reproduce la pobreza.

6 Se llama cultura de la pobreza a un concepto antropológico creado por el antropólogo Oscar Lewis mientras estudiaba los problemas de la gente que vive en chabolas y barrios urbanos. En su estudio (1961-1966) Lewis describió a los pobres de las ciudades de México, Nueva York y Lima. 
La visión de la inevitabilidad de la pobreza despertó un primer debate con antropólogos como Stokes (1962), quien clasificó los asentamientos pobres como asentamientos de la desesperanza y asentamientos de la esperanza. La réplica a este razonamiento provino de quienes estudiaban los asentamientos en las ciudades de Latinoamérica. Por su parte Turner $(1967 ; 1969)$ demostró como la pobreza encierra una gran racionalidad debido a que los pobres que solían asentarse en las ciudades no eran ciudadanos inmóviles y desesperanzados como se creía, sino todo lo contrario, trabajaban sin descanso para mejorar su condición. Ellos construían su vivienda, mejoraban el entorno de su barrio y si no había empleo se generaba una actividad, es decir producir, ahorrar e invertir para el desarrollo. Si bien esto sucedía en un contexto con precariedad de medios, las acciones llevadas a cabo, sin lugar a dudas, construían un tipo de ciudad (Turner en Cravino, 2009).

Pradilla (1982) analiza este tema desde una postura crítica preguntándose de qué manera los sectores sociales de escasos recursos en Latinoamérica se ven imposibilitados en el acceso al suelo y a una vivienda adecuada, principalmente por el hecho de no poseer ingresos o por tener muy bajos ingresos y no poder ser sujetos de crédito para el sector financiero; y por tener la vivienda en venta o alquiler un elevado precio en el mercado, producto de su oferta limitada en las economías capitalistas dependientes. Este autor describe las características del acceso al suelo en la realidad latinoamericana, primero realizando un análisis pormenorizado de las tipologías del acceso al suelo, tales como los emplazamientos sobre tierras no adecuadas, urbanizaciones piratas, $\mathrm{y}$ posteriormente analizando las principales características de la autoconstrucción de la vivienda.

Hacia fines de la década de los años ‘80 y principios de los ‘90, los debates sobre la informalidad urbana y la pobreza abandonaron aquellas consideraciones teóricas que tuvieron un carácter fundante en los años 70 , y se concentraron hacia el análisis y reflexión sobre las políticas nacionales e internacionales de intervención en urbanizaciones informales. Desde la sociología, los primeros 
debates sobre pobreza urbana en Latinoamérica datan de los años 70, y proponían abordar el tema desde la exclusión como desventaja social y aquellas prácticas discriminatorias hacia los sectores sociales de bajos recursos de las distintas aglomeraciones urbanas (Merklen, 2005; Cravino, 2008; Grimson, 2009).

Las urbanizaciones informales han sido vinculadas históricamente desde el imaginario colectivo de la sociedad en general y de algunos medios masivos de comunicación, como lugares propensos a los hechos de violencia, el delito e inseguridad, la marginalidad y la pobreza. Autores latinoamericanos, como es el caso de Cravino (2006; 2012) y Segura (2013) han estudiado esta problemática desde los actores sociales principalmente, es decir, la visión antropológica de las relaciones sociales especializadas en un territorio co-construido. Este tipo de investigaciones representan un antecedente valioso para esta tesis para comprender el territorio desde la mirada del actor como principal hacedor y creador de lugares, haciendo referencia a los movimientos sociales y a los sentidos de pertenencia a un lugar.

A modo de síntesis, al revisar los antecedentes acerca del proceso de ocupación y apropiación territorial en urbanizaciones informales, el estado del arte dice que existen investigaciones de carácter separatista, donde se pueden observar trabajos sobre la ocupación territorial o la apropiación del espacio con distintos enfoques, o algunos que vinculan dos conceptos como urbanizaciones informales y ocupación territorial cuando se habla acerca del acceso al suelo. Estos trabajos quedan sesgado ya que cuando se habla de problemáticas territoriales, resulta necesario articular procesos, lugares y actores a fin de lograr una comprensión clara de la totalidad (Esquema 6). 
Esquema 6. Síntesis principales conceptos del marco teórico.

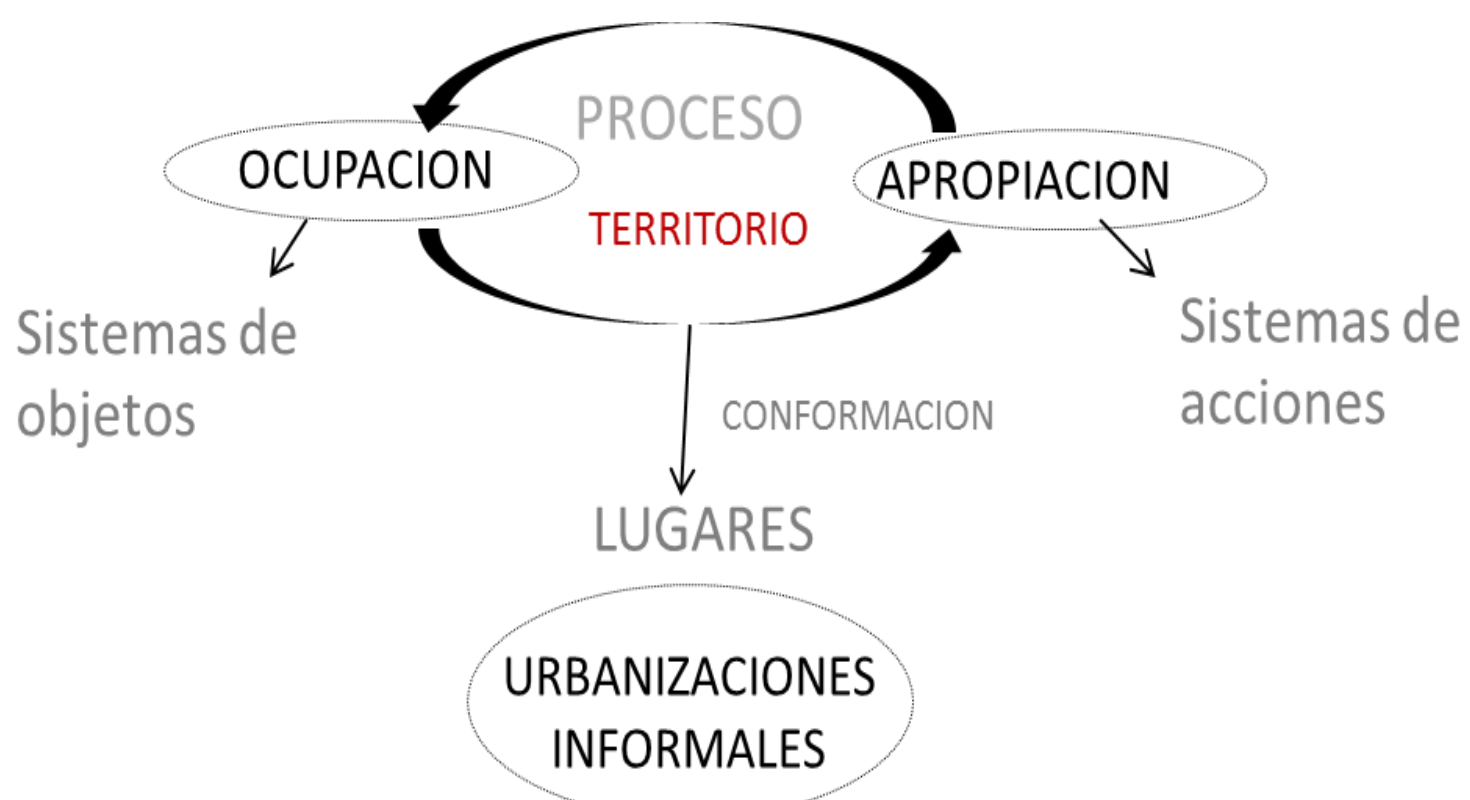

Fuente. Elaboración propia, 2019. 


\title{
Capítulo 2
}

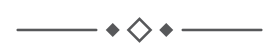

\section{La urbanización capitalista en América Latina}

\begin{abstract}
$-\bullet \diamond-$
"Consideramos al espacio como una instancia de la sociedad, al mismo nivel que la instancia económica y la instancia cultural-ideológica. La economía está en el espacio, así como el espacio está en la economía. Lo mismo ocurre con lo político-institucional y con lo cultural-ideológico. (...) En ese caso el

espacio no puede estar formado únicamente por las cosas, los objetos geográficos, naturales o artificiales, cuyo conjunto nos ofrece la naturaleza. El espacio es todo eso más la sociedad. (...) Lo que da vida a esos objetos, son los procesos sociales representativos de una sociedad en un momento dado »
\end{abstract}


El segundo capítulo de esta tesis de doctorado aborda aquellos aspectos que caracterizan a las ciudades latinoamericanas dentro de un contexto globalizado eminentemente capitalista. Para ello se plantea una estructura en cinco partes, introduciendo algunos ejemplos donde se analizan particularidades comunes en relación con los macro procesos que forman parte de los temas centrales en este trabajo, tales como la producción de suelo urbano, la informalidad urbana como estrategia de acceso al suelo, el mercado de tierras y el derecho a la ciudad en las principales ciudades latinoamericanas. Se busca el alcance del objetivo propuesto para este apartado, que consiste en profundizar en el conocimiento acerca de la problemática de la informalidad urbana en latinoamericana, entendida como el resultado en parte, de la expansión urbana por fuera de la planificación y la dificultosa calidad en el acceso al suelo en el contexto del modelo capitalista actual.

\subsection{La ciudad fragmentada}

La producción de la ciudad en el capitalismo se transformó en las últimas décadas en un tema complejo de estudio, reflexión y debates. En la actualidad, y a la luz de los procesos de expansión urbana, de las dificultades de acceso al suelo y a la ciudad para los sectores de menores recursos y de los conflictos que emergen de la revalorización de áreas postergadas en las sociedades latinoamericanas, este tema toma relevancia dentro de los movimientos sociales, territoriales y en los ámbitos académicos, donde es abordado desde distintas disciplinas como la sociología urbana, la economía, la arquitectura, la geografía y la antropología, entre otras. En primer lugar, para comenzar este apartado denominado La ciudad fragmentada, y para comprender el porqué de la elección de este título, resulta necesario hacer referencia a la ciudad latinoamericana capitalista y las características que la definen por lo menos en el contexto actual. En este sentido, cabe mencionar que América Latina se caracteriza por ser una región periférica en el sistema político-económico mundial, dependiente económica, financiera y tecnológicamente de los países centrales con sus respectivas manifestaciones sociales y territoriales comunes y particulares en cada ciudad. En este sentido, la 
imposición del patrón neoliberal de acumulación de capital, ha dado lugar a una creciente desigualdad del desarrollo capitalista entre los países centrales y los dependientes, como es el caso de los países de América Latina, y entre estos últimos, se ha acentuado la fragmentación y la diferenciación en sus formas territoriales.

Existen rasgos generales propios de la Región que han sido gestados históricamente y agudizados durante el neoliberalismo que hacen viable la construcción de explicaciones latinoamericanas en torno a particularidades comunes (Pradilla Cobos, 2014). Por este motivo, es posible hacer referencia a la ciudad latinoamericana de manera generalizada, aunque existan particularidades de acuerdo con cada país y sociedad si se analiza minuciosamente. Esto no quiere decir que todas las ciudades latinoamericanas lleven adelante exactamente los mismos procesos.

En este trabajo de tesis, se considera que las particularidades comunes que caracterizan a la Región, mayormente en relación al objeto de estudio, resultan de un interés mayor y más valioso si se analizan en conjunto, lo que permitiría explicar los procesos actuales. Estas particularidades comunes tienen que ver con que estos territorios se caracterizan principalmente por presentar fenómenos tales como la dispersión, la fragmentación, la segregación, la exclusión y la informalidad urbana, a tal punto que el proceso de urbanización informal ha acabado por ser el elemento dominante en la producción de ciudades en los países latinoamericanos.

Es posible observar en las imágenes de la Figura 1 algunas situaciones de carácter similar en ciudades de distintos países de América Latina. Por un lado, un escenario urbano perteneciente a la ciudad de Buenos Aires en donde se puede diferenciar el emplazamiento comercial y financiero de Puerto Madero, una de las zonas empresariales más importantes de la ciudad, pero en contraste muy cerca también, la presencia de una urbanización informal, que conforma parte de la denominada Villa 31 (una de las más grandes y emblemáticas del país) debajo de la autopista Buenos Aires- La Plata. Esta situación se observa de igual 
manera en la ciudad de Caracas, Venezuela, donde también es posible identificar el mismo contraste entre la informalidad urbana y una zona de torres que parecerían funcionar como residencia en altura. La imagen muy precaria de sucesión de techos que no siguen un determinado trazado urbano se encuentra separada de la zona de torres por una autovía. Esta imagen expresa una gran polarización a pesar de que ambas urbanizaciones se encuentran a una distancia relativamente cercana. El caso de Brasil y sus reconocidas favelas es uno de las más señalados desde hace tiempo, tanto que las favelas han llegado a convertirse en motivo de visitas de turistas de todo el mundo. En la Figura 1 se puede observar el emplazamiento de una favela con sus típicas construcciones, y en el fondo de la imagen, casi como un marco, torres de vivienda que nada tienen que ver con el cuadro asociado a la informalidad que representa este tipo de urbanización, relacionado con el hábitat de sectores pobres o de escasos recursos de la sociedad y estigmatizados por la violencia y el delito.
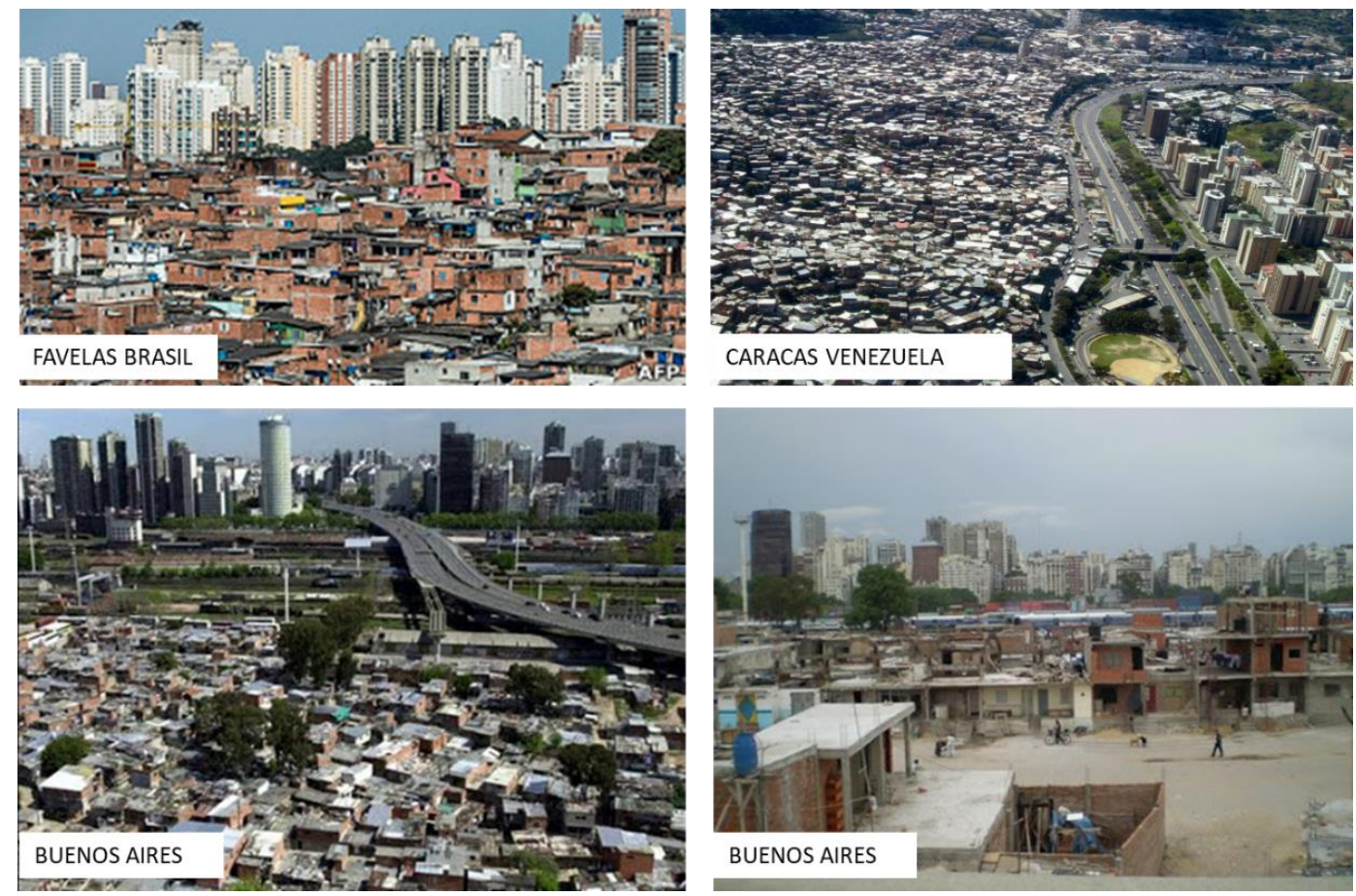

Figura 1. La ciudad fragmentada en Latinoamérica, contrastes y polarización. Fuente. Imágenes tomadas de internet. 
A partir de lo enunciado se debe mencionar que la producción informal del territorio no es un fenómeno reciente en América Latina, sino que desde hace décadas es posible identificar procesos de este tipo en la mayoría de las ciudades más importantes. Sin embargo, el modelo de ciudad fragmentada en América Latina cobró impulso como tal a partir de los años ochenta, en el marco de una fuerte reestructuración económica y política que replanteó el posicionamiento de las principales ciudades frente al fenómeno global del neoliberalismo.

Abordar la complejidad de la ciudad latinoamericana actual implica conocer sus características y condiciones que se enmarcan en dentro de los contextos históricos y estructurales del proceso capitalista. Es por ello que el estudio de fenómenos como la fragmentación urbana, resulta de gran relevancia, en la medida en que refleja la influencia que tienen en la configuración de las ciudades algunos de los procesos mencionados tales como la reestructuración económica y los cambios en el mundo del trabajo, la composición de los hogares y la diversificación de pautas culturales y del consumo. Al mismo tiempo, dichos procesos provocan significativas transformaciones en los patrones de estratificación social que se manifiestan en la localización de la población en el espacio urbano. De tal forma, para ilustrar estos procesos resulta adecuado mencionar los conceptos de quartered cities (ciudades fragmentadas) introducido por Marcuse (1996) y el concepto layered cities (ciudades en capas), considerando que las áreas de una ciudad se encuentran separadas por espacio y tiempo y que constituyen el soporte de diferentes grupos y sectores sociales que interactúan entre sí a través de relaciones que reflejan su distancia y desigualdad social (Marcuse \& Van Kempen, 2000; Veiga \& Rivoir, 2001).

Se evidencia así la tendencia hacia la polarización, que pone de manifiesto el aumento de las desigualdades entre sectores sociales de la población urbana de manera fragmentada, con una diversificación de la estructura social y con un incremento de la ocupación sin planificación por parte de los sectores medios y medios bajos sobre las áreas periféricas. En este sentido, la ciudad fragmentada como concepto que representa a la ciudad latinoamericana no resulta una simple 
consecuencia de las desigualdades socioeconómicas, sino que es el resultado de la diferenciación social en el espacio y constituye procesos que se retroalimentan.

\subsection{La producción del territorio en la ciudad capitalista de América Latina}

El neoliberalismo es ante todo una teoría de prácticas político-económicas que afirma que la mejor manera de promover el bienestar del ser humano consiste en no restringir el libre desarrollo de las capacidades y de las libertades empresariales del individuo dentro de un marco institucional, caracterizado por el derecho a la propiedad privada, mercados libres y libertad de comercio. El papel del Estado, radica en crear y preservar el marco institucional apropiado para el desarrollo de estas prácticas (Harvey, 2007). Topalov, en 1979 advertía, "La ciudad capitalista está en crisis; subempleo, pobreza, carencia de viviendas y de equipamientos colectivos, polución, opresión en todos los aspectos de la vida cotidiana, he ahí los frutos amargos y universales de la carrera por la ganancia capitalista y del autoritarismo del Estado de los monopolios."

En este marco, el presente apartado busca analizar el rol de la urbanización como mecanismo de producción territorial dominante llevado adelante en la ciudad capitalista latinoamericana actual, entendiendo a la misma como una forma de socialización y territorialización de las fuerzas productivas y sus procesos derivados tales como el proceso de ocupación y apropiación territorial en contextos de informalidad urbana.

El proceso dinámico y a la vez dialéctico que supone la ocupación y la apropiación del territorio no puede analizarse sin comprender primero las modalidades de acceso al suelo y las distintas estrategias adoptadas por distintos grupos sociales para acceder al territorio en ciudades que, como se ha mencionado, presentan características tan asociadas con la fragmentación y la polarización. En este sentido, se encuentran por un lado aquellos que gozan de diferentes privilegios en cuanto al acceso al suelo y a la vivienda, y por el otro, los que constituyen el último eslabón del sistema dominante, quienes luchan por el 
acceso a la tierra dentro de un contexto socio espacial y económico que expulsa a los más vulnerables y con falta de recursos.

Para comprender el territorio y modo en que éste se produce y reproduce, en primer lugar, se debe tener en cuenta que la urbanización en el caso de América Latina se presenta como un fenómeno multidimensional, y el mismo sólo puede estudiarse de una manera integrada, articulada y dialéctica. A través del análisis histórico es posible identificar el efecto de los diversos procesos migratorios del campo a la ciudad que produjeron transformaciones a nivel urbano en muchas de las ciudades de la Región. Estas transformaciones provocaron la extensión urbana más allá de los límites, lo que provocó la creación de áreas periféricas difusas donde se evidencian simultáneamente procesos formales e informales de producción del hábitat. En este sentido Harvey (2012) explica que, durante el proceso de globalización neoliberal en América Latina, la acumulación por desposesión ocurrió bajo las formas de privatización de las economías dependientes, afectando a los sectores más pobres de sociedad que fueron despojados de todo derecho a la ciudad.

En América Latina la producción del espacio de la urbanización capitalista es, y ha sido en particular una forma de poder social, de este modo las ciudades se convierten en espacios ideales para el despliegue de los procesos neoliberales. Se entiende que dichos procesos según Theodore, Peck y Brenner (2009) cuentan con ciertas metas, específicamente en cuanto a las políticas urbanas que tienen que ver con el crecimiento económico orientado al mercado, el consumo por parte de las elites y el control de poblaciones excluidas. De este modo, los espacios urbanos en la ciudad capitalista latinoamericana pasan a desempeñar papeles estratégicamente significativos con consecuencias extremadamente polarizadoras como se puede observar en la Figura 2 y Figura 3. Las áreas urbanas en el caso de ciudades de Argentina y Brasil, en donde existe una marcada polarización del espacio urbano que se evidencia en el contraste que existe entre dos tipos de edificación que forman el escenario urbano. 


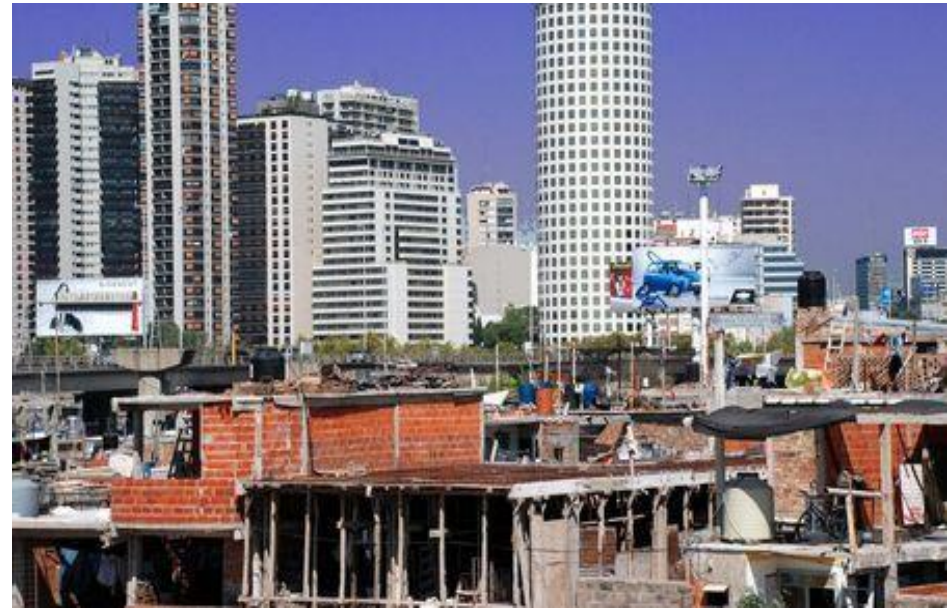

Figura 2. Ejemplo polarización: La villa 31 de Buenos Aires y zona de Puerto Madero. Fuente. Imagen tomada de intenet, 2019.

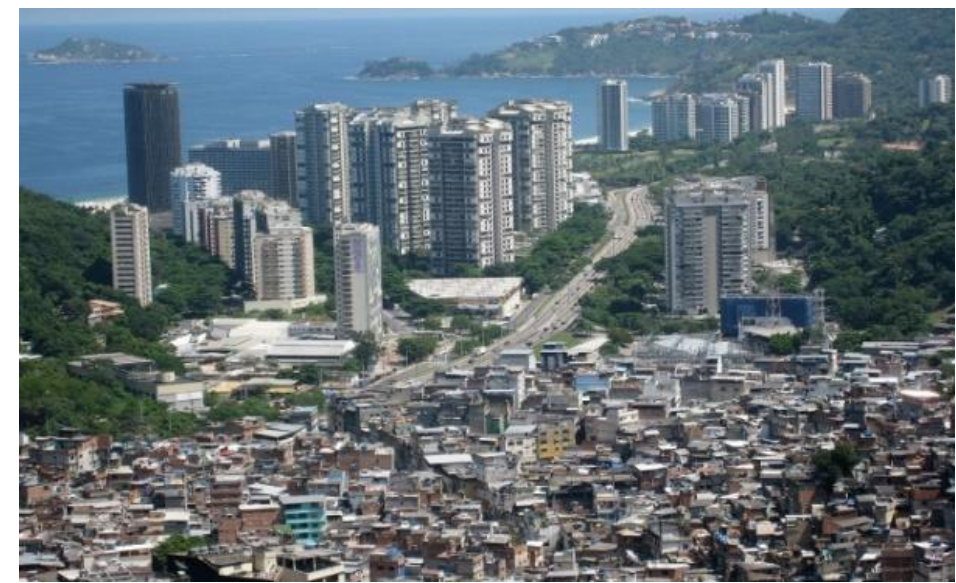

Figura 3. Ejemplo : La polarización urbana en Brasil. Fuente. Imagen tomada de internet, 2019.

Siguiendo esta línea Jaramillo (2008) asume que la estructura espacial de las ciudades latinoamericanas tiene rasgos peculiares vinculados al carácter periférico de la acumulación capitalista. Estos rasgos se manifiestan en un acelerado crecimiento poblacional, demanda de espacio construido e infraestructura básica, que en simultaneo, se ve acompañado de un lento crecimiento económico, que se combina con un régimen de salarios bajos y una masa marginal ${ }^{7}$ que puja por entrar en el mercado que se construye alrededor de

7 Término acuñado por Jaramillo para hacer referencia a un grupo de la población que no es absorbida laboralmente por la economía capitalista y que no necesariamente es funcional al sistema. 
las grandes ciudades. Pírez (2013) señala que la urbanización en las ciudades de América Latina en los últimos años se caracterizó por el peso continuo, y aún creciente de procesos de des mercantilización social por medio de diferentes procedimientos, tales como la producción irregular de suelo urbano, la distribución clandestina de servicios, la autoproducción de vivienda y equipamientos, etcétera. Cicolella (2012) explica que en la mayoría de las ciudades latinoamericanas se verifican los siguientes fenómenos: expansión de la mancha urbana, poli centrismo o al menos, tendencias al mismo; tendencias a la ciudad-región y al crecimiento reticular; expansión de la base económica, especialmente basada en servicios; difusión o proliferación de nuevos objetos urbanos (shoppings, hipermercados; urbanizaciones cerradas, edificios inteligentes, etc.); suburbanización difusa, tanto de élites como de sectores pobres o populares, incremento de la polarización social; incremento o consolidación de la segregación residencial; aparición de nuevos distritos de negocios o formación de redes de distritos corporativos y reestructuración neoliberal (desregulación-privatizaciones) como factor explicativo de estos procesos territoriales.

En este contexto, analizar las estrategias y formas de acceso al mercado de tierra y vivienda que adoptan los grupos más desfavorecidos de la sociedad, permite comprender y explicar el proceso actual de producción de suelo urbano dentro del modelo de ciudad capitalista latinoamericana. Muchas veces en América Latina se aplicaron medidas asistenciales muy puntuales que atendieron a situaciones críticas, principalmente en relación con la situación de la vivienda. Sin embargo, estas medidas no resultan suficientes ya que, por lo general, tienden a consolidar una cultura asistencialista y se encuentran muy lejos de resolver las problemáticas estructurales a las que las ciudades latinoamericanas se ven sometidas. En tal sentido el diseño, implementación y evaluación de las políticas públicas en materia planificación urbana, vivienda y hábitat, se posiciona como un componente fundamental a los efectos de incorporar la participación social, las iniciativas existentes, el diagnóstico previo y seguimiento de la situación. De este modo resultaría posible fomentar un cambio de paradigma tal como propone 
Harvey (2012) en relación a la forma en que actualmente se producen y reproducen las ciudades y sus territorios en pos de la inclusión y la distribución equitativa, en definitiva, de fomentar la producción de ciudades más justas.

\subsection{La ocupación informal de territorio como estrategia de acceso al suelo en América Latina}

Los patrones de estructuración urbana en América Latina están determinados en forma compleja por las lógicas de formación de las rentas del suelo urbano, tanto en los territorios periurbanos o intersticiales metropolitanos, así como en las áreas ya integradas donde se articulan las viejas y nuevas condiciones estructurales de la acumulación de capital (Jaramillo, 2008). La informalidad urbana en América Latina puede ser explicada, por un lado, como consecuencia de las condiciones macroeconómicas tales como la falta de empleo, la baja salarial y el consecuente empobrecimiento de la población; y por el otro lado, de acuerdo a las políticas del Estado y el funcionamiento de los mercados de suelo.

Respecto del funcionamiento del mercado, en las ciudades latinoamericanas, se puede observar la coexistencia de dos mercados de suelo urbano que funcionan en simultáneo, con reglas del juego distintas. Por un lado, se encuentra el mercado formal, sometido a las regulaciones estatales de la propiedad y el urbanismo, y por el otro lado, el denominado mercado informal que predomina en las áreas vulnerables donde se asienta la población de bajos recursos en lo que se denomina urbanización informal, sin tenencia legítima de títulos de propiedad. En este sentido, el mercado informal articulado y subsumido a la lógica del mercado formal entra muchas veces en el juego de definición de las rentas del suelo urbano (Calderon, 2013).

Cabe recordar que la urbanización informal representa una característica predominante en las ciudades de América Latina, contracara de la deficiente o directamente la falta de planificación por parte del Estado. La misma implica modalidades y no una única modalidad de ocupación del suelo, que van desde la 
ocupación directa ocupación de tierra pública o privada alentada por el Estado o no, hasta el acceso mercantilizado mediante el mercado informal del suelo, denominado urbanización pirata (Cravino; Jaramillo, 2012). En este sentido, el acceso al suelo según autores como el caso de Abramo (2010), es visto como una oportunidad de obtener una vivienda para miles de familias latinoamericanas. Ese afán por encontrar un lugar digno donde residir forma parte de la producción del territorio, y en las ciudades latinoamericanas, entre los sectores populares subyace la lógica de la necesidad ${ }^{8}$, que impulsa este accionar. En este contexto, el mercado de tierra y vivienda latinoamericano, como todo mercado, funciona como un espacio de coordinación de agentes, dentro de un proceso social y económico en la búsqueda de seguridad, localización, movilidad social, diferenciación social, objetivación de gustos, estatus, establecimiento o reforzamiento de diferencias y distinciones.

En general la sociología urbana ha sido la disciplina social que ha observado al mercado inmobiliario como un medio de diferenciación de los grupos sociales y de las actividades económicas en el espacio (Calderon, 2013). Desde esta óptica, en las ciudades de América Latina el mercado informal por lo general se encuentra asociado a una idea de precariedad, aunque no siempre es así. Puede decirse entonces que en cuanto a la ocupación informal del territorio se evidencian algunas características principales compartidas entre las ciudades y grandes metrópolis latinoamericanas.

En cuanto a la estructura social, las ciudades latinoamericanas presentan ciertas particularidades generales como son las modalidades de acumulación, su lugar en el sistema global de división del trabajo, y en este contexto, el mercado del suelo las traduce como manifestación en el espacio (Jaramillo, 2008). En este sentido, la urbanización en las sociedades latinoamericanas según Pírez (2014) puede ser caracterizada por dos rasgos principales: por un lado, el predominio de

8 Existen actores que se determinan en razón de lo que podemos denominar la lógica de la necesidad. Esta se muestra relevante en tanto que se desarrolla fuera (total o parcialmente) del mercado y de las políticas públicas (Pirez, Actores Sociales y gestión de la ciudad, 1995). 
procesos sociales (no estatales) de desmercantilización en un contexto de producción y consumo mercantilizados, y por el otro lado la existencia de fuertes desigualdades urbanas. Dichas desigualdades son otro rasgo distintivo que se asociada íntimamente con el predominio de formas mercantiles de producción y consumo y sus efectos segregadores, como ya se ha mencionado (Pírez, 2014).

La desigualdad social referida a la existencia de diferencias entre los distintos grupos socioeconómicos en cuanto al acceso a recursos y oportunidades representa en tal sentido, una de las características de las sociedades capitalistas. La desigualdad conduce a una situación de fragmentación social, entendida como divisiones y debilitamiento en el tejido social, e incluso, a la desaparición de los lazos entre grupos sociales, como así también a una escasa movilidad social. Autores como es el caso de Marcuse y Van Kempes (2000) hablan de la segregación urbana como fenómeno y la definen como la separación espacial de los diferentes grupos sociales en una ciudad o un área geográfica de acuerdo a diferencias étnicas, religiosas, de ingresos, etc. De esta forma, es posible identificar en una ciudad los diferentes barrios donde cada grupo social mantiene su propio espacio. Esta también es una característica de las grandes metrópolis Latinoamericanas, por ejemplo, en el caso de Brasil las favelas representan la segregación de los residentes que viven diferenciados del resto de la ciudad.

Una de las facetas, pero no la única de la ocupación informal que ha sido más explorada en Latinoamérica, tiene que ver con las urbanizaciones informales, generalmente localizadas en las periferias de las principales ciudades. Esta informalidad se caracteriza, principalmente a partir de las limitaciones o restricciones en cuanto a calidad habitacional, seguridad y bienestar, tanto individual como colectiva. Desde esta perspectiva, la ocupación informal del suelo urbano en las grandes ciudades latinoamericanas puede asociarse con una práctica habitual de los sectores de bajos recursos económicos excluidos de la demanda solvente de la producción capitalista.

A través de la ocupación informal de suelo urbano, muchas familias intentan satisfacer la necesidad de acceder a una vivienda a través de la autoconstrucción 
como parte del proceso de urbanización informal en la periferia de las principales ciudades latinoamericanas. Tal es el caso de las urbanizaciones informales en las periferias de la ciudad de Bogotá y Medellín en Colombia, en las ciudades de México DF y Guadalajara en México (Figura 4), por citar ejemplos de algunas ciudades latinoamericanas.
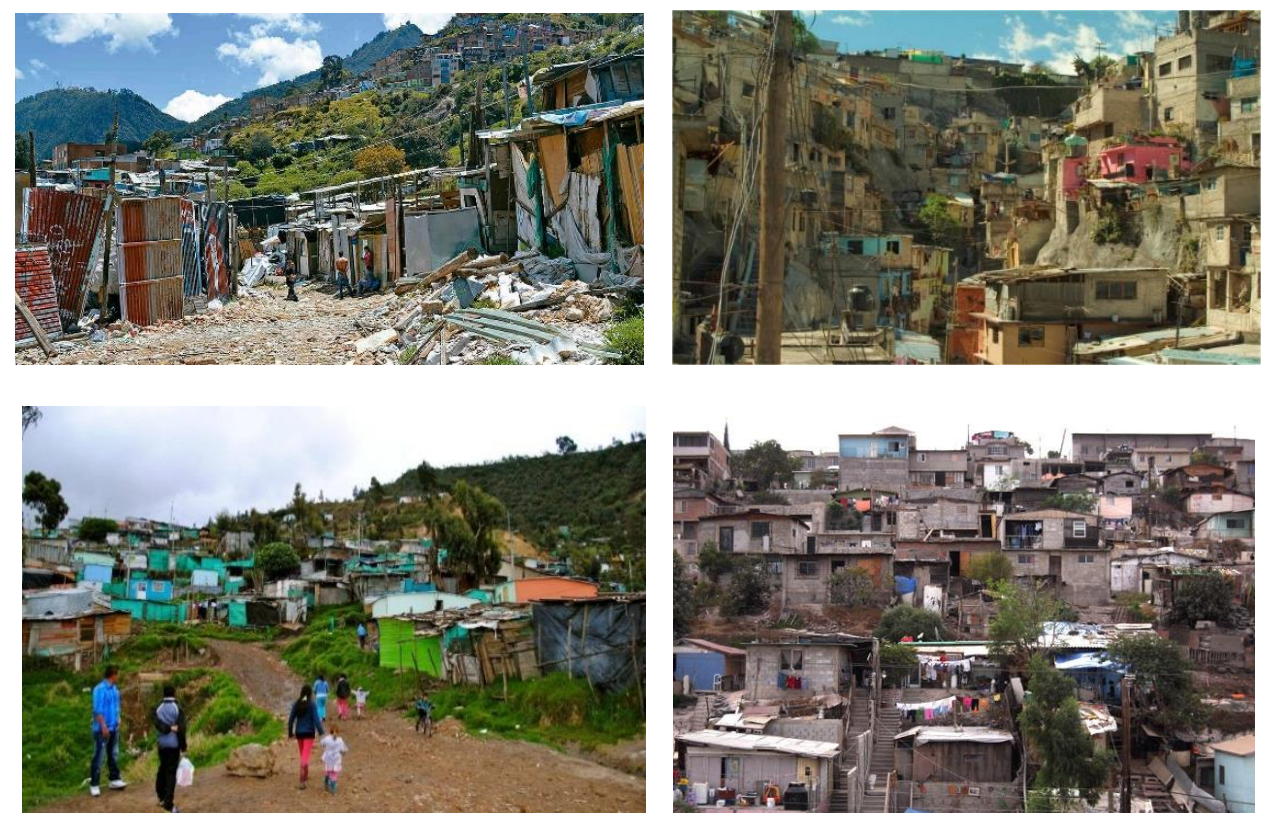

Figura 4. Viviendas autoconstruidas en Colombia y México.

Fuente. Imágenes extraídas de https://scielo.conicyt.cl/scielo.php?pid=S071883582014000100002\&script=sci_arttext. https://regeneracion.mx/64-1-de-viviendas-enmexico-son-improvisadas-se-construyeron-sin-supervision/

Otro tipo de ocupación informal del territorio que se produce en las principales metrópolis de América Latina es la que se constituye a partir de la localización de urbanizaciones informales ya no como parte de las periferias de las ciudades, sino que formando parte de la dinámica urbana del centro de la ciudad. A modo de ejemplo, un caso emblemático lo representan las villas urbanas de la ciudad de Buenos Aires, cuyo crecimiento poblacional se relaciona con la migración interna rural-urbana producida durante las décadas de 1940 y 1950, consecuencia de la política argentina de promoción de la industrialización y sustitución de importaciones y los procesos migratorios procedentes de países limítrofes desde la década de 1960. Este tipo de urbanización se caracteriza por presentar viviendas de diferentes grados de precariedad, de alta densidad 
poblacional y con buena localización en relación con los centros de producción y consumo (Cravino, del Río y Duarte, 2010). A diferencia de las urbanizaciones que se localizan sobre áreas periféricas, esta disposición determina otro tipo de relación entre actores que comparten un área central, como así también determina otro tipo de relación entre los actores y la producción del territorio (Figura 5).
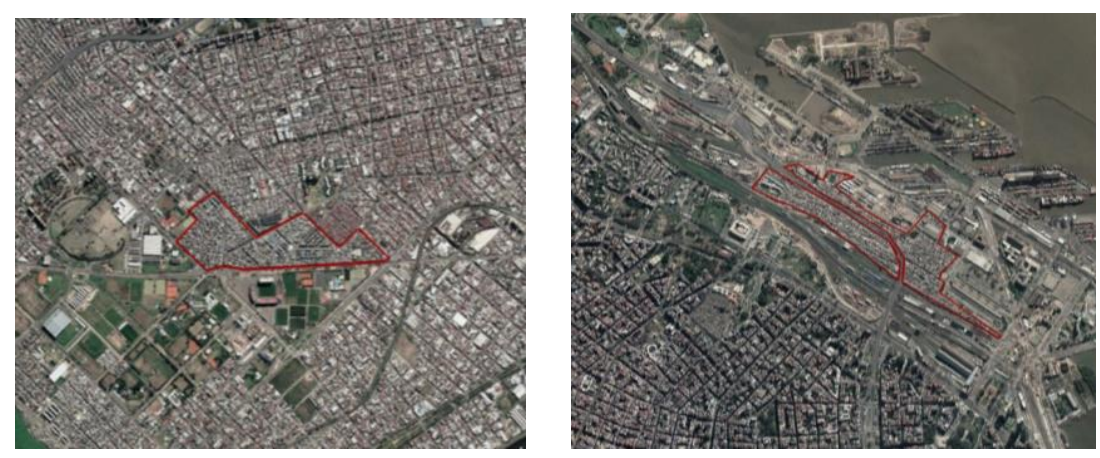

Figura 5. La villa 1-11-14 de Buenos Aires parte del tejido del centro urbano (izq) y la Villa 31 de Buenos Aires en la zona de Retiro (der).

Fuente. Google Earth, 2018.

En el caso brasileño, la falta de regulación en el mercado de suelo generó informalidad tempranamente, resultando como su expresión más común las favelas (Figura 6) localizadas en la gran mayoría de los centros urbanos del país.

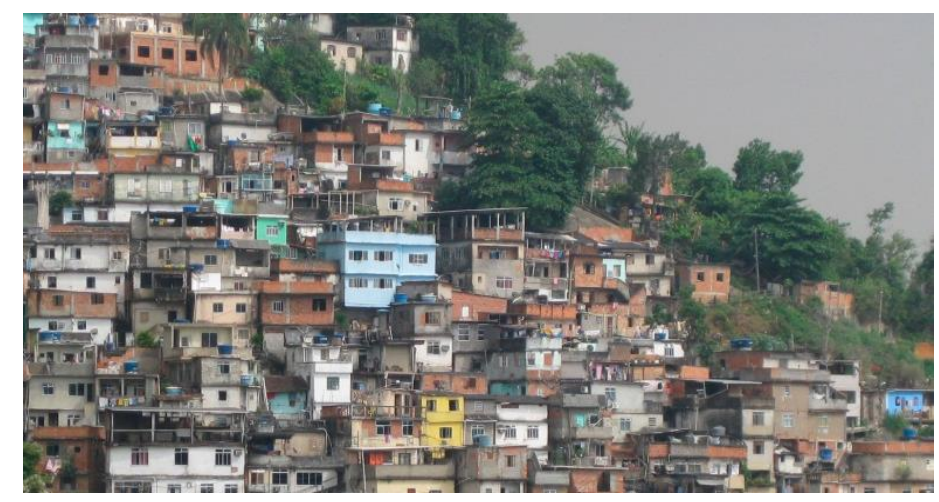

Figura 6. Favela sobre morro en Brasil.

Fuente. http://www.protocolo.com.mx/internacional/brasil-cunde-el-miedo-en-las-favelasantes-de-los-juegos-olimpicos-de-rio/ 
En muchos casos estas urbanizaciones son producto de la ocupación informal de tierras consideradas legalmente como reservas y/o no urbanizables por motivos ambientales o topológicos, como es el caso de los morros, donde se construye en terrenos que superan la pendiente máxima habilitada para ser urbanizada, lo que genera recurrentes conflictos por el desprendimiento y deslizamiento del suelo (Di Virgilio, 2014). Otro tipo de informalidad en Latinoamérica lo representan las urbanizaciones cerradas, que no se relacionan necesariamente con la situación de precariedad sino todo lo contrario, pero que de igual modo se localizan sobre áreas periféricas. Son variados los estudios que se pueden encontrar acerca de la implantación de estas urbanizaciones en áreas sin servicios y no destinados a este tipo de uso, por ejemplo, en la Provincia de Buenos Aires, en Argentina.

A modo de síntesis, en las ciudades latinoamericanas, coexisten formas de producción de la ciudad informal muy distintas, pero que conviven al mismo tiempo, ya sea informalidad en cuento a la tenencia del suelo, a la localización en áreas no destinadas a urbanizar, a la autoconstrucción de la vivienda, etc. De este modo, resulta posible afirmar que cada vez son más los usos en el territorio que responden a estrategias de urbanización sin una adecuada planificación, guiados por la lógica del mercado, generando desigualdades; otros que responden a la lógica de la necesidad de aquellos que tienen menores posibilidades de acceso al suelo por la vía formal, sumado a una lógica de un Estado deficiente en materia de planificación.

En Latinoamérica la ciudad formal y la informal conviven en un mismo territorio, y esto trae aparejadas problemáticas de toda índole, principalmente aquellas que involucran profundos procesos de segregación social $y$ fragmentación urbana. Ya sea en los centros urbanos o en las periferias de las ciudades de América Latina, el suelo y el acceso al mismo se han convertido en terreno de disputa. 


\subsection{El mercado de suelo como elemento determinante de la producción urbana en América Latina}

Una característica esencial de la estructuración de la ciudad neoliberal en las ciudades latinoamericanas tiene que ver con el rol del mercado como uno de los elementos determinantes de la producción de suelo urbano, impulsado fundamentalmente desde los años 80. En este sentido, la crisis del modelo fordista urbano durante esos años se manifestó en las ciudades a través de dos ejes de cambio: por un lado, la tendencia hacia la flexibilización urbana por sobre el urbanismo modernista y regulador vigente y por el otro, la caída del financiamiento estatal en vivienda, equipamientos e infraestructura y de algunos servicios urbanos colectivos (Abramo, 2012). En este contexto, el mercado aparece como el mecanismo principal de coordinación de la producción de la ciudad ya sea a través de la privatización de las empresas públicas, o por la hegemonía del capital privado en la producción de suelo urbano. De este modo la presencia y accionar del mercado se ha manifestado a través del tiempo como el elemento determinante en la producción de la ciudad.

En el caso latinoamericano, la producción de las ciudades resultó fundamentalmente del funcionamiento de dos lógicas de coordinación social, por un lado, la lógica de la ganancia en el ámbito del marcado y la lógica de la política en el ámbito del Estado; pero también de una tercera, la lógica de la necesidad en el ámbito de la sociedad (Pirez, 2014). Esta última lógica conjuga acciones individuales y colectivas en la producción de la urbanización informal siguiendo un ciclo de ocupación, autoconstrucción, auto urbanización y, finalmente la consolidación del barrio como tal. En este sentido, aparece una variante de producción de suelo urbano extendida popularmente en América Latina, que es la que articula la lógica del mercado con la de la necesidad, y se manifiesta socialmente como mercado informal de suelo.

En este sentido Abramo (2003) sostiene que, en América Latina, tanto el mercado formal del suelo como el denominado mercado informal producen simultáneamente, y por razones particulares y vinculadas a sus propias lógicas de 
funcionamiento y de reproducción de los capitales, una ciudad com-fusa en donde el funcionamiento del mercado formal produce un tipo de ciudad compacta y difusa, así como el funcionamiento del mercado informal del suelo también produce una ciudad popular o informal compacta y difusa. La producción urbana y de los mecanismos promotores del uso del suelo en el marco de la ciudad neoliberal conduce a una lógica interna de funcionamiento del mercado formal y del informa, que promueve un círculo donde la compactación alimenta la difusión y ésta fomenta la compactación. Como resultado, esta estructura promueve demandas de equipamientos y servicios con espacialidades diversas, y se convierte en un factor que dificulta la elaboración de políticas urbanas equitativas en términos tanto sociales como espaciales.

Duhau y Giglia (2008) recurren a la expresión división social del espacio residencial para referirse a las formas espaciales que adopta la distribución residencial intraurbana o intra metropolitana de los distintos estratos socioeconómicos que conforman la población de una aglomeración urbana, y denominan estructura socio-espacial al conjunto de las formas que adquiere dicha división. De tal modo que la división social del espacio será producida o transformada por agentes tanto públicos como privados. Esto se vincula con los procesos de segregación social del espacio urbano que corresponde a la aglomeración de familias de una misma condición social, más allá de cómo sean definidas las diferencias sociales.

Sabatini (2006) afirma que en América Latina la atención ha estado centrada en la segregación socioeconómica, pasando por alto otras formas de separación social en el espacio urbano. Lo anterior se explica debido a que las desigualdades sociales representan la característica más destacada de la estructura social de las ciudades latinoamericanas. En ese sentido, el autor hace una diferenciación de las dimensiones que implica la segregación distinguiendo dos dimensiones objetivas, por un lado, el grado de concentración espacial de los grupos sociales y la homogeneidad social que presentan las diferentes áreas internas de las ciudades; y una dimensión subjetiva por el otro, que se refleja en el prestigio (o desprestigio) 
social de las distintas áreas o barrios de cada ciudad (Sabatini 2006). Este aspecto adquiere relevancia en el análisis de los procesos territoriales de las ciudades latinoamericanas ya que la segregación se constituye como una condición de la pobreza, asociada al surgimiento o reforzamiento de los estigmas territoriales.

De este modo se configuran territorios segregados y aumenta la debilidad de los vínculos entre los sectores de bajos recursos y el mercado, así como su aislamiento respecto a otros sectores de la sociedad (Kaztman, 2003). Como consecuencia de ello, la ciudad se expresa espacialmente en un conjunto de segmentos entre los que se encuentran territorios pobres y barrios que revelan su estructura social, así como ciertos espacios que dejan al descubierto la creciente polarización de la distribución territorial de una población con características sociales, económicas, políticas y culturales distintas a las del pasado (Blanco, 2012).

\subsection{El derecho a la ciudad en América Latina: La disputa por el territorio}

En la actualidad, los procesos de globalización tienden a reducir el territorio a una mera mercancía, un soporte y un objeto externo a la subjetividad de quien lo habita (De Sousa Santos, 2002). Las ciudades crecen y se desarrollan, muchas veces a un ritmo que deja a un lado a una parte de los ciudadanos, sin embargo, en algunas ciudades sus habitantes batallan por construir su propio hábitat, guiados por intereses particulares. Como resultado, en el caso de las metrópolis latinoamericanas se produce una disputa por la ocupación y apropiación del territorio en la que múltiples actores sociales definen y redefinen sus lugares constantemente como espacios de disputa económica, política y simbólica. De este modo, el territorio es co- construido por actores sociales antagónicos que resignifican los espacios, los habitan, los transforman, los recrean de acuerdo a sus intereses, a sus formas de vida y maneras de reproducción social. En este sentido, la estructura territorial se manifiesta en los contextos más diversos bajo la forma de oposiciones espaciales donde el espacio habitado, o apropiado, funciona como una especie de simbolización espontánea del espacio social urbano. 
Para Bourdieu (1999), en una sociedad jerarquizada no hay espacio que no esté jerarquizado y no exprese las distancias sociales. De esta forma, el territorio entendido como una construcción social se traduce en el espacio físico, poniendo de manifiesto que el poder que da la posesión del capital en sus diversas formas se manifiesta también territorialmente. Esto se da bajo una determinada relación entre la distribución territorial, tanto de los actores como de la estructura espacial de los bienes o servicios, privados o públicos.

Desde que el territorio se inscribe simultáneamente en las estructuras espaciales y en las mentales, pasa a ser uno de los lugares donde se afirma y ejerce el poder, sin duda bajo la forma más sutil, que es la de la violencia simbólica como violencia inadvertida (Bourdieu, 1999). En este sentido, la capacidad de dominación del territorio muchas veces depende del capital que se tiene. La carencia de capital entonces mantiene a distancia, ya sea física o simbólicamente, a quienes no poseen el suficiente como para hacerse de un espacio determinado. En palabras de Bourdieu (1999) la falta de capital intensifica la experiencia de la finitud, es decir encadena a un lugar.

En las principales ciudades de América Latina las disputas por el territorio involucran a los distintos grupos sociales, ya sea en la ocupación de las áreas periféricas donde urbanizaciones informales y urbanizaciones cerradas conviven juntos pero separados, o bien hacia el interior de los centros urbanos como sucede en el caso de la Villa 31 (en la ciudad autónoma de Buenos Aires), donde la informalidad con todos los estigmas y representaciones en el imaginario social que conlleva, se inserta en la trama urbana de la ciudad formal.

Los territorios de las principales ciudades latinoamericanas, en síntesis, no son espacios homogéneos, indiferenciados ni continuos, y ni sus habitantes ni la infraestructura urbana se encuentran distribuidos de manera uniforme, como tampoco son constantes ni equivalentes los valores, los significados y los sentimientos con que se asocia a las distintas zonas de una ciudad (Segura, 2012). En este marco Duhau (2004) señala que las disputas por el territorio implican a los distintos actores sociales, la comunidad; el Estado y el mercado, y la 
competencia entre los usos que habrá de darse a un espacio determinado según el dominio sea público o privado, y los usos y formas de aprovechamiento del mismo. En consecuencia, en las ciudades latinoamericanas existen disputas por parte de los distintos sectores sociales que resulta vulnerados en sus derechos y que intentan accionar de diversas maneras con el fin de acceder al suelo urbano, a los servicios, etc. En pocas palabras lo que Lefebvre (1979) y Harvey (2015) denominan acceder al derecho a la ciudad.

A modo de síntesis, en este capítulo se arribó a la idea de que la urbanización en América Latina como parte de un macro proceso económico, social, político y económico, forma parte del proceso del desarrollo del capitalismo dependiente con sus manifestaciones espaciales. En el conjunto de características comunes a la urbanización latinoamericana se evidencian cada día más las limitaciones y la complejidad que conlleva este sistema que vulnera en sus derechos a los que tienen menor capacidad de acumulación de capital. De este modo se generan situaciones en donde en una misma ciudad se evidencian contradicciones en lo que refiere a la distribución territorial. Entre esos desequilibrios se destacan fenómenos como la polarización y la segregación urbana, fundamentalmente por la prioridad por parte del mercado (avalado por el Estado) de preservar las inversiones y los recursos que beneficien la reproducción del capital a nivel social y que se manifiestan especialmente, dejando a un lado a los sectores de bajos recursos. Para dichos sectores, su derecho a la ciudad se ve cada vez más vulnerado en el acceso al suelo urbano, en la carencia de acceso a las condiciones básicas necesarias para el hábitat y principalmente en el estigma social que se genera a su alrededor. Si bien la urbanización capitalista latinoamericana tiene condiciones que permiten hablar de ella en su visión más global, también es cierto que cada territorio lleva adelante sus procesos específicos y concretos en cada una de las dinámicas propias del capitalismo y de su acumulación. Estos procesos se caracterizan en relación a las formas internas del mercado, la ocupación del territorio y el desarrollo urbano-regional. Para dar cuenta de ello, en el siguiente capítulo, se focalizará en el caso de Argentina, poniendo énfasis en el AMBA y la problemática de la informalidad urbana. 


\section{Capítulo 3}

\section{$-\bullet \bullet-$ \\ La problemática de la informalidad urbana en Argentina con referencia al Area Metropolitana de Buenos Aires.}

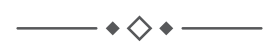

«Buenos Aires y su Área Metropolitana fueron un lugar de transformaciones rápidas y espectaculares cambios, que se pueden resumir bajo el término de metropolización: terciarización de la economía, privatización de los servicios urbanos, desarrollo del sector inmobiliario ligado a las nuevas formas de consumo y de esparcimiento, así como también aumento de la pobreza y de las desigualdades » 
El presente capítulo integra el último de la serie que conforma la primera parte de esta tesis de doctorado que corresponde, metodológicamente, con el abordaje del objeto de estudio en el nivel superior de análisis. La particularidad de este capítulo, a diferencia a los anteriores, radica en el cambio de escala geográfica. Se propone pasar del análisis a nivel macro con el foco sobre los procesos de la urbanización capitalista en América Latina, para puntualizar en la problemática de la informalidad urbana en Argentina, haciendo especial referencia al Área Metropolitana de Buenos Aires (en adelante $\mathrm{AMBA}^{9}$ ). Se dedica especial atención a los procesos de carácter económico, social y político que, en conjunto, explican la producción de la informalidad urbana en el territorio desde fines de los años 80 e inicio de los 90.

Este capítulo incluye una revisión histórica acerca de los cambios socio territoriales producidos en el AMBA a partir de diversas fuentes y autores que contribuyen a una mejor comprensión de la relación entre la problemática de la informalidad urbana, el mercado de tierra y el acceso al suelo. Es a partir de esta relación, que se analizan y explican algunas de las causas principales de la informalidad urbana y las tipologías que surgen como consecuencia. Finalmente, este capítulo hace las veces de nexo entre la primera y segunda parte de la tesis, a partir de reconocer y explicar la problemática en el AMBA, dando paso al siguiente nivel de abordaje en donde el análisis se concentra metodológicamente en la meso escala, en el nivel intermedio de análisis de la problemática de las urbanizaciones informales focalizando en el proceso de ocupación territorial en el Partido de La Plata.

\footnotetext{
${ }^{9}$ El criterio de regionalización elegido es el Área Metropolitana de Buenos Aires (AMBA), que comprende la Ciudad de Buenos Aires -capital de la república- y los 40 municipios que la rodean. Se trata de una mega ciudad que se extiende desde Campana hasta La Plata, con límite físico en el Rio de la Plata e imaginario en la Ruta Provincial 6, y recorre una superficie de 13.285 km2. Según el censo de 2010, la población del AMBA representan el 37\% de los habitantes de la Argentina. Desde una mirada territorial se mantiene en constante crecimiento, por lo que sus límites son cada vez más difusos.
} 


\subsection{Revisión histórica: Los cambios socio-territoriales en el AMBA}

La comprensión de las problemáticas actuales como la informalidad urbana en el territorio del AMBA y, como se desarrollará en capítulos posteriores, en el Partido de La Plata, se enriquece si se analizan los procesos territoriales del pasado, desde el origen de la urbanización, que han dejado una fuerte impronta en la estructura socio-territorial. Estos procesos, como los distintos modelos de gobierno y gestión territorial en cada momento histórico, combinan modos de desarrollo económico que se ajustan dentro de cada contexto a un modelo de organización territorial dominante y global. Es decir que responden a una lógica de mayor alcance, íntimamente relacionada con los procesos de globalización de la economía, la sociedad y la cultura (Casariego Ramírez, 1995)

En Argentina las políticas económicas y sociales que se desarrollaron fundamentalmente desde los años '90, tuvieron efectos visibles sobre la organización y configuración del territorio. Dichas políticas podrían equipararse con las aplicadas por el modelo neoliberal en otras partes del mundo durante los mismos años. Principalmente, tienen que ver con la apertura de la economía, la desregulación de diversas actividades, la privatización de empresas públicas, y el intento de inserción en un bloque regional, en este caso, el Mercado Común del Cono Sur (MERCOSUR) (Blanco, 1996). Durante los años '90 lo que se denomina actualmente como el Área Metropolitana de Buenos Aires no permaneció al margen de esta situación, sino que fue escenario del proceso de reestructuración económica, el empobrecimiento de una parte importante de la población, del deterioro en la prestación de los servicios urbanos básicos y de la privatización de sus espacios públicos. El cambio de estrategia económica y política, basada en la desregulación y la apertura externa propias del neoliberalismo, acarrearon cambios significativos en la producción y en la correspondiente base económica, tanto a nivel nacional como a nivel urbano (Vidal Koppmann, 2007). 
De este modo, se fue configurando lo que podría denominarse actualmente como una territorialidad neoliberal10 ${ }^{10}$, principalmente en zonas periféricas urbanas. Esta idea hace alusión a distintas formas de dominación y subordinación que remiten al poder, pero también al mismo tiempo a las variadas formas de resistencia tanto material como simbólica y a las modalidades de reconstrucción del tejido social, dándole al territorio del AMBA un carácter determinado como territorio abierto de las disputas (Mazzeo, 2004; Stratta \& Barrera, 2009 en González, 2010). En tal sentido se profundizó una crisis urbana, fundamentalmente desde las políticas implementadas durante los años de dictadura cívico militar que se acentuó durante los neoliberales años '90 que persiste en la actualidad y que tiene consecuencias que implican cada vez mayor desigualdad.

Pírez afirma (1995) “Buenos Aires Metropolitana se caracteriza por ser una ciudad desigualitaria social y territorialmente, de tal modo que ha llegado a una situación en la que su infraestructura y sus servicios no logran garantizar el funcionamiento adecuado para que las actividades propias de la ciudad puedan desenvolverse correctamente". Los efectos de la crisis urbana repercutieron en la morfología de la ciudad, no solo en el AMBA sino también en varias ciudades de América Latina, en donde se acentuaron los procesos de segregación y fragmentación que ya se venían dando desde los '70, pero que se acrecentaron durante los años '90 y que con el correr de las últimas décadas, terminaron por constituir una tendencia que continúa en aumento.

Particularmente en el AMBA, el empobrecimiento e incremento de las desigualdades sociales de amplios sectores de la población ${ }^{11}$ modificó la articulación entre identidades sociales, espaciales y políticas, que en su momento caracterizaron al modelo de acumulación de industrialización sustitutiva. Los

\footnotetext{
10 Se entiende por territorialización a los procesos fundantes, creadores y delimitadores de territorios. La territorialidad neoliberal hace referencia al proceso constitutivo de un territorio a partir de las configuraciones espaciales resultado de relaciones de poder en la ciudad.

${ }^{11}$ Los datos censales del año 1991 y 2001, ponen de manifiesto lo que se denomina pobreza estructural y aquellas personas con Necesidades Básicas Insatisfechas (NBI). Al respecto, tomando como referencia el total del país, la población en hogares con NBI, pasa del 19.9\% en 1991 al 17.7\% en 2001.
} 
impactos de la crisis industrial y la reestructuración económica durante los años '90 afectaron especialmente al AMBA en términos territoriales, donde la desindustrialización devino en una crisis de las antiguas zonas industriales ubicadas en el área central y en el primer cordón del Gran Buenos Aires e impactaron negativamente sobre los barrios donde residía la fuerza de trabajo. Una de las expresiones con mayor repercusión territorial del proceso económico señalado fue la crisis del empleo, en tal sentido, la tasa de desocupación creció entre el 6,3\% y el 16,4\% de la población económicamente activa entre 1991 y el 2003 (EPH ${ }^{12}$ - INDEC). Como consecuencia, el desempleo en el AMBA resultó en la incapacidad de absorción de nuevos trabajadores y la expulsión de otros. Territorialmente, se fue consolidando una ciudad-centro cada vez más signada por las actividades financieras y un área periférica heterogénea.

El crecimiento del área metropolitana se produjo en relación con la expansión hacia los bordes externos como un proceso encarado en un primer momento por sectores de ingresos medio-bajos y bajos empobrecidos mediante una modalidad de ocupación del suelo de muy baja densidad, en ámbitos caracterizados por serias carencias de infraestructura básica y con un prolongado tiempo de consolidación de la ocupación. Sin embargo, desde principios de la década de los '90 también surgió como contracara en el AMBA una proporción creciente de segundas residencias que se convirtieron gradualmente en viviendas de residencia permanente para los sectores medios y medios altos. De este modo se consolidó al mismo tiempo el fenómeno de la suburbanización de los grupos de más altos ingresos, al que se ha denomina como la suburbanización de las élites y el boom de las urbanizaciones cerradas (Torres, 1999).

La diferenciación social del espacio que se generó durante la década de los '90, supuso la aplicación de la lógica de la estratificación social al territorio y su concreción en segregación territorial. Las zonas del Área Metropolitana entonces, adquirieron una significación social que las diferenció acumulativamente y que se

\footnotetext{
12 Encuesta Permanente de Hogares.
} 
concretó en la distribución desigual del equipamiento urbano, infraestructuras y servicios disponibles (Pírez, 2001). En este sentido, uno de los principales cambios observables en la morfología territorial del AMBA se dio a partir de un modelo disperso, segmentado y fragmentando de ciudad. La noción de fragmentación en este sentido, incorpora elementos espaciales como las discontinuidades físicas del territorio, las dimensiones sociales de repliegue de diversos sectores sociales, como urbanizaciones informales o lógicas de urbanización tales como los barrios cerrados, y aspectos políticos tales como la dispersión de los actores y la autonomización de los dispositivos de gestión y regulación urbana (Prévot Schapira, 2001; Vidal Koppmann, 2007).

Resulta necesario mencionar que, históricamente, Buenos Aires funcionó como el centro nacional dominante y único, definiendo por décadas las formas territoriales de la expansión y desarrollo partir de las infraestructuras de comunicación de los equipamientos y del sistema nacional hacia el puerto. Dicho de otro modo, en Argentina ha predominado una lógica de ocupación del territorio que ha ido consolidando el rol hegemónico de Buenos Aires como centro urbano y económico. Cabe mencionar que las lógicas de ocupación del territorio, responden a diversos intereses políticos, sociales y económicos. Las mismas se encuentran directamente vinculadas con los intereses de aquellos actores sociales que definen áreas diferenciadas en cuanto al modo de producción y apropiación del territorio. De acuerdo con esas lógicas resulta posible explicar la expansión del AMBA en un contexto histórico que ha terminado por delimitar los procesos que configuraron el territorio actual. En este sentido, Pírez (2001) explica la expansión de Buenos Aires y su Área Metropolitana, pudiendo sintetizarla en tres grandes y significativos momentos históricos:

1. El inicio metropolitano: supuso que desde fines del siglo XIX (1870-1930) Buenos Aires, como aglomerado urbano y capital de un país agrícola exportador se estructurara territorialmente en dos ejes; norte-sur y centro-periferia. El primero separó a la población por niveles socioeconómicos, en el norte los grupos sociales de mayores recursos y en el sur, los de menores recursos económicos. La periferia se convirtió de este modo en el asentamiento de los grupos que ascendieron 
socialmente y la segunda generación de inmigrantes que accedió a la pequeña propiedad residencial. Los sectores de menores recursos que no accedían al mercado debían, ya desde entonces, resolver por sí mismos su asentamiento en la ciudad. La expansión territorial se sustentó, durante este período, con base en el trazado de la red ferroviaria que partiendo del centro conectaba con localidades cercanas del norte y el oeste. El crecimiento de los tranvías, y luego de los autobuses complementó esa red. De este modo se ocupó la Capital Federal y se inició lo que Sargent llamó en 1974 como la creación del Gran Buenos Aires. Esta creación se dio dentro de un proceso en el que la especulación inmobiliaria fue introduciendo tierras al mercado urbano.

2. La suburbanización popular: La población Metropolitana aumentó por efecto de las migraciones internas y se expandió fuera de la Capital Federal, en 1914 se asentaba en los suburbios casi cuatro quintas partes de la población, y en 1960 ese número había aumentado más de la mitad. Esa sub-urbanización fue posible por la red articulada de ferrocarriles y colectivos, así como por la producción de infraestructura por parte del Estado. La expansión de población de bajos recursos se produjo durante esta etapa, fundamentalmente, por medio de "loteos populares". A fines de los años “60, las modalidades de expansión se alteraron con el deterioro de la economía nacional, empeorando las condiciones de vida.

A mediados de los '70, la economía se expandió hacia el mercado internacional, promoviendo transformaciones territoriales de contenido neoliberal que beneficiaron al mercado y a los sectores de mayores recursos de la población. Durante el proceso militar (1976 - '83) esta situación se consolidó e inició una reestructuración territorial que continuó durante los años '90. En estos años el área urbana se expandió hacia la zona norte principalmente, con urbanizaciones residenciales para los sectores con mayores ingresos, y en el resto lo hizo con base en la lógica de la necesidad, anclada en la pobreza urbana como se explicó anteriormente. Esa tendencia se acentuó con la aplicación de políticas, principalmente en el ámbito del acceso a la tierra y a la vivienda, que provocaron que muchas familias de bajos recursos fueran expulsadas de la Capital Federal. Una 
de ellas fue la sanción del Decreto Ley $8912^{13}$ de Ordenamiento Territorial y Uso del Suelo (1977), que tuvo como uno de los principales efectos el impacto sobre el acceso al suelo al eliminar la oferta formal de los loteos populares.

\section{Modernización metropolitana y suburbanización "tardía” de las elites} (desde 1980): Las transformaciones caracterizadas por la globalización comenzaron a tener impacto en el territorio argentino, como se mencionó al inicio del capítulo, a partir de los cambios ocurridos a comienzos de la década de los ‘90. Entre ellos se pueden mencionar la reforma del Estado, la desregulación de la economía y la privatización de los servicios urbanos de infraestructura de la ciudad. Esos cambios, además de disminuir la presencia del Estado en materia de intervención, fortalecieron el protagonismo del sector privado en la economía y en especial, en la producción de la ciudad.

De este modo se inició un doble proceso territorial, por un lado, se produjo una fuerte expansión caracterizada por la ocupación con base en asentamientos residenciales de baja densidad, de clases medias y medias altas, articulados a nuevas formas de localización de las actividades comerciales y de esparcimiento. Por el otro lado se evidenció una mayor ocupación del área central, orientada hacia grupos de ingresos medios y altos y fundamentalmente, a las actividades vinculadas con la globalización como, por ejemplo, actividades relacionadas con los grandes centros comerciales. De este modo, este período marcó un punto de inflexión principalmente con el desarrollo de diferentes formas de urbanizaciones cerradas destinadas a los sectores de la sociedad más acomodados.

A partir de la revisión histórica es posible reconocer los procesos que configuraron el territorio, y sus bases históricas, que imprimieron a la ciudad los rasgos que la definen actualmente. Para el AMBA, esos rasgos podrían sintetizarse en las fuertes desigualdades sociales y territoriales que tienden a consolidarse y ampliarse, así como los procesos de acumulación fragmentados territorialmente.

13 Ley de Ordenamiento territorial y uso del suelo 8912 http://www.gob.gba.gov.ar/legislacion/legislacion/l-8912.html 
Entre ellos se puede mencionar la oferta limitada y segmentada de servicios, con predominio de una orientación mercantil que no logró incluir a toda la población; la producción urbana basada en la lógica económica del mercado, con predominancia de formas privadas de planificación y el modo de producción de suelo urbano desde una lógica de ganancia económica que promueve el crecimiento indiscriminado y con escasa planificación.

Estos procesos suponen la conformación de un territorio que en la actualidad se manifiesta crecientemente unidimensional, su carácter de bien de cambio subordina al de bien de uso, y es en ese contexto que las desigualdades del territorio metropolitano tienden a consolidarse y ampliarse. Debido a ello, una hipótesis afirma que la lógica actual predominante de ocupación se sustenta en la construcción de centros únicos sobredimensionados constituyendo la base de los conflictos sociales en el AMBA, en tanto que define áreas fragmentadas y sectores sociales excluidos en sus posibilidades de participación, es decir excluidos de su derecho a la ciudad (Pírez, 2001).

La intensificación de la actividad industrial posibilitó mejores oportunidades laborales que se generalizaron a partir de la segunda posguerra con particularidades propias en cada país latinoamericano que se corresponde con un crecimiento urbano periférico a la estructura urbana central, siguiendo pautas de asentamiento concéntricas que fueron completando las coronas suburbanas y densificando el centro (Goldwaser, 2013). En la Figura 7 se presenta una síntesis del crecimiento y expansión del AMBA entre los años 1782 y 2001, la imagen evidencia en parte el proceso de expansión metropolitana. Resulta posible observar el crecimiento y la evolución de la mancha urbana y su extensión en forma de "mancha de aceite" siguiendo un patrón más bien vinculado con la extensión de las vías de comunicación y sin una lógica de planificación urbana subyacente, como se puso de manifiesto en el análisis histórico. 


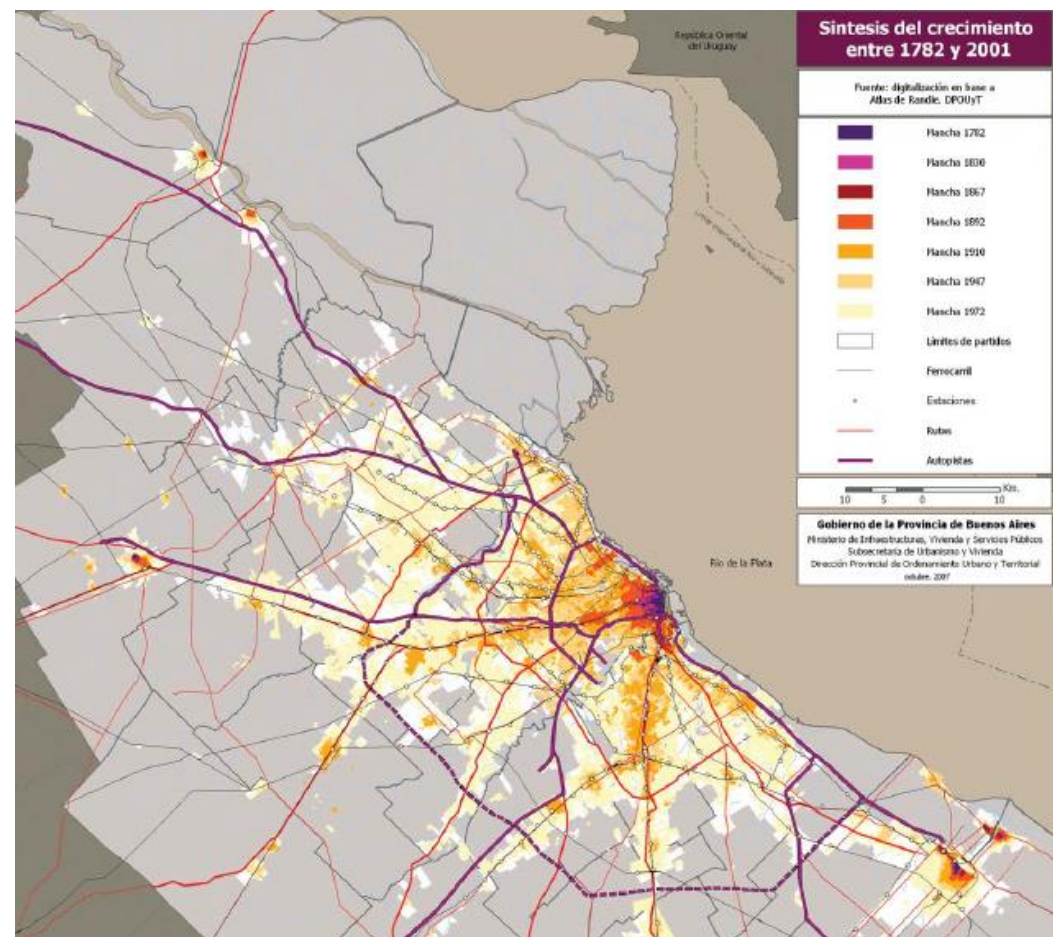

Figura 7. Crecimiento de la mancha urbana Metropolitana de Buenos Aires 1782-2001. Fuente: Gobierno de la Prov. de Buenos Aires, www.gobierno gba.gov.ar

En la figura 8, se observa la configuración actual del territorio del AMBA con los Partidos que la componen, pudiendo observarse también la extensión de la mancha urbana que incluye el territorio que abarca el Partido de La Plata, que se analizara en profundidad durante la segunda parte de este trabajo.

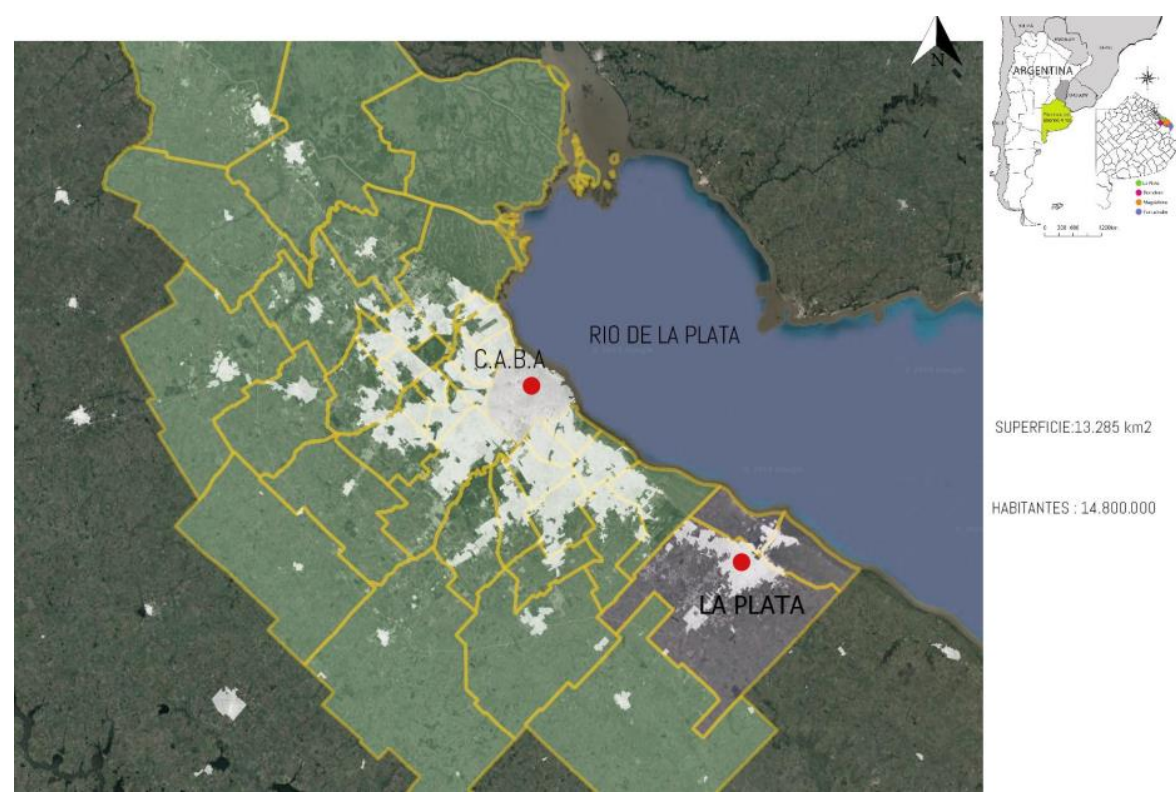

Figura 8. Configuración actual del territoriol del AMBA. Fuente. Elaboración propia, Google Earth, 2019. 
En este apartado se puso de manifiesto la incidencia en el territorio que produjeron las variaciones contextuales, en donde las relaciones entre las características de los procesos de desarrollo urbano metropolitano vinculados con la aplicación de política urbana y habitacional a escala metropolitana tendieron a la profundización del desarrollo geográfico desigual, lo que ha caracterizado el proceso de expansión en el AMBA. Se configuró de este modo, un suburbio empobrecido y en constante expansión, vinculado con procesos de fragmentación del territorio crecientes en la actualidad. Esto constituye las marcas distintivas a través de las cuales es posible analizar los procesos que tuvieron lugar durante las últimas décadas, apuntando en este sentido, a profundizar sobre las relaciones que se establecen entre contextos de proximidad física y distancia social.

\subsection{Informalidad urbana el AMBA: Mercado de tierra y acceso al suelo}

Un amplio conjunto de cuestiones explica las dificultades que deben enfrentar los sectores de menores recursos económicos de la población para adquirir de manera legal en el mercado un terreno que cuente con servicios básicos. En primer lugar, los salarios y oportunidades de empleo que permitan acceder a la compra de bienes resultan insuficientes debido a causas vinculadas con la estructura socioeconómica del país que deja sectores excluidos. En segundo lugar, estos sectores de la población por lo general, no son sujetos de crédito bancario por su situación, cayendo en un círculo que acrecienta la falta de oportunidades y, por último, los altos precios del suelo que lo convierten en una mercancía de muy dificultosa disponibilidad, más aún cuando el mercado juega un rol independiente, con escasa regulación e intervención por parte del Estado.

Como se ha mencionado, Argentina es uno de los países de mayor grado de urbanización de América Latina y muestra una temprana urbanización respecto de los demás países de la región, ya que, desde la década de los años '30 del siglo pasado, junto con Cuba y Uruguay, se consideró como un país urbano, y en la década del '50, el $62,2 \%$ de la población total vivía en centros urbanos. Actualmente más del $90 \%$ de la población vive en núcleos mayores a los 2.000 
habitantes mientras que en la década del '80 lo hacía casi el 83\%14. El aglomerado más grande del sistema urbano del país, AMBA, concentra alrededor del 35\% de la población nacional, lo que corresponde al 38\% de la población urbana y produce el $48 \%$ del producto bruto interno argentino. En este sentido, la configuración del área urbana de Buenos Aires es el reflejo de los particulares y complejos procesos socio-territoriales que condicionaron su conformación histórica como se revisó en el apartado anterior.

La problemática de la informalidad urbana hace referencia algún tipo de conflicto con relación a las normas e instituciones del Estado y del mercado, se trata de formas de acceso a la tierra y/o a la vivienda en las que, en general, intervienen agentes inmobiliarios que, o no se adhieren a las reglas institucionales establecidas, o bien no entran bajo su protección (Feige, 1990). La informalidad urbana se origina cuando la situación de tenencia, con respecto al uso legal o urbanístico, con relación por ejemplo al trazado urbano, no se ajusta a la normativa que regula las relaciones de acceso y ocupación de la tierra y de la vivienda. Esto remite, al orden jurídico que regula las relaciones sociales y que se expresa territorialmente en los patrones de localización residencial y en la situación habitacional predominante entre diferentes sectores sociales. De esta manera, la informalidad se define por la forma en que se resuelve la relación con el mercado de tierra y vivienda, y con el sistema de propiedad (Herzer, Di Virgilio y Rodríguez, 2008).

Asumir esta definición de informalidad no supone adherirse solamente a un tipo de clasificación de la informalidad correspondiente con un carácter de tipo dual sobre la existencia de un mercado formal de tierra y vivienda versus otro informal. Muy por el contrario, y de manera aún más compleja, la informalidad es parte constituyente de la estructura productiva y territorial de la ciudad y pone de manifiesto el carácter segmentado de un único mercado de tierra y vivienda que refleja la heterogeneidad del sistema. Sin embargo, es posible diferenciar 
operaciones de tipo formal e informal, en los términos que se abordaron con anterioridad, que se interrelacionan generando dos tipos de "submercados" que se retroalimentan y que parecen guiarse por la misma lógica, la económica, que es la lógica que representa al sistema que los contiene. No resulta posible eludir el hecho de que la estructura socio espacial de la ciudad constituye el soporte material a través del cual se crean y se mantienen las relaciones sociales necesarias para el desarrollo del capital; y que, a su vez, es la resultante de una multiplicidad de complejos procesos políticos, económicos y culturales (Di Virgilio, 2015).

En este marco, la noción de informalidad no sólo supone considerar la forma a través de la cual los sectores de menores recursos logran resolver el acceso a la tierra y la relación con el sistema de propiedad, sino también el papel restrictivo del mercado formal de tierra y vivienda que permanece fuera del alcance de amplios sectores de la población. Tal como señala Portes (1999), "la diferencia básica entre lo formal y lo informal no estriba en el carácter del producto final o bien que se produce, sino en la forma en que ese producto es producido o intercambiado". En el caso de Argentina, esta situación restrictiva es resultado, entre otros factores, de un Estado con muy baja intervención en materia de planificación urbana, que a lo largo de las distintas etapas políticas y económicas que atravesó el país, no ha conseguido lograr una regulación y tratamiento adecuado del mercado, que se guía según sus propias reglas e intereses, prácticamente sin regulación ni control estatales, dando como resultado un crecimiento urbano sin restricciones.

En este sentido, sería importante la implementación de instrumentos y otras formas de planificación, en respuesta a la problemática del acceso (o no acceso) al suelo, lo que como se ha dicho, termina excluyendo a la población de menores recursos del derecho digno de habitar la ciudad. La urbanización informal en el Área Metropolitana de Buenos Aires se desarrolló sobre tierra vacante u ociosa, principalmente durante la década de 1930, destacándose las villas (en principio como asentamientos de emergencia) como principal forma de ocupación del suelo por parte de los inmigrantes desocupados que llegaban a Buenos Aires en la búsqueda de oportunidades de trabajo. En este contexto, comenzaron a surgir nuevos barrios y las villas empiezan a formar parte de las áreas próximas a la 
ciudad, ocupando áreas centrales, cercanas a polos industriales o zonas anegables, principalmente las cuencas inundables de los ríos Matanza-Riachuelo y Reconquista, que atraviesan el Área Metropolitana. Por su parte el Estado durante esos años construyó algunas viviendas de tipo transitorias, siendo la actual Villa 31, una de la villas más grandes y reconocidas de la Provincia de Buenos Aires, resultado de dicho proceso constructivo. Como producto de las sucesivas crisis económicas que atravesó el país, lo que inicialmente fue un asentamiento transitorio en la década del '30, culminó en la consolidación de villas en el Área Metropolitana, convirtiéndose en una solución habitacional de carácter permanente y continúa siendo la principal vía de acceso al suelo para los sectores de menores recursos de la población excluidos del mercado formal, constituyéndose el denominado mercado de suelo informal o submercado informal.

Los años de la dictadura cívico militar Argentina entre 1976 y 1983, se caracterizaron por un estado de valorización financiera que introdujo transformaciones económicas al contraer deuda externa, y luego colocar activos financieros en el mercado local, con el propósito de valorizarlos a partir de las diferencias entre las tasas de interés externas y las internas (Basualdo, 2010). Estas transformaciones estructurales tuvieron su correlato en una profundización de la brecha urbana, y fundamentalmente afectaron a la población de urbanizaciones informales, acrecentando su situación de informalidad y, consecuentemente, de marginalidad. No obstante, se implementaron por parte del Estado políticas de erradicación y traslados de familias que residían en algunas de las villas más consolidadas de la ciudad de Buenos Aires, hacia municipios del Gran Buenos Aires, así como otras medidas de orientación similar como, por ejemplo, la desregulación del mercado inmobiliario. Cabe destacar que estas medidas sólo lograron profundizar la segregación y la fragmentación territorial con un aumento de la estigmatización de referida a este tipo de urbanización. Una vez finalizados los años de dictadura, y con la llegada del período democrático, en la Argentina, la modalidad de acceso al suelo que caracterizó a al nuevo período principalmente correspondió con la toma u ocupación de terrenos vacantes y esta modalidad se incrementó durante los años sucesivos. Ya durante la década de 1990 se estructura 
definitivamente un mercado informal de suelo, debido principalmente a la crisis que da por resultado el crecimiento de población en situación de déficit habitacional. Desde fines de los ' 90 en adelante, el mercado informal del suelo en la AMBA se dinamizó aún más, los cual trajo aparejados diversos procesos de mercantilización del suelo que incidieron en los modos de ocupación y formas de acceso a la tierra, principalmente la ocupación de las áreas periféricas.

La toma de tierras en el AMBA se convirtió en una forma habitual de ocupación del suelo urbano, como consecuencia de la expulsión de la ciudad de la población sin posibilidades de acceder al suelo través de mecanismos del mercado formal. Estas urbanizaciones se localizaron en un primer momento en los municipios del sur y del oeste de las zonas periféricas, alejadas de las áreas centrales, respondiendo a criterios de racionalidad urbanística, como el trazado regular de calles, la previsión de espacios verdes y la incorporación progresiva de servicios urbanos básicos. De este modo, se fue expendiendo la urbanización informal hacia la periferia, tomando áreas vacantes, como principal manera de acceder al suelo por parte de los sectores más relegados, mientras que la mancha urbana se expandía, y al mismo tiempo las villas más antiguas de la ciudad se consolidaban en las zonas centrales (Figura 9).

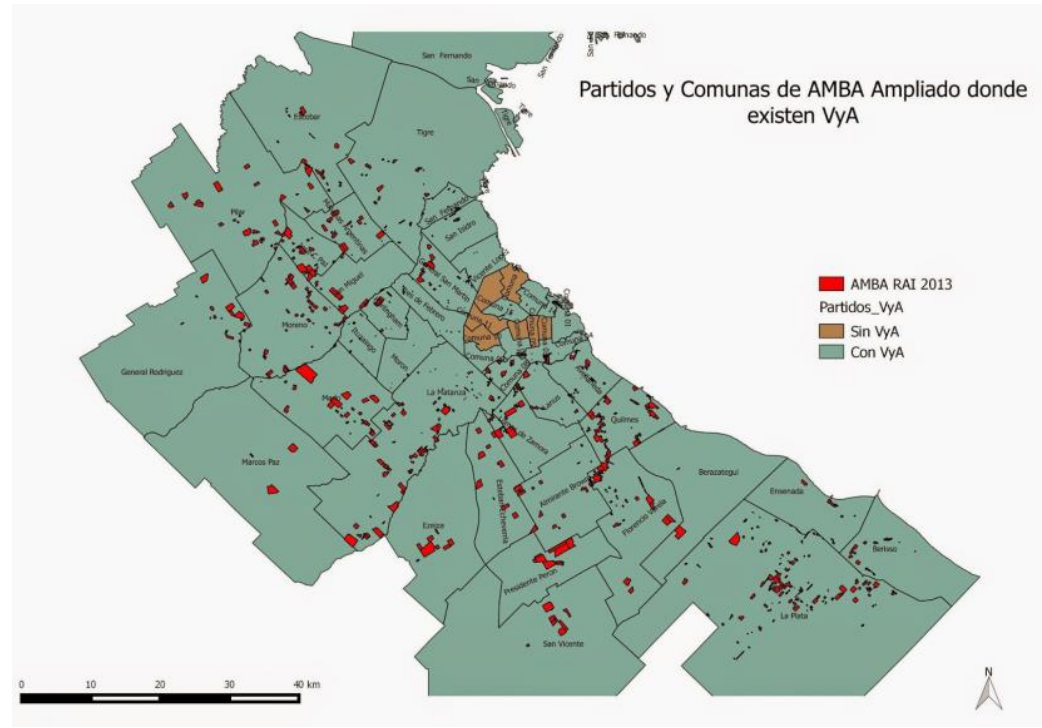

Figura 9. Localización de las urbanizaciones informales del AMBA, 2013.

Fuente. http://lasocialinformacion.blogspot.com/2015/01/villas-y-asentamientos-en-ambaampliado.html 2013. 
Según la organización no gubernamental TECHO ${ }^{15}, 1$ de cada 10 personas vive en urbanizaciones informales en Argentina, en base al relevamiento realizado en el año 2016. Entre 2014 y 2015, el Registro Público Provincial de Villas y Asentamientos Precarios (RPPVAP) reconoció un total de 982 villas y asentamientos informales sólo entre los 24 Partidos del GBA, de las cuales 268 registros están en el espacio territorial del primer cordón y 714 en el segundo ${ }^{16}$.

En lo que respecta al AMBA, la cantidad de urbanizaciones infórmales, se eleva a 1.271, entre villas, asentamientos informales y otros tipos de urbanizaciones informales que no entran en la categoría de villas ni de asentamiento informal, como se explicara más adelante. Este número representa a aproximadamente, una cantidad de 385.394 hogares en situación de informalidad y precariedad socio territorial (Figura 10). En un contexto de rápido crecimiento urbano, como es el del AMBA, la informalidad vinculada al hábitat popular pone en evidencia varias cuestiones, por un lado, que una parte importante de la población no cuenta con los ingresos necesarios para hacer frente a los precios establecidos por el mercado formal de tierra y vivienda, quedando por fuera del acceso al mismo. Y por otro que históricamente se ha fomentado escasamente, desde el Estado la instrumentación de líneas de financiamiento hipotecarias de largo plazo que faciliten el acceso a la tierra y a la vivienda a través del crédito u otras políticas vinculadas con formas más inclusivas de acceso a la tierra y regulación de los mercados.

15 TECHO, Relevamiento de Asentamientos Informales - 2016 http://relevamiento.techo.org.ar/downloads/informe_relevamiento_TECHO_2016.pdf.

${ }^{16}$ En el Conurbano se delinean cordones de Partidos, que permiten diferenciar Partidos del primer y segundo cordón. El primero se consolidó entre las décadas de 1930 y de 1950, siendo el gran receptor de las migraciones internas que propició la política sustitutiva de importaciones, alojando gran parte de la industria marcando el desarrollo industrial y moldeó la matriz productiva del Oeste. El segundo cordón, se consolidó entre 1960 y 1980, recibiendo población de migraciones internas de otros centros urbanos del país y países limítrofes. Su desarrollo se sustentó primero en la producción de loteos populares y posteriormente bajo tomas y ocupaciones de tierra, dando lugar nuevos asentamientos populares. La falta de cobertura de redes de agua y cloaca se suma a la precariedad material del hábitat popular, todo un contexto de crecimiento poblacional que, para el 2010 señaló por primera vez la primacía del segundo cordón por sobre el primero, con implicancias en la densificación de sus tejidos urbanos, especialmente las áreas de urbanización informal. 


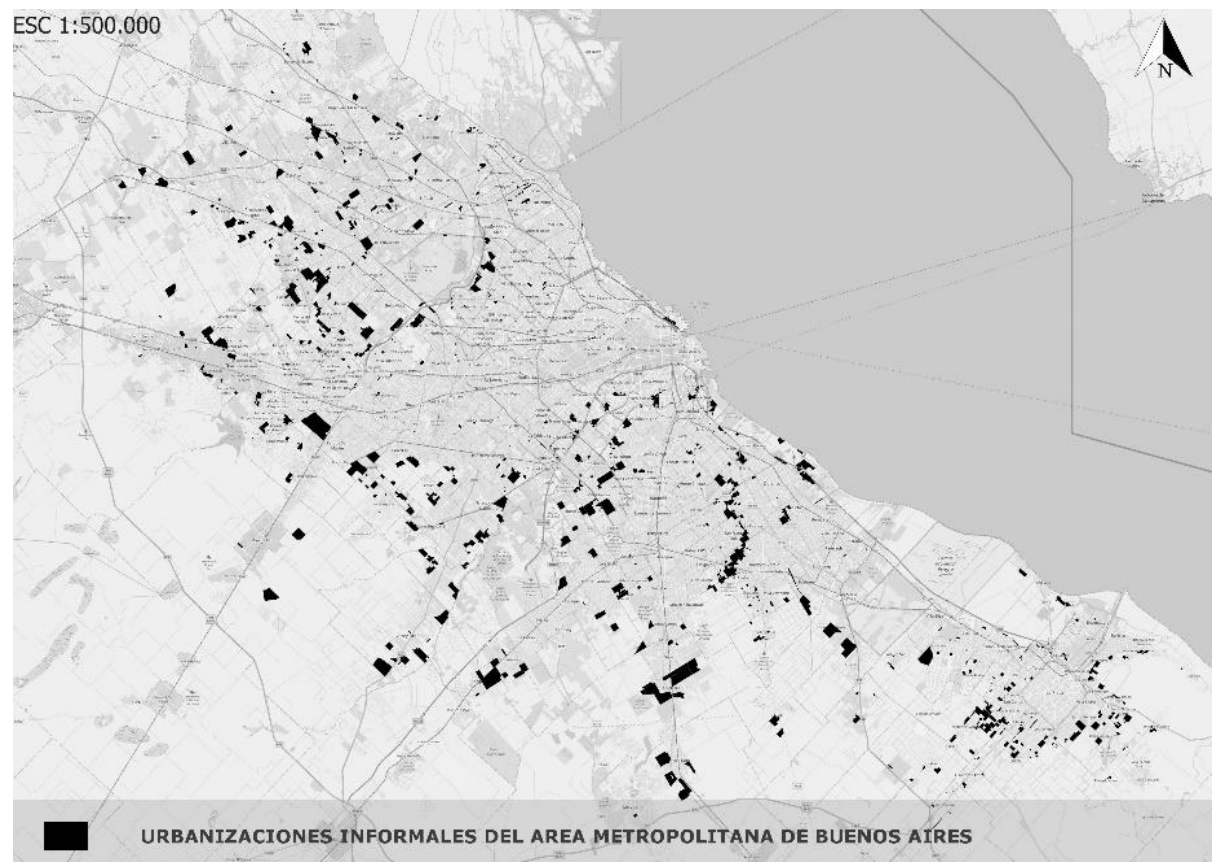

Figura 10. Urbanizaciones informales la AMBA. Fuente. Elaboración propia 2018, datos del RPPVA, 2015.

Esto indica que aun cuando es evidente el aumento de la inversión social y de las respuestas para mitigar el impacto de las sucesivas crisis socioeconómicas entre los sectores de menores ingresos, el sistema de protección social y las políticas urbanas, en particular las de construcción de vivienda social, distan de ser incluyentes y muestran vacíos que reproducen la vulnerabilidad y la estratificación en el acceso al suelo urbano (Di Virgilio, Arqueros, Mejica y Guevara, 2011). Por no tener asegurado un nivel de ingreso tal que les permita afrontar los costos de la formalidad se ven obligados a resolver de manera informal su acceso al hábitat.

La informalidad en el acceso al mercado de tierra y vivienda raramente no se vincula con situaciones de pobreza, pues en gran medida este tipo de inserción da cuenta de la incapacidad de amplios sectores de la población para generar ahorros que permitan disponer de bienes para ser invertidos en el mercado inmobiliario. En este marco, la informalidad en el acceso al hábitat constituiría la expresión más crítica del proceso de informalidad urbana, en la medida en que es tributaria de la imposibilidad de generar ingresos monetarios que aseguren la inserción formal al mercado inmobiliario. 
El acceso de los sectores populares al mercado de tierra y vivienda en la Ciudad no depende sólo de la forma en la que se resuelve su inserción en el mercado de trabajo; está mediada también por otros factores y decisiones de política que pueden orientarse a facilitar procesos de inserción o bien pueden reproducir lógicas fragmentadas. A través de la normativa, con los programas y proyectos impulsados desde los diferentes niveles jurisdiccionales el Estado regula tanto la esfera de producción y de acceso al suelo urbano como la de su comercialización (Clichevsky, 1990).

\subsection{Tipologías de urbanizaciones informales en el AMBA}

Las urbanizaciones informales en Argentina, y en particular en el AMBA, se expresan principalmente en dos modalidades urbanas que corresponden a procesos sociales e históricos distintos. Por un lado, las llamadas "villas" o "villas miseria" ubicadas principalmente sobre las áreas centrales de las ciudades, y por otro, los denominados "asentamientos informales" o "tomas de tierra" que se encuentran ubicados más hacia zonas con características periféricas como menor densidad poblacional. Tanto las villas como los asentamientos informales refieren a urbanizaciones producidas por sectores de la población con escasos recursos económicos en su lógica de la necesidad de habitar (Cravino, 2009).

Morfológicamente las villas se presentan como barrios a los cuales se accede generalmente a través de pasillos estrechos y tienden a crecer en altura ya que la disponibilidad de suelo suele escasa o nula. Los asentamientos informales, más recientes cronológicamente que las villas, buscan mantener la trama urbana como continuidad del tejido de la ciudad formal organizados con el objetivo de lograr con el paso del tiempo establecerse y regularizar la situación tanto de tenencia de la propiedad, como la situación con los servicios urbanos básicos. De no continuar con el tejido formal y no seguir las reglas mínimas del trazado urbano, esto no sería posible; los terrenos se encuentran, en su mayoría, subdivididos en parcelas que conforman manzanas respetando el trazado de las calles y su densidad poblacional es menor a la que se observa en las villas (TECHO, 2013). 
En los centros de las ciudades que pasaron por un proceso de urbanización rápido y temprano como es el caso de Buenos Aries, por lo general prevalece la tipología de villa por sobre la de asentamiento informal, en términos de la cantidad de población que concentra. Mientras que en las conurbaciones y zonas de expansión urbana la situación se produce a la inversa, es decir que existe una mayor cantidad de asentamientos informales. Para definir las tipologías utilizadas en este trabajo de tesis que determinan la situación de informalidad urbana en Argentina, más precisamente para el caso del AMBA, se toma el criterio adoptado por el Registro Público Provincial de Villas y Asentamientos Precarios (RPPVAP, 2015) que establece tres tipologías:

1) Villas: Urbanizaciones o auto urbanizaciones informales producto de ocupaciones de tierra urbana vacante o de la afectación de tierras fiscales por el Estado para asentar a las familias provisoriamente, cuyas características son tramas irregulares (no son barrios amanzanados sino organizados en intrincados pasillos), viviendas construidas con materiales precarios, alta densidad poblacional, escaso o nulo espacio verde e infraestructura auto provista. Cabe mencionar que el término "villa" es el más utilizado en Argentina para referirse a los barrios informales o como sinónimo de cualquier barrio pobre u ocupación de tierra. Las distintas modalidades con que se usa le aportan una gran complejidad al término. Sin embargo, algunas personas evitan utilizar este término por considerar que presenta una connotación peyorativa, reemplazándolo por otras denominaciones tales como "asentamiento", "barrio precario" o "barrios carenciados" (Cravino, 2006).

2) Asentamiento informa o precario: Barrios informales (en términos dominiales) con trazados urbanos que tienden a ser regulares y planificados, y que generalmente (aunque no de modo excluyente) cumplen algunas de las siguientes características: son decididos y organizados colectivamente, los ocupantes buscan legitimarse como propietarios, las viviendas tienen algún grado de firmeza en cuanto a sus materiales y construcción, y su ubicación puede encontrarse sobre tierras degradadas. 
3) Otros (tipos de urbanizaciones informales sin categorizar): Corresponde a barrios con situaciones particulares que conforman parte de la misma problemática. Al interior de este tipo los casos más típicos incluidos son: mixtura entre villa/asentamiento para dar cuenta de aquellos casos que presentan una combinación de tramas urbanas asociados a los diferentes momentos históricos de formación y del proceso de expansión del barrio; villa o asentamiento urbanizado (en forma parcial o completa) utilizada en aquellos barrios con intervención del Estado en programas de urbanización integrales que hayan modificado en forma concluyente sus niveles de consolidación e integración socio-urbana. Dentro de la tipología Otros, también es posible encontrar algunas formas de informalidad que merecen una mención, tales como:

Asentamiento histórico consolidado o semi consolidado: hace referencia a asentamientos que por su nivel de consolidación en los materiales constructivos y el grado de presencia de servicios no se diferencia sustantivamente de los barrios lindantes, a pesar de lo cual persisten irregularidad en la titularidad del dominio; loteo "clandestino" o loteo "pirata" se vincula con situaciones de irregularidad dominial asociada al mercado de compra-venta informal dirigidos a sectores populares, donde un actor "intermediario" (sin ser el titular del dominio) promueve el loteo.

Conjunto habitacional "tomado": se utiliza para hacer referencia a conjuntos de vivienda construidos por el Estado, que sin contar con el final de obra fueron ocupados de forma precaria por hogares que sufren situaciones de déficit habitacional, en donde se visibilizan situaciones de informalidad dispersa, frecuentemente asociadas a la ocupación progresiva de loteos remanentes subdivididos con anterioridad a la sanción de la ley 8912/77.

A partir de las tipologías anteriormente definidas, en la Figura 11, se presenta un cuadro síntesis de las principales características de las dos tipologías de urbanización informal más extendidas en el territorio del AMBA. 


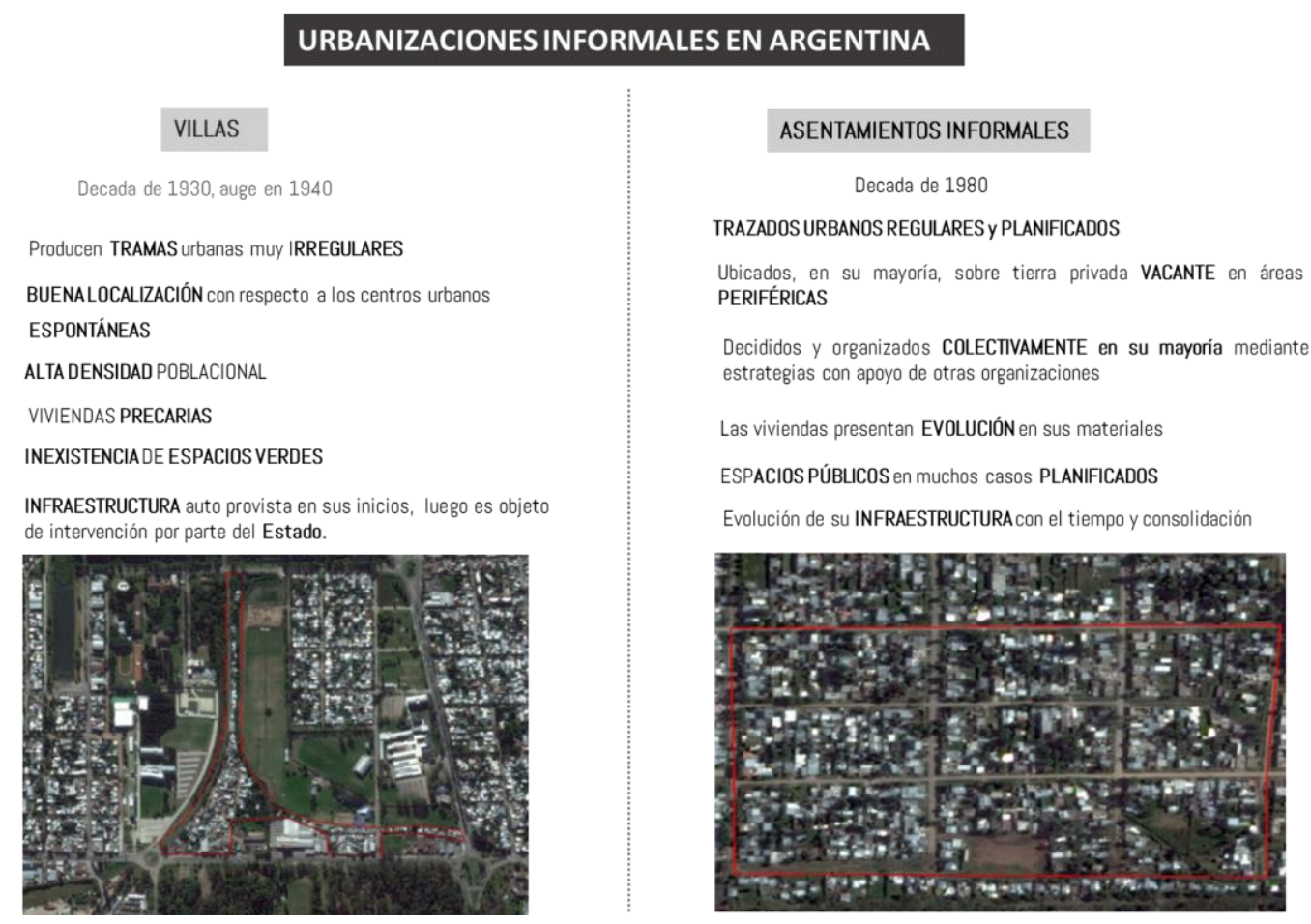

Figura 11. Tipologías de urbanizaciones informales en Argentina.

Fuente. Elaboración propia, 2018 a partir de Cravino, 2012; Clichevsky, 2012; Art.27/11 Ley 14449 .

A modo de síntesis del capítulo, la informalidad urbana resulta ser un fenómeno muy complejo de abordar en el contexto de una problemática tan arraigada como lo representa la distribución desigual del ingreso y la pobreza estructural. Por este motivo, resulta necesario reflexionar sobre la adopción de una visión integradora y a la vez superadora que aborde de manera conjunta las políticas urbanas y las sociales integradas en pos de una ciudad más inclusiva para todos sus habitantes. En este sentido las políticas de urbanización deberían contemplar como problemática principal a resolver las distintas formas de desigualdad, pero concretamente comprender que la integración urbana y la integración social tienen implicancias mutuas y que cualquier intervención debe reconocer la importancia del ejercicio pleno e integral de los derechos sociales, como lo representa el derecho a la ciudad. 
Esquema 1. Síntesis capítulo 3

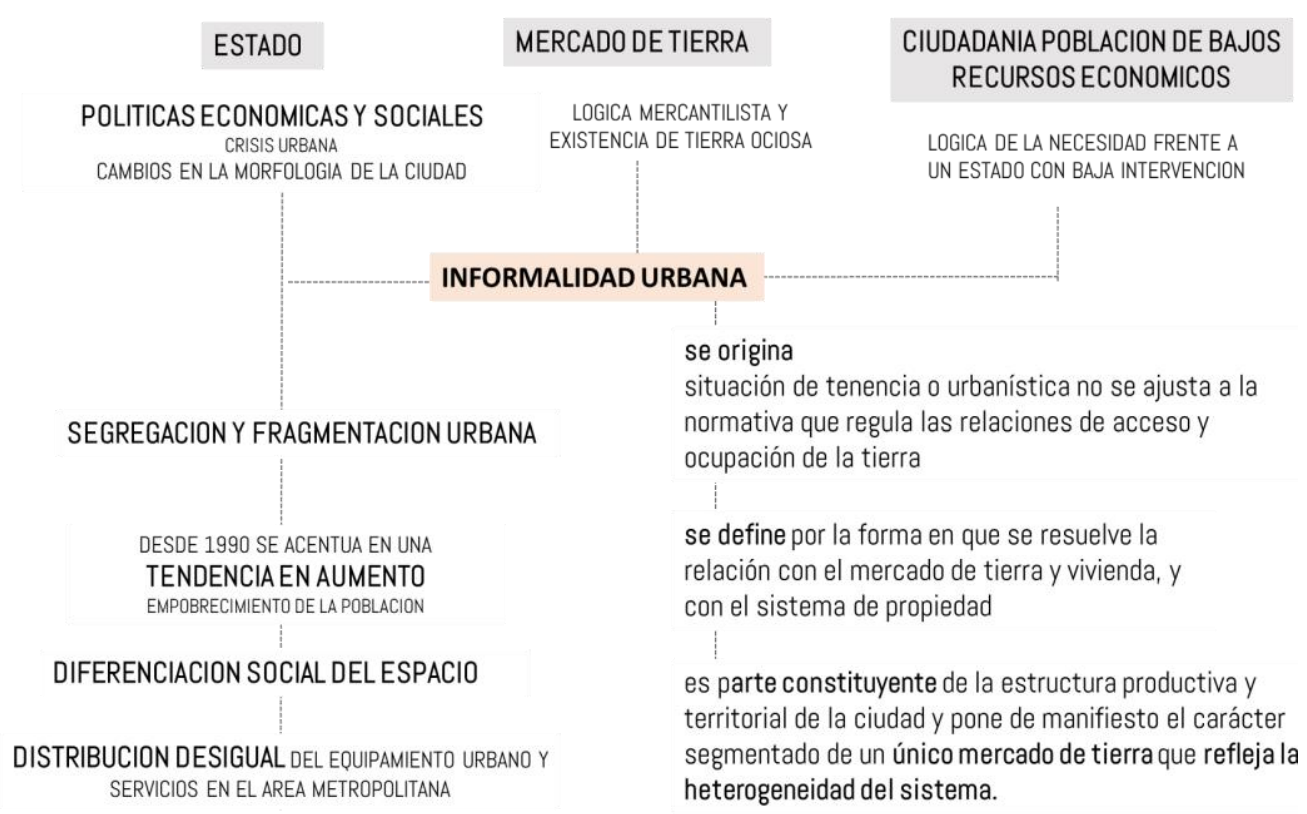

Fuente. Elaboración propia, 2019.

En el siguiente capítulo se profundiza aún más en el análisis de la problemática de la informalidad urbana haciendo foco en el Partido de La Plata, denominado dentro de metodología planteada como nivel medio de abordaje y análisis o meso escala. Esto significa un cambio en la escala de análisis con fin de lograr un acercamiento mayor al objeto de estudio luego de haber presentado el análisis en un nivel superior de abordaje. Para ello se propone, en primer lugar, el análisis de la informalidad urbana en el área periférica del Partido de La Plata atendiendo a la configuración territorial, producto de la expansión y la ocupación del suelo y las tipologías más representativas de las urbanizaciones informales extendidas sobre dicho territorio. El análisis hasta el momento resultó necesario para dar un marco de referencia que permite una mirada integral de la problemática en los tres niveles de abordaje. En la segunda parte de este trabajo de tesis se retoman los macro procesos y conceptos (globales y locales) presentados en la primera parte, con el fin de profundizar y complejizar aún más el abordaje del objeto de estudio. 


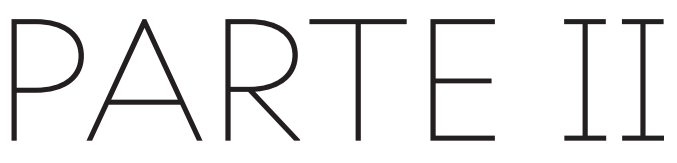

«El Ser es la sociedad total; el tiempo son los procesos, y las funciones, así como las formas son la existencia »

Santos, 1996 


\title{
Capítulo 4
}

\section{La Problemática de la informalidad urbana en el Partido de La Plata, Buenos Aires, Argentina}

\begin{abstract}
$-\bullet \diamond \bullet$
«La producción en cada lugar es el motor del proceso, porque transforma las relaciones del todo y crea nuevos vínculos entre las áreas »
\end{abstract}


Establecer los componentes más significativos que permiten definir y explicar una porción de territorio resulta una tarea muy compleja en la que queda implícita una determinada concepción teórica y donde juega un papel fundamental la forma en la que se operacionalizan aquellas variables que surgen de tal perspectiva. En este sentido, como se ha mencionado en el capítulo anterior, muchas de las ciudades latinoamericanas han sido objeto en las últimas décadas de múltiples transformaciones, muchas de ellas asociadas a fenómenos de reestructuración económica y a cambios socio culturales en el marco de la globalización y los cambios en el sistema económico en el mundo.

En lo que se refiere a la gestión del suelo urbano y el acceso al mismo, el juego de roles entre el Estado y el sector privado ha variado durante las últimas décadas, lo que se expresa principalmente en la retracción del Estado como regulador y en un fuerte impacto o avance del mercado inmobiliario bajo sus propias reglas. Estas situaciones afectan la configuración territorial que adoptan las ciudades generando un tipo de ciudad dual ${ }^{17}$ desde lo social y lo espacial, como sucede en el caso de la ciudad de La Plata y su área periférica. De esta manera, se pone de manifiesto como el territorio se organiza a partir de racionalidades sociales, económicas y ambientales, mediadas por racionalidades políticas, y todas ellas se conjugan de manera diversa según el lugar que se analice.

Resulta necesario primero contextualizar y explicar la configuración y organización del territorio donde se desarrollan las urbanizaciones informales, en este caso, ese territorio corresponde al área periferia del Partido de La Plata, Buenos Aires Argentina. El objetivo de este capítulo consiste en analizar la problemática de las urbanizaciones informales en el Partido de La Plata,

17 El uso del término ciudad dual como sinónimo de metrópolis tardo capitalista (Castells 19891995; Sassen 2000) es muy habitual entre los teóricos de la ciudad ideológicamente encuadrables dentro de la órbita neo marxista. El término ejerce una crítica social que pretende desenmascarar la superestructura capitalista y denunciar las injusticias urbanas. Esta postura ha adquirido un protagonismo tras varias décadas de globalización, que han generado unos grados de polarización social en occidente. 
explicando en primer lugar la configuración territorial actual, para posteriormente analizar el contexto en el que se produce el proceso de expansión urbana sobre la periferia y la forma en la que se lleva adelante la ocupación del territorio en la periferia del Partido. Se logra de este modo una caracterización a nivel general de la totalidad de las urbanizaciones informales del Partido, presentando algunas características comunes, así como la construcción y el establecimiento de las distintas tipologías que prevalecen. Este análisis se presenta como punto de partida para alcanzar la comprensión integral del objeto de estudio en un segundo nivel de abordaje y análisis correspondiente con la meso escala.

\subsection{Expansión urbana y ocupación del territorio en la periferia del Partido} de La Plata

La configuración actual del territorio de la periferia del Partido de La Plata es resultado, en parte, de los procesos de expansión del casco urbano fundacional que han provocado a la ocupación del suelo urbano principalmente en las áreas de borde de la periferia. Es posible asociar la expansión por fuera de los bordes del tejido planificado original con los diversos acontecimientos de carácter político y económico que como se ha mencionado, tuvieron lugar a nivel global y en Argentina desde mediados de los 80 que repercutieron en la distribución territorial de la población.

Entre algunos de los sucesos más significativos que provocaron y aceleraron la expansión y ocupación del territorio se encuentran las políticas económicas que adoptó la Argentina a partir de los años ‘80 y el impacto sobre las modalidades de ocupación del territorio, los precios del suelo urbano de acuerdo a la lógica del mercado y con escasa regulación por parte del Estado, el aumento de población con la llegada de migrantes en búsqueda de oportunidades laborales, muchos provenientes de distintas provincias del país y otros de países limítrofes que no encontraron asentamiento en los centros urbanos, principalmente debido a los altos precios del suelo. En este sentido, cabe mencionar que los factores que 
influyeron en la configuración actual de la periferia del Partido de La Plata, deben enmarcarse dentro de cada contexto histórico. Asimismo, es necesario tener en cuenta que la baja intervención del Estado en materia de planificación urbana y regulación adecuada del mercado ha sido una constante de cada período, con algunas excepciones donde se han implementado por parte del Estado algún tipo de políticas más bien dirigidas hacia la construcción de vivienda y facilitación de créditos. Al presente, no se han dirigido políticas de intervención por parte del Estado que tenga en cuenta una planificación integral del territorio.

El Partido de La Plata (Figura 12) es uno de los 135 Partidos de la provincia de Buenos Aires cuya cabecera es la homónima ciudad de La Plata, capital de la provincia de Buenos Aires, la misma se puede encuadrar dentro del grupo de las denominadas ciudades intermedias 18.
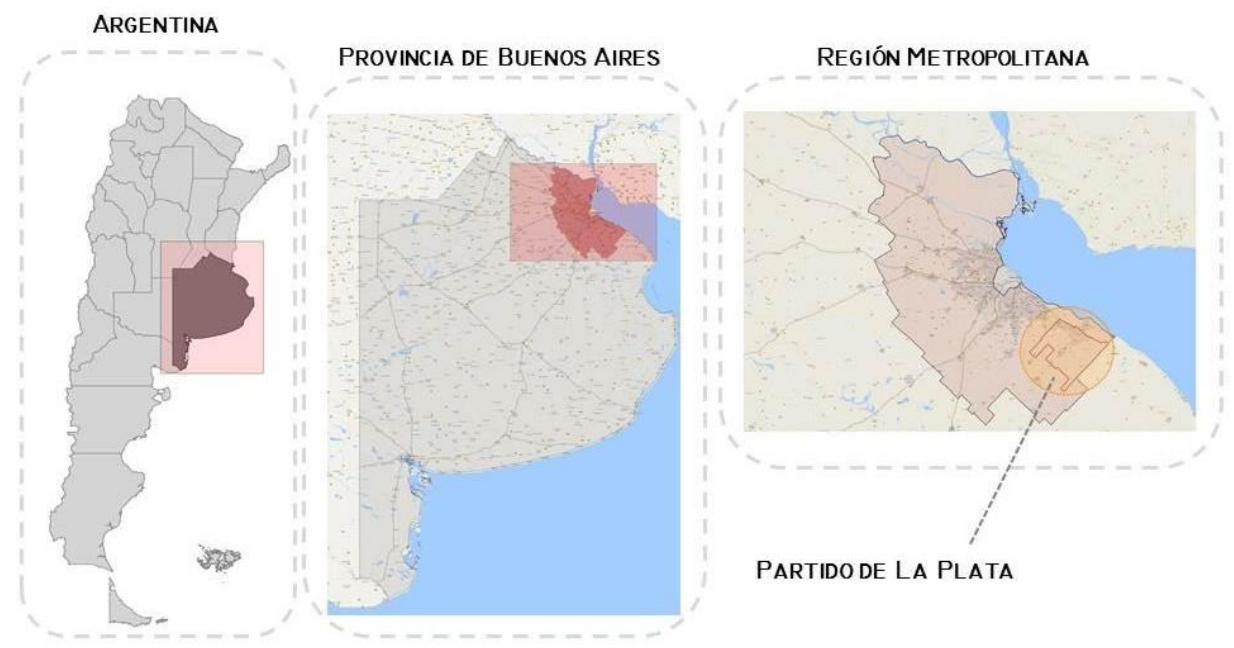

Figura 12. Localización geográfica del Partido de La Plata Fuente. Elaboración propia, 2017.

18 Las ciudades se consideran intermedias no solo en relación a la cantidad de población y dimensiones determinadas ya que esto varia de país a país, sino, sobre todo, con relación a las funciones que desarrollan: el papel de mediación en los flujos (bienes, información, innovación, administración, etc.) entre los territorios rurales y urbanos de su área de influencia y los otros centros o áreas, más o menos alejados. Funciones de intermediación entre los espacios locales/territoriales y los espacios regionales/nacionales e, incluso, globales. 
En cuanto su localización, el Partido de La Plata se encuentra ubicado al sur de la Región Metropolitana de Buenos Aires y a 56 km de la Ciudad Autónoma de Buenos Aires, conformando junto con las localidades vecinas de Ensenada y de Berisso, la denominada Microrregión del Gran La Plata (Figura 13). Entre las principales características de la Microrregión del Gran La Plata se encuentra su estructura socioeconómica definida por un significativo peso del sector terciario, en particular, el sector de la administración pública que se concentra fundamentalmente dentro de los límites del casco urbano de la ciudad de La Plata. Dado el carácter de capital provincial, sede de la Universidad Nacional de La Plata y de numerosas entidades empresariales y financieras, también se caracteriza por la importancia de las grandes industrias de las ramas metalmecánica y petrolera emplazadas sobre el área portuaria, la destilería y petroquímica Repsol-YPF, astilleros Río Santiago y siderurgia SIDERAR.

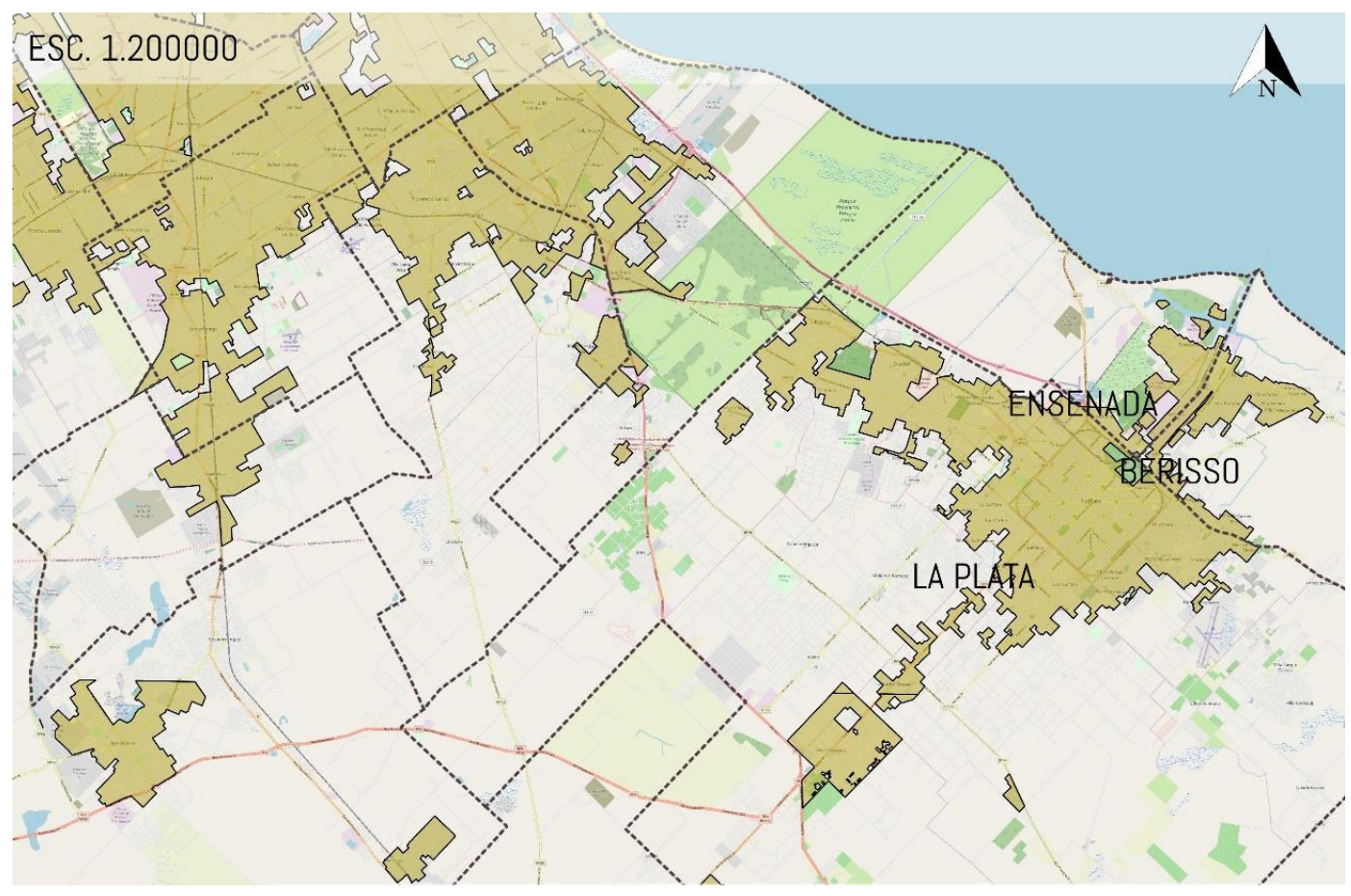

Figura 13. El Gran La Plata y su lugar en el Area Metropolitana de Buenos Aires (AMBA). Fuente. Elaboración propia Qgis, 2019. 
En relación con las actividades económicas que se desarrollan en la microrregión, la horticultura y floricultura intensivas bajo cubierta son las actividades que tienen particular relevancia en el área periférica del Partido de La Plata por su gravitación en los mercados metropolitano y nacional. Se lo considera uno de los principales Partidos con producción hortícola y florícola del AMBA, aun habiendo transitado por una profunda crisis desde los últimos años de la década del '90. La superficie bajo cubierta en la zona de La Plata paso de 1.389,9 hectáreas en el 2001 (CHFBA, 2005) a superar las 2.500 ha destinadas a la producción de hortalizas y flores en el año 2009 (Stavisky, 2010), indicando un aumento del 79\%. Para la realización de esta tesis, se considera el área que corresponde con el Partido de La Plata y que conforma lo que se denomina metodológicamente como meso escala de abordaje y análisis, integrado por las delegaciones de Abasto, City Bell, El Peligro, Joaquín Gorina, Lisandro Olmos, La Plata (casco urbano), Los Hornos, Manuel B. Gonnet, Melchor Romero, Ringuelet, Tolosa, Villa Elvira y Villa Elisa (Figura 14).
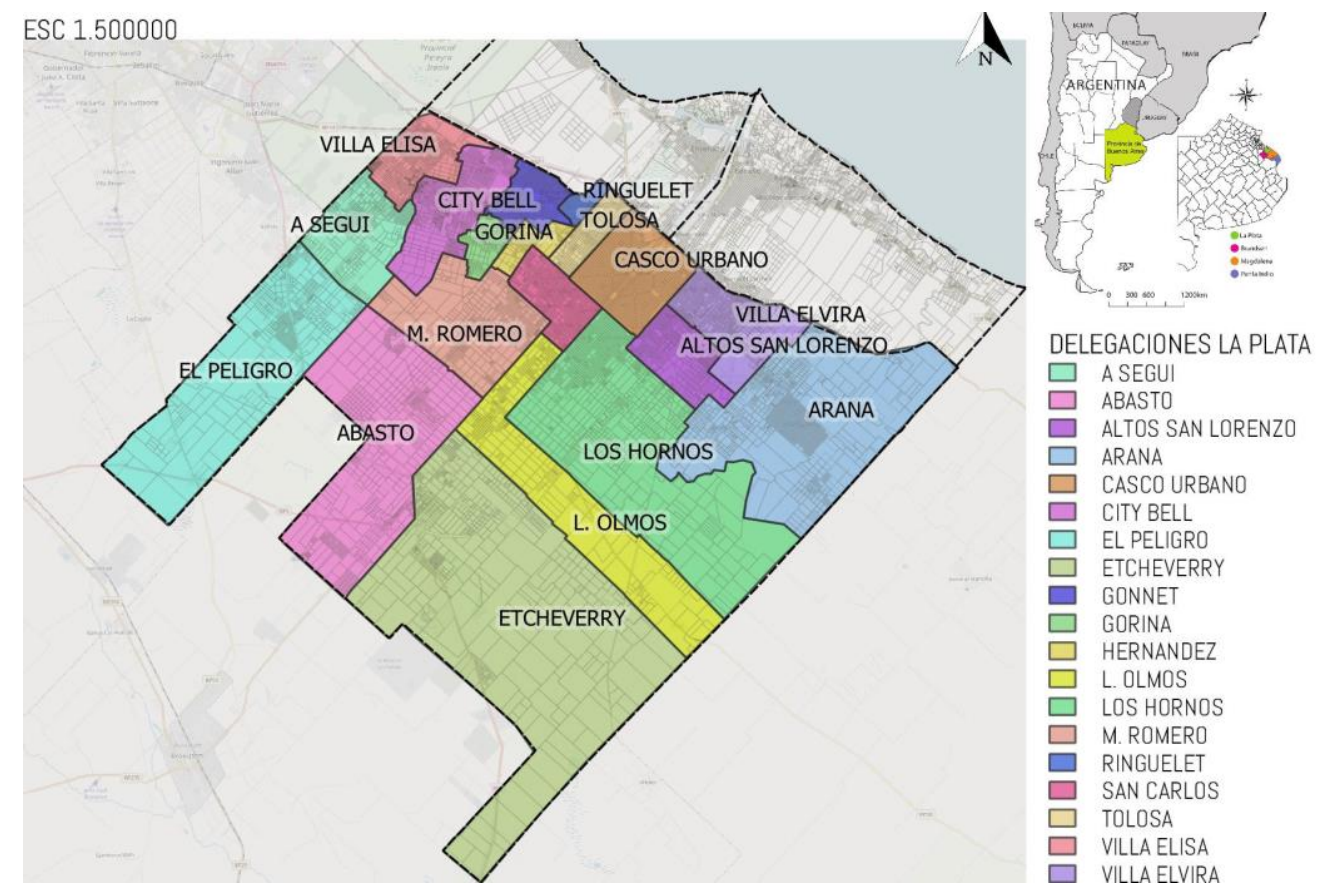

Figura 14. Localidades del Partido de La Plata.

Fuente. Elaboración propia QGIS, 2018. 
En términos demográficos, según datos del Instituto Nacional de Estadística y Censos (INDEC en adelante), el Partido de La Plata alcanzaba en el último censo oficial del año 2010 un total de 654.324 habitantes, mientras que los censos de los años 1991, 2001 y el último del 2010 arrojaban un total de 521.936, 563.943 y 654.324 habitantes respectivamente (Gráfico 1). En la actualidad, la población del Partido se estima en 708.733 habitantes según proyecciones del INDEC, con una tendencia de crecimiento a 733.741 habitantes en el Partido de La Plata estimadas para el año 2025.

Gráfico 1.Variación intercensal de la población del Partido de La Plata.

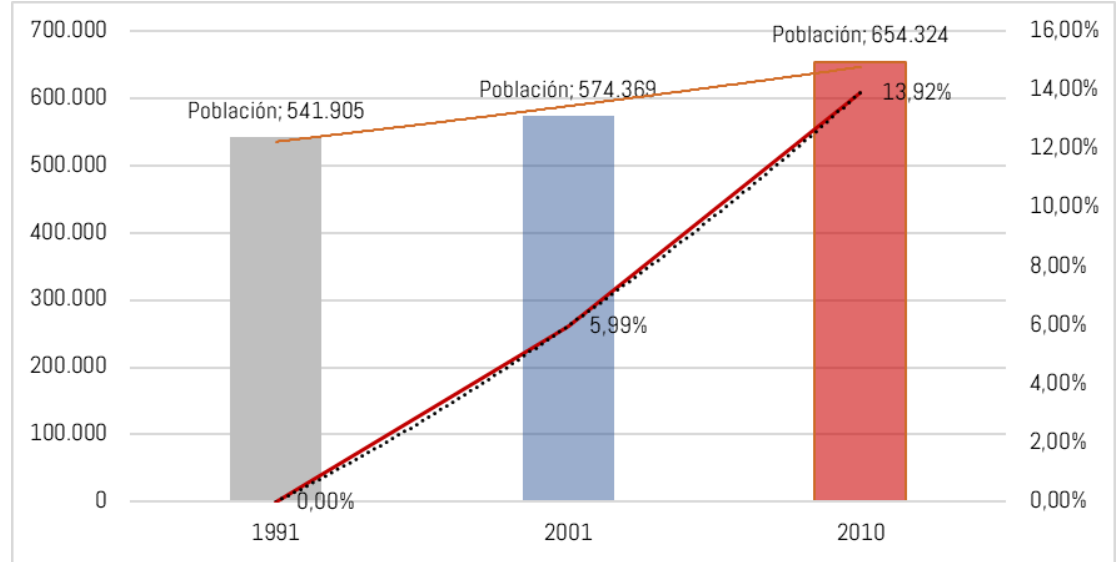

Fuente. Elaboración propia con datos de INDEC 1991-2001-2010.

El conocimiento de los datos poblacionales reflejados en los censos realizados a través de los años y las proyecciones estimadas para los años futuros, resulta relevante debido a que el aumento de la tasa poblacional y los consecuentes procesos de crecimiento urbano derivados, en la periferia del Partido de La Plata, se reflejan en las diferentes modalidades de ocupación del suelo urbano y en las modificaciones en la estructura urbana existente sobre todo en las áreas periféricas del Partido, que crecen desorganizadas y a niveles muy acelerados. En relación a la distribución territorial de la población, se observa que la mayor densidad de población del Partido de La Plata se localiza hacia el área central, es decir la zona que corresponde al centro urbano en el casco fundacional planificado. 
De igual modo sucede en el análisis de los datos que arroja la variación intercensal, el aumento de la población y la expansión urbana, donde se observa que no hubo grandes modificaciones en el patrón de ocupación del área urbana que continuó con una alta concentración de población en el centro y la expansión por fuera de los bordes planificados de manera proporcional (Figura 15). Esto quiere decir que si bien en el casco urbano se concentra la mayor densidad poblacional, cada vez son más las superficies de la periferia que continúan expandiéndose, ya sea por desborde del casco urbano en ciertas zonas y la decisión de sectores de la población de habitar alejados de las áreas centrales, o por los altos precios del suelo que expulsan población hacia las zonas más alejadas, donde esos valores se reducen.

En el Partido de La Plata esta expansión de los sectores medios y altos por fuera de los bordes establecidos en el casco urbano fundacional se inició hacia la zona noreste, incrementándose a partir de la construcción de la autopista La Plata-Buenos Aires y el aumento de los sub centros incipientes durante los años 90, como los de las localidades de Gonnet y City Bell. Del mismo modo, pero principalmente siguiendo otra lógica de ocupación que responde a la de la necesidad, los sectores sociales con menores recursos económicos también se expandieron por fuera de los límites, pero se localizaron provocando la expansión en mayor medida hacia las zonas sureste y suroeste, acentuándose este proceso luego de la crisis socio económica acontecida en la Argentina durante el año 2001. Esta situación implicó que la expansión del área urbana por fuera de los límites planificados resulte en una periferia difusa y desorganizada, y si bien el centro urbano (casco fundacional) es el área más densamente poblada del Partido, la expansión de la ciudad resulta una tendencia en aumento que debe atenderse para poder controlar y ordenar ese crecimiento a través de herramientas e instrumentos de la planificación urbana. 


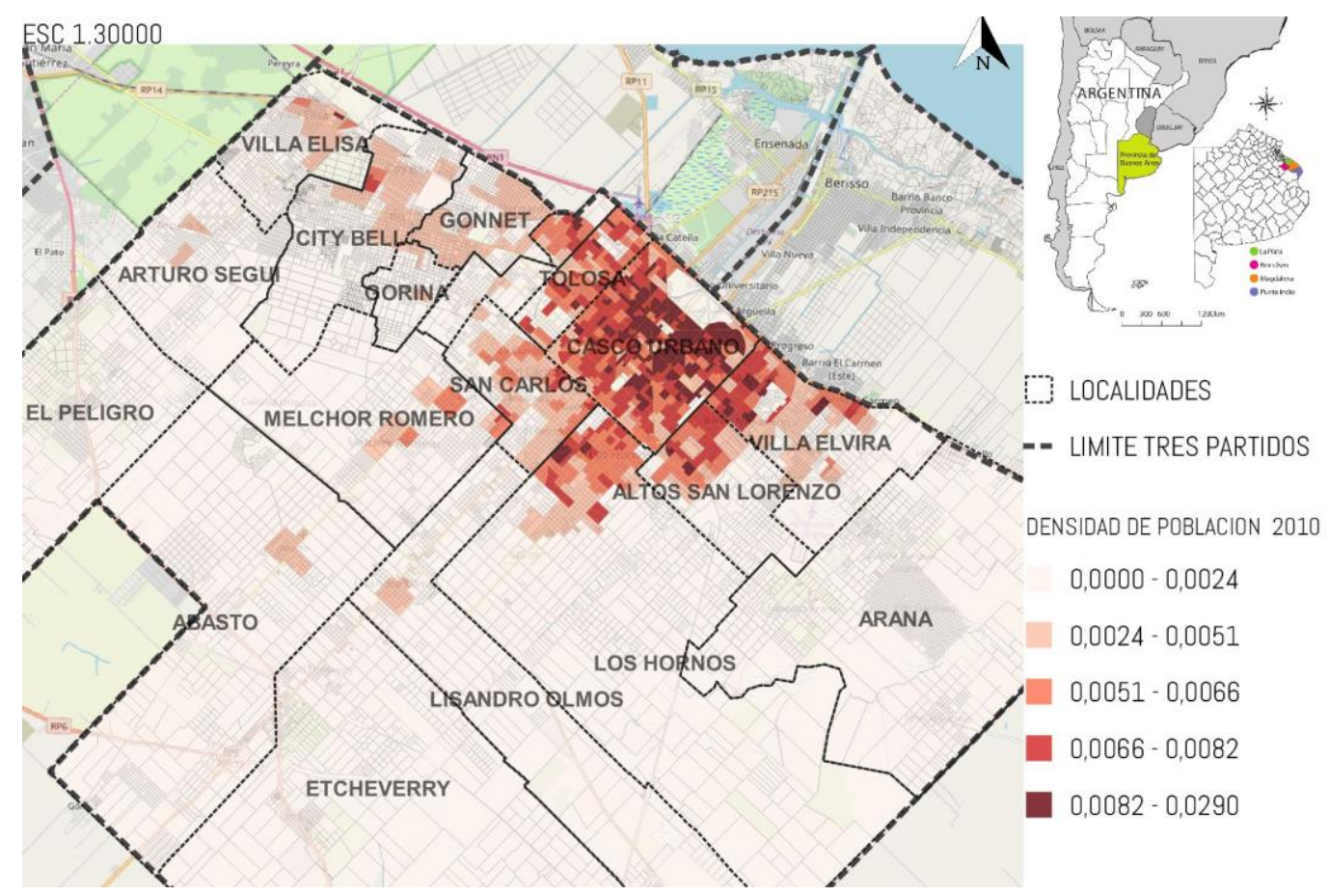

Figura 15. Densidad de población Partido de La Plata 2010. Fuente. Elaboración Propia SIG, 2018 con datos INDEC 2001-2010.

En la Tabla 1 se puede observar la relación entre la superficie del Partido de La Plata (926 Km2), la cantidad de habitantes (654,34 hab.) y la densidad de población (706.6hab $/ \mathrm{km} 2$ ) por un lado, y el porcentaje de población urbana y rural según datos del último censo de población y viviendas del año 2010. De acuerdo los datos obtenidos es posible determinar que la mayor cantidad de población del Partido habita en áreas urbanas (96.9\%) concentrándose en una pequeña parte del total de la superficie del Partido, y que sólo el 3.1\% de la población del Partido habita en zonas rurales.

Tabla 1. Datos poblacionales Partido de La Plata.

\begin{tabular}{|c|c|c|c|c|c|}
\hline PARTIDO & $\begin{array}{c}\text { SUPERFICIE } \\
\text { (KM2) }\end{array}$ & $\begin{array}{c}\text { POBLACION } \\
\text { (HAB) }\end{array}$ & $\begin{array}{c}\text { DENSISDAD } \\
\text { (HAB/KM2) }\end{array}$ & $\begin{array}{c}\text { URBANA } \\
(\%)\end{array}$ & $\begin{array}{c}\text { RURAL } \\
(\%)\end{array}$ \\
\hline LA PLATA & 926 & 654,324 & 706,6 & 96,9 & 3,1 \\
\hline
\end{tabular}

Fuente. Instituto Nacional de Censos y Estadísticas INDEC, 2010. 
En cuanto a la variación intercensal, en relación a la expansión del área urbana del Partido, tal como se observa en la Tabla 2, el área construida suburbana resulta ser la que más ha crecido aumentando su superficie en proporción entre los años 1990 y 2010, habiendo alcanzado un crecimiento de 106.8\% mientras que el área urbana tuvo una variación del 43\% y el área rural del 33.3\%.

Tabla 2. Crecimiento área construida urbana, suburbana y rural Partido La Plata.

\begin{tabular}{|l|c|c|c|c|}
\hline \multicolumn{5}{|c|}{ PARTIDO DE LA PLATA } \\
\hline Área Construida (ha) & 1990 & 2000 & 2010 & Variación \% \\
\hline Urbana & 4831,6 & 7815,8 & 11172,8 & 43 \\
\hline Suburbana & 2280,9 & 2525,1 & 5221 & 106,8 \\
\hline Rural & 366,4 & 422,5 & 563,1 & 33,3 \\
\hline TOTAL & $\mathbf{7 4 7 8 , 9}$ & 10763,4 & 16956,9 & $\mathbf{5 7 , 5}$ \\
\hline
\end{tabular}

Fuente: Elaboración propia en base a datos Atlas de Crecimiento Urbano UTDT -CIPUV.

Cabe mencionar que la expansión urbana residencial hacia la periferia significó una competencia por el territorio entre los diferentes usos del suelo y las actividades que se desarrollan en él. Así, el aumento de la ocupación de nuevas superficies en los límites físicos de la ciudad planificada y por fuera de ellos ha provocado la retracción de suelo rural, que en muchos casos cambió su uso por el residencial (Gráfico 2).

De este modo, en la periferia del Partido de la Plata, la tierra que originalmente era destinada exclusivamente a explotaciones primarias intensivas (agrícola intensivo) adoptó otro tipo de usos de suelo propios de áreas urbanas, principalmente ocupación residencial. Esta situación generó desde los años 90 una revalorización del suelo que desencadenó en una acelerada especulación por parte de los agentes inmobiliarios y los sectores vinculados con la lógica económica del mercado. 
Gráfico 2. Crecimiento del área urbana, suburbana y rural en el Partido de La Plata (1990-2000-2010).

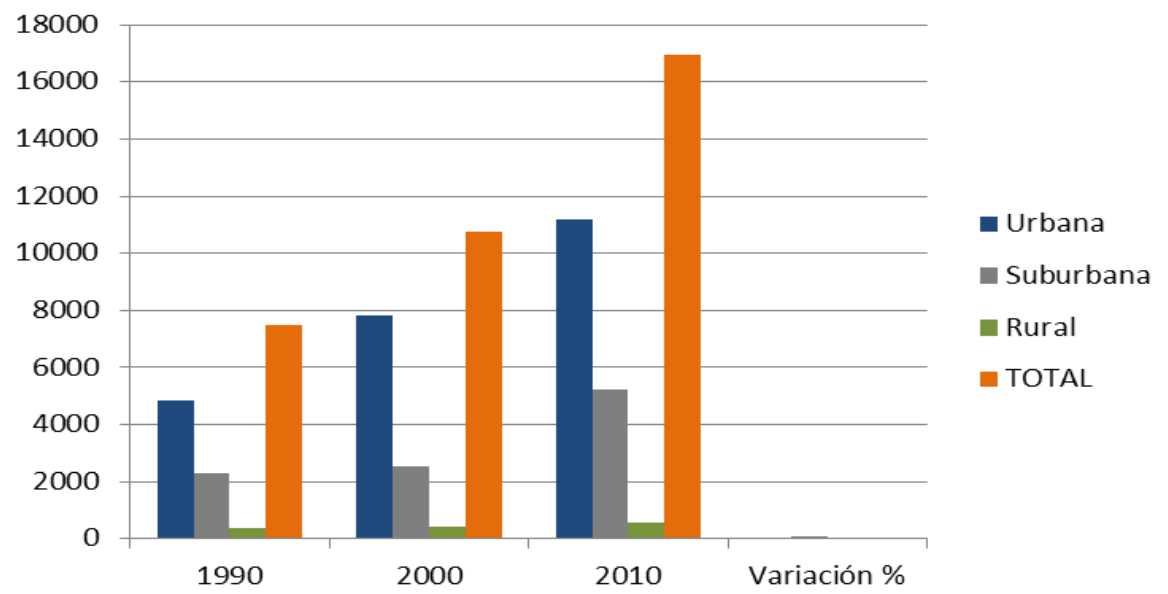

Fuente. Atlas de Crecimiento Urbano https://atlasurbano.herokuapp.com/\#/

La variación y aumento de área construida suburbana se produjo debido a múltiples factores, tales como la emigración de población en busca de nuevas oportunidades laborales y un nuevo hábitat desde el centro hacia la periferia. Durante las últimas dos décadas esto se tradujo en un aumento en la ocupación de nuevas áreas hacia los límites físicos de la ciudad, concretamente en la frontera entre los ámbitos urbanos y no urbanos (Frediani, 2010). Principalmente durante el período intercensal, la variación responde al desplazamiento de la población que habitaba dentro del casco urbano hacia barrios de la periferia, muchas veces como resultado del aumento de los precios del suelo en el centro de la ciudad (Tabla 3).

Tabla 3. Precios promedio del suelo urbano residencial (en U\$S/m2) según oferta parcela < 1000 de m2 por ejes de crecimiento, Partido de La Plata 1999-2001 y 2012-2013.

\begin{tabular}{|l|c|c|c|}
\hline Ejes de crecimiento & $\mathbf{1 9 9 9 - 2 0 0 1}$ & $\mathbf{2 0 1 2 - 2 0 1 3}$ & Var. en \% \\
\hline Casco urbano & 330 & 633 & 92 \\
\hline Eje Noroeste & 67 & 140 & 109 \\
\hline Eje Sudoeste & 45 & 103 & 129 \\
\hline Eje Sudeste & 40 & 87 & 118 \\
\hline Total, Partido & 94 & 189 & 101 \\
\hline
\end{tabular}

Fuente. Del Río y González (2014) en base al relevamiento de precios del suelo del Proyecto H636 (SCyT-UNLP) "Ciudad, Mercado Inmobiliario y Conflicto." 
La racionalidad del sector privado generó una especulación que produjo una variación en los precios de la tierra a lo largo de la última década, estableciéndose una marcada diferencia de precios de suelo entre diversas zonas del Partido. Las localidades de las zonas noreste como City Bell o Villa Elisa, por ejemplo, presentan precios del suelo más elevados que las localidades de las zonas Sur o Sureste como Los Hornos o Altos de San Lorenzo. Al mismo tiempo, la cercanía al casco urbano también valoriza la tierra, por este motivo, al interior de las localidades sobre todo en las del sur, aquellos terrenos más cercanos al casco urbano o en su defecto a vías principales de comunicación, se valorizan con precios más altos que los que se encuentran más alejados y por lo tanto menos accesibles. Siguiendo esta lógica la expansión por fuera de los límites planificados del casco urbano se produjo tanto por parte de los sectores de la población con menores recursos económicos y dificultades para solventar el pago de la renta del suelo en áreas centrales, como los sectores de mayores ingresos de la sociedad, con la expansión de las urbanizaciones cerradas (Frediani, 2010). En este sentido se generó (y continua) no solo pérdida de tierras productivas, sino también, y desde un punto de vista socio territorial, la aparición de espacios cada vez más especializados y estratificados sobre una estructura socioeconómica desigual (Pintos en Frediani, 2010).

El desplazamiento de la población provocó que el área construida suburbana pasara de 2280,9 hectáreas en el año 1990 a 2525,1 hectáreas en el año 2001 y 5221 hectáreas en el año 2010, según datos del Atlas de Crecimiento Urbano UTDT -CIPUV (Figura 16). Esta tendencia de crecimiento pone en evidencia la discontinuidad y desorganización del territorio, siendo necesario estudiar alternativas para la expansión y ocupación del territorio, que incluya la intervención y planificación por parte del Estado, principalmente para que el área de la periferia de la ciudad no siga creciendo como un lugar de disputa y conflicto permanente, entre áreas vacantes, urbanizaciones informales, áreas productivas, urbanizaciones cerradas, etc. 

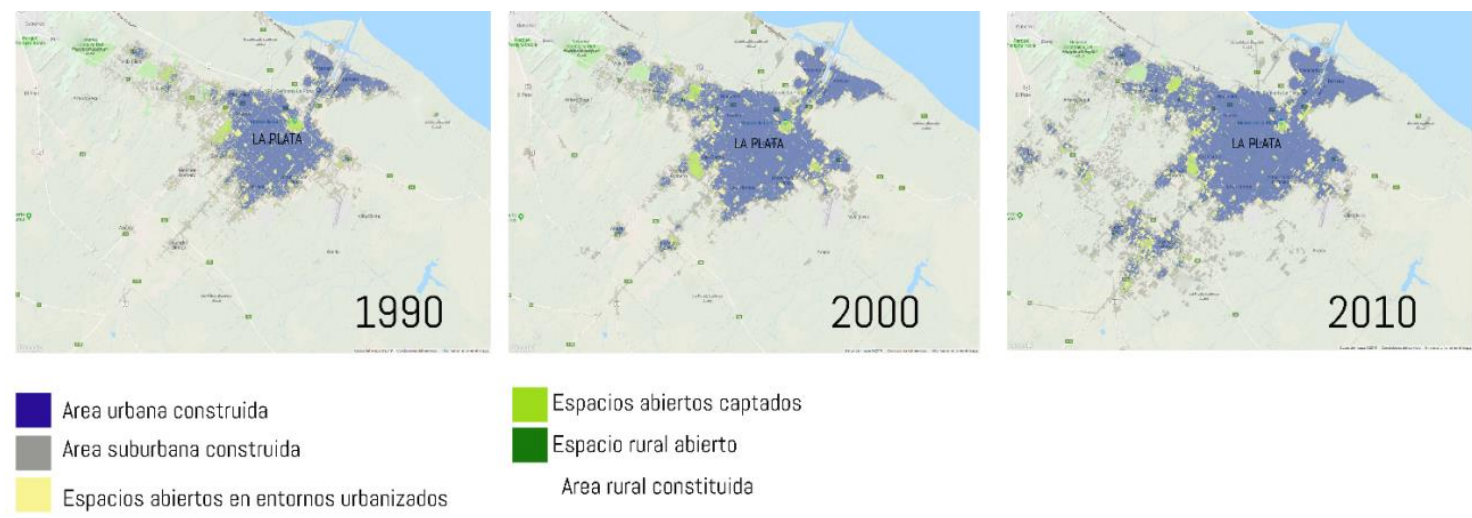

Figura 16. Crecimiento del área urbana del Partido de La Plata 1990, 2000 y 2010. Fuente. UTDT -CIPUV, Centro de Investigación de Políticas Urbanas y de Vivienda, Atlas de Crecimiento Urbano (2013). https://atlasurbano.herokuapp.com/\#/

De este modo, la expansión urbana hacia las zonas periféricas se produjo con una escasa planificación por parte de un Estado con baja intervención en materia de planificación urbana y adaptación de los servicios y equipamientos a los nuevos niveles de población. Así la expansión se dio bajo una racionalidad dominante del mercado inmobiliario y de los sectores privados, por lo que la ocupación del territorio no ha seguido un patrón establecido por las normas vigentes de ocupación y usos del suelo, quedando definida una periferia sumamente heterogénea en cuanto a los usos como se observa en la Figura 17.

Queda así definida una periferia que se caracteriza entonces por su dispersión, discontinuidad y baja densidad, pudiendo reconocerse un crecimiento urbano de baja densidad con áreas en proceso de expansión y/o consolidación, sometidas a procesos de valorización espacial diferenciales. Principalmente por la precariedad habitacional, la ocupación no planificada de la tierra y el aumento continúo de migraciones internas y externas de población. La retracción de la oferta de suelo urbano dirigida a los sectores populares y con menos recursos de la sociedad, trajo aparejada como modalidad dominante de acceso al suelo, la ocupación de terrenos vacantes, fiscales y/o particulares, a través de nuevas urbanizaciones informales, como se explicará en el apartado siguiente. 


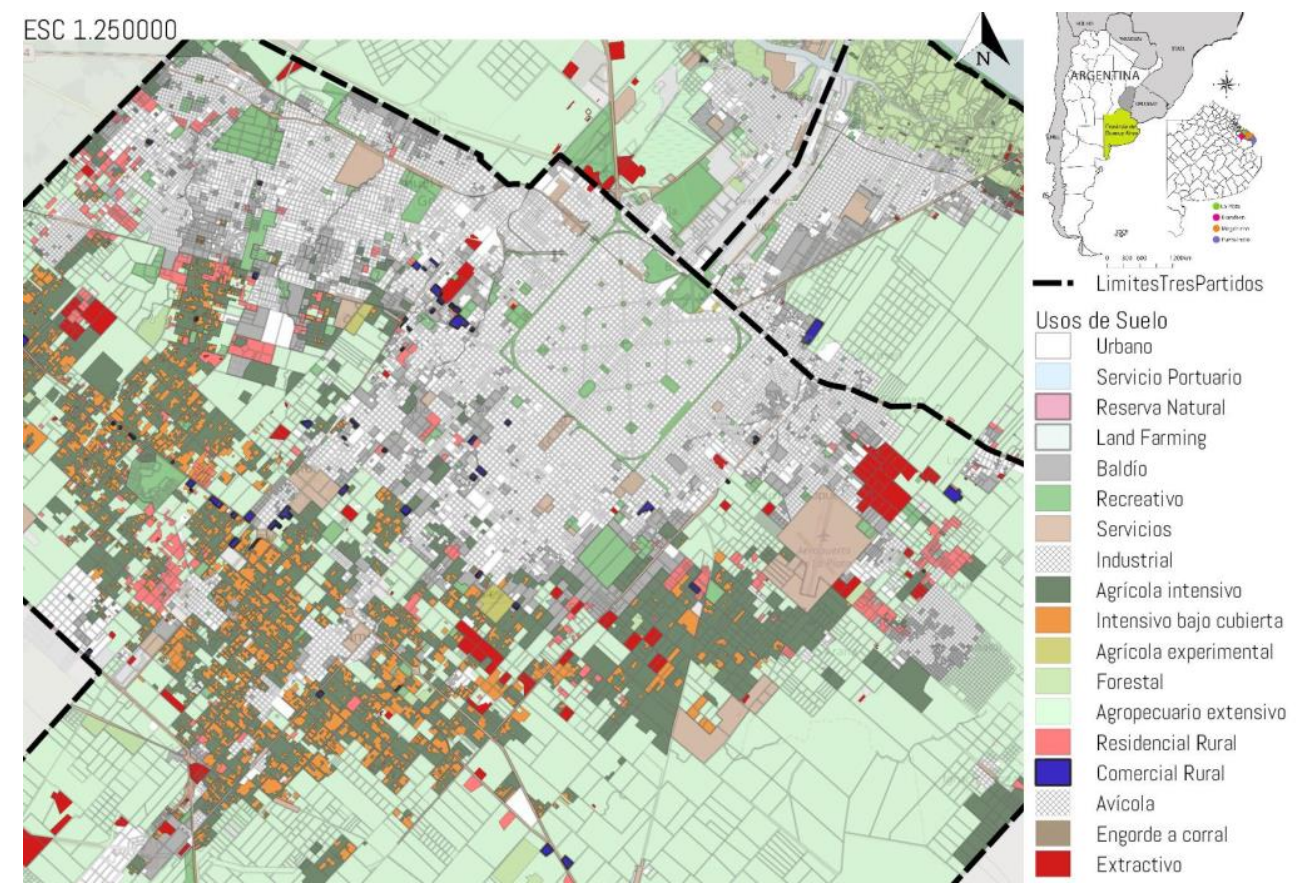

Figura 17. Usos del suelo Partido de La Plata 2016.

Fuente: Elaboración propia, con herramienta SIG, a partir de datos de CISAUA 2016.

A modo de síntesis, el análisis de la expansión urbana en el Partido de La Plata ha permitido reconocer los principales problemas y desafíos de las actuales políticas urbanas. Entre las consecuencias más significativas de la expansión urbana residencial, cabe mencionar que se agudizaron procesos de polarización, fragmentación y segregación territorial en el Partido de La Plata de acuerdo con la lógica de la auto segregación de las clases medias altas que buscando retirarse de los grandes centros urbanos, se asentaron en la periferia conformando las denominadas urbanizaciones cerradas, por un lado. Por el otro lado, con otra lógica también se acrecentó la segregación socio territorial de los sectores de menores recursos económicos que conformaron áreas de urbanización informal a través la ocupación de tierras vacantes en áreas periféricas.

De este modo la periferia del Partido de La Plata se constituyó como un territorio de disputa en el cual la ciudad tradicional abierta y continua se sustituyó por fragmentos discontinuos y, como consecuencia, tuvieron lugar procesos de fragmentación territorial, exclusión social y fuertes procesos de desigualdad e informalidad urbana. 
Esquema 7.Síntesis de la Meso escala

LA MESO ESCALA : LA PERIFERIADEL PARTIDODE LA PLATA

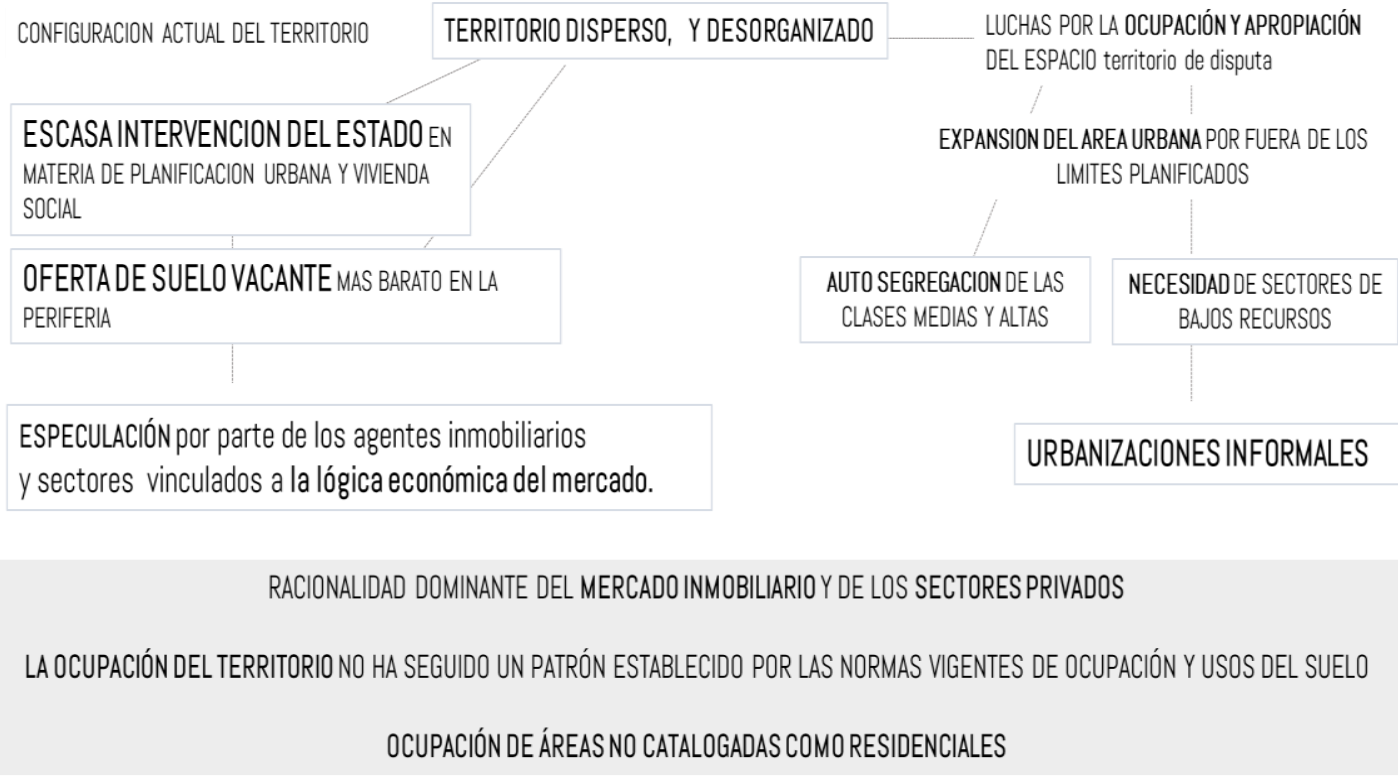

CONFORMACIÓN DEUNA CIUDAD CADAVEZMÁS EXTENSAY DIFUSA

Fuente. Elaboración propia, 2019.

\subsection{Urbanizaciones informales del Partido de La Plata}

En el apartado anterior se señaló que una de las principales consecuencias del proceso de expansión urbana, la baja intervención estatal, las dificultades en el acceso al suelo y la necesidad de tierras en el Partido de La Plata, resulta en el aumento de las urbanizaciones informales, llevadas adelante por sectores de la población con escasos recursos económicos, con dificultades para acceder a la tierra y a la vivienda por las vías formales del mercado, principalmente en zonas periféricas, sobre terrenos vacantes o en zonas de fragilidad ambiental. Hacia el año 2015, según el Registro Público de Villas y Asentamientos de la Provincia de Buenos Aires, en el Partido de La Plata existían un total de 128 urbanizaciones informales (Figura 18). Este dato se modifica día tras día debido al dinamismo de los procesos sociales y territoriales, que producen cambios en la morfología de 
la ciudad, pero a fines prácticos de esta tesis se trabaja sobre el dato oficial disponible al momento de escritura.

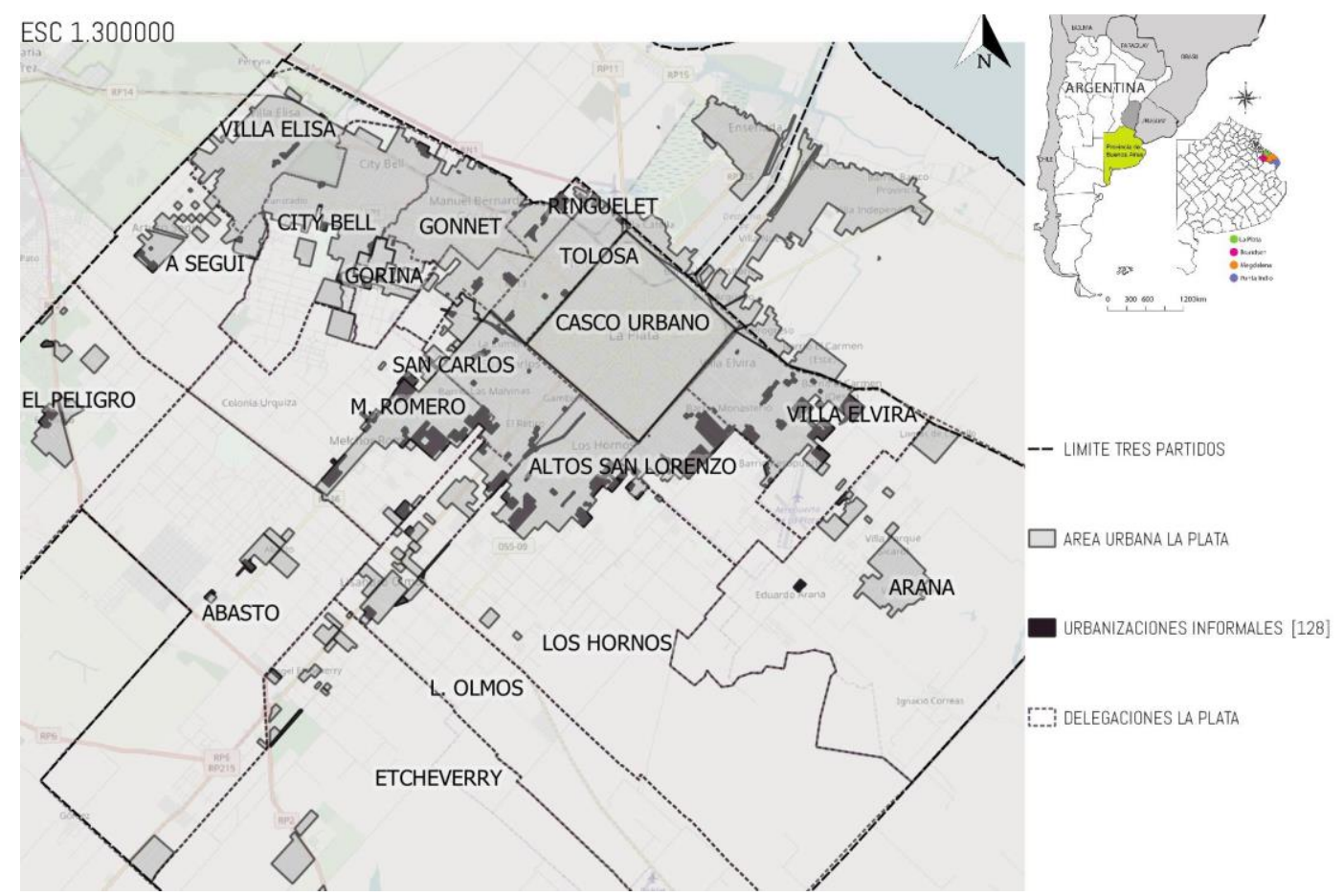

Figura 18. Urbanizaciones informales del Partido de La Plata: Distribución por localidades. Fuente: Elaboración propia con herramienta SIG 2018.

Las urbanizaciones informales se suelen localizar preferentemente sobre las áreas periféricas del Partido, estando sujetas a múltiples problemáticas, relacionadas con la situación dominial, la infraestructura de servicios básicos, el acceso al transporte público, servicios de salud pública y riesgo por cercanía a áreas de fragilidad ambiental y contaminación. Se ha mencionado además que la periferia del Partido se convirtió en un área difusa y heterogénea con múltiples usos, muchas veces no compatibles entre sí, y con gran cantidad de tierras vacantes objeto de la especulación inmobiliaria o lotes para las tomas de tierra. Esta situación se agrava al haber población con algún tipo de vulnerabilidad, ya que la periferia, además, se ha convertido en un territorio de disputa por la tenencia y el uso que se le da al suelo y muchas veces en territorios estigmatizados, segregados y fragmentados, social y territorialmente.

En relación con la distribución territorial que adoptan las urbanizaciones informales en el Partido de La Plata, las mismas suelen localizarse 
preferentemente, hacia las localidades del sudeste y sudoeste del Partido, siendo dichas localidades las que presentan la mayor proporción de suelo ocupado por este tipo de urbanizaciones. No obstante, de acuerdo con el momento histórico que se analice, y como se profundizará en capítulos posteriores de la tesis, la localización ha ido variando a medida que se fue modificando la morfología de la ciudad y expandiendo el área urbana. Por este motivo pueden encontrarse algunas urbanizaciones muy antiguas, por ejemplo, en la localidad de Tolosa o en relación con las zonas norte y noroeste.

En la actualidad, la tendencia de crecimiento informal manifiesta un marcado patrón dominante de ocupación hacia las localidades de las zonas sur y sureste. Este tipo de localización se debe principalmente al carácter de estos ejes de crecimiento que se relacionan con áreas donde los precios del suelo urbano suelen ser menores que en el resto de la periferia, por lo tanto, más accesibles. Al mismo tiempo, la gran cantidad de suelo vacante existente y el hecho de no tener una vinculación directa con la Capital Federal, como sí lo están los ejes noroeste y noreste, los convierten en localizaciones donde los sectores de menores recursos económicos encuentran alternativas para su asentamiento.

Del análisis se desprende que el total de superficie ocupada por urbanizaciones informales en el Partido de La Plata alcanza 875,19 hectáreas. Esta ocupación tiene la característica principal de llevarse a cabo sin planificación, no respetando las áreas urbanizables, sobre terrenos privados o fiscales con condiciones ambientales que implican un riesgo. Es posible afirmar que las localidades que tienen mayor cantidad de suelo ocupado por urbanizaciones informales dentro del Partido son Melchor Romero (19), Villa Elvira (17), Los Hornos (16); Altos de San Lorenzo (15) y San Carlos (12), todas ellas pertenecientes a las zonas sur oeste y sureste del Partido, que como se ha mencionado, se relacionan con procesos de expansión vinculados con población de menores recursos económicos y áreas de mayor vulnerabilidad y segregación socio territorial (Tabla 4). 
Tabla 4. Urbanizaciones informales por localidad (\%) y la ocupación en hectáreas (\%).

\begin{tabular}{|l|c|c|c|c|}
\hline LOCALIDAD & TOTAL & $\%$ & SUPERFICIE HAS & $\%$ \\
\hline Villa Elvira & 17 & $13 \%$ & 171,09 & $20 \%$ \\
\hline Altos de San Lorenzo & 15 & $12 \%$ & 157,06 & $18 \%$ \\
\hline Arana & 2 & $2 \%$ & 12,97 & $1 \%$ \\
\hline Los Hornos & 16 & $13 \%$ & 161.87 & $19 \%$ \\
\hline Olmos & 5 & $4 \%$ & 52,27 & $6 \%$ \\
\hline Etcheverry & 2 & $2 \%$ & 15,9 & $2 \%$ \\
\hline Abasto & 2 & $2 \%$ & 15,54 & $2 \%$ \\
\hline El Peligro & 2 & $2 \%$ & 26,58 & $3 \%$ \\
\hline Melchor Romero & 19 & $15 \%$ & 235,81 & $27 \%$ \\
\hline Arturo Seguí & 4 & $3 \%$ & 21,1 & $2 \%$ \\
\hline Gorina & 3 & $2 \%$ & 10,95 & $1 \%$ \\
\hline City Bell & 7 & $5 \%$ & 23,57 & $3 \%$ \\
\hline Gonnet & 4 & $3 \%$ & 3,14 & $0 \%$ \\
\hline Villa Elisa & 4 & $3 \%$ & 11,1 & $1 \%$ \\
\hline Ringuelet & 4 & $3 \%$ & 35,46 & $4 \%$ \\
\hline Tolosa & 7 & $5 \%$ & 17,81 & $2 \%$ \\
\hline Hernández & 3 & $2 \%$ & 19,91 & $2 \%$ \\
\hline San Carlos & 12 & $9 \%$ & 44,93 & $5 \%$ \\
\hline TOTAL & 128 & $100 \%$ & 875,19 & $100 \%$ \\
\hline
\end{tabular}

Fuente. Elaboración propia Qgis, 2018 con datos del Registro Público Provincial de Villas y Asentamientos Precarios (RPPVAP), 2015.

Esta tendencia hacia la ocupación en localidades ubicadas hacia el sudeste y sudoeste, como se observa en la Figura 19, incrementa el carácter que presentan dichos ejes vinculado a mayores condiciones de vulnerabilidad social, ambiental y menor cantidad de recursos que otras localidades del Partido de La Plata ubicadas, por ejemplo, hacia la zona norte del Partido, como es el caso de City Bell o Villa Elisa, más relacionadas con los sectores de la población de mayores recursos y vinculadas hacia la Capital Federal. 


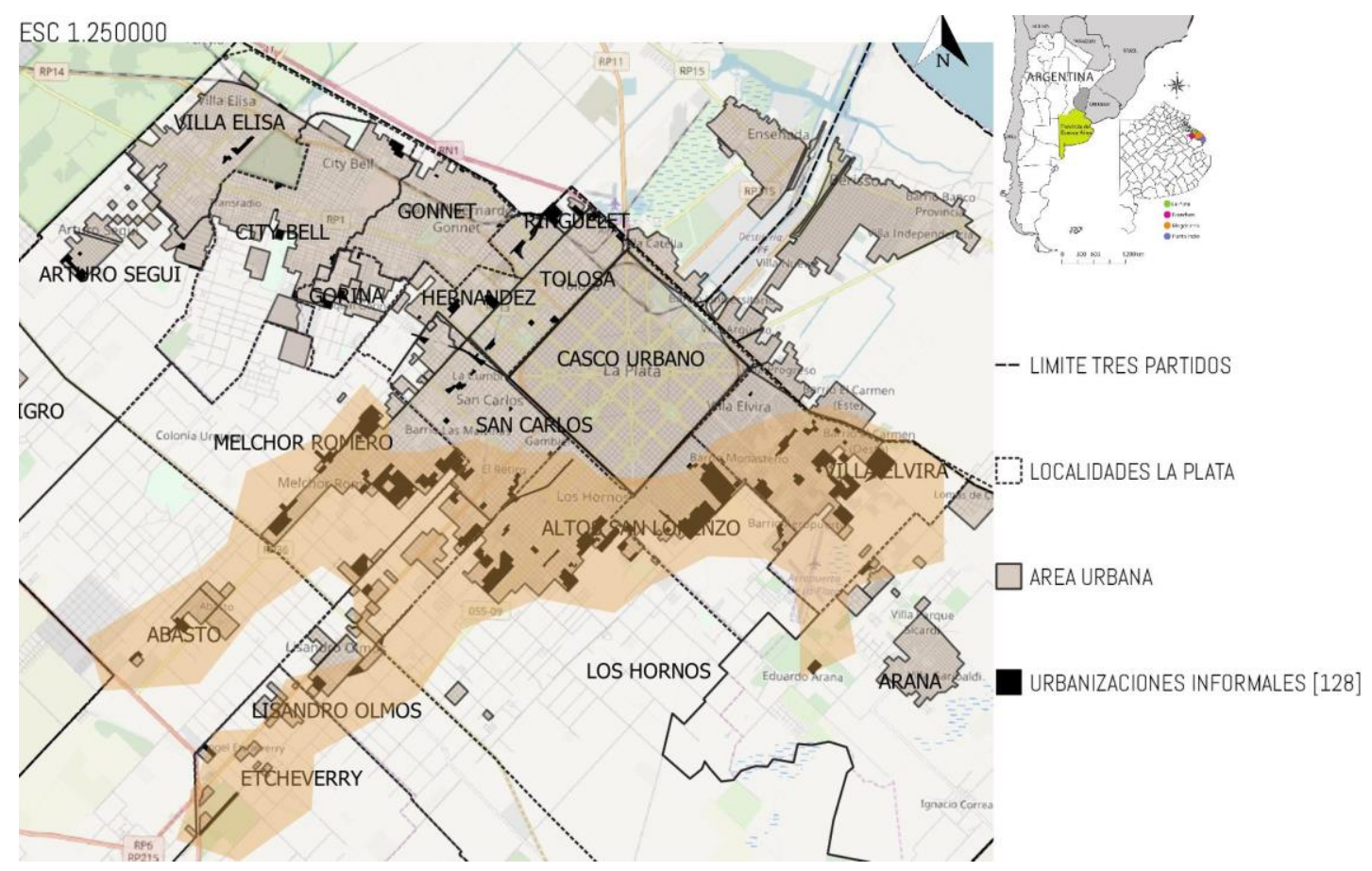

Figura 19. Concentración de Urbanizaciones del Partido de La Plata.

Fuente. Elaboración propia SIG 2018.

Hasta el momento se desprenden del análisis dos cuestiones centrales que definen la problemática de la informalidad urbana en el Partido de La Plata; por una parte, una lógica del Estado incapaz de dar respuesta a esta problemática que se manifiesta en la dispersión en el territorio a través de este tipo de urbanizaciones; por otra parte, una lógica de la necesidad que se traduce en urbanizaciones informales ubicadas en zonas de vulnerabilidad social y ambiental con el estigma social que esto supone, sobre terrenos que carecen de valor de mercado y, por lo tanto, no entran en la lógica del mercado para el crecimiento formal de la ciudad.

Como consecuencia, tejido de la ciudad tradicional y formal entra en tensión con la urbanización informal, transformando la morfología urbana de la periferia en un tejido que desdibuja la trama urbana original y hace las veces de nexo entre las zonas urbanas que continúan avanzando sobre las productivas, dejando espacios vacantes de especulación y fomentado un tipo de ciudad que dista mucho del ideal de ciudad justa y accesible para todos sus habitantes. Se pone de 
manifiesto así, el desconocimiento de las consecuencias negativas para la población con menores recursos económicos de la sociedad que reside en estas urbanizaciones, por parte del Estado, que debería ser quien garantice el acceso digno y justo al suelo y la vivienda. Del mismo modo se evidencia el impacto de los altos costos que implica o implicaría para el propio gobierno local y para la población en general, en el caso de llevarse adelante un proceso de regularización, la expansión urbana en condiciones de informalidad en términos de adecuación de servicios, redes de transporte, etc.

Esquema 8. Síntesis Informalidad urbana en la Meso Escala

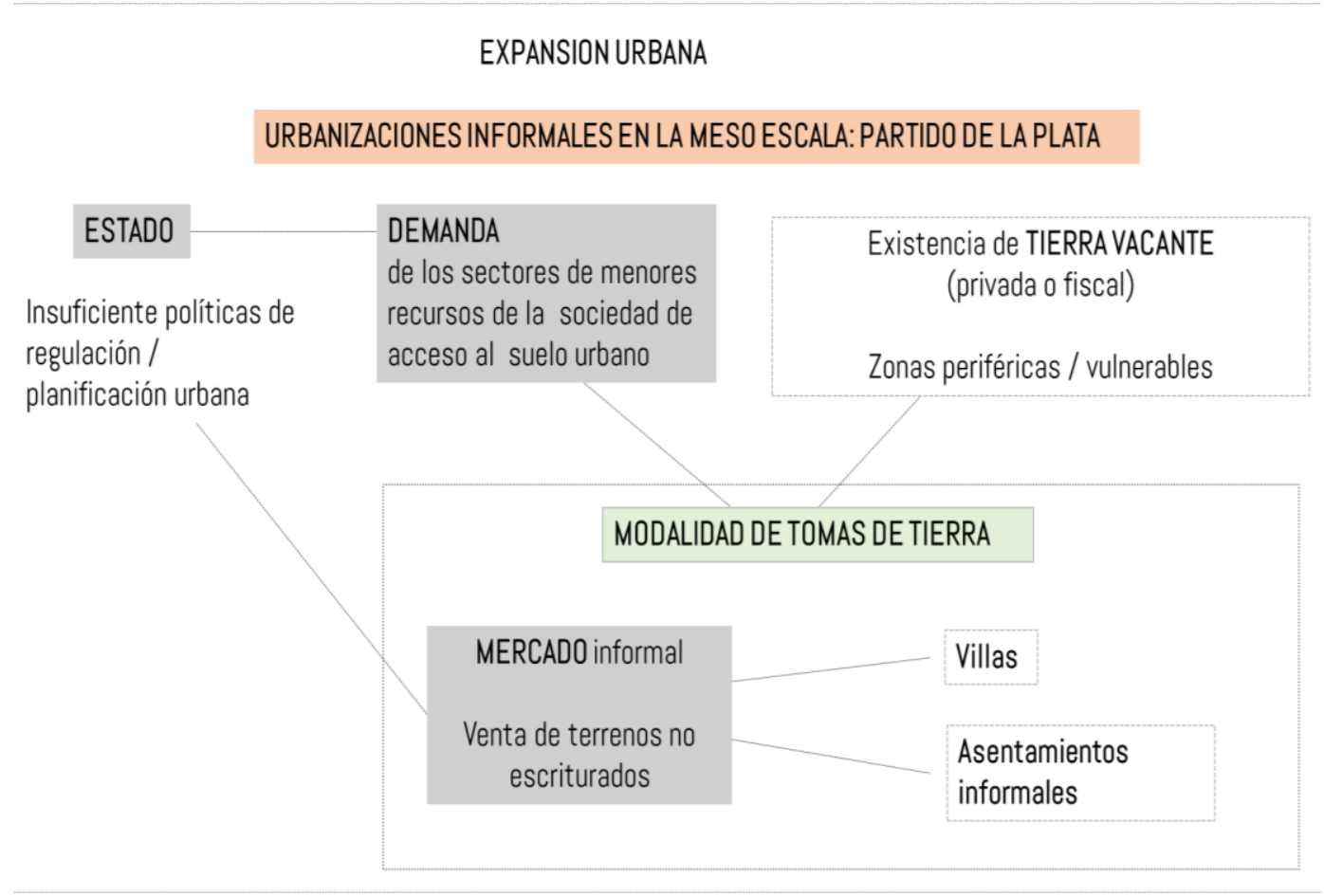

Fuente. Elaboración propia, 2018. 


\subsubsection{Tipologías de urbanizaciones informales en el Partido de La Plata}

En el caso del Partido de La Plata entre las tipologías de urbanizaciones informales que más se pueden observar en el territorio, según datos del relevamiento llevado adelante por parte del Registro Público de Villas y Asentamientos de la Provincia de Buenos Aires en el año 2015, se reconocen una gran cantidad de asentamientos informales (88), seguidos por la tipología correspondiente a villas (29) y por último en menor medida, otros tipos de urbanizaciones informales (11) que en su mayoría tienen que ver con la ocupación de inmuebles abandonados (Figura 20). En este sentido, es posible afirmar que la tipología más extendida entre las urbanizaciones informales en la periferia del Partido de La Plata corresponde la de los asentamientos informales, y ésto se debe principalmente al modo de acceder al suelo urbano a través de la toma masiva de tierras en la periferia y las estrategias adoptadas, que en su mayoría consiste en tomas organizadas sobre terrenos fiscales vacantes.

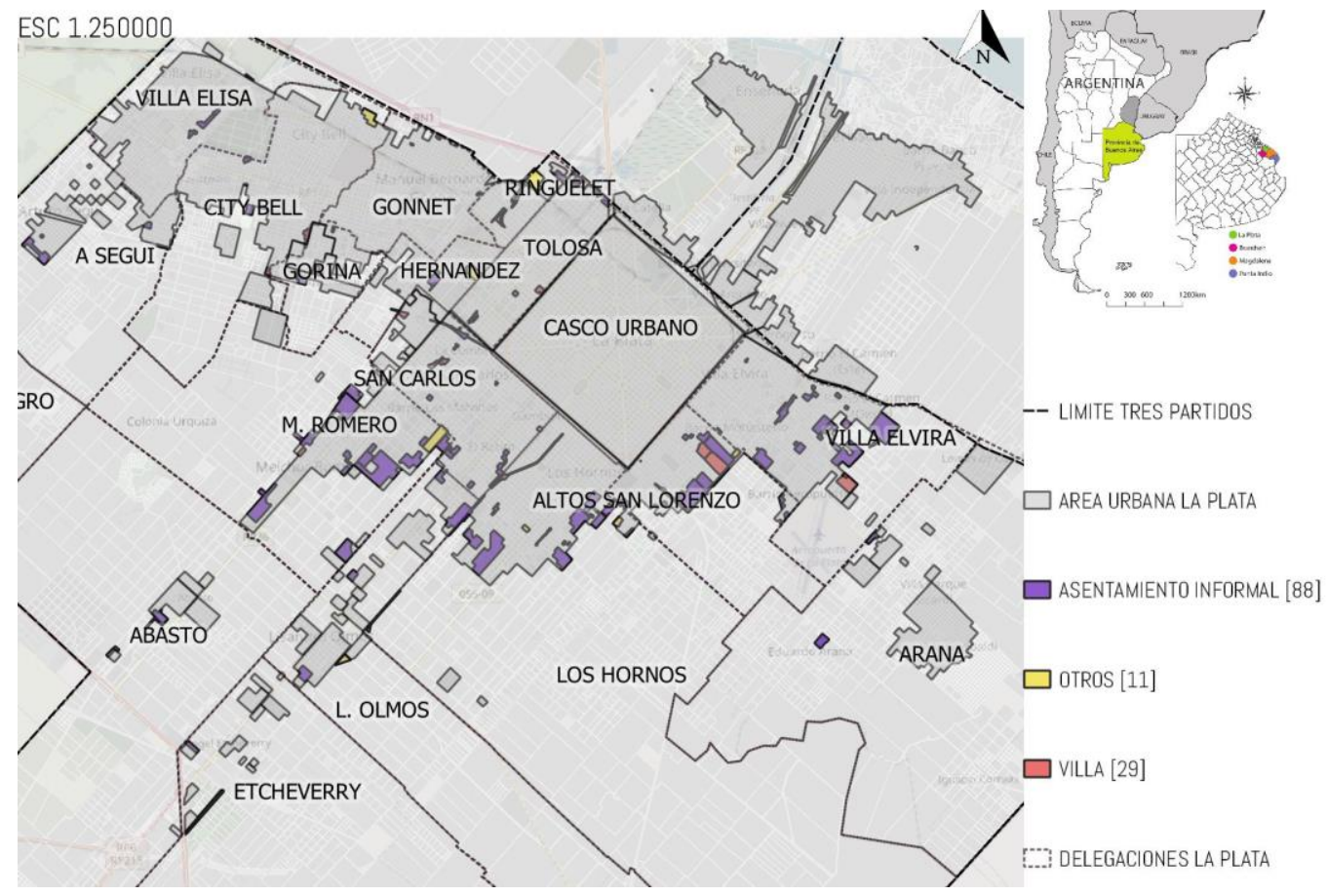

Figura 20. Tipologías de urbanizaciones informales Partido de La Plata.

Fuente. Elaboración propia con herramienta SIG, 2018. 
Esta lógica también se puede reconocer en otras ciudades como es el caso de Buenos Aires, en donde resulta mayor la presencia de villas en cercanías con las zonas centrales como lo es el caso de las ya conocidas villa 31 y 1-11-14, y su Área Metropolitana, donde resulta común encontrar asentamientos informales, con un carácter periférico sobre terrenos vacantes en áreas de expansión. El proceso de ocupación informal en la periferia del Partido de La Plata a través de la modalidad de asentamiento informal comenzó a acelerarse a desde fines de los años '80, y fundamentalmente a partir de los años 90. Como consecuencia de la expansión residencial muchas familias provenientes de otras provincias del interior del país y países limítrofes llegaron a la ciudad de La Plata con el fin de mejorar sus condiciones laborales, y debido a los elevados precios de suelo, ocuparon terrenos ubicados en la periférica a través de la modalidad de la toma de tierras.

La ocupación informal, en el caso de la modalidad de los asentamientos, tal como se explicó en el apartado anterior, se produjo respetando el trazado de la ciudad, constituyendo loteos y abriendo calles, pero no se dio aleatoriamente, sino que en muchos casos intervinieron distintos promotores que como se verá más adelante, fomentaron a la ocupación ilegal de terrenos vacantes, prometiendo a las familias un lugar de residencia permanente. La lógica adoptada por los actores sociales en el caso de los asentamientos, suele comenzar con la toma masiva de tierras con el fin de la posterior adecuación de los servicios y las normas urbanísticas. Esta modalidad facilita los procesos de regularización dominial, y es en gran medida el motivo por el cual muchas de las urbanizaciones ligadas a la ocupación de áreas periféricas suelen presentar esta tipología.

En un primer momento se relevó la cantidad de urbanizaciones informales discriminadas por tipologías al interior de las distintas localidades del Partido (Tabla 5). Según los datos obtenidos, Melchor Romero es la localidad con mayor cantidad de urbanizaciones informales del Partido con una totalidad de 17, de las cuales el $82 \%$ corresponde a la tipología de asentamiento informal. Las villas por su parte se localizan más próximas a las áreas centrales, como es el caso de la 
villa "La Vía" en la localidad de Los Hornos, que data del año 1984 o "Las Margaritas" del año 1998 en la Localidad de Romero.

Tabla 5. Tipologías de urbanizaciones informales, por localidad en el Partido de La Plata.

\begin{tabular}{|l|c|c|c|c|c|c|c|}
\hline \multirow{2}{*}{ LOCALIDAD } & \multicolumn{2}{|c|}{ VILLA } & \multicolumn{2}{c|}{$\begin{array}{c}\text { ASENTAMIENTO } \\
\text { INFORMAL }\end{array}$} & \multicolumn{2}{c|}{ OTRO TIPO UI } & TOTAL \\
\hline Villa Elvira & 3 & $17,65 \%$ & 14 & $82,35 \%$ & 0 & $0,00 \%$ & 17 \\
\hline Altos de San Lorenzo & 6 & $40,00 \%$ & 8 & $53,33 \%$ & 1 & $6,67 \%$ & 15 \\
\hline Arana & 0 & $0,00 \%$ & 2 & $100,00 \%$ & 0 & $0,00 \%$ & 2 \\
\hline Los Hornos & 2 & $12,50 \%$ & 12 & $75,00 \%$ & 2 & $12,50 \%$ & 16 \\
\hline Olmos & 0 & $0,00 \%$ & 4 & $80,00 \%$ & 1 & $20,00 \%$ & 5 \\
\hline Etcheverry & 1 & $50,00 \%$ & 1 & $50,00 \%$ & 0 & $0,00 \%$ & 2 \\
\hline Abasto & 0 & $0,00 \%$ & 2 & $100,00 \%$ & 0 & $0,00 \%$ & 2 \\
\hline El Peligro & 0 & $0,00 \%$ & 0 & $0,00 \%$ & 2 & $100,00 \%$ & 2 \\
\hline Melchor Romero & 2 & $10,53 \%$ & 16 & $84,21 \%$ & 1 & $5,26 \%$ & 19 \\
\hline Arturo Seguín & 0 & $0,00 \%$ & 4 & $100,00 \%$ & 0 & $0,00 \%$ & 4 \\
\hline Gorina & 1 & $33,33 \%$ & 2 & $66,67 \%$ & 0 & $0,00 \%$ & 3 \\
\hline City Bell & 3 & $42,86 \%$ & 3 & $42,86 \%$ & 1 & $14,29 \%$ & 7 \\
\hline Gonnet & 3 & $75,00 \%$ & 1 & $25,00 \%$ & 0 & $0,00 \%$ & 4 \\
\hline Villa Elisa & 0 & $0,00 \%$ & 4 & $100,00 \%$ & 0 & $0,00 \%$ & 4 \\
\hline Ringuelet & 2 & $50,00 \%$ & 1 & $25,00 \%$ & 1 & $25,00 \%$ & 4 \\
\hline Tolosa & 4 & $57,14 \%$ & 3 & $42,86 \%$ & 0 & $0,00 \%$ & 7 \\
\hline Hernández & 0 & $0,00 \%$ & 2 & $66,67 \%$ & 1 & $33,33 \%$ & 3 \\
\hline San Carlos & 2 & $16,67 \%$ & 9 & $75,00 \%$ & 1 & $8,33 \%$ & 12 \\
\hline TOTAL & 29 & $22,66 \%$ & 88 & $68,75 \%$ & 11 & $8,59 \%$ & 128 \\
\hline
\end{tabular}

Fuente. Elaboración propia, 2019.

La localidad con mayor cantidad de villas es Tolosa, ubicada en la zona noroeste del Partido. Esto se explica debido a que Tolosa s una de las localidades más antiguas del Partido, anterior inclusive al trazado urbano del casco, por lo que las villas ahí localizadas suelen tener un origen diferente a las villas de otras localidades o aún a la de otros asentamientos informales de la periferia. Este es el caso de las villas "La Favelita", "La Boliviana”, "La Laguna” y "La Bajada II", anteriores a la década del 2000 (Figura 21). 

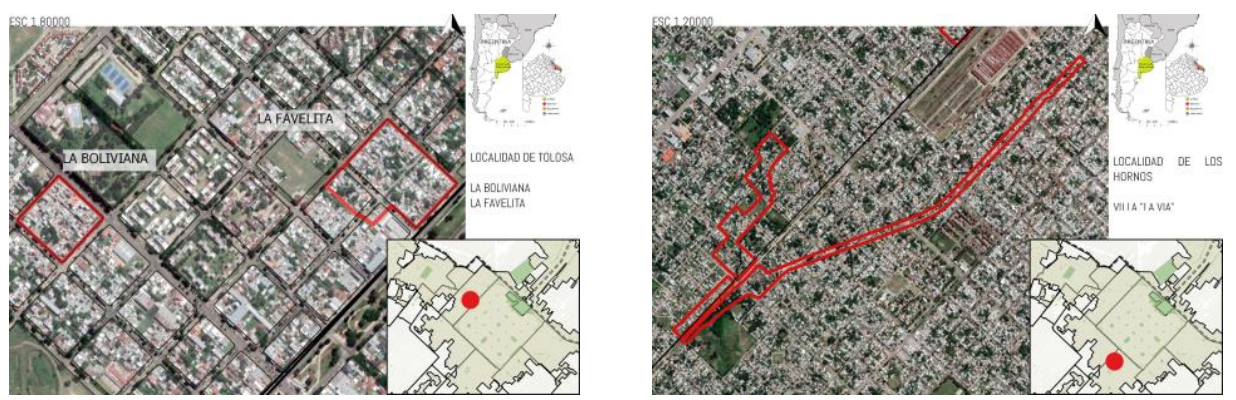

Figura 21. Villas en las localidades de Los Hornos y Tolosa.

Fuente: Elaboración propia, 2019.

Queda demostrado que la urbanización informal convive en la periferia del Partido junto con otros usos y modalidades de expansión urbana, contribuyendo a la producción de un territorio heterogéneo socialmente en cuanto a la diversidad de usos y modalidades que se presentan sobre el territorio. La problemática de la informalidad urbana se caracteriza así por adoptar una modalidad que despliega lógicas y estrategias diferentes en función de los intereses específicos de los actores intervinientes, dando como resultado las tipologías analizadas que pueden encontrarse sobre la periferia del Partido de La Plata.

En el siguiente capítulo se profundizará en el análisis de la ocupación territorial en la meso escala a partir de un análisis por dimensiones, con el objetivo de comprender el modo en que los sectores de menores recursos de la población acceden al suelo urbano en el Partido de La Plata. De esta forma, el reconocer ciertos patrones compartidos en relación a la ocupación informal del territorio contribuye a comprender con mayor profundidad e integrar los diferentes aspectos de la problemática. De este modo se puede pensar herramientas para lograr una mejora en la calidad de vida y acceso al suelo de estos sectores de la población, que se encuentran desprotegidos y en emergencia, con escasa intervención por parte del Estado. 


\title{
Capítulo 5
}

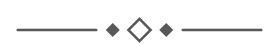

\section{Ocupación territorial en la meso escala:}

\section{Las urbanizaciones informales del Partido de La Plata}

\begin{abstract}
$-\bullet \diamond-$
«El intento más exitoso del ser humano de rehacer el mundo en el que vive de acuerdo con el deseo más íntimo de su corazón. Pero si la ciudad es el mundo que el ser humano ha creado, es también el mundo en el que a partir de ahora está condenado a vivir. Así pues, indirectamente y sin un sentido nítido de la naturaleza de su tarea, al hacer la ciudad, el ser humano se ha rehecho a sí mismo»
\end{abstract}

Harvey, 2013 
El presente capítulo constituye la segunda parte del análisis de la informalidad urbana en la meso escala a partir de la identificación de dimensiones significativas, luego de la caracterización general presentada en el capítulo anterior. El objetivo radica en alcanzar una mayor profundidad en el análisis, por lo que el establecimiento de dimensiones constituye una herramienta a partir de la cual el lector podrá reconocer problemáticas que en la integralidad del análisis contribuyen a la comprensión de la informalidad urbana y la ocupación del territorio. La comprensión y explicación de territorios tan heterogéneos como es el caso de la periferia del Partido de La Plata demandan estrategias diferenciadas para su desarrollo, en este sentido, resulta posible reconocer una serie de atributos y cualidades físicas del espacio que se encuentran inscriptas en las formas concretas adoptadas durante el proceso de configuración y organización territorial.

Para llevar a cabo el análisis de la ocupación territorial en urbanizaciones informales en la meso escala se establecen tres dimensiones: la dimensión temporal; la dimensión físico espacial y la dimensión social demográfica, que permiten operacionalizar variables e indicadores. Resulta posible de este modo no solo diagnosticar, sino comprender con mayor profundidad la problemática sin dejar de lado la totalidad del proceso. Durante este nivel de abordaje las cuestiones teóricas y abstractas elaboradas previamente comienzan a manifestar una correlación empírica con un territorio en particular. La selección de las tres dimensiones permite identificar los aspectos que en conjunto contribuyen a la comprensión integral de la problemática en cuestión, desde tres aristas bien diferenciadas pero que dialogan entre sí y que se vinculan directamente con los procesos, las cuestiones territoriales (físicas) y las que tienen que ver con la población (actores).

En primer lugar, se plantea el análisis de la dimensión temporal a través de la cual se establece una relación entre los contextos sociales, políticos y económicos que tuvieron lugar en Argentina en distintos momentos históricos y el proceso de ocupación informal en la periferia del Partido de La Plata. Cabe mencionar que 
esta relación entendida como acontecimientos en proceso, tiempo y espacio (Santos, 1976) contribuye a la explicación de las causas y las consecuencias de la informalidad urbana, en este caso en la meso escala. Para llevar adelante este análisis, metodológicamente se establecen tres períodos en función del año de origen de las urbanizaciones informales. El primer período corresponde a las urbanizaciones informales que surgieron anteriores al año 1989, el segundo comprende las urbanizaciones informales surgidas entre los años entre 1989 y el año 2001, y el tercer período de análisis toma aquellas urbanizaciones informales surgidas entre el 2001 y el año 2015.

En general una temporalidad o el hecho de temporalizar hace referencia a ubicar un proceso en una secuencia histórica, es decir, poner en relación un determinado asunto con el presente desde el cual se lo interroga e indagar acerca de los acontecimientos del pasado. Temporalizar entonces implica establecer una relación entre el transcurrir del tiempo, la acción humana y la transformación, es decir, que consiste en traer el pasado al presente por un interés o pregunta específica. En este sentido, resulta posible proporcionar un eje para organizar la información ya que parte del propósito consiste poner en relación el pasado, el presente y el futuro (Girola, 2011).

La dimensión físico espacial es la que toma en cuenta, entre las cuestiones territoriales, los atributos físicos del espacio que hacen al ámbito urbano. Las mismas se vinculan con la localización de las urbanizaciones informales en la periferia del Partido de La Plata, es decir que, dependiendo de las características de la localización estas variables pueden modificarse, así como su impacto en el tipo de urbanización y en el modo de habitar de su población. Esta dimensión establece tres variables de análisis, que corresponden con la cobertura de servicios básicos, las condiciones de accesibilidad en relación con la movilidad urbana y las condiciones ambientales en las urbanizaciones informales del Partido. 
Por último, la dimensión social demográfica establece como variable de análisis el tamaño de las urbanizaciones informales a partir de la cantidad de familias que habitan. De este modo, resulta posible determinar tres tipos de urbanizaciones informales: pequeña, que alberga entre 8 y 100 familias; mediana, entre 101 y 500 familias; y grande con más de 500 familias. La Tabla 6 es una síntesis de la matriz en donde se operacionalizan las dimensiones, variables e indicadores seleccionados para el análisis.

\begin{tabular}{|c|c|c|c|}
\hline $\begin{array}{l}\text { UNIDAD DE } \\
\text { ANÁLISIS }\end{array}$ & DIMENSION & VARIABLE & INDICADOR \\
\hline \multirow{5}{*}{$\begin{array}{l}\text { TIPOLOGIAS } \\
\text { URBANIZACIONES } \\
\text { INFORMALES }\end{array}$} & \multirow{3}{*}{$\begin{array}{l}\text { TEMPORAL } \\
\text { CONTEXTUAL }\end{array}$} & \multirow{3}{*}{ Año de ORIGEN } & Anteriores a 1989 \\
\hline & & & 1er Período (1989-2001) \\
\hline & & & 2do Período (2001-2015) \\
\hline & \multirow{8}{*}{$\begin{array}{l}\text { FISICO } \\
\text { ESPACIAL }\end{array}$} & \multirow{4}{*}{$\begin{array}{l}\text { Cobertura de } \\
\text { SERVICIOS URBANOS BÁSICOS }\end{array}$} & Nivel 1 de cobertura \\
\hline & & & Nivel 2 de cobertura \\
\hline \multirow{4}{*}{$\begin{array}{l}\text { Villas } \\
\text { Asentamientos } \\
\text { Informales- }\end{array}$} & & & Nivel 3 de cobertura \\
\hline & & & Nivel 4 de cobertura \\
\hline & & \multirow{2}{*}{ Condiciones AMBIENTALES } & Niveles de Peligrosidad hídrica \\
\hline & & & Presencia de basurales y cavas \\
\hline \multirow{5}{*}{ Otros } & & \multirow{2}{*}{ Condiciones de ACCESIBILIDAD } & Acceso a vías principales \\
\hline & & & Niveles de Pavimentación \\
\hline & \multirow{3}{*}{$\begin{array}{l}\text { SOCIAL } \\
\text { DEMOGRAFICA }\end{array}$} & \multirow{3}{*}{$\begin{array}{l}\text { TAMAÑO de urbanizaciones } \\
\text { según cantidad de familias }\end{array}$} & Grande \\
\hline & & & Mediano \\
\hline & & & Pequeño \\
\hline
\end{tabular}

Tabla 6. Síntesis matríz de dimensiones, variables e indicadores de análisis. Fuente. elaboración propia, 2018.

Cabe mencionar que los datos oficiales más actuales a partir de los cuales se trabaja en este capítulo corresponden al Registro Público Provincial de Villas y Asentamientos Precarios (RPPVAP), llevado a cabo en el año 2015. Por este motivo se debe tener en cuenta que el corte temporal toma en cuenta solamente la información disponible al momento de escritura de la tesis. 


\subsection{Dimensión temporal}

La informalidad urbana se ha constituido en un fenómeno que desde hace décadas se manifiesta como parte de la configuración territorial de las periferias de las principales ciudades de los distintos países latinoamericanos, y la periferia del Partido de La Plata como se ha comentado en apartados anteriores, no es la excepción. Algunas características comunes a las urbanizaciones informales tienen que ver con el modo de acceder al suelo y las formas de asentamiento, ilegales en cuanto a la tenencia e irregulares sobre terrenos vacantes ya sean privados o fiscales. Del mismo modo se relacionan con la precariedad de los materiales con los que se construyen (autoconstruyen) las viviendas, la falta de acceso a los servicios urbanos básicos, la deficiente infraestructura urbana y la vulnerabilidad respecto de las condiciones ambientales. Estas características se acrecientan o modifican con el transcurso de los años, por ello resulta relevante determinar los contextos de acuerdo con cada período histórico y las condiciones que emergen de la localización de las urbanizaciones informales en el territorio, así como su evolución en el tiempo. De este modo resulta posible comprender y explicar la situación en la actualidad para pensar alternativas de intervención a futuro.

En la periferia del Partido de La Plata es posible identificar urbanizaciones informales que incrementan su densidad poblacional cada año y en relación con la morfología de su tejido, se pone de manifiesto un proceso de consolidación a partir de la identificación de viviendas construidas utilizando cada vez materiales más resistentes y definitivos, así como el agregado de niveles en altura. También se reconoce la presencia de varios establecimientos de tipo comercial, en su mayoría informales al interior de algunos barrios que denotan el proceso de consolidación y el carácter definitivo de la urbanización. Se pone de manifiesto que las urbanizaciones informales con el paso del tiempo consiguen consolidarse como un lugar, un barrio, aun no siendo sus habitantes los propietarios legales de la tierra. 
Cada año se incrementa la cantidad de nuevas urbanizaciones informales que surgen, muchas veces, como anexos de otras más antiguas que se encuentran en expansión y desbordan debido a la gran cantidad de población. En la Figura 22Figura se presenta una sucesión imágenes satelitales del Partido de La Plata, correspondientes con los años 1990, 2001 y 2015, en donde se pone de manifiesto la expansión del área urbana en cada período. En color naranja se encuentran las urbanizaciones informales, poniéndose en evidencia la relación entre la expansión de la mancha urbana y la localización de las urbanizaciones informales en la periferia del Partido.

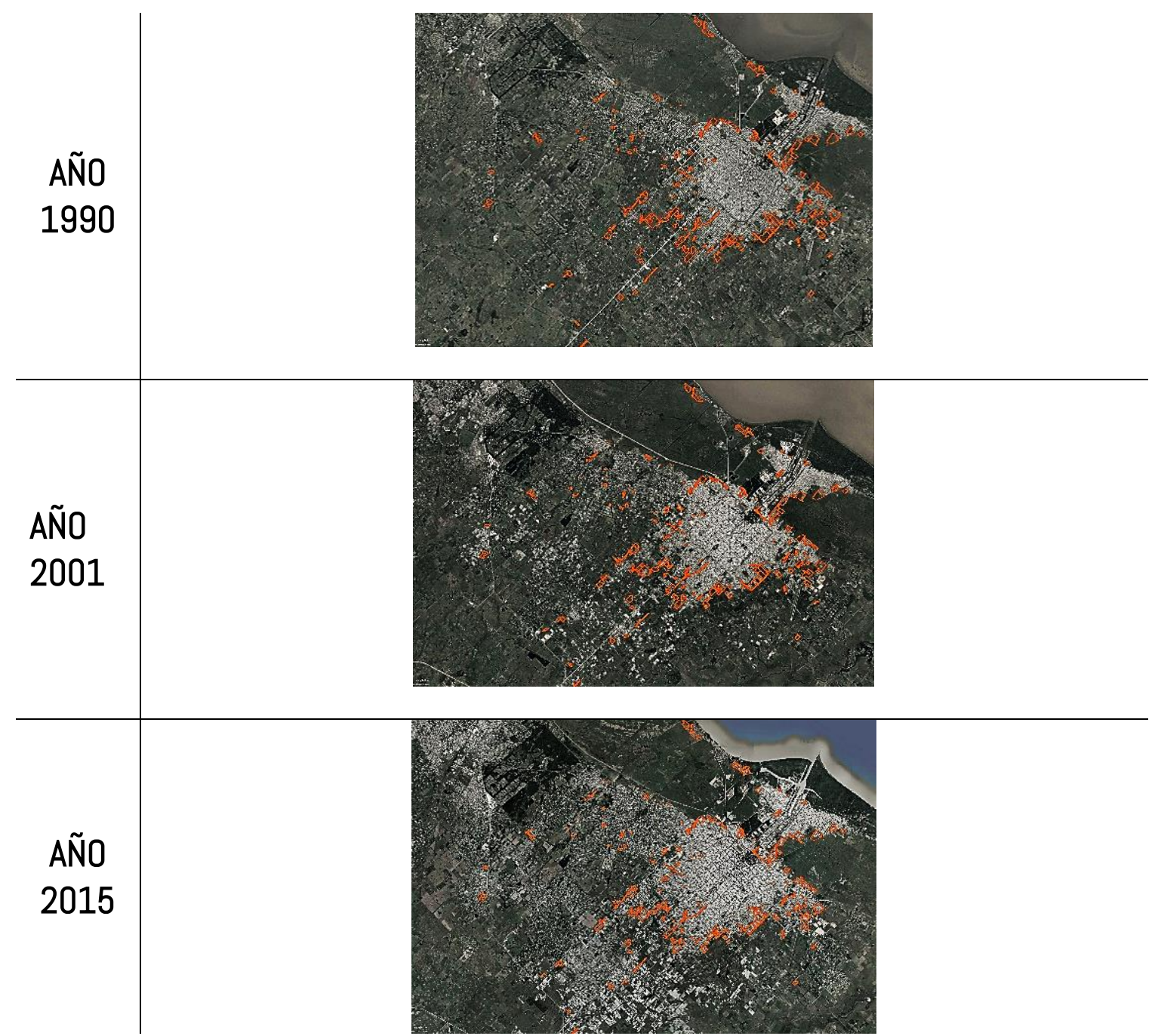

Figura 22. Expansión del área urbana del Partido de La Plata (1990, 2001 y 2015).

Fuente. Elaboración propia Google Earth 2018. 
Del mismo modo en la Figura 23 es posible observar la expansión de algunas de las áreas urbanas al comparar las imágenes satelitales de los años 2001 y 2015 tomando en cuenta las zonas que presentaron un mayor aumento de informalidad urbana. Si se pone el foco en las urbanizaciones informales identificadas en el año 2015 y se lo compara con las imágenes satelitales de mayor antigüedad, es posible reconocer el modo en que muchos de los barrios se consolidaron y en cuestión de 10 años se completaron áreas que se encontraban vacantes.

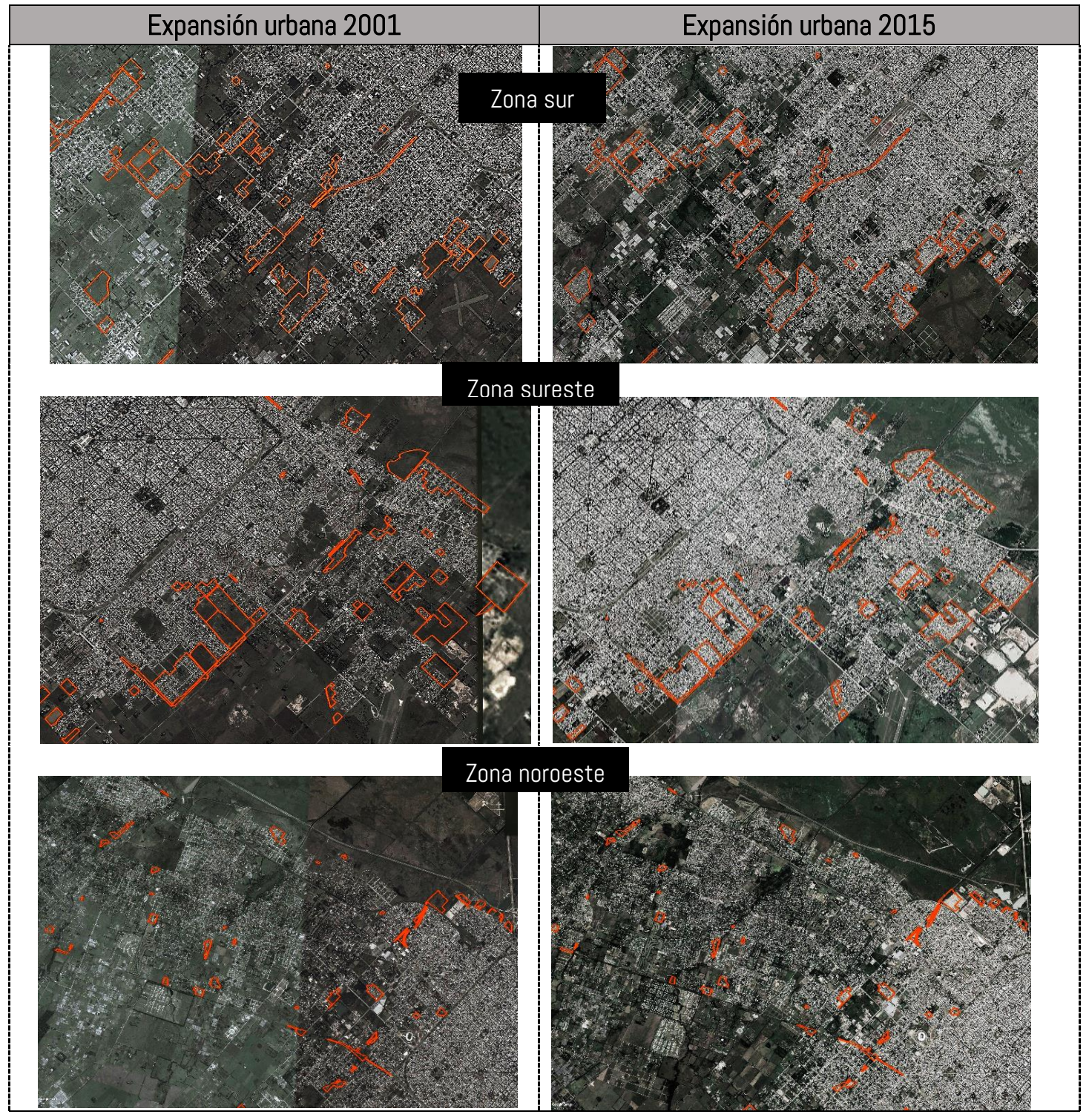

Figura 23. Expansión del área urbana y urbanizaciones informales en la zona sur; sureste y noroeste del Partido (variación 2001 - 2015). Fuente.Elaboración propia, Google Earth 2018. 
Como se mencionó, en términos metodológicos, para el abordaje de la dimensión temporal se tomó como variable de análisis el año de origen de las urbanizaciones informales del Partido de La Plata, según datos del RPPVAP (2015). Del mismo modo se tuvo en cuenta la localización, es decir, en qué zonas de crecimiento urbano se ubicaron las urbanizaciones informales en cada período. Estas dos variables en combinación arrojaron información acerca del proceso de ocupación del territorio con la posibilidad de interpretar e inferir ciertos patrones en cuanto a la localización según el contexto histórico determinante para cada período analizado.

La importancia de contextualizar el año de origen de las urbanizaciones informales radica en el hecho de que las transformaciones, fundamentalmente en los planos económico y social, que comenzaron a experimentarse en la Argentina durante la década de 1980 y que se acentuaron drásticamente en la década siguiente, constituyeron un fenómeno de gran magnitud que repercutió en la organización del territorio y que fomentó en gran medida el surgimiento este tipo de urbanización. En este sentido, el análisis contextual de la informalidad urbana permite visualizar la dimensión e importancia del problema.

Si bien en cada uno de los tres períodos propuestos surgieron nuevas urbanizaciones informales, durante el período de análisis comprendido entre los años 1989 y 2001, fue en el que surgió una mayor cantidad de urbanizaciones informales, encontrándose un total de 61 nuevas urbanizaciones, lo que corresponde casi con el 50\% del total de urbanizaciones informales del Partido al año 2015 (128) (Figura 24). Este fuerte crecimiento de la informalidad urbana durante este período se debe principalmente al proceso de reestructuración económica que se produjo durante esos años, vinculado con el modelo económico vigente caracterizado como de economía abierta luego del cambio político que trajo consigo la promulgación de la Ley de Reforma del Estado y de Emergencia Económica en 1989 y la implementación del Plan de Convertibilidad en 1991. 
En este sentido, el aumento de la tasa de desocupación y la precarización del empleo asalariado fueron algunos de los aspectos más negativos que trajeron como consecuencia un marcado crecimiento del mercado informal del suelo (Torres, 2001).

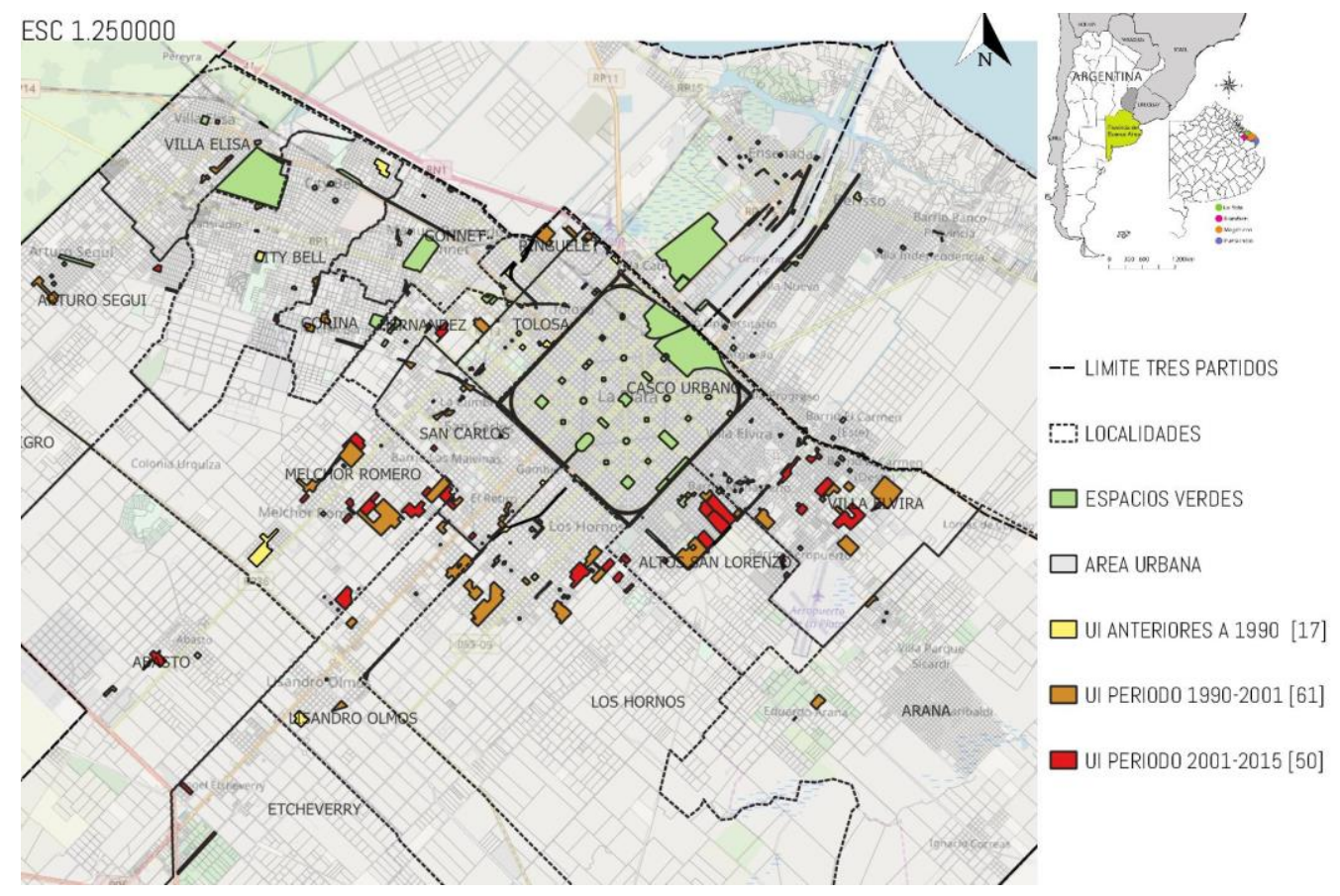

Figura 24. Síntesis del análisis temporal urbanizaciones informales del Partido de La Plata. Fuente. Elaboración propia SIG, 2018 con datos del RPPVAP, 2015.

En la Tabla 7 se incluyen las tipologías de urbanizaciones informales en relación con los períodos analizados. De la síntesis se desprende que, en cada período, una de las tipologías más extendidas resultó ser la de asentamiento informal, esto significa que fue la tipología que más aumentó, constituyéndose en la forma más popular de ocupación informal de suelo urbano en la Periferia del Partido de La Plata. Esto se pone en evidencia aun en la actualidad y representa una tendencia que se mantiene en cuanto al modo de asentamiento y tipo de ocupación más frecuentemente adoptada por las urbanizaciones informales del Partido.

En términos cuantitativos, del análisis por tipología se desprende que de la totalidad de asentamientos informales en el Partido (88); el 6,82\% surgieron anteriores a la década de 1990, el 48,86\% durante el período siguiente entre la 
década de los 90 y el año 2001 y el 44,32\% entre los años 2001 y 2015, que corresponde al último período del análisis.

La tipología villa por su parte presenta un crecimiento más estable sin saltos contrario a lo que sucede con los asentamientos, siendo del total (29) el 31\% anteriores a 1990, el 34,48\% correspondientes al período entre los años 19902001 y el 34,48\% al período 2001-2015. Estos datos ponen de manifiesto el incremento de la tipología de asentamiento informal con respecto a las villas y otras tipologías, consolidándose actualmente como la más extendida del Partido. Del mismo modo, como se analizó para el caso del AMBA, este crecimiento se relaciona directamente con el contexto y la modalidad de ocupación que adopta esta tipología en relación con la toma de tierra vacante localizada sobre áreas periféricas.

Tabla 7. Tipologías y cortes temporales en el Partido de La Plata.

\begin{tabular}{|l|c|c|c|c|c|c|c|}
\hline \multicolumn{1}{|c|}{ TIPOLOGIA } & TOTAL & \multicolumn{2}{|c|}{$\begin{array}{c}\text { Anteriores a } \\
1990\end{array}$} & \multicolumn{2}{c|}{$\begin{array}{c}\text { Período } \\
1990-2001\end{array}$} & \multicolumn{2}{c|}{$\begin{array}{c}\text { Período } \\
2001-2015\end{array}$} \\
\hline Villa & 29 & 9 & $31,03 \%$ & 10 & $34,48 \%$ & 10 & $34,48 \%$ \\
\hline Asentamiento informal & 88 & 6 & $6,82 \%$ & 43 & $48,86 \%$ & 39 & $44,32 \%$ \\
\hline Otras & 11 & 2 & $18,18 \%$ & 8 & $72,73 \%$ & 1 & $9,09 \%$ \\
\hline TOTAL & 128 & 17 & $13,28 \%$ & 61 & $47,66 \%$ & 50 & $39,06 \%$ \\
\hline
\end{tabular}

Fuente. Elaboración propia, 2018.

En el siguiente apartado se presenta el análisis desagregado de los tres períodos establecidos. Cada uno presenta información cuantitativa que se explica y se apoya en el análisis histórico del recorte temporal establecido de manera cualitativa. De este modo los datos y la cartografía se construyeron representativos para un momento histórico dado, teniendo en cuenta que los procesos y los contextos son los que determinan la configuración del territorio. Como se ha mencionado al comienzo del capítulo, no es posible analizar la problemática de la informalidad urbana sin tomar en consideración la incidencia de dichos contextos en el proceso de configuración y organización territorial. 


\subsubsection{Primer Período: Urbanizaciones informales anteriores a 1990}

El primer período de dentro de la dimensión temporal corresponde con los años previos a la década de 1990. Como se puede observar en la Figura 25, durante esos años surgieron en el Partido de La Plata un total de 17 urbanizaciones informales, la mayoría de ellas ubicadas en las localidades de Tolosa y Gonnet principalmente hacia las zonas norte y noroeste del Partido.

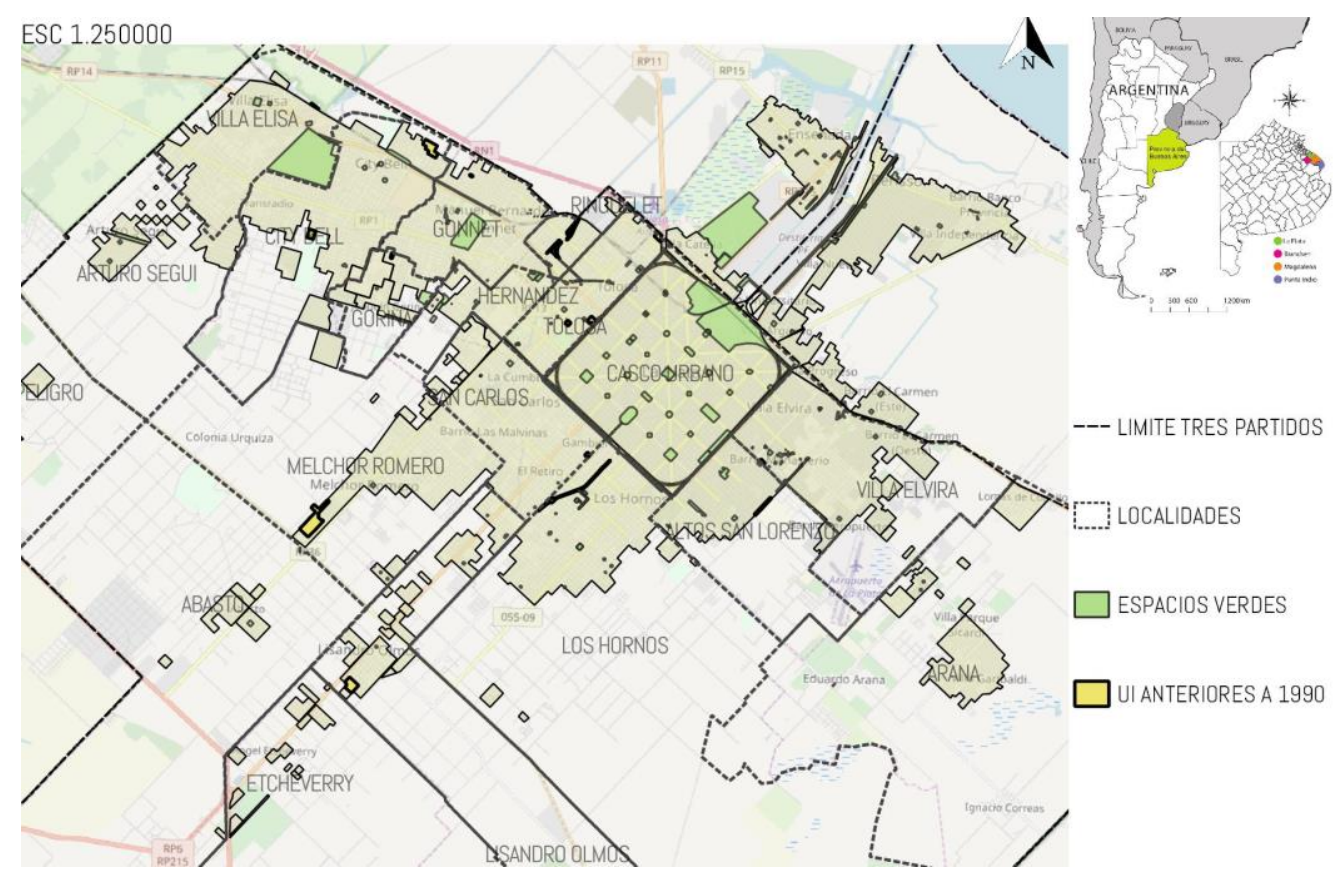

Figura 25. Urbanizaciones informales en el primer período de análisis temporal.

Fuente. Elaboración propia, 2018.

Para comprender y explicar cómo fue la ocupación del territorio durante este período, resulta necesario adentrarse en el proceso histórico de la época y en este sentido cabe recordar que partir de los años '30, en Argentina comenzó una etapa de industrialización por sustitución de importaciones que consolidó el proceso de organización territorial que se había iniciado a fines del siglo XIX. En este sentido, en el Partido de La Plata los talleres de las localidades de Tolosa y Los Hornos constituyeron sectores importantes para la economía local. Del mismo modo la industria textil, metalmecánica y de productos para el campo, fueron ramas fundamentales que se instalaron conjuntamente con grandes talleres de reparación de vagones ferroviarios. 
Durante este modelo se impulsó también en Argentina la industria de bienes de consumo, hecho que dio posibilidades de empleo para grandes sectores de la población que fueron expulsados del campo y migraron a las ciudades debido a la falta de una política agraria adecuada a la modernización que tenía lugar en ese momento. Al mismo tiempo durante este período, en el Partido de La Plata comenzó un estancamiento económico como resultado del reflujo de actividades vinculadas hacia la Capital Federal (Ravella, 1997). Esto provocó una dependencia con la Capital, de modo que el conglomerado urbano se estructuró sobre la red vial extraurbana existente. Este proceso se acompañó con la aparición de pequeñas y medianas empresas vinculadas a la industria automotriz que se localizaron en la cercanía de La Plata, así como el crecimiento de las PYMES metalmecánica y de máquinas herramientas (Frediani, 2010).

En consecuencia, desde 1960 se acentúo la extensión de la mancha urbana con prolongaciones a lo largo de los principales ejes circulatorios y la conurbación del eje Noroeste a través de los Caminos Centenario y Gral. Belgrano. Con la extensión de la mancha urbana comenzaron a surgir en la periferia del Partido nuevos modos de ocupación del territorio, que se profundizaron en el período siguiente, posterior a 1990. Estas nuevas modalidades se caracterizaron por la ocupación ilegal de la tierra por parte de migrantes internos e inmigrantes de países limítrofes en búsqueda de mejores oportunidades laborales. La ocupación se produjo sin ningún plan de urbanización ni de servicios, lo que implicó serios problemas para las personas y el ambiente en relación a las malas condiciones de habitabilidad y falta de salubridad.

En cuanto a localización que supuso este modo de ocupación durante el primer período se destaca la cercanía con las principales vías de comunicación, con terrenos ocupados principalmente hacia la periferia noroeste como desborde del casco urbano de la ciudad de La Plata. Este patrón de localización en cuanto a la cercanía con la red viaria principal durante el período facilitó el acceso tanto a la Capital Federal como al casco urbano de la ciudad, favoreciendo a través del transporte público la movilidad de los habitantes de las urbanizaciones 
informales. Entre las tipologías que pueden identificarse al interior del primer período se desprende del análisis que del total de las 17 urbanizaciones informales, 9 de ellas corresponden con la tipología de villa, 6 con la de asentamiento informal y 2 refieren a otros tipos de urbanización informal sin una categorización específica (Figura 26).

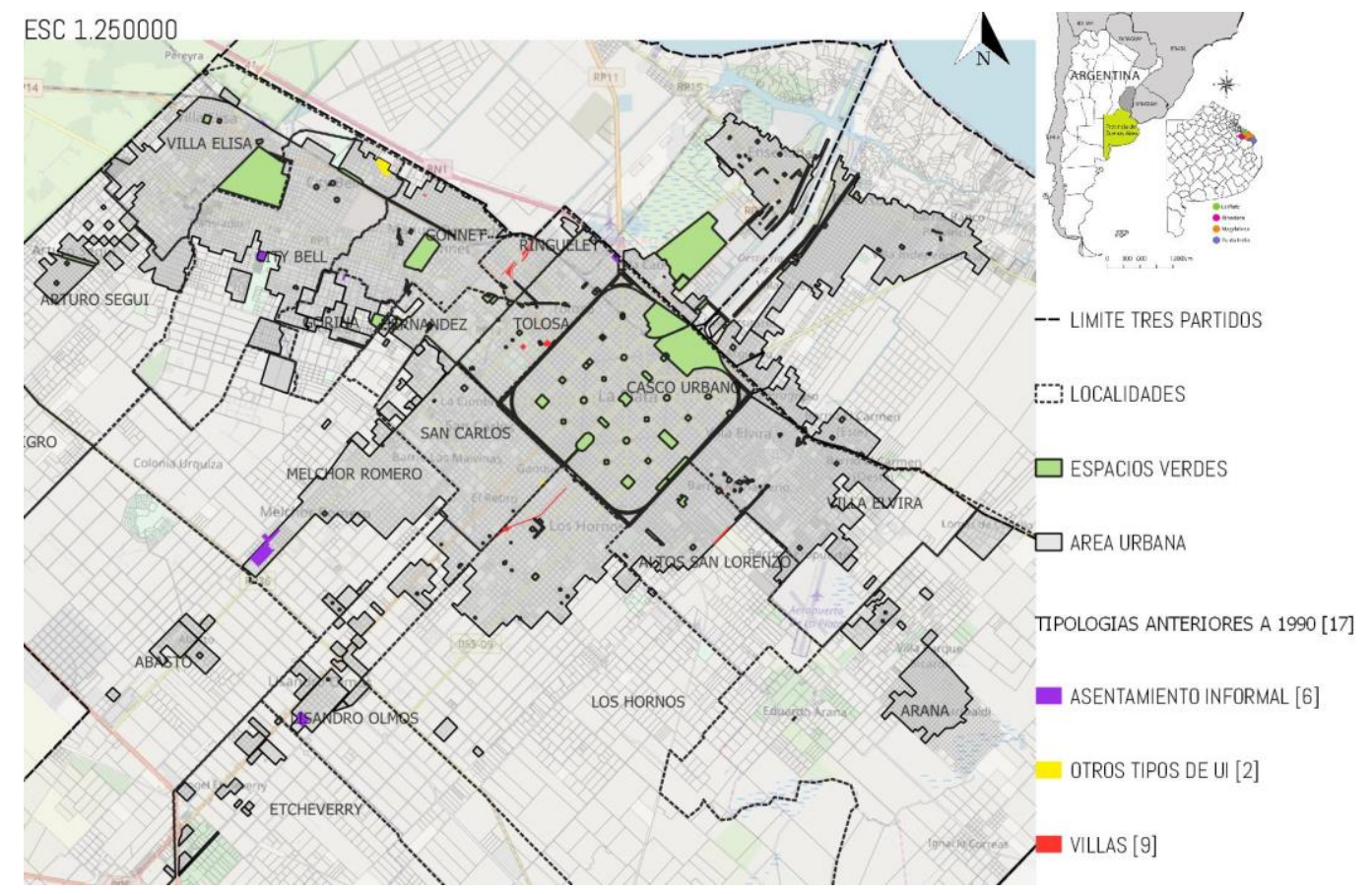

Figura 26. Primer Período: Tipologías de urbanizaciones informales. Fuente. Elaboración propia, con herramienta SIG, 2018.

Entre las primeras urbanizaciones informales en la periferia del Partido de La Plata se distinguen algunas que corresponden con la tipología de villas como es el caso de "La Favelita" (1983) y "La Boliviana” (década de 1980) en la localidad de Tolosa. La ocupación del territorio durante este período se debió, principalmente, al carácter transitorio que suponía esta tipología de urbanización informal que era entendida en ese tiempo como un tipo de urbanización temporal. Sin embargo, algunas de ellas como es el caso de "El Mercadito" en la localidad de Ringuelet que surgió a principios de la década de los años 1990 alimentando al Mercado Regional, no solo continúan en pie sino que se han consolidado adoptando una identidad propia (Figura 27). 

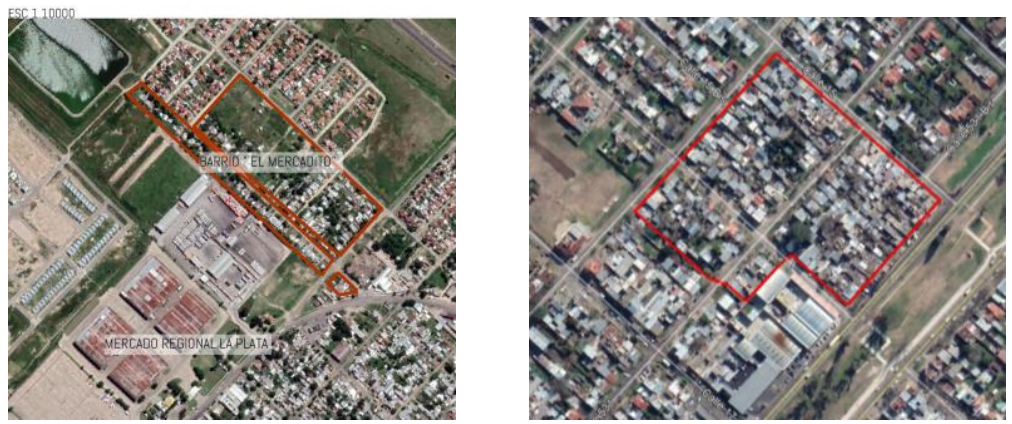

Figura 27. "El Mercadito" y "La Favelita" surgidas en el período y consolidadas en la actualidad. Fuente. Elaboración propia, 2019.

A modo de síntesis, los principales cambios durante este período tuvieron que ver con la definición del carácter productivo del área que contribuyó al crecimiento de las localidades hacia las zonas del sector norte del partido de La Plata. Los talleres de Tolosa y la funcionalidad del Puerto de Ensenada y Berisso, así como los frigoríficos y los cambios en el sistema de transporte fomentaron la ocupación informal de estas áreas, en principio de manera transitoria siguiendo la tipología que corresponde con la de villas y consolidándose con el paso del tiempo.

Esquema 9. Síntesis primer período de análisis temporal.

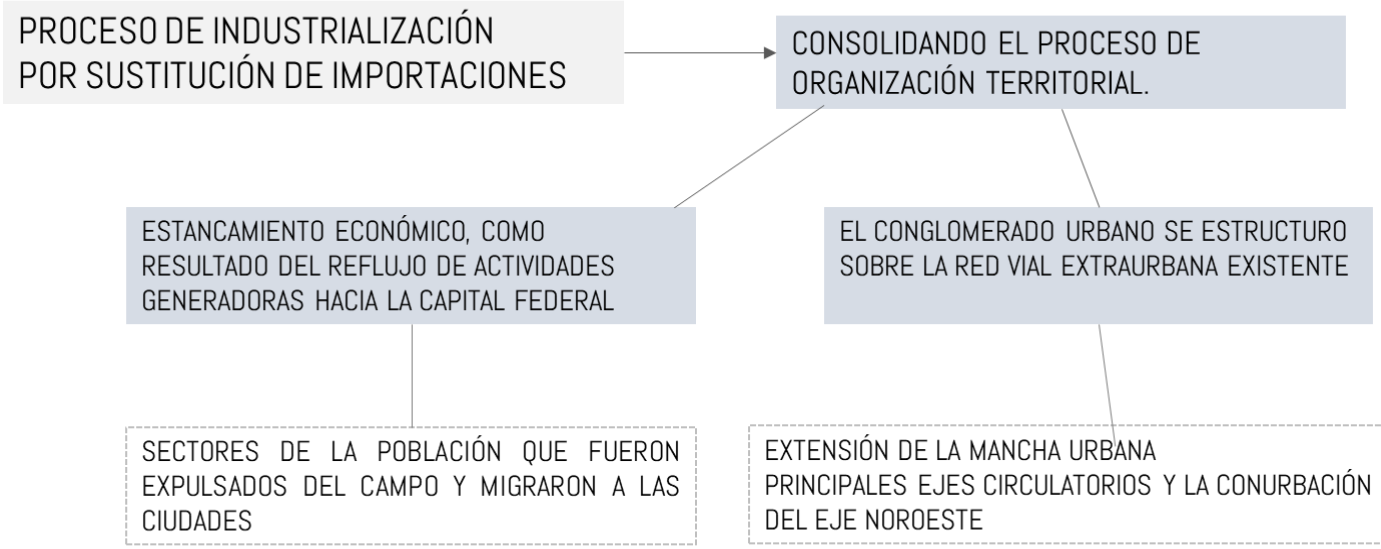

OCUPACIÓN ILEGAL DE TIERRA SIN NINGÚN PLAN DE URBANIZACIÓN NI DE SERVICIOS

Fuente. Elaboración propia, 2018. 


\subsubsection{Segundo Período: Urbanizaciones informales entre 1990 y 2001}

El segundo período considera los años comprendidos entre el comienzo de la década de 1990 y el año 2001, escenario de una gran crisis económica y social en Argentina. Durante este período surgieron en el Partido de La Plata un total de 61 nuevas urbanizaciones informales, entre las cuales se pueden distinguir tipológicamente 43 asentamientos informales, 10 villas y 8 urbanizaciones informales sin categorizar. Dicho período se considera largo y significativo en materia económica en la Argentina, ya que, tanto en el comienzo como hacia el final, los procesos económicos y sociales de reestructuración generaron un gran impacto en las formas de acceder al suelo urbano que modificaron los patrones de ocupación y apropiación territorial.

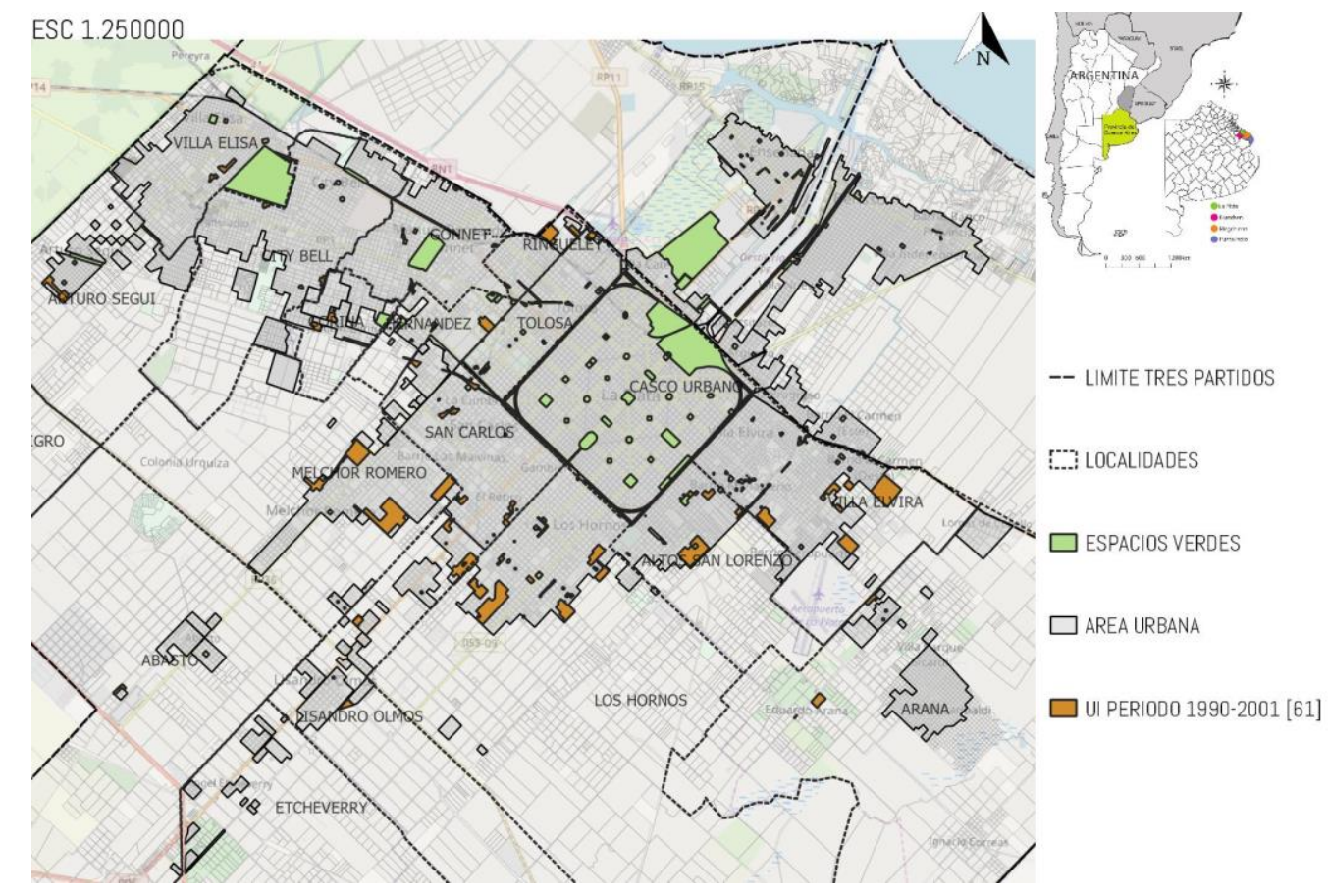

Figura 28. Urbanizaciones informales en el segundo período de análisis temporal. Fuente. Elaboración propia, 2018. SIG.

Dos tipos de ocupación territorial tuvieron mayor protagonismo durante en este período: por un lado, las urbanizaciones cerradas que intensificaron fuertemente la ocupación de suelo en la periferia, vinculadas con sectores de la población de mayores ingresos que optaron por auto excluirse por fuera del casco 
urbano, fundamentalmente por temas como la inseguridad y la búsqueda de una vida alejada de la vorágine del centro urbano (entre otros factores). Por otro lado, se incrementaron las urbanizaciones informales asociadas en este caso con los sectores de menores ingresos y recursos de la población, que se vieron excluidos durante este período hacia la periferia, en parte por el alto precio de suelo urbano en las áreas centrales.

Los procesos que transformaron el territorio en este período se asociaron principalmente con estas dos formas de ocupación y expansión hacia la periferia, con la consecuente ocupación de áreas que no habían sido planificadas y tampoco aptas para la urbanización. Estas transformaciones constituyeron un punto de inflexión en el análisis de los procesos de urbanización ya que se adoptaron ciertos patrones de ocupación que se convirtieron en una tendencia que continua en la actualidad. Durante el segundo período los profundos cambios que se produjeron a nivel económico, político y social señalaron el inicio de la reactivación de la industria de la construcción y el mercado inmobiliario, prácticamente estancados durante la década anterior, contribuyendo así a generar nuevos espacios urbanos. Del mismo modo la incorporación al mercado inmobiliario de tierras e inmuebles del Estado, como resultado de la aplicación del Decreto-Ley 8912 ${ }^{19}$, acompañaron y facilitaron este auge constructivo. De igual manera, la flexibilización de las normas urbanísticas y de ordenamiento territorial, junto con el debilitamiento del Estado frente al protagonismo de los agentes inmobiliarios privados nacionales e internacionales produjeron una alteración de los patrones de urbanización y un replanteo de la planificación urbana y de las modalidades de gestión (Frediani, 2010; Vidal Koppmann, 2013).

En este contexto, entre los factores que explicarían el incremento de las urbanizaciones informales durante este período, es posible mencionar la crisis socioeconómica que sufrió el país a mediados de la década del '90, que tuvo gran 
impacto para los sectores de medios y escasos recursos de la población, producto de una distribución regresiva del ingreso. Como consecuencia de ello, se produjo el desplazamiento forzado de un amplio contingente de excluidos del modelo, que se reflejó en un fuerte crecimiento de las urbanizaciones informales. Asimismo, cabe señalar el auge de la tipología de asentamiento informal durante estos años principalmente caracterizada por la toma de tierras, privadas o fiscales, como estrategia de acceso al suelo. Las villas, por su parte, en este período dejaron de ser urbanizaciones transitorias y se consolidaron en una tipología que se mantiene aún en la actualidad (Figura 29).

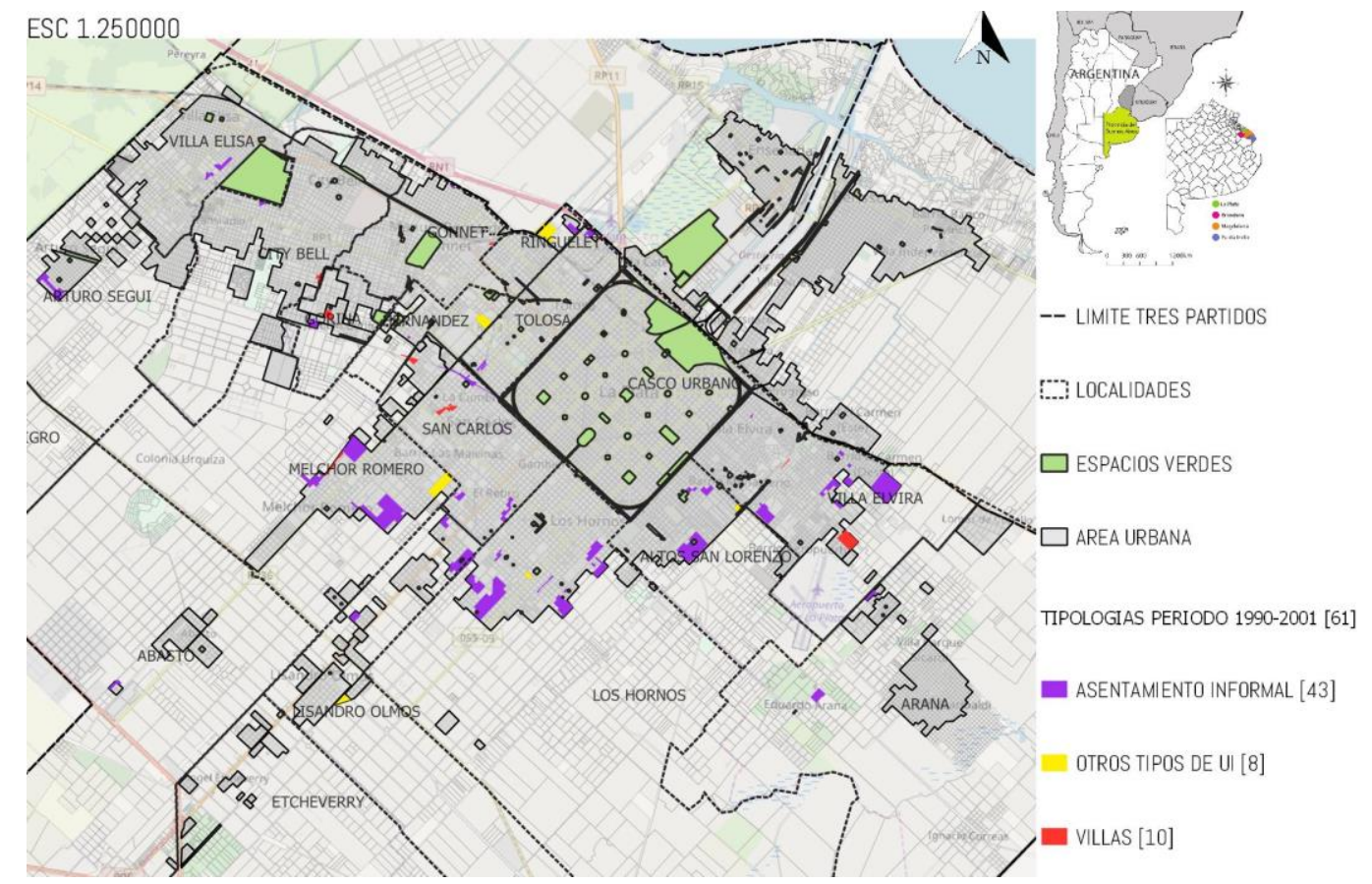

Figura 29. Segundo Período: Tipologías de urbanizaciones informales. Fuente. Elaboración propia, 2018.SIG.

Durante este período la población del Partido de La Plata tuvo un aumento considerablemente, coincidente con el período intercensal 1991-2001, pasando de los 541.905 habitantes que arrojó el censo de año 1991 a los 574.369 habitantes registrados en el censo realizado en el año 2001. Este aumento en la población aceleró el proceso de expansión urbana hacia las áreas periféricas, es decir por fuera de los bordes del casco urbano fundacional. Un ejemplo de esto lo representa la intensificación en la ocupación hacia fines de los años 90 de localidades como la de Villa Elvira por parte de un gran número de migrantes 
interprovinciales y extranjeros que se asentaron hacia las zonas sureste y suroeste del Partido. Si bien la expansión urbana ha constituido un proceso que se produjo de manera progresiva y continua desde la fundación de la ciudad, durante este período en particular se aceleró, y, por lo tanto, se comenzó a evidenciar la gran dispersión urbana que persiste actualmente en el Partido de La Plata. Una de las consecuencias negativas más representativas de este período, vinculada con el proceso de ocupación del territorio, tiene que ver con la fragmentación socio espacial que se generó, consecuencia de la desigualdad en la periferia del Partido de La Plata junto con una marcada polarización territorial.

Esquema 10. Síntesis segundo período de análisis temporal.

NUEVOS ESPACIOS URBANOS INICIO DECADA 1990

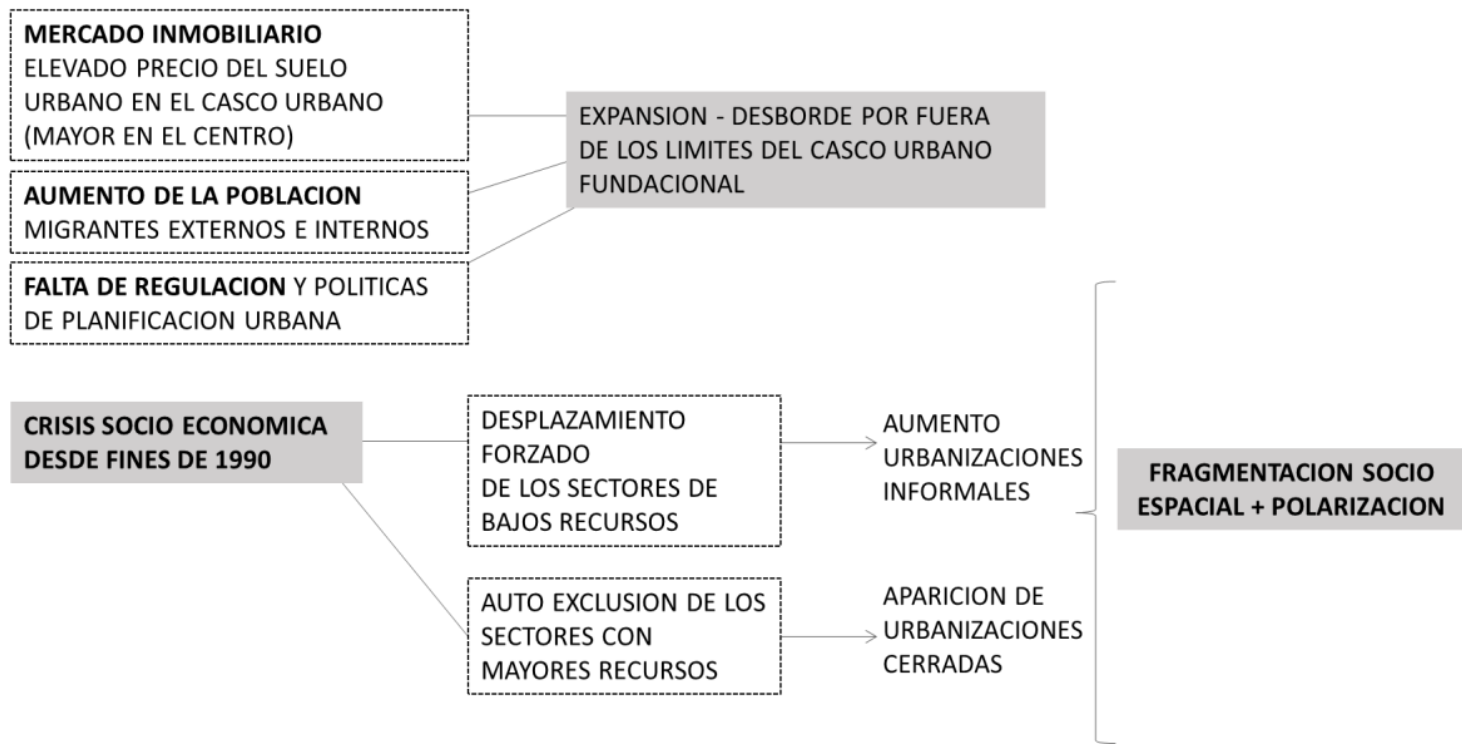

Fuente. Elaboración propia, 2018.

\subsubsection{Tercer Período: Urbanizaciones anteriores a los años entre 2001 y 2015}

El tercer período dentro de análisis de la dimensión temporal abarca los años comprendidos entre el 2001 y 2015. Durante este intervalo surgieron en la periferia del Partido de La Plata un total de 50 nuevas urbanizaciones informales con respecto al período anterior. De esas urbanizaciones, 39 corresponden a la tipología de asentamiento informal y 10 a la de villas (Figura 30). Al igual que en 
el período anterior, resulta posible observar que la mayoría de las urbanizaciones informales se localizaron fundamentalmente hacia las zonas sureste y suroeste. Esta preferencia en cuanto a la localización se debió a la fuerte expansión urbana hacia esas zonas impulsada principalmente por el precio del suelo más bajo que en el casco urbano, y, por lo tanto, más accesible para los sectores de menores recursos económicos de la población. Otro factor que contribuyó en la expansión hacia esas zonas sur del Partido fue la gran cantidad de suelo vacante producto de la ocupación dispersa y sin planificación, que convirtió a estas tierras en potenciales espacios para llevar adelante las tomas de tierra y asentarse (informalmente). En este sentido las localidades hacia las zonas sur del Partido suelen encontrarse relegadas socialmente en comparación con las zonas del norte que se vinculan con la Capital Federal a través de la autopista Buenos Aires-La Plata, sumado al hecho de haber sido durante los años 90 el destino de los sectores medios y altos auto desplazados del centro de la ciudad.

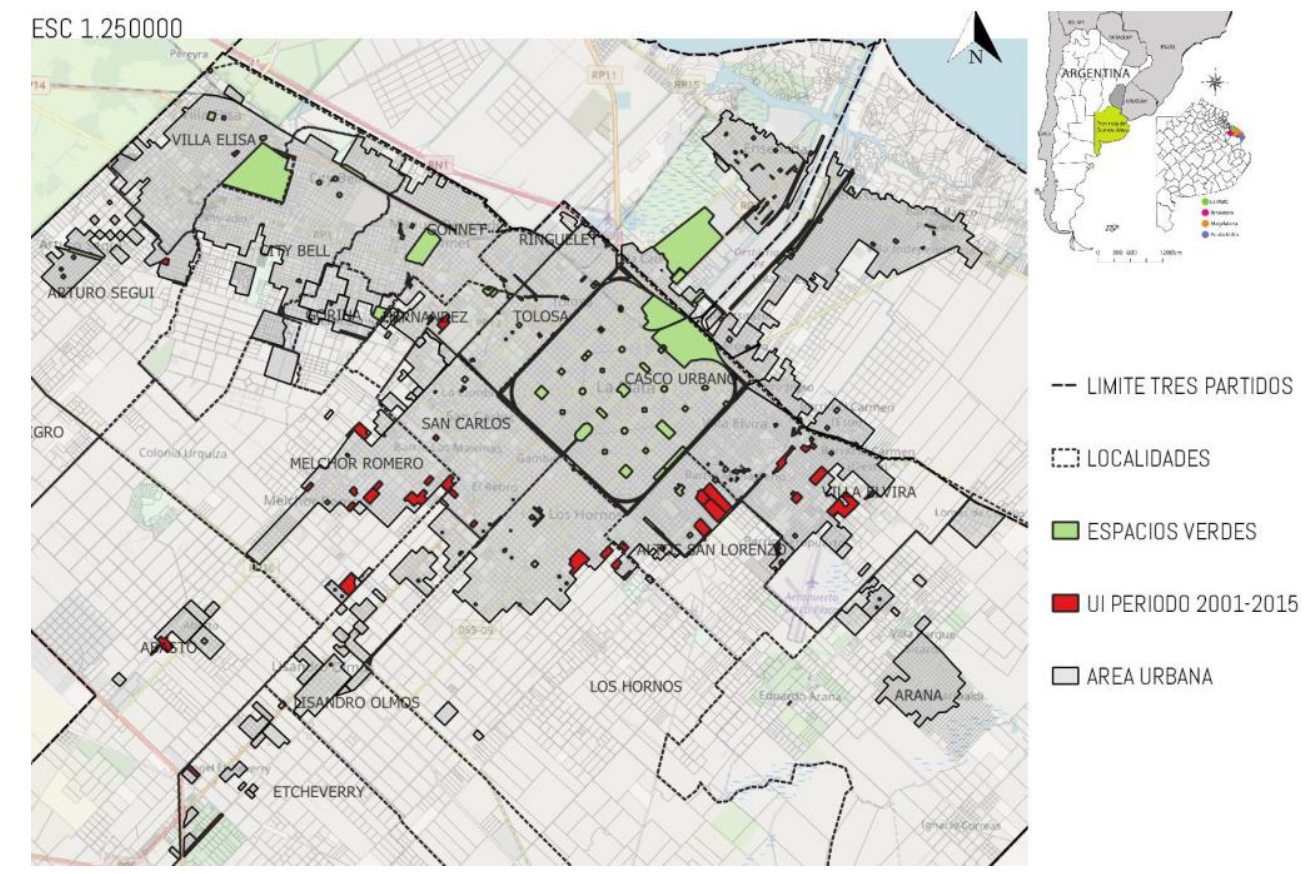

Figura 30. Urbanizaciones informales en el tercer período de análisis temporal. Fuente: Elaboración propia con herramienta. SIG, 2018.

Como consecuencia de la crisis económica y social que vivió la Argentina en el año 2001, muchas familias se encontraron enfrentando fuertes problemas económicos que no les permitieron solventar la renta del suelo en el casco urbano 
o en localidades que presentaban precios del suelo elevados. Como consecuencias, debieron alejarse y localizarse hacia las zonas con precios de suelo más accesibles, en muchos casos ocupando tierras de manera informal. Este proceso se vio reflejado en un aumento de las urbanizaciones informales y precisamente, las localidades del sur fueron las receptoras.

Dentro de las tipologías de urbanizaciones informales que se pueden encontrar durante este período, la que más se ha consolidado ha sido la de asentamiento informal. Cabe recordar que esta tipología tuvo su auge en el período anterior. Esto se debe a que durante este período se consolidó como principal estrategia de acceso al suelo la toma organizada de tierras. Cabe mencionar que producto de la crisis económica, muchos de los asentamientos informales y villas más antiguas comenzaron a consolidarse. Sumado esto, el período también se caracterizó por la llegada de nuevos habitantes, provenientes de provincias del interior del país muy afectadas por la crisis del 2001 como fue el caso de Chaco y Misiones (Figura 31).

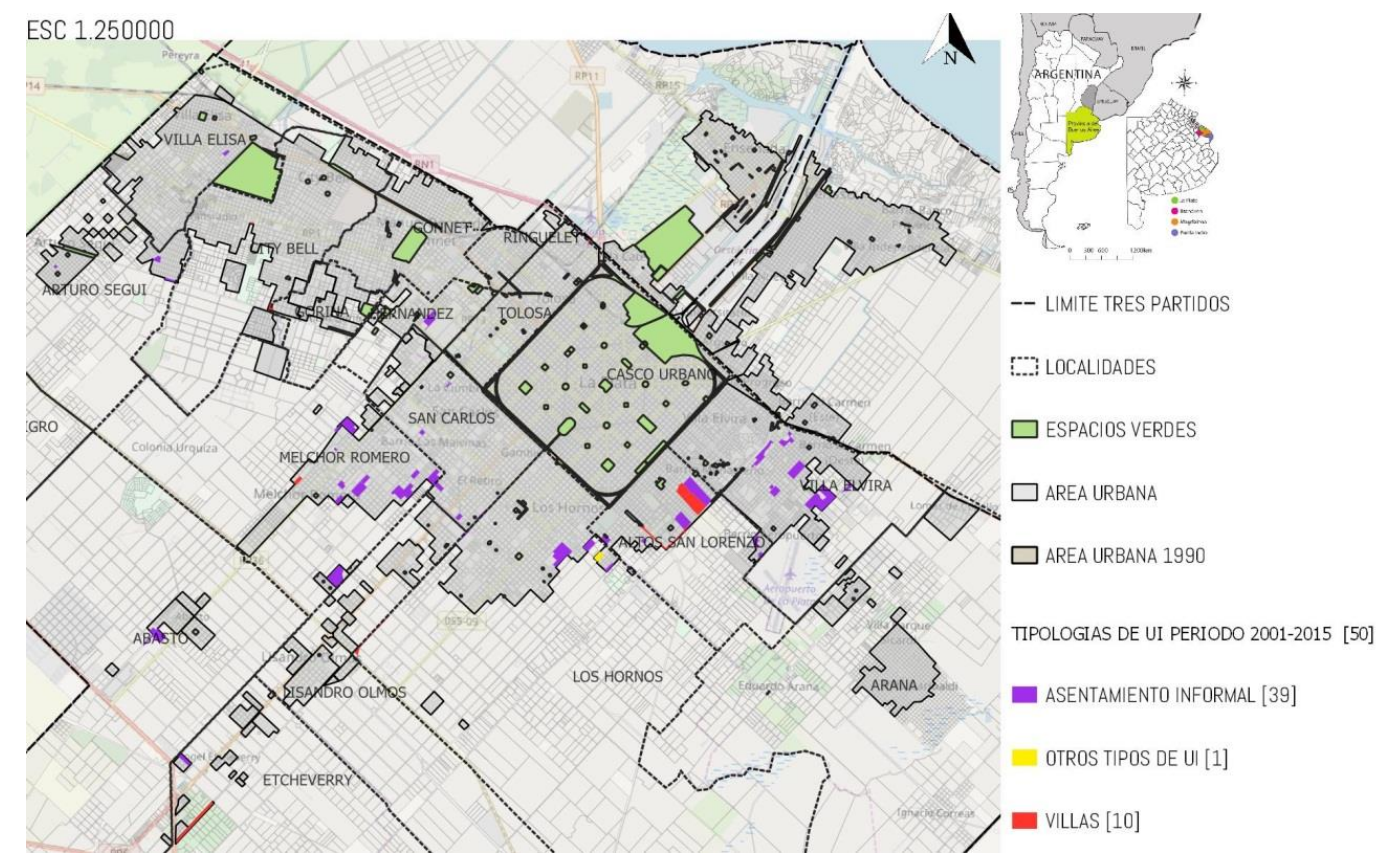

Figura 31. Tercer Período de análisis: Tipologías de urbanizaciones informales. Fuente. Elaboración propia, 2018. SIG. 
Cabe mencionar que en el año 2001 el 38,5\% de los argentinos no superaba la línea de pobreza y el 13,6\% la de indigencia. En el 2002 estos indicadores ascendían a las cifras de 54,3\% y 27,7\% respectivamente. A nivel nacional, el índice de pobreza creció más de la mitad de mayo de 2001 a octubre de 2002. En ese mismo año la tasa de desempleo trepo a un 20,8\%, provocando el deterioro general de estos índices socio-demográficos. Esto constituyó un cuadro crítico general que afectó fuertemente a los sectores de menores recursos y los empujó a modificar sus estrategias de vida (Tabla 8). Tras la caída abrupta de los ingresos en los hogares también se vio comprometido el acceso de estos sectores al empleo, la educación, la salud y la vivienda.

Tabla 8. Síntesis dimensión temporal por localidades.

\begin{tabular}{|c|c|c|c|c|c|c|c|}
\hline \multirow{2}{*}{$\begin{array}{l}\text { LOCALIDAD } \\
\text { Villa Elvira } \\
\end{array}$} & \multirow{2}{*}{$\begin{array}{c}\text { TOTAL } \\
100 \% \\
17 \\
\end{array}$} & \multicolumn{2}{|c|}{ Anteriores a 1989} & \multicolumn{2}{|c|}{ 1er Periodo 1989-2001 } & \multicolumn{2}{|c|}{$\begin{array}{c}\text { 2do Periodo 2001- } \\
2015\end{array}$} \\
\hline & & 1 & $5,88 \%$ & 10 & $58,82 \%$ & 6 & $35 \%$ \\
\hline Altos de San Lorenzo & 15 & 1 & $6,67 \%$ & 5 & $33,33 \%$ & 9 & $60 \%$ \\
\hline Arana & 2 & 0 & $0,00 \%$ & 2 & $100,00 \%$ & 0 & $0 \%$ \\
\hline Los Hornos & 16 & 1 & $6,25 \%$ & 9 & $56,25 \%$ & 6 & $38 \%$ \\
\hline Olmos & 5 & 1 & $20,00 \%$ & 4 & $80,00 \%$ & 0 & $0 \%$ \\
\hline Etcheverry & 2 & 0 & $0,00 \%$ & 0 & $0,00 \%$ & 2 & $100 \%$ \\
\hline Abasto & 2 & 0 & $0,00 \%$ & 1 & $50,00 \%$ & 1 & $50 \%$ \\
\hline El Peligro & 2 & 0 & $0,00 \%$ & 2 & $100,00 \%$ & 0 & $0 \%$ \\
\hline Melchor Romero & 19 & 1 & $5,26 \%$ & 6 & $31,58 \%$ & 12 & $63 \%$ \\
\hline Arturo Seguí & 4 & 0 & $0,00 \%$ & 1 & $25,00 \%$ & 3 & $75 \%$ \\
\hline Gorina & 3 & 1 & $33,33 \%$ & 2 & $66,67 \%$ & 0 & $0 \%$ \\
\hline City Bell & 7 & 2 & $28,57 \%$ & 2 & $28,57 \%$ & 3 & $43 \%$ \\
\hline Gonnet & 4 & 2 & $50,00 \%$ & 2 & $50,00 \%$ & 0 & $0 \%$ \\
\hline Villa Elisa & 4 & 1 & $25,00 \%$ & 2 & $50,00 \%$ & 1 & $25 \%$ \\
\hline Ringuelet & 4 & 2 & $50,00 \%$ & 2 & $50,00 \%$ & 0 & $0 \%$ \\
\hline Tolosa & 7 & 3 & $42,86 \%$ & 3 & $42,86 \%$ & 1 & $14 \%$ \\
\hline Hernández & 3 & 0 & $0,00 \%$ & 2 & $66,67 \%$ & 1 & $33 \%$ \\
\hline San Carlos & 12 & 1 & $8,33 \%$ & 6 & $50,00 \%$ & 5 & $42 \%$ \\
\hline TOTAL & 128 & 17 & $13,28 \%$ & 61 & $47,66 \%$ & 50 & $39 \%$ \\
\hline
\end{tabular}

Fuente. Elaboración propia, 2018.

El análisis arroja que los patrones de ocupación durante este período responden a la tendencia a localizarse hacia las áreas del sur del Partido como sucedía en el período anterior. Como consecuencia, barrios ya consolidados fueron anexando nuevas tierras y expandiéndose a través de la modalidad de la 
urbanización informal, al mismo tiempo que otros comenzaron procesos de regularización.

$\mathrm{Al}$ año 2015 se pudo reconocer una mixtura que se mantiene al interior de las urbanizaciones informales y pone de manifiesto la consolidación de la tipología de asentamiento informal como predominante. En este sentido también se evidencia en algunos barrios el inicio de procesos de regularización en cuanto la propiedad de la tierra a través de leyes de regularización dominial tales como la Ley $\mathrm{N}^{\circ} 24.374$ (Ley Pierri) y la 14.449 (Ley de acceso justo al hábitat) ${ }^{20}$. En la Figura 32 se puede observar la expansión de la mancha urbana original del Partido durante los tres períodos analizados y el modo en que las urbanizaciones fueron completando áreas antes vacías o en proceso de consolidación y/ o expansión.
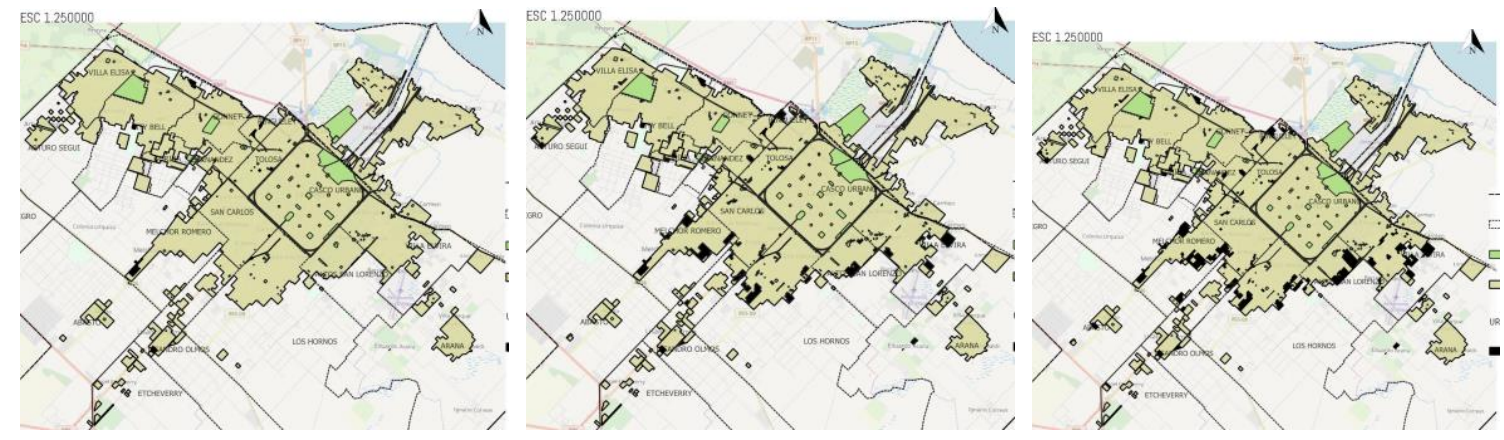

Figura 32. Síntesis de los tres períodos y el área urbana actual. Fuente. Elaboración propia 2018, SIG.

Del análisis de los tres períodos se desprende una marcada tendencia de expansión urbana con la consecuente ocupación del territorio hacia las zonas sureste y suroeste del Partido, dando como resultado una mayor concentración de urbanizaciones informales en las localidades de Altos de San Lorenzo, Villa Elvira, Los Hornos y Romero, que en su mayoría responde a la tipología de asentamiento informal.

${ }^{20}$ Ley N. ${ }^{\circ} 24.374:$ http://servicios.infoleg.gob.ar/infolegInternet/anexos/04999/755/texact.htm. Ley N¹4.449: http://www.gob.gba.gov.ar/legislacion/legislacion/l-14449.html. 
La política pública habitacional ante esta situación debería abordar la problemática teniendo en cuenta su carácter estructural, que se inscribe sobre una distribución poco equitativa de la riqueza, evidente en el incremento de la informalidad urbana. Si bien durante el último período analizado se comenzó a esbozar una política habitacional en cuanto a la puesta en marcha de programas destinados específicamente a la construcción de viviendas nuevas, al mejoramiento de viviendas deficitarias, de infraestructura básica y obras complementarias, resulta insuficiente frente a la problemática y sus múltiples aristas que requieren de soluciones integrales. El análisis temporal puso de manifiesto la relación entre los contextos históricos y los procesos territoriales, constituyendo una dimensión fundamental para la comprensión de la problemática de la informalidad urbana.

\subsection{Dimensión físico espacial}

La ocupación de tierras vacantes, privadas o fiscales, con diversas problemáticas ambientales, con muy mala o directamente sin infraestructura de servicios básicos y con malas condiciones de accesibilidad, produjo durante varias décadas situaciones de vulnerabilidad para los habitantes de urbanizaciones informales en la periferia del Partido de La Plata. Esta situación de vulnerabilidad social y territorial continúa condicionando el modo de vida de quienes habitan en condiciones de algún tipo de informalidad en las localidades periféricas del Partido.

En el presente apartado se propone el análisis de las cuestiones que hacen a la dimensión físico espacial, metodológicamente, quiere decir las cuestiones que tienen relación con el sistema espacial, como la infraestructura de servicios urbanos básicos, la accesibilidad en materia de infraestructura de transporte y localización, y las problemáticas más relevantes vinculadas con el soporte natural y medio ambiental. Para una mejor organización el análisis se estructura a través de tres variables principales que este trabajo se considera que constituyen las de mayor incidencia entre los aspectos que hacen a la informalidad urbana, y que 
además son las que mayor impacto negativo tienen sobre la vida de los habitantes de urbanizaciones informales.

Las variables de análisis dentro de la dimensión físico-espacial pueden discriminarse en: a) La cobertura de servicios urbanos básicos: se operacionaliza y toma como indicadores para el análisis la cobertura de las 4 redes principales de servicios urbanos básicos, agua corriente; gas natural; red cloacal y energía eléctrica. El objetivo es reconocer el nivel de acceso (si es que lo hay) de las urbanizaciones informales a los principales servicios urbanos básicos. b) Las condiciones de accesibilidad: se relacionan con la movilidad urbana, acceso al transporte público y la conexión con las principales vías que comunican a las urbanizaciones informales con el centro urbano de la ciudad de La Plata. Se toma en cuenta que es en el casco urbano donde se desarrolla la mayor parte de las actividades principales como empleo educación y salud. Del mismo modo se toma en cuenta dentro de esta variable la accesibilidad desde el casco urbano hacia el interior de las urbanizaciones informales, por ejemplo, para la recolección de basura, el acceso del transporte público y privado, así como servicios de salud o seguridad. Este no es un punto menor, ya que muchas veces, y como se explicará más adelante, debido al estado de las calles o al temor a la inseguridad, entre otras causas, muchos servicios urbanos e incluso las líneas de transporte público cambian los recorridos, generando una complicación para quienes habitan en estos barrios. c) Las condiciones ambientales: se relaciona con la localización en relación a los arroyos, basurales y cavas. Este punto resulta fundamental debido a que la cercanía a focos de contaminación y cursos de agua disminuye la calidad de vida de los habitantes de las urbanizaciones informales y aumenta el riesgo de sufrir tanto enfermedades, como de ser víctimas de inundaciones.

Cabe mencionar que las tres variables de análisis cuando se presentan en déficit disminuyen la calidad de vida y aumentan los niveles de vulnerabilidad de los habitantes de urbanizaciones informales, aún en mayor medida cuando éstas se encuentran en combinación. 


\subsubsection{Cobertura de servicios urbanos básicos}

Los servicios urbanos básicos “constituyen una condición para la vida urbana misma, para vivir en una aglomeración y aprovechar sus beneficios. Su falta implica una carencia grave para quienes están asentados en la ciudad (...) "Por su medio se distribuyen las condiciones para desarrollar las actividades urbanas para aprovechar la oferta urbana total, además de bienes que satisfacen necesidades particulares, muchas de ellas básicas" (...) (Pírez, 2008). En este sentido, el abastecimiento de los servicios públicos urbanos (energía eléctrica, agua corriente, cloacas y gas natural) en determinados sectores de la ciudad permite dar respuesta a algunas de las necesidades urbanas básicas de la población, que contribuye a una mejora en la calidad de vida.

La precariedad, la falta de infraestructura y el bajo acceso a los servicios urbanos básicos, sostenida por la indiferencia del Estado, generan necesidades que se transforman, muchas veces, en conexiones clandestinas. Con el paso del tiempo este tipo de conexiones y soluciones parciales ejecutadas por los mismos vecinos se consolidan y se transforman en obstáculos para iniciar procesos de regularización debido a la situación de precariedad e informalidad. La ausencia de regulación estatal hace que la provisión irregular de servicios aumente la situación de precariedad de estos barrios, poniendo en juego la seguridad de los propios habitantes.

El análisis de la situación en relación con la cobertura de los servicios urbanos básicos en las urbanizaciones informales resulta de importancia para obtener una visión general de las falencias y cómo afectan directamente en la calidad de vida de los habitantes de estos espacios periféricos en la meso escala. Para analizar el nivel de acceso en relación con la cobertura de los servicios urbanos básicos, se tomó como unidad de análisis todo el universo de las urbanizaciones informales que se localizan en la periferia del Partido de La Plata, que ya fueron analizadas y categorizadas de manera general en el capítulo anterior. Se tomaron como referencia cuatro indicadores que corresponden al nivel de cobertura del servicio 
de energía eléctrica, el nivel de la cobertura de la red de gas natural, el nivel de la cobertura de la red cloacal y por último el nivel de la cobertura del agua corriente. ${ }^{21}$ En términos metodológicos, se definieron tres rangos de cobertura de los servicios mencionados, que establecen si la urbanización que se está analizado cuenta con una cobertura total; parcial o inexistente del servicio en cuestión (Tabla 9).

Tabla 9. Cobertura de servicios básicos valores asignados.

\begin{tabular}{|l|}
\hline \multicolumn{1}{|c|}{ Tabla de valores cobertura de servicios básicos } \\
\hline Cobertura inexistente $=0$ \\
\hline Cobertura parcial $=0,5$ \\
\hline Cobertura total $=1$ \\
\hline
\end{tabular}

Fuente. Elaboración propia, 2018.

A cada nivel se le asignó un puntaje del 1 al 4, donde 1 es el nivel mínimo, lo que significa que esa urbanización que no cuenta con cobertura de ningún servicio, y 4 el puntaje máximo, es decir que cuenta con la cobertura total de los 4 servicios urbanos básicos. Con los resultados se arribó a una síntesis en donde se establecieron cuatro niveles de cobertura en relación al acceso los servicios. A partir de esta síntesis se elaboró la cartografía temática que grafica la distribución de las urbanizaciones informales y la cobertura de los servicios, de este modo es posible relacionar la localización con la mayor o menor carencia de los mismos.

Del análisis se desprende que la mayoría de las urbanizaciones del Partido de La Plata se encuentra dentro de los rangos que varían entre el abastecimiento de tres, dos o un sólo servicio, o bien la ausencia de todos ellos. No se ha encontrado, hasta el momento de elaboración de esta tesis, ninguna urbanización informal que cuente con la cobertura total de los cuatro servicios urbanos básicos, en todos los casos, al menos uno de ellos resulta en falta (Tabla 10).

\footnotetext{
${ }^{21}$ El análisis se realiza a partir de los datos del Registro Público de la Provincia de Buenos Aires del año 2015 http://www.mosp.gba.gov.ar/subsecretarias/reg_vilyasent.php
} 
Tabla 10. Síntesis de acceso a los servicios urbanos básicos.

\begin{tabular}{|l|c|c|c|c|c|c|c|c|c|}
\hline \multirow{2}{*}{ LOCALIDAD } & TOTAL & \multicolumn{2}{|c|}{$\begin{array}{c}\text { NIVEL 1 } \\
\text { (valor }=0)\end{array}$} & \multicolumn{2}{c|}{$\begin{array}{c}\text { NIVEL 2 } \\
(0,5-2)\end{array}$} & \multicolumn{2}{c|}{$\begin{array}{c}\text { NIVEL 3 } \\
(2,5-3,5)\end{array}$} & \multicolumn{2}{c|}{$\begin{array}{c}\text { NIVEL 4 } \\
\text { (valor 4) }\end{array}$} \\
\hline Villa Elvira & 17 & 11 & $65 \%$ & 6 & $35 \%$ & 0 & $0 \%$ & 0 & $0 \%$ \\
\hline Altos de San Lorenzo & 15 & 5 & $33 \%$ & 10 & $67 \%$ & 0 & $0 \%$ & 0 & $0 \%$ \\
\hline Arana & 2 & 2 & $100 \%$ & 0 & $0 \%$ & 0 & $0 \%$ & 0 & $0 \%$ \\
\hline Los Hornos & 16 & 14 & $88 \%$ & 2 & $13 \%$ & 0 & $0 \%$ & 0 & $0 \%$ \\
\hline Olmos & 5 & 3 & $60 \%$ & 2 & $40 \%$ & 0 & $0 \%$ & 0 & $0 \%$ \\
\hline Etcheverry & 2 & 2 & $100 \%$ & 0 & $0 \%$ & 0 & $0 \%$ & 0 & $0 \%$ \\
\hline Abasto & 2 & 2 & $100 \%$ & 0 & $0 \%$ & 0 & $0 \%$ & 0 & $0 \%$ \\
\hline El Peligro & 2 & 2 & $100 \%$ & 0 & $0 \%$ & 0 & $0 \%$ & 0 & $0 \%$ \\
\hline Melchor Romero & 19 & 12 & $63 \%$ & 7 & $37 \%$ & 0 & $0 \%$ & 0 & $0 \%$ \\
\hline Arturo Seguí & 4 & 1 & $25 \%$ & 3 & $75 \%$ & 0 & $0 \%$ & 0 & $0 \%$ \\
\hline Gorina & 3 & 1 & $33 \%$ & 2 & $67 \%$ & 0 & $0 \%$ & 0 & $0 \%$ \\
\hline City Bell & 7 & 2 & $29 \%$ & 5 & $71 \%$ & 0 & $0 \%$ & 0 & $0 \%$ \\
\hline Gonnet & 4 & 1 & $25 \%$ & 3 & $75 \%$ & 0 & $0 \%$ & 0 & $0 \%$ \\
\hline Villa Elisa & 4 & 0 & $0 \%$ & 3 & $75 \%$ & 1 & $25 \%$ & 0 & $0 \%$ \\
\hline Ringuelet & 4 & 0 & $0 \%$ & 3 & $75 \%$ & 1 & $25 \%$ & 0 & $0 \%$ \\
\hline Tolosa & 7 & 3 & $43 \%$ & 4 & $57 \%$ & 0 & $0 \%$ & 0 & $0 \%$ \\
\hline Hernández & 3 & 1 & $33 \%$ & 2 & $67 \%$ & 0 & $0 \%$ & 0 & $0 \%$ \\
\hline San Carlos & 12 & 7 & $58 \%$ & 5 & $42 \%$ & 0 & $0 \%$ & 0 & $0 \%$ \\
\hline TOTAL & 128 & 69 & $54 \%$ & 57 & $45 \%$ & 2 & $2 \%$ & 0 & $0 \%$ \\
\hline
\end{tabular}

Fuente. Elaboración Propia, 2018, a partir de RPPVAP, 2015.

Del resultado del análisis del nivel de acceso a los servicios básicos urbanos básicos, se puso de manifiesto que la mayoría de las urbanizaciones informales del Partido se ubican dentro de los niveles 1 o 2 (54\% y 45\% respectivamente). Como se puede observar en la Figura 33, la mayoría de las urbanizaciones informales que corresponden con el nivel 1 se encuentran principalmente en las localidades de las zonas sureste y suroeste. Este dato se corresponde con el análisis en capítulos anteriores, donde se mencionó que estas localidades de la zona sur, se encuentran en una situación de desabastecimiento y abandono mayor que en otras zonas de la periferia. Mientras tanto, en las localidades vinculadas con las zonas del noroeste como Ringuelet y Villa Elisa es posible encontrar urbanizaciones que alcanzan un nivel 3, es decir que cuentan con al menos dos servicios básicos. 


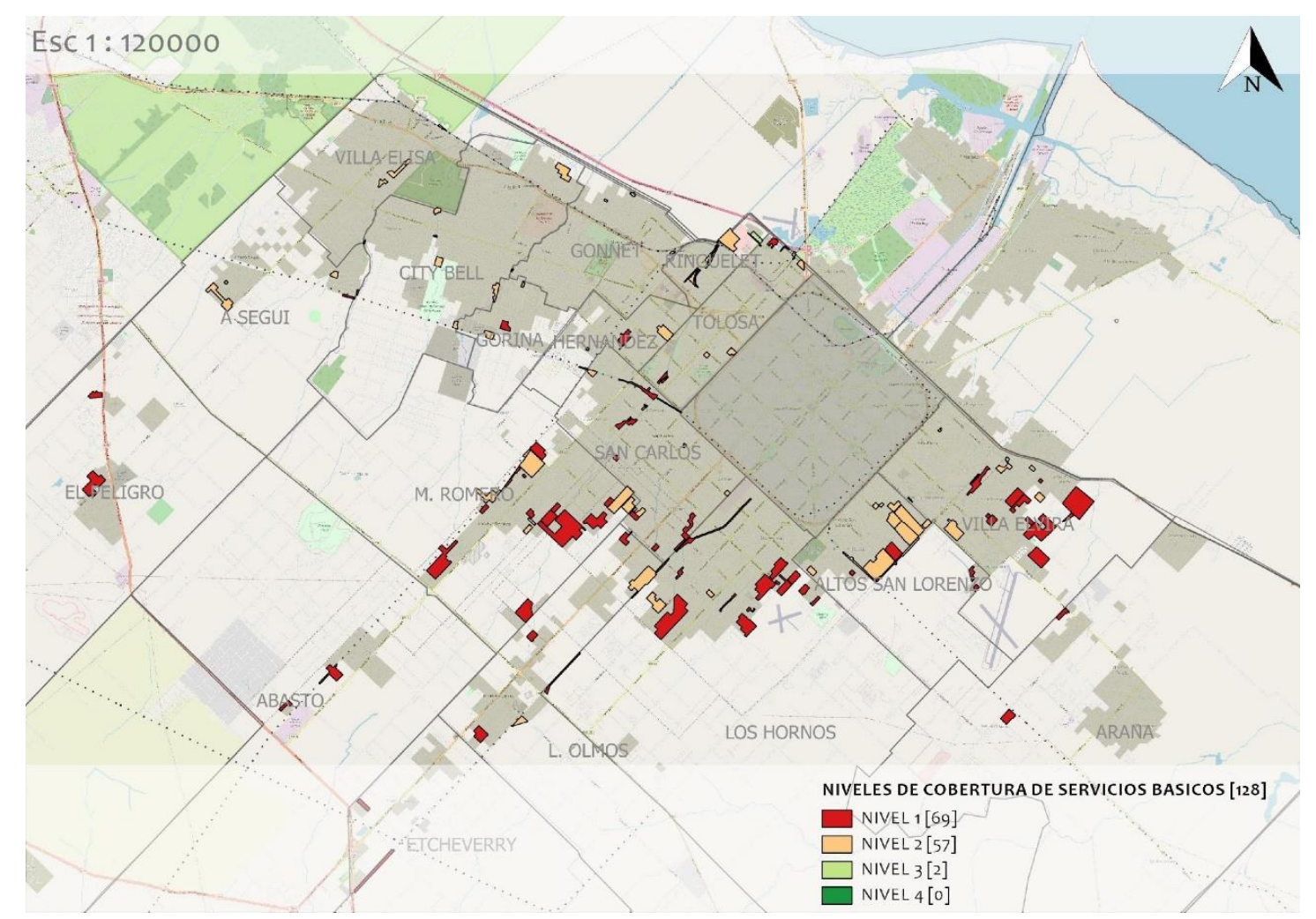

Figura 33. Niveles de acceso a los servicios urbanos básicos.

Fuente. Elboración propia, con datos de RPPVAP, 2015.

El Gráfico 3 muestra que el 54\% de las urbanizaciones informales del Partido no logra acceder al total de los servicios urbanos básicos, y del análisis se desprende que, por lo general, aquellas urbanizaciones abastecidas por 1 o 2 servicios, suelen contar con el servicio de energía eléctrica y/o el de agua corriente, por lo que el gas y el servicio de la red cloacal son los que representan el mayor déficit a la hora de cuantificar el acceso a los mismos.

En los apartados siguientes se presenta el análisis desagregado para cada indicador, esto permitió alcanzar la síntesis e identificar los niveles de cobertura, así como clasificar la situación particular de cada localidad en relación a cada uno de los servicios urbanos básicos analizados. 
Gráfico 3. Acceso a los servicios urbanos básicos por localidad y porcentaje.

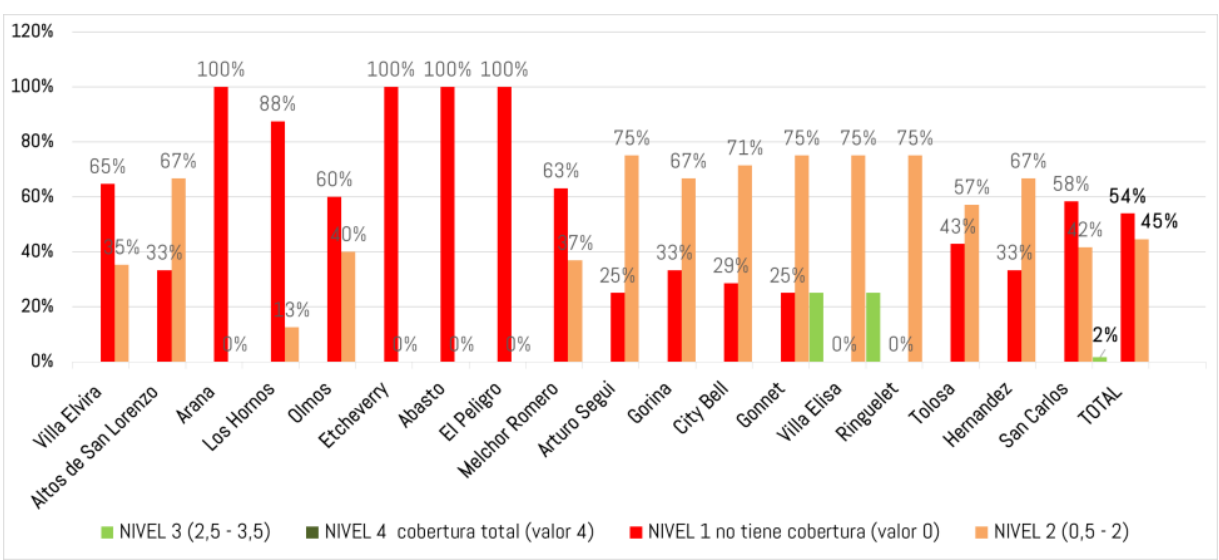

Fuente. Elaboración propia, 2019.

\section{Acceso a la red de energía eléctrica}

En relación con el abastecimiento de la red de energía eléctrica, a partir del análisis de los datos se desprende que el $70 \%$ de las 128 urbanizaciones informales del Partido de La Plata no cuenta con el acceso a dicha red (Gráfico 4). Esto, representa 89 urbanizaciones informales que no tienen cobertura formal de la red eléctrica. El 28\% de las urbanizaciones informales cuenta con una cobertura parcial, y tan sólo el 2\% tiene acceso total a la red de energía eléctrica

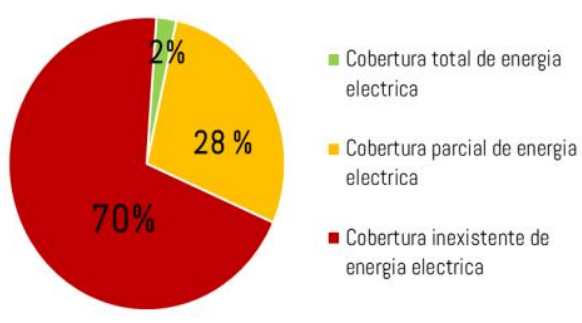

Gráfico 4. Acceso a la energía eléctrica \%. Fuente. Elaboración propia, 2019
(Tabla 11). En el análisis se incluyeron todas las tipologías de urbanización informal presentadas en el capítulo 4. Uno de los factores que explicaría la falta de acceso a este servicio urbano, tiene que ver, en parte, con que muchos de los habitantes de las urbanizaciones informales acceden a la energía eléctrica a través de conexiones ilegales que ellos mismos colocan, muchas veces peligrosas, realizadas de manera muy precaria. Esta modalidad ilegal de acceso a la energía eléctrica, con el riesgo que conlleva, se ha convertido en un patrón común entre las urbanizaciones informales de todo el Partido de La Plata. 
Tabla 11. Cobertura de energia eléctrica por localidad.

\begin{tabular}{|l|c|c|c|c|c|c|c|}
\hline \multicolumn{1}{|c|}{ LOCALIDAD } & $\begin{array}{c}\text { TOTAL } \\
\text { Urb. } \\
\text { informales }\end{array}$ & $\begin{array}{c}\text { COBERTURA TOTAL } \\
\text { DE ENERGÍA } \\
\text { ELÉCTRICA }\end{array}$ & \multicolumn{2}{c|}{$\begin{array}{c}\text { COBERTURA PARCIAL DE } \\
\text { ENERGÍA ELÉCTRICA }\end{array}$} & $\begin{array}{c}\text { COBERTURA } \\
\text { INEXISTENTE DE } \\
\text { ENERGÍA ELÉCTRICA }\end{array}$ \\
\hline Villa Elvira & 17 & 0 & $0 \%$ & 2 & $12 \%$ & 15 & $88 \%$ \\
\hline Altos de San Lorenzo & 15 & 0 & $0 \%$ & 2 & $13 \%$ & 13 & $87 \%$ \\
\hline Arana & 2 & 0 & $0 \%$ & 0 & $0 \%$ & 2 & $100 \%$ \\
\hline Los Hornos & 16 & 1 & $6 \%$ & 0 & $0 \%$ & 15 & $94 \%$ \\
\hline Olmos & 5 & 0 & $0 \%$ & 1 & $20 \%$ & 4 & $80 \%$ \\
\hline Etcheverry & 2 & 0 & $0 \%$ & 0 & $0 \%$ & 2 & $100 \%$ \\
\hline Abasto & 2 & 0 & $0 \%$ & 0 & $0 \%$ & 2 & $100 \%$ \\
\hline El Peligro & 2 & 0 & $0 \%$ & 0 & $0 \%$ & 2 & $100 \%$ \\
\hline Melchor Romero & 19 & 1 & $5 \%$ & 6 & $32 \%$ & 12 & $63 \%$ \\
\hline Arturo Seguín & 4 & 0 & $0 \%$ & 3 & $75 \%$ & 1 & $25 \%$ \\
\hline Gorina & 3 & 0 & $0 \%$ & 1 & $33 \%$ & 2 & $67 \%$ \\
\hline City Bell & 7 & 0 & $0 \%$ & 4 & $57 \%$ & 3 & $43 \%$ \\
\hline Gonnet & 4 & 0 & $0 \%$ & 3 & $75 \%$ & 1 & $25 \%$ \\
\hline Villa Elisa & 4 & 1 & $25 \%$ & 3 & $75 \%$ & 0 & $0 \%$ \\
\hline Ringuelet & 4 & 0 & $0 \%$ & 1 & $25 \%$ & 3 & $75 \%$ \\
\hline Tolosa & 7 & 0 & $0 \%$ & 4 & $57 \%$ & 3 & $43 \%$ \\
\hline Hernández & 3 & 0 & $0 \%$ & 2 & $67 \%$ & 1 & $33 \%$ \\
\hline San Carlos & 12 & 0 & $0 \%$ & 4 & $33 \%$ & 8 & $67 \%$ \\
\hline TOTAL & 128 & 3 & $2 \%$ & 36 & $28 \%$ & 89 & $70 \%$ \\
\hline
\end{tabular}

Fuente. Elaboración propia, 2018.

En relación con la distribución espacial, se puede mencionar que el hecho de una localidad presente mayor cantidad de urbanizaciones informales que otra, en términos generales, no determina un mayor o menor abastecimiento del servicio en cuestión. Por ejemplo, hay localidades como Villa Elvira o Melchor Romero, con gran cantidad de urbanizaciones informales, en el caso de Villa Elvira el 88\% y el 63\% en el caso de Romero que no cuentan con el abastecimiento del servicio de energía eléctrica (Figura 34).

En relación con las tipologías analizadas, cabe mencionar que la problemática de la precariedad en las instalaciones eléctricas, resulta aún mayor en la tipología de villas. Esto se debe, en parte a que la las villas presentan una mayor irregularidad urbana y precariedad en relación con el material de las viviendas, que conlleva el riesgo de electrificación de paredes y techos. Como consecuencia se producen gran cantidad de electrocuciones e incendios por año, muchos de las cuales se cobran la vida de los habitantes de este tipo de urbanización. 


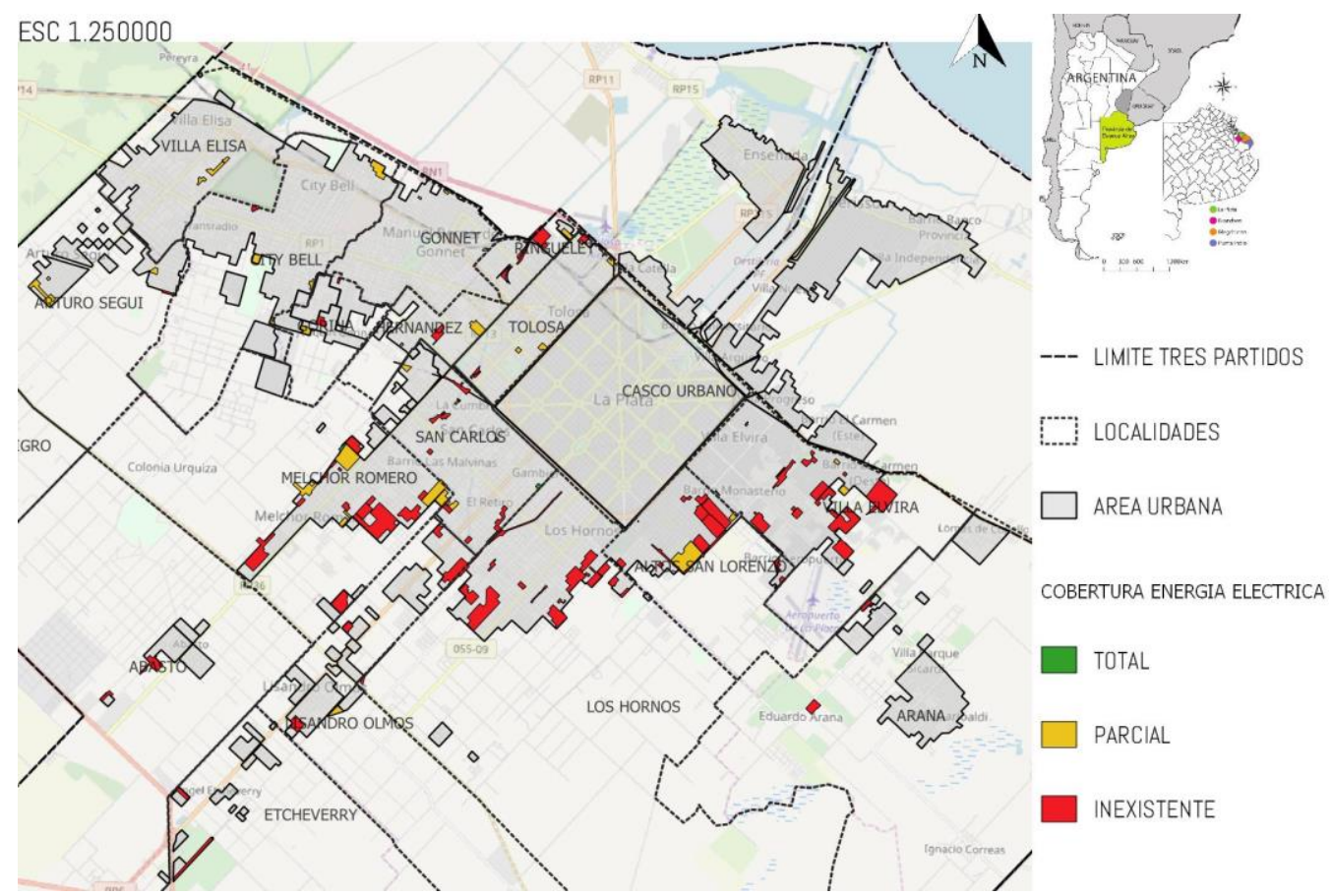

Figura 34. Acceso a la red de energía eléctrica.

Fuente. Elaboración propia, con herramienta SIG, 2018.

En las urbanizaciones informales las interrupciones en el suministro de energía eléctrica son frecuentes, y tienen sus causas no sólo en los problemas derivados de la precariedad de la instalación (incendios, cortes de cables y otros accidentes que obligan a cortar la energía), sino también en el desbalance entre el consumo que requiere la cantidad de habitantes de cada barrio y la capacidad de las instalaciones.

La provisión del servicio de energía eléctrica en las urbanizaciones informales en el Partido de La Plata involucra a distintos actores que asumen diversas responsabilidades. En la periferia del Partido, la empresa concesionaria (Edelap) brinda la energía eléctrica hasta transformadores comunitarios, pero luego esa conexión debe de establecer redes provisorias de distribución que permitan la llegada de luz a cada una de las viviendas. Como consecuencia de esta diferencial provisión, los habitantes de las urbanizaciones informales no son considerados clientes por parte de la empresa prestataria, por lo que, al registrarse cualquier tipo de inconveniente no se reconocen los derechos de los que si gozan los habitantes del resto de la ciudad formal. 
Cabe mencionar que muchos de los habitantes de urbanizaciones informales se encuentran indocumentados por diversos motivos, y no cuentan con la tenencia del suelo ni de la vivienda y, por lo tanto, la empresa prestataria les niega el suministro de energía eléctrica. En las imágenes (Figura 35) se pueden observar algunas conexiones clandestinas a la red de energía eléctrica en dos urbanizaciones informales de la periferia del Partido de La Plata en las localidades de Altos de San Lorenzo y Los Hornos.
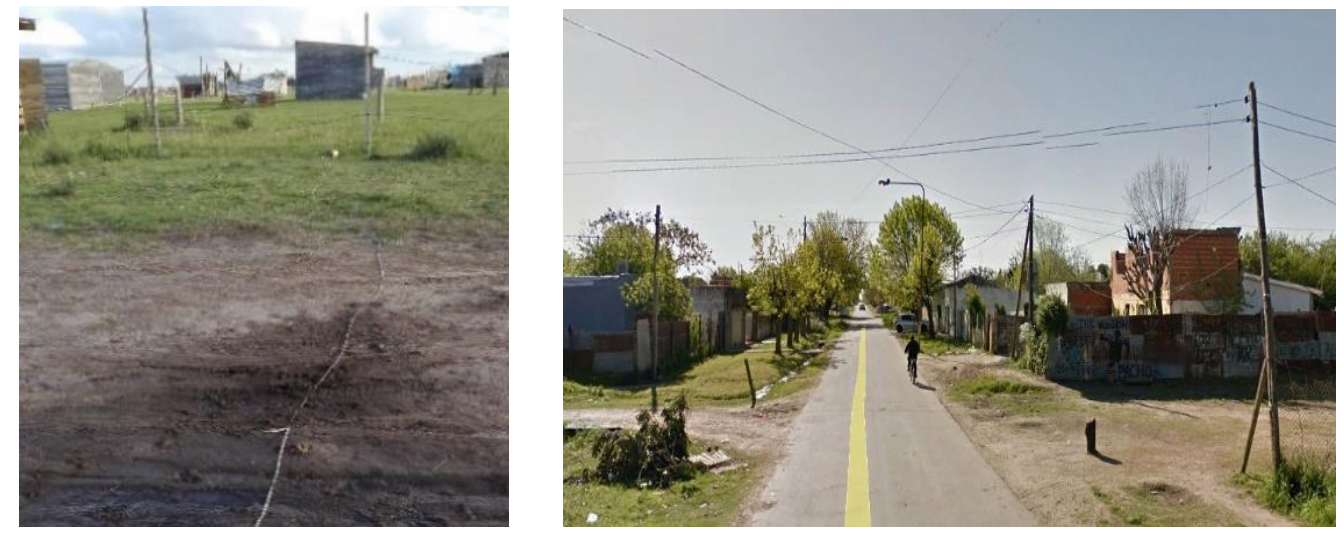

Figura 35. Conexiones clandestinas en dos barrios informales del Partido de La Plata en la localidad de Altos de San Lorenzo (izquierda) y en la localidad de Los Hornos (derecha).

Fuente. Imágenes tomadas en salidas de trabajo de campo durante el año 2018.

Es posible encontrar en la actualidad otros estudios que apoyan los datos aquí presentados, entre ellos el trabajo llevado adelante por la ONG TECHO (2016), en donde figura que, en el Partido de La Plata, se torna notoria la cantidad de barrios precarios con conexión irregular a la energía eléctrica. Este estudio establece el 83\% de conexiones irregulares para el sector, indicando que los "enganchados al servicio" superan la media provincial de 50\%. Estas cifras resultan alarmantes, si se analizan dentro de un contexto en donde la vulnerabilidad de estas urbanizaciones condiciona cada vez más los derechos como ciudadanos y atenta contra el legítimo derecho de habitar la ciudad con todas sus componentes en condiciones dignas. 


\section{Acceso a la red de gas natural}

En relación con el abastecimiento de la red de gas natural en las urbanizaciones informales del Partido de La Plata, el análisis arroja que de las 128 urbanizaciones el 88\% no cuenta con ningún tipo de conexión a la red de gas, mientras que el 12\% presenta una cobertura parcial del servicio (Gráfico 5). En este sentido, muchos de los habitantes suelen utilizar garrafas y hornos a leña para cocinar y para calefaccionar el hogar.

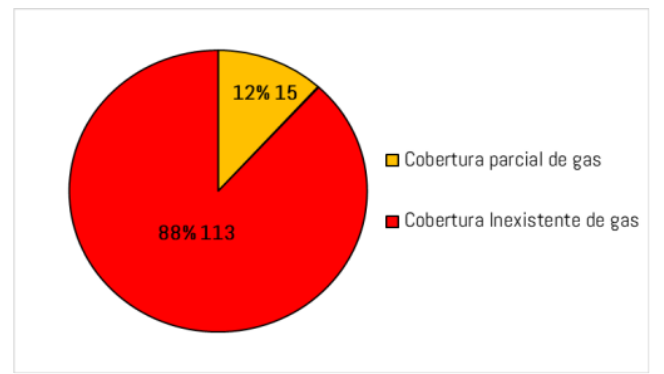

Gráfico 5. Acceso ala red de gas natural (\%) Fuente. Elaboración propia, 2019

Estos datos ponen de manifiesto que sólo algunas viviendas cuentan con conexiones de gas natural, en muchos casos, esta situación suele presentarse en la tipología de asentamiento informal. Esto se debe a la mayor facilidad que presenta la disposición de las viviendas para establecer la conexión del servicio. Por último, el análisis arroja que ninguna de las urbanizaciones informales del Partido cuenta con la cobertura total de gas natural, es decir, no hay ningún barrio en donde todos sus habitantes cuenten con la posibilidad de acceder al gas natural (Gráfico 5).

Como se mencionó anteriormente, resulta muy habitual en este tipo de barrios el uso de garrafas, especialmente en situaciones de bajas temperaturas durante las temporadas de invierno, para calefacción, o lo que resulta peligroso, iniciar fogatas en áreas cercanas a las viviendas que por lo general son de materiales inflamables. Esto trae diversos riesgos aparejados para la población, tales como riesgo de intoxicación y hasta incendio de viviendas, produciendo en muchos casos la pérdida total de la vivienda y hasta la muerte de sus habitantes. 
Tabla 12. Cobertura de la red de gas.

\begin{tabular}{|l|c|c|c|c|c|}
\hline \multirow{2}{*}{ LOCALIDAD } & $\begin{array}{c}\text { TOTAL } \\
\text { Urb. Informales }\end{array}$ & \multicolumn{2}{c|}{$\begin{array}{c}\text { COBERTURA PARCIAL DE } \\
\text { LA RED DE GAS }\end{array}$} & \multicolumn{2}{c|}{$\begin{array}{c}\text { COBERTURA INEXISTENTE DE LA } \\
\text { RED DE GAS }\end{array}$} \\
\hline Villa Elvira & 17 & 3 & $18 \%$ & 14 & $82 \%$ \\
\hline Altos de San Lorenzo & 15 & 2 & $13 \%$ & 13 & $87 \%$ \\
\hline Arana & 2 & 0 & $0 \%$ & 2 & $100 \%$ \\
\hline Los Hornos & 16 & 0 & $0 \%$ & 16 & $100 \%$ \\
\hline Olmos & 5 & 1 & $20 \%$ & 4 & $80 \%$ \\
\hline Etcheverry & 2 & 0 & $0 \%$ & 2 & $100 \%$ \\
\hline Abasto & 2 & 0 & $0 \%$ & 2 & $100 \%$ \\
\hline El Peligro & 2 & 0 & $0 \%$ & 2 & $100 \%$ \\
\hline Melchor Romero & 19 & 1 & $5 \%$ & 18 & $95 \%$ \\
\hline Arturo Seguí & 4 & 0 & $0 \%$ & 4 & $100 \%$ \\
\hline Gorina & 3 & 1 & $33 \%$ & 2 & $67 \%$ \\
\hline City Bell & 7 & 1 & $14 \%$ & 6 & $86 \%$ \\
\hline Gonnet & 4 & 1 & $25 \%$ & 3 & $75 \%$ \\
\hline Villa Elisa & 4 & 2 & $50 \%$ & 2 & $50 \%$ \\
\hline Ringuelet & 4 & 0 & $0 \%$ & 4 & $100 \%$ \\
\hline Tolosa & 7 & 0 & $0 \%$ & 7 & $100 \%$ \\
\hline Hernández & 3 & 1 & $33 \%$ & 2 & $67 \%$ \\
\hline San Carlos & 12 & 2 & $17 \%$ & 10 & $83 \%$ \\
\hline TOTAL & 128 & 15 & $12 \%$ & 113 & $88 \%$ \\
\hline
\end{tabular}

Fuente. Elaboración propia, 2018.

En cuanto a la distribución territorial, en la Figura 36 se observa que el mayor porcentaje de cobertura se relaciona, en su mayoría, con las áreas más cercanas al casco urbano fundacional, o bien hacia las zonas de las localidades en sectores históricos o de mayor consolidación, donde resulta más sencillo el hecho de establecer una conexión de la infraestructura necesaria para brindar el servicio. Esta situación se debe principalmente a que las posibilidades de acceder a los servicios urbanos básicos aumentan cuando la urbanización informal se encuentra cercana al casco urbano o áreas consolidadas, ya que resulta más sencillo el proceso de regulación de la situación en barrios cercanos a la red existente, que la extensión de la misma hacia los sectores más alejados. 


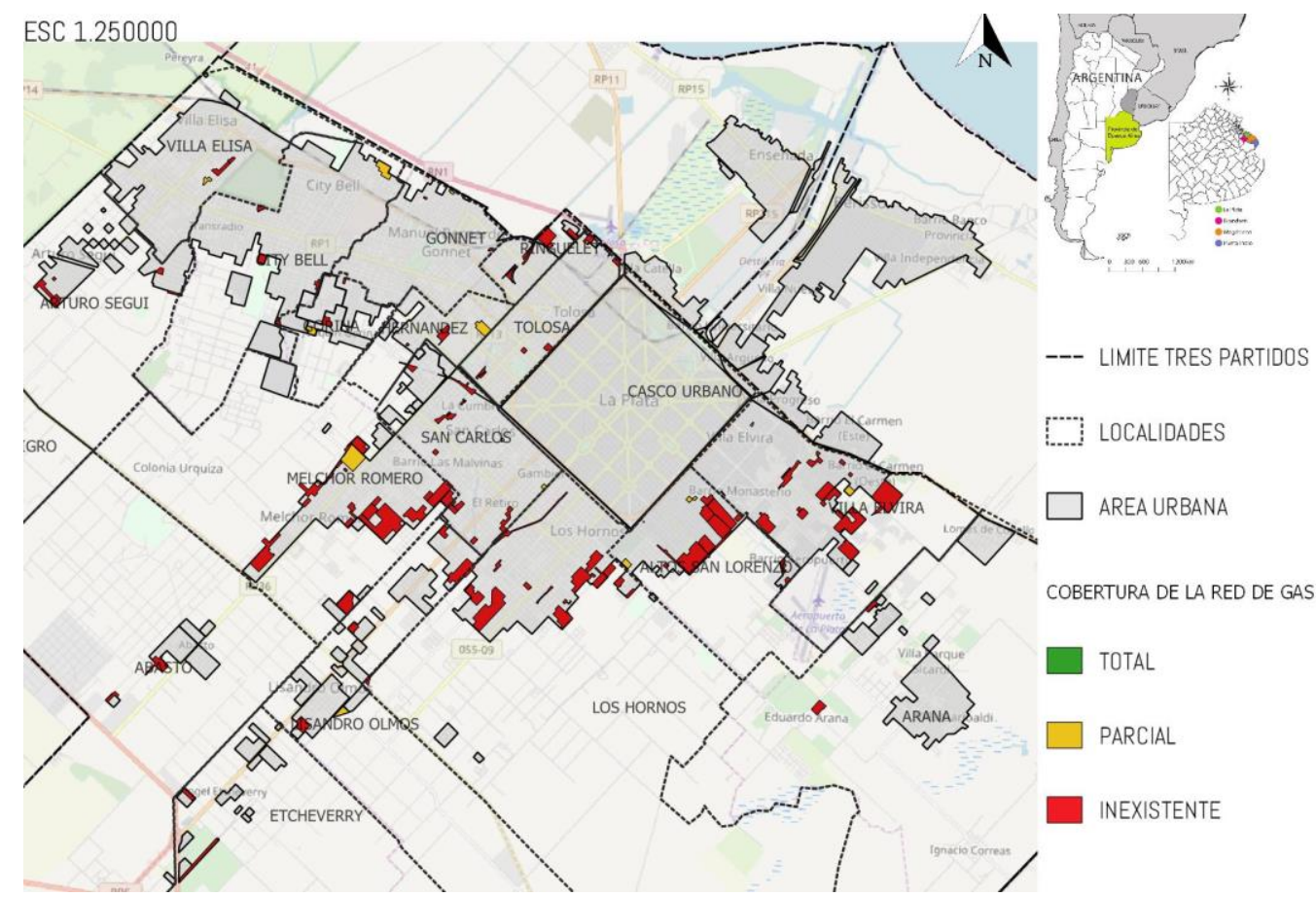

Figura 36. Acceso a la red de gas natural.

Fuente. Elaboración propia, con herramienta SIG, 2018.

Dada la falta de acceso a la red de gas natural, los habitantes de las urbanizaciones informales, muchas veces terminan dependiendo de garrafas de gas licuado. Durante la temporada invernal, debido a la gran demanda para calefaccionar, se generan problemas de abastecimiento registrándose escasez de garrafas y subas de precio considerables. Esta suba en el precio convierte a las garrafas en inaccesibles para muchos y la energía eléctrica, muchas veces, termina suplantando la ausencia de ese suministro. Por este motivo, resulta mayor la cantidad de urbanizaciones informales que si cuentan con servicio de energía eléctrica en comparación con el de gas natural. Sin embargo, cabe mencionar al respecto la existencia de subsidios por parte del Estado, para la compra de garrafas en viviendas que no estén conectadas a la red de gas natural $^{22}$. El mismo está dirigido a las personas que viven en zonas sin servicio de gas o que no se encuentren conectados a la red de distribución domiciliaria.

22 Programa Hogar https://www.anses.gob.ar/programa-hogar. 


\section{Acceso a la red de agua corriente}

En el análisis de los servicios urbanos básicos, no puede faltar el análisis del acceso al agua corriente, ya que resulta vital para el ser humano, principalmente para el consumo personal. Con respecto a este servicio, se observa una situación similar a la que se desprende del análisis de los otros servicios urbanos básicos. Casi el $70 \%$ de las urbanizaciones informales analizadas no cuenta con acceso

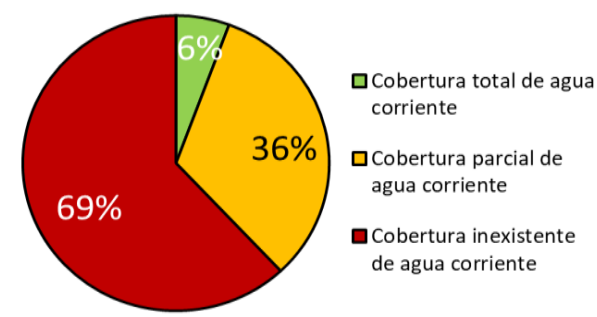

Gráfico 6. Acceso agua corriente (\%). Fuente. Elaboración propia, 2019 formal al agua corriente de red pública (Gráfico 6). Al mismo tiempo, se reconoce que, del total de las urbanizaciones informales del Partido de La Plata, el 25\% cuenta con cobertura parcial y solo el $6 \%$ accede por completo a la red de agua corriente (Tabla 13).

Tabla 13. Cobertura de la red de agua corriente por localidad.

\begin{tabular}{|l|c|c|c|c|c|c|c|}
\hline \multirow{2}{*}{ LOCALIDAD } & $\begin{array}{c}\text { TOTAL } \\
\text { Urb. } \\
\text { Informales }\end{array}$ & \multicolumn{2}{c|}{$\begin{array}{c}\text { COBERTURA TOTAL } \\
\text { DE AGUA CORRIENTE }\end{array}$} & $\begin{array}{c}\text { COBERTURA PARCIAL } \\
\text { DE AGUA CORRIENTE }\end{array}$ & $\begin{array}{c}\text { COBERTURA } \\
\text { INEXISTENTE DE AGUA } \\
\text { CORRIENTE }\end{array}$ \\
\hline Villa Elvira & 17 & 0 & $0 \%$ & 5 & $29 \%$ & 12 & $71 \%$ \\
\hline Altos de San Lorenzo & 15 & 0 & $0 \%$ & 9 & $60 \%$ & 6 & $40 \%$ \\
\hline Arana & 2 & 0 & $0 \%$ & 0 & $0 \%$ & 2 & $100 \%$ \\
\hline Los Hornos & 16 & 0 & $0 \%$ & 2 & $13 \%$ & 14 & $88 \%$ \\
\hline Olmos & 5 & 0 & $0 \%$ & 2 & $40 \%$ & 3 & $60 \%$ \\
\hline Etcheverry & 2 & 0 & $0 \%$ & 0 & $0 \%$ & 2 & $100 \%$ \\
\hline Abasto & 2 & 0 & $0 \%$ & 0 & $0 \%$ & 2 & $100 \%$ \\
\hline El Peligro & 2 & 0 & $0 \%$ & 0 & $0 \%$ & 2 & $100 \%$ \\
\hline Melchor Romero & 19 & 0 & $0 \%$ & 4 & $21 \%$ & 15 & $79 \%$ \\
\hline Arturo Seguín & 4 & 2 & $50 \%$ & 0 & $0 \%$ & 2 & $50 \%$ \\
\hline Gorina & 3 & 1 & $33 \%$ & 0 & $0 \%$ & 2 & $67 \%$ \\
\hline City Bell & 7 & 1 & $14 \%$ & 1 & $14 \%$ & 5 & $71 \%$ \\
\hline Gonnet & 4 & 1 & $25 \%$ & 0 & $0 \%$ & 3 & $75 \%$ \\
\hline Villa Elisa & 4 & 2 & $50 \%$ & 2 & $50 \%$ & 0 & $0 \%$ \\
\hline Ringuelet & 4 & 1 & $25 \%$ & 3 & $75 \%$ & 0 & $0 \%$ \\
\hline Tolosa & 7 & 0 & $0 \%$ & 2 & $29 \%$ & 5 & $71 \%$ \\
\hline Hernández & 3 & 0 & $0 \%$ & 1 & $33 \%$ & 2 & $67 \%$ \\
\hline San Carlos & 12 & 0 & $0 \%$ & 1 & $8 \%$ & 11 & $92 \%$ \\
\hline TOTAL & 128 & 8 & $6 \%$ & 32 & $25 \%$ & 88 & $69 \%$ \\
\hline
\end{tabular}

Fuente. Elaboración propia, 2018. 
En la mayoría de los barrios del Partido que no cuentan con acceso a la red de agua corriente, se suele instalar lo que se denomina canilla comunitaria a través de la cual se abastece de agua potable a todo el barrio. Para muchos, es posible acceder al servicio a través de una conexión irregular, hecha por los propios vecinos y conectada de manera informal a la red pública. Como consecuencia de esta situación, el agua para consumo de los hogares corre riesgo permanente de contaminarse con aguas servidas, desechos cloacales y agua de lluvia. Sumado a esto, el hecho de que el agua filtrada de las pinchaduras de las mangueras utilizadas para la conexión informal embarra las calles provocando un estado pantanoso permanente. En muchos casos ésta es la única manera en que los habitantes de urbanizaciones informales logran el acceso al agua potable, así los vecinos se organizan de modo puedan llenar bidones para tener agua en sus viviendas. Cabe mencionar que la puesta de canillas comunitarias como solución parcial, es producto de la gestión de los vecinos y las organizaciones sociales que funcionan en los barrios. Ellos mismos se encargan de comprar los materiales en juntas vecinales y ejecutar, en algunos casos, las obras a través de cooperativas.

En este sentido, son muy pocos los casos donde el Estado interviene desde el principio, atendiendo a las necesidades de las habitantes. Otras de las soluciones, parciales, que suelen utilizar los vecinos de estas urbanizaciones para sobrellevar la falta de acceso a la red de agua es recurrir a pozos o perforaciones. En estos casos, la situación de riesgo para la salud se vincula a la falta de control acerca de la calidad del agua subterránea. Al alto grado de contaminación subterránea se suma, frecuentemente, el riesgo de contaminación vinculado a la proximidad entre los pozos de agua y los pozos ciegos.

En cuanto a la distribución territorial se observa que las localidades que presentan urbanizaciones informales con cobertura total con las de Arturo Seguí, Gorina, City Bell, Gonnet, Villa Elisa y Ringuelet. Todas pertenecientes de la zona norte (noreste) del Partido, mientras que las localidades de las zonas sureste y suroeste, en su mayoría, presentan conexiones parciales o en su defecto, ningún tipo de conexión a la red de agua potable (Figura 37). 


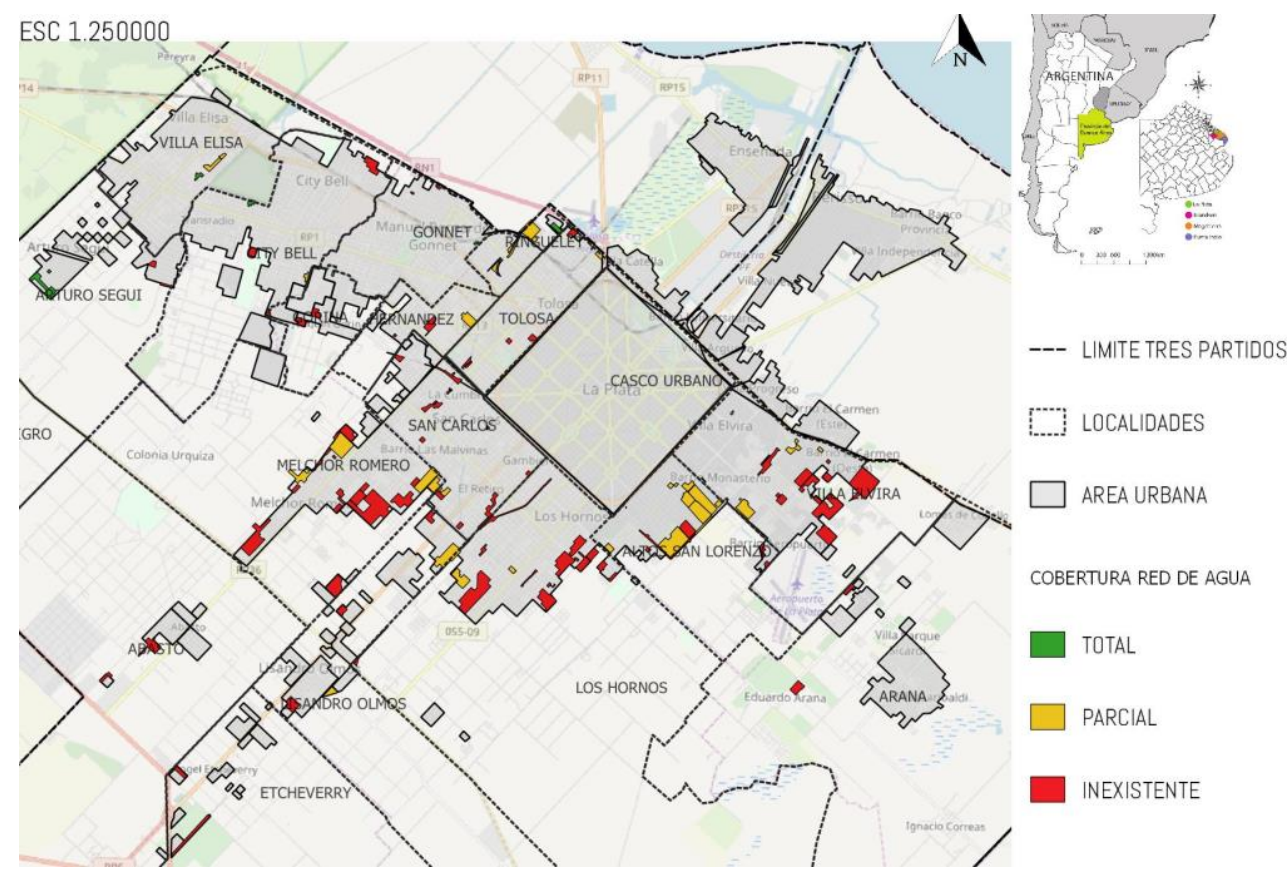

Figura 37. Acceso a la red de agua corriente.

Fuente. Elaboración propia, 2019.

La gran cantidad de urbanizaciones que no cuentan con acceso formal al agua corriente de red pública pone de manifiesto la vulnerabilidad que sufre la población que se encuentra sometida a graves consecuencias para la calidad de vida. El acceso al agua, es acceso a la salud que implica una necesidad y un derecho básico, que en estos casos se ve impedida por las condiciones que acarrea la informalidad. La falta de acceso al agua suficiente, salubre, aceptable, asequible y accesible para el uso personal y doméstico afecta el derecho a la vida, a la salud, la alimentación, la vivienda digna y a un nivel de vida adecuado (Techo, 2016).

\section{Acceso a de la red de desagüe cloacal}

En el caso del sistema de desagüe cloacal, el análisis arroja que el 92\% de las urbanizaciones informales del Partido de La Plata no cuenta con ningún tipo de cobertura, mientras que el 7\% de las urbanizaciones presenta un acceso parcial y solo el 1\% cuenta con la cobertura total de servicio, es decir que todos los habitantes acceden al sistema formal de desagüe cloacal (Gráfico 7). 


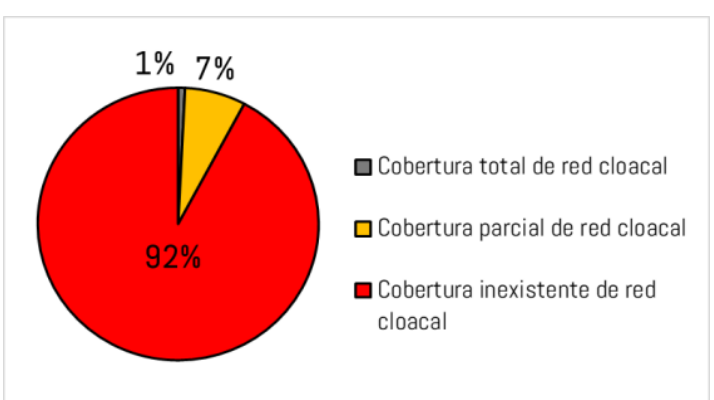

Gráfico 7. Acceso a la red cloacal (\%) Fuente. Elaboración propia, 2019
Por lo general, la eliminación de los residuos cloacales se realiza a través de conexiones irregulares al desagüe, la utilización de pozos ciegos o cámaras sépticas, o en los casos más extremos, directamente los residuos son arrojados en los arroyos, zanjas, etc. Estos sistemas, resultan altamente contaminantes para los cuerpos de agua donde se arrojan los desechos y principalmente perjudiciales para la salud de las familias que habitan en los barrios.

Existen algunos casos, en los que hay algún tipo de acceso a la red cloacal pública, pero muchas veces, se ve conectada la red de desagüe pluvial, tratándose en estos casos de una conexión que, si bien es formal en apariencia, se encuentra conectada con el alcantarillado o desagüe pluvial cuya capacidad de transporte de efluentes es mucho menor que la red cloacal correspondiente. Una disposición inadecuada de los residuos cloacales provoca la contaminación del suelo, del aire y de las fuentes de agua; genera ámbitos propicios para los insectos, moscas, y atrae a animales, principalmente domésticos como perros, gatos, pero también roedores que pueden actuar como vectores de transmisión de enfermedades.

En consecuencia, la falta en el acceso a una adecuada eliminación de los residuos cloacales constituye una de las principales causas de enfermedades infecciosas y parasitarias que afectan fundamentalmente a la población infantil. Esta situación se agrava debido a que en muchos casos también se accede al agua para consumo a través del sistema de pozos como se mencionó en el apartado anterior. Al no poder realizar una adecuada eliminación de los residuos cloacales, se pone en riesgo la salud de los habitantes, ya que las napas de donde se extrae el agua para consumo humano tienen una alta probabilidad de encontrarse contaminadas por excretas debido a que el sistema de eliminación de pozo ciego no cuenta con ningún sistema de tratamiento para las aguas servidas. 
Tabla 14. Cobertura de la red cloacal por localidad.

\begin{tabular}{|l|c|c|c|c|c|c|c|}
\hline \multicolumn{1}{|c|}{ LOCALIDAD } & $\begin{array}{c}\text { TOTAL } \\
\text { Urb. Informales }\end{array}$ & $\begin{array}{c}\text { COBERTURA } \\
\text { TOTAL DE RED } \\
\text { CLOACAL }\end{array}$ & \multicolumn{2}{c|}{$\begin{array}{c}\text { COBERTURA } \\
\text { PARCIAL DE RED } \\
\text { CLOACAL }\end{array}$} & \multicolumn{2}{c|}{$\begin{array}{c}\text { COBERTURA } \\
\text { INEXISTENTE DE RED } \\
\text { CLOACAL }\end{array}$} \\
\hline Villa Elvira & 17 & 0 & $0 \%$ & 1 & $6 \%$ & 16 & $94 \%$ \\
\hline Altos de San Lorenzo & 15 & 0 & $0 \%$ & 6 & $40 \%$ & 9 & $60 \%$ \\
\hline Arana & 2 & 0 & $0 \%$ & 0 & $0 \%$ & 2 & $100 \%$ \\
\hline Los Hornos & 16 & 0 & $0 \%$ & 1 & $6 \%$ & 15 & $94 \%$ \\
\hline Olmos & 5 & 0 & $0 \%$ & 0 & $0 \%$ & 5 & $100 \%$ \\
\hline Etcheverry & 2 & 0 & $0 \%$ & 0 & $0 \%$ & 2 & $100 \%$ \\
\hline Abasto & 2 & 0 & $0 \%$ & 0 & $0 \%$ & 2 & $100 \%$ \\
\hline El Peligro & 2 & 0 & $0 \%$ & 0 & $0 \%$ & 2 & $100 \%$ \\
\hline Melchor Romero & 19 & 0 & $0 \%$ & 1 & $5 \%$ & 18 & $95 \%$ \\
\hline Arturo Seguín & 4 & 0 & $0 \%$ & 0 & $0 \%$ & 4 & $100 \%$ \\
\hline Gorina & 3 & 0 & $0 \%$ & 0 & $0 \%$ & 3 & $100 \%$ \\
\hline City Bell & 7 & 0 & $0 \%$ & 0 & $0 \%$ & 7 & $100 \%$ \\
\hline Gonnet & 4 & 0 & $0 \%$ & 0 & $0 \%$ & 4 & $100 \%$ \\
\hline Villa Elisa & 4 & 0 & $0 \%$ & 0 & $0 \%$ & 4 & $100 \%$ \\
\hline Ringuelet & 4 & 1 & $25 \%$ & 0 & $0 \%$ & 3 & $75 \%$ \\
\hline Tolosa & 7 & 0 & $0 \%$ & 0 & $0 \%$ & 7 & $100 \%$ \\
\hline Hernández & 3 & 0 & $0 \%$ & 0 & $0 \%$ & 3 & $100 \%$ \\
\hline San Carlos & 12 & 0 & $0 \%$ & 0 & $0 \%$ & 12 & $100 \%$ \\
\hline TOTAL & 128 & 1 & $1 \%$ & 9 & $7 \%$ & 118 & $92 \%$ \\
\hline
\end{tabular}

Fuente. Elaboración propia, 2018.

En cuanto a la distribución territorial, como se puede observar en la Figura 38, la misma se presenta bastante uniforme, debido a que casi la totalidad de las urbanizaciones informales del Partido no cuentan con la cobertura de este servicio. Solo 9 de las 128 urbanizaciones informales cuentan con una cobertura parcial, como situaciones aisladas, en las localidades de Villa Elvira, Altos de San Lorenzo, Los Hornos y Romero, y solo una urbanización en Ringuelet cuenta con la cobertura total. Es posible identificar, en este sentido, que estas urbanizaciones se encuentran cercanas al casco urbano, por lo que la conexión con la red existente resulta más sencilla que las urbanizaciones que se encuentran más alejadas. 


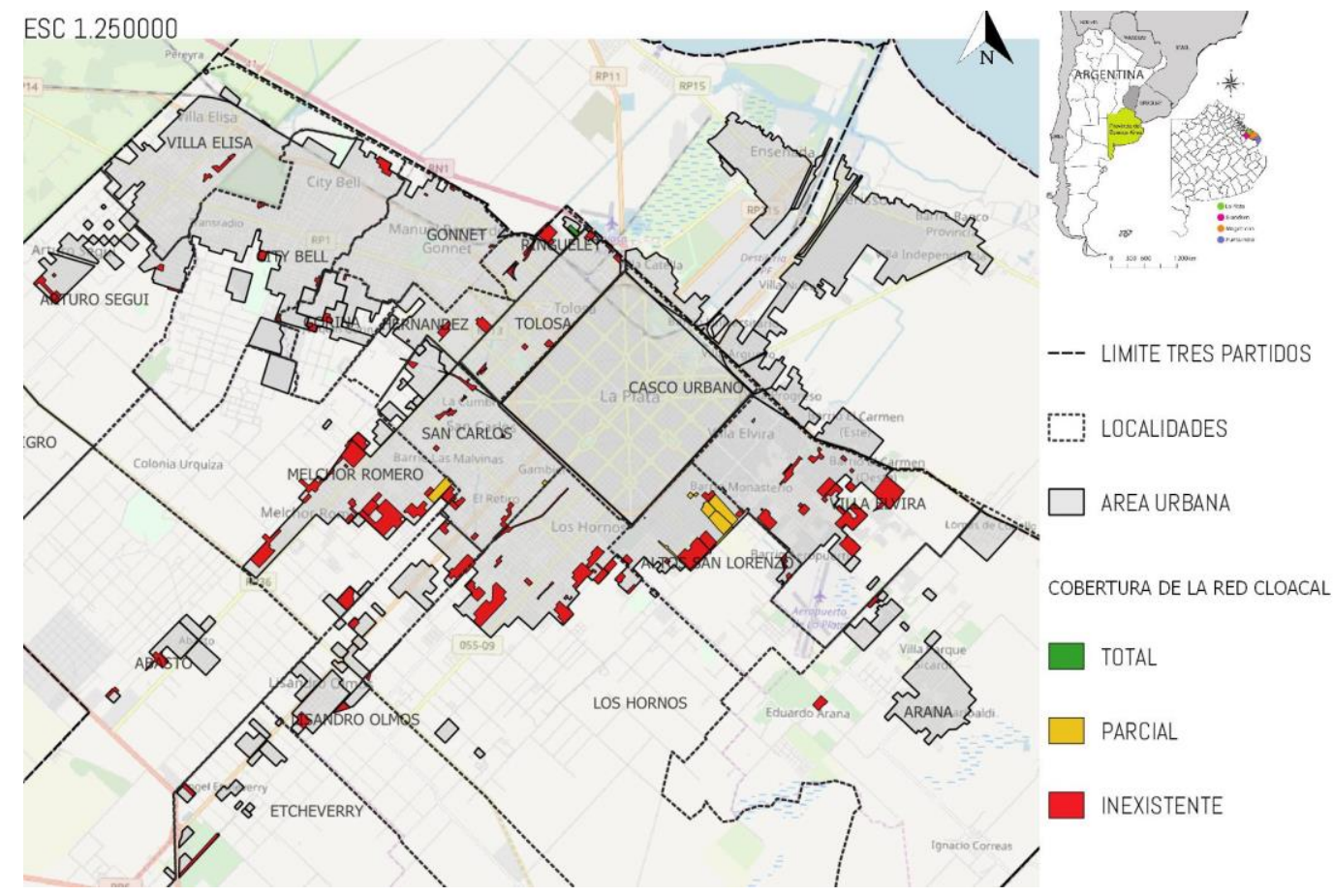

Figura 38. Acceso a la red cloacal.

Fuente. Elaboración propia, 2018. SIG.

Por último, dentro del análisis, cabe mencionar que la problemática de la falta de acceso a la red cloacal no se limita solamente a las urbanizaciones informales, de acuerdo con los datos del último Censo de Población y Vivienda (INDEC, 2010), casi la mitad de los hogares de la Argentina no cuenta con acceso a la red cloacal. Ese dato invita a la reflexión acerca de la gravedad de la situación que abarca a grandes sectores de la sociedad y no sólo los habitantes de villas y asentamientos informales. La falta de acceso a la red cloacal tiene que ver con los costos que implica para el Estado (o Empresa Privada, según el caso) de llevar este servicio a poblaciones dispersas y alejadas de los centros urbanos, resultando ser el más costoso de los servicios.

\subsubsection{Las condiciones de accesibilidad}

El artículo XIII de la Carta Mundial por el derecho a la Ciudad (2005) manifiesta: "Las ciudades deben garantizar a todas las personas el derecho de movilidad y circulación en la ciudad de acuerdo a un plan de desplazamiento urbano e interurbano y a través de un sistema de transportes públicos accesibles, a 
precio razonable y adecuados a las diferentes necesidades ambientales y sociales." Frente a esto, se propone, el análisis de la tercera variable dentro de la dimensión físico espacial, que corresponde con las condiciones de accesibilidad en urbanizaciones informales. Entendiendo que los modos de acceder la ciudad, se expresan en diferentes patrones de ocupación del territorio, y no es la misma situación para quien vive y trabaja en el casco urbano que para aquellos que se encuentran en zonas periféricas. Esta variable se vincula con la localización de las urbanizaciones informales, en relación a la cercanía con la estructura vial y las principales redes de comunicación de transporte público y privado. A partir del análisis resulta posible estimar el acceso a las funciones que se desarrollan en el casco urbano a través de las vías y avenidas principales que se comunican con la periferia.

El análisis de las condiciones de accesibilidad constituye una problemática a tener en cuenta para comprender las consecuencias negativas de la informalidad y la dispersión urbana en la periferia del Partido de La Plata. Esta situación, resultado de la expansión urbana desordenada, sumado a la gran concentración de actividades terciarias en el casco urbano, ha traído como consecuencia que gran cantidad de población deba transitar largas distancias para realizar sus actividades, al mismo tiempo que muchas áreas periféricas del Partido no cuentan con una buena cobertura de transporte público de pasajeros que facilite esta tarea. Al respecto, cabe señalar que la cobertura espacial del actual sistema de transporte público no es homogénea, es decir que la mayor cantidad de ramales converge hacia el centro del casco urbano, lugar donde se localiza la mayor parte de las principales actividades del Partido (administrativas, comerciales, de servicio, educativas, financieras, otras) y donde se encuentran las mayores densidades de población y, por ende, la mayor demanda de transporte público.

En este sentido, en el casco urbano se encuentra el sector donde se registran las frecuencias más altas del sistema, y se reconocen las mejores condiciones de accesibilidad y conectividad del Partido. Por lo tanto, muchas de las localidades 
de la periferia del Partido, presentan muy malas condiciones en cuanto a la accesibilidad, frecuencias y recorridos de transporte público (Figura 39). Sin embargo, hay que mencionar que no todas las periferias son iguales en este sentido, ni la falta de acceso al transporte público repercute de igual forma. Asimismo, cabe señalar que la población de las urbanizaciones informales adquiere patrones de movilidad diferentes a los del resto de la población. Muchos de ellos suelen recurrir al uso de vehículos como motocicletas, bicicletas o se movilizan a pie.

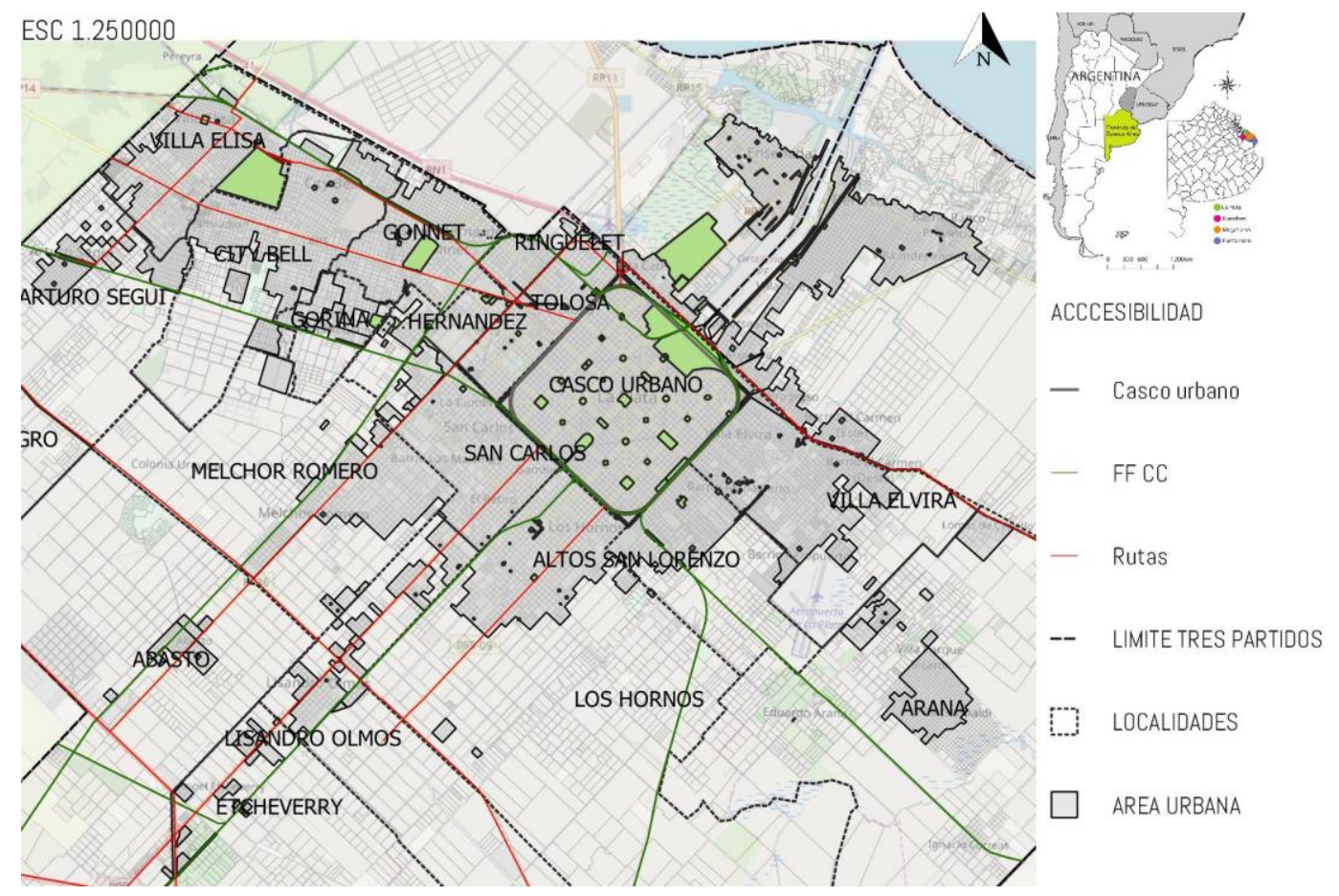

Figura 39. Jerarquización de vías y prinicpales conexiones en La Pata y su área periférica. Fuente. Elaboración propia,con herramienta SIG, 2019.

En la mayoría de las urbanizaciones informales, sus habitantes, a pesar de vivir en áreas periféricas, manifiestan realizar todo tipo de actividades diarias dentro del casco urbano como trabajar y llevar a los niños al colegio. Para realizar estas actividades, deben trasladarse todos los días en transporte público o particular, pero esta tarea se dificulta, dependiendo de varios factores, tales como la cercanía a las avenidas y calles principales de comunicación con el casco urbano, y un dato, que no es menor, que tiene que ver con la posibilidad de entrar y salir del barrio. 
Debido a cuestiones que tienen que ver con el estado de las calles se producen dificultades para entrar y salir del barrio. Un ejemplo de ello lo representa la situación en días de lluvia, donde se vuelve casi imposible la tarea de llegar a la parada del colectivo, ya que las calles son en su mayoría de tierra. Esto sumado al hecho de que, generalmente, el colectivo cuenta con pocas paradas, en su mayoría alejadas o en la entrada de los barrios, por lo que deben caminar varias cuadras para alcanzarlas.

La problemática del estado de las calles se agrava cuando resulta necesario el ingreso de servicios tales como ambulancias, recolección de basura, policía o autos de alquiler (taxis y remisses) por lo que muchas veces los vecinos se encuentran "varados" en diversas situaciones dentro del barrio. Sucede que al no encontrarse pavimentadas las calles, muchas veces estos servicios no llegan a cubrir la totalidad del barrio, por lo que, por ejemplo, con la recolección de residuos, se establecen contenedores comunitarios en puntos determinados, donde todo el barrio deposita su basura. Estos contenedores suelen encontrarse alejados de muchas de las viviendas, y el traslado de la basura a los mismos se convierte en una tarea pesada de llevar a diario, de modo que es muy común que por este motivo, se formen basurales a cielo abierto.

En cuanto a la distancia en kilómetros que se establece entre las urbanizaciones informales del Partido de La Plata y el casco urbano, el análisis refleja que, siguiendo la lógica de la necesidad, se sitúan los más cerca posible las y principales vías de acceso, y a una distancia media de aproximadamente $5 \mathrm{~km}$ al casco urbano fundacional. La urbanización informal más alejada encuentra a 15 km de distancia, en la localidad de Etcheverry, mientras que las más cercanas, lo hacen aproximadamente a menos de $1 \mathrm{~km}$ de distancia del casco urbano. En este sentido Marsili afirma que (...) la localización de las urbanizaciones informales, cercana a las vías principales de transporte y conexión, facilita a sus habitantes las posibilidades de acceder al trabajo diario, a centros educativos, de salud y demás. Sin bien las urbanizaciones informales en el Partido de La Plata se localizan en áreas periféricas, es posible reconocer un patrón de asentamiento y ocupación en 
cuanto a la ubicación sobre áreas próximas a las vías principales de acceso al casco urbano. Este patrón se hace visible a partir del primer anillo que rodea al casco urbano que cuenta con un área de buffer de $5 \mathrm{~km}$ y que contiene a la mayoría de las urbanizaciones informales del Partido (Figura 40).

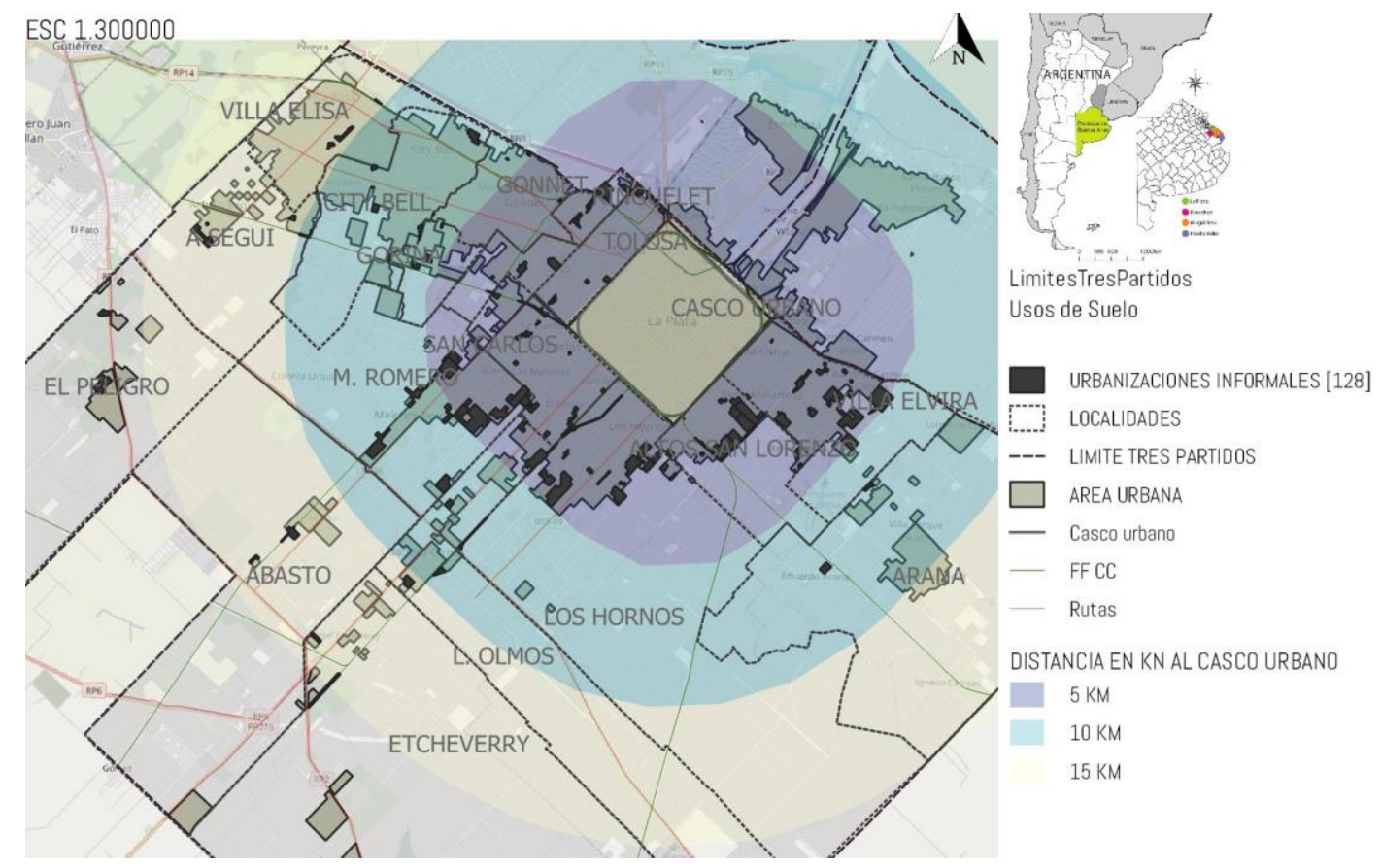

Figura 40. Urbanizaciones informales y acceso al casco urbano Partido de La Plata. Fuente. Elaboración propia, herramienta SIG, 2018.

Del análisis por tipología y el cruce con la localización en relación al casco urbano (Figura 41) es posible identificar que la mayoría de las urbanizaciones que corresponden a la tipología de asentamiento informal, si bien se localizan más alejadas en la periferia, se ubican con mayor cercanía a los accesos de las avenidas principales que se vinculan directamente con el área central dentro del primer y segundo anillo, encontrándose a no más de $10 \mathrm{~km}$ de distancia del casco urbano.

Cabe mencionar que muchas de las urbanizaciones informales más próximas al casco urbano se fueron expandiéndose a partir del trazado y extensión de las avenidas principales hacia la periferia. En este sentido, muchas de ellas suelen localizarse cercanas a avenidas principales como la avenida 44, la avenida 7 y las avenidas 60, 52 y 520, por destacar algunas de las principales vías de conexión. 
Esto representa, además, una forma de acceder rápidamente al transporte público, ya que muchas veces los colectivos no ingresan a los barrios debido al estado de las calles, como se ha mencionado anteriormente. Hacia la zona sur se concentra la mayor cantidad de urbanizaciones informales, esta tendencia indica la localización en inmediaciones a la Av. 90 entre 7 y Ruta 11, y vinculadas a los corredores viales de la Av. 520 y la Ruta 36.

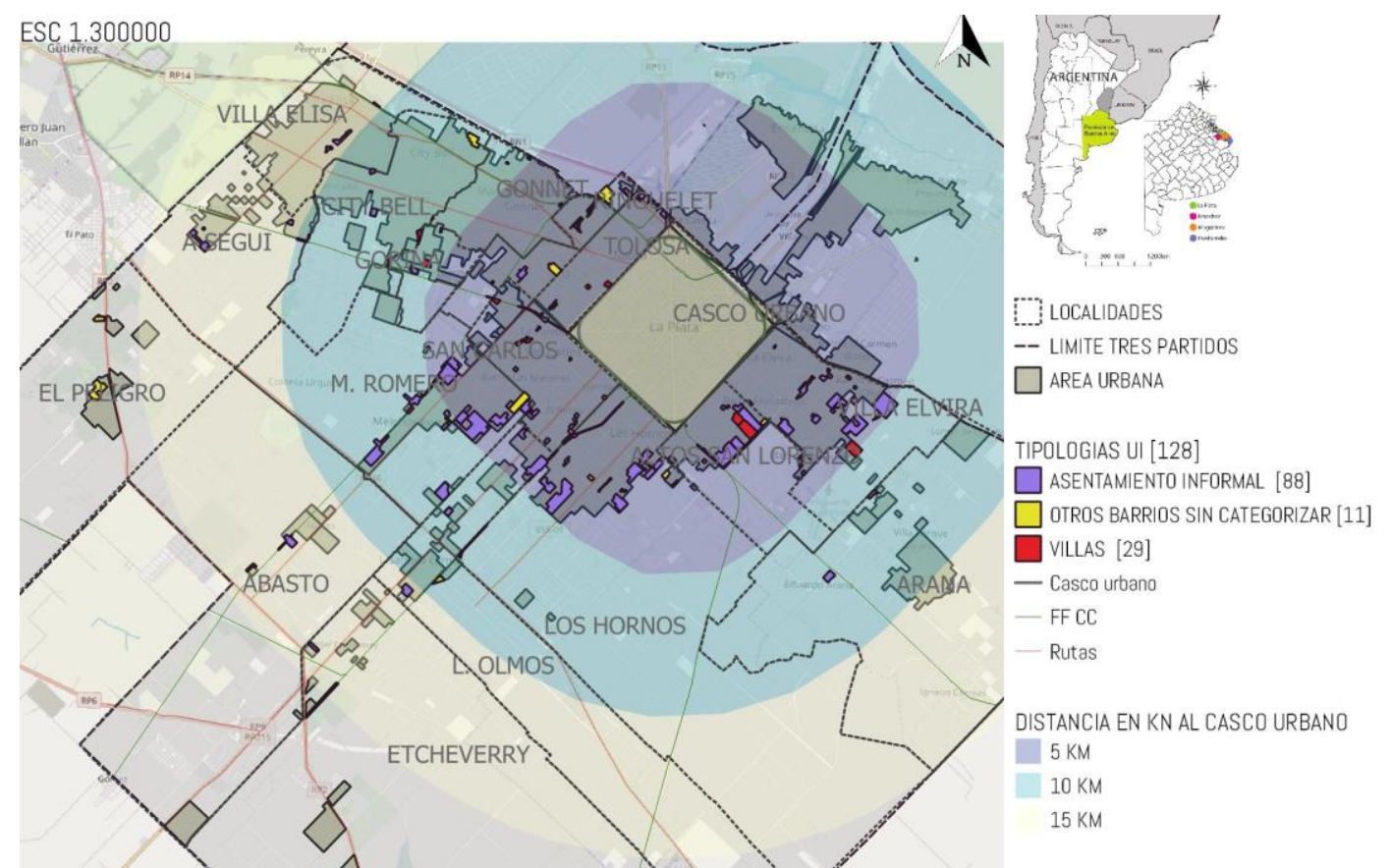

Figura 41. Tipologías de urbanizaciones informales y accesibilidad en el Partido de La Plata. Fuente. Elaboración propia, 2018.

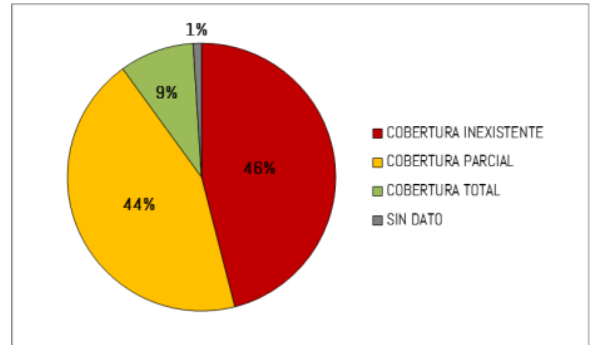

Gráfico 8. Pavimentación (\%).

Fuente. Elaboración propia, 2018
Otro indicador dentro del análisis de las condiciones de accesibilidad, tiene que ver con la situación y el estado de pavimentación de las calles. En este sentido, el análisis arroja que el $46 \%$ de las urbanizaciones informales del Partido no cuentan con ningún tipo pavimentación y el $44 \%$ cuenta con una cobertura parcial. Esto indica que solo algunas áreas de los barrios tienen sus calles pavimentadas y otras presentan algún tipo de mejora. Sólo el 9\% de las urbanizaciones informales cuentan con el 100\% de sus calles pavimentadas (Figura 42). 


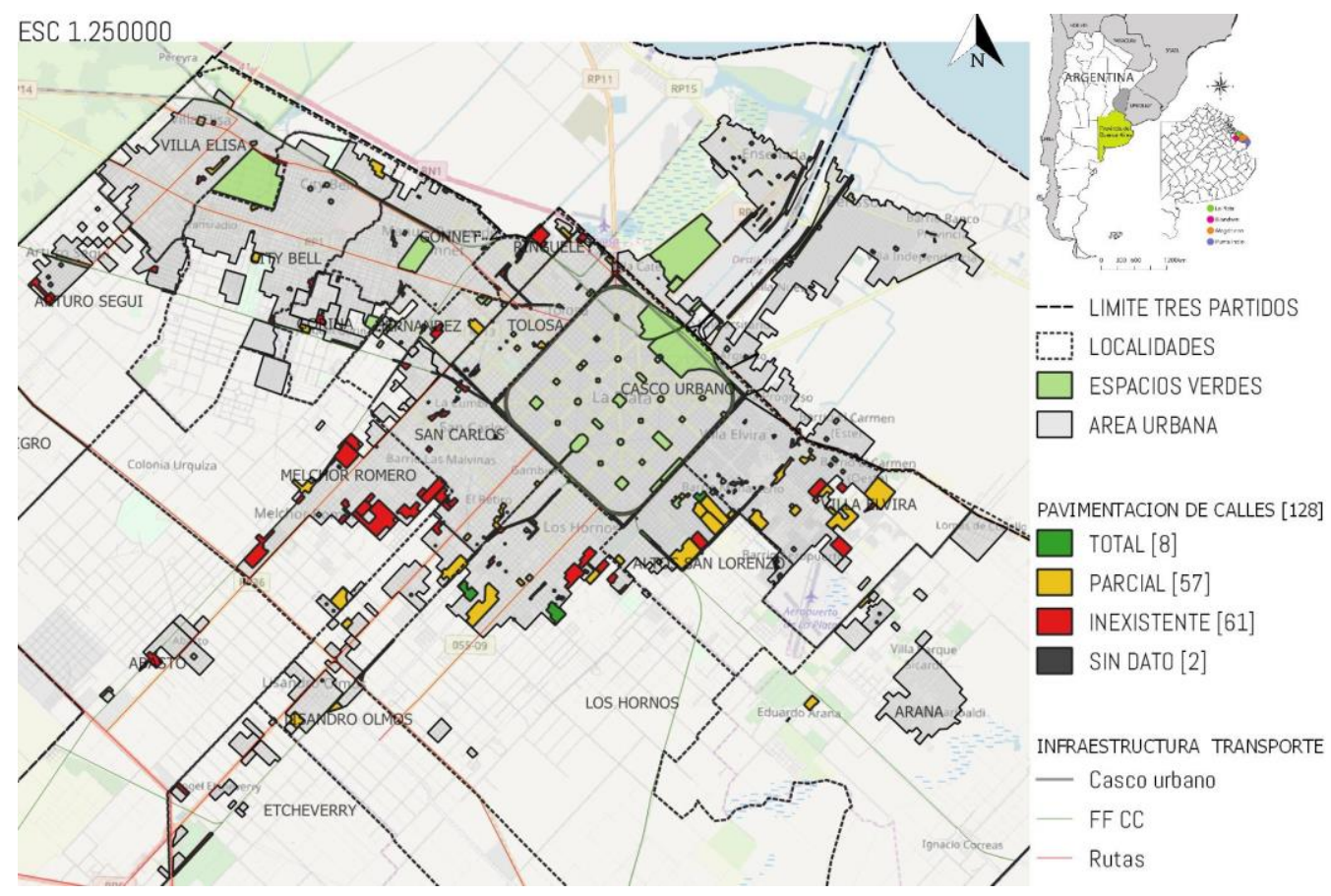

Figura 42. Pavimentación de calles en urbanizaciones informales del Partido de La Plata. Fuente. Elaboración propia, 2018. SIG.

Las situaciones de carencia en cuanto a la infraestructura urbana, acrecientan la segregación de tipo espacial y también la profundizan en el aspecto social, ya que los habitantes de las urbanizaciones informales ven vulnerados sus derechos, como ciudadanos de poder acceder a los servicios urbanos básicos que el Estado debería asegurar. Resulta necesario que el Estado asegure el acceso a una mejor calidad de vida para todos los habitantes de la ciudad y en especial para aquellos que no cuentan con los recursos suficientes.

\subsubsection{Las condiciones ambientales}

La última variable de análisis dentro de la dimensión físico-espacial tiene que ver con las condiciones ambientales en las urbanizaciones informales. Este análisis contempla las problemáticas ambientales a las que están expuestas las urbanizaciones informales, muchas veces producto de la localización sobre áreas no aptas para el asentamiento humano. Entender la ocupación del territorio también en relación a las condiciones ambientales aporta elementos para 
establecer ciertos patrones de ocupación propios de la informalidad urbana del Partido de La Plata.

En primer lugar, es preciso mencionar que el Partido de La Plata se encuentra asentado sobre una llanura aluvial, donde pueden diferenciarse dos zonas de topografías diferentes, denominadas llanura costera y llanura alta. La primera ocupa pequeños sectores en el límite con los partidos de Ensenada, Berisso y Magdalena, encontrándose en estas áreas las cotas más bajas. La segunda zona comprende casi la totalidad del Partido, destacándose un interfluvio principal, de relieve plano, que actúa como divisoria de aguas entre las dos vertientes principales, la del Río de la Plata hacia el norte, y el río Samborombón hacia el sur.

El Partido de La Plata se encuentra parcialmente localizado sobre las cuencas de los arroyos Pereyra y San Juan y totalmente sobre las cuencas de los arroyos Carnaval, Martín, Rodríguez, Don Carlos, del Gato, Pérez, Regimiento, Jardín Zoológico, Circunvalación, Maldonado, Garibaldi y El Pescado. Pueden destacarse dos cuencas principales en función de la cantidad de población que se asienta sobre las mismas: la cuenca del arroyo del Gato, y la cuenca del arroyo Maldonado. La cuenca del arroyo del Gato se caracteriza por ser una de las más extensas de la región y la más densamente poblada. En ella se concentra la mayoría de las actividades urbanas, industriales y fruti hortícolas, involucrando más de la mitad del casco fundacional de la ciudad y las localidades periféricas de Tolosa, Ringuelet, Hernández, Gonnet, San Carlos y Los Hornos (Figura 43).

Por su parte la cuenca del arroyo Maldonado se extiende hacia el sudeste del área urbana del Partido de La Plata y comprende, principalmente, las localidades de Altos de San Lorenzo y Villa Elvira, desaguando sus excedentes en los bañados localizados en el Partido lindante de Berisso. Las cuencas a su vez están integradas por gran cantidad de arroyos que recorren todo el Partido, algunos de los cuales se encuentran canalizados y subterráneos, y otros continúan a cielo abierto. Debido a ello, las tierras ubicadas sobre el cauce de los mismos se 
consideran terrenos inundables, y por su condición ambiental quedan vacantes siendo muchas veces ocupados de manera informal por grupos que responden a la lógica de la necesidad. Esta situación, genera riesgo hídrico, debido a que las tierras ubicadas sobre el cauce de los arroyos, principalmente, se consideran espacios susceptibles de ser afectados por precipitaciones y desbordes de estos cuerpos de agua. En el Partido de La Plata esto ha quedado demostrado en las inundaciones del 2002 y 2013.

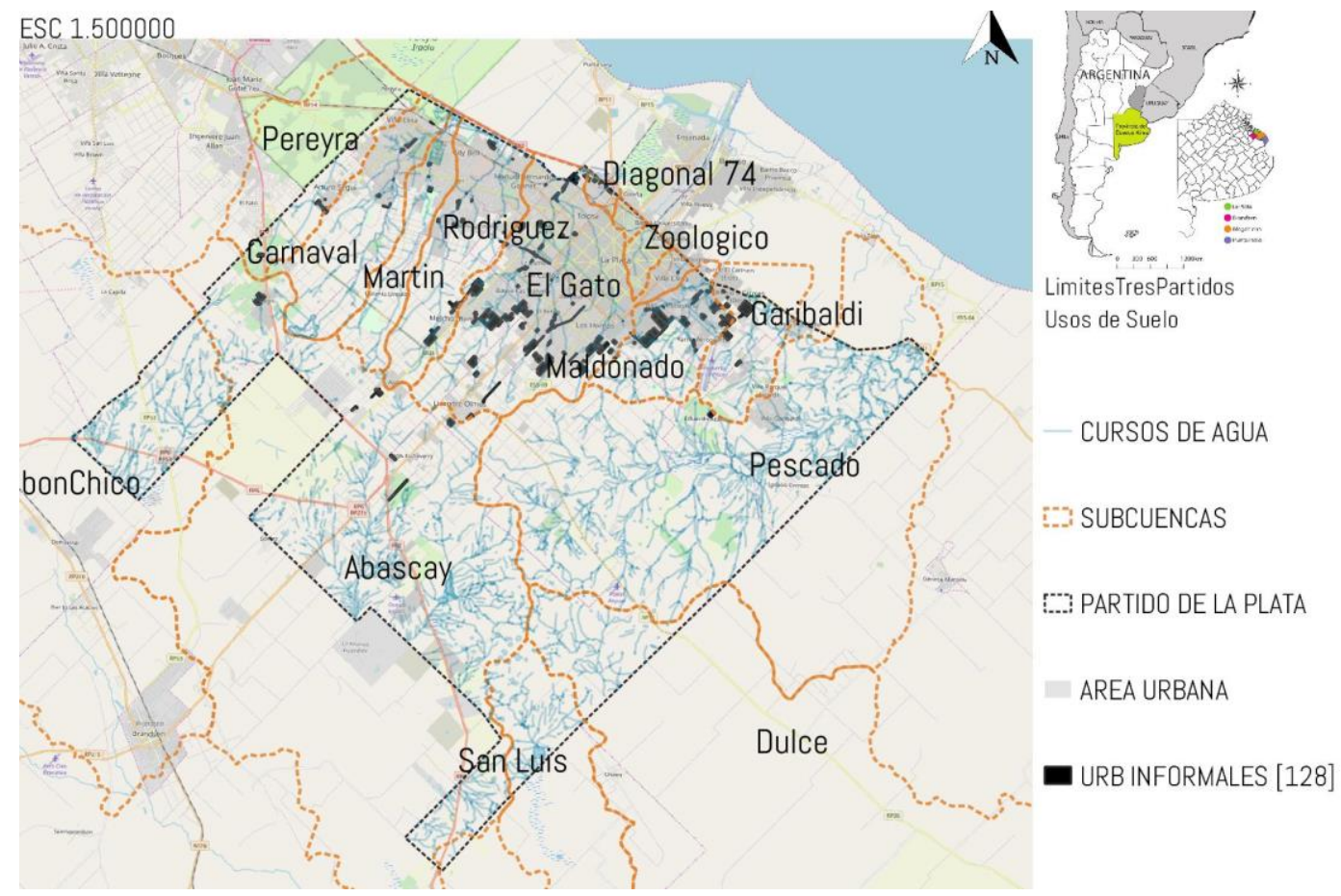

Figura 43. Cuencas y arroyos del Partido de La Plata, 2016.

Fuente. Elaboración propia con herramienta SIG a partir de datos de CISAUA 2016.

El Partido de La Plata concentra el 78\% de los asentamientos del AMBA, esto quiere decir 20.491 familias viviendo en situación de extrema precariedad y vulnerabilidad. En relación con la distribución de las urbanizaciones informales, las cuencas del Partido que mayor concentración presentan son; Pereyra, Carnaval, Martin Rodríguez, El Gato, Maldonado, Garibaldi, Pescado y Abascay, Circunvalación y Diagonal 74. De ellas Pereyra, Garibaldi y Abascay, son las que mayores superficies abarcan en el territorio, sin embargo, tienen muy poca población en comparación con otras. Las cuencas de los arroyos del Gato y 
Maldonado son las que mayor cantidad de urbanizaciones informales presentan, pudiéndose reconocer 60 dentro de la cuenca del arroyo del Gato (40\%) y 20 en la cuenca del arroyo Maldonado (20\%) (Tabla 15).

Tabla 15. Cuencas y urbanizaciones informales del Partido de La Plata.

\begin{tabular}{|l|c|c|c|c|}
\hline \multicolumn{2}{|c|}{ CUENCAS } & \multicolumn{3}{c|}{ URBANIZACIONES INFORMALES } \\
\hline NOMBRE & Sup. HA & Cant. UI & Sup. HA & Cant. familias \\
\hline Pereyra & $6.685,29$ & 3 & 21,08 & 299 \\
\hline Carnaval & $5.334,61$ & 7 & 16,8 & 431 \\
\hline Martin & $2.897,83$ & 3 & 8,2 & 245 \\
\hline Rodriguez & $5.411,49$ & 13 & 73,02 & 1508 \\
\hline El Gato & $10.712,27$ & 60 & 508,4 & 9797 \\
\hline Maldonado & 3.416 & 23 & 254,4 & 5934 \\
\hline Garibaldi & $36.14,92$ & 7 & 73,29 & 1098 \\
\hline Pescado & $36.267,68$ & 1 & 8,87 & 90 \\
\hline Abascay & $51.410,24$ & 6 & 63,04 & 771 \\
\hline Circunvalación & 486,8 & 1 & 0,56 & 30 \\
\hline Diag. 74 & 297,7 & 4 & 9,47 & 288 \\
\hline \multicolumn{1}{|c|}{ TOTAL } & $126.534,83$ & 128 & $1.037,06$ & 20491 \\
\hline
\end{tabular}

Fuente. Elaboración propia, con información CISAUA 2016 y RPPVAP, 2015.

Uno de los indicadores dentro del análisis de la variable ambiental tiene que ver la peligrosidad, enmarcada en el grado de vulnerabilidad que presenta el medio físico, respecto a la amenaza de la lluvia ${ }^{23}$. Este medio físico se define por el estudio integrado del clima de la región y los registros meteorológicos, vinculados con los mapas de Topografía, Hidrografía, Geomorfología y Suelos, donde se delimita el grado de anegabilidad de cada unidad geomórfica (CISAUA, 2016). Los niveles de peligrosidad se encuentran en relación con el riesgo hídrico, teniendo en cuenta las zonas inundables, y las que no tienen una infraestructura pluvial adecuada ni suficiente.

Una manera práctica y usual de representar grados de peligrosidad es a través del código del semáforo, rojo-máximo, naranja - mediano, amarillo - bajo y verde -

23 La vulnerabilidad es entendida como la predisposición o susceptibilidad que tiene una población de ser afectada. El riesgo, por su parte, se obtiene a partir de relacionar la amenaza, o probabilidad de ocurrencia de un fenómeno de una intensidad específica, con el grado de vulnerabilidad de la población expuesta. Por lo tanto, el carácter del riesgo puede variar dependiendo de la naturaleza de la amenaza a la cual está referido (Cardona 1993). 
mínimo (BID, 2010). De este modo, se indican como peligrosas las áreas que presentan suelos anegables, como los cauces de arroyos, las cañadas, las planicies naturales de inundación, las cubetas, los bañados, las lagunas o desde otro punto de vista, las áreas deprimidas por procesos de actividades extractivas de suelos. Para el análisis de esta variable, se superpusieron los niveles de peligrosidad con las urbanizaciones informales del Partido, obteniendo como resultado el mapa de la Figura 44, donde se pueden observar aquellas urbanizaciones informales que se encuentran en áreas de peligrosidad. A esta problemática se suma el estado de contaminación de los arroyos, con distintos tipos de basura. En este sentido, el análisis arroja que el $60 \%$ de las urbanizaciones informales del Partido se encuentran directamente atravesadas por arroyos o se localizan sobre las planicies de inundación.

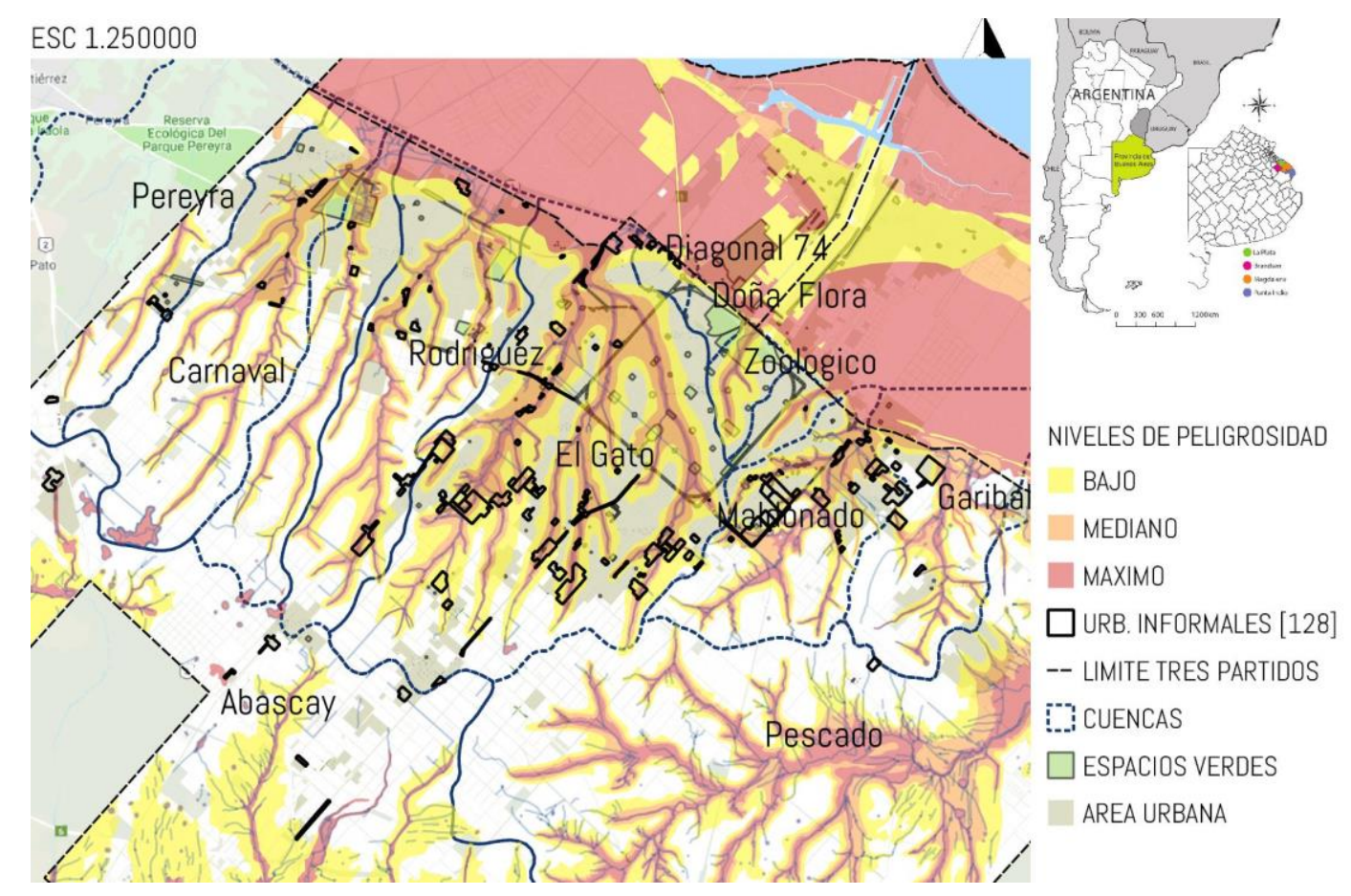

Figura 44. Niveles de peligrosidad hídrica en urbanizaciones informales Partido de La Plata. Fuente. Elaboración propia con herramienta SIG, 2018.

En la Figura 45 se observa el paso del arroyo Maldonado por detrás de viviendas muy precarias en la localidad de Villa Elvira. Esta imagen se repite en la mayoría de las urbanizaciones informales del Partido, constituyendo una problemática relevante dentro de la variable ambiental. 


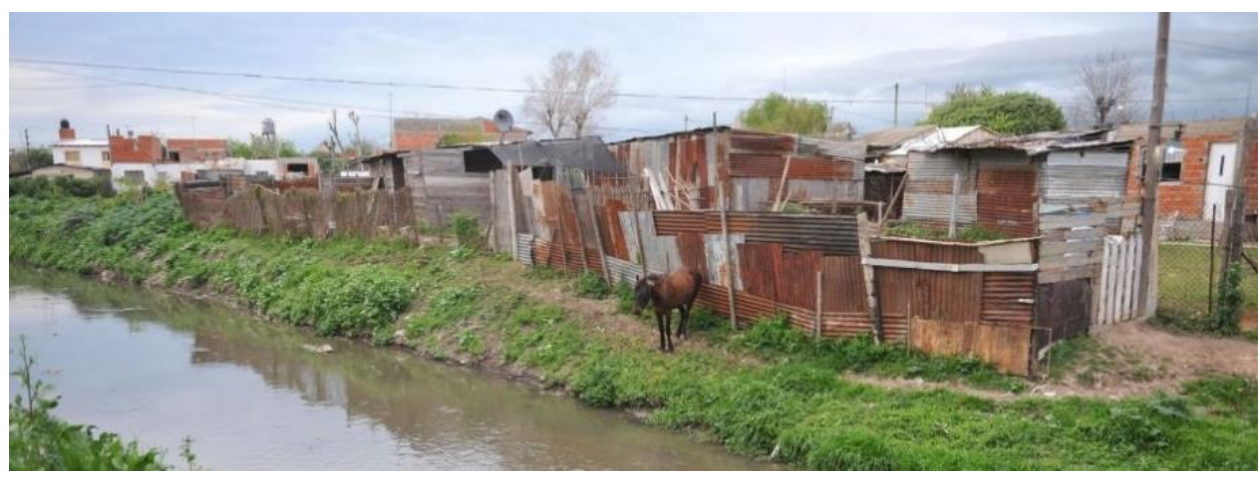

Figura 45. Asentamiento de Villa Elvira sobre el arroyo Maldonado.Fuente. https://www.0221.com.ar/nota/2018-6-6-16-58-0-denuncian-a-absa-por-tirar-liquidoscloacales-en-el-arroyo-maldonado-de-la-plata.

Otro aspecto que visibiliza la fragilidad ambiental de estas áreas, y que afecta a la población que vive en urbanizaciones informales es la presencia de basurales a cielo abierto, compuestos por distintos tipos de basura (orgánica, chatarra, etc.) y la quema periódica de basura, debido a la falta de recolección de la misma, generalmente por problemas relacionadas con acceso a los barrios como se ha mencionado en el análisis de las condiciones de accesibilidad (Figura 46).
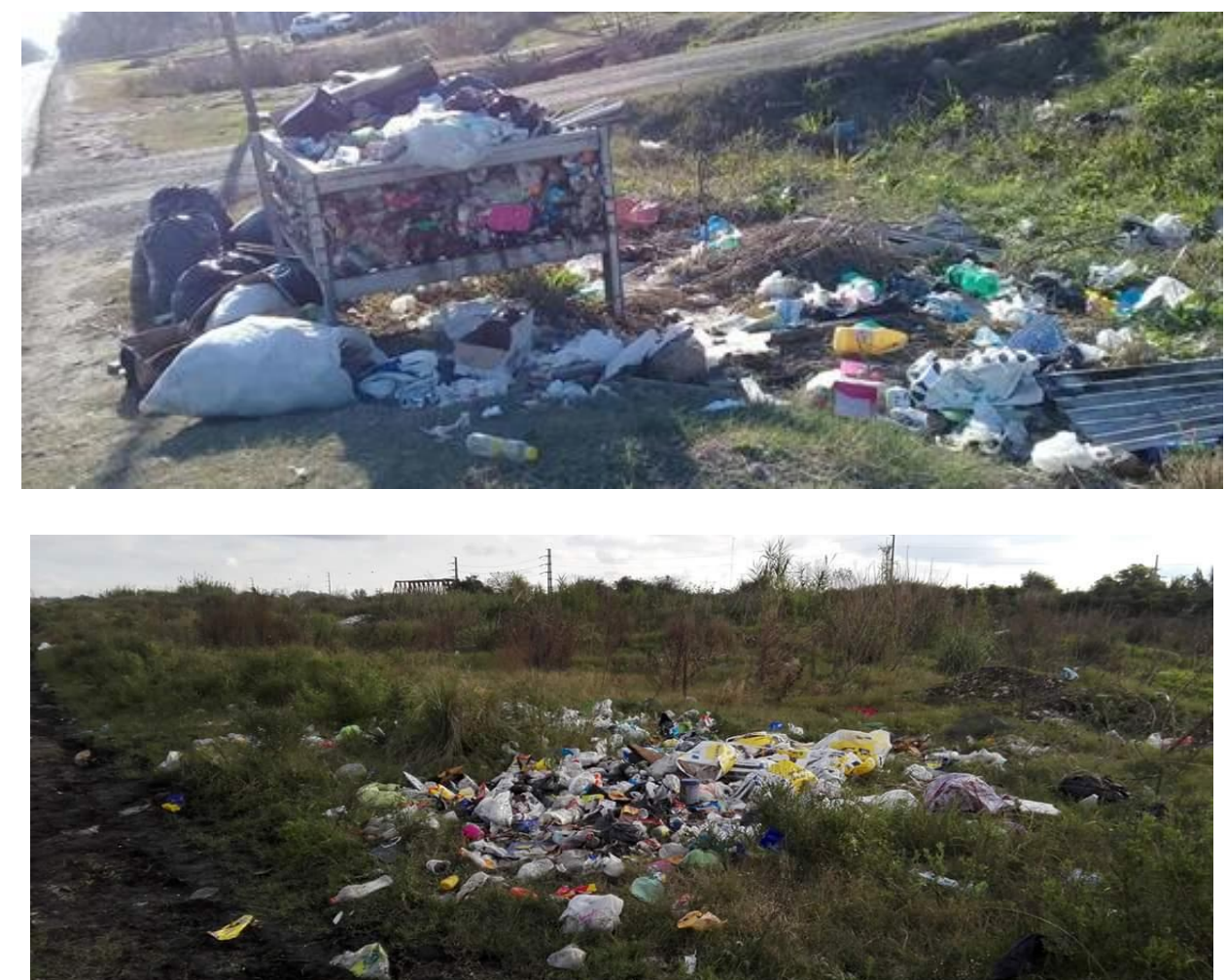

Figura 46. Basural a cielo abierto en la localidad de Altos de San Lorenzo y Los Hornos. Fuente. 2017 https://www.crespogaston.com.ar/basurales-en-la-plata/. 
La Figura 47 muestran los basurales del Partido y las urbanizaciones informales, poniéndose de manifiesto la cercanía que existe entre ellos. En este sentido, estudios como el realizado por Techo (2016), afirman que 7 de cada 10 urbanizaciones informales se encuentran a menos de 10 metros de un factor de riesgo. La necesidad de habitar se impone ante las mínimas condiciones, por lo que enfermedades como el asma, alergias, enfermedades infecciosas, mordedura de ratas y otros, son sólo algunas de las situaciones derivadas de la situación ambiental con las que conviven a diario los habitantes de urbanizaciones informales.

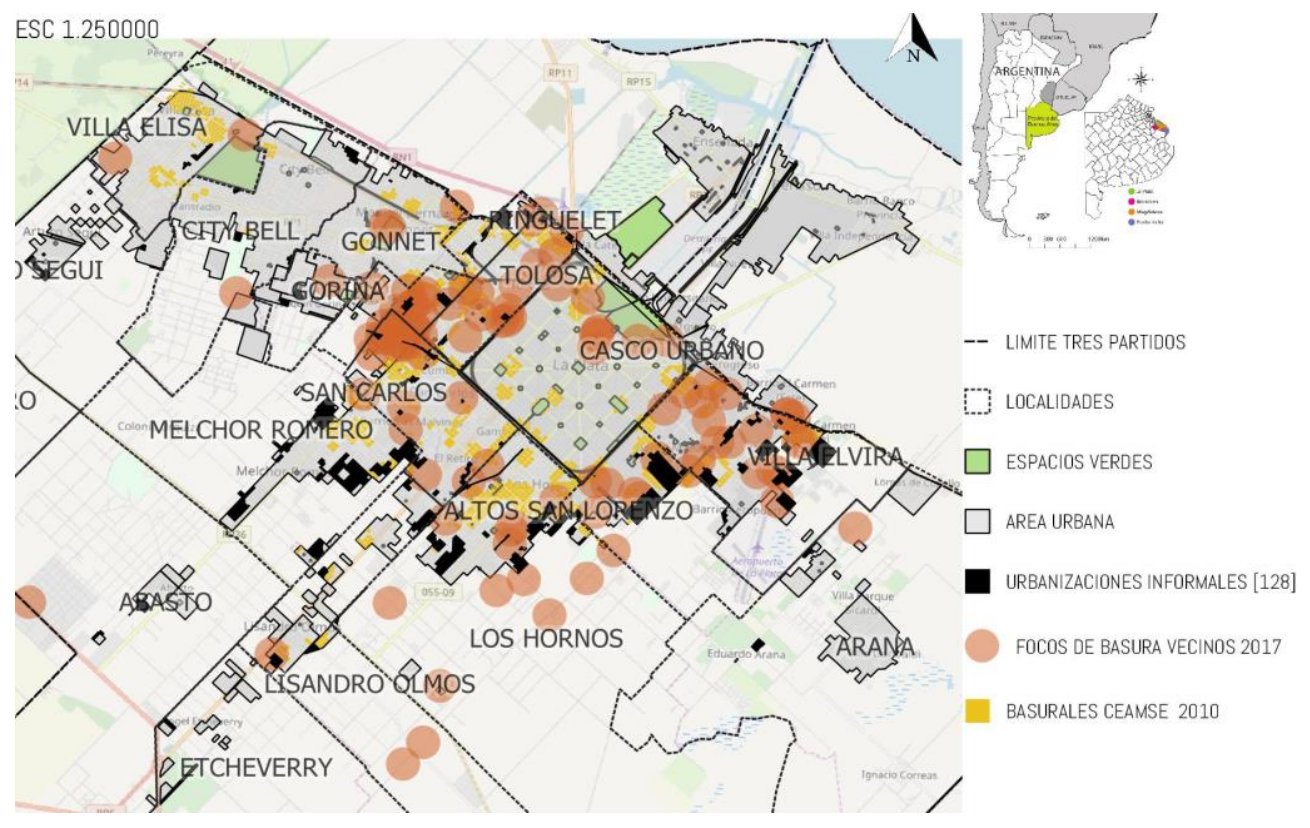

Figura 47. Basurales y focos de basura.

Fuente. Elaboración propia (2018) con información del CEAMSE, 2010.

La problemática de la basura se agrava debido a que el sistema de recolección de residuos, en la mayoría de los casos, funciona de manera insuficiente. La frecuencia de recolección es variable; en el 27,4\% de los asentamientos, el camión ingresa con una frecuencia de 5 o más días por semana; en el 29,2\% ingresa entre 2 o 4 veces por semana y el 5,3\% recibe el servicio una vez por semana o menos (Techo, 2016). Vale destacar que la falta de regularidad en la recolección de residuos tiene un efecto sanitario negativo, por ejemplo, es común que los perros rompan las bolsas de basura apiladas en las calles y pasillos, desperdigando desperdicios por el barrio, lo que contribuye a empeorar la situación de base. 
En los casos que no cuentan directamente con servicio de recolección de residuos los vecinos recurren a distintos métodos para deshacerse de la basura producida. Por ejemplo, resulta muy común recurrir a la quema de basura como la principal estrategia de eliminación. Esto afecta de manera negativa tanto a las personas que inhalan el humo, como al medio ambiente. Una de las estrategias más frecuentemente adoptadas, frente a la falta o mala recolección del servicio al interior de los barrios consiste en trasladar la basura fuera de los predios de la urbanización, esto obliga a los vecinos a caminar con la basura varias cuadras hasta un punto donde sí pase el camión recolector.

En síntesis, tanto la ausencia de recolección de residuos como su prestación irregular provocan y/o agravan las problemáticas ambientales y de salud que afectan a los habitantes de las urbanizaciones informales, por el hecho de habitar cercanos a basurales a cielo abierto. La acumulación de residuos domiciliarios en los contenedores ubicados en la vía pública o en basurales en formación, produce olores nauseabundos y favorece la transmisión de enfermedades tanto por el contacto directo con los residuos como por la vía indirecta a través de vectores o transmisores -mosquitos, roedores, moscas, etc. La gran cantidad de familias que recurren a la quema de basura obliga a alertar sobre los daños para la salud y el ambiente que esta práctica acarrea, debido al humo tóxico que se genera por la acumulación de productos que no son biodegradables.

El último indicador a analizar dentro de la situación ambiental, tiene que ver con la presencia de cavas, siendo que estos espacios causan un grave deterioro del ambiente y constituyen áreas de riesgo si se encuentran en cercanía a la urbanización. En la Figura 48 se observa la distribución territorial de las urbanizaciones informales del Partido en relación a la localización de las cavas consideradas de máximo impacto ambiental. Estos pasivos ambientales suelen convertirse en vaciaderos clandestinos de residuos que pueden afectar las aguas subterráneas. Del mismo modo, las cavas y canteras inundadas situadas cerca de zonas urbanizadas se convierten en lugares peligrosos también por la posibilidad de derrumbe y riesgo de accidentes. 


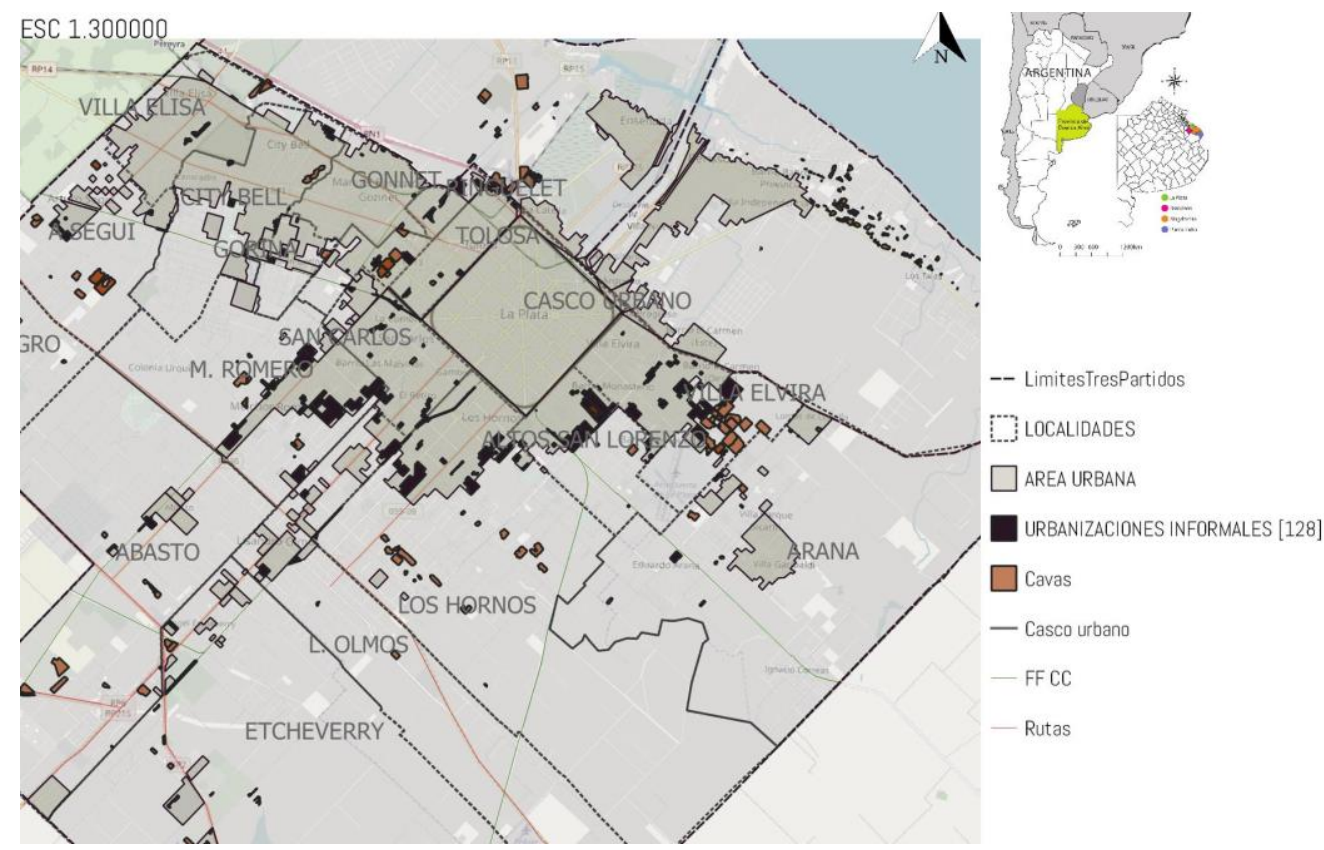

Figura 48. Cavas y urbanizaciones informales en el Partido de La Plata.

Fuente. Elaboración propia, con herramienta SIG, 2018 con datos de CISAUA 2016.

Estas situaciones se pueden observar con mayor profundidad en tres ejemplos, uno en la localidad de Altos de San Lorenzo, en el barrio "La Cava" y dos urbanizaciones en la localidad de Hernández, los barrios "Nini" y "Mercosur" (Figura 49).
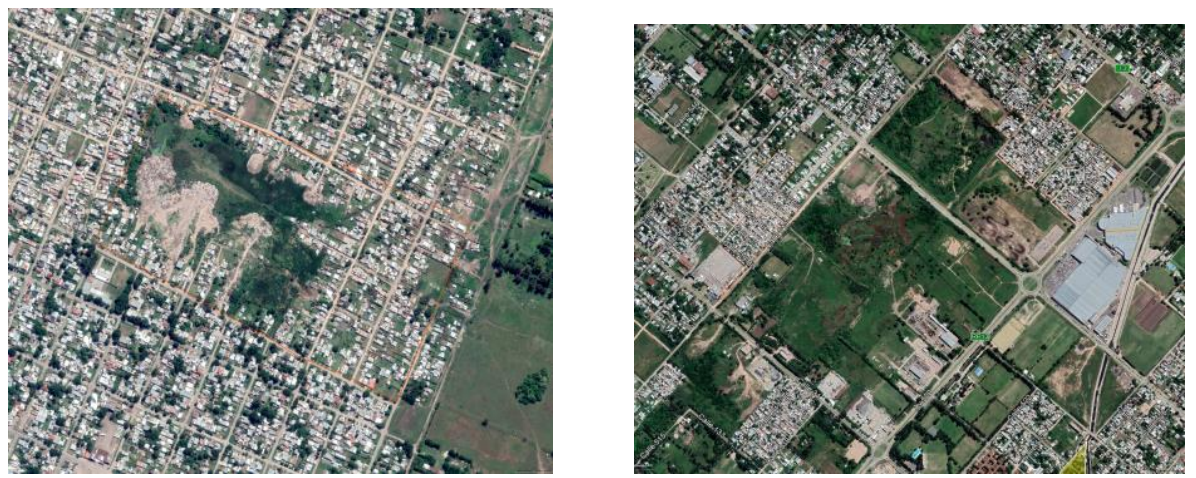

Figura 49. Urbanizaciones informales cercanas a cavas y canteras en el Partido. Fuente. Elaboración propia, 2019 Google Earth.

Los factores analizados dentro de la dimensión físico espacial, en conjunto, generan situaciones de riesgo y vulnerabilidad en detrimento de la salud de los habitantes de las urbanizaciones informales, por el hecho de constituir áreas con altos grados de contaminación del aire, agua y suelo. A modo de síntesis, el 
análisis de la dimensión físico espacial arroja que, ya sea por la falta de acceso a los servicios urbanos básicos, a las vías principales de conexión con el centro urbano (y las actividades) de la ciudad y la situación y estado de las calles, los habitantes de las urbanizaciones informales en el Partido de La Plata, encuentran graves problemas que desmejoran su calidad de vida.

En este sentido, el funcionamiento de los mercados formal e informal y las políticas del Estado conllevan a una segregación espacial cada vez más acentuada, de modo que la localización de las urbanizaciones informales en la periferia termina acrecentando los problemas urbanos y ambientales ya mencionados. Es posible determinar que ante esta situación de base la población con escasos recursos persigue un cierto patrón de ocupación sobre las tierras en desuso, que en algunos casos carecen de valor en el mercado formal y tal como arroja el análisis, las mismas, presentan severas restricciones tanto desde el punto de vista del medio natural como del antropizado, conllevando riesgos son muy altos. Del análisis se desprende también, que las situaciones más graves se dan, en general, por la localización de la población sobre áreas de riesgo de diferentes tipos, siendo el que más prevalece en el caso del Partido de La Plata, el de inundación.

Los patrones de ocupación informal identificados en el territorio se caracterizan, en líneas generales, por presentar una localización sobre suelos no aptos para el desarrollo residencial, sin acceso a los servicios urbanos básicos, a la vera de arroyos, cercanos o sobre cavas, canteras y áreas inundables. Finalmente cabe mencionar que muchas veces las variables analizadas, en las urbanizaciones informales, se dan en combinación aumentando el nivel de segregación socio territorial y la vulnerabilidad de los habitantes.

\subsection{Dimensión social demográfica}

La última dimensión dentro del análisis de la ocupación territorial en la meso escala es la social demográfica, y tiene que ver con las cuestiones que hacen a las características de la población de las urbanizaciones informales. En apartados anteriores se analizaron cuestiones que tienen que ver con el contexto y el 
soporte físico, como los servicios urbanos, la accesibilidad y las condiciones ambientales. En esta dimensión se pone especial énfasis en la cuestión social, que es la que atraviesa las demás dimensiones, en relación con la población (cantidad de familias) que habitan dentro de las urbanizaciones informales en el Partido de La Plata y sus características.

En principio, resulta necesario hacer referencia a la cantidad de población y qué características presenta, en las urbanizaciones informales del Partido de La Plata. Para ello, en este apartado se establece como variable de análisis el tamaño de la urbanización informal, a partir del indicador de la cantidad de familias que habita en cada una de ellas. Metodológicamente se clasificó la totalidad de las urbanizaciones informales del Partido de La Plata en tres grupos: el primer grupo concentra las urbanizaciones informales que se denominan pequeñas, y son aquellas que contienen entre un mínimo de 8 y un máximo de 100 familias; el segundo grupo incluye las urbanizaciones informales medianas, que contienen entre un mínimo de 100 y un máximo de 500 familias y por último, las urbanizaciones grandes que tienen una cantidad de habitantes que supera las 500 familias (Tabla 16).

Esta clasificación se basa en el estudio realizado por Techo para todo el país, en donde se contemplaron otros rangos debido al alcance a nivel nacional de los datos. Si bien para esta tesis se aplicó parte de la metodología, se ajustaron los rangos establecidos según las particularidades del Partido de La Plata. Estas categorías fueron definidas de acuerdo a los datos del Registro Público de Villas y Asentamientos Precarios del año 2015, que contempla a la cantidad de familias como único dato oficial de población. Cabe mencionar que por familia se entiende a un núcleo mínimo de 4 personas según lo establecido por el Instituto Nacional de Estadísticas y Censos (INDEC, 2010). Sin embargo, resulta muy común que en este tipo de urbanizaciones las familias sean más numerosas, compuestas por $4 \mathrm{y}$ 6 integrantes. Es muy común que, en situaciones de informalidad urbana, en una vivienda habite más de una familia, por lo que la cantidad de familias no puede establecerse en relación a la cantidad de viviendas. Si bien puede analizarse la 
cantidad de viviendas, no puede estimarse que al interior habiten un núcleo 4 personas como establece la definición.

Tabla 16. Tamaño de las urbanizaciones informales en el Partido de La Plata.

\begin{tabular}{|l|c|}
\hline \multicolumn{1}{|c|}{ CLASIFICACION } & CANTIDAD DE FAMILIAS \\
\hline Urbanizaciones informales pequeñas & Entre 8 y 100 familias \\
\hline Urbanizaciones informales medianas & Entre 100 y 500 familias \\
\hline Urbanizaciones grandes & Más de 500 familias \\
\hline
\end{tabular}

Fuente. Elaboración propia, 2019.

Es preciso mencionar la relación entre el tamaño de la urbanización informal y las características del mismo, ya que, mientras que las urbanizaciones más pequeñas pueden llegar ocupar una superficie menor que la de una manzana, las más grandes llegan a ser pequeñas ciudades en sí mismas, debido a su gran tamaño y densidad poblacional (Techo, 2016). En algunos casos, sobre todo dentro de la tipología de villas, debido a la poca regularidad en el trazado, cuando la cantidad de población comienza a superar y a expandirse de los límites de la ocupación original, muchas veces los barrios se densifican, añadiendo dos y tres niveles de altura en las viviendas.

Otra cuestión a tener a tener en cuenta, dentro de la dimensión demográfica y en cuanto a la dinámica social, es la organización vecinal. Mientras que en los barrios más pequeños se da una participación más directa, donde prácticamente todo el barrio se moviliza en conjunto, en los más numerosos la organización suele darse a través de referentes y existe la conjunción de varias organizaciones sociales trabajando al mismo tiempo. El análisis del tamaño de las urbanizaciones en relación a la cantidad de familias arrojó que más de la mitad de las urbanizaciones informales del Partido de La Plata son pequeñas (56\%), algo más de un tercio de las urbanizaciones informales se clasifican como medianas (37\%) y poco más de la décima parte de se pueden considerar grandes (7\%) con más de 500 familias (Tabla 17). 
Tabla 17. Tamaño de las urbanizaciones informales en el Partido de La Plata.

\begin{tabular}{|l|c|c|c|c|c|c|c|}
\hline & $\begin{array}{c}\text { TOTAL } \\
\text { Urb. } \\
\text { LOCALIIDAD }\end{array}$ & \multicolumn{2}{c|}{$\begin{array}{c}\text { PEQUENA } \\
\text { informas }\end{array}$} & \multicolumn{2}{c|}{$\begin{array}{c}\text { MEDIANA } \\
(100-500 \text { familias })\end{array}$} & \multicolumn{2}{c|}{$\begin{array}{c}\text { GRANDE } \\
\text { (+ de 500 familias) }\end{array}$} \\
\hline Villa Elvira & 17 & 9 & $53 \%$ & 5 & $29 \%$ & 3 & $18 \%$ \\
\hline Altos de San Lorenzo & 15 & 7 & $47 \%$ & 6 & $40 \%$ & 2 & $13 \%$ \\
\hline Arana & 2 & 2 & $100 \%$ & 0 & $0 \%$ & 0 & $0 \%$ \\
\hline Los Hornos & 16 & 9 & $56 \%$ & 6 & $38 \%$ & 1 & $6 \%$ \\
\hline Olmos & 5 & 5 & $100 \%$ & 0 & $0 \%$ & 0 & $0 \%$ \\
\hline Etcheverry & 2 & 1 & $50 \%$ & 1 & $50 \%$ & 0 & $0 \%$ \\
\hline Abasto & 2 & 1 & $50 \%$ & 1 & $50 \%$ & 0 & $0 \%$ \\
\hline El Peligro & 2 & 1 & $50 \%$ & 1 & $50 \%$ & 0 & $0 \%$ \\
\hline Melchor Romero & 19 & 10 & $53 \%$ & 6 & $32 \%$ & 3 & $16 \%$ \\
\hline Arturo Seguín & 4 & 3 & $75 \%$ & 1 & $25 \%$ & 0 & $0 \%$ \\
\hline Gorina & 3 & 1 & $33 \%$ & 2 & $67 \%$ & 0 & $0 \%$ \\
\hline City Bell & 7 & 3 & $43 \%$ & 4 & $57 \%$ & 0 & $0 \%$ \\
\hline Gonnet & 4 & 4 & $100 \%$ & 0 & $0 \%$ & 0 & $0 \%$ \\
\hline Villa Elisa & 4 & 3 & $75 \%$ & 1 & $25 \%$ & 0 & $0 \%$ \\
\hline Ringuelet & 4 & 1 & $25 \%$ & 3 & $75 \%$ & 0 & $0 \%$ \\
\hline Tolosa & 7 & 3 & $43 \%$ & 4 & $57 \%$ & 0 & $0 \%$ \\
\hline Hernández & 3 & 1 & $33 \%$ & 2 & $67 \%$ & 0 & $0 \%$ \\
\hline San Carlos & 12 & 8 & $67 \%$ & 4 & $33 \%$ & 0 & $0 \%$ \\
\hline TOTAL & 128 & 72 & $56 \%$ & 47 & $37 \%$ & 9 & $7 \%$ \\
\hline
\end{tabular}

Fuente. Elaboración propia, 2018 con datos del RPPVAP (2015).

En relación a la localización y la distribución en el territorio, el análisis arrojó que las urbanizaciones más grandes se ubican principalmente en localidades como Altos de San Lorenzo, Los Hornos, Villa Elvira y Melchor Romero hacia el sureste y suroeste. Por su parte, las urbanizaciones medianas, se pueden encontrar de manera más habitual repartidas en casi todas las localidades del Partido presentando una distribución territorial más homogénea, por lo que la mayor cantidad de urbanizaciones informales del Partido corresponden a la categoría de pequeña y mediana. $\mathrm{Si}$ bien las urbanizaciones pequeñas representan más del 56\% del total, en ellas habita menos del 10\% del total de las familias. Por su parte, los asentamientos grandes, que representan solamente un $7 \%$ del total, suman entre ellos más de un cuarto de la cantidad total de familias (Figura 50). 


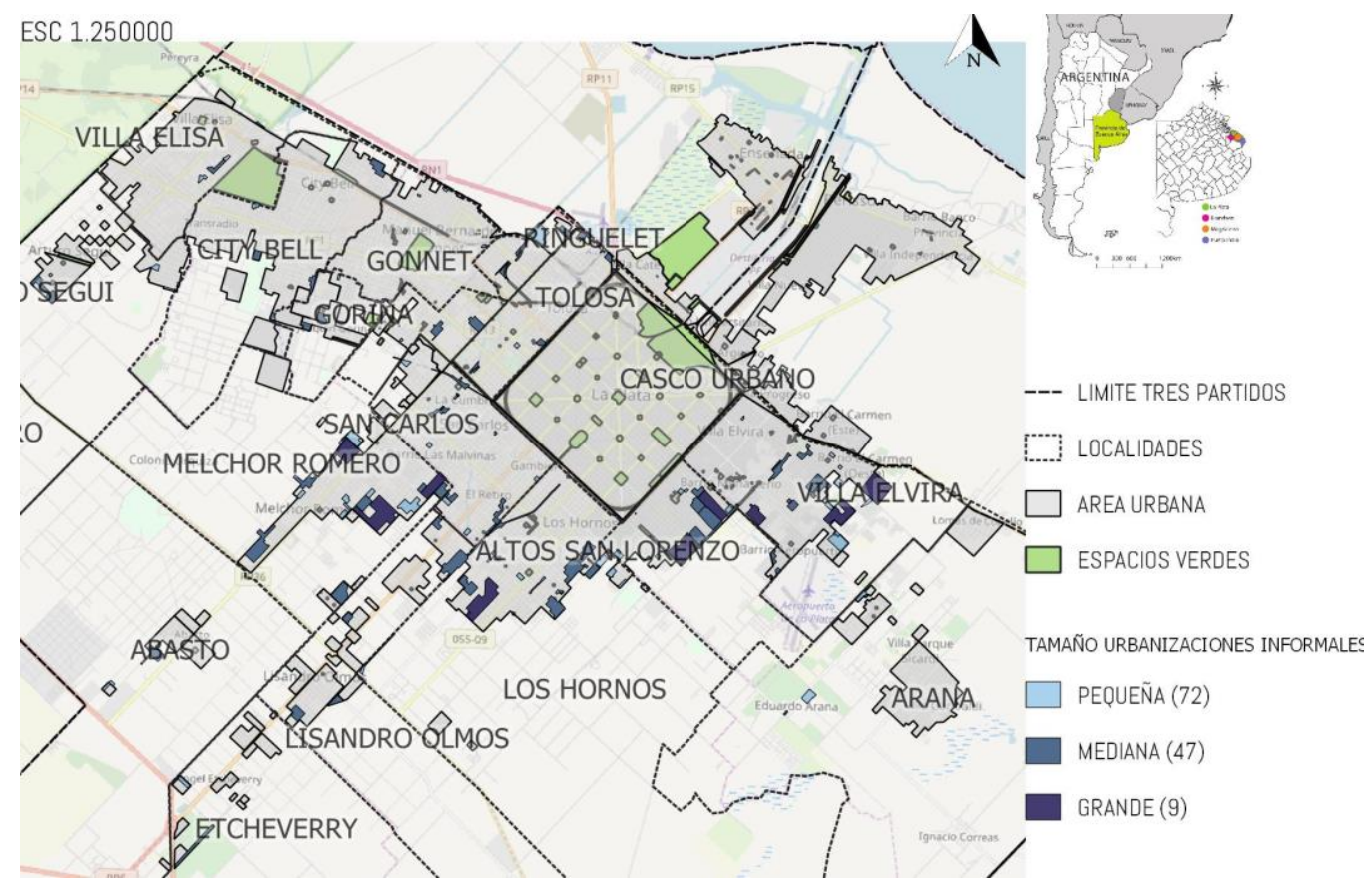

Figura 50. Tamaño urbanizacion informales según cantidad de familias. Fuente. Elaboración propia, con herramienta SIG 2018.

Gráfico 9. Tamaño urbanizaciones informales.

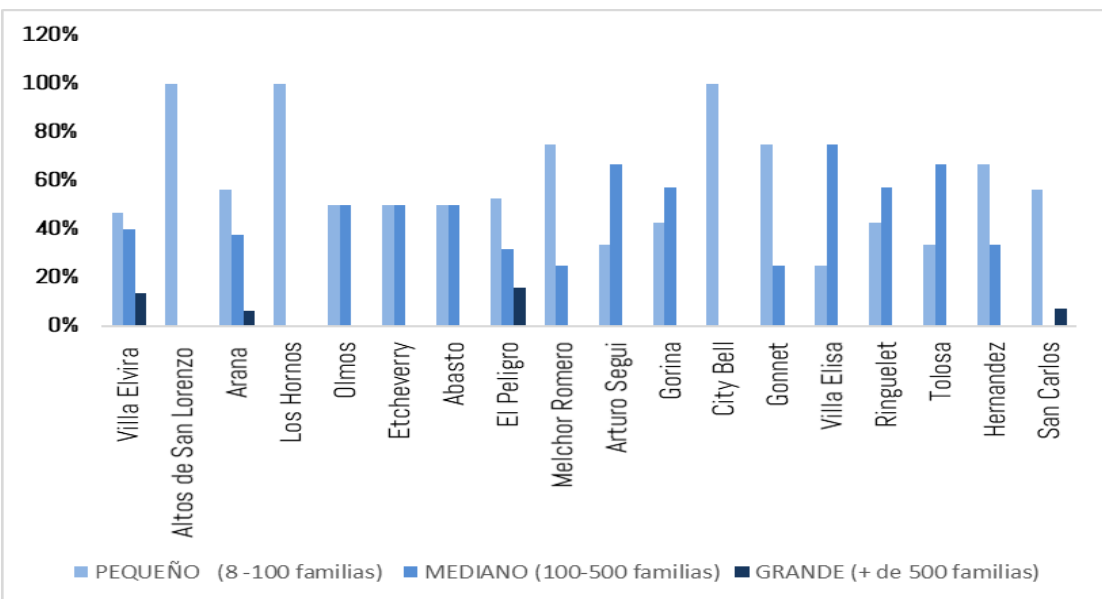

Fuente. Elaboración propia, 2019.

Otro aspecto acerca de la población que habita en las urbanizaciones informales que resulta importante conocer en el análisis de la dimensión demográfica, tiene que ver con el índice de NBI ${ }^{24}$ (Necesidades Básicas

${ }^{24}$ El concepto de necesidades básicas insatisfechas (NBI) permite la delimitación de grupos de pobreza estructural y representa una alternativa a la identificación de la pobreza considerada 
Insatisfechas). Si bien este dato fue relevado por el censo Nacional de Hogares y Viviendas del año 2010, el mismo indica que las localidades que coinciden con los radios censales con mayores índices de hogares con NBI, son aquellas que contienen mayor cantidad de urbanizaciones informales, como por ejemplo el caso de Altos de San Lorenzo, Romero o Villa Elvira, mientras que localidades como City Bell y Villa Elisa, solo presentan niveles altos de NBI en las zonas aisladas, donde se pueden encontrar urbanizaciones informales (Figura 51).

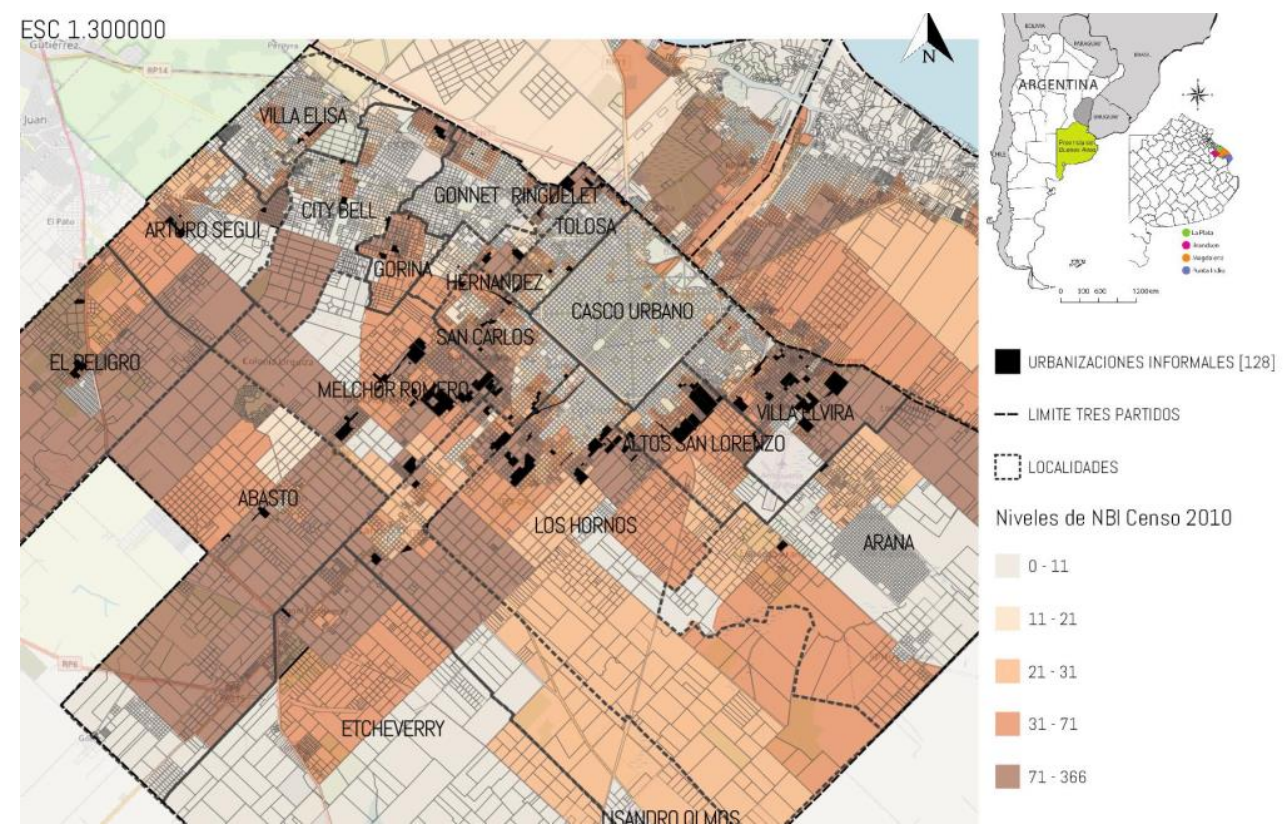

Figura 51. Índice NBI en el Partido de La Plata y urbanizaciones informales. Fuente. Elaboración propia en base a datos del INDEC 2010.

El crecimiento de la informalidad urbana en el Partido de La Plata se convierte en una problemática relevante cuando los datos analizados en la dimensión temporal arrojan que la cantidad de familias viviendo en condiciones de informalidad sufrió un aumento del 722\% entre la década de 1990 y el año 2015, marcando una tendencia de crecimiento hacia el futuro muy poco alentadora (Tabla 18).

únicamente como insuficiencia de ingresos. Por medio de este abordaje se identifican dimensiones de privación absoluta y se enfoca la pobreza como el resultado de un cúmulo de privaciones materiales esenciales. Fuente. Instituto Nacional de Estadística y Censos INDEC. 
Tabla 18. Cantidad de Familias por período

\begin{tabular}{|c|c|c|c|}
\hline PERIODO & CANTIDAD DE FAMILIAS & CANTIDAD DE UI & VARIACION \\
\hline HASTA 1990 & 2493 & 19 & $47 \%$ \\
\hline HASTA 2001 & 13645 & 75 & $50 \%$ \\
\hline HASTA 2015 & 20481 & 128 & $722 \%$ \\
\hline
\end{tabular}

Fuente. Elaboración propia, 2018.

Este dato no resulta menor ni aislado, sino que se representa la gravedad que la problemática de la informalidad urbana supone. La gran cantidad de familias y las condiciones a las que se encuentran sometidas, es el principal indicador que demuestra que esta es una problemática urgente a resolver. El incremento de población en el análisis de la variación intercensal 1990-2015 indica que, si se mantienen las mismas condiciones contextuales, la tendencia continuará en aumento para los próximos años.

A modo se síntesis de este capítulo, el análisis de la dimensión temporal refuerza la idea que los sucesos históricos y contextuales han contribuido en la generación de ciertos patrones de ocupación del área periférica, donde las urbanizaciones informales han ido tomando terrenos vacantes, primero en áreas cercanas al casco urbano y luego expandiéndose hacia las zonas sur, sureste y suroeste del Partido de La Plata. Dentro de la dimensión espacial, también fue posible identificar ciertos patrones comunes en cuanto a la ocupación que pueden definirse a través de falta de acceso a los servicios básicos. Del análisis se desprende que casi el 100\% de las urbanizaciones informales del Partido se encuentran dentro del nivel 1 o 2 de abastecimiento de servicios urbanos básicos, lo que quiere decir que no tienen un adecuado acceso a los mismos, y que la localización, así como la irregularidad en la urbanización también contribuye a esta situación. Las condiciones ambientales, por su parte reflejan que la ocupación se lleva adelante en terrenos degradados y frágiles ambientalmente, cerca de cursos de agua y en constante riesgo de inundación, con presencia de basurales y cercanos a cavas y canteras. En este sentido también se pone de manifiesto un patrón que se replica entre las urbanizaciones informales del Partido. 
Las condiciones de accesibilidad indicaron que la ocupación se produce principalmente en cercanías a vías principales de conexión, por donde transita el transporte público, necesario para que los habitantes realicen sus actividades. Por último, el patrón indica que, en la periferia del Partido de La Plata, las urbanizaciones informales tienden ubicarse dentro de la categoría de medianas a pequeñas, y en general se componen de entre 100 y 500 familias. Cabe destacar que estos números se modifican día a día, siendo muy común que varios asentamientos pequeños se comiencen a expandir y anexar a otros (Esquema 11).

Esquema 11. Síntesis del Proceso de ocupación territorial en la meso escala.

\section{PATRONES DE OCUPACIÓN TERRITORIALEN LA MESO ESCALA}

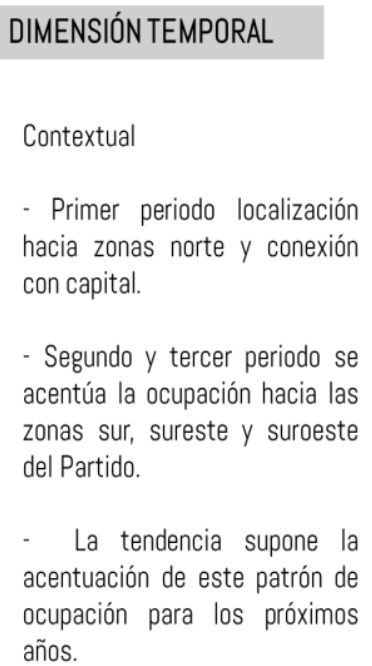

La tendencia supone la acentuación de este patrón de ocupación para los próximos años.

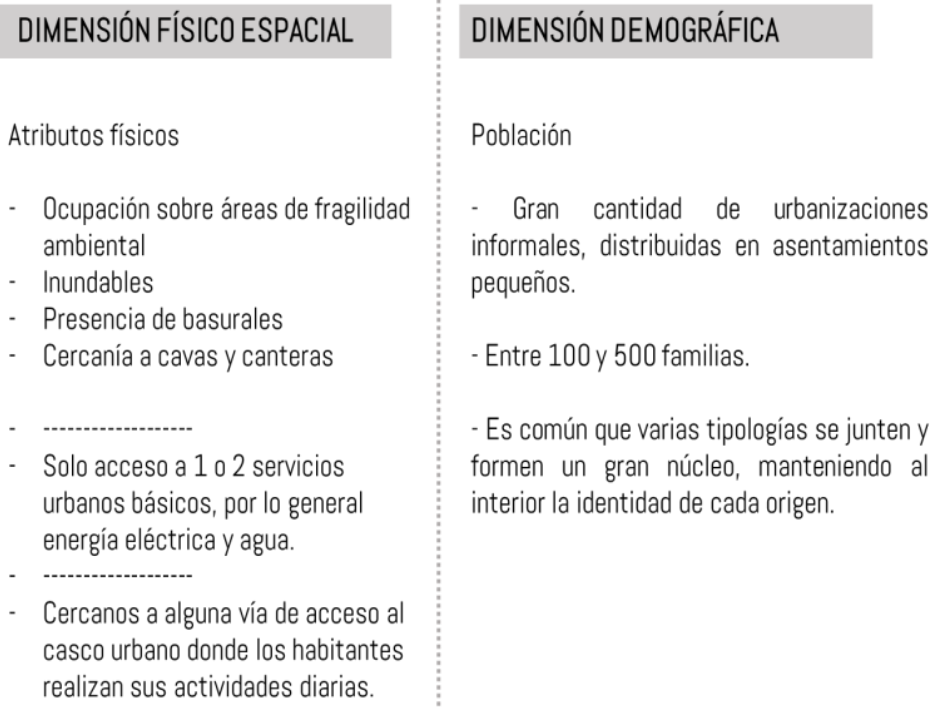

Fuente. Elaboración propia, 2019

Estos patrones de ocupación otorgan ciertas características al espacio físico de las urbanizaciones informales. En su mayoría tienen que ver con la forma de ocupación y las características del contexto en que se produce la ocupación, los atributos físicos del espacio, como la falta de acceso a los servicios urbanos básicos, la falta de acceso al transporte público, y las condiciones ambientales. Esto, sumado a la organización de la población señala que los patrones comunes que adoptan las urbanizaciones informales, se encuentran ligados a la necesidad 
de acceso al suelo urbano, a un lugar donde habitar. Cada día es posible observar nuevos territorios que se van anexando a urbanizaciones informales ya existentes, sumando población y expandiendo la situación de informalidad con las consecuencias segregativas que estos procesos conllevan. En este sentido, la falta de implementación de políticas adecuadas para la provisión de suelo urbano y regulación del mismo por parte del Estado, junto a la existencia de procesos de empobrecimiento de la población y encarecimiento del suelo hacen prever que informalidad urbana es una problemática en aumento para el futuro. En este sentido, este trabajo contribuye a poner de manifiesto la carencia que existe en materia de intervención e invita a la reflexión sobre cómo abordar la problemática desde una visión integral y con mayor justicia social.

\subsection{Los actores sociales en la meso escala}

A partir del análisis del proceso de ocupación territorial en la meso escala y la caracterización de la totalidad de las urbanizaciones informales del Partido de la Plata, así como la identificación de ciertos patrones comunes de ocupación, surge la pregunta: ¿Cómo incide el proceso de ocupación territorial en los modos de apropiación en las urbanizaciones informales? ¿Qué actores, con que lógicas y de qué manera intervienen en este proceso? Para dar respuesta a esa pregunta es necesario recordar, en primer lugar, que el sector público, guiado por la lógica política del Estado; el sector privado con la lógica económica del mercado y la ciudadanía, que responde fundamentalmente a la lógica de la necesidad; en y con el medio, los objetos, las acciones, los acontecimientos y el poder, se conjugan en el territorio, lo definen y re definen constantemente.

En ese sentido, es cierto que diversas lógicas generan distintos patrones de ocupación que repercuten en los modos de apropiación. En el caso del Partido de La Plata, surge una diferencia importante si se contraste por ejemplo el casco y la periferia, o si se comparan los modos de ocupación del territorio través del tiempo, como quedó demostrado en el análisis de la dimensión temporal. Pero son los actores, con sus lógicas los que finalmente definen el territorio, y dentro 
de la periferia del Partido de La Plata, coexisten distintas lógicas que llevan a identificar diversos patrones que determinan un crecimiento difuso, discontinuo, dejando grandes áreas vacantes.

Resulta posible identificar la convivencia de diversas situaciones, donde actúan múltiples lógicas de ocupación desvinculadas entre sí, lo que configura un marco heterogéneo y complejo, cuya gestión e intervención exigen de interpretaciones estrechamente ligadas tanto con la dimensión físico espacial como temporal de los fenómenos en cuestión. Esta situación se acrecienta ante la escasa planificación e intervención por parte del Estado, sin embargo, en algunos casos, el mismo, ha participado en intervenciones con el objetivo de atender a los requerimientos de los sectores con mayor grado de vulnerabilidad, brindando el acceso a los bienes y servicios urbanos cuando fuera necesario. En este sentido, se pueden identificar algún tipo de políticas habitacionales orientadas a sectores socio-económicos medios, como fue el caso de los créditos PROCREAR para primera vivienda. Sin embargo, estas políticas no constituyeron una planificación territorial, teniendo en cuenta la lógica del mercado y su accionar ante los precios del suelo, por lo que la ciudad igualmente siguió expandiéndose hacia zonas alejadas y sin servicios. Los sectores de la sociedad más vulnerables, por su parte, terminan ocupando el territorio de la forma que encuentran, respondiendo fundamentalmente a la lógica de la necesidad, producto del crecimiento de las dificultades socio-económicas, el desempleo y la exclusión social, enfrentando el problema habitacional con sus propios recursos en contextos de insuficiente intervención estatal y baja regulación del mercado.

En la periferia del Partido de La Plata, las acciones no coordinadas, llevadas adelante por diversos actores sociales, generan como consecuencia escenarios de fuertes contrastes. En este marco se constituye la periferia como un híbrido en el que se conjugan algunas urbanizaciones desarrolladas por el Estado; relocalizaciones de urbanizaciones informales; urbanizaciones informales; emprendimientos privados orientados a sectores medios y medios altos; viviendas particulares de fin de semana y tipologías residenciales agrupadas bajo 
la forma de urbanizaciones cerradas. En el Esquema 12, se muestran los actores principales que intervienen en el territorio en la meso escala y los tipos de acciones que pueden surgir de su interacción, en un tiempo y en un espacio determinados.

Esquema 12. Actores sociales en el territorio.

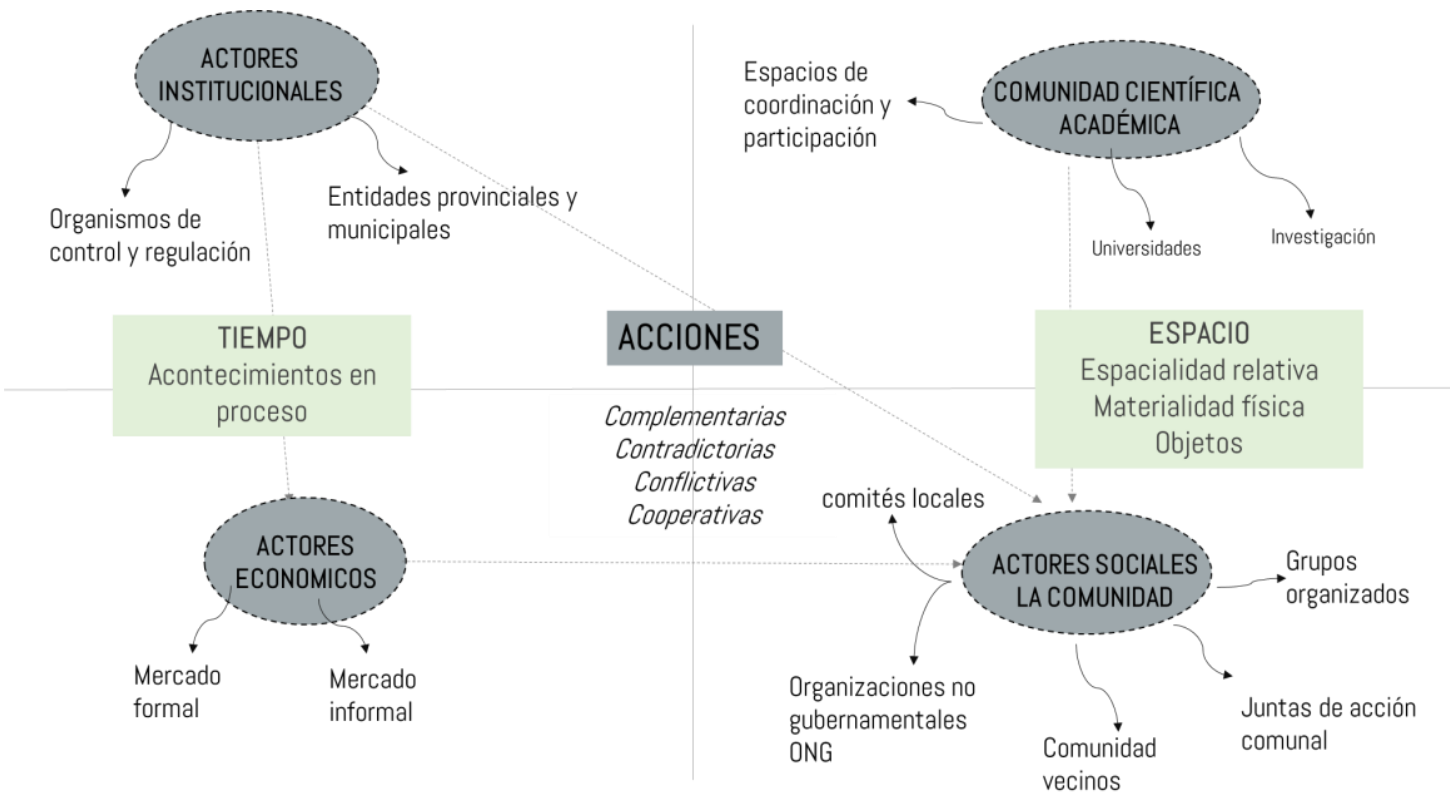

Fuente. Elaboración propia, 2018.

Los procesos de globalización tienden a reducir el territorio a una mercancía, un soporte y un objeto externo a la subjetividad de quien lo habita, en este marco, los actores luchan por construir un espacio habitable guiados por intereses particulares. En las urbanizaciones informales, el proceso de la ocupación del territorio comienza incluso desde antes de la "toma" del terreno propiamente dicho y se va acentuando, a medida que los actores se establecen territorio.

Este proceso se origina a partir de la organización de actores sociales que deciden y elijen el espacio donde se llevará adelante la ocupación. Es a partir de la organización social que se establecen las relaciones sociales entre los actores, que comienzan a generar acciones en el territorio y lo transforman, lo dotan de significados y finalmente lo convierten en lugar a través apropiación del territorio. En el capítulo siguiente se analiza un caso particular en la periferia del 
Partido de La Plata, donde se conjuga lo presentado hasta el momento con la empiria, en la micro escala. Los patrones de ocupación, así como las acciones por parte de los actores se analizan desde el concepto de apropiación y la construcción de lugar, para profundizar aún más en el aspecto simbólico dentro del abordaje del objeto de estudio de esta tesis.

Esquema 13. Los actores sociales en el proceso de ocupación

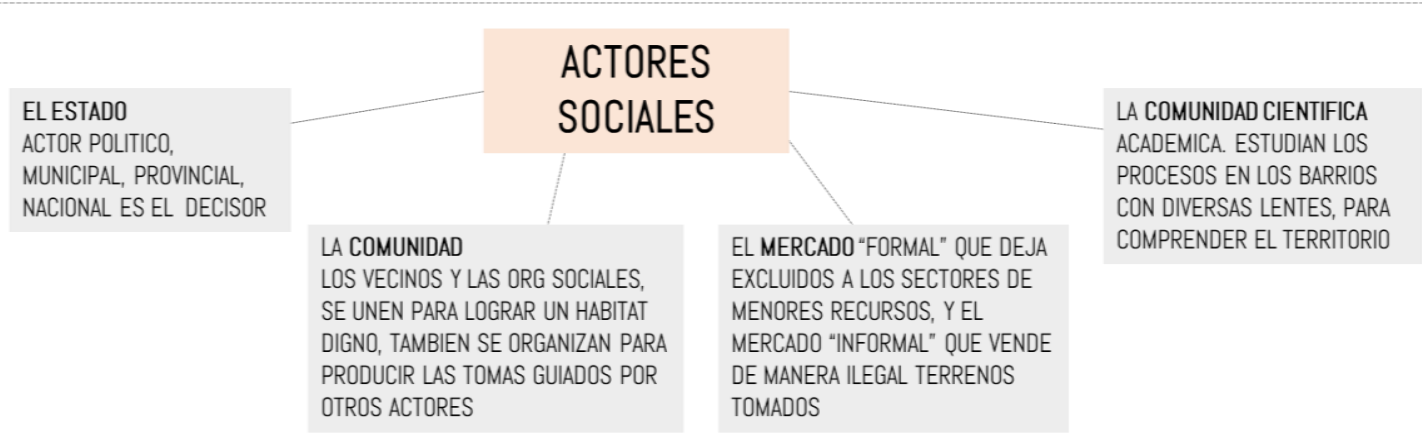

DIVERSAS LOGICAS GENERAN DISTINTOS PATRONES DE OCUPCION Y APROPIACIÓN

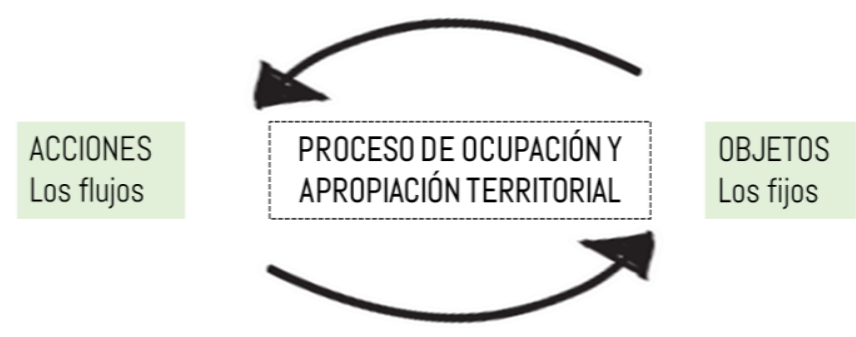

Fuente. Elaboración propia, 2018. 


\title{
Capítulo 6 \\ $-\bullet \bullet-$
}

\section{Ocupación territorial en la micro escala:}

\section{El caso del Barrio Puente de Fierro}

\begin{abstract}
$-\bullet \bullet-$
"..Habitar, para el individuo o para el grupo es apropiarse de algo. Apropiarse no es tener en propiedad, sino hacer su obra, modelarla, formarla, poner el sello propio. Esto es cierto tanto para pequeños grupos, por ejemplo, la familia, como para grandes grupos sociales, por ejemplo, quienes habitan una ciudad o una región. Habitar es apropiarse de un espacio... »
\end{abstract}

Lefebvre, 1975 
El presente capítulo se desarrolla dentro de lo que metodológicamente se denomina nivel inferior de abordaje y análisis, correspondiente con la micro escala. En los apartados que componen este capítulo se toma un caso en particular al interior de las urbanizaciones informales del Partido de La Plata presentadas en el capítulo anterior. El objetivo consiste en confrontar el cuerpo teórico y la realidad en un ida y vuelta constante. La selección del caso radica en la importancia y el peso que tiene esta emblemática urbanización informal, principalmente por ser una de las de mayor tamaño y pobladas del Partido. Se profundiza en el análisis de la historia del barrio y el rol de los actores sociales que lo impulsaron indagando acerca del proceso de creación del barrio y su consolidación como tal. Del mismo modo, el objetivo planteado para el desarrollo de este capítulo también consiste en explicar el proceso de ocupación y apropiación en el barrio Puente de Fierro. Este análisis se desarrolla a partir del reconocimiento de los atributos del espacio físico, la indagación en el proceso histórico y los relatos de los actores intervinientes en la conformación del lugar.

Para alcanzar los objetivos planteados, se requirió un acercamiento al territorio, que consistió en visitas al barrio, indagando en los distintos procesos a través de la historia del barrio, desde su creación hasta la actualidad. Este acercamiento fue posible gracias a la participación de los vecinos, vecinas y referentes del barrio en las Mesas de Trabajo Permanentes (MTP) realizadas en Puente de Fierro desde el año 2016, en el marco de una Agenda Científica Participativa denominada "Puente de Fierro Territorio Posible" ${ }^{25}$ que busca incentivar la unión entre la ciencia y los actores sociales para la resolución de problemáticas territoriales. Las visitas se realizaron periódicamente junto con el

\footnotetext{
25 http://idihcs.fahce.unlp.edu.ar/red-cientifica-latinoamericana-territorios-posibles/Proyecto PIO UNLP CONICET “Gestión Integral del Territorio: Vulnerabilidades y Procesos de Intervención y Transformación con Inteligencia Territorial. Métodos y técnicas científicas ambientales, sociales y espaciales: Dos casos en el Gran La Plata". Este proyecto de investigación-acción-participativa, se puso en marcha durante dos años desde julio 2014, y tuvo como objetivo, en su primer año, identificar problemáticas ambientales y sociales en dos lugares afectados por las inundaciones del 2 de abril de 2013. El segundo año el objetivo fue co-construir y co-ejecutar una Agenda de Transformación con Inteligencia Territorial.
} 
equipo de trabajo, coordinando y participando en conjunto con los vecinos y organizaciones sociales más representativas.

El trabajo de campo constituye un proceso continuo por lo que no es posible darlo por finalizado, dado el vínculo creado entre los actores (vecinos, tesistas, científicos, organizaciones sociales, etc.) y entre los actores con el territorio, que fortaleció el compromiso de transformación. En este sentido, en este trabajo se muestra sólo una parte del trabajo realizado en el barrio, pero resultan necesario aclarar que aún restan gran cantidad de temas que trabajar con conjunto con la comunidad para la solución de las problemáticas territoriales, tanto en Puente de Fierro, como en otros territorios posibles.

En cuanto a la estructura, y organización del capítulo, en primer lugar, se presenta una caracterización general del barrio, en la que se abordan las características principales que lo distinguen de otras urbanizaciones informales. Este capítulo se apoya en la posibilidad de la aplicación de la teoría en un caso concreto, sustentado en los relatos de los vecinos y referentes que contribuyeron a reconstruir las etapas en historia del barrio, desde la ocupación y creación del mismo, su consolidación y expansión, hasta la actualidad.

En cada etapa del trabajo en el territorio y con los actores, el sentido de pertenencia producto del proceso de ocupación y apropiación se puso de manifiesto, principalmente en la voz de los vecinos y referentes. Para dar cuenta de este proceso se presenta en el primer apartado un análisis de la historia del barrio Puente de Fierro y los procesos sociales con sus manifestaciones territoriales. El barrio se conforma como una urbanización de tipología mixta caracterizada una parte como asentamiento informal y otra parte como villa, lo que brinda una riqueza para el análisis que otras urbanizaciones no permitirían.

Si bien el presente análisis no puede extrapolarse a otros casos de idéntica manera, por la diversidad de cada situación en particular, el mismo se constituye como una manera de mirar un lugar, cómo surgió, quienes llevaron adelante el proceso de ocupación y apropiación que terminó por convertir un espacio vacío 
en un lugar. En este sentido, sí cabe destacar la replicabilidad de la metodología utilizada para el análisis en otros casos particulares.

Entre las técnicas de investigación que se utilizaron durante las visitas al caso de estudio, se encuentra la participación en distintas actividades como se mencionó, principalmente la participación en las Mesas de Trabajo Permanente que se realizan una vez al mes y cuentan con la participación de vecinos del barrio, así como a otros actores -científicos, tesistas, funcionarios públicos y en ocasiones del mundo empresario- dando lugar a un intercambio con los habitantes, llegando a construir vínculos entre habitantes y otros actores, en ocasiones positivos y fecundos. Estos vínculos permitieron no sólo comprender la forma de vida y la dinámica territorial, sino realizar las entrevistas en profundidad, que resultaron cargadas de información valiosa para dar cuenta del proceso de ocupación y apropiación territorial.

Por lo antes mencionado, este capítulo resulta de gran importancia dentro de la presente tesis doctoral, ya que no sólo representa un cambio en el nivel de abordaje y escala, sino que es aquí donde se hace especial referencia a la dialéctica subyacente en el proceso de ocupación y apropiación del territorio y la conformación de un lugar a partir de la experiencia empírica durante el trabajo de campo y el trabajo con los vecinos y referentes.

\subsection{El proceso histórico del barrio Puente de Fierro y la ocupación del territorio}

El barrio Puente de Fierro se caracteriza por ser una urbanización informal que se encuentra ubicada en la localidad de Altos de San Lorenzo en el Partido de La Plata. Es considerada una de las urbanizaciones informales más importantes del Partido, debido a su extensión territorial, de casi 60 hectáreas y la gran cantidad de familias que residen, alrededor de 1.500 (RPPVAP, 2015). Este fue uno de los motivos de selección y justificación del caso de estudio, sumado al grado de consolidación que presenta en la actualidad y el fuerte sentido de 
pertenencia que manifiestan sus habitantes, vinculado directamente con el proceso de ocupación y apropiación de lo que se dará cuenta en este capítulo (Figura 52). Del mismo modo que otras urbanizaciones informales de América Latina en general y Argentina en particular, el barrio Puente de Fierro se originó como resultado, en parte, de insuficientes políticas públicas en materia de urbanización inclusiva para los sectores sociales más vulnerados en sus derechos básicos, tales como el acceso a la tierra y una vivienda digna, a una buena alimentación, trabajo digno, educación en todos los niveles y salud pública.

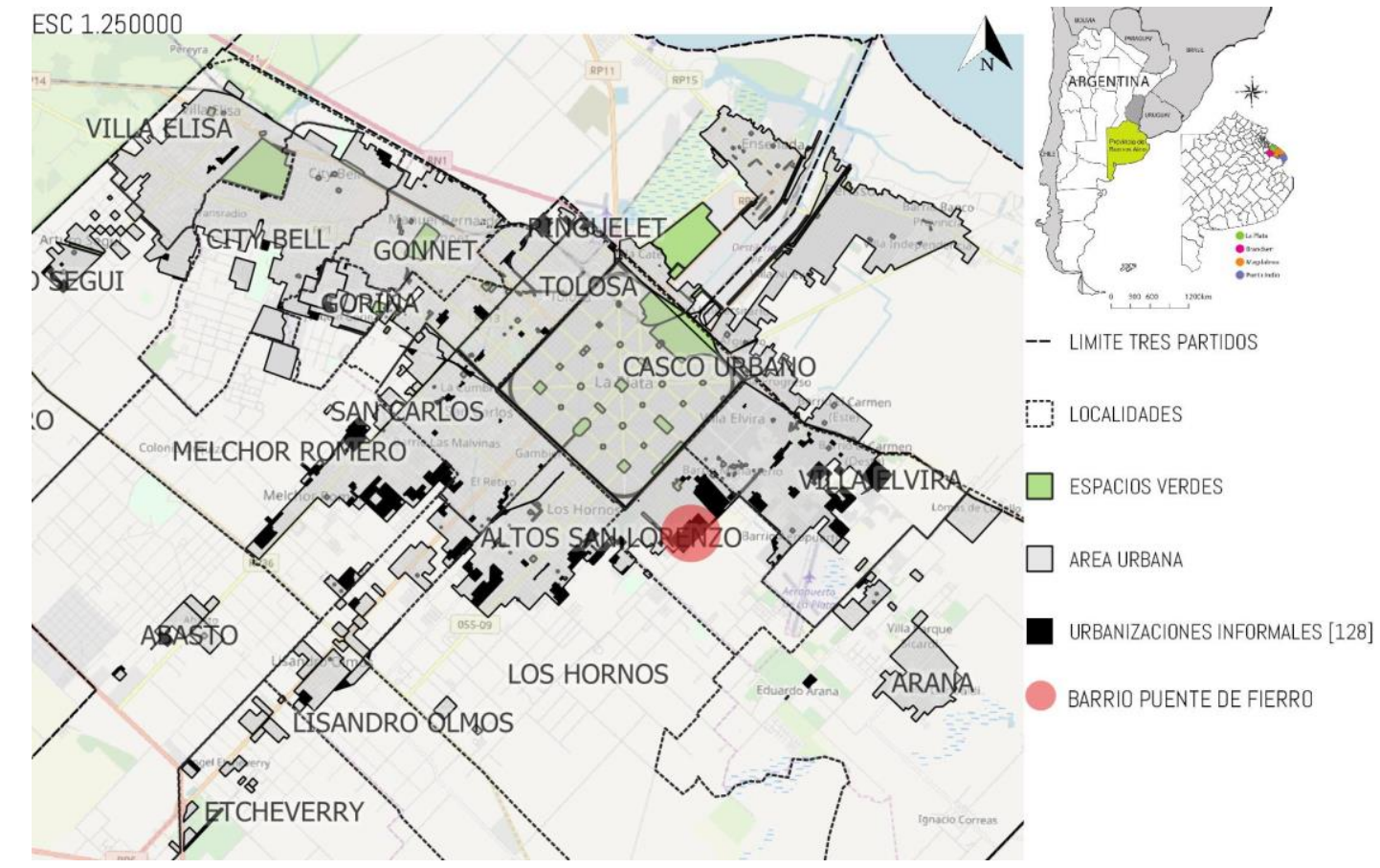

Figura 52. Localización del barrio Puente de Fierro en la Localidad de Altos de San Lorenzo, Partido de La Plata. Fuente. Elaboración propia con herramienta SIG, 2018.

El Barrio Puente de Fierro surgió como urbanización informal, resultado de la toma de tierras durante la década de los 90 . El barrio se encuentra localizado actualmente en la periferia sudeste del Partido de La Plata, en la localidad de Altos de San Lorenzo. Este suburbio se ha caracterizado por ser una periferia débil, consolidada de manera tardía, por ejemplo, si se compara con el desarrollo de Tolosa, Gonnet, o City Bell, localidades vinculadas al eje Buenos Aires-La Plata. Esto puede explicarse, en primer lugar, debido a que la primera expansión de población hacia la periferia platense se dio en las zonas hacia el norte de la 
región, que presentaban una mejor conexión hacia la Capital Federal, principalmente por cuestiones económicas, de intercambio y de accesibilidad al empleo.

La población de la periferia de la zona sureste del Partido se fue localizando en mayor medida, según aspectos relacionados, principalmente, con el alto precio del suelo en el casco urbano de la ciudad de La Plata, y con procesos migratorios que se produjeron durante los años 90 en Argentina como ya se ha mencionado. Estos factores en conjunto contribuyeron a que muchas familias encontraran en estas zonas lugares para residir, ya sea por tener un precio del suelo relativamente más bajo que en otras, o por la existencia de gran cantidad de lotes vacantes, algunos que se fueron ocupando de modo ilegal y conformando urbanizaciones informales como es el caso de Puente de Fierro (Figura 53).

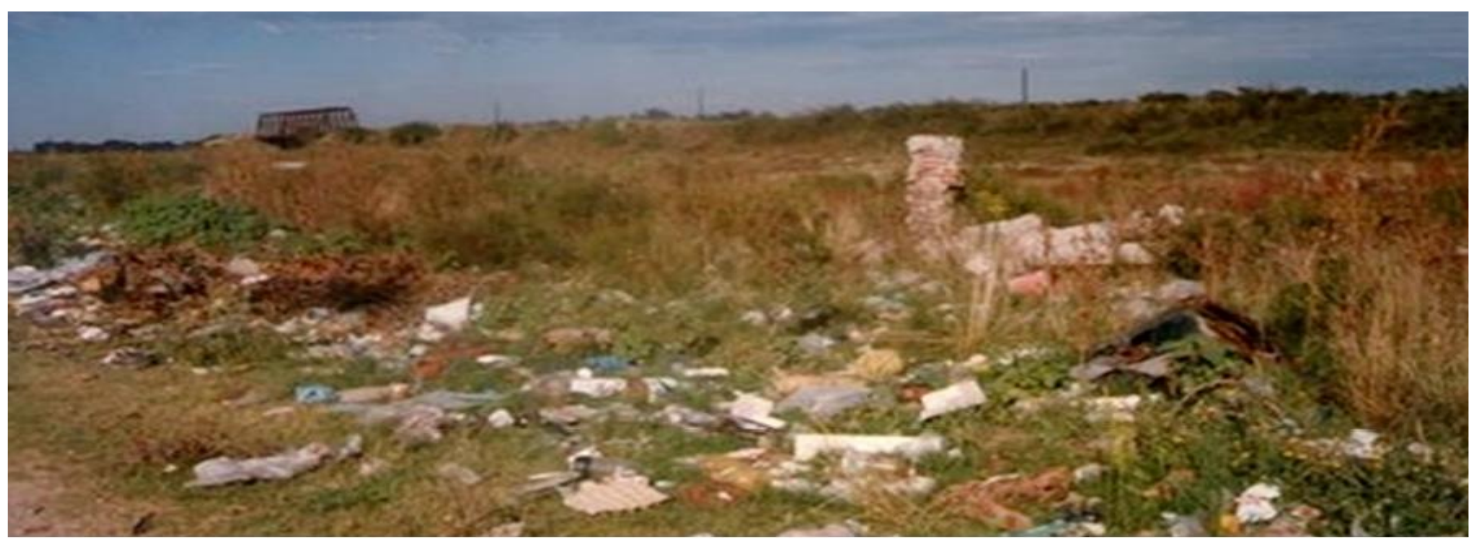

Figura 53. Puente de Fierro en 1990, antes de la creación del asentamiento. Fuente. Imagen tomada por vecino fundador en 1990.

La localidad de Altos de San Lorenzo con 41.435 habitantes según datos del último censo 2010 , se ubica a $3 \mathrm{~km}$ del centro urbano y comenzó a poblarse lentamente a partir de los años 1940 y 1950, producto de los primeros loteos, adquiridos, fundamentalmente, por empleados del ferrocarril, trabajadores de los frigoríficos de Berisso y diversos cuentapropistas. Cabe mencionar que entre los años 1940 y 1990 aquellos barrios situados entre la Avenida Circunvalación 72 de La Plata y el actual Barrio de Puente de Fierro en la localidad de Altos de San Lorenzo eran en mayor medida territorios rurales con grandes extensiones de 
tierra. Esta localidad forma parte de la zona en la que se desarrolló la línea del entonces Ferrocarril del Sur (luego Ferrocarril General Roca) que vincula a La Plata con la ciudad de Buenos Aires, al igual que otras localidades del Partido como Tolosa, Ringuelet, Manuel $\quad$ B. Gonnet, City Bell, Villa Elisa, Joaquín Gorina y Arturo Seguí. Hasta la década de 1970, de manera adyacente a la localidad de Altos de San Lorenzo, funcionó la Estación Central del Ferrocarril Provincial. En el año 1882 el gobierno de la provincia de Buenos Aires comenzó con la construcción de nuevos ramales del ferrocarril que comunicaron a La Plata (capital de la Provincia) con el Ferrocarril del Oeste y el Ferrocarril del Sur.

En la Figura 54 se observan fotografías aéreas que corresponden con el área donde hoy se sitúa el barrio Puente de Fierro, en tres cortes temporales correspondientes a los años 1966, 1972 y 1985. Estas imágenes son previas a la ocupación, aunque es posible identificar que desde el año 1966 la expansión urbana del casco fundacional hacia la periferia sureste registraba un crecimiento, extendiéndose la mancha urbana y completando áreas hasta el momento vacías. Esta expansión como se ha analizado en capítulos anteriores, se produjo fundamentalmente desde los años 30, a partir del cambio económico producto del modelo de sustitución de importaciones, lo que fomentó un gran desplazamiento de población hacia las zonas urbanas.

La imagen que corresponde con el segundo corte temporal, en 1972, deja ver los efectos de dicho desplazamiento, que se dio principalmente por parte de migrantes expulsados del campo y de localidades menores del interior del país provocando un incremento de la población urbana en grandes ciudades y capitales provinciales. Se observa en este sentido un avance de la mancha urbana en la localidad de Altos de San Lorenzo, que se mantiene en aumento hasta la última imagen de 1989 inclusive. De este modo, es posible asociar esta tendencia con las transformaciones territoriales que profundizaron la organización territorial relacionadas con la expansión de la mancha urbana hacia la periferia como desborde del casco urbano fundacional. 


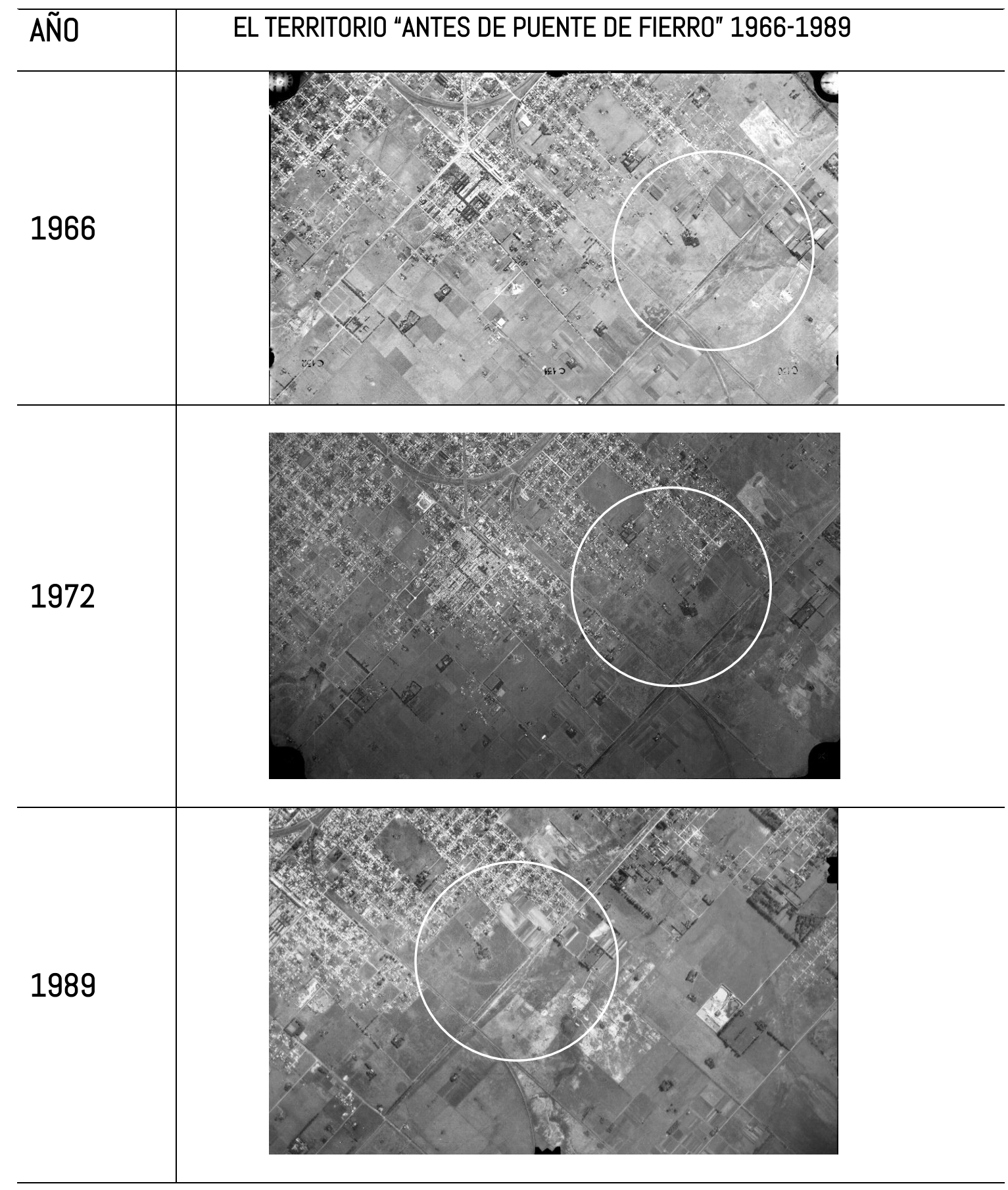

Figura 54. Fotografías aéreas del emplazamiento actual de Puente de Fierro 1966-1972-1989. Fuente. Elaboración propia, a partir de aerofotos de la Dirección Provincial de Geodesia. 
A partir de la década de 1990 hasta el presente la localidad de Altos de San Lorenzo se fue configurando como un espacio heterogéneo, con una configuración espacial fragmentada, en el que las condiciones económicas, habitacionales y urbanas desmejoran a medida que se aleja de la avenida 72 , denominación que adquiere en ese tramo la avenida de Circunvalación, límite del trazado fundacional de la ciudad) hacia el espacio rural (Segura, 2011). Principalmente debido a la expansión de entramado urbano y aumento de la población ligado a las migraciones internas que se produjeron en el país durante esos años. En cuanto al surgimiento del barrio Puente de Fierro, se puso de manifiesto, en los relatos de sus impulsores y referentes más antiguos a los que se entrevistó, que, al momento de la ocupación, "no pasarían de más de 10 familias." Al mismo tiempo, los referentes coinciden en que la ocupación no fue espontánea, sino que, se dio de manera organizada previamente de modo que los ocupantes se repartieron los terrenos entre las familias decididas a asentarse.

En este sentido, uno de los referentes que fueron impulsores del barrio afirma (...) “Caminábamos diez pasos para allá, los del centro los repartíamos en dos, y así logramos hacer un barrio de un basural... eran muy poquitas casas sobre la 83, 84, ahí eran poquitas casas que necesitaban. Había en el fondo todo un terreno que era depósito. La gente necesitaba un terreno, empezamos a limpiar y de repente se transformó en una marea colonizadora que fue de la 23 bis hasta la 28 casi 29 y de la 85 a la 90, que son muchas manzanas. Y después repartimos terreno" (...) (Fragmento de entrevista realizada en el 2018 a uno de los impulsores del barrio ver anexo 1). En la Figura 55 se presenta una secuencia de la ocupación, consolidación y expansión del territorio donde se encuentra localizado Puente de Fierro en el período actual, a partir de la información satelital disponible a partir del año 2004. Los cortes temporales, en correlación con los presentados previos a la ocupación, corresponden a los años 2004, 2009 y 2015 y 2019. Resulta posible observar cómo se fue ocupando el área y su expansión, y en este sentido cabe mencionar que en la actualidad el asentamiento continúa expandiéndose más allá de sus límites originales. 


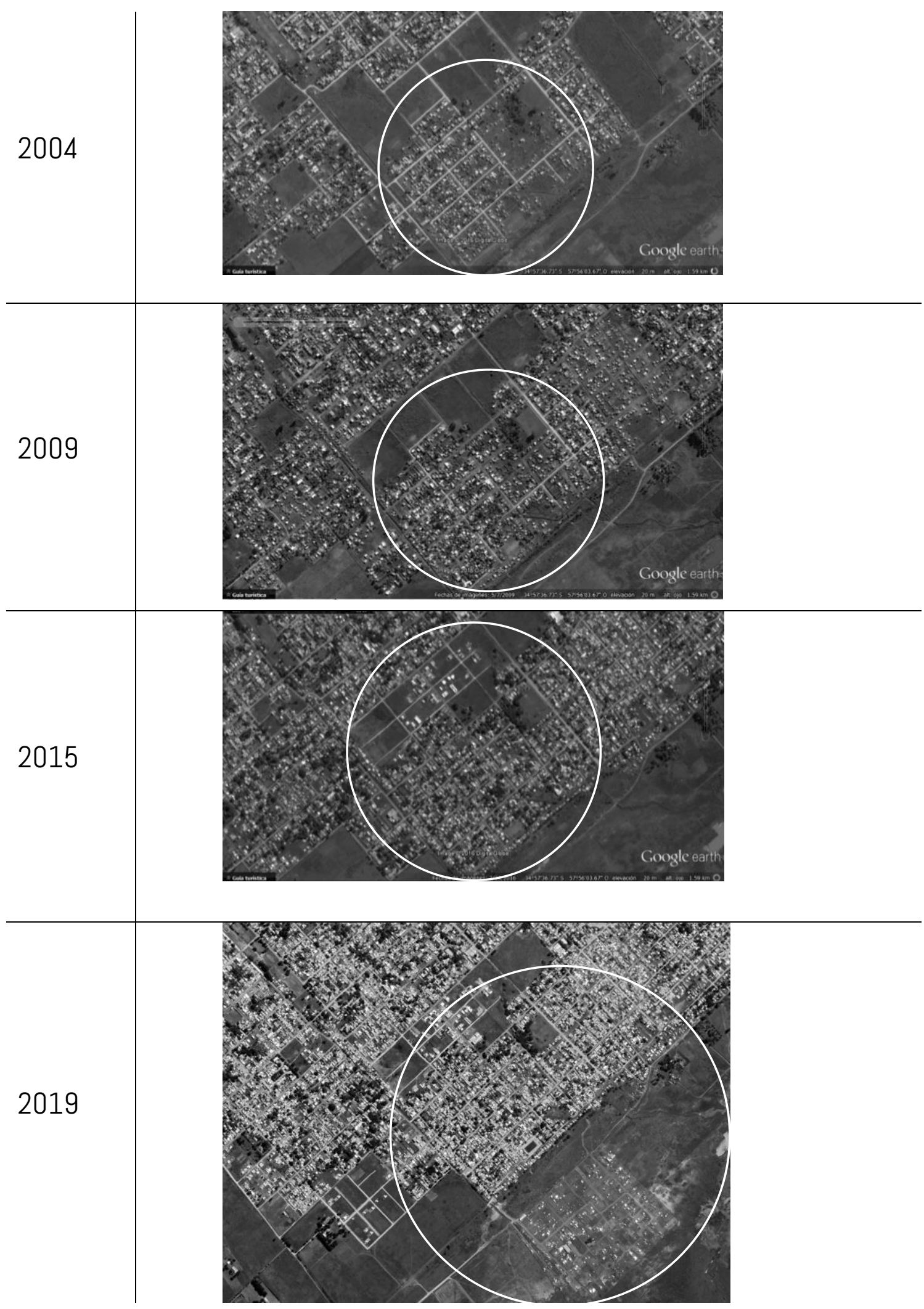

Figura 55. Consolidación del barrio Puente de Fierro entre los años 2004-2019 Fuente. Elaboración propia, imágenes satelitales Google Earth, 2019. 


\subsubsection{Puente de Fierro: patrimonio histórico y lugar de significado}

El "Puente de Fierro" elemento que da nombre al barrio se encuentra ubicado en la intersección de las calles 29 y 90, y está conformado por una estructura de hierro de 5 metros de alto que perteneció a un ramal ferroviario del ferrocarril del Sud que data de 1904. Toda su estructura es desarmable y está totalmente unida con remaches y tornillos. Por debajo de él circuló un ramal del Ferrocarril Roca con transporte de carga, que finalizaba su recorrido en la "Estación La Plata Compañía General” o “Km 80", en la intersección de las avenidas 60 y 122, comunicándose con el puerto de La Plata (Figura 56).

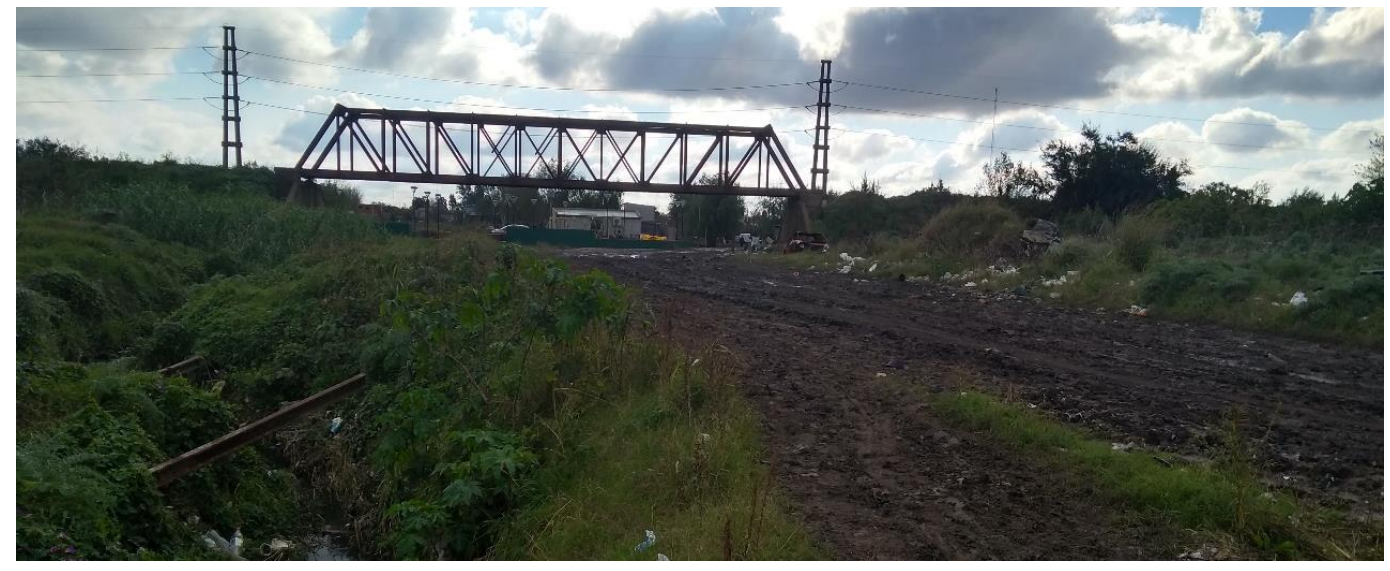

Figura 56. El Puente de Fierro, desde las calles 91 y 29.

Fuente. Imágenes tomadas por el equipo de trabajo en Puente de Fierro 2016-2019

El puente se transformó en un lugar con un significado muy ligado con la memoria de la sociedad argentina durante la década de 1970, debido a que fue un sitio utilizado por organismos paramilitares y, en 1976, por el gobierno de facto en actos de fusilamiento. El caso más resonante en la memoria del barrio, y uno de los más mencionados por vecinos y referentes al preguntar sobre el tema, fue el de "Patulo" Rave, militante de la UES ${ }^{26}$ Berisso, ejecutado en 1975 el emplazamiento del puente.

${ }^{26}$ La Unión de Estudiantes Secundarios o Unión Estudiantil Secundaria es una organización política argentina de estudiantes secundarios creada en 1953. 
En el año 2006 el concejo Deliberante, dispuso la Ordenanza 10076 y en sus artículos declaró que el "Puente de Fierro", ubicado en la calle 90 entre 29 y 30 , sería Patrimonio Histórico por los hechos de lesa humanidad que se cometieron en dicho lugar. En la Figura $\mathbf{5 7}$ es posible observar las marcas que dejaron las balas sobre los terraplenes del puente y también se observan las placas conmemorativas, ambos símbolos de la fuerte identidad de este lugar.
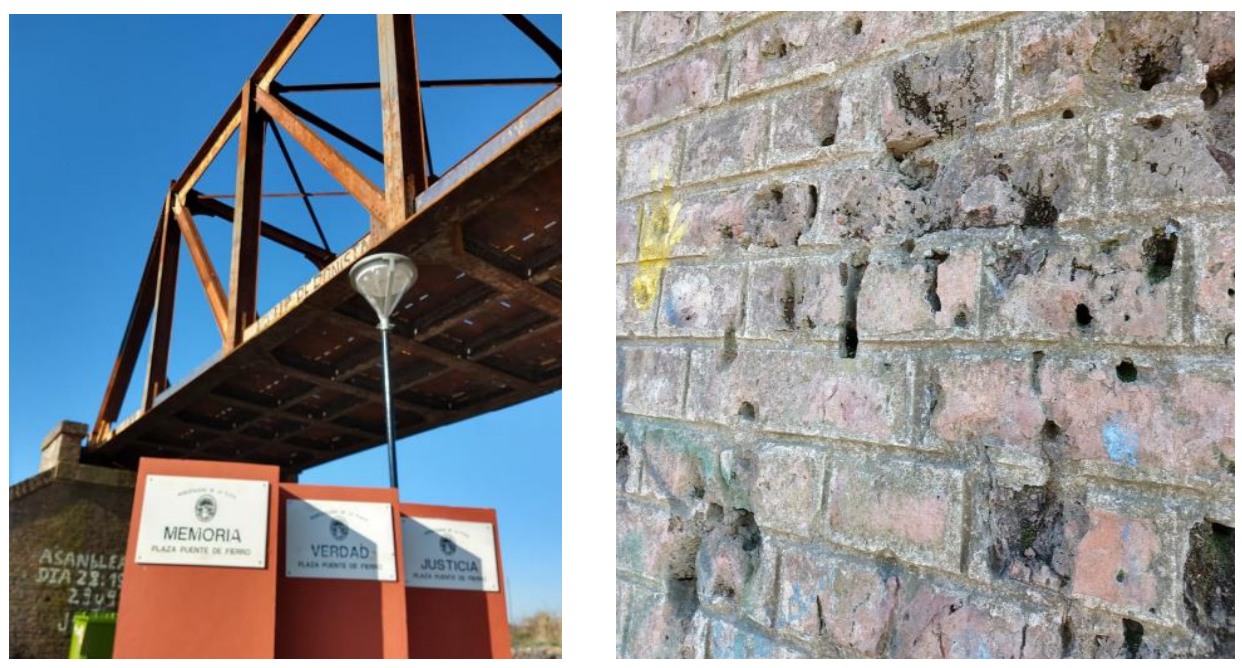

Figura 57. El puente de fierro, símbolo recordatorio de "Memoria verdad y justicia"

Fuente. Imágenes tomadas por el equipo de trabajo en Puente de Fierro 2016-2019

El emplazamiento del puente, luego de los sucesos que tuvieron lugar en la década de los 70, se transformó en un basural de grandes dimensiones, hasta que en el año 2016, se logró la limpieza total para convertirlo en una plaza seca, con juegos para niños y lugares de esparcimiento para los vecinos (Figura 58). La transformación del espacio fue posible por el accionar en conjunto de los vecinos, referentes y las organizaciones sociales del barrio, el Proyecto de Investigación de la UNLP-CONICET y la Municipalidad de La Plata junto al gobierno nacional que proveyeron los fondos necesarios para ello.

Este lugar es considerado como el corazón de Puente de Fierro, lugar que le otorga su nombre al barrio y que los vecinos reconocen como propio. Se evidencia de este modo, como la acción colectiva permitió que lo que era un basural, con ratas y focos de enfermedades se convirtiera en un lugar que los vecinos utilizan a diario, además del reconocimiento y la puesta en valor de la 
memoria histórica, no sólo para el Puente de Fierro, sino para toda la comunidad del Partido de La Plata.
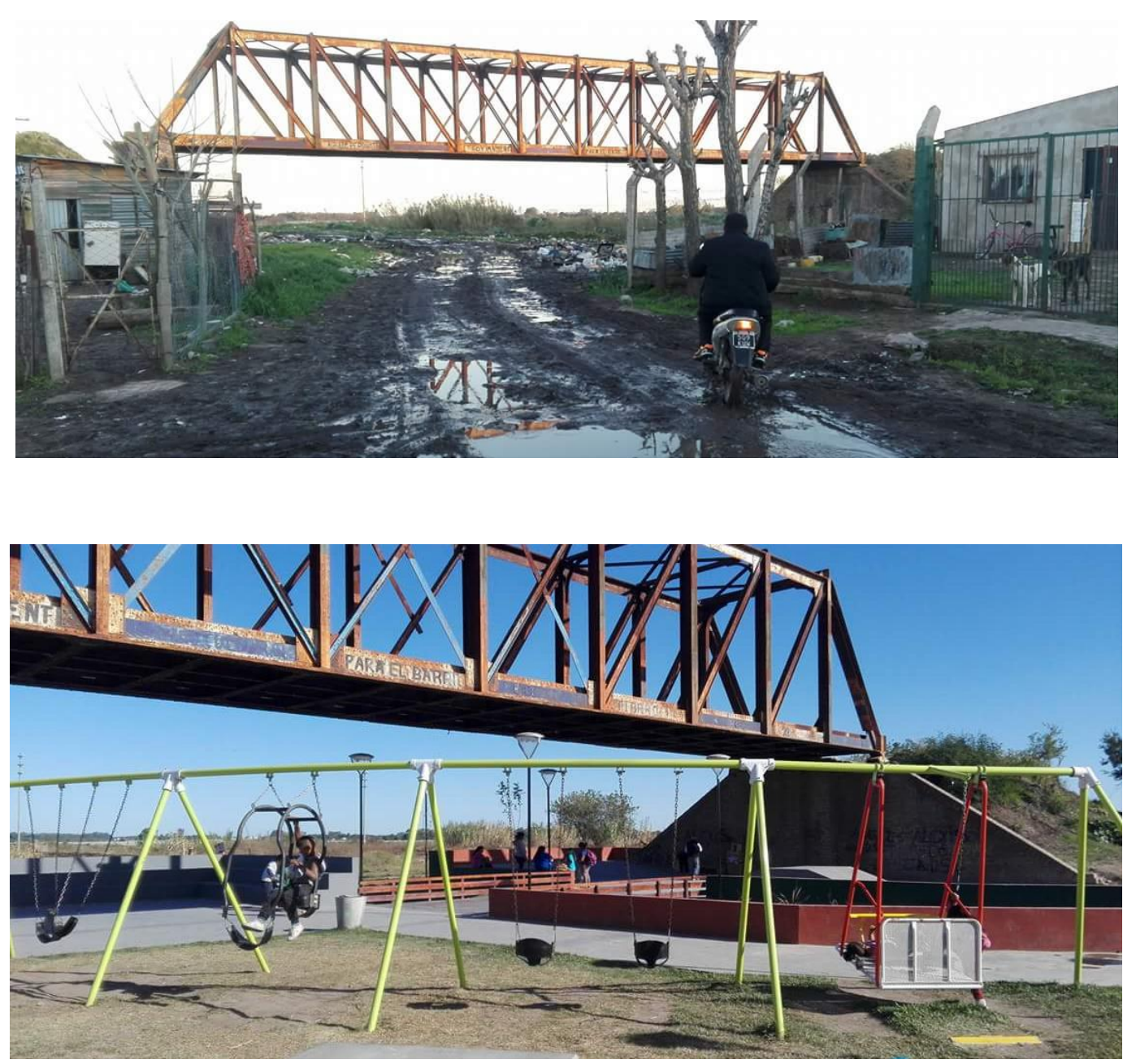

Figura 58. El Puente de Fierro antes y después.

Fuente. Imágenes tomadas por el equipo de trabajo los años 2016 y 2018 respectivamente.

En síntesis, Puente de Fierro representa un espacio construido, apropiado y cargado de sentido, en donde el énfasis otorgado al habitar, como proceso de apropiación y significación, busca explicar los motivos por los cuales un espacio devino en un lugar con sentidos y valoraciones propias. Es por ello que el habitar el Barrio Puente de Fierro remite tanto a la relación de los actores con el entorno tanto como a las relaciones entre los actores sociales entre sí, y a través del análisis histórico del barrio se hace posible comprender las variaciones en la conformación y significación del lugar. 


\subsection{La configuración actual del Barrio Puente de Fierro}

El barrio Puente de Fierro se originó durante la década de 1990, principalmente debido al impulso de varias familias agrupadas y organizadas. La extensión ocupa el espacio de las manzanas comprendidas entre las calles 22, 29, 84 y 90 . Sin embargo, el barrio se ha expandido más allá de los límites originales y continúa haciéndolo en la actualidad (Figura 59). En este sentido, cabe mencionar que los límites remiten a relaciones sociales, a los modos en que los actores se clasifican e imaginan entre sí y a las formas en que se relacionan en virtud de tales clasificaciones e imaginarios (Simmel, 1986). Las configuraciones espaciales participan de muchas maneras en la naturalización del espacio social. Así, las oposiciones sociales objetivadas en el espacio tienden a reproducirse en el lenguaje y las prácticas como principios de visión y división (Bourdieu, 2002). En definitiva, en categorías de percepción y clasificación de objetos, lugares y actores. De esta manera, las categorías espaciales funcionan como categorías sociales que simbolizan las posiciones de cada uno de los actores en el espacio social, vinculando tales posiciones a dimensiones morales y al mismo tiempo organizan las relaciones entre los actores (Segura, 2011).

En este sentido, dentro de los límites establecidos por los habitantes del barrio es posible establecer 5 lugares diferenciados, cada uno con identidades propias, que sugirieron a partir de los relatos de los vecinos durante el trabajo de campo. Cabe mencionar, que, a pesar de que para el imaginario de los vecinos y habitantes estos lugares conformen una totalidad como urbanización aun diferenciando identidades al interior de cada uno, para el Registro Público Provincial de Villas y Asentamientos Precarios (RPPVAP) comprende distintas tipologías de urbanización informal, por lo que, para el análisis, resulta importante diferenciarlas. 


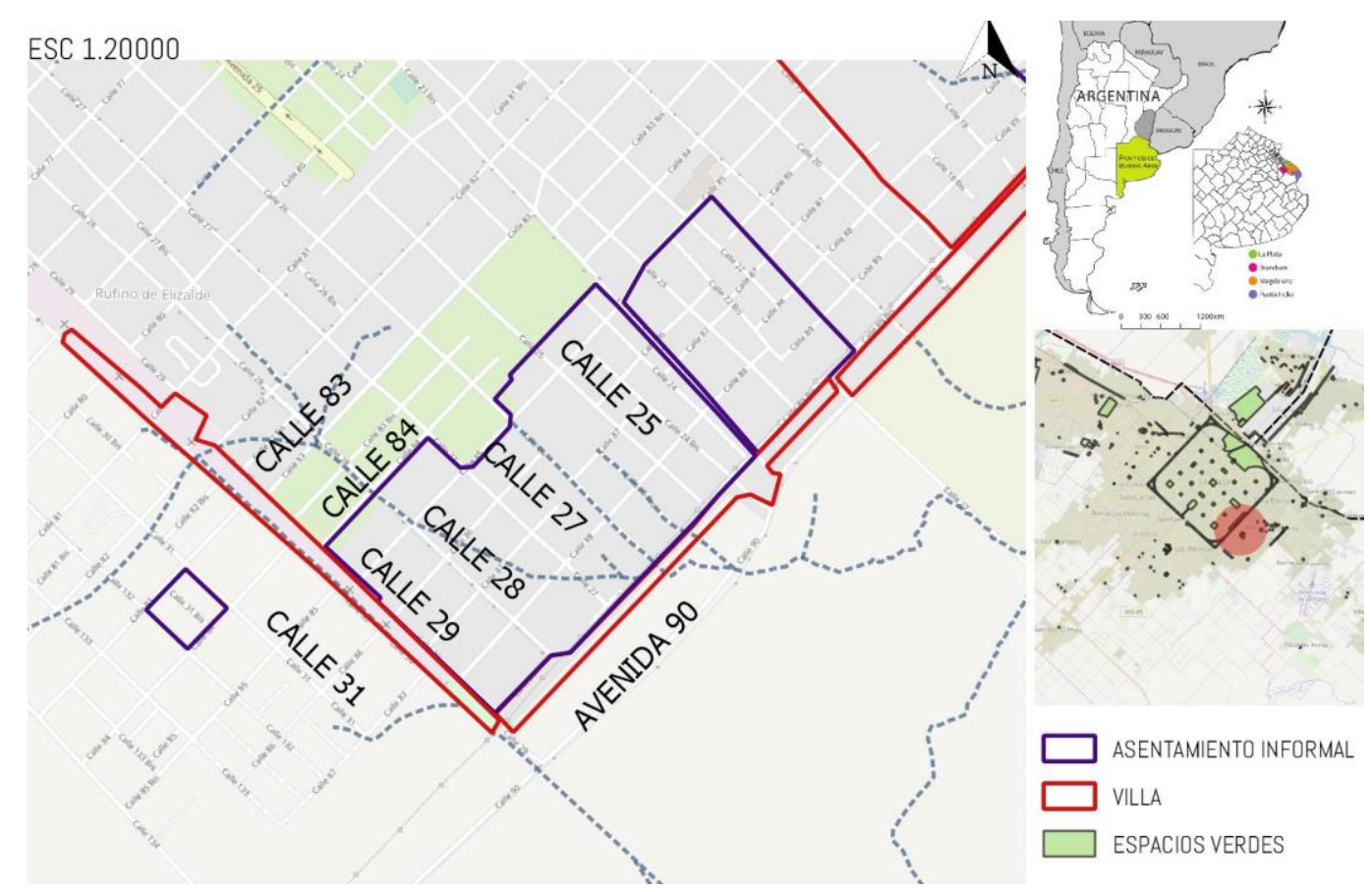

Figura 59. Delimitación espacial del barrio Puente de Fierro Fuente. Elaboración propia 2019 con herramienta SIG datos RPPVAPP 2015.

En primer lugar, se puede observar en la Figura 60, la disposición general del barrio con sus límites establecidos, y con letras A; B; C; D y E, los cinco lugares que el RPPVAP identifica tipológicamente. Además de los límites que indican las distintas tipologías, existe el imaginario de los vecinos que resulta más complejo, debido a que, si bien ellos identifican el barrio como una unidad, también hacen algún tipo de diferenciación. Si bien los vecinos no siguen el criterio tipológico del RPPVAP y las entidades oficiales, algunas cuestiones pueden coincidir. A continuación, se analiza cada uno de los 5 lugares identificados, como tipología, y sus características principales, con los nombres con los que se los identifica y el momento histórico en el cual fueron creados y como se consolidaron cada uno dentro de la totalidad del barrio. 


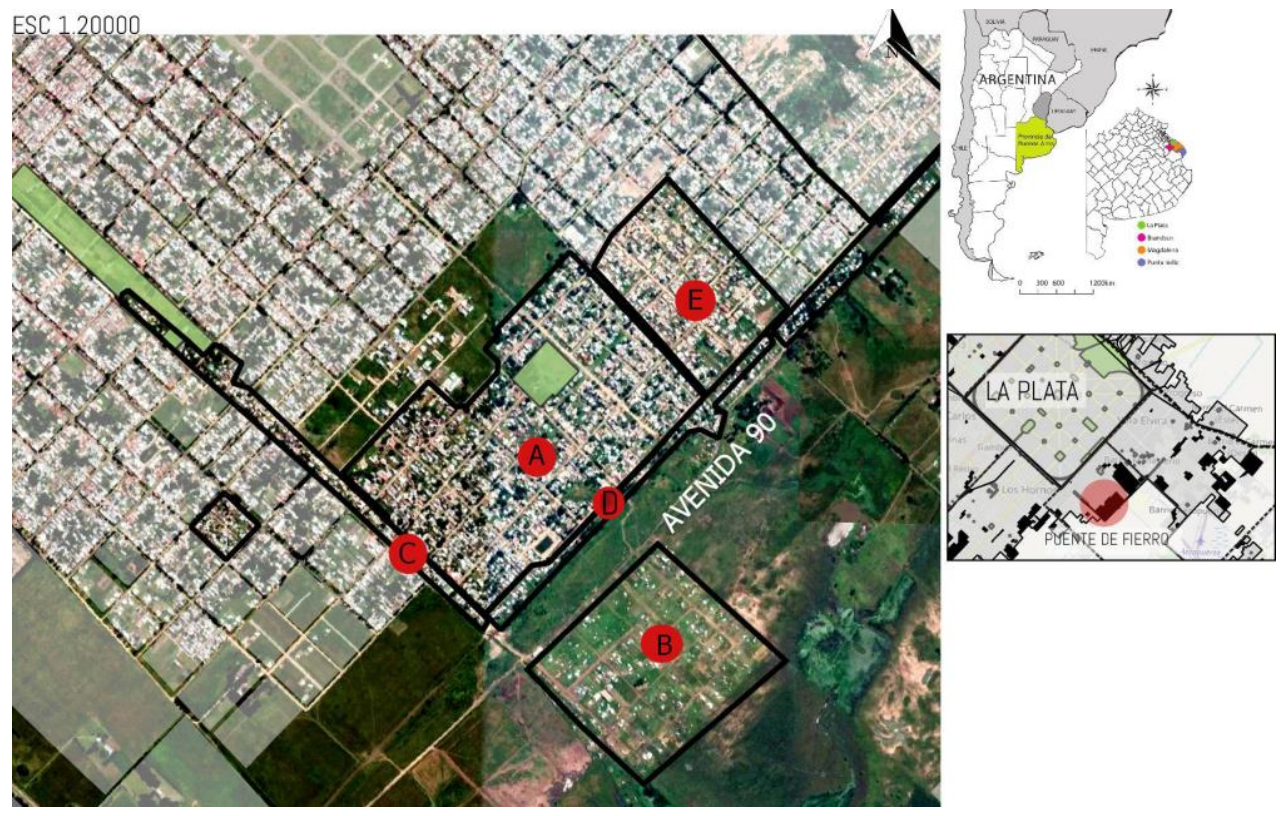

Figura 60. El barrio Puente de fierro y sus lugares.

Fuente. Elaboración propia, 2018 con Google Earth.

En primer lugar, denominado con la letra " $\mathrm{A}$ " se encuentra la parte del asentamiento que responde a la tipología establecida previamente como asentamiento informal, cumpliendo con las características que suele presentar este tipo de urbanización. Este sector ocupa el territorio desde la calle 85 hasta la avenida 90 y desde la calle 30 hasta la calle 22 aproximadamente, según testimonios de los vecinos, y se encuentra loteado y organizado para la regularización de la situación dominial. Este lugar dentro del barrio se lo conoce como Puente de Fierro, Puente de Fierro Original o Puente de Fierro 1, de este modo lo reconocen los vecinos como el primer asentamiento (Figura 61).

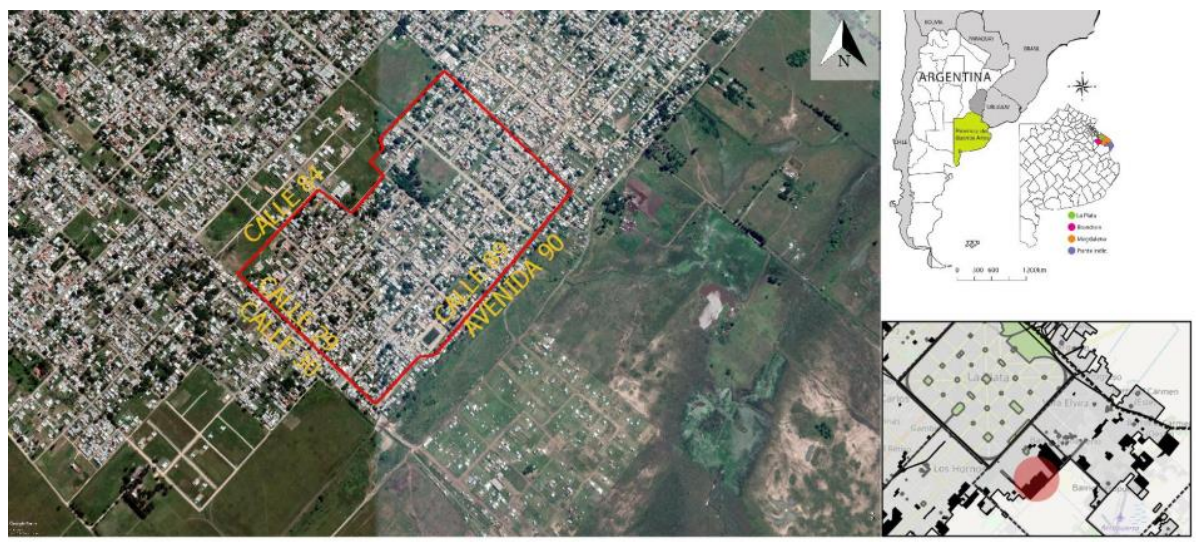

Figura 61. Puente de Fierro 1 o sector "A".

Fuente. Elaboración propia, 2019 con herramienta SIG. 
Este lugar es identificado por parte de los vecinos como el asentamiento más antiguo, producto de la década de los 90, algunos de ellos dicen que nació en 1990, otros en el año 1994, y hay quienes comentan que surgió como barrio en 1997. De cualquier modo, es posible identificar este tipo de asentamiento con las tipologías de asentamientos informales producto de los cambios durante fines de los años 80. Se explicó en capítulos anteriores que esta tipología específicamente, tuvo su auge y se expandió como modalidad de ocupación de suelo durante la década de los años 90 (Figura 62).
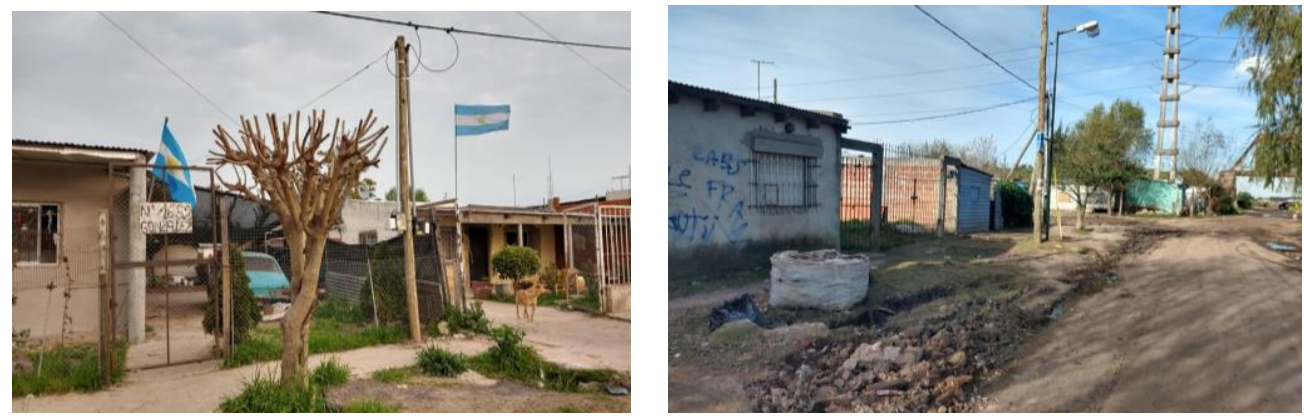

Figura 62. Tipología asentamiento informal dentro de Puente de Fierro. Fuente. Imágenes tomadas por el quipo de trabajo en visitas (2016-2019).

En segundo lugar, se identifica otro sector al interior del barrio denominado con las letras "C" y "D", sobre las calles 29 y 89 respectivamente, que constituye dos urbanizaciones en forma de "tiras". Según el relevamiento oficial, estos sectores corresponden con la tipología de villa ya que morfológicamente no siguen un trazado urbano, sino que la disposición pareciera tener un carácter más desordenado propio de esta tipología (Figura 63).
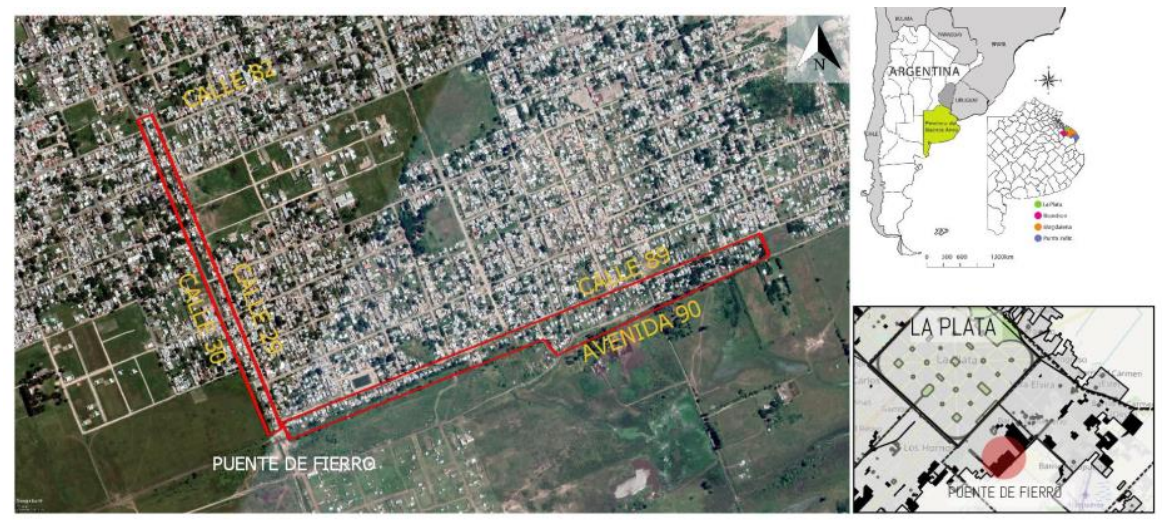

Figura 63. Puente de Fierro sector " $\mathrm{D}$ " y " $\mathrm{C}$ "

Fuente. Elaboración propia, 2019 con herramienta SIG. 
Esta zona dentro del barrio se constituye como la más marginal en cuanto a las condiciones de habitabilidad, y es el lugar señalado por los vecinos como "el más peligroso". Allí se pueden observar las casillas más precarias, principalmente en las viviendas ubicadas sobre la calle 89 y la Avenida 90. Estas urbanizaciones surgieron años más tarde que el primer asentamiento o zona " $\mathrm{A}$ ", más precisamente entre los años 2003 y 2007. Estos asentamientos son consecuencia de la crisis socio económica que sufrió la Argentina en el año 2001, y a partir de la cual muchas familias quedaron sin una vivienda donde habitar. El sector sobre la calle 89 tienen la particularidad de encontrarse dispuesto longitudinalmente, como se observa en la Figura 64, de un lado se encuentran viviendas muy precarias, casillas en su mayoría, y del lado opuesto gran cantidad de la vegetación. Algunas casillas quedan ubicadas sobre el antiguo terraplén ferroviario y otras muy cercanas a zanjones y pasos de arroyo, lo que aumenta las condiciones de vulnerabilidad de la población.
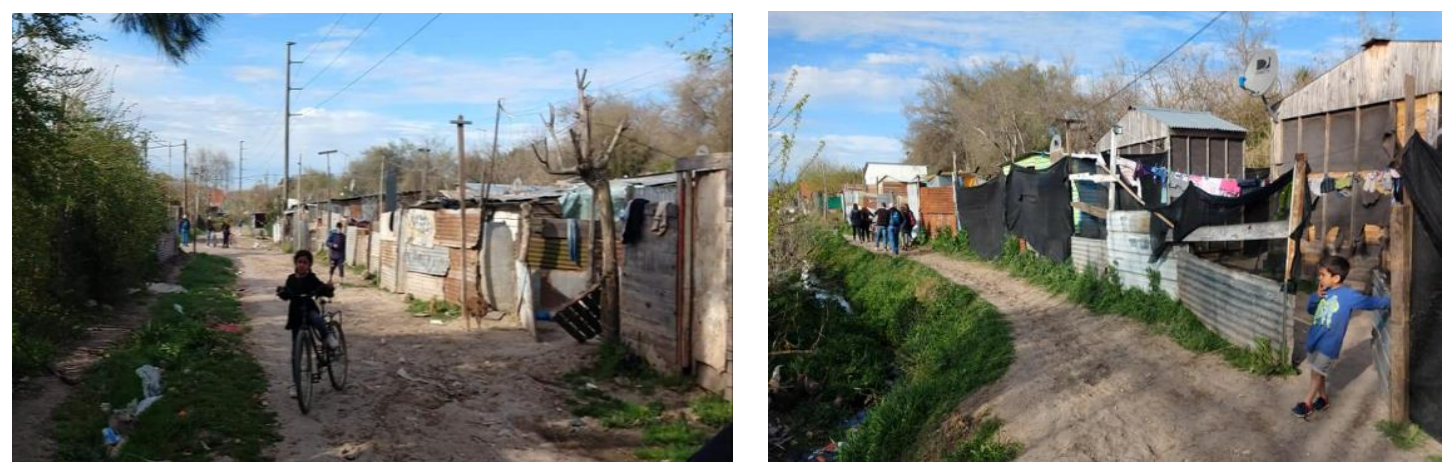

Figura 64. Tipología villa dentro de Puente de Fierro.

Fuente. Imágenes tomadas por el equipo de trabajo en Puente de Fierro 2016-2019

Con la letra "E" se encuentra el sector del barrio denominado "Puente de Fierro 2" que ocupa desde la calle 23bis a la calle 22, como una continuación del Puente de Fierro original (Figura 65). Si bien este lugar parece formar parte de la totalidad del barrio, hay vecinos que lo señalan como un lugar aparte, aunque tipológicamente está clasificado como un asentamiento informal, siguiendo la misma lógica que Puente de Fierro original. Este asentamiento, fue creado en el año 2007 según datos del RPPVAP, sin embargo, algunos de los vecinos señalan que surgió al mismo tiempo que el Puente de Fierro 1, aunque ellos lo encuentran muy diferente y no lo consideran parte del barrio "original". 

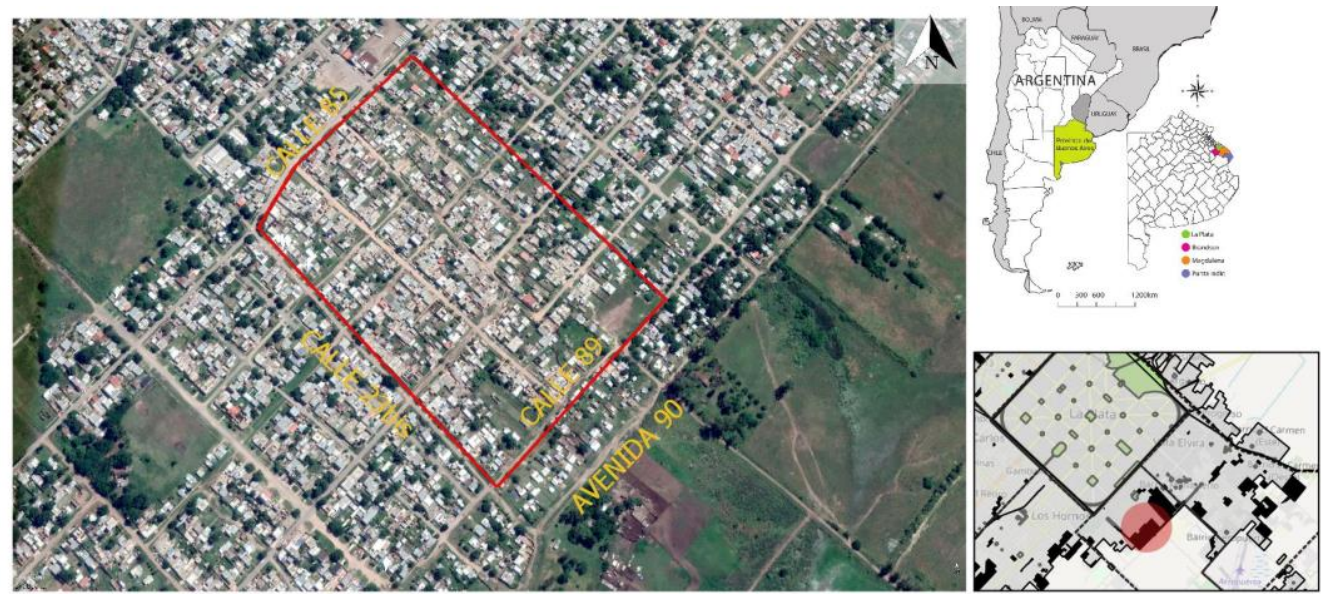

Figura 65. Puente de Fierro 2, o sector "E".

Fuente. Elaboración propia, 2019 con herramienta SIG.

Como se puede observar en la Figura 66, las viviendas de este sector presentan materiales constructivos más resistentes, siguiendo la misma lógica que la tipología de asentamiento informal. No se perciben condiciones de precariedad tan extremas como en el sector que corresponde a la tipología de villa. Los habitantes de este sector, si bien reconocen formar parte del barrio Puente de Fierro, hacen algunas diferencias al manifestar que (...) Acá en esta parte estamos mejor porque trabajamos, somos gente humilde que compramos nuestro terrenito y nos estamos levantando de a poco las casitas, hay oficios acá, está el plomero, el albañil, somos gente que trabaja (...) (Fragmento de entrevista con vecino del sector E, 2019).
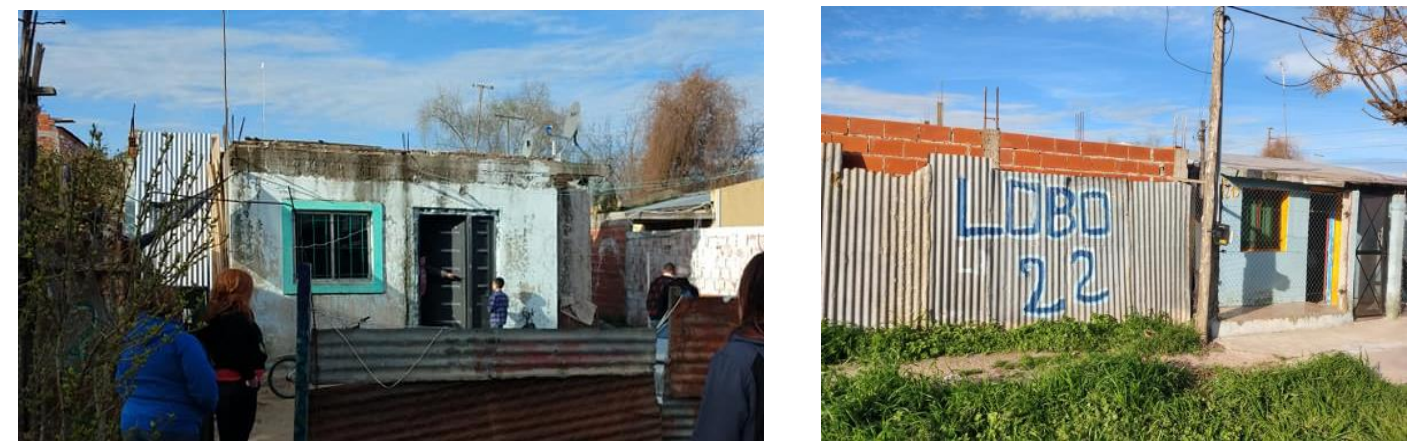

Figura 66. Puente de Fierro 2 o sector "E".

Fuente. Imágenes tomadas por el equipo de trabajo en Puente de Fierro 2016-2019.

Por último, denominado con la letra "B", se encuentra el "Barrio Evita" el sector más nuevo, que aún no ha sido relevado por los organismos oficiales por el 
hecho de ser muy reciente, en este sentido, los vecinos señalan que el barrio fue creado en el año 2017. Por las características de la ocupación, este lugar correspondería con a la categoría de asentamiento informal, aunque en su primera fase, dado que la mayor parte de las viviendas, constructivamente, son más afines a la tipología villa (Figura 67). El barrio Evita surgió como expansión del Puente de Fierro original más allá de los límites de las calles 90 y 30, principalmente a partir de la toma organizada de terrenos privados. En este sentido, uno de los referentes entrevistados expresó que (...) "la mayoría de los que viven ahí son hijos o familiares de gente que vive o que vivían en el barrio Puente de Fierro original, que se organizaron para ocupar los terrenos vacíos que estaban atrás del puente" (...) (Fragmento entrevista con referente barrial, año 2018 ver anexo 2).

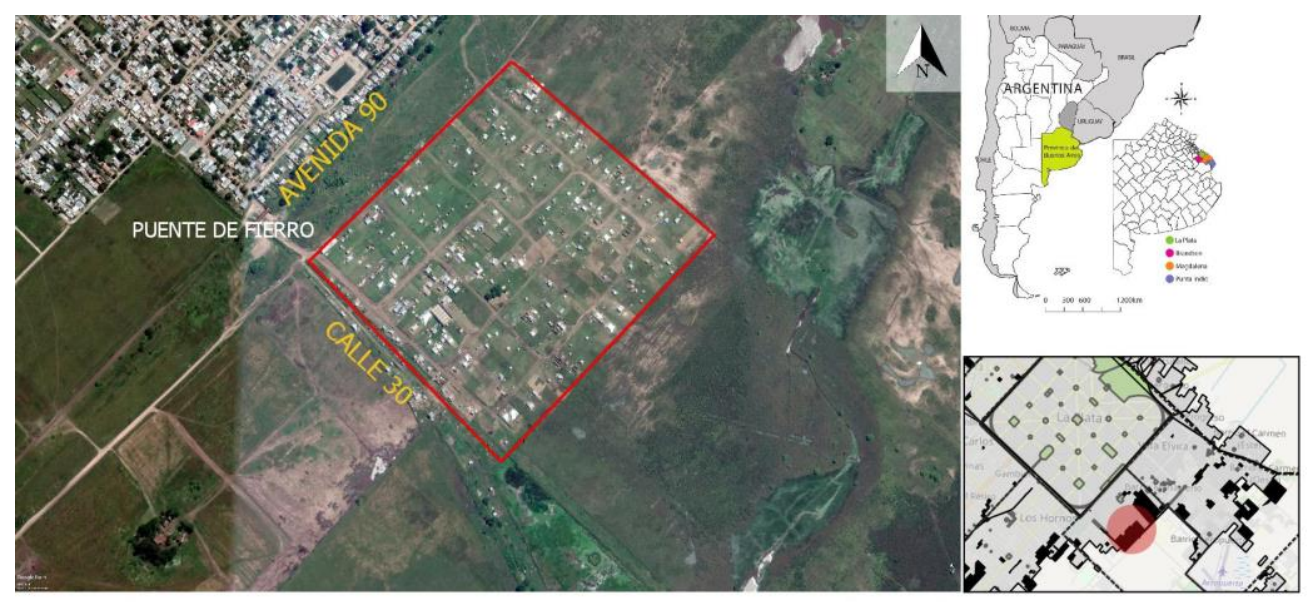

Figura 67. Barrio Evita, o sector "B".

Fuente. Elaboración propia con herramienta SIG y Google Earth, 2019.
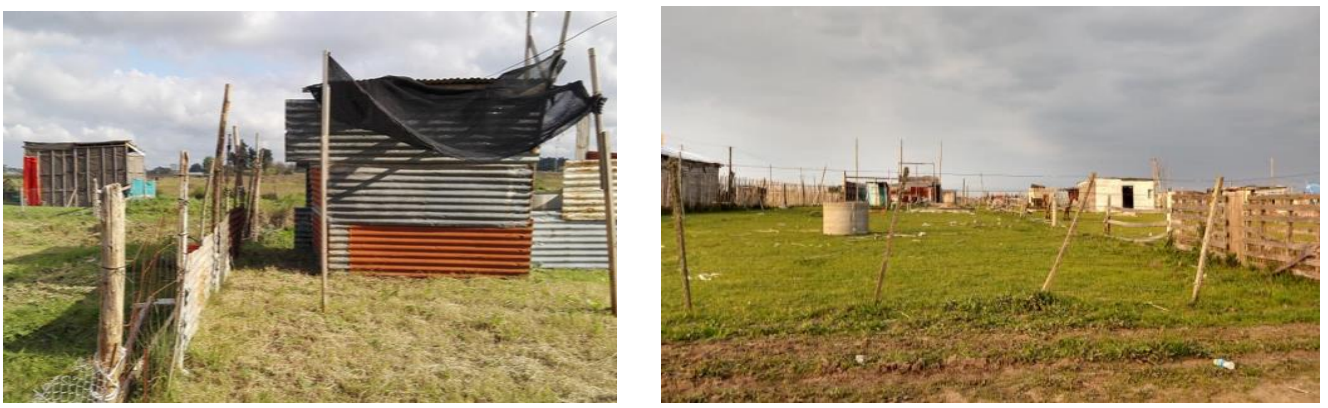

Figura 68. Barrio Evita, expansión de Puente de Fierro.

Fuente. Imágenes tomadas por el equipo de trabajo en Puente de Fierro 2016-2019. 
A modo se síntesis, se desprende del análisis que lo que es considerado como barrio no se define únicamente a partir del catastro administrativo, sino que resulta una herramienta fundamental en la comprensión, también a partir de la perspectiva de los actores. De esta manera, los sentidos atribuidos a lo que constituye el barrio como tal, dependen de los actores sociales y de los contextos de interacción en los que se encuentran insertos. La lógica práctica de los actores sociales, que puede observarse tanto en los recorridos que realizan habitualmente para trasladarse, como en los espacios de sociabilidad en los que enmarcan sus acciones, sugiere que los límites físicos no son los únicos que utilizan como marco de referencia (Segura, 2012).

Los habitantes establecen los límites sociales y simbólicos, en que los espacios físicos se asocian con características sociales y morales. Por este motivo, al interior de Puente de Fierro operan distintas categorías clasificatorias que definen diferentes "sectores dentro del barrio" o incluso "distintos barrios dentro de un mismo barrio". De esta manera, según se desprende de las entrevistas que "un sector sería Puente de Fierro" que abarcaría de la calle 24 a la calle 31 y de la 84 a la avenida 90, y al mismo tiempo "un barrio dentro del barrio", que se extiende a modo de franja por la avenida 90 desde la intersección con la calle 31 hasta aproximadamente la avenida 19.

Esta última franja, como se mencionó, es la señalada (estigmatizada) como la que presenta las condiciones de mayor vulnerabilidad física y social, siendo, además, el sector que los mismos residentes advierten como "peligroso". Por su parte, las avenidas 90 y 31 son entendidas como los límites simbólicos que los residentes utilizan para referirse a lo que significa pertenecer al barrio. Esta diferenciación entre los sectores expresa, en parte, el sentido de pertenencia de los habitantes con un determinado sector dentro de la totalidad del Barrio Puente de Fierro, dando cuenta del fuerte proceso de la apropiación que tiene lugar en el territorio. El momento en que los distintos lugares se establecieron parece uno de los criterios para comprender la diferenciación entre ellos. La diferencia temporal entre partes antiguas y nuevas se traduce, en una estructura organizacional 
diferencial, ya que cada lugar expresa sus espacios organizados de formas distintas. La división entre lugares se pone de manifiesto en diferencias en cuanto a los atributos físicos del espacio, y las condiciones de habitabilidad. Para dar cuenta de ello, en el apartado siguiente, se presenta el análisis del acceso a los servicios urbanos básicos dentro del barrio y los distintos lugares analizados hasta el momento.

\subsubsection{El acceso a los servicios urbanos básicos en la micro escala}

En cuanto a la dotación de servicios urbanos básicos, se parte de la base del análisis a partir de la metodología empleada en el capítulo 5, que arrojó que el Barrio Puente de Fierro puede caracterizarse como urbanización informal de nivel 2, es decir, abastecido parcial o totalmente sólo por 1 o 2 servicios básicos. Cabe mencionar que los datos oficiales corresponden al año 2015, por lo que, en la actualidad, esto puede tener algún tipo de variación.

En el caso de Puente de Fierro, la información puede variar según la zona o tipología al interior del barrio que se analice. Esta diferenciación tiene que ver principalmente con la tipología de urbanización, y está vinculada con el contexto del proceso de conformación del barrio. Los lugares más antiguos dentro del barrio, cuentan con una organización mejor establecida, en términos de presencia de organizaciones sociales, políticas, comedores comunitarios y vínculos con las instituciones públicas. Muchos de los vecinos históricos han iniciado diversos procesos de regularización dominial, dado el tiempo que llevan ocupando los terrenos, lo que implica una mayor facilidad para la conexión y regularización del servicio. En la Figura 69 se observa el acceso a los distintos servicios urbanos básicos para los sectores dentro del barrio. Sin embargo, a partir de las visitas se puede inferir que este sector solamente cuenta con la conexión clandestina a la red de energía eléctrica, no pudiendo acceder aun a los demás servicios urbanos básicos. 


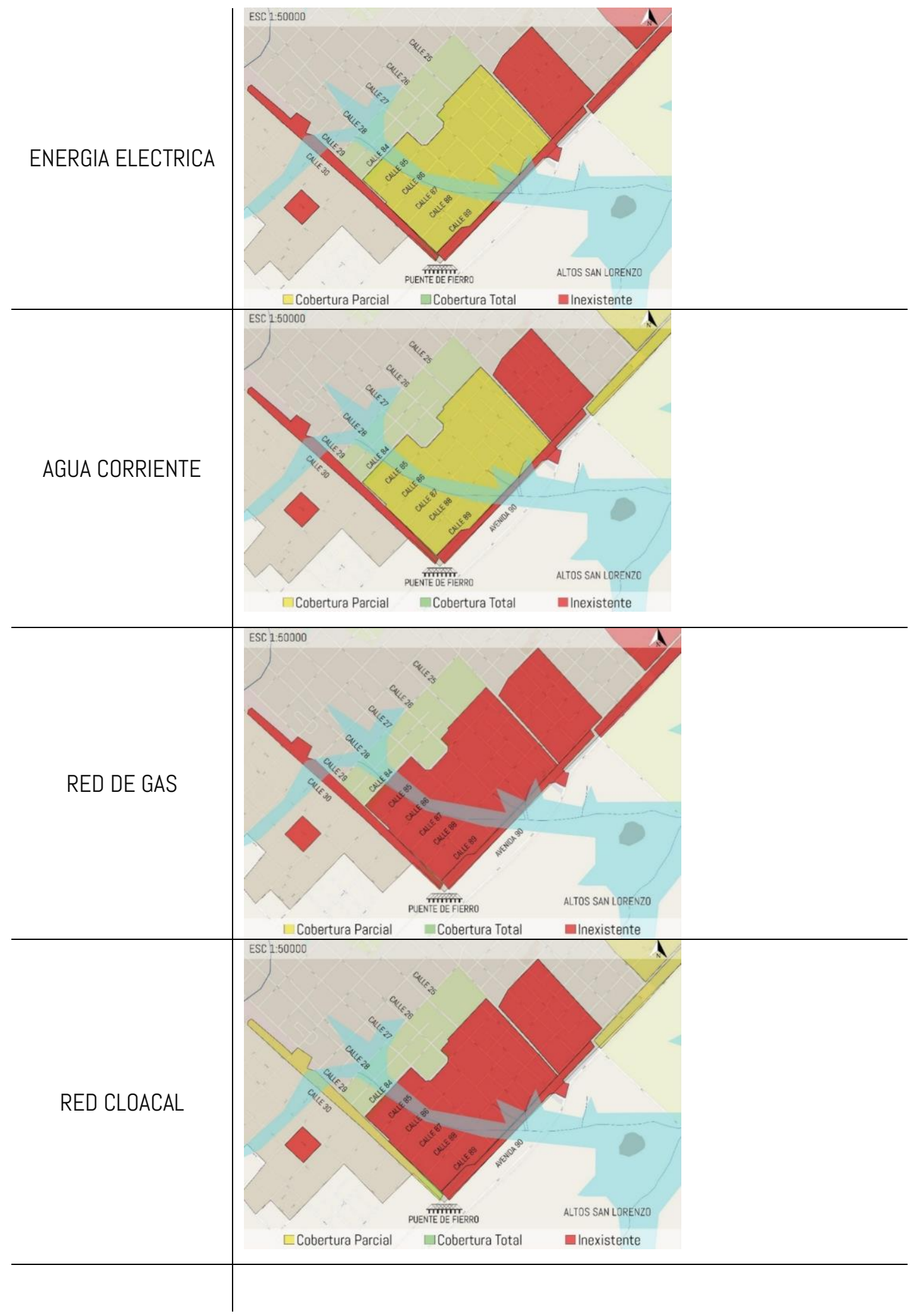

Figura 69. Abastecimiento de servicios básicos en el barrio Puente de Fierro.

Fuente. Elaboración propia (2018) con herramienta SIG, a partir de datos del RPPVAP (2015). 
En relación con el acceso a la energía eléctrica, el análisis arrojó que los sectores al interior del barrio que corresponden con la tipología de asentamiento informal, cuentan con un tipo de conexión parcial, mientras que las ocupaciones categorizadas tipológicamente como villas, sobre la calle 30 y la avenida 90, no cuentan en absoluto con el abastecimiento de dicho servicio urbano. En la actualidad, se han iniciado algunas conexiones parciales regularizando la situación, y muchos vecinos que viven en los sectores de mayor antigüedad del barrio han podido acceder a la regularidad en el servicio. Mientras tanto, en los sectores más nuevos, con mayor grado de precariedad en las viviendas aún acceden a la red de energía eléctrica de modo informal, colgándose a la energía eléctrica. Cabe mencionar que esta situación de precariedad en la conexión al servicio, ha ocasionado incendios en algunas viviendas del barrio, según referentes y vecinos (Figura 70).
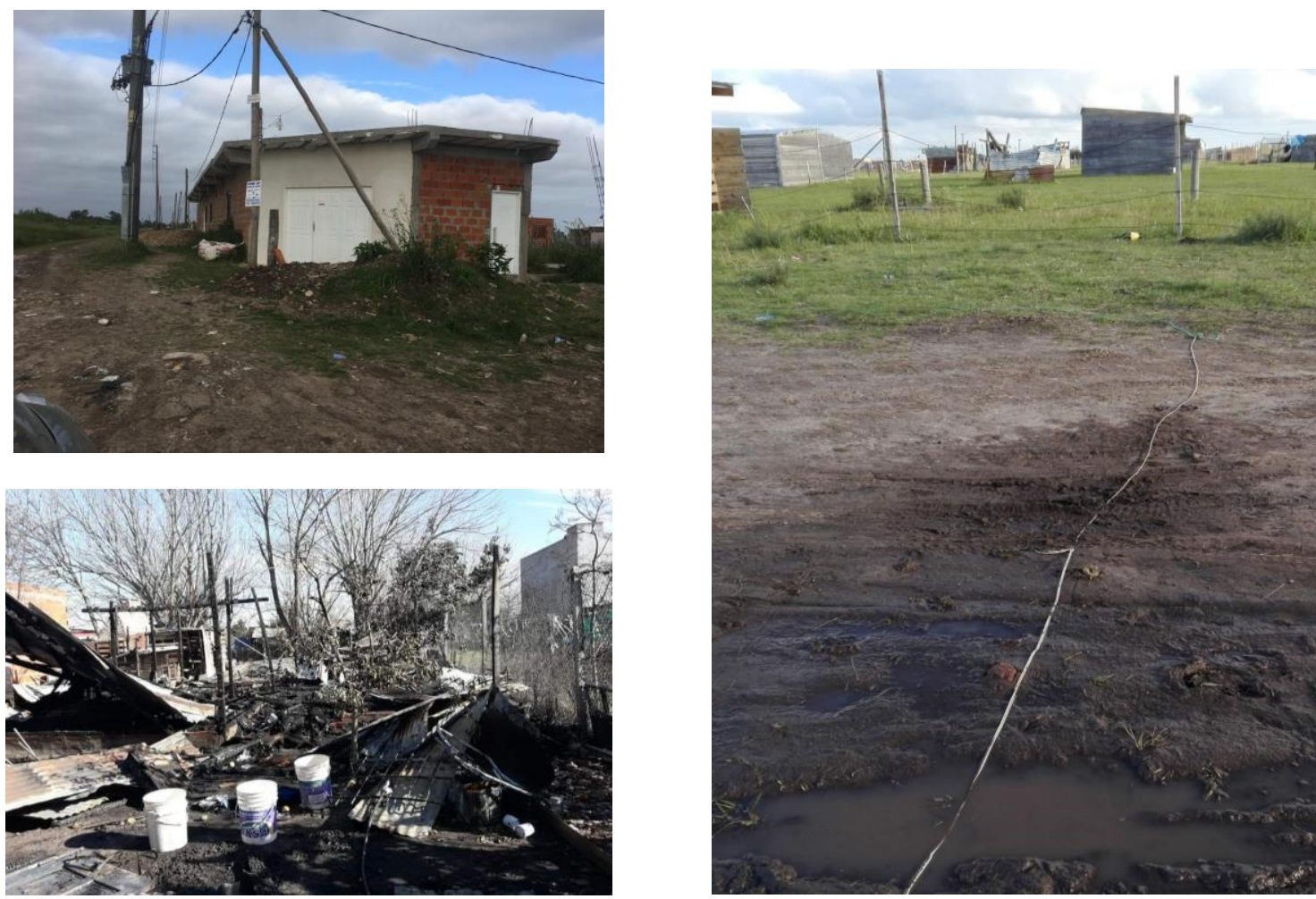

Figura 70. Conexiones precarias en distintos sectores del barrio y restos de una vivienda incendiada por accidente eléctrico.

Fuente. https://www.facebook.com/pg/Revista-Puente-de-Fierro-Territorio-Posible 
El caso del acceso a la red de agua corriente, el mismo no dista demasiado de lo que sucede con la energía eléctrica, pudiendo observarse que las manzanas que pertenecen a la tipología de asentamiento informal dentro del barrio, cuentan también con una mejor provisión en el servicio de agua potable y en el eléctrico. Las franjas sobre avenida 90 y calle 31, por su parte, categorizadas tipológicamente como villas, al no contar con una organización territorial definida, presentan mayores complicaciones a la hora de regularizar la situación de servicios básicos. Es en estos casos donde suelen presentarse las situaciones más complejas, incendios y otras complicaciones asociadas a la manera informal de acceso al servicio (Figura 71).

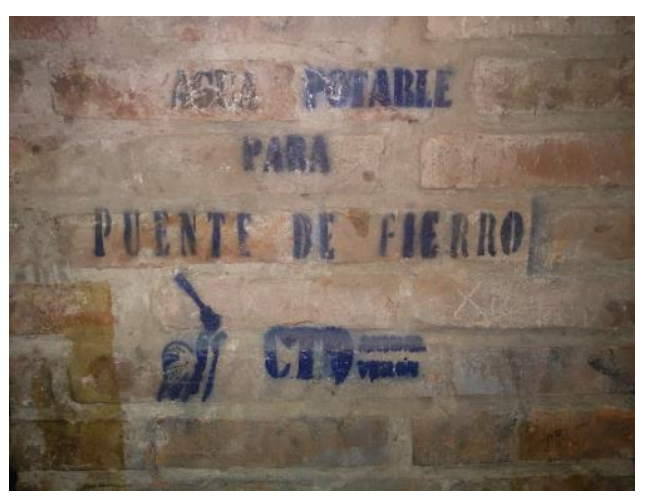

Figura 71. Grafiti en el barrio reclama "Agua potable para Puente de Fierro". Fuente. Imágenes tomadas por el equipo de trabajo en Puente de Fierro 2016-2019.

En relación con el acceso al servicio de gas natural, se desprende del análisis la falta total de este servicio de igual modo para todos los sectores del barrio. En este sentido los vecinos manifiestan que habitualmente suelen utilizar garrafas comunitarias para cocinar y en algunos casos calefaccionar. Por último, en cuanto al acceso a la red de desagüe cloacal, las viviendas suelen utilizar como sistema de eliminación de residuos cloacales, la eliminación a pozo absorbente, que como se explicó en el capítulo anterior, trae aparejadas situaciones de insalubridad para la población. En la Figura 72, se observan imágenes de conexiones informales, con caños que pasan a través de las zanjas a cielo abierto. En el espacio de las viviendas, esta situación se agrava con la presencia de basura y animales de todo tipo, generando enfermedades, según mencionan los vecinos. Cabe destacar que los servicios de gas y cloacas son lo que se encuentran en 
menor medida en Puente de Fierro, según han manifestado los vecinos. Esta situación no es particular del caso de estudio, sino que se extiende a otras urbanizaciones informales del Partido, como se expresó en el capítulo 5.
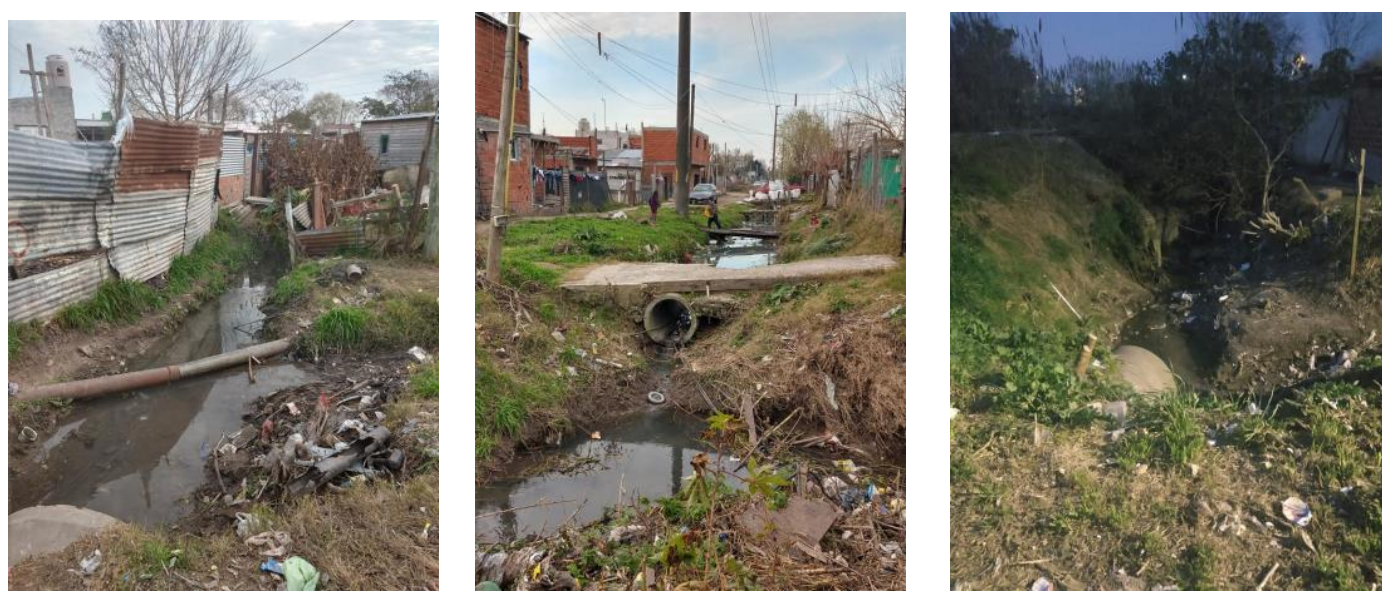

Figura 72. Imágenes de conexiones informales al desagüe.

Fuente. Imágenes tomadas por el equipo de trabajo en Puente de Fierro 2016-2019

El análisis de los atributos del espacio físico expresa la situación de criticidad que existe en relación con el abastecimiento de los servicios urbanos básicos en Puente de Fierro, que pone de manifiesto el bajo grado en cuanto al acceso de los mismos. Como consecuencia, las malas condiciones de habitabilidad perjudican la salud de los vecinos del barrio, aumentando la vulnerabilidad, independientemente de la diferenciación por sector. Esta situación se agrava y resulta peligrosa para los habitantes del barrio, principalmente en los casos donde se realizan conexiones clandestinas al servicio de energía eléctrica y las viviendas muy cercanas a focos de contaminación, debido al sistema de eliminación de los residuos cloacales por falta de infraestructura adecuada.

\subsubsection{Las condiciones de accesibilidad en la micro escala}

Del mismo modo que se presentó el análisis del acceso a los servicios urbanos básicos, también se analizaron las condiciones de accesibilidad, dentro de la dimensión físico espacial en la micro escala. Del análisis de esta variable en el capítulo anterior se desprendió que el barrio Puente de Fierro es una urbanización que se localiza dentro del primer anillo de $5 \mathrm{~km}$ de distancia al 
casco urbano. Esto quiere decir que se encuentra relativamente cerca al casco urbano, en términos de localización. Sin embargo, resulta relevante considerar las posibilidades reales con las que cuentan los vecinos de Puente de Fierro de acceder de un modo adecuado a las actividades en el casco urbano. Para este análisis, resulta de carácter fundamental, no sólo considerar la infraestructura vial, sino además los testimonios de los vecinos quienes conocen las dificultades que a veces se generan al intentar "entrar y salir del barrio".

Como se mencionó al principio del capítulo, el barrio, se encuentra localizado en la periferia Sudeste del Partido de La Plata, en la Localidad de Altos de San Lorenzo. Esta localidad se encuentra vinculada con el casco fundacional de la ciudad de La Plata, principalmente a través de la avenida 31 que conforma parte del anillo de circunvalación del casco urbano fundacional; la avenida 25, que además es acceso al barrio Puente de Fierro; la avenida 19 y por último es posible acceder por la avenida 13. Si bien hay otras formas de vinculación con la localidad, se consideran a estas últimas, las vías principales de conexión, por ser las más utilizadas y las que más cantidad de líneas, ramales y frecuencias de transporte público presentan (Figura 73).

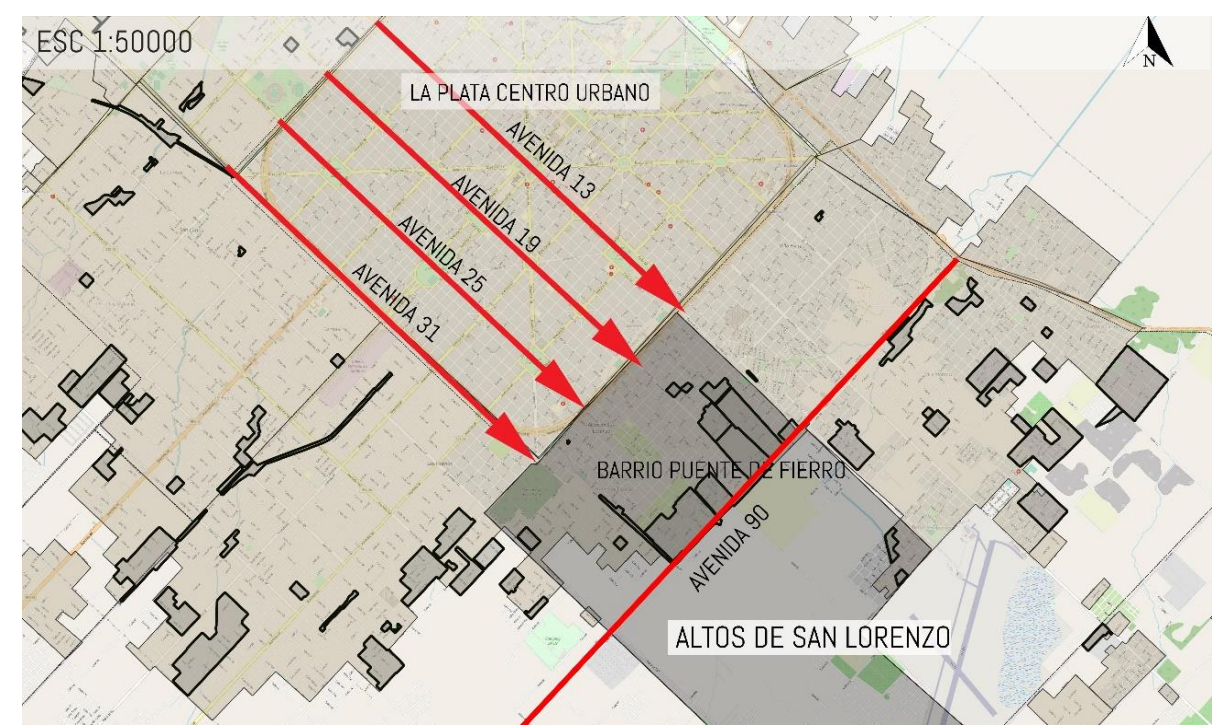

Figura 73.Principales vías de conexión entre Altos de San Lorenzo y el casco urbano. Fuente: Elaboración propia, 2018.

Los vecinos manifestaron en las entrevistas que el acceso al barrio es, muchas veces, una tarea dificultosa. Esto se debe, principalmente a la presencia de 
grandes baches, que son provocados por el mal estado de las calles, que en su mayoría no se encuentran pavimentadas. (...) "Cuando llueve se hace muy difícil para los chicos ir al colegio porque este todo embarrado y se hace difícil atravesar" (...) (Extracto entrevista con referente del barrio, 2018 ver anexo 2). "Hay que arreglar las calles para que entren los tres micros, el gran drama es que las calles no existen... Nosotros no existimos en el mapa..." (Referente barrial 2017).

Muchas veces la dificultad para salir del barrio debido al estado de las calles genera situaciones complicadas para los vecinos (Figura 74). Para ejemplificar, un vecino destaca que "... el colectivo no entra siempre", las líneas de transporte muchas veces, se encuentran en paradas que quedan alejadas de algunos sectores del barrio como por ejemplo el Barrio Evita. Por su parte, las empresas de transporte privado y los taxis (con excepción de la remiseria del barrio) también ponen de manifiesto cierta resistencia a entrar en el barrio, alegando que es muy "inseguro". Dadas estas condiciones, los vecinos deben caminar hasta la parada del colectivo, y en días de lluvia, debido a que las calles son en su mayoría de tierra, la llegada a la parada se dificulta. Las condiciones de accesibilidad, tanto desde el barrio hacia el casco urbano de la ciudad de La Plata, o viceversa se complican para los habitantes de Puente de Fierro. Esto genera una situación de aislamiento al interior del barrio, debiendo los habitantes buscar soluciones que mejoren su calidad de vida por si mismos o con acciones colectivas como comunidad.

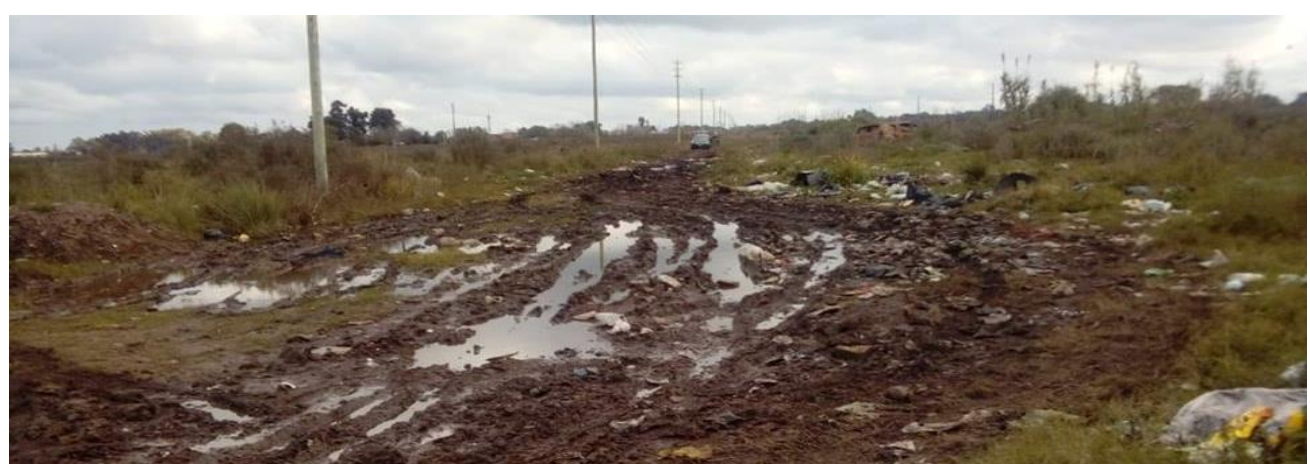

Figura 74. Estado de calles sin pavimentación.

Fuente. Imágenes tomadas por el equipo de trabajo en Puente de Fierro 2016-2019. 


\subsubsection{Las condiciones ambientales en la micro escala}

El barrio Puente de Fierro junto con las otras 22 urbanizaciones informales de la localidad de Altos de San Lorenzo, forman parte del territorio que abarca la cuenca del arroyo Maldonado. Esta cuenca tiene una superficie de 254,4 hectáreas y contiene alrededor de 5.934 familias que habitan en la informalidad (Figura 75).

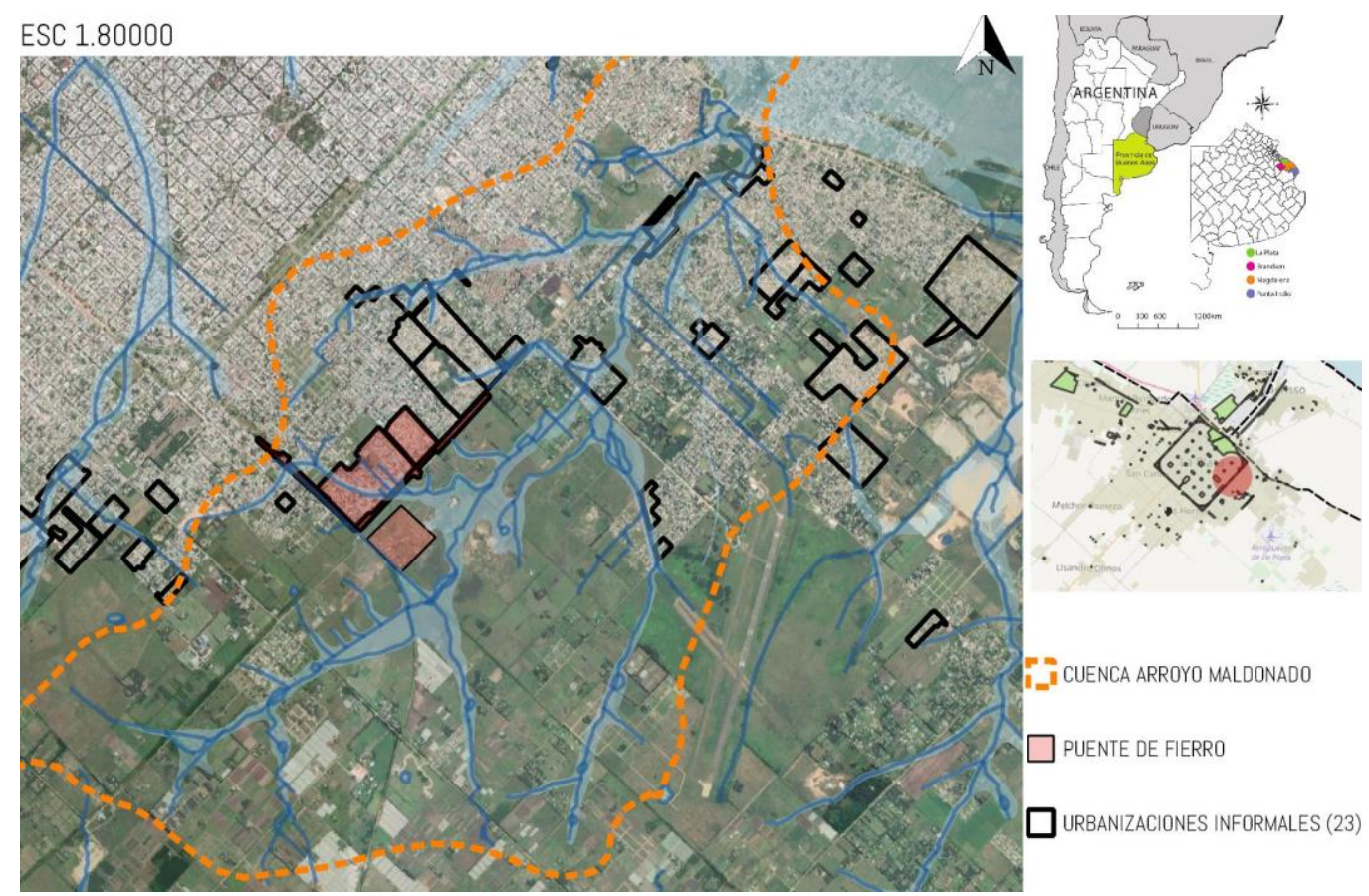

Figura 75. Puente de Fierro en la Cuenca del arroyo Maldonado. Fuente. Elaboración propia, 2019.

Para el análisis de la situación ambiental en Puente de Fierro, del mismo modo que en el capítulo anterior, se tomó como variable el nivel de peligrosidad en referencia al riesgo de inundación, entendiendo que la peligrosidad puede clasificarse en 4 rangos (Alta, Media, Baja y Muy Baja o Nula). De este modo se pudo reconocer que el Barrio Puente de Fierro está compuesto por una gran superficie de las áreas que coinciden con los lugares que tienen algún nivel de peligrosidad, reflejado en los porcentajes que arroja la Tabla 19 y que espacializan en la Figura 76. 


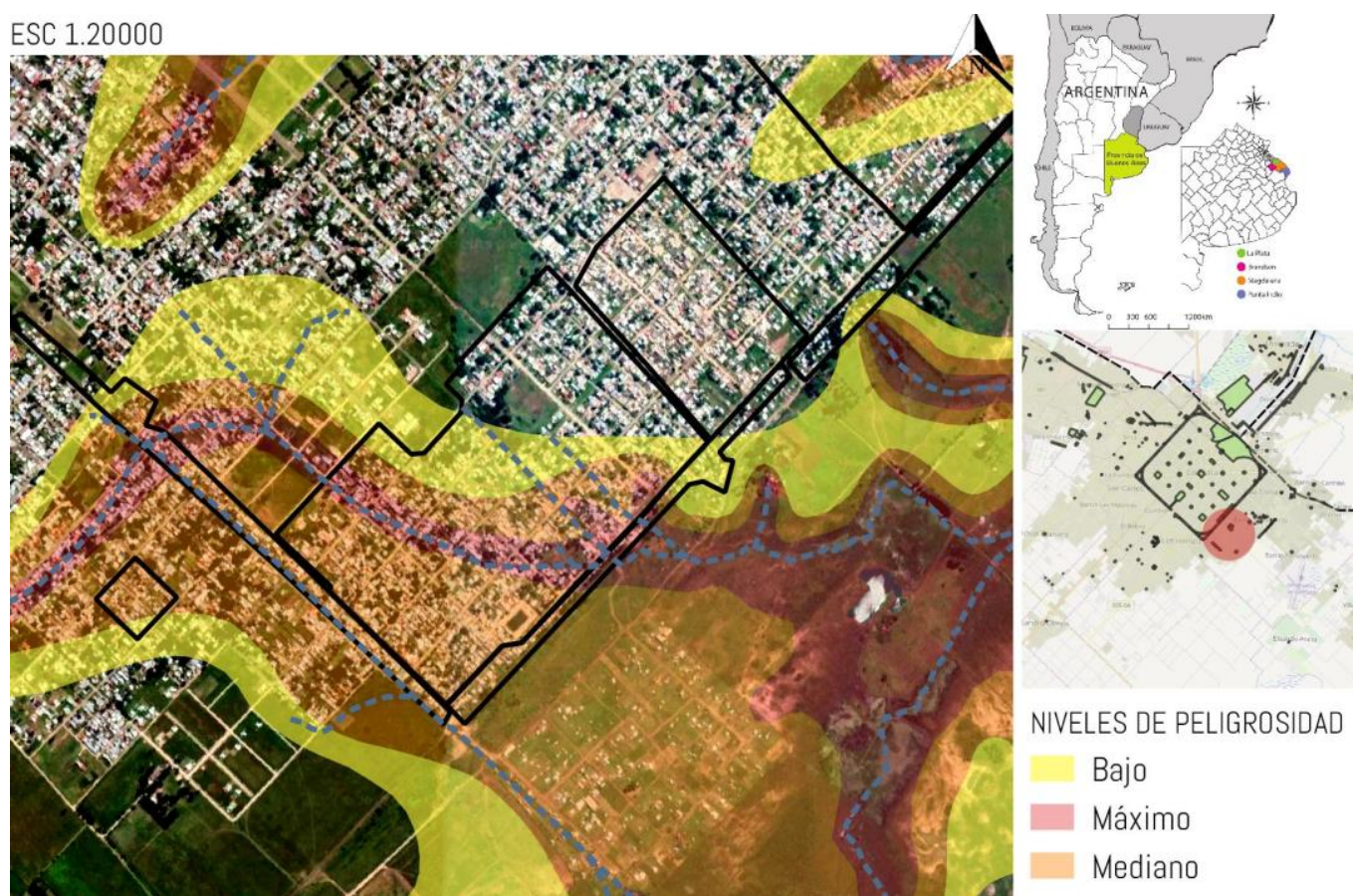

Figura 76. Niveles de peligrosidad hidrica en Puente de Fierro.

Fuente: Elaboración propia, con herramienta SIG e información CISAUA 2016.

La mayor parte de la superficie ocupada del barrio se encuentra sobre las áreas que corresponden con un nivel medio de peligrosidad. Si bien los datos oficiales arrojan que el barrio Puente de Fierro no presenta una situación crítica como otras urbanizaciones informales del Partido, los habitantes manifestaron sufrir constantes inundaciones y anegamiento de calles. La problemática cobra relevancia por la gran cantidad de población que habita en Puente de Fierro, en un nivel de peligrosidad medio, ya se considera una grave problemática para los vecinos en riesgo de inundación.

Tabla 19. Niveles de peligrosidad hídrica en Puente de Fierro.

\begin{tabular}{|l|c|c|c|c|}
\hline \multicolumn{5}{|c|}{ PELIGROSIDAD [En superficie - hectáreas] } \\
\hline & Alta & Media & \multicolumn{1}{l|}{ Baja } & Baja-nula \\
\hline Valor absoluto & 0,52 & 6,3 & 5,72 & 25,75 \\
\hline Porcentaje & $1,36 \%$ & $16,45 \%$ & $14,94 \%$ & $67,25 \%$ \\
\hline
\end{tabular}

Fuente. Elaboración propia, 2019 a partir de datos de CISAUA, 2016. 
Resulta importante señalar, y como puede observarse en la Figura 77, que la expansión del barrio ha ocupado las áreas más propensas a inundación, siguiendo un patrón de asentamiento y ocupación perjudicial. Tomando en comparación los años 2004, 2011 y 2019 se pone de manifiesto que la expansión y completamiento del barrio no ha modificado el patrón de asentamiento sobre áreas de peligrosidad, y tampoco se han realizado por parte del Estado, obras de saneamiento según consignan los vecinos.

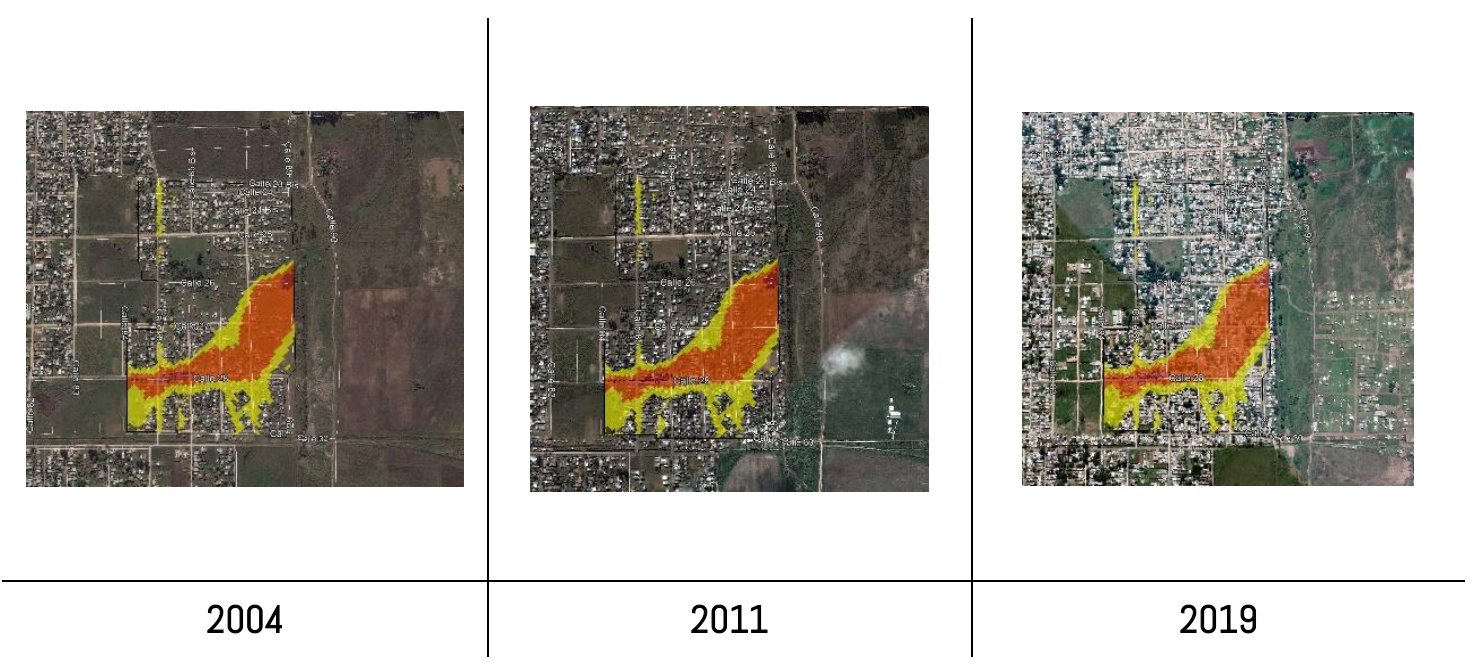

Figura 77. Análisis de crecimiento en relaciona los niveles de peligrosidad Fuente. Elaboracion propia, Google Earth, 2019 y CISAUA 2016.

Las imágenes de la Figura $\mathbf{7 8}$ fueron tomadas luego de una fuerte lluvia en distintos sectores del barrio, algunos sectores de mayor consolidación y otros como el caso del barrio Evita, mucho más reciente y sin ningún tipo de consolidación. Las imágenes resultan contundentes, evidenciando las condiciones del barrio luego de este tipo de evento ambiental. Las calles se convierten en fango y resulta muy difícil circular, tanto para vehículos como para los propios habitantes que deben caminar sobre el barro, con los peligros que supone, especialmente para niños, ancianos y personas con movilidad reducida. 

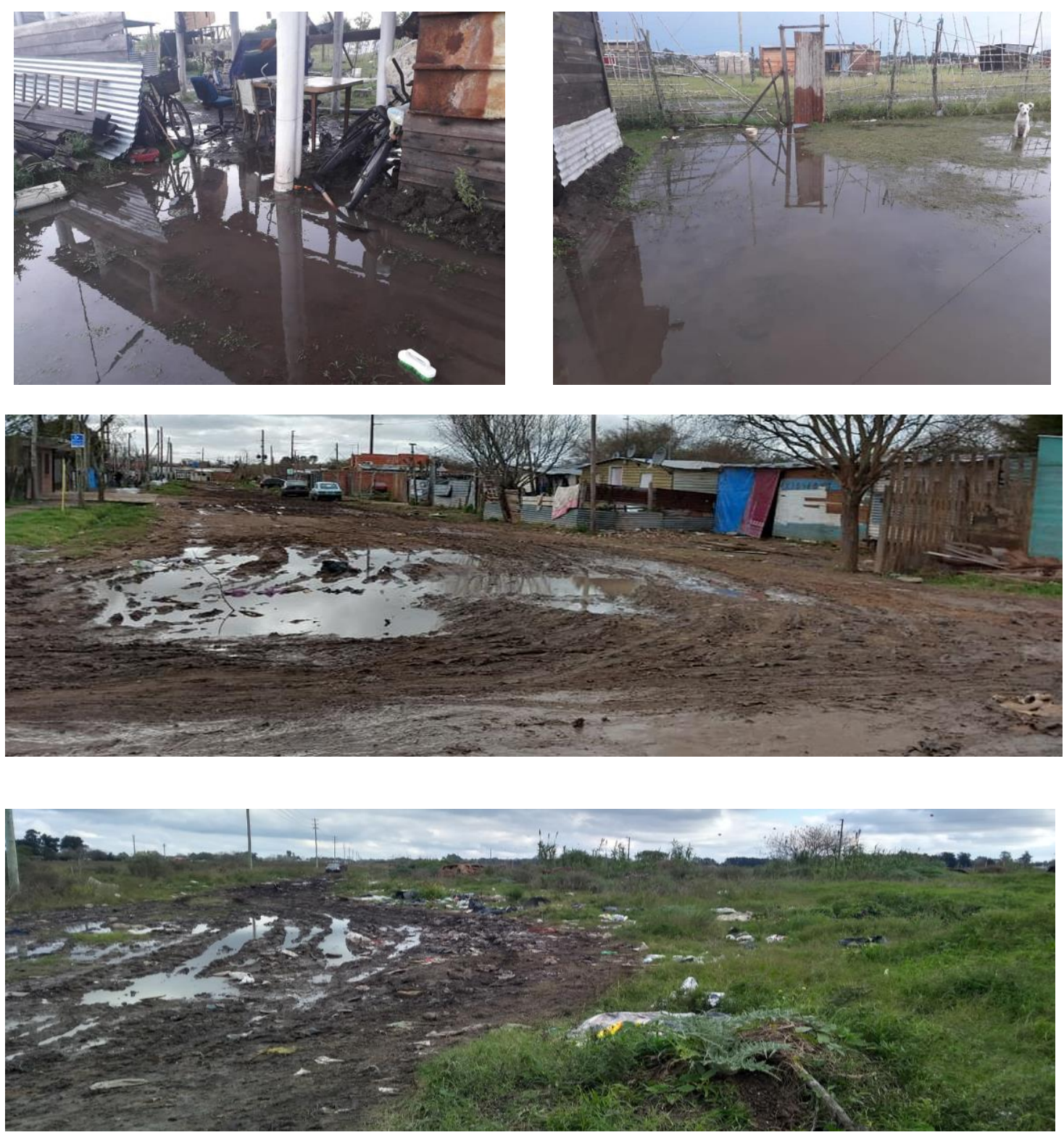

Figura 78. Puente de Fierro, después de la lluvia.

Fuente. Imágenes tomadas por el equipo de trabajo en Puente de Fierro 2016-2019

Dentro del análisis de las condiciones ambientales, otra de las problemáticas en Puente de Fierro y en la mayoría de las urbanizaciones informales del Partido, como se presentó en el capítulo anterior, es la contaminación por acumulación de basura. Es posible observar gran cantidad de basurales, de todos los tamaños y composición, siendo uno de los más relevantes el que se creó sobre el emplazamiento debajo de la estructura del puente de fierro. 
Este gran basural gracias a la iniciativa colectiva de los vecinos y las organizaciones sociales junto con la municipalidad y la UNLP, fue posible de erradicar en el año 2016. Sin embargo, aún existen gran cantidad de micro basurales y chatarra desperdigados por las calles del barrio, donde se observa todo tipo de basura tanto orgánica (ramas, etc.) como inorgánica, (plásticos, bolsas y chatarra) (Figura 79). Esta situación se agrava, además al existir focos de contaminación como los zanjeos, donde suele acumularse basura. Los vecinos al referirse al tema de la basura expresan (...) "Acá hay ratas por la basura, los chicos juegan al lado de la basura y ha habido casos de chicos que fueron mordidos por las ratas en el barrio" (...). (Fragmento de entrevista con vecina, 2018).
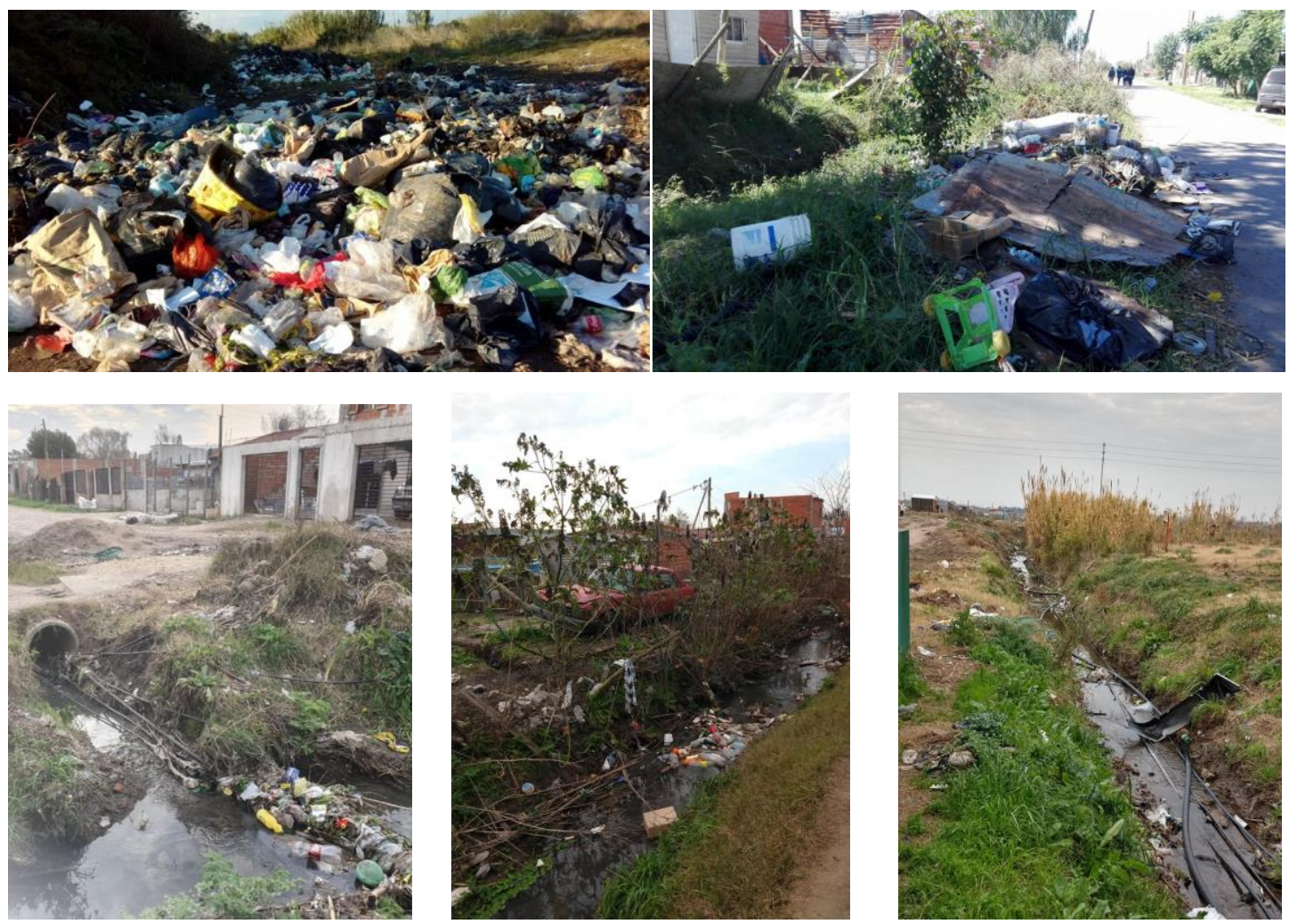

Figura 79. Tipos de basura en la micro escala.

Fuente. Imágenes tomadas por el equipo de trabajo en Puente de Fierro 2016-2019.

Lo presentado hasta el momento contribuye a la comprensión de que los lugares deben ser entendidos como el resultado de las condiciones en las que surgieron, si se los aísla de este contexto, se estarían omitiendo todas las condiciones que influyeron sobre el desarrollo de construcción de los mismos. 
Poder entender e interpretar el contexto en que se enmarcan los procesos contribuye a la comprensión del accionar de los actores, y los resultados de esas acciones. En este sentido, reconstruir los discursos de los actores sociales que habitan en situaciones de informalidad, los posiciona como principales impulsores en el proceso de ocupación y apropiación del territorio y los convierte, al mismo tiempo, en sujetos transformadores pertenecientes a un contexto, a una historia y a un lugar determinado.

\subsection{El sentido de lugar: la experiencia de habitar Puente de Fierro}

En este apartado se busca comprender e interpretar los sentidos en procesos complejos, para determinar qué discursos y prácticas tienen los vecinos que viven en urbanizaciones informales, en particular en el asentamiento informal Puente de Fierro. Se pone especial atención a las prácticas de los habitantes del barrio a la luz de los contextos político-sociales y las representaciones de los sentidos que los propios actores tienen sobre el territorio. El análisis incluye la dimensión simbólica, en tal sentido, y como afirma Reguillo (2000), en ocasiones se confunde el "escenario situacional (la marginación, la pobreza, la exclusión)" con las representaciones internas de los habitantes de las urbanizaciones informales, o se establece simplemente una relación mecánica entre las prácticas y sus representaciones. En otras ocasiones, dichas prácticas se limitan a una "dimensión descriptiva y empíricamente observable" sin llegar a una problematización contundente.

Es en esta dicotomía que existen análisis previos que han conciliado ambas posiciones, donde los habitantes son pensados como "sujetos de discurso, y con capacidad para apropiarse (y movilizar) los objetos tanto sociales y simbólicos como materiales, es decir, como agentes sociales.” En este sentido, Lindón (2007) señala que, “... las metodologías urbanas tradicionales observan el espacio urbano desde afuera de la experiencia espacial, desde afuera del sujeto habitante, por eso suelen tratar al espacio urbano como objeto" (Lindón, 2007). 
Durante el trabajo de campo se entrevistó a las voces más representativas del barrio Puente de Fierro, los creadores e impulsores del barrio y participantes activos dentro de la comunidad. Se le preguntó principalmente, acerca de la situación actual del barrio, profundizando sobre el proceso de ocupación y apropiación territorial, el contexto histórico y la creación del mismo.

En este sentido, los entrevistados manifestaron un conjunto de expectativas, problemáticas y prácticas compartidas que remiten a una experiencia común vinculada con habitar en Puente de Fierro. Esta experiencia hace referencia aspectos que se han presentado y analizado en el apartado anterior que refuerzan el vínculo que los actores crean con el barrio. Se destaca la situación de tenencia del suelo urbano y la posibilidad de acceder a un terreno propio a través de la toma; las dificultades vinculadas con la ausencia de infraestructura urbana como el acceso deficiente a los servicios urbanos básicos; la mala calidad en la accesibilidad y conexión de transporte para lograr acceder al trabajo, la salud y la educación, en el caso de poder acceder de alguna forma, y la historia del barrio con su carga simbólica en la memoria de los vecinos.

La entrevista y la participación directa permitió aplicar el enfoque dialéctico acerca del proceso de ocupación y apropiación a partir de reconocer los procesos en términos de acciones, tanto en la organización para la toma de los terrenos y las redes vecinales, así como los procesos actuales de consolidación y participación social en el barrio. En este sentido, la compresión de los lugares en términos de acciones y objetos (Santos 1996) resulta de gran utilidad ya que remite de manera directa a dos dimensiones combinadas, presentes en la construcción de un territorio, una vinculada a lo material o a sus objetos y, otra, a lo procesual o a sus acciones. En el primer caso, refiere a lo que está y existe en el territorio, los procesos y las escalas intervinientes, pero superpuestos, la localización y los niveles de relación entre los sectores y las piezas urbanas, dicho, en otros términos, el resultado espacial. El segundo caso, remite a la fenomenología del territorio, en cuanto a la comprensión de las múltiples dinámicas que lo configuraron en el tiempo, pero vistas de manera desagregada. 
En las urbanizaciones informales en general, y en el barrio Puente de Fierro en particular, el rol de las organizaciones sociales y de los diferentes actores resulta fundamental para definir procesos y comprender las prácticas sociales. En este sentido, cabe destacar la presencia de múltiples organizaciones sociales que se manifiestan en el territorio y que trabajan para mejorarlo. Hasta el momento, en Puente de Fierro, se han podido reconocer mediante la realización de las Mesas de Trabajo Permanente y los testimonios de los referentes y vecinos alrededor de 30 organizaciones sociales, de todo tipo, que trabajan de manera colaborativa y permanente para mejorar el barrio y participar en la resolución de las distintas problemáticas que se presentan.

Durante las entrevistas los referentes barriales manifestaron la importancia de la presencia de las organizaciones sociales, y la manera en la que "el barrio se une" para la resolución de problemáticas comunes, así como para efectuar los reclamos ante el Estado, por ejemplo, cuando sufren situaciones como inundaciones $\mathrm{y}$ hechos de inseguridad. De este modo, los actores sociales, referentes en el territorio, se convierten en mediadores entre los vecinos del barrio, vulnerados en sus derechos, y aquellas instancias estatales de lucha, organizacionales o privadas. Los referentes y las organizaciones sociales participan del proceso de construcción del lugar (el barrio) donde se generan escenarios de creciente pobreza, desigualdad y desempleo.

Se construyen así redes de resolución de problemas y comienzan acciones para dar soluciones y mejorar la calidad de vida y del hábitat. Es en este marco que se empieza a visibilizar la apropiación del territorio como una práctica simultánea al proceso de ocupación territorial. A partir del trabajo de campo con los actores y los testimonios acerca de la conformación del lugar, surge la pregunta sobre de la dialéctica subyacente entre la de ocupación y apropiación del territorio, que se aborda en el siguiente apartado. 


\subsection{La dialéctica entre la ocupación y la apropiación territorial en la micro escala}

Se parte de entender que, como señala Milton Santos (2000) (...) "el espacio está formado por un conjunto indisoluble, solidario y también contradictorio, de sistemas de objetos y sistemas de acciones, no considerados aisladamente, sino como el contexto único en el que se realiza la historia" (...). En este apartado se articula y sintetizan los resultados del análisis en los diferentes niveles de abordaje y las escalas territoriales, explicando la dialéctica subyacente en el proceso de ocupación y apropiación territorial en la micro escala. Para ello se parte del establecimiento de una relación conceptual de la apropiación con la creación de sentido de lugar, definido como el resultado entre acciones, concepciones y atributos físicos del espacio.

Para dar respuesta al último objetivo particular de esta tesis, se establece una relación conceptual entre la apropiación y la creación de sentido de lugar, definido como el resultado entre acciones, concepciones y atributos físicos del espacio, y se propone explorar la apropiación en la micro escala, en base al análisis de la configuración (aspectos materiales) y la utilización del territorio (aspectos simbólicos). Así, la apropiación, remite a la transformación de un espacio, con características intrínsecas, para que sea un lugar significativo desde la experiencia del actor. Es posible entonces, identificar un lugar a través de un proceso que en su primera etapa presenta una relación con los atributos físicos del espacio para luego proceder a una identificación de las concepciones sociales de la apropiación a través del establecimiento de dimensiones que operacionalizan el análisis, como las acciones, la identificación simbólica y el apego al lugar.

Con el fin de comprender la dialéctica subyacente durante el proceso de ocupación y apropiación territorial, se analizó la ocupación y apropiación territorial en términos de sistemas de objetos y los sistemas de acciones (Santos, 1996), así como las redes que se generan entre los actores y el vínculo con el 
territorio, lo que determina la creación de los lugares. Las relaciones sociales que configuran el territorio y lo convierten en lugar son el resultado del proceso de ocupación y apropiación territorial, entonces el proceso de ocupación y apropiación se manifiesta como es, uno solo, a través del cual los actores transforman el territorio en un lugar con características propias cargado de significados, a través de prácticas socialmente construidas.

De este modo, se pone de manifiesto el proceso de ocupación y apropiación territorial, llevado adelante por el grupo, fundamentalmente centrado en el análisis, por un lado, de las transformaciones del territorio, y que se relacionan con los fijos materiales (sistemas de objetos) y por el otro lado, con las dimensiones que consideran el espacio simbólico de la apropiación, como la identificación colectiva y el apego al lugar, en tanto procesos afectivos, cognitivos e interactivos desplegados (Vidal y Pol, 2005). El resultado de esta interacción se manifiesta territorialmente en la creación de un lugar concreto, en este caso se tomó como caso de estudio el Barrio Puente de Fierro, que presenta determinadas características que lo distinguen de otras urbanizaciones informales. Entre ellas las características particulares del espacio físico, una identidad marcada y que tiene que ver con la historia del barrio y un fuerte apego al lugar por parte de sus residentes.

El Esquema 14 presenta una síntesis de la operacionalización para el análisis de la apropiación territorial en la micro escala, entendiendo que el proceso de ocupación y apropiación del territorio, es posible de operacionalizar, al comprender que las componentes simbólicas y físicas (objetos y acciones) actúan como un par dialéctico, que es producto del vínculo entre los actores y el territorio, y a la vez también lo recrean. 
Esquema 14. Operacionalización de la apropiación territorial en la micro escala.

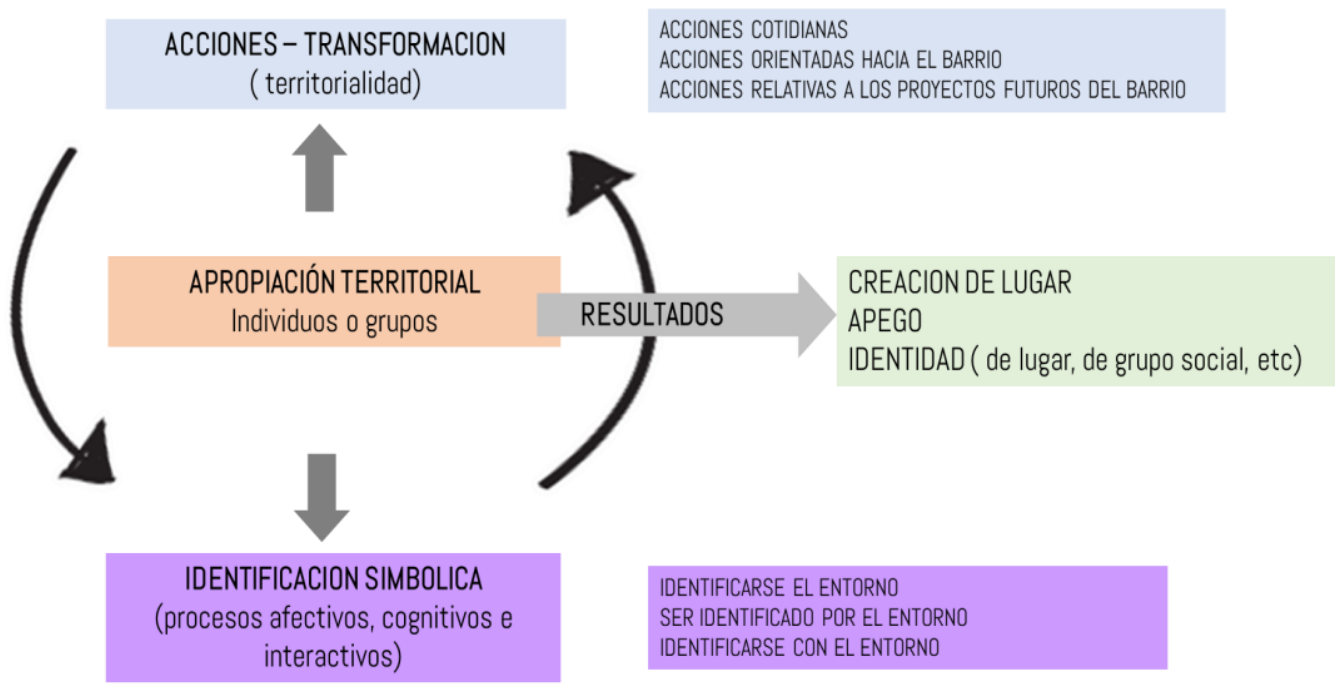

Fuente. Elaboración propia, 2018.

Santos (1996) afirma, "el objeto es el testimonio actual de la acción", pero, ¿qué sería de los objetos sin las acciones? Los objetos carecen de realidad en sí mismos, su contenido es estructurado a través de un devenir espacio-temporal de acciones, cuya trama sistémica los provee de funciones diversas en cada etapa del proceso de totalización. Todo objeto posee una estructura técnica y un contenido social. En este contexto, la acción en tanto proceso, se vincula directamente con la idea de praxis, esto es, las prácticas sociales que participan de la producción de un orden, cuya naturaleza es, simultáneamente, jerárquica y cotidiana.

Entonces, si los objetos son cristalizaciones de la acción social, la acción es el significante del objeto, ella le asigna una razón de existencia, otorgándole una función, una estructura y un sentido. "Son las acciones las que, en último término, definen los objetos, dándoles un sentido" (Santos, 1996) debido a que en la acción reside la intencionalidad social, y por su intervención, esa finalidad se plasma, se individualiza, se objetiva y materializa. De este modo, si la acción implica la ejecución de funciones, esas funciones realizadas a través de formas sociales conducen a la creación y al uso de los objetos (Santos, 1996). 
Esquema 15. La dialéctica entre los objetos y las acciones, la ocupación y la apropiación.

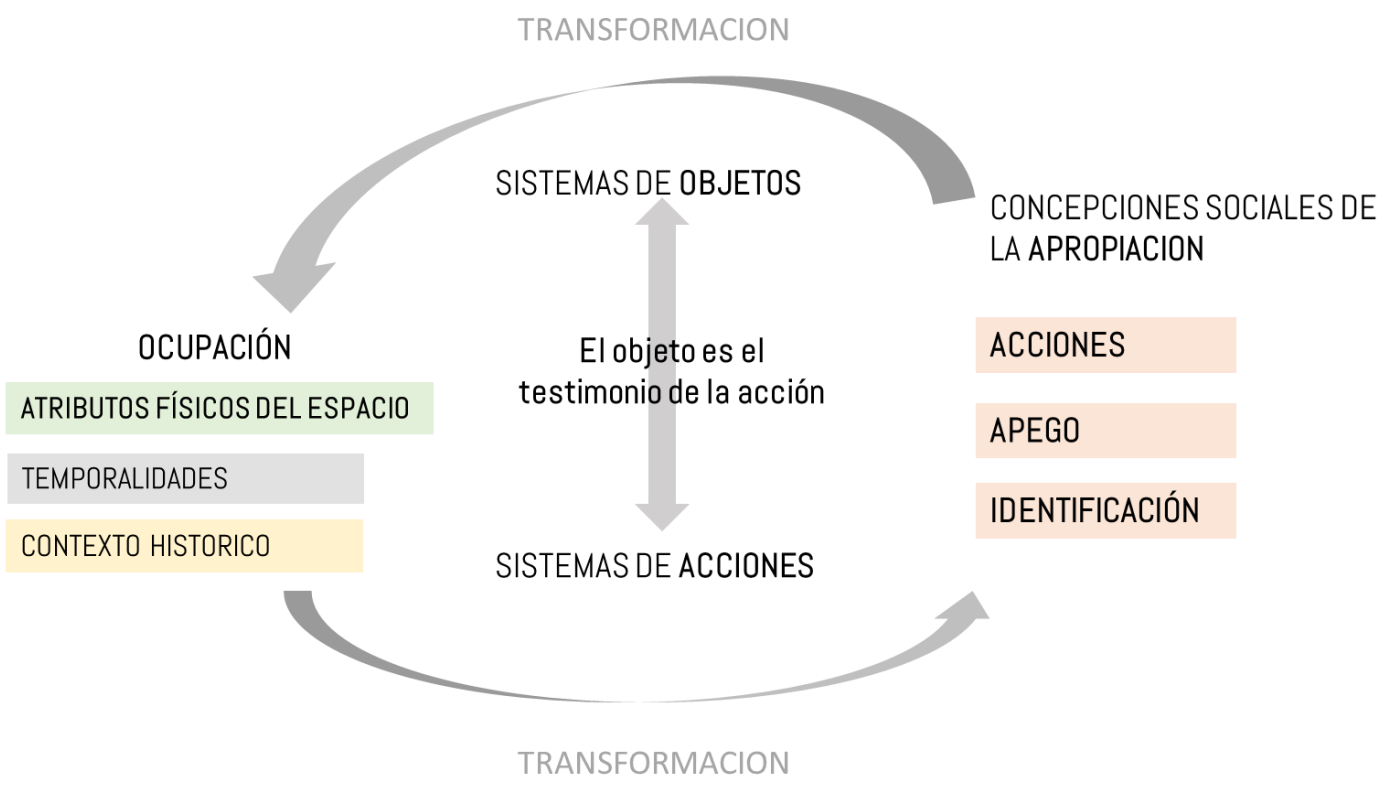

Fuente. Elaboración propia, 2019.

El territorio podría ser entendido a partir de la consideración de un conjunto de fijos y flujos (Santos, 1978), los elementos fijos, fijados en cada lugar, permiten acciones que modifican el propio lugar, flujos nuevos o renovados que recrean las condiciones ambientales y las condiciones sociales, y redefinen cada lugar. Los flujos son un resultado directo o indirecto de las acciones y atraviesan o se instalan en los fijos, modificando su significación y su valor, al mismo tiempo que ellos también se modifican (Santos, 1982; 1988). El trazado y apertura de calles, el establecimiento de las viviendas y las formas de organización social para producir la toma de la tierra vacante donde se instala un asentamiento, representan acciones que modifican el territorio, al convertirlo en un lugar y a la vez, el lugar modifica simbólicamente a los actores sociales al apropiarse de él, por lo que el proceso resulta de la interacción de los fijos y flujos, de los objetos y las acciones.

Los sistemas de objetos, refieren a aquellos elementos que brindan información empírica de modo que sea posible comprender la ocupación y apropiación del territorio a través de las condiciones espaciales del lugar. A partir 
de la toma de fotografías en la micro escala, durante el trabajo de campo fue posible observar y plasmar estos aspectos relacionados con el soporte material (los fijos), que van desde el tipo y calidad de las viviendas que se pueden encontrar en el barrio Puente de Fierro, hasta las condiciones del lugar más vinculadas con el soporte físico y la configuración actual del barrio analizado en el apartado anterior.

Resulta de importancia diferenciar, en primera instancia, a las cosas de los objetos, comprendidas las primeras como las formas desprovistas de contenido, carentes de un significado social inherente a su producción y uso, y entendidos los objetos en tanto formas-contenido, poseedoras de valores, significados y representaciones sociales, programadas funcional y estructuralmente a través de un proceso de producción socialmente organizado. De esta manera, el objeto se traduce en la forma material de la intención preexistente que le dio origen, y su forma es explicada por la actuación que de él se espera aún antes de asumir su configuración.

Las cosas por su parte, adquieren una significación ex post a su configuración existencial, en otros términos, existen como tales antes de constituirse en objetos. Por el contrario, los objetos nacen en tanto objetos, asumiendo una configuración ex ante en función de las intencionalidades y racionalidades que animaron su producción y disposición. Los objetos se convierten en un testimonio de las acciones, así una vivienda autoconstruida (Figura 80) no es solamente una construcción sobre un espacio originalmente vacío, sino que representa, por un lado, la precariedad de las condiciones de habitabilidad en el entorno del barrio. Por el otro lado, es representativo de la toma del territorio, y la organización de los participantes en la ocupación, llevadas a cabo por un grupo, que por motivos que se han explicado en capítulos anteriores, son guiados por la lógica de la necesidad a la ocupación de suelo de manera informal. 

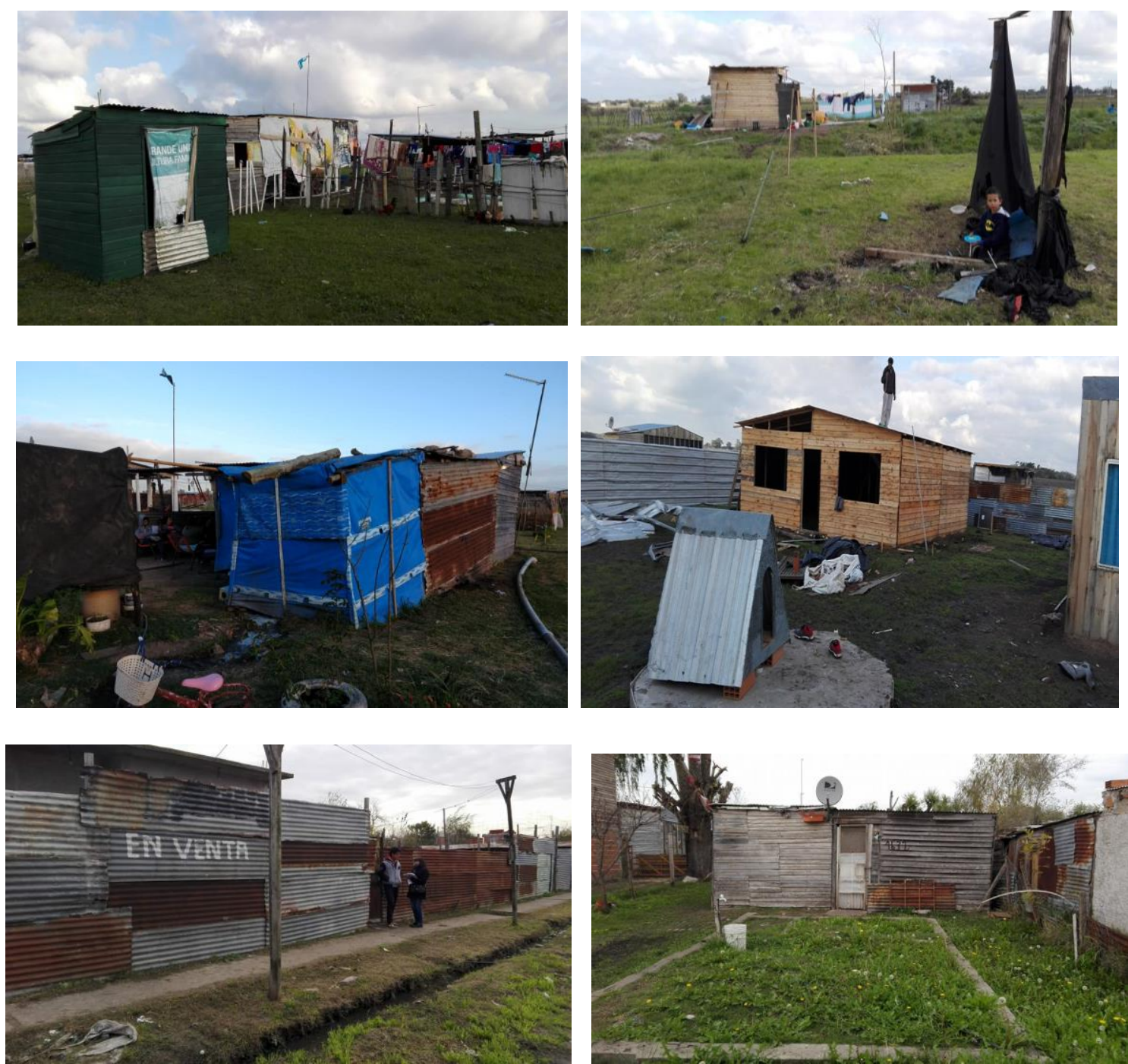

Figura 80. Viviendas en Puente de Fierro.

Fuente. Imágenes tomadas por el equipo de trabajo en el barrio Puente de Fierro 2016 - 2019.

Dentro de los objetos que pueden reconocerse en el barrio que representan símbolos y prácticas recurrentes de la población de esta urbanización se pueden observar algunos que tienen que ver con las creencias, y el modo de vida, que, en muchos casos, representan parte de una cultura remanente del lugar de nacimiento. Los habitantes del barrio recrean sus prácticas culturales, y muy lejos de abandonarlas al ocupar el territorio, las utilizan para cargar de símbolos ese espacio apropiado y así comenzar a transformarlo en un lugar (Figura 81). Cuando las personas se identifican fuertemente con un espacio tienden a personalizarlo $\mathrm{y}$, frecuentemente, los mismos objetos son utilizados como 
indicadores o símbolos, que sirven para entender que un territorio ha sido ocupado y transformado.
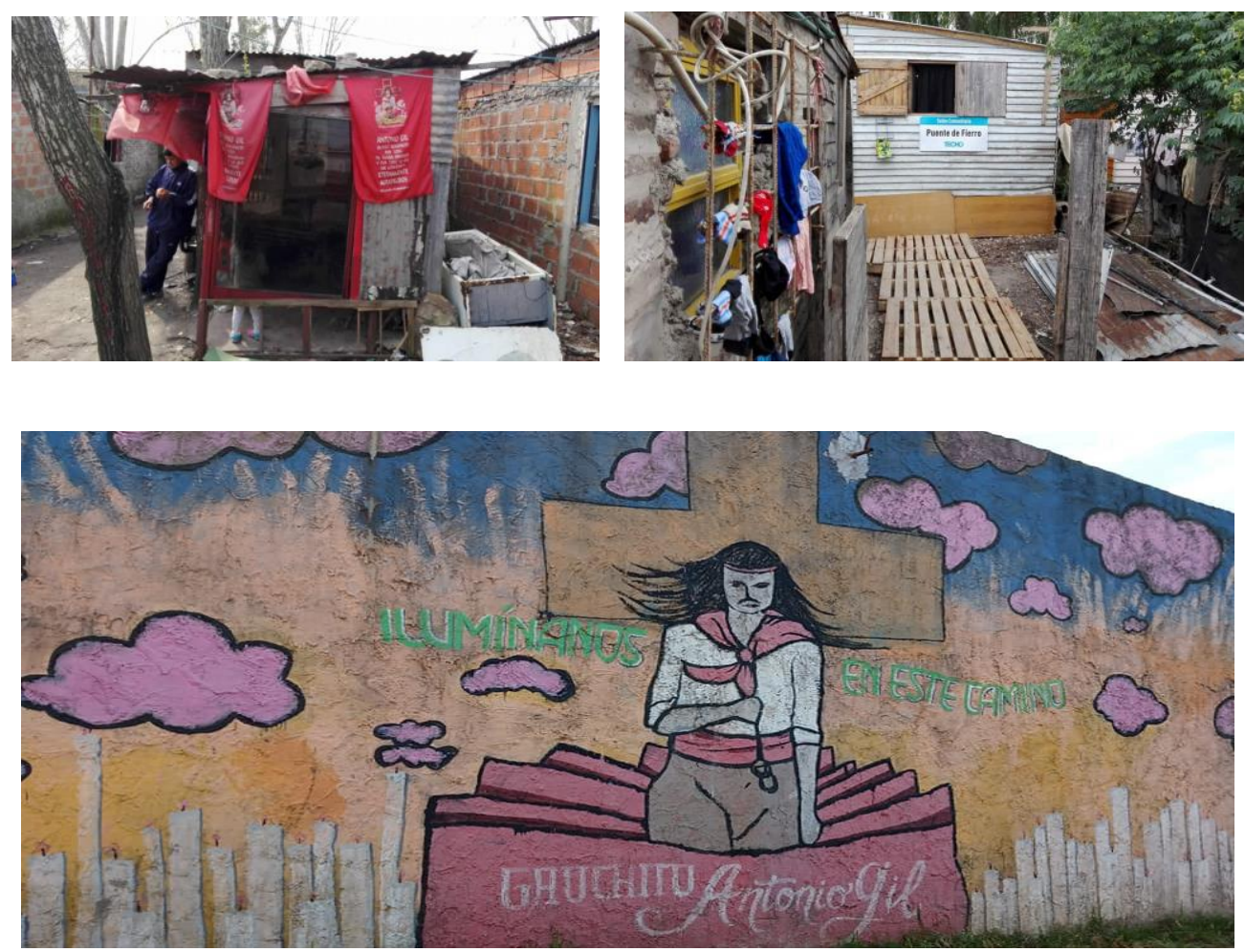

Figura 81. Símbolos y prácticas que se mantienen en Puente de Fierro.

Fuente. Imágenes tomadas por el equipo de trabajo en el barrio Puente de Fierro 2016 - 2019.

Como se mencionó en los primeros capítulos, para Chombart de Lauwe (1979) la apropiación viene dada por dos parámetros, siendo el primero, el derecho a la propiedad y el segundo, el derecho al espacio y su entorno; y es en el segundo donde se presentan mayores transformaciones por parte de los actores dadas las acciones que los mismos residentes producen y reproducen a través de sus acciones en un tiempo y espacio determinado. En este sentido, en el caso de las urbanizaciones informales, la vivienda y su entorno representan un claro ejemplo del primer mecanismo de autoproducción de este tipo de urbanizaciones, así como el proceso de conformación y consolidación del barrio.

En este capítulo, para el análisis de la ocupación y apropiación territorial en la micro escala, se pone especial atención a las acciones llevadas adelante por los actores en el territorio, y para ello, como técnica de recolección de información, 
se realizaron entrevistas a los vecinos del barrio Puente de Fierro, algunos de ellos fundadores, de primera, segunda o tercera generación, vecinos que habitan el barrio hace relativamente pocos años y también vecinos que se encuentran participando activamente en cuestiones de mejoramiento barrial a través de la pertenencia a distintas organizaciones sociales. En este sentido, en el barrio Puente de Fierro existe una extensa red interna de contención y acción social, con más de 30 organizaciones políticas, sociales, cooperativas, comedores e iglesias. Luego de realizar el trabajo de campo y pasar tiempo en el barrio Puente de Fierro y en compañía de su gente, se hace necesario aclarar que el sentido de pertenencia hacia el barrio se presenta como algo muy importante para los habitantes.

Tanto la identidad barrial, es decir, "el ser vecino de Puente" como en muchos casos el hecho de pertenecer a una organización política, comunitaria, cooperativa, religiosa o de otro tipo, se manifiestan como características fundamentales a través de las cuales los habitantes se definen a sí mismos en un lugar determinado que representa el barrio Puente de fierro. De esta forma, los habitantes definen el lugar, al ocuparlo y apropiarse de él y participando activamente para su mejora, y al mismo tiempo este lugar re define las relaciones sociales y de cooperación, así como a los mismos residentes. Se percibe en el barrio que existe una transición entre el ser "ocupantes ilegales" (con el estigma que conllevan) a ser "vecinos del barrio" y ésto resultó evidente durante la realización de las entrevistas.

Los mecanismos a través de los cuales se produce la transición tienen que ver con el vínculo que se va creando entre los actores y el territorio, hasta que llega un momento (a partir de la creación del vínculo sujeto-territorio) en el que dejan de ser esos ocupantes ilegales que se organizaron para tomar lo que no les pertenece legalmente, para comenzar a trabajar colectivamente en defender y mejorar su barrio, su lugar. Esta transición y cambio en la dinámica entre los actores y el territorio, resulta interesante de profundizar ya que se relaciona directamente con la dialéctica del proceso de ocupación y apropiación. 


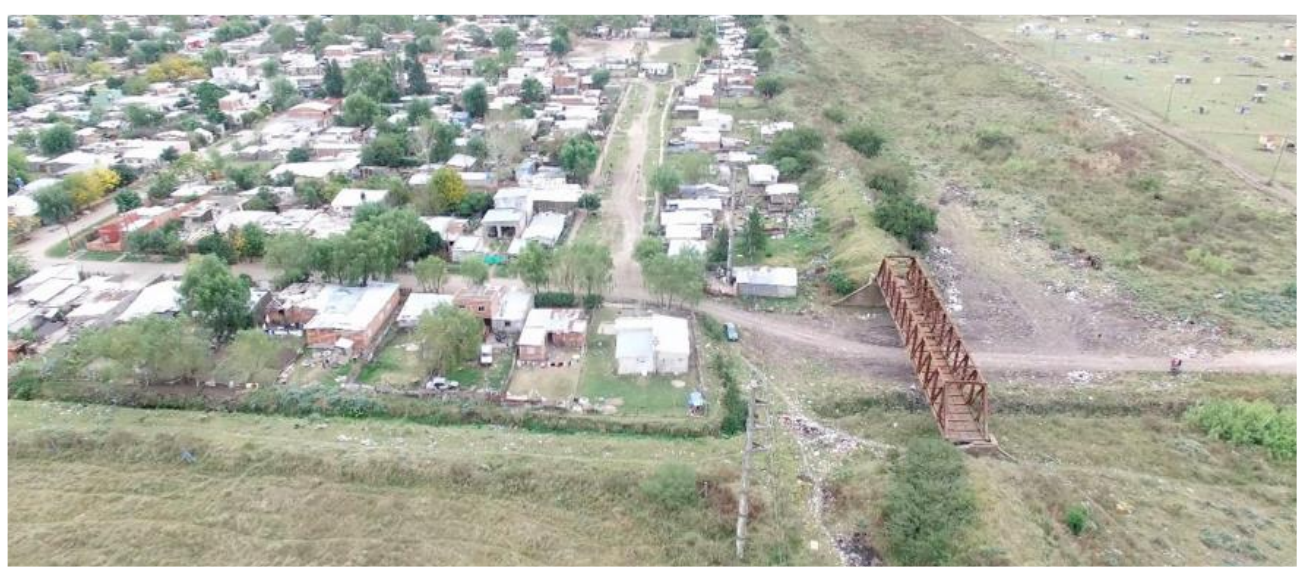

Figura 82. El barrio Puente de Fierro, y el símbolo, el Puente original de hierro.

Fuente. Canevari, 2017.

Como se ha mencionado en capítulos anteriores, son varias las posturas teóricas, las dimensiones y los elementos que componen al proceso de la apropiación como tal, pero para el análisis de la ocupación y apropiación y su operacionalización en la micro escala, se retoma la propuesta de Vidal y Pol (2005), debido a que ella no limita al territorio solamente como una referencia geográfica en la cual se suscitan las prácticas sociales, sino que, por el contrario, afirma que los grupos o individuos, al ocupar y apropiarse de un territorio, lo transforman físicamente (acción-transformación), dotándolo a su vez de características simbólicas que lo posicionan como un lugar (identificación simbólica).

Retomando del apartado teórico que el concepto de apropiación puede ser explicado a través de la identificación, la acción en el entorno (el barrio en este caso), y el apego al mismo. En este sentido, para dar cuenta de este concepto se trabajará con tres dimensiones de análisis: la acción, la identificación y el apego al barrio (Tabla 20). Dentro del modelo de análisis de la apropiación, la dimensión de la acción se divide en tres componentes, que corresponden con las acciones cotidianas en el lugar; las acciones orientadas hacia el lugar y acciones en torno a los proyectos de futuro del lugar. Esta división en tres componentes permite precisar la dimensión de la acción, en la que se señalan principalmente las interacciones sociales cotidianas, las prácticas y las actividades habituales y las menos habituales e incluso de carácter ritual. Los indicadores que configuran la 
dimensión de la identificación, por su parte recogen, tres procesos implicados en la identificación mencionados por Graumann (1983), identificar el entorno, ser identificado por el entorno e identificarse con el entorno. En cuanto a la dimensión que contempla el apego al lugar, se encuentran el hecho de sentirse del barrio, querer seguir viviendo en el barrio, en relación con una componente simbólica y afectiva.

Tabla 20. Dimensiones y variables de la apropiación territorial en la micro escala.

\begin{tabular}{|c|c|c|}
\hline DIMENSION & COMPONENTE & INDICADORES \\
\hline $\begin{array}{l}\text { APEGO AL } \\
\text { LUGAR }\end{array}$ & SIMBOLICA & $\begin{array}{l}\text { Sentir el barrio como algo propio. } \\
\text { Sentirse apegado al barrio. } \\
\text { Intención de continuar viviendo en el } \\
\text { barrio. } \\
\text { Gusto por vivir en ese barrio. } \\
\text { Sentirse del barrio. }\end{array}$ \\
\hline IDENTIFICACION & SIMBOLICA & $\begin{array}{l}\text { Diferencia con otros barrios. } \\
\text { Memoria personal en lugares del barrio. } \\
\text { Orgullo de pertenecer a ese barrio. } \\
\text { Nombre del barrio. } \\
\text { Definición del lugar de donde uno dice } \\
\text { que es cuando le preguntan de dónde es. }\end{array}$ \\
\hline \multirow{3}{*}{ ACCIONES } & Cotidianas & $\begin{array}{l}\text { Acciones realizadas en el barrio. } \\
\text { Compra en el barrio, pasar tiempo en el } \\
\text { barrio, relación, conocimiento y confianza } \\
\text { con gente del barrio, ubicación de la red } \\
\text { de relaciones primarias y secundarias. }\end{array}$ \\
\hline & Orientadas hacia el lugar & $\begin{array}{l}\text { Acciones en relación al barrio. } \\
\text { Pertenencia a entidades del barrio, } \\
\text { informarse de lo que pasa en el barrio, } \\
\text { conocimiento de actividades organizadas } \\
\text { en el barrio, asistencia a las actividades, } \\
\text { asistencia a actividades colectivas, } \\
\text { asistencia a las fiestas del barrio }\end{array}$ \\
\hline & $\begin{array}{l}\text { Relacionadas con futuros } \\
\text { proyectos de barrio }\end{array}$ & $\begin{array}{l}\text { Compromiso y visión hacia el barrio. } \\
\text { Conocimiento de los proyectos, la opinión } \\
\text { propia es tenida en cuenta, iniciativa de } \\
\text { los responsables compartiendo las } \\
\text { decisiones, iniciativa de la gente del } \\
\text { barrio sin compartir decisiones, iniciativa } \\
\text { de la gente del barrio compartiendo } \\
\text { decisiones desde el principio. }\end{array}$ \\
\hline
\end{tabular}

Fuente. Elaboración propia, 2018 en base a Vidal \& Pol 2005. 


\subsubsection{Primera dimensión de análisis: Apego al lugar (componente simbólica)}

Esta dimensión de la apropiación hace referencia a los lazos afectivos que se tienen sobre un espacio o territorio dado. Son los sentimientos de carácter positivo, que se determinan basándose en las preferencias y deseos de los habitantes, ya que "el apego implica un sentimiento de seguridad asociado a su proximidad y contacto, y una pérdida de esa figura produce miedo y angustia" (Hidalgo, 1998). Durante las entrevistas, uno de los referentes expresó “(..) El barrio es como una casa, el barrio lo querés hacer y queremos que cada día esté más lindo y dejar el ejemplo para nuestros hijos de que con unidad todo se puede... No hay un no posible, todo es posible (...)" (Extracto de entrevista con referente ver anexo 1)

En el censo “Trabajo digno, identidades, necesidades y sueños" ejecutado en Puente de Fierro en el año 2017 (ver anexo 2) se realizaron algunas preguntas a los vecinos acerca de los cambios en el barrio y si estos fueron para bien o para mal, o ambos. La mayoría de las personas censadas, el 40\% coincidió en que el barrio en cierta medida había mejorado. No obstante, un gran número de vecinos, sostuvo que el barrio había empeorado o que se mantenía igual hacía años. En este sentido, el $28 \%$ indico que, en parte, había mejorado en algunas cuestiones y en otras empeoró, el 18\% respondió que el barrio siempre está igual y el 11\% respondió que sólo había empeorado (Tabla 21).

En base a estos resultados, cabe señalar que las mejoras que los vecinos censados parecen encontrar en el barrio, rápidamente son identificadas por ellos en relación con la iniciativa colectiva. Ellos manifiestan que, si hubo cambios positivos en relación con la infraestructura y la calidad de vida, tuvieron que ver con la unión y la insistencia, y no únicamente por acción del Estado municipal en materia de intervención. 
Tabla 21. Apego al lugar.

\begin{tabular}{|c|c|c|c|c|}
\hline \multicolumn{5}{|c|}{ ¿Piensa que el barrio cambió en los últimos años? } \\
\hline & & Frecuencia & Porcentaje & Porcentaje válido \\
\hline \multirow{5}{*}{ Válidos } & Mejoró & 45 & 8,2 & 40,5 \\
\hline & Empeoró & 13 & 2,4 & 11,7 \\
\hline & Mejoró y empeoró & 32 & 5,9 & 28,8 \\
\hline & Siempre igual & 21 & 3,8 & 18,9 \\
\hline & Total & 111 & 20,3 & 100,0 \\
\hline $\mathrm{Ns} / \mathrm{Nc}$ & Sistema & 435 & 79,7 & \\
\hline & Total & 546 & 100,0 & \\
\hline
\end{tabular}

Fuente. Censo "Trabajo digno, identidades, necesidades y sueños" en Puente de Fierro, 2017 ver anexo 2.

A raíz de esta pregunta, surgieron otros interrogantes que merecen ser analizados, en relación a los anhelos de algunos vecinos en torno a vivir en otro barrio (Ver encuesta anexo 2). La respuesta representa un indicador del apego al lugar que sienten los residentes dentro de la componente simbólica de la apropiación. En este sentido, los resultados arrojaron que a un 54\% de las personas censadas le gustaría permanecer en el barrio (Tabla 22). Si bien la mayoría de los vecinos pretende continuar viviendo en Puente de Fierro, muchos de ellos manifiestan que para que su deseo fuera completo en un 100\% sería necesaria la intervención municipal para brindar las condiciones mínimas de habitabilidad que necesitan. Cabe destacar que muchos de los encuestados son segunda o tercera generación de familias en el barrio, lo cual incrementa el sentido de pertenencia en relación con el apego al lugar por la memoria familiar, infancia y experiencia de vida en el barrio.

Tabla 22. Intención de permanecer en el barrio.

\begin{tabular}{|c|c|c|c|c|}
\hline \multicolumn{2}{|c|}{} & Frecuencia & Porcentaje & Porcentaje válido \\
\hline \multirow{3}{*}{ Válidos } & $\mathrm{Si}$ & 50 & 9,2 & 45,9 \\
\cline { 2 - 5 } & No & 59 & 10,8 & $54, \mathbf{1}$ \\
\cline { 2 - 5 } & Total & 109 & 20,0 & 100,0 \\
\hline
\end{tabular}

Fuente. Censo "Trabajo digno, identidades, necesidades y sueños" en Puente de Fierro, 2017 ver anexo 2. 


\subsubsection{Segunda dimensión de análisis: Identificación (componente simbólica)}

Esta categoría incluye aquellos procesos identitarios que tienen relación con la categorización personal; en esta categoría figuran las manifestaciones de identidad del lugar (Proshansky, 1978), identidad urbana (Lalli, 1988) e identidad social urbana (Pol y Valera, 1994). Es preciso mencionar que todas ellas se encuentran conformadas por recuerdos, preferencias personales, memorias o cualquier otra referencia originada en la vida de las personas que guarde alguna relación con los espacios habitados (Vygotsky, 1934 en Pol, 1994).

Tanto el apego al lugar como la identificación tienen una componente simbólica; ésto tiene que ver con el hecho de que los espacios "tienen la capacidad de aglutinar determinados significados en su seno, es decir, tienen la capacidad de cargarse de significado simbólico" (Valera, 1996). Algunos eventos, como la inundación del 2 de abril de 2013 que causó grandes estragos en el barrio también ponen de manifiesto la identificación entre los actores y el territorio (...) "Después de la inundación (del 2 de abril de 2013) nos dimos cuenta que somos todos hermanos, pasamos por un momento muy feo y no nos importaba nada más que estar todos juntos. Nos dimos cuenta que unidos podemos lograr muchas cosas" (...) (Vecino del barrio de hace más de 20 años, 2018).

En el capítulo anterior se analizó la configuración del barrio, y se determinó que éste se compone por cinco lugares diferenciados, tanto por los vecinos como por las tipologías que representan (villa y asentamiento informal). El hecho de que los vecinos se identifiquen como parte de uno u otro lugar dentro de la totalidad que representa al barrio, pone de manifiesto la componente identitaria de la apropiación que existe en Puente de Fierro. En este sentido, los grafitis o murales en las calles de Puente de Fierro son un ejemplo que representa algunas manifestaciones de las estrategias a través de las cuales los individuos o grupos establecen vínculos afectivos o identificativos con el entorno o territorio que habitan. Sirven como indicadores, que en algunos casos refieren a memorias 
dentro del barrio, representados en personajes y situaciones vividas que forman parte de la experiencia, no siempre negativa de habitar (Figura 83).

Los vecinos manifiestan orgullo de pertenecer al barrio, pero marcan diferencias entre los distintos sectores, a través de expresiones tales como: "aquella zona es más peligrosa que esta" o "esta parte del barrio es diferente porque acá somos gente de trabajo...". Sin embargo, los vecinos entrevistados y censados coinciden que el barrio responde a un mismo nombre "Puente de Fierro" que los identifica a todos simbólicamente, con excepción del barrio Evita, que es interpretado por los vecinos como una extensión, la más reciente, del asentamiento original y que lleva otro nombre. Los habitantes de barrio Evita, en parte son antiguos residentes del Puente de Fierro original, hijos y nietos de habitantes históricos que vieron la posibilidad de tomar los terrenos vacíos y construir su vivienda propia.
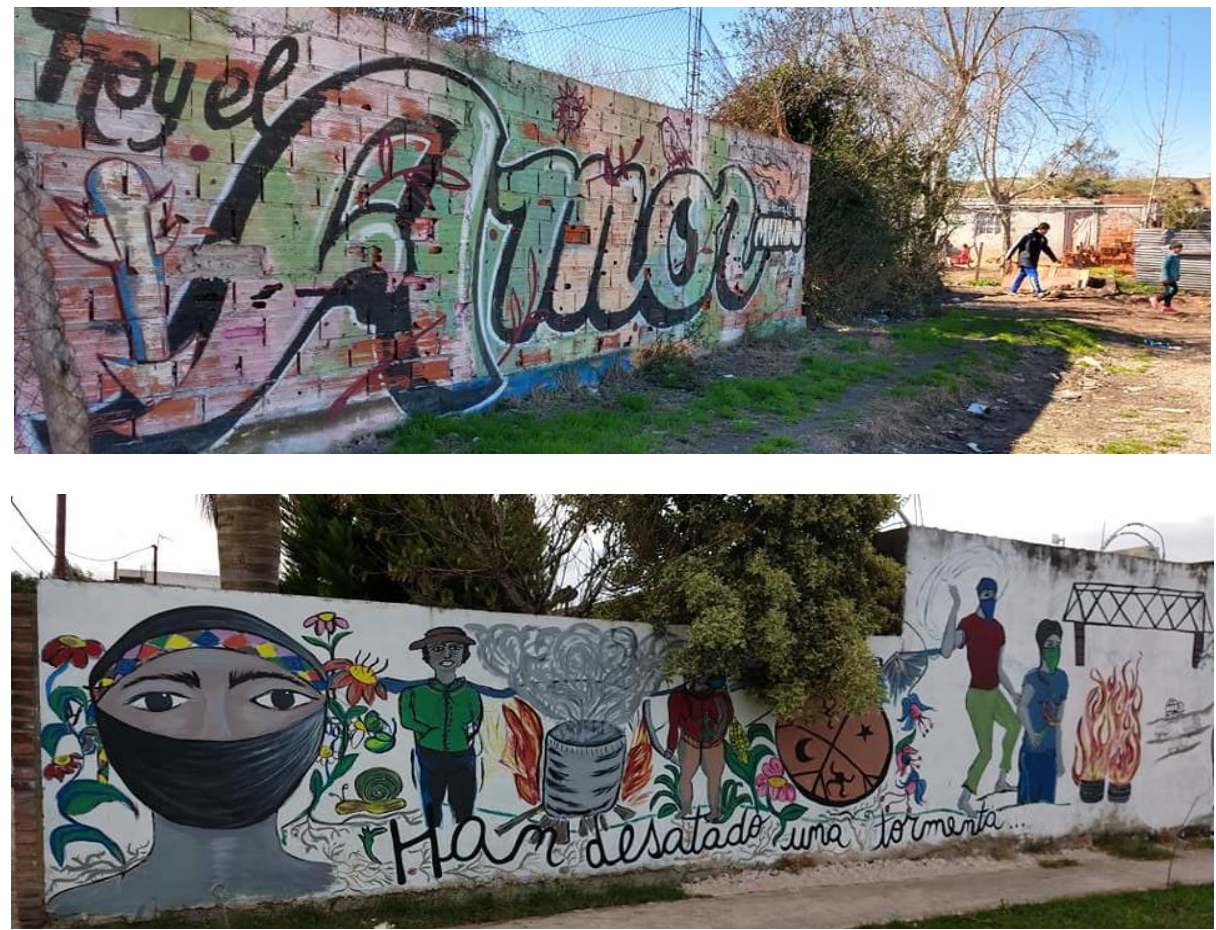

Figura 83. Manifestaciones de la identificación barrial con murales en Puente de Fierro. Fuente. Imágenes tomadas por el equipo de trabajo en el barrio Puente de Fierro 2016 - 2019.

Cuando se pregunta a algún habitante/vecino del barrio de dónde es y a dónde pertenece, la respuesta es Puente de Fierro, indistintamente de la zona al interior 
a la que se haga referencia, o de donde se encuentre ubicada su vivienda o del lugar donde haya nacido. Aun así, se marca la diferencia con otros barrios cercanos, es decir, se encuentran algunas identificaciones con lugares al interior del barrio, pero al comparar con otras urbanizaciones, la identificación y la representación en el imaginario colectivo de los vecinos del barrio es mayor.

El sentido de pertenencia y la identificación con el barrio se manifiestan a través de las acciones que se realizan en el barrio, como se profundizará en el siguiente apartado, dado que las mismas se proponen para la totalidad del barrio, sin identificar de manera sectorizada uno u otro lugar. Por el contrario, los mismos vecinos mencionan que "es necesario que todos formen parte de las noticias y decisiones que se tomaran hacia el barrio." Un ejemplo de ello lo constituyen las Mesas de Trabajo Permanente en el barrio ${ }^{27}$, a las que acuden residentes de todos los lugares al interior de Puente de Fierro, y de todas las organizaciones sociales, ya que, en su mayoría, entienden que el acto de formar una unidad otorga beneficios mayores en cuanto a posibilidades de mejora.

\subsubsection{Tercera dimensión de análisis: Las acciones}

Las acciones constituyen manifestaciones posibles de encontrar a nivel individual o de manera colectiva, cuando este proceso es reconocido y compartido por una comunidad o un amplio número de personas. Por ello, se busca detectar la carga de significados que la comunidad ha establecido en los espacios o prácticas resultado de "una construcción social que opera entre las personas que configuran esta comunidad o que utilizan este espacio o se relacionan con/en él" (Valera, 1996).

\footnotetext{
27 Se trata de una iniciativa innovadora de gestión integral del territorio en la urbanización informal más grande de La Plata, Buenos Aires, Argentina, que mediante la ejecución de más de treinta Mesas mensuales de Trabajo ha producido notables buenos resultados acompañado la construcción de Políticas Públicas. Proyecto de Investigación PIO UNLP-CONICET 2104-2016. Actualmente Proyecto de Investigación "La Ciencia y la Gente, otras Políticas Públicas" con sede en IdIHCS UNLP-CONICET. http://idihcs.fahce.unlp.edu.ar/territoriosposibles/puente-de-fierroterritorio-posible-mesa-de-trabajo-permanente-y-agenda-cientifica-2014-2026-pio-om/
} 
La participación y la comunicación son mecanismos que favorecen la apropiación; la primera permite coordinar acciones orientadas a la transformación mientras que la segunda dota de contenido a la identificación del barrio. A través de la acción sobre el entorno, las personas y los grupos transforman el espacio, dejando en él su impronta, es decir, señales y marcas cargadas simbólicamente. Mediante la acción, la persona o grupo incorpora el entorno en sus procesos cognitivos y afectivos de manera activa y actualizada. Las acciones dotan al espacio de significado individual y social, a través de los procesos de interacción (Pol, 1996; 2002).

Cabe mencionar que, en términos metodológicos, las acciones hacia el futuro del barrio, junto con las acciones de carácter cotidiano (como hacer la compra en el barrio y relacionarse con los vecinos) y las acciones orientadas hacia el barrio (como asistir a las actividades que se realizan en el barrio) se operacionalizaron a través de diferentes indicadores, en cuestionarios y entrevistas, al igual que las demás dimensiones (identificación y apego al lugar). Lo anteriormente expresado se pone de manifiesto en las siguientes palabras de un vecino del barrio, al señalar que (...) "Nosotros queremos hacer de Puente un territorio posible trabajando en equipo, somos una gran familia, respetando el trabajo de cada institución... siempre tratando de solucionar cosas, con muchísimos proyectos para el barrio (...)" (Fragmento de entrevista con referente, ver anexo 1).

\section{Acciones cotidianas - Acciones realizadas en el barrio}

Entre las acciones cotidianas que se realizan en el barrio Puente de Fierro se encuentran las actividades diarias en el barrio como pasar tiempo en el barrio la relación, conocimiento y confianza con gente del barrio, la ubicación de la red de relaciones primarias y secundarias. Si bien estas acciones tienen un carácter cotidiano, algunas de ellas, que merece la pena mencionar, acontecen durante los fines de semana como las ferias de ropa y ollas comunales, de las que toda la comunidad participa (Figura 84). Se ha mencionado que la participación y la comunicación son mecanismos que favorecen la apropiación, y ésto se manifiesta 
en el fortalecimiento de las redes sociales a partir de las acciones cotidianas realizadas en el barrio.
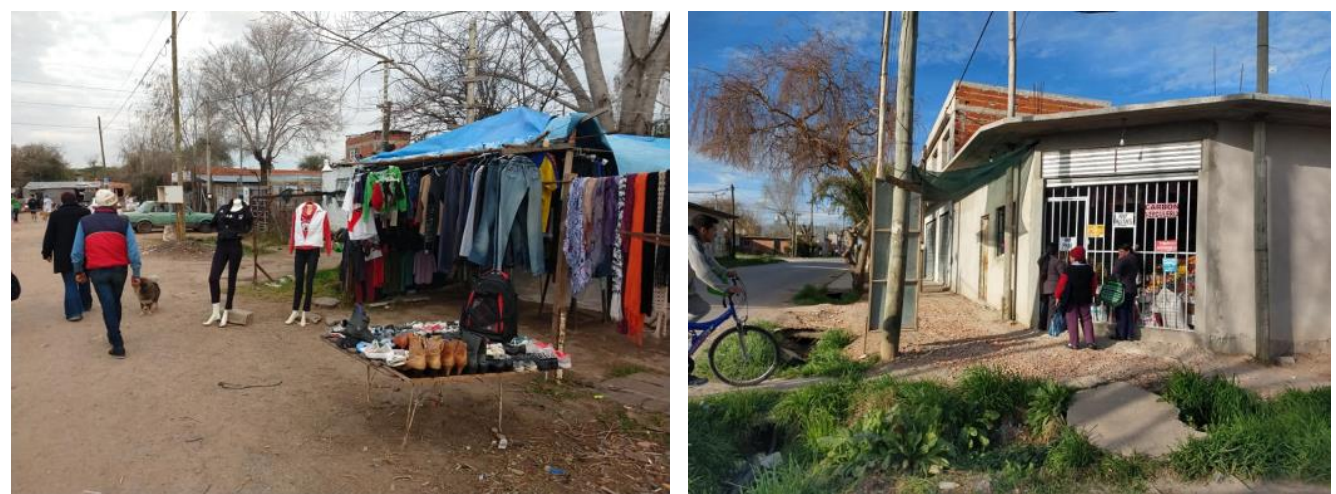

Figura 84. Algunas acciones cotidianas en el barrio.

Fuente. Imágenes tomadas por el equipo de trabajo en el barrio Puente de Fierro 2016 - 2019.

Otras acciones cotidianas que se realizan en el barrio tienen que ver con las que tienen lugar en los comedores, merenderos y copas de leche que diariamente alimentan a los niños del barrio que llegan después del colegio, para tomar la que tal vez sea su única comida de la jornada. En la imagen de la Figura 85 se observan las fachadas de dos de los comedores a los cuales se ha podido acceder a través de sus organizadoras, mujeres referentes del barrio que trabajan colectivamente todos los días para asegurar el alimento de los niños a través de donaciones principalmente.
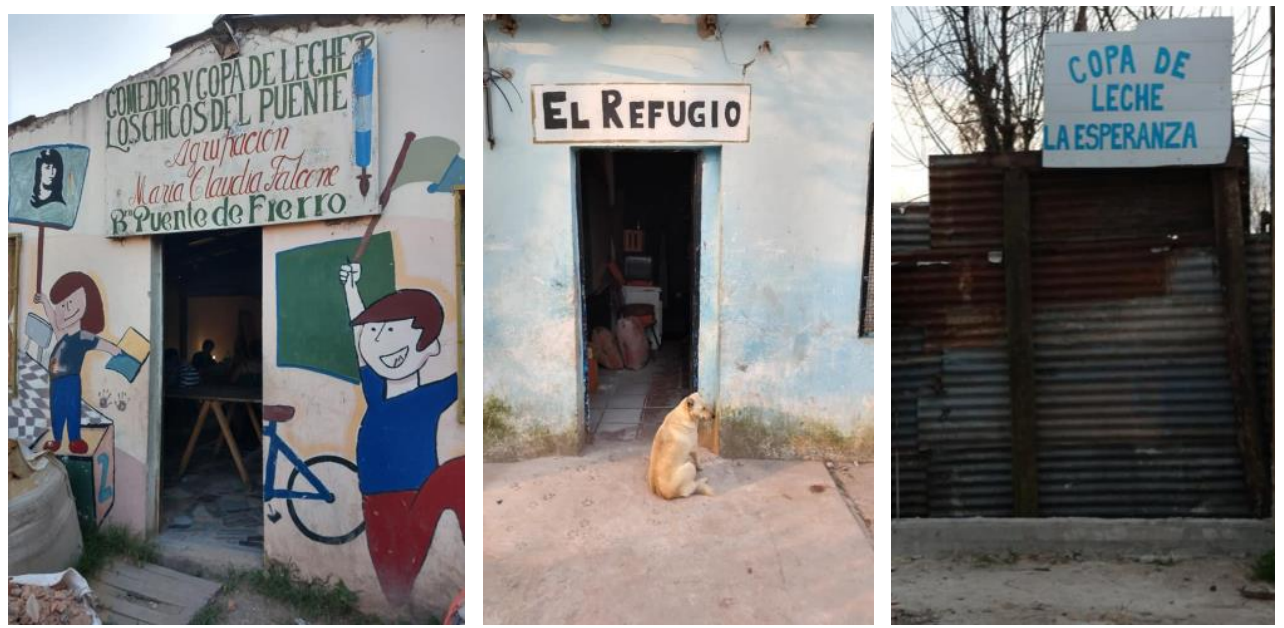

Figura 85. Comedores, copas de leche y merenderos en Puente de Fierro.

Fuente. Imágenes tomadas por el equipo de trabajo en el barrio Puente de Fierro 2016 - 2019

Estas son acciones que se realizan a diario en Puente de Fierro, y que manifiestan la fuerte apropiación que evidencia el vínculo entre los vecinos y el 
lugar, así como otras acciones que tienen que ver con distintas actividades, las actividades deportivas. Los niños y jóvenes del barrio suelen utilizar la placita del barrio y la canchita donde suelen reunirse para jugar al fútbol, uno de los deportes preferidos, también se desarrollan otro tipo de actividades de recreación como las murgas o reuniones de la banda de rap de Puente de Fierro (Figura 86).
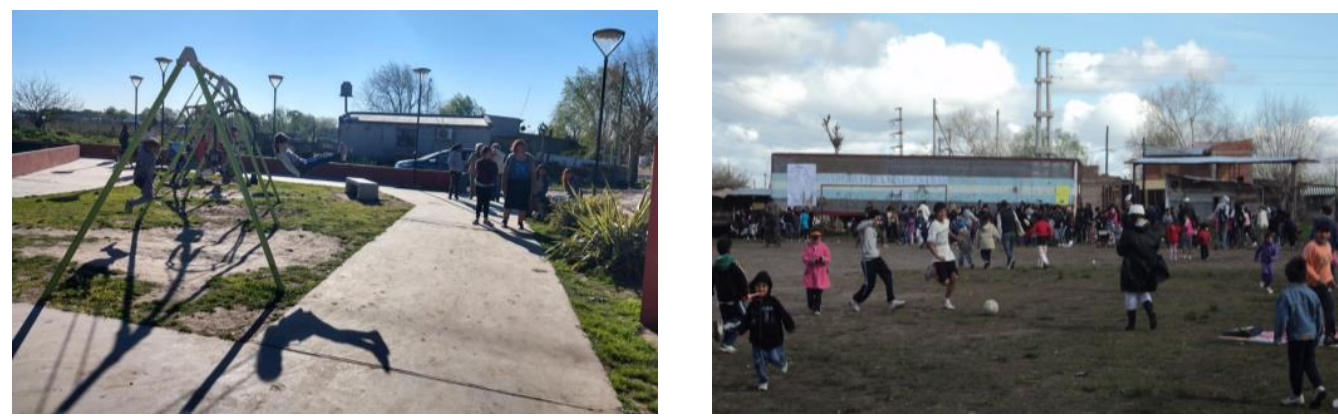

Figura 86. La placita y la canchita de Puente de Fierro, dos espacios diarios de recreación. Fuente. Imágenes tomadas por el equipo de trabajo en Puente de Fierro 2016 -2018.

\section{Acciones orientadas hacia el lugar - Acciones en relación al barrio}

Las acciones al interior de una comunidad pueden articularse en torno a su carácter colectivo y compartido y se encuentran muy vinculadas con la participación de los vecinos en relación con las acciones hacia el barrio. Estas acciones tienen que ver con la pertenencia a entidades del barrio, informarse de lo que pasa en el barrio, conocimiento de actividades organizadas en el barrio, asistencia a actividades colectivas como por ejemplo a las fiestas del barrio. Un ejemplo de ello, tiene que ver con aquellas cuestiones en relación las condiciones ambientales y de saneamiento. Como se observa en la Figura 87, acciones como la de recoger la basura y limpiar las calles, ponen de manifiesto el conocimiento y el interés de los vecinos de participar de actividades de mejora del barrio.

En la imagen se observa cómo los vecinos luego de recibir donaciones de barriles por parte de la empresa YPF, decidieron trabajar en conjunto y pusieron en marcha un proyecto comunal para transformarlos en cestos de basura que colocaron en distintas esquinas de todo Puente de Fierro. Esta acción pone de 
manifiesto la intención de enseñar a los demás vecinos del barrio a colocar los residuos en cestos y a cuidar el entorno. Si bien muchas de estas acciones deberían proceder por parte del Estado (como por ejemplo la colocación de cestos) cuando ésto no sucede, son los mismos vecinos, organizaciones sociales y cooperativas los que buscan alternativas y soluciones.
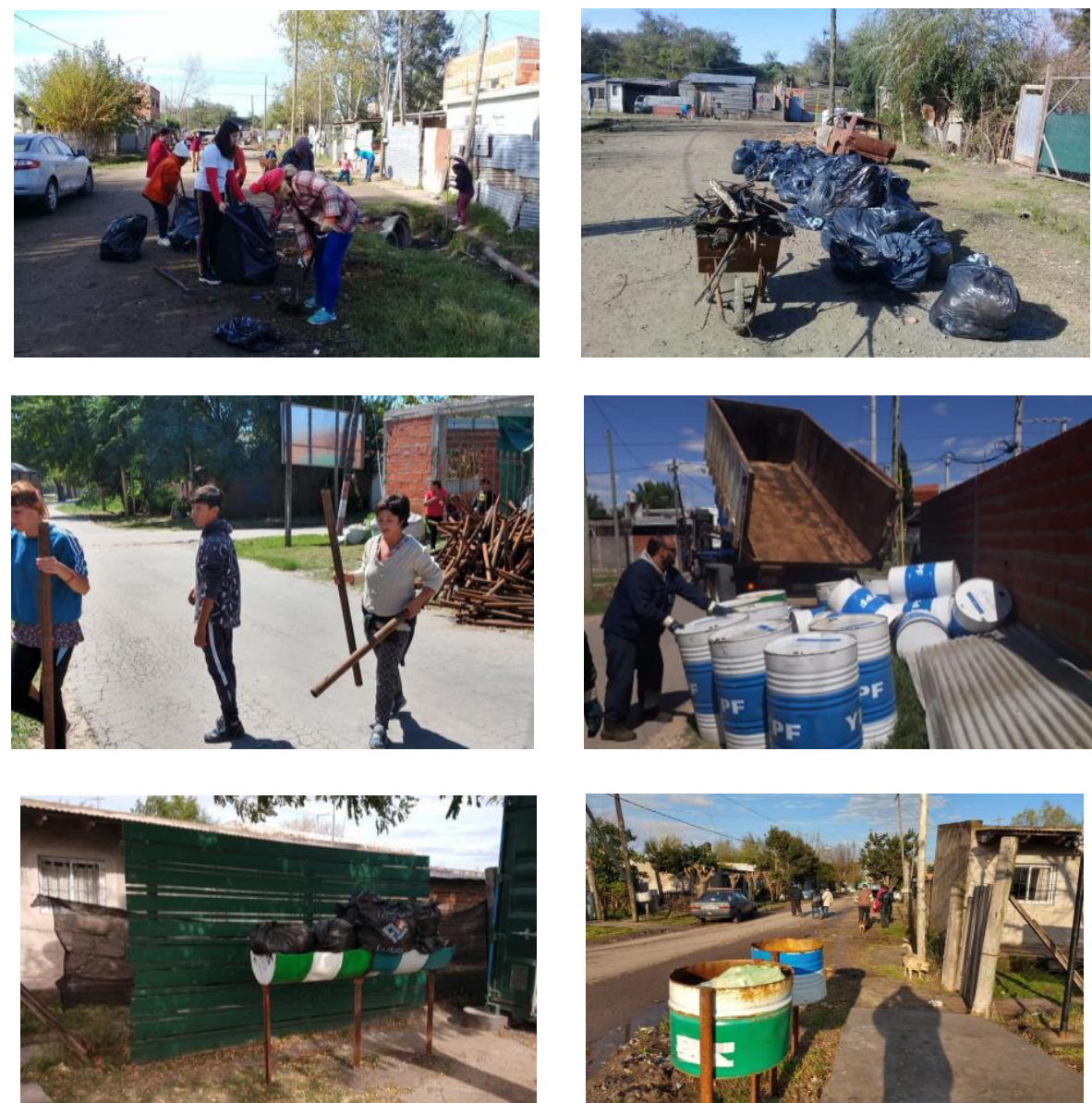

Figura 87. Algunas Acciones orientadas hacia el lugar.

Fuente. Imágenes tomadas por el equipo de trabajo en el barrio Puente de Fierro 2016 - 2019.

Entre las acciones que se realizan en relación al barrio, también pueden destacarse aquellas que forman parte de proyectos en conjunto con la Universidad Nacional de La Plata (proyectos de extensión) y diversas ONG's, cuya finalidad consiste en ofrecer algún tipo de servicio o conocimiento sobre una temática específica. A modo de ejemplo, en la Figura 88, las imágenes muestran parte de las jornadas de vacunación para perros en las calles del barrio Puente de Fierro. Esta acción se llevó adelante pensando en el futuro del barrio, no sólo en 
relación con la salud de los animales, que en su mayora están en las calles y comen de la basura, sino fundamentalmente en beneficio de las condiciones de habitabilidad y salud de los residentes del barrio.

Otro proyecto de los de mayor relevancia en relación con las acciones orientadas hacia el lugar lo constituye la iniciativa de ladrillos ecológicos para la construcción de viviendas a partir de la reutilización de desechos plásticos. Esta iniciativa, no sólo se lleva adelante en comedores y copas de leche en el barrio por los mismos vecinos, sino que, además las organizaciones sociales también reciben donaciones de los mismos. A partir de la iniciativa de los ladrillos ecológicos, los vecinos buscan la construcción de viviendas sustentables y a bajo costo, poniendo de manifiesto el sentido de pertenencia y la participación colectiva.
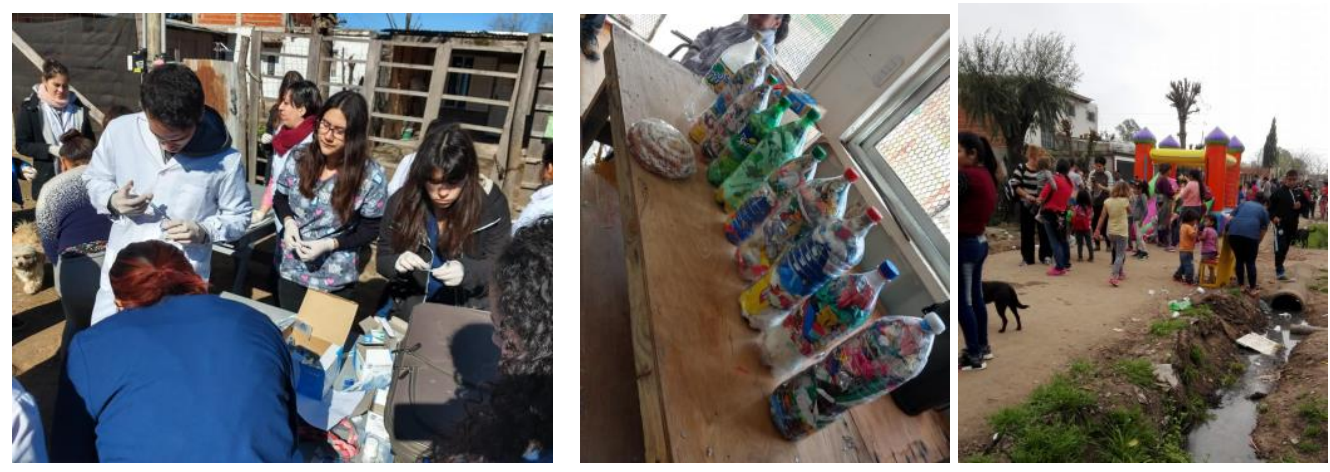

Figura 88. Acciones en relacion al barrio.

Fuente. Imágenes tomadas por el equipo de trabajo en el barrio Puente de Fierro 2016 - 2019.

Las acciones mencionadas ponen de manifiesto un interés y una preocupación de parte de los vecinos por el presente y futuro del barrio, visibilizando una fuerte apropiación del territorio. Del mismo modo se manifiesta el apego al lugar y la identificación simbólica que los residentes sienten en torno al barrio. El apego y la identificación como parte de la componente simbólica de la apropiación; en este sentido, ambas componentes (material y simbólica) no son excluyentes, sino que, por el contrario, se operacionalizan para una mejor interpretación del análisis, pero no surgen de manera aisladas, sino que se manifiestan en conjunto, o, dialécticamente. 
Acciones relacionadas con futuros proyectos del barrio - Compromiso y visión hacia el barrio

La última de las acciones en relación con el análisis de la apropiación territorial en la micro escala, la representan aquellas que se vinculan con los proyectos futuros del barrio, tomando el compromiso y la visión como indicadores. Para el análisis de estas acciones se tiene en cuenta el conocimiento acerca de los proyectos futuros para el barrio y la opinión propia sobre los mismos, así como la iniciativa de la gente del barrio de compartir las decisiones desde el principio. En este sentido, se mencionó anteriormente, que desde el año 2016 se llevan a cabo mensualmente, las Mesas de Trabajo Permanente (MTP), "Puente de Fierro Territorio Posible" abiertas a los vecinos del barrio, y a la comunidad en general, la Universidad Nacional de La Plata y otras universidades, empresas, actores de la gestión, etc. Las mismas tienen lugar en el barrio Puente de Fierro, y surgieron por iniciativa de los vecinos, las organizaciones sociales y con participación activa de la Universidad de La Plata (Figura 89).
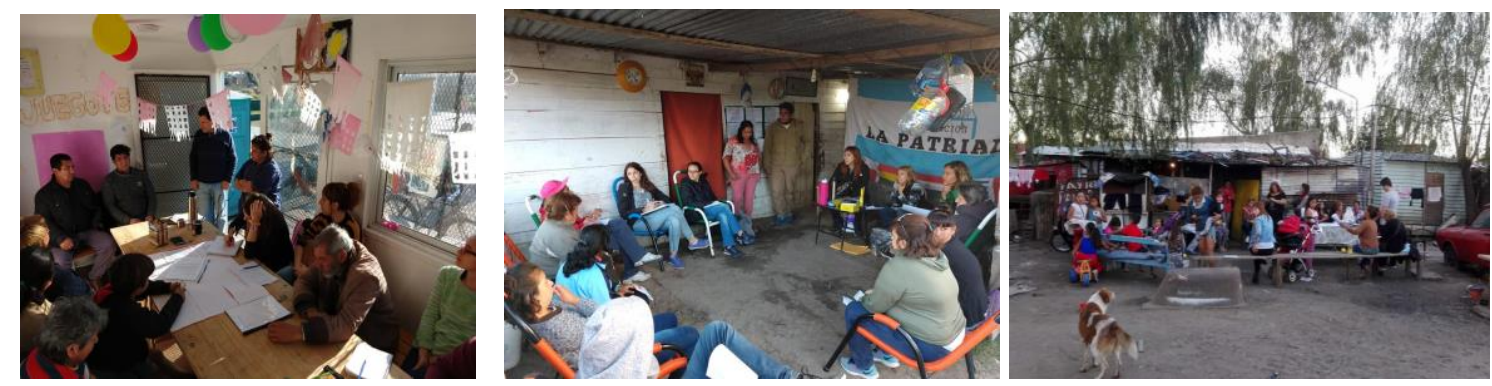

Figura 89. Las Mesas de Trabajo Permanente en Puente de Fierro.

Fuente. Imágenes tomadas por el equipo de trabajo en el barrio Puente de Fierro 2016 - 2019.

Durante las primeras MTP se plantearon temas acordados por los participantes organizaciones sociales y vecinos del barrio que les interesaba tratar. La premisa partió de cuatro preguntas guía: ¿quiénes somos? ¿dónde estamos?, ¿qué queremos hacer y ¿que estamos haciendo? Estas preguntas y las ideas que surgieron en más MTP desde el primer momento evidenciaron la acción transformadora por parte de los vecinos y el compromiso de mejorar la situación del barrio. Como producto de la participación y constancia en la realización de las 
MTP surgieron varios proyectos en relación con el barrio, que dan cuenta del compromiso y la visión de los vecinos. Entre ellos se destaca la conformación de la Revista del barrio "Trazando Puentes" (Figura 90). En ella los habitantes del barrio, junto con profesionales y tesistas de la Facultad de Comunicación Social (UNLP), encontraron una forma de comunicar y visibilizar las problemáticas en el barrio y de este modo presentárselo a quienes no lo conocen.

Uno de los temas que surgió durante el último tiempo en las MTP como consecuencia de los resultados que arrojó el censo ejecutado en el 2017 por el equipo de investigación UNLP-CONICET lo constituye la necesidad de instalar en el barrio un centro de formación profesional. Los vecinos manifestaron que una de sus mayores preocupaciones tenía que ver con el hecho de no conseguir empleo, por este motivo, y junto con la UNLP-CONICET, se llevan adelante las tratativas para instalar un centro de formación profesional en el barrio brindando a los habitantes la posibilidad de aprender un oficio y de ese modo lograr el acceso a un empleo formal.
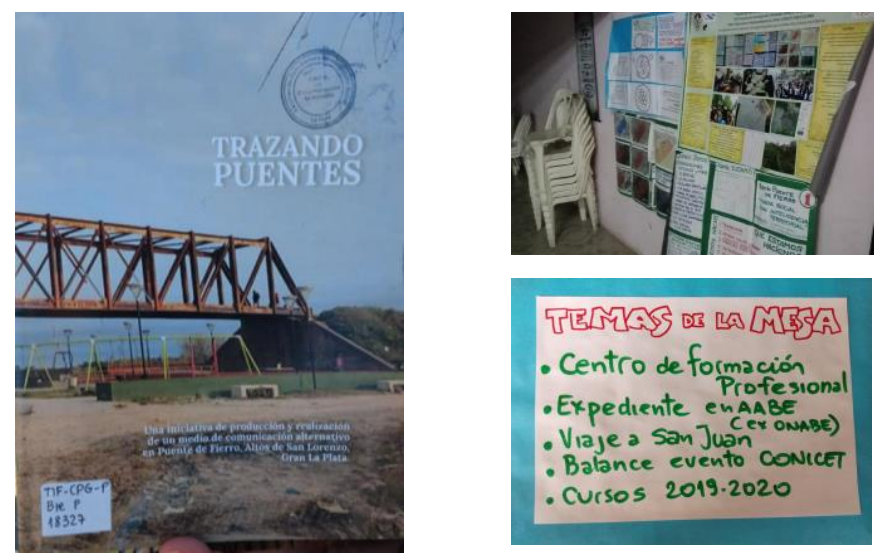

- Centro de formación

- Expediente enAaBe

Viaje a San Juán onabes

- Balance evento conice

- Cursos 2019.2020

Figura 90. La revista de Puente (izq) y temario planteado en mesas de trabajo (der).

Fuente. Imágenes tomadas por el equipo de trabajo en el barrio Puente de Fierro 2016 - 2019.

Las acciones vinculadas con los proyectos del barrio que ponen de manifiesto la apropiación territorial a partir del compromiso y visión, se evidencian también en el modo en que los vecinos se expresan en relación con los anhelos y el orgullo que sienten por las transformaciones que reconocen en el barrio, producto de la unión que generan espacios como las MTP. “(...) En el día a día, trabajamos en 
conjunto, se habla y se trabaja, es la unión del barrio. Costó un montón, pero la cuestión es que tiramos todos para que el barrio progrese, ahora se ven hechos fundamentales. Si nos retrotraemos al Puente de la época militar te puedo decir que he vivido desde chica muchas cosas en el barrio, pero lo que se ha logrado ahora... los chicos tienen su plaza, es otra cosa (...)" (Fragmento de entrevista con referente ver anexo 1)

La relación entre el modo colectivo que tienen los habitantes de Puente de Fierro de abordar los problemas del barrio, la acción hacia el barrio y la identificación con éste, invita a continuar indagando en la relación entre la ocupación y apropiación territorial, la construcción de lugares y la participación ciudadana. Queda demostrado que los objetos no son ajenos ni independientes del accionar de los actores, estos tampoco pueden ser abordados ni aprehendidos directamente en sí mismos, sino a través de las prácticas, ya que sólo se construyen y reconstruyen en las acciones a la luz de lo que se hace. Es a partir del resultado de las acciones que se pone de manifiesto en la empiria la teoría de Santos (2000) que asegura que los objetos son el testimonio de la acción, y al mismo tiempo los objetos ponen en evidencia la transformación del territorio que los actores llevan adelante a través de las acciones dentro del proceso de ocupación y apropiación territorial.

Del análisis se desprende que, en el proceso de ocupación y apropiación territorial, subyace la dialéctica en relación con el significado asociado a las características físicas (atributos) del espacio, y a las interacciones simbólicas que se producen entre los sujetos que lo ocupan y lo transforman en lugar a través de las acciones. A partir de las dimensiones, componentes e indicadores antes expuestos se generaron herramientas que permitieron operacionalizar el concepto de apropiación. Del mismo modo, a partir de las entrevistas y la participación en el barrio se pudo profundizar en la función, el valor y significado que los habitantes de Puente de Fierro construyen a partir de sus percepciones y experiencias. De este modo fue posible comprender que los procesos de 
interacción con el territorio, confirman la relación que se origina entre las personas y los lugares.

En tal sentido, resulta posible afirmar que los patrones de ocupación le dan sentido a las acciones colectivas, que ponen de manifiesto y a la vez fortalecen el sentido de pertenencia, el apego y la identificación con el lugar. Se pone en evidencia que los vecinos se unen en comunidad porque no tienen cloacas, porque se inundaron o hacen colectas porque dos familias perdieron sus casas en un incendio provocado por la conexión ilegal ("estar colgados") a la energía eléctrica. Estas acciones están vinculadas con características físicas del espacio, es decir, con atributos físicos que quedan definidos a través de los patrones de ocupación y que ponen de manifiesto a su vez la apropiación territorial.

\subsection{El objeto como testimonio de la acción}

La placita (Figura 91), constituye uno de los objetos que ponen de manifiesto la transformación del territorio en un lugar, por acción colectiva de los vecinos e intervención del municipio, y donde se realizan la mayoría de las reuniones y MTP. Los vecinos, al ver la transformación que pueden lograr, modifican su visión, la enriquecen y sienten un mayor compromiso hacia el barrio, manifestando el sentido de pertenencia, el apego y la identificación con el lugar.

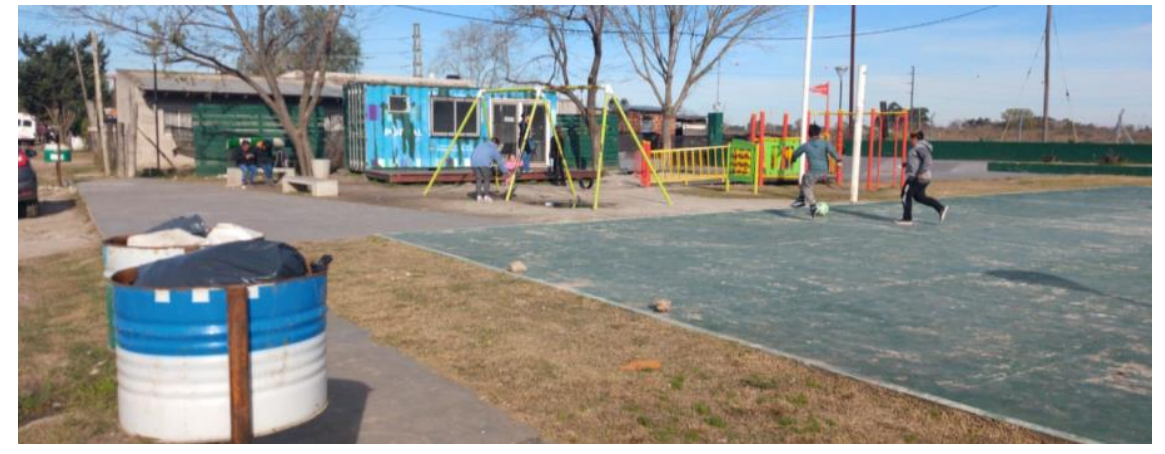

Figura 91. La placita de Puente de Fierro, uno de los primeros logros del barrio. Fuente. Imágenes tomadas por el equipo de trabajo en el barrio Puente de Fierro 2016 - 2019.

La canchita de Puente de Fierro (Figura 92) representa uno de los lugares dentro del barrio más usados y apropiados por los vecinos. Aquí los vecinos 
interactúan, hacen deporte fortaleciendo las relaciones sociales y el vínculo con el territorio. La canchita también constituye un objeto testimonio de la acción ya que este lugar en el pasado carecía de césped y no tenía arcos de fútbol, era sólo un lote vacío, que por acción colectiva de los actores (la comunidad), la UNLPCONICET (mundo científico-académico) y el municipio (Estado) se transformó en un lugar recreativo para el uso común de todo el barrio.

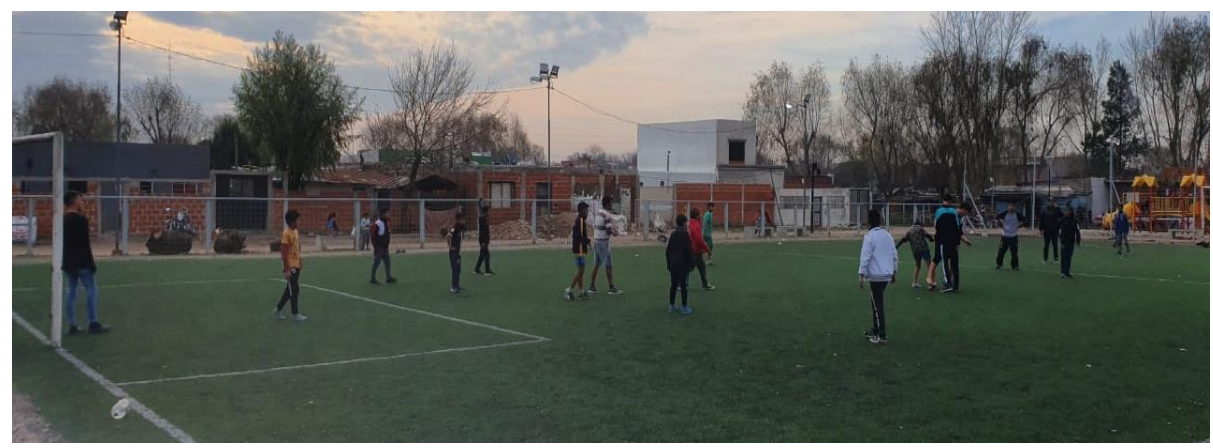

Figura 92. La canchita de Puente de Fierro como lugar de recreacion y encuentro. Fuente. Imágenes tomadas por el equipo de trabajo en el barrio Puente de Fierro 2016 - 2019

El Puente de Fierro, lugar que le da nombre el barrio, presentado en apartados anteriores, constituye un símbolo y a la vez otro ejemplo de que la acción colectiva puede lograr la transformación. Como se pudo ver al inicio del capítulo, este lugar formaba parte de un gran basural, que ha sido erradicado, gracias a la acción de los vecinos, y las organizaciones sociales formando parte de las Mesas de Trabajo Permanentes junto a la UNLP, que reclamaron al municipio la limpieza del mismo. De este modo se proyectó una plaza seca y se reconoció el valor patrimonial y simbólico del puente como lugar de memoria, justicia y verdad con la instalación de placas recordatorias, en relación a los crímenes de lesa humanidad que allí tuvieron lugar (Figura 93).

En la actualidad, este lugar es escenario de reuniones de vecinos, encuentros en días de verano y también se han realizado allí Mesas de Trabajo para seguir pensando el futuro del barrio, ya que es identificado por todos como un lugar que pertenece al barrio. Esto representa un claro ejemplo de transformación territorial a partir de acciones concretas, donde se refleja que la apropiación, el apego al lugar y la identificación se encuentran presentes en el compromiso y 
empuje de los vecinos como comunidad. De este modo, los vecinos, junto con las organizaciones sociales, la UNLP y la Municipalidad se unieron, dejando de lado las diferencias para trabajar en conjunto en la mejora del barrio, llevando adelante las acciones necesarias para erradicar el basural debajo del puente y transformarlo en una plaza que todos reconocen como propia y representativa de la identidad del lugar.

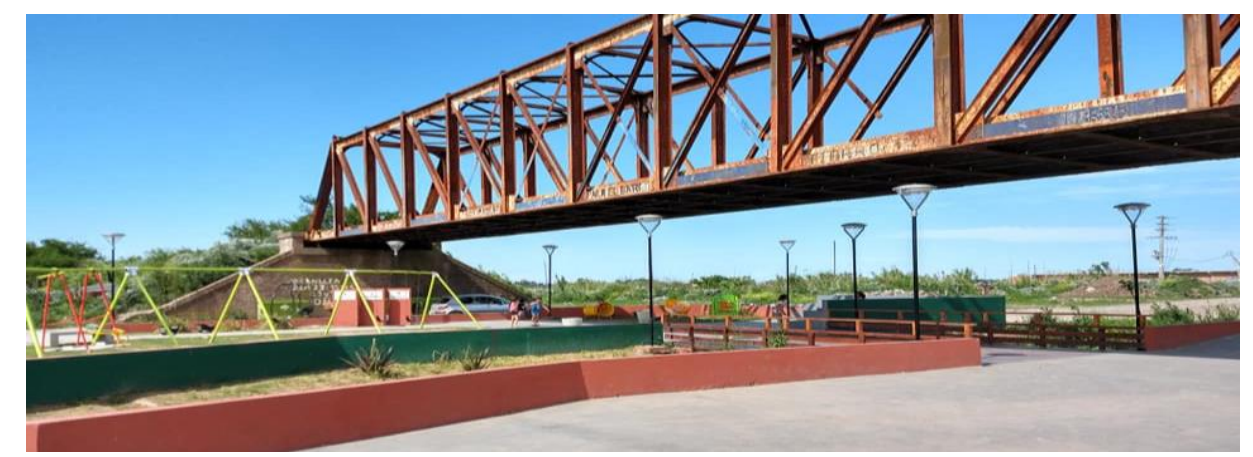

Figura 93. El Puente de fierro en la actualidad.

Fuente. Imágenes tomadas por el equipo de trabajo en el barrio Puente de Fierro 2016 - 2019.

A modo se síntesis, la dialéctica entre la ocupación y la apropiación se pone de manifiesto en las transformaciones que los actores producen el territorio, ya sean materiales o simbólicas, a la vez que el territorio también los transforma a ellos de manera simultánea. El proceso de ocupación y apropiación se constituyen entonces como un único proceso mediante el cual el territorio es transformado colectivamente en un lugar. A través de la acción los actores sociales principalmente la comunidad, en colaboración muchas veces con otros actores (Ciencia, Estado, Municipios, ONG's etc.) buscan solucionar las distintas problemáticas que se presentan en el barrio, en palabras de ellos, "problemas de todos".

“... Nosotros existimos, somos gente que soñamos un barrio lindo para nuestros hijos, ponemos expectativa e ilusión para mejorarlo..." 
Capítulo 7

$-\diamond \diamond$

Conclusiones

$\longrightarrow \bullet \bullet-$ 
El presente capítulo tiene como objetivo exponer las conclusiones a las que se arribó a partir del trabajo realizado en relación a la problemática de la informalidad urbana y el análisis de proceso de ocupación y apropiación territorial en el Partido de La Plata. En primer lugar, se plantean las consideraciones finales acerca del cumplimiento de los objetivos propuestos, en relación con los aspectos teórico-metodológicos y empíricos. En segundo lugar, se presentan algunas reflexiones y futuras líneas de trabajo, con el fin de abrir nuevos interrogantes y líneas de investigación.

\subsection{Consideraciones finales}

A partir del trabajo realizado, fue posible cumplir con el objetivo general de contribuir a la producción de conocimiento acerca de la problemática de la informalidad urbana en el Partido de La Plata, ofreciendo aportes teóricometodológicos para el análisis crítico de las dimensiones territoriales y sus implicancias simbólicas en el proceso de ocupación y apropiación territorial en urbanizaciones informales, en el período comprendido entre el año 1989 y la actualidad. Del análisis a nivel macro se desprende la presencia en América Latina y en Argentina de un modelo urbano poco sustentable y esencialmente excluyente, caracterizado por la fragmentación territorial, la polarización y la segregación socio espacial. Se verificó que, en el marco de un proceso de crecimiento difuso, las transformaciones se evidencian en las formas de ocupación y expansión del territorio sin planificación, sobre áreas no destinadas al uso urbano, contribuyendo a la conformación de espacios periféricos desiguales.

De este modo, se arribó a la idea de que los habitantes de urbanizaciones informales, enmarcados en la lógica de la necesidad utilizan estrategias como la toma de terrenos vacantes, para la ocupación del territorio constituyendo espacios de extrema precariedad. Dichos sectores suelen demandar el apoyo del Estado y cuando no lo encuentran suficientemente, recurren ocasionalmente al apoyo de proyectos de investigación de instituciones académicas y científicas que cumplan un rol de acompañamiento y mediación entre las oficinas públicas y la comunidad organizada y no organizada en períodos de tiempo superiores al corto plazo. 
Los conceptos utilizados y analizados durante toda la tesis para profundizar en el conocimiento acerca de esta problemática, contribuyeron a comprender el proceso a partir del cual los actores ocupan el territorio, apropiándose de él material y simbólicamente, a través del tiempo. Estas diferencias contribuyeron a identificar la diversidad en cuanto a las tipologías de urbanizaciones informales que pueden encontrarse en el territorio, a pesar de las similitudes de base que comparten en relación con la problemática estructural de la desigualdad urbana.

Se identificó como tipología predominante tanto en el análisis del AMBA como en la meso escala (Partido de La Plata) a la de asentamiento informal, seguida por la tipología de villa, en este sentido se evidenció el carácter transitorio original de las villas más antiguas que se consolidaron a través del tiempo, sumado a la aparición de nuevos asentamientos con una lógica de ocupación en relación con la toma organizada de terrenos a partir de los años 80. Se verificó a partir del análisis que la problemática de la informalidad urbana con sus manifestaciones espaciales, se constituye como el resultado de los procesos históricos y las relaciones de poder reflejados en el territorio. Evidencian asimismo una insuficiencia en la concepción y ejecución de políticas públicas, básicamente aquellas referidas al hábitat, como también la potenciación de estrategias sociales de respuesta a la necesidad extrema, tales como la autoorganización, el trabajo colectivo y la resiliencia.

Los aportes originales de esta investigación se manifiestan en la producción de conocimiento a través de elementos descriptivos, interpretativos y explicativos acerca de las particularidades del proceso de ocupación y apropiación territorial en las urbanizaciones informales del Partido de La Plata y puntualmente en el caso de estudio, el barrio Puente de Fierro. Para ello, a lo largo de esta tesis se analizaron procesos que vinculan la ocupación y apropiación del territorio con las dinámicas que integran la urbanización informal en los tres niveles de abordaje propuestos.

Del análisis resulta posible reflexionar acerca de la producción y reproducción de las desigualdades sociales en el territorio, pudiéndose comprobar que, a través 
de la comprensión de los mecanismos adoptados por los actores sociales, se pone de manifiesto la simultaneidad del proceso de ocupación y apropiación territorial, planteada desde la teoría en el nivel superior de abordaje y contrastada en el nivel medio e inferior de abordaje durante el trabajo empírico en Puente de Fierro.

\subsubsection{El proceso de ocupación y apropiación territorial en urbanizaciones informales desde la perspectiva geográfica}

En el comienzo de esta tesis se plantearon algunos interrogantes a partir de los cuales fue posible relacionar los conceptos principales en relación con el abordaje de la ocupación y apropiación territorial en contextos de informalidad urbana. Esto contribuyó al establecimiento de las dimensiones necesarias para el análisis integral de la problemática, que permitió comprender los contextos y circunstancias en los que se desarrolla la informalidad urbana y el rol de los actores sociales.

El análisis desde un nivel de mayor de abstracción en el primer capítulo, a partir del planteamiento de las consideraciones generales acerca de las nociones sobre espacio y territorio, permitió fundamentar y explicar la postura epistemológica adoptada en esta tesis doctoral en geografía. A partir de comprender al territorio como una construcción social se comprobó que los actores sociales, a través de sus acciones, transforman el territorio dotándolo de significados convirtiéndolo en un lugar. Desde esta concepción vinculada con la geografía crítica con fuerte anclaje en el análisis histórico, fue posible sentar las bases teóricas que permitieron complejizar el pensamiento que permitió el análisis de la problemática desde otras aristas.

Para la definición del marco teórico se indagó en las diferentes posturas, que hacen referencia a los conceptos más significativos para esta tesis. Para ello, se trabajó en relación con algunos autores que han abordado la problemática desde corrientes teóricas y disciplinares más próximas al Geografía Crítica. Esto permitió realizar el abordaje del objeto de estudio desde una perspectiva geográfica integral 
y crítica, lo que posibilitó el cruce de la teoría con el trabajo participativo en Puente de Fierro, poniendo en valor la dialéctica subyacente entre la teoría y la empiria.

La información obtenida en este trabajo de tesis resultó fundamental, ya que a partir de ella fue posible confrontar tanto la teoría como la empiria durante el trabajo de campo. De este modo se verificó la dialéctica subyacente en el proceso de ocupación y apropiación territorial en la micro escala a partir de adentrarse en la compleja relación sujeto - territorio. Desde el primer capítulo, se expusieron los principales conceptos y referentes teóricos acerca del territorio, su apropiación y ocupación, la informalidad urbana y los procesos de urbanización en un contexto político y económico. Esto permitió una aproximación interdisciplinaria e integral, que se suma a aquellos trabajos realizados que buscaron de alguna forma invalidar las fronteras disciplinarias.

En el plano personal es oportuno mencionar la riqueza del proceso de trabajo vivido estos años, considerando mi formación disciplinar de origen -la Arquitectura- así como el trabajo en equipo que se viene realizando desde años antes con mis directores -Geógrafos ambos- lo cual permitió incorporar la riqueza de una perspectiva geográfica en la tesis.

\subsubsection{Aspectos referidos al abordaje del objeto de estudio}

Este trabajo realiza un aporte al análisis y comprensión del proceso de ocupación y apropiación territorial en urbanizaciones informales en el Partido de La Plata a través de la construcción de los fundamentos teóricos, principalmente desde la mirada de la geografía. El abordaje metodológico permitió analizar el objeto de estudio en todas sus dimensiones y escalas, en base a la complejidad que éste supuso en cada etapa. A partir del abordaje teórico-metodológico propuesto en niveles de abstracción que contemplan distintas complejidades y escalas de análisis se puso de manifiesto la incidencia de macro procesos en la urbanización capitalista latinoamericana. Esto posibilitó la aproximación entre la problemática de la informalidad urbana y su naturaleza de alcance global, focalizando en las 
formas capitalistas de producción y reproducción social en las ciudades latinoamericanas.

Se comprobó la incidencia de los macro procesos globales y locales en las transformaciones territoriales. Esto permitió verificar, a partir de la articulación entre el análisis de los macro procesos y conceptos en el nivel superior de abordaje y análisis, que la informalidad urbana es parte de las consecuencias del sistema global de producción que conforma la denominada urbanización capitalista. Se verificó que los cambios producidos como consecuencia del sistema dominante actual, tuvieron su expresión en la configuración del territorio del AMBA. En este sentido, es posible afirmar que una de esas expresiones la constituye la informalidad urbana con sus distintas tipologías (principalmente las villas y los asentamientos informales). De este modo, fue posible encuadrar el trabajo entendiendo que la configuración del territorio se encuentra en relación directa con los contextos económicos, sociales y políticos en cada período histórico también a nivel local.

A partir de establecer una relación entre los niveles de abordaje superior y medio resultó posible anclar los conceptos elaborados en la instancia teórica en un territorio concreto en un nivel medio de abordaje y análisis. Se arribó así a la identificación de algunos patrones comunes de ocupación que caracterizan a las urbanizaciones informales del Partido de La Plata, producto del contexto histórico, en referencia con la localización, los atributos físicos del espacio y las características de la población.

1- Se constató que las urbanizaciones informales más antiguas se asentaron sobre los ejes noreste, en relación con el acceso hacia Capital Federal, mientras que las más nuevas se localizaron en dirección a las localidades de las zonas sureste y suroeste del Partido.

2- Del análisis del acceso a los servicios urbanos básicos se desprende que el $54 \%$ de las urbanizaciones informales no acceden más que a 1 ó 2 servicios urbanos básicos, por lo general energía eléctrica y/o agua potable. 
3- Del análisis de las condiciones de accesibilidad se verificó que en el Partido de La Plata las urbanizaciones informales se localizan a no más de $15 \mathrm{~km}$ del casco urbano donde se encuentran las principales actividades diarias.

5- Del análisis de las condiciones ambientales se concluye que el $60 \%$ de las urbanizaciones informales del Partido se encuentran directamente atravesadas por arroyos o se localizan sobre las planicies de inundación. Siendo las cuencas de los arroyos del Gato y Maldonado las que mayor cantidad de urbanizaciones informales presentan, pudiéndose reconocer 60 urbanizaciones informales dentro de la cuenca del Gato (40\%) y 20 urbanizaciones informales en la cuenca del Maldonado (20\%).

6- Se verificó que el $56 \%$ de las urbanizaciones informales del Partido corresponden a la categoría "pequeñas" es decir, tienen entre 8 y 100 familias; algo más de un tercio de las urbanizaciones informales se clasifican como medianas (37\%) y un $7 \%$ se pueden considerar grandes con más de 500 familias.

El nivel inferior de abordaje y análisis evidenció el proceso de ocupación y apropiación territorial en la micro escala, a partir del reconocimiento de los atributos físicos del espacio y el trabajo de campo junto con los actores sociales, lo que posibilitó conocer la historia del barrio y el proceso a través del cual se llegó a conformar un lugar de significado. Se verificó que, ante la situación de precariedad determinada por las condiciones vinculadas con la ocupación territorial informal, los actores llevan adelante acciones que transforman las condiciones del barrio. Estas iniciativas ponen de manifiesto la apropiación que refleja el fuerte vínculo que se genera entre los actores y su territorio. Al mismo tiempo que los actores transforman el territorio, se transforman a sí mismos. Esta tesis comprobó que a partir del reconocimiento de la dialéctica subyacente en el proceso de ocupación y apropiación territorial fue posible establecer una relación conceptual con la creación de sentido de lugar, definido como el resultado entre las acciones, las concepciones simbólicas y los atributos físicos del espacio. 


\subsubsection{Ocupación y apropiación del territorio y la comunidad: Los vecinos de Puente de Fierro}

El trabajo de campo permitió integrar el conocimiento acerca de diversos procesos (históricos, materiales, identitarios, simbólicos, y sociales) que se generan en la vinculación de los actores con el territorio, los cuales a su vez permitieron interpretar la realidad y conocer el sentido que socialmente se le atribuye a un lugar. Se comprobó que lo que es considerado como barrio a partir de la perspectiva de los actores constituye una herramienta fundamental para comprender la apropiación territorial.

A partir del trabajo de campo, se verificó el modo en que los actores se vinculan, relacionan e involucran en el barrio como forma de vida. Fue posible verificar la relación entre el modo en que los actores conviven con el territorio y las cargas simbólicas subyacentes que se manifiestan a partir de la acción colectiva.

Se constató en el trabajo de campo el modo en el que los habitantes de Puente de Fierro conocen, valoran y sienten su barrio. Cabe destacar que la comprensión del proceso de ocupación y apropiación territorial podría resultar de utilidad en el ámbito de las políticas urbanas y sociales. A partir de los resultados obtenidos, es posible reflexionar sobre propuestas que no pasen por alto los aspectos simbólicos de la informalidad urbana y la construcción de lugares, y, por el contrario, que puedan utilizarse para orientar las intervenciones territoriales y garantizar que estas cubran las necesidades y expectativas de sus habitantes.

Se verificó a partir de la experiencia empírica que habitar Puente de Fierro no sólo remite a la relación de los actores con el entorno, sino también a las relaciones entre los actores sociales entre sí. A medida que estas relaciones se fortalecen, también lo hace el vínculo con el territorio fomentando acciones transformadoras. Se constató que el hecho de conocer, interpretar y reconstruir los discursos de los actores sociales que habitan en situaciones de informalidad, contribuye a posicionarlos como principales impulsores en el proceso de ocupación y apropiación del territorio y los convierte, al mismo tiempo, en sujetos 
transformadores pertenecientes a un contexto, a una historia y a un lugar determinado. Se verifica que a partir del quehacer durante 38 Mesas de Trabajo Permanente realizadas en el marco del Proyecto de Investigación UNLP-CONICET entre 2016 y 2019, que los actores con mayor participación en ellas (mujeres del barrio, tesistas e investigadores) han experimentado mayores transformaciones como sujetos en los cuatro planos planteados por Bozzano (2017) en su hipótesis: subjetivas, sociales, ambientales y decisionales.

Cabe destacar que las actividades realizadas para el abordaje de la micro escala en el nivel inferior de análisis, no se podrían haber llevado adelante sin la participación y el compromiso de los referentes barriales y vecinos de Puente de Fierro, quienes además de participar junto al equipo en la ejecución del censo y las Mesas de Trabajo Permanente, guiaron el camino hacia la comprensión de los vínculos entre los actores y el territorio. Formar parte del proceso desde el lugar de observadora y al mismo tiempo compartir la experiencia de participar de las acciones colectivas para mejorar el barrio junto a ellos, fue un acompañamiento que permitió evidenciar la manifestación del vínculo entre los actores y el territorio a partir del mejoramiento del barrio durante estos años.

Se comprobó el vínculo entre los actores y el territorio en relación con las tres dimensiones de la apropiación trabajadas a partir de las entrevistas, vale decir los resultados del censo, las visitas al barrio y la participación en las MTP:

1- Apego al lugar: se constató el apego al lugar en los vecinos de Puente de Fierro a partir de sentir el barrio como algo propio, sentirse apegados al barrio, la intención de continuar viviendo en el barrio, el gusto por vivir en ese lugar y sentirse parte del mismo. En los resultados del Censo realizado por el equipo de investigación UNLP-CONICET se verificó que menos del 10\% de los habitantes manifestó la idea, deseo o voluntad de irse a vivir a otros lugares.

2- Identificación simbólica: se comprobó la identificación simbólica a partir de la diferenciación con otros barrios, la memoria personal en lugares al interior del barrio, el orgullo de pertenecer a Puente de Fierro como comunidad y el nombre que lleva el barrio en relación con su historia. 
3- Acciones: se identificaron tres tipos de acciones en el barrio que ponen de manifiesto la apropiación del territorio:

- Acciones cotidianas realizadas en el barrio: Compra en el barrio, pasar tiempo en el barrio, relación, conocimiento y confianza con gente del barrio relación, ubicación (dentro o fuera del barrio) de la red de relaciones primarias y secundarias (familia, amigos, compañeros de trabajo).

- Acciones orientadas hacia el lugar: Pertenencia a entidades del barrio, informarse de lo que pasa en el barrio, conocimiento de actividades organizadas en el barrio, asistencia a las actividades, asistencia a actividades colectivas (asambleas, reuniones sobre el barrio), asistencia a las fiestas del barrio.

- Acciones relativas a los proyectos futuros del barrio: Ponen de manifiesto el compromiso y visión de los vecinos, incluyen la participación en los problemas y las soluciones pensando el mejoramiento futuro en coparticipación con otros actores (municipales, pertenecientes al ámbito académico, ONG's etc.). Conocimiento de los proyectos, la opinión propia es tenida en cuenta, iniciativa de los responsables compartiendo las decisiones, iniciativa de la gente del barrio sin compartir decisiones, iniciativa de la gente del barrio compartiendo decisiones desde el principio

\subsubsection{La ocupación y apropiación territorial en relación con la comunidad, la ciencia y el Estado}

Es relevante tanto para el ambiente académico como para la sociedad en su conjunto que se conozca la voz de las familias que viven en situaciones de informalidad, quienes muchas veces no son escuchados suficientemente por el Estado ni por actores del mundo científico y académico. A partir de los relatos de los vecinos, se puso en evidencia un conjunto de expectativas, problemas y prácticas compartidas que remiten a una experiencia común vinculada con habitar en Puente de Fierro. Esta experiencia hace referencia al vínculo con el barrio, el 
sueño de un lugar propio y las múltiples dificultades relacionadas con las condiciones de habitabilidad.

La experiencia del trabajo en conjunto y colaborativo entre la ciencia, la comunidad y el Estado, produjo transformaciones significativas en el territorio de Puente de Fierro. Esto, traducido en acciones llevadas adelante a través de las Mesas de Trabajo Permanentes, no sólo ponen de manifiesto el vínculo que se genera entre los actores y el territorio, expresado a través de los sentidos de pertenencia y el apego al lugar como dimensiones de la apropiación; sino que la participación colectiva, además, refuerza la relación con los demás actores y con el territorio, tanto para la organización de la toma y ocupación de terrenos, como para la búsqueda de soluciones a las problemáticas producto de la informalidad. Si bien se reconoce la importancia del Estado como actor clave de la problemática, ello no ha constituido una cuestión central objeto de estudio propio de esta tesis, dado que se priorizó el pensar y el hacer de los actores comunitarios. Sin embargo, se estima pertinente profundizar las articulaciones ente Estado y comunidad en otras investigaciones

\subsection{Reflexiones del proceso y futuras líneas de trabajo}

Entre las futuras líneas de trabajo se propone la posibilidad de replicar la metodología de análisis tanto hacia otras tipologías de urbanización informal en la micro escala en el Partido de La Plata, como en otros territorios donde la informalidad urbana tenga una presencia considerable. Resulta necesario plantear acciones que fomenten y revaloricen aquellos aspectos positivos que surgieron del análisis del proceso de ocupación y apropiación territorial y que se pusieron de manifiesto durante el trabajo de campo. Algunos de esos aspectos relacionados con las redes de colaboración que se crean entre los vecinos fortalecen el vínculo con el territorio y refuerzan la apropiación, que conduce al deseo de trabajar como una unidad dentro del barrio para mejorarlo. En tal sentido, se plantea la posibilidad de instrumentar un enfoque de derechos colectivos en las políticas territoriales, así como el abordaje de estrategias para la limitación de la expansión territorial sobre áreas no urbanizables como verdades problemáticas actuales y urgentes. Por 
último, se evidencia la necesidad de contribuir a la organización popular para una práctica emancipatoria y colectiva de urbanización.

Se propone también profundizar en algunas líneas de acción que dispongan de instrumentos útiles para la intervención en temas de promoción de procesos de autogestión colectiva y producción social del hábitat; entendidas éstas como alternativas para disminuir el impacto de la problemática de la informalidad urbana, teniendo en cuenta que son los vínculos que se crean entre los actores sociales y el territorio los que terminan por definir un lugar. Ello en pos de lograr territorios más justos y propender a una mayor equidad en la distribución del suelo, bienes y servicios, es posible pensar que, a través del análisis del proceso de ocupación y apropiación territorial, éste, pueda llegar a ser reorientado, dado el carácter dialéctico del mismo, de manera que resulte en un mayor beneficio para los sectores de menores recursos de la sociedad.

En este contexto, se propone fomentar procesos de co participación orientados a una verdadera co-gestión integral del territorio a través del empleo de instrumentos de intervención adecuados por parte del Estado, como por ejemplo aquellos presentes en la ley 14.449 de Acceso Justo al Hábitat (2012), así como la evaluación de las distintas lógicas y patrones de ocupación y apropiación, fundamentalmente atendiendo a la mirada de los actores en la micro escala.

Del mismo modo se plantea la posibilidad de explorar en búsquedas orientadas a la identificación de modelos de detección de situaciones de riesgo y vulnerabilidad socio territorial y ambiental en relación con la problemática de la informalidad urbana, capaces de ser replicados en otros territorios. A partir del reconocimiento de situaciones de riesgo para la población vulnerable, será más factible y viable co construir escenarios futuros, con el fin de proponer alternativas a la producción de la informalidad urbana, pensándola desde el proceso de ocupación y apropiación, desde una visión que integre los aspectos en relación con el contexto y los atributos del espacio físico, así como también desde la voz representativa de los actores sociales y sus acciones en el territorio. 
En definitiva, el aprendizaje durante estos años permitió confirmar que mediante la investigación con una geografía no sólo crítica sino transformadora que profundice en las marchas y contramarchas del proceso de ocupación y apropiación territorial en las urbanizaciones informales aporta valiosos resultados para que el diálogo entre políticas públicas, comunidad y sistema científico produzca resultados concretos en un tema que atañe a más de 130 millones de personas que habitan en urbanizaciones informales de América Latina. 
BLIBLIOGRAFIA

- $•$

$\bullet \diamond$ 
ABRAM0, P. (2011) La producción de las ciudades latinoamericanas: mercado inmobiliario y estructura urbana. Olacchi.

ABRAM0, P. (2012) La ciudad com-fusa: mercado y producción de la estructura urbana en las grandes metrópolis latinoamericanas. Eure, 37.

AÓN, L. Y FREDIANI, J. (2010) La categoría de patrón territorial y el concepto de lugar aplicados al espacio residencial de la periferia del partido de La Plata. Revista Párrafos Geográficos. Volumen 9, Número 1. ISSN 1853-9424.

ARQUERO, S. y CANESTRARO, María L. (2011) Intervenciones del Estado en la regularización de Villas y Asentamientos: alcances, límites y contradicciones. En La cuestión urbana interrogada. Transformaciones urbanas y ambientales y políticas en Argentina. Parte 2. Editorial Café de las Ciudades. Buenos Aires.

BAYÓN, M. C. y SARAVI, G. (2007) De la acumulación de desventajas a la fractura social. "Nueva" pobreza estructural en Buenos Aires. Cap. 2. En De la pobreza a la exclusión. Continuidades y rupturas de la cuestión social en América Latina. Gonzalo Saraví (editor) Prometeo Libros. México.

BASUALDO, E. (2003) Las reformas estructurales y el Plan de Convertibilidad durante la década de los noventa. El auge y la crisis de la valorización financiera. Realidad Económica, 200. Buenos Aires.

BASUALDO, E. (2006) La reestructuración de la economía argentina durante las últimas décadas de la sustitución de importaciones a la valorización financiera. En Basualdo, E. y Arceo, E. (Ed.), Neoliberalismo y sectores dominantes. Tendencias globales y experiencias nacionales. Buenos Aires: CLACSO. Recuperado de http://bibliotecavirtual.clacso.org.ar/ar/libros/grupos/basua/C04Basualdo.pdf

BLANCO, J. (1996) Área Metropolitana de Buenos Aires: Transformaciones territoriales en el marco de la globalización. EURE - Revista de estudios urbanos regionales, 22-67.

BLANCO, J. (2007) Espacio y territorio. Elementos teórico - conceptuales implicados en el análisis geográfico. En Fernández Caso M. V. y Gurevich, R. (coord.) Geografía. Nuevos temas, nuevas preguntas. Un temario para su enseñanza. Buenos Aires: Biblos.

BOURDIEU, P. (1999) Efecto de lugar. En P. Bourdieu, La miseria del mundo. Buenos Aires: FCE.

BOURDIEU, P. (2003) La miseria del mundo. Fondo de Cultura Económica, México.

BOZZANO, H. (2009) Territorios posibles, procesos lugares y actores. Buenos Aires: Lumiere. 
BOZZANO, H. (1990) Los procesos de estructuración de espacios periurbanos. Hacia una definición del borde metropolitano de Buenos Aires. Revista Interamericana de Planificación, XXIII (89).

BOZZANO, H. RESA, S. et al. (1997) Patrones territoriales y código de planeamiento. El caso de La Plata, Argentina. En Memorias de EGAL6. Encuentro de Geógrafos de América Latina. Recuperado de:

http://observatoriogeograficoamericalatina.org.mx/egal6/Geografiasocioeconomi ca/Ordenamientoterritorial/726.pdf

BOZZANO, H., RESA, S. et al. (1997) Organización y patrones territoriales para una propuesta de código de planeamiento en el municipio de La Plata. Teoría práctica y participación. En: Boletín de la Universidad de Cuyo, pp. 235-247. Mendoza: VII Jornadas Cuyanas de Geografía.

BOZZANO, H. Y RESA, S. (2007) El lugar: Criterios teórico-metodológicos para su definición. Aplicación a General Belgrano, Buenos Aires. La Plata (inédito).

BRIONES, G. (1996) Metodología de la investigación cuantitativa en las ciencias sociales. Bogotá, Colombia: ARFO Editores e Impresores Ltda.

BUZAI, G. Y BAXENDALE, C. (2006) Análisis Socioespacial con Sistemas de Información Geográfica. Buenos Aires: Lugar Editorial.

CALDERON, J. (2013) Planificando la ciudad informal. Mimeo.

CANAESTRO, M. (2013) ¿Ilegales, irregulares, informales...? Aportes para un debate sobre el suelo. NóMadas. Critical Journal of Social and Juridical Sciences, 249-370. doi:10.5209/rev_NOMA.2013.42351.

CANALES CERÓN, M. (2006) Metodologías de la investigación social. Santiago de Chile: Lom Ediciones.

CARUT, C. Y CIRIO, G. (2015) Territorio, Territorialidad y Territorialidades: una lectura desde los grandes proyectos y transformaciones inmobiliarias costeras en Buenos Aires. Los casos de Puerto Madero y Nueva Costa del Plata. En Bozzano, H. y Velarde, I. (Comp.), Transformaciones socioterritoriales y proceso de intervención en la región rioplatense. Buenos Aires: Editorial Imago Mundi.

CASARIEGO RAMÍREZ, J. (1995) Sobre el espacio y la modernidad. Una reflexión desde la experiencia norteamericana, Ciudad y Territorio, III, № 106.

CASTELLS, M. (2004) La cuestión urbana. Siglo XXI. México.

CATENAZZI, A., DA REPRESENTACAO, N. Y LOMBARDO; J. (2003) La cuestión urbana en los noventa en la RMBA. Instituto del Conurbano. Ediciones Al Margen, UNGS, 2003. 
CICOLELlA, P. (2012) Revisitando la metrópolis latinoamericana más allá de la globalización. En Revista Iberoamericana de Urbanismo (RIURB) n 8. ISSN 20136242.

CLICHEVSKY, N. (2000) Informalidad y segregación urbana en América Latina. Una aproximación. Santiago de Chile: CEPAL.

CLICHEVSKY, N. (2007) "Informalidad Urbana: abordajes teórico-metodológicos y políticas estatales. Algunas reflexiones sobre sus interrelaciones". Buenos Aires.

CORAGGIO, J. L. (1994) Territorios en transición. Critica a la planificación Regional en América Latina. Toluca, México: Universidad Autónoma del Estado de México.

CORAGGIO, J. (2002) La Economía Social como vía para otro desarrollo social. Documento de lanzamiento del debate sobre "Distintas propuestas de Economía Social", en Urbared. Red de Políticas Sociales. Recuperado de:

http://www.redetis.iipe.unesco.org/publicaciones/economiasocialcoraggio.pdf

CORTIZO, D. (2018) Tierra vacante y expansión urbana. Aporte teórico metodológico para una futura intervención desde un enfoque sostenible. El caso del Partido de La Plata. Tesis de maestría Facultad de Arquitectura y Urbanismo (FAU-UNLP). Disponible en: http://sedici.unlp.edu.ar/handle/10915/72414

COWMAN, S. (1992) Triangulation: a means of reconciliation in nursing research. Journal of Acvanced Nursing.

CRAVINO, C (2006) Las villas de la ciudad. Mercado e informalidad urbana. UNGS, Los Polvorines.

CRAVINO, María Cristina (Organizadora). (2008) Los mil barrios (in)formales. Aportes para la construcción de un observatorio del hábitat popular del Área Metropolitana de Buenos Aires. - 264 - Editorial Instituto del Conurbano- UNGS.

CRAVINO, M. C. (2009) La metamorfosis de la ciudad informal en el Área. Revista Líder Vol. 15 Año 11 ISSN: 0717-0165, pp. 31 - 55.

CRAVINO, M. C., DEL RIO, J. P., \& DUARTE, J. I. (2010) Los barrios informales del Área Metropolitana de Buenos Aires: evolución y crecimiento en las últimas décadas. Ciudad y territorio N. o 163.

CRAVINO, M.C. (2012) Repensado la ciudad informal en América latina. Buenos Aires: Universidad Nacional de General Sarmiento UNGS.

CORTIZO, D.; RODRÍGUEZ TARDUCCI, R.; FREDIANI, J. (2018) La problemática de los "falsos vacantes" en el Gran La Plata: ¿tierras vacantes o asentamientos informales? I Jornadas Platenses de Geografía, 17 al 19 de octubre de 2018, La Plata, Argentina. En: Actas. La Plata: Universidad Nacional de La Plata. Facultad de 
Humanidades y Ciencias de la Educación. Departamento de Geografía. Disponible en: http://www.memoria.fahce.unlp.edu.ar/trab_eventos/ev.11259/ev.11259.pdf

CUENYA, B. (1985) Asentamientos populares en el Gran Buenos Aires. Dos estudios de caso. Buenos Aires: CEUR.

DE MATTOS, C. (1993) La obstinada marginalidad de las políticas territoriales: el caso latinoamericano. Estudios Regionales. Número 35.

DE SOUSA SANTOS B. (2009) "Una Epistemología del Sur. La reinvención del conocimiento y la emancipación social". CLACSO. México: Siglo XXI.

DELFINI, M. \& PICCHETTI, V. (2005) Desigualdad y pobreza en Argentina en los noventa. Política y cultura, (24), 187-206. Recuperado en 24 de noviembre de 2019, de http://www.scielo.org.mx/scielo.php?script=sci_arttext\&pid=S018877422005000200009\&lng=es\&tlng=es.

DEL RÍO, J. (2016) Tensiones entre hipoteca, suelo y política urbana. El caso Pro. Cre.Ar en el Partido de La Plata, provincia de Buenos Aires, 2016. Estudios Socioterritoriales. Revista de Geografía, (19), 135-151, enero-junio 2016.

DEL RÍO, J. (2010) Los asentamientos populares en la Región Metropolitana de Buenos Aires: Emergencia y reproducción del territorio en los procesos neoliberales de Construcción de ciudad (1980-2010). Geograficando. Año 6, No. 6, p. 147-164. Fahce-UNLP.

DEL RÍO, J. (2012) El lugar de la vivienda social en la ciudad. Un análisis de la política habitacional donde el mercado de localizaciones intraurbanas - 269 - y las trayectorias residenciales de los habitantes. Tesis doctoral en Geografía Fahce UNLP.

DEL RÍO J.; DUARTE (2012) Aportes para la construcción de un observatorio del hábitat popular en el Área Metropolitana de Buenos Aires. Instituto del Conurbano Universidad Nacional de General Sarmiento. (Disponible en http://www.infohabitat.com.ar/web/)

DI VIRGILIO, M. M. (2015) Urbanizaciones de origen informal en Buenos Aires. Lógicas de producción de suelo urbano y acceso a la vivienda. Estudios demográficos y urbanos, pp. 651-690.

DI VIRGILIO, M., GUEVARA, T., \& ARQUEROS, M. (2014). Un análisis comparado sobre la implementación de políticas de regularización de asentamientos informales en Argentina, Brasil y México. Revista INVI, 29(80), 17-51.

DI VIRGILIO, M.; HERZER, H.; MERLINSKY, G. y RODRIGGUEZ, M. C. (Compiladoras) (2011) La cuestión urbana interrogada: Transformaciones urbanas, ambientales y políticas públicas en Argentina. Café de las Ciudades, Buenos Aires. 
DI VIRGILIO, M. (2007) Trayectorias residenciales y estrategias habitacionales en familias de sectores populares y medios del Gran Buenos Aires. Tesis de Doctorado. Facultad de Ciencias Sociales. UBA. Mimeo.

Donato Lombardo, J. (2009). Transposición del orden social en espacial. En Poggiese, H. y Cohen Egler, T. (Comp.). Otro desarrollo urbano. Ciudad incluyente, justicia social y gestión democrática. CLACSO.

DUHAU, E. (1998). Hábitat Popular y política urbana. UAM Acapolzaco. México

DUHAU, E. (2013). La división social del espacio metropolitano. Una propuesta de análisis. Nueva Sociedad N. o 243.

DUHAU, E. \& GIGLIA, A. (2004) Conflictos por el espacio y el orden urbano. Estudios demográficos y urbanos, N. 56 . El colegio de México, México D.F.

ERIK OLIN, W. (2010) Envisioning Real Utopias. Berkeley.

FREDIANI, J. C. (2010) Lógicas y tendencias de la expansión residencial en áreas periurbanas. El Partido de La Plata, Buenos Aires, Argentina, entre 1990 y 2010. Tesis Doctoral. La Plata, Argentina.

FREDIANI, J.; RODRÍGUEZ TARDUCCI, R.; CORTIZO, D. (2012) Valor diferencial del suelo urbano y localización de la población en áreas de vulnerabilidad territorial en el Partido de La Plata. XI INTI International Conference La Plata, 17 al 20 de octubre 2012, La Plata, Argentina. Inteligencia territorial y globalización: Tensiones, transición y transformación. Disponible en: http://www.memoria.fahce.unlp.edu.ar/trab_eventos/ev.2653/ev.2653.pdf

FREDIANI, J. C., CORTIZO, D., RODRÍGUEZ TARDUCCI, R., \& GIGLIO, M. L. (2019) La ciudad invisibilizada: una aproximación a los falsos vacantes en el Partido de La Plata. Estudios Del hábitat,17(1), e067. Disponible en: https://doi.org/10.24215/24226483e067

GARCÍA, R. (2006) “Sistemas Complejos”. Barcelona: Gedisa

GERMANI, G. (1980) "El Concepto de marginalidad. Significado, raíces históricas y cuestiones teóricas con particular referencia a la marginalidad urbana". Ediciones Nueva Visión. Buenos Aires.

GOLDWASER, B. (2013) La villa, el barrio y el country. Tres situaciones en un solo territorio. Partido de Escobar, Provincia de Buenos Aires. Tesis de doctorado en Antropología, Facultad de Filosofía y Letras de la Universidad de Buenos Aires.

GONZALEZ, P. (2010) Los asentamientos populares en la Región Metropolitana de Buenos Aires: Emergencia y reproducción del territorio en los procesos neoliberales de construcción de ciudad (1980-2010). Geograficando. Obtenido de http://www.fuentesmemoria.fahce.unlp.edu.ar/art_revistas/pr.4747 
GRAUMANN, C.F. (1983) On multiple identities. International Social Sciences Journal, 35, 309-321.

HAESBAERT, R. (2013). Del mito de la desterritorialización a la multiterritorialidad. Cultura y representaciones sociales, 8(15), 9-42. Recuperado en 25 de noviembre de 2019, de http://www.scielo.org.mx/scielo.php?script=sci_arttext\&pid=S2007$81102013000200001 \& \operatorname{lng}=\mathrm{es} \&$ tlng=es.

HARVEY, D. (2012) “Ciudades rebeldes, del derecho a la ciudad a la revolución urbana". Madrid, España: Ediciones Akal, S.A, 2013.

HARVEY, D. (1977) “Urbanismo y desigualdad social”. España: Editorial Siglo XXI.

HARVEY, D. (1989) From Managerialism to entrepreneurialism: The transformation in urban governance in late capitalism. Geografiska Annaler. Series B, Human Geography, volumen 71, número 1, 3-17. Recuperado de http://dx.doi.org/10.2307/490503

HARVEY, D. (2001) "Espacios del capital. Hacia una geografía crítica”. Madrid: Akal. Edinburgh University Press.

HARVEY, D. (2003) “Espacios de esperanza”. Madrid: Ediciones Akal.

HIERNAUX, N. Y LINDÓN, A. (1993) El concepto de espacio y el análisis regional. Revista Secuencia, Número 25. pp. 89-110.

HIERNAUX, N. Y LINDÓN, A. (2002) Modos de vida y utopías urbanas. En: Ciudades, Procesos de Metropolización, núm. 53, enero-marzo, Puebla: Red Nacional de Investigación Urbana, pp. 26-32. ISSN 0187-8611

JANOSCHKA, M. (2002) El nuevo modelo de la ciudad latinoamericana: fragmentación y privatización. EURE (Santiago), 28 (85), Pp. 11-20. Recuperado de http://www.scielo.cl/scielo.php?script=sci_arttext\&pid=S0250716120020085000 02\&lng=es\&tlng=es

JARAMILLO, S. (2008) Reflexiones sobre la "informalidad" fundiaria como peculiaridad de los mercados del suelo en las ciudades de América Latina. Territorios.

KAROL, J. (2014) Reconocimiento de actores sociales en la planificación y la gestión Urbana. Notas Teóricas. Cátedra de Teorías Territoriales y Planificación Territorial. KTD. Recuperado de http://blogs.unlp.edu.ar/planificacionktd/

LAURÍN, A. (1999) Ensayo Metodológico para un estudio particular: Las transformaciones territoriales fronterizas del proceso de integración física. Boletín Geográfico Nº 21 Invierno. 
LEFEBVRE, H. (1968) “El derecho a la ciudad”.

LEFEBVRE, H. (1971) “La producción del espacio. Anthropos”. Paris.

LINDÓN, Alicia. (2007) La ciudad y la vida urbana a través de los imaginarios urbanos. EURE (Santiago), Vol.33. Nº9, pp.7-16.

LOMBARDO, J. Y DI VIRGILIO, M. M. (2006) Vínculos y relaciones entre espacio urbano y reproducción social en el contexto de economías emergentes. El caso de cinco municipios de la Región Metropolitana de Buenos Aires. En Revista Geográfica, número 136. Instituto Panamericano de Geografía e Historia (IPGH), ONU. México.

LOMBARDO, J. (2007) La construcción del espacio urbano. El caso de Región Metropolitana de Buenos Aires. En Lombardo, J. (Comp.). Paradigmas Urbanos. Conceptos e ideas que sostienen la ciudad actual. Los Polvorines. UNGS/ ALEUP/ CLACSO. MARCUSE, P., \& VAN KEMPEN, O. (2000). Globalizing cities. Oxford: Blackwell.

LONG N. (2007) Sociología del desarrollo: una perspectiva centrada en el actor. México: CIESAS

MARRADI, A., ARCHENTI, N. Y PIOVANI, J. (2007) Metodología de las Ciencias Sociales. Buenos Aires: Emecé.

MAX-NEEF, M. (2004) Fundamentos de la transdisciplinariedad. Universidad Austral De Chile, Valdivia, Chile. Recuperado de http://www.maxneef.cl/download/Max_Neef_Fundamentos_transdisciplinaridad. pdf

MERKLEN, D. (1991) Asentamientos en La Matanza. La terquedad de lo nuestro, Catálogos editora, Buenos Aires.

MERKLEN, Denis (2005) Pobres ciudadanos. Las clases populares en la era democrática. (Argentina 1983-2003). Editorial Gorla.

MERKLEN, D. (2004) Sobre la base territorial de la movilización popular y sobre sus huellas en la acción. Revista Laboratorio/online. Número 16. Buenos Aires.

OSLENDER, U. (2002) Espacio, lugar y movimientos sociales: hacia una "espacialidad de resistencia". Scripta Nova. Revista electrónica de geografía y ciencias sociales, Volumen VI, número 115. Universidad de Barcelona. ISSN: 11389788. Recuperado de http://www.ub.es/geocrit/sn/sn-115.htm

OZLAK, O. (1991) Merecer la ciudad: Los pobres y el derecho al espacio urbano. Buenos Aires, Argentina: Estudios Cedes. Editorial Humanitas.

PAUL-HENRY, C. D. (1979) Appropiation de l'espace et changement social. 
PERLES ROSELLÓ, M. J. Y MÉRIDA RODRÍGUEZ, M. (2010) Patrón territorial y conformación del riesgo en espacios periurbanos. El caso de la periferia Este de la ciudad de Málaga. Scripta Nova. Revista Electrónica de Geografía y Ciencias Sociales. Volumen XIV, número 329. Barcelona: Universidad de Barcelona. [ISSN: 11389788].

PIREZ, P. (1995) Actores Sociales y gestión de la ciudad. Ciudades. Recuperado el 2019, de http://www.cedet.edu.ar/Archivos/Bibliotecas/pirez_actores.pdf

PIREZ, P. (2006) La privatización de la expansión metropolitana de Buenos Aires. En Economía, sociedad y territorio, volumen 6, número 21.

PIREZ, P. (2013) La urbanización y la política de los servicios urbanos en América Latina. Andamios.

PIREZ, P. (2014) Mercantilización y des mercantilización de las metrópolis latinoamericanas. Revista América Latina en Movimiento N. 267. Dossier La cuestión urbana de hoy.

PIICKENHAYN, J. (1994) “Epistemología y geografía”. Primera edición. Buenos Aires: Plus Ultra.

POZO SOLÍS, A. (2007) Mapeo de actores sociales. Lima: Mimeo. Recuperado de: http://www.preval.org/documentos/ma0018.doc

PRÉVOT SCHAPIRA, M. F. (2001) Fragmentación espacial y social: conceptos y realidades. Perfiles latinoamericanos 18-19, pp. 35-56.

PRÉVOT SCHAPIRA, M. F. (2005) Buenos Aires, la métropole divisée. Gouvernance urbaine et défi metropolitaine dans les annés 90. L'Ordinaire Latinoamericain 200/201, pp. 99-108.

RAFFESTIN, C. (1993) “Por uma geografía do poder”. pp. 269. São Paulo: Ática.

REGUILLO R. (2005) La construcción simbólica de la ciudad. Ciudad, desastre y comunicación. México. ITESO

RELLI, M. (2011) Notas sobre la política de la provincia de Buenos Aires frente a la irregularidad dominal del hábitat popular urbano, 1991-5005. En La cuestión urbana interrogada. Transformaciones urbanas y ambientales y políticas en Argentina. Parte 2. Editorial Café de las Ciudades. Buenos Aires.

REVILLA BLANCO, M. (1996) El concepto de movimiento social: Acción, identidad y sentido. Última Década, pp. 1-18. ISSN 0717-4691. Recuperado de http://www.redalyc.org/articulo.oa?id=19500501

RODRÍGUEZ TARDUCCI, R. (2018) Asentamientos informales en el Partido de La Plata: Una aproximación a las modalidades de ocupación del territorio. Estudios 
Socioterritoriales, 23 Recuperado en 17 de noviembre de 2019, de http://www.scielo.org.ar/scielo.php?script=sci_arttext\&pid=S1853$43922018000100008 \& \operatorname{lng}=e s \&$ tlng=es.

SANTOS, M. (1996) "A natureza do espaço. Técnica e tempo. Razão e emoção". São Paulo: Hucitec.

SANTOS, M (1996B) “De la totalidad al lugar”. Barcelona: Oikos-Tau.

SAUTU, R. (2000) Los Métodos Cuantitativos y Cualitativos en la Investigación Educativa. En Boletín de la Academia Nacional de Educación, Número 42. Buenos Aires.

SAUTU, R., BONIOLO, P., DALLE, P. Y ELBERT, R. (2005) Manual de metodología. Construcción del marco teórico, formulación de los objetivos y elección de la metodología. Buenos Aires: Colección Campus Virtual. Clacso Libros. ISBN: 9871183-32-1.

SCHNEIDER, S., \& TARTARUGA, I. (2006) Territorio y enfoque territorial: de las referencias cognitivas a los aportes aplicados al análisis de los procesos. En M. MANZANAL, \& G. y. NEIMAN, Desarrollo Rural. Organizaciones, Instituciones y Territorio. (págs. 71-102). Buenos Aires: Ciccus.

SARAVI, G. (2007) Nuevas realidades y nuevos enfoques: exclusión social en América Latina. En De la pobreza a la exclusión. Continuidades y rupturas de la cuestión social en América Latina. México: Prometeo Libros.

SEGURA, R. (2012) Elementos para una crítica de la noción de segregación residencial socio-económica: desigualdades, desplazamientos e interacciones en la periferia de La Plata. Quid 16 N. o 2 Instituto de Investigaciones Gino Germani, Facultad de ciencias sociales Universidad de Buenos Aires (UBA).

SILVA, A. (1992) Imaginarios urbanos. Bogotá y Sao Paulo, Cultura y comunicación urbana en América Latina. Bogotá: Tercer Mundo Editores.

SILVEIRA, M.L. (2003) Por una epistemología geográfica. En Bertoncello, R. y Carlos, A. (Comp.), Procesos territoriales en Argentina y Brasil. Instituto de Geografía. Facultad de Filosofía y Letras Universidad de Buenos Aires.

SMOLKA, M., \& MULLAHY, L. (2010). Perspectivas Urbanas: Temas críticos en políticas de suelo e América Latina. Cambridge, Massachusetts: Lincoln Institute of Land Policy.

SOJA, E. (1985) "La espacialidad de la vida social: hacia una reteorización transformativa" en Gregory y Urry editores, Social Relations and Spatial Structures, Macmillan, London. (traducción de H. Torres) 
TAYLOR, S. Y BOGDAN, R. (1987) Introducción a los métodos cualitativos de investigación. La búsqueda de significados. Grupo Planeta (GBS). España.

THEODORE, N., PECK, J. \& BRENNER, N. (2009) Urbanismo neoliberal: la ciudad y el imperio de los mercados. Temas sociales.

TOPALOV, C. (1979) "La urbanización capitalista, algunos elementos para su análisis".

VARELA, O. Y CRAVINO, M. C. (2009) Mil nombres para mil barrios Los asentamientos y villas como categorías de análisis y de intervención. En Cravino et.al. (Coord.), Los mil barrios (in)formales: aportes para la construcción de un observatorio del hábitat popular del área metropolitana de Buenos Aires. Pp. 134. Los Polvorines: Univ. Nacional de General Sarmiento.

VECSLIR, L. Y CICCOLELLA, P. (2012) Transformaciones territoriales recientes y reestructuración metropolitana en Buenos Aires. Ri URB Revista Iberoamericana de Urbanismo, número 8, pp.1-7.

VIDAL M., TOMEU, P., URRÚTIA, E. (2005) La apropiación del espacio: una propuesta teórica para comprender la vinculación entre las personas y los lugares. Anuario de Psicología [Internet]. Recuperado de: https://www.redalyc.org/comocitar.oa?id=97017406003.

VIDAL-KOPPMANN, S. (2007) Transformaciones socio-territoriales de la Región Metropolitana de Buenos Aires en la última década del siglo xx. La incidencia de las urbanizaciones privadas en la fragmentación de la periferia. Tesis de doctorado. Facultad Latinoamericana De Ciencias Sociales (FLACSO)- Sede Académica Argentina Programa de doctorado en Ciencias Sociales.

\section{Fuentes Periodísticas}

Nota en "La Nación diario" versión online. SEGURA R (2015). Territorio, desigualdad y experiencia urbana.

https://www.lanacion.com.ar/opinion/ramiro-segura-territorio-desigualdad-yexperiencia-urbana-nid1790934.

Nota en revista online (2015) "Agencia Nova, noticias de Argentina y el mundo." 
http://www.agencianova.com.ar/nota.asp?n=2015_1_25\&id=45935\&id_tiponota= 10.

Nota en diario "La izquierda" (junio 2017).

http://www.laizquierdadiario.com/Juicio-a-la-CNU-La-Plata-Papa-les-decia-queno-nos-pegaran-que-eramos-criaturas.

Nota en diario “El Día” versión online (2019).

https://www.eldia.com/nota/2019-9-15-3-33-41-ya-son-mas-de-130-000-los-

platenses-que-viven-en-barrios-de-emergencia-informacion-general.

Entrevista en Radio Universidad con referentes de Puente de Fierro (2019)

https://www.facebook.com/upak.laplata/videos/2379533555462216/.

\section{Fuentes y servicios (páginas) Web}

COMISION ECONOMICA PARA AMERICA LATINA Y EL CARIBE (CEPAL), https://www.cepal.org/es

DECRETO-LEY 8912/77. Texto Ordenado por Decreto 3389/87 con las modificaciones del Decreto-Ley $N^{\circ} 10128$ y las Leyes $N^{\circ} 10653,10764,13127$, 13342 y 14449. Ley de ordenamiento territorial y uso del suelo http://www.gob.gba.gov.ar/legislacion/legislacion/l-8912.html

ONU - HABITAT. Por un mejor futuro urbano sitio web.

https://onuhabitat.org.mx/index.php/hacer-de-los-asentamientos-informalesparte-de-la-ciudad

POBREZA EN EL AMBA (2017). Informe Digital Metropolitano https://metropolitana.org.ar/idm. Posted By Fundación Metropolitana27 febrero, 2017 @ 18:41 Marzo, 2017. Por Gabriela Cévalo Boro.

PUBLICACIÓN DE LAS NACIONES UNIDAS. (2017). Plan de Acción Regional para la implementación de la Nueva Agenda Urbana en América Latina y el Caribe 20162036. Santiago : Publicación de las Naciones Unidas.

https://www.cepal.org/sites/default/files/events/files/par_esp_c1700844_web1. pdf.

PUENTE DE FIERRO, TERRITORIO POSIBLE Mesa de Trabajo Permanente y Agenda Científica 2014 - 2026 PIO OM.

http://idihcs.fahce.unlp.edu.ar/territoriosposibles/puente-de-fierro-territorioposible-mesa-de-trabajo-permanente-y-agenda-cientifica-2014-2026-pio-om/

RPPVAP, Registro Público Provincial de Villas y Asentamientos precarios, de la Provincia de Buenos Aires (2015). Relevamiento de Villas y asentamientos precarios, aplicativo web.

http://190.188.234.6/registro/público/ 
TECHO (2016) Informe Un Techo Para Mi País.

https://www.techo.org/

https://www.techo.org/argentina/

UTDT -CIPUV, Centro de Investigación de Políticas Urbanas y de Vivienda, Atlas de Crecimiento Urbano (2013). Atlas de crecimiento urbano universidad Torcuato Di Tella.

https://www.utdt.edu/ver_contenido.php?id_contenido=9267\&id_item_menu=18 003. 
ANEXOS

$\longrightarrow \diamond \bullet$

$\bullet \diamond$ 
ANEXO 1

$-\ldots-$

\section{ENTREVISTAS A ACTORES CLAVE}




\section{ANEXO 1- Entrevistas con actores clave}

En este apartado se encuentran las entrevistas realizadas para este trabajado de tesis, a los actores clave del sector público y de la ciudadanía, referentes barriales y vecinos, así como académicos y expertos en el estudio de la problemática de la informalidad urbana y la ocupación y apropiación territorial. Las entrevistas son una herramienta fundamental para conocer la mirada del actor en el territorio, para indagar acerca del proceso de ocupación y apropiación territorial, las modalidades llevadas a adelante por los habitantes de urbanizaciones informales y referentes, por un lado, y por el otro para indagar acerca del rol del sector público, sobre que estrategias o instrumentos existen frene a esta problemática y cuales se aplican. Por su parte, el conocimiento académico contribuye en el entendimiento desde la teoría, analizable en la empiria, por lo que las entrevistas aquí presentadas se dividen en tres tipos fundamentales.

$\checkmark$ Entrevista TIPO 1: Referentes y fundadores del barrio Puente de Fierro.

$\checkmark$ Entrevista TIPO 2: Actores vinculados con el mundo académico.

$\checkmark$ Entrevista TIPO 3: Actores vinculados con el sector público.

\section{ENTREVISTA TIPO 1}

\section{Modelo de entrevista a referentes y fundadores del barrio Puente de Fierro}

Esta entrevista se llevó a cabo principalmente junto a dos de las lideresas más presentes en el barrio Puente de Fierro, con larga trayectoria de trabajo para y por el barrio, en el marco de organizaciones sociales y movimientos surgidos de los vecinos. Actualmente, ambas son referentes y manejan comedores infantiles dentro del barrio. También participan desde el 2016 de las mesas de trabajo permanente que se llevan a cabo cada mes, en conjunto con las organizaciones sociales, los vecinos y la universidad para pensar entre todos soluciones a las problemáticas que enfrenta el barrio y sus habitantes. Cabe mencionar que las entrevistas fueron realizadas entre los años 2018 y 2019. 
A continuación, se presenta la guía básica de preguntas para los referentes barriales. Esta guía es factible de replicar para el análisis del proceso de ocupación y apropiación territorial en otras urbanizaciones informales, en Argentina o en cualquier otro país / ciudad donde exista el iteres de conocer acerca de tal proceso.

La entrevista propiamente dicha se divide en tres apartados, el primero explora sobre el presente del barrio al preguntar al entrevistado la opinión que le merece la situación actual. Esta pregunta funciona como disparador, al ser abierta incita a que el entrevistado comience por contar desde su visión como es el barrio en la actualidad. En el segundo punto las preguntas se orientan hacia los orígenes del barrio, y el inicio de la ocupación. También se pretende conocer sobre la identidad del barrio, al preguntar si tiene nombre y si lo tiene a que se debe. El tercer punto pretende ir más profundo al preguntar por la estrategia de ocupación la situación dominial y el proceso de toma de terrenos, este apartado se pregunta al final de la entrevista, entendiendo que este tipo de preguntas pueden incomodar a los entrevistados, al preguntar por la toma ilegal de terrenos y la organización de la misma.

\section{Guía 1 de preguntas a referentes y fundadores barriales:}

\section{1- Sobre el presente del barrio...}

¿Qué opinión tiene usted acerca de la situación actual del barrio?

\section{2- Sobre el proceso de ocupación y apropiación en el barrio...}

La historia del barrio...

1. ¿Cómo comenzó el barrio?

2. ¿Que había antes en este lugar?

3. ¿El barrio tiene nombre? ¿Cómo se llama? ¿Porque se llama de esta manera?

4. ¿Cómo fue el proceso de creación y crecimiento del barrio? ¿Quienes participaron? ¿De qué manera?

3- Sobre la situación de tenencia del suelo y el proceso de toma de los lotes/ terrenos vacantes...

1. ¿Cuándo se produjo la toma? ¿Quiénes participaron de ella? 
2. ¿Cómo se enteraron de la existencia de los lotes? Si los terrenos ya existían vacíos... ¿Porque no se tomaron anteriormente?

3. ¿Alguien impulso / organizo la toma?

4. ¿Conoce el origen de los lotes? Si son privados, fiscales, etc.

\section{Guía 2 de preguntas a referentes y vecinos}

1. ¿Cómo se llama el lugar donde vive? ¿Conoce otra forma de nombrarlo?

2. ¿Cuándo llegó usted al barrio? ¿Dónde vivía antes?

3. ¿Qué conoce de la historia del barrio?

4. ¿Conoce referentes barriales? ¿Y organizaciones? ¿Qué opinión le merecen?

5. ¿Hace actividades con otra gente del barrio? (Tomar algo, un deporte, algún trabajo...)

6. ¿Existen redes de comunicación entre los vecinos? (Sea vía Facebook, WhatsApp, etc.)

7. ¿Qué es lo que más necesita el barrio? ¿Por qué piensa que no lo tiene? ¿Qué se lo impide?

8. ¿Qué habría que hacer para cambiar esas cosas? ¿Qué acciones? ¿Cómo conseguirlo?

9. ¿Qué tiene de bueno su barrio? ¿Qué es lo que menos le gusta?

10. ¿Se iría a vivir a otro lado? ¿Por qué?

\section{Entrevista con Referente 1 del barrio Puente de Fierro}

\section{(Transcripción del audio original)}

Yo nací y me crie acá, mis padres nacieron y me criaron acá, mis abuelos, mis tíos, es una generación bastante vieja. Tengo hijos y nietos acá. Yo vivía en 31 y 79 después mi abuelo compro un terreno en 31 y 85 y nos vinimos a vivir acá. Esto era campo, toda la 31 era eucaliptus, acacias había una planta llena de pinches, hiedra que te ponía colorada la piel, y nosotros veníamos al puente de Fierro a andar en bicicleta, era todo campo.

Esto fue por los años 70, Pasaba el tren, no había casas. Esto era estancias, la 31 era campo hasta 79, en 79 estaba la línea 61 y campo. Cuando se fueron a vivir mis padres no tenían baño e iban al molino que había en 30 en la estación Elizalde. Algunas casas tenían título de propiedad, otras no.

Mas sobre el puente de fierro había gente que sembraba. Gradualmente empezó a formarse el barrio. Desde 31 hasta 30 había una sola señora que tiraba un cable desde mi casa todo el campo y se le daba la luz a esta señora. Otro vecino vino de San Juan. Era todo casitas y barro, muy precario todo, es más el agua había esas antiguas bombas, no teníamos agua, no teníamos luz, y fue de a poco se fue ocupando y avanzando.

De 31 a 30 las manzanas tienen título d propiedad, de 86 para la 90 son tierras fiscales ocupadas. Acá teníamos un señor que fue el que inicio todo y midió a ojo y le fue dando a la gente. No había agrimensor, nada. Era un señor que se fijó en tierras que era todo fiscal. Había gente q en otros lugares necesitaba terreno y se fue pasando de boca en boca, gente de otras provincias. De Bolivia, Perú, Paraguay y otras provincias. Todos vivimos juntos en el barrio. Hay buena relación entre los vecinos de donde sean. 
Actualmente a mí me da placer que se haya construido la placita, mis hijos venían a andar en bici acá. Había casas, pero no tanto como ahora. Me da placer y me pongo feliz que todos tengan su casita. La gente que vive en el barrio está contenta, en mi cuadra nadie se mete con nadie. Hay vecinas que los hijos no tenían donde vivir y hoy x hoy pasando el puente tienen su pedacito de terreno. El barrio evita es gente de acá que se pasaron para allá. La situación no está para comprar un terreno, son terrenos ocupados.

Con los años se acercó gente de la gestión, pudimos hacer con los referentes las plazas, una canchita. Pero es como todo, vienen prometen y después no cumplen nada. Si no nos hubiéramos organizado como barrio no pasaba nada. Aunque tuviéramos distintas maneras de pensar se logró algo.

Nosotros conocíamos el barrio como Elizalde porque teníamos la estación, después se dijo altos de san Lorenzo, después se denominó puente de fierro, l agente vieja dice Elizalde, la gente nueva le dice Puente de Fierro. Lo fueron llamando así por el puente. Antiguamente era Elizalde porque teníamos la estación para comunicarnos con el fondo era la estación de tren donde tomaba la gente la ir para magdalena. La relación con los alrededores es buena.

Hace 3 años fuimos a un evento y se nos rompió el auto, paramos un taxi y le decimos me lleva a tal lugar y no nos quiso llevar porque el barrio está muy mal visto, pero en la convivencia como nos conocemos está todo bien. Acá entran ambulancias, no van al fondo, por el tema del barro, ni los bomberos por la situación de la calle. Surgen muchos incendios por estufas, se incendian mucho. La gente en el barrio se organiza y está feliz, obvio que hay cosas que mejorar, puede haber gente jodida, pero nos llevamos bien.

\section{Entrevista con fundador externo al barrio- Actor clave en la creación de Puente}

\section{de Fierro.}

En este caso, la entrevista es de carácter desestructurado, se mantuvo una conversación donde se habló principalmente acerca del nacimiento del barrio Puente de Fierro tal como es. (Transcripción del audio original)

Pasamos muchas cosas juntos, vivimos muchas cosas juntos. Pasé mucho tiempo de mi vida ahí y bueno. Pase muchos años de mi vida en Puente de Fierro haciendo cosas con los vecinos y tratando de lo que era un basural transformarlo en un barrio de trabajadores. Siempre hay algo nuevo para hacer. Yo estoy ahora en este barrio y si hay algo, bueno, siempre surgen cosas por que luchar. Son otras realidades, pero siempre hay un querer el mejoramiento de la calidad de vida de los vecinos. Esta bárbara lo que hacen, me parece bárbaro, muchas de las chicas que están trabajando en las organizaciones hemos trabajado juntos, y bueno, siempre por los que menos tienen. Cuando llegué a Puente de Fierro no había nada, era un páramo eso. Era una descarga de basural. Era una humareda constante. Yo no me acuerdo bien, pero en los 90 o antes llegué. Logramos urbanizar, repartí los terrenos yo y mi vista estuvo fija en la otra cuadra de allá de la 83 y de ahí sacamos los terrenos. Caminábamos diez pasos para allá, diez pasos para allá, los del centro los repartíamos en dos, y así bueno, logramos hacer un barrio de un basural, sacamos un barrio. Todo eso a través del tiempo y siempre conociendo a los vecinos y por el mejoramiento de la calidad de vida. En ese entonces no había ningún plan no había nada, era absolutamente solidario. 
Está bien que el plan ayuda y ayudó a las familias, pero en un tiempo nosotros habíamos recreado la solidaridad a través de nada, no es que había un pagamento para hacer algo en beneficio de los vecinos. Era algo que todos sabíamos que teníamos que hacer y lo logramos entre todos. En el logro de todos esos servicios que aportamos: a partir del terreno pelado que hemos traído luz, agua, abrimos calles, en un momento se logró traer asfalto y luz, nosotros cuando empezamos con cables de antenas de televisión traíamos de la 82 hacia el barrio, una bomba sola había de agua. Peleamos por el agua, trajimos el agua. Son barrios postergados que necesitan mejorar. $Y$ en eso estamos, hay unas chicas que están laburando muy bien en distintas organizaciones. El agrimensor era yo, pero a través de mi vista y caminar, salió bastante bien, dentro de todo pudimos repartir una tierra que estaba abandonada y pudimos dársela a la gente que necesitaba. Mi familia es de política, siempre hemos militado adentro del peronismo y siempre hemos trabajado en los que menos tienen.

Tengo un hermano desaparecido yo también, tengo hermanos que siempre han militado, yo, mis parientes siempre hemos estado militando en lo que es el peronismo. $Y$ en un periodo, hubo una parte de La Plata en la cual necesitaban gente y bueno, dije yo voy a ir y como yo conocía mucha gente dije "no quiero ir a un barrio que tenga que estar en puja", siempre hay esas pequeñas diferencias de gente del barrio, entonces dije "no, voy a elegir un lugar que no haya mucha gente, que no haya nadie". Entonces eran muy poquitas casas sobre la 83, 84, ahí eran poquitas casas que necesitaban. Y había en el fondo todo un territorio ahí que era depósito. Y bueno, la gente necesitaba acá un terreno, y digo bueno, vamos a hacer así, y empezamos a limpiar y de repente se transformó en una marea colonizadora que fue de la 23 bis hasta la 28 casi 29 y de la 85 a la 90, que son muchas manzanas. Y después repartimos terrenos. Una particularidad del barrio era que era gente joven, no eran viejos. Eran jóvenes que querían independizarse de sus casas y todos ahí, a Puente de Fierro. Bueno, Puente de Fierro le pusimos por el puente, pero por una reunión de vecinos. $Y$ entonces en ese venir de gente hacia el barrio fuimos repartiendo las parcelas, se fue armando, y después nos dimos cuenta que faltaba un comedor, que faltaba un ropero, una guardería, y las fuimos armando con los vecinos.

Después a través de la política hemos conseguido muchas cosas, y también del trabajo de la gente. Porque vuelvo a repetirte, era un tiempo que no había planes sociales, en cual todo era de changas, y a partir de la política conseguimos hacer un comedor en el cual pudimos alimentar a los chicos, era el comedor Mabel Amuchástegui, era un centro comunitario del barrio Puente de Fierro con personería jurídica que teníamos ahí y a través de eso pudimos tener nuestro comedor. Fue la primera organización del barrio, y la segunda la armamos nosotros que era M. Amuchástegui que estaba en 24 bis y 90, era un comedor comunitario que habíamos hecho también un ropero, una biblioteca y teníamos también en Puente de Fierro, porque vimos también en ese momento la necesidad de tener una escuela para adultos porque había mucha gente del norte que no sabía ni leer ni escribir que trabajaba ahí conmigo, y se logró escolarizar a mucha gente grande. Esos fueron los tres primeros, comedores y escuela.

Funcionaba la escuela donde estaba el comedor, que ahora funciona, pero bueno se dejó un poco. Estaba en 83 entre 26 y 27. En realidad el barrio empezaba en 84 porque en ese sector había una plaza que fue ocupada, entre 85, 27 y 28. Funcionaba una plaza que el que loteo del otro lado tenía que dar una parte para espacio público. Las primeras familias me acuerdo, fueron Blanco, P., Quiroga, M. Gómez que trabajo en el comedor conmigo. Esos son los primeros que empezamos, en realidad empezamos con las Blanco, y un par de gente que yo conocía que a partir de ellos yo empecé a trabajar ahí y empezamos a caminar el barrio y a darle participación a los vecinos y bueno, después se produjo esa marea de gente en cual íbamos dando terrenos y a partir de ahí nos vimos en la necesidad de armar todo ese tipo de complementos. Lo hacía con gusto, no veía yo que se podía hacer por plata. 
Por ahí si uno lo hace por plata o por otros intereses que no sea el hacer bien te resulta mucho más difícil. Porque un barrio el cual tienes que caminar en el barro, trenes que caerte a veces en una zanja, no es saludable, pero te mueve la voluntad de ayudar a la gente. Eso es primordial. Conflictos mucho, pero no tanto como con la gente en si porque con la gente teníamos todos un mismo discurso a partir de reuniones que hacíamos y abriendo la cabeza a todo el mundo, discutíamos y hacíamos cosas, pero siempre me escucharon un poco a mí y escuchaba yo también a la gente y de ahí salían las decisiones para encarar, que eran siempre las mismas, el bienestar de la gente. Eso es lo que nos movía. En un momento llegaron muchos del norte argentino: muchos de Jujuy, Salta, que nosotros le dábamos la bienvenida, gente muy trabajadora, muy buena que ayudo mucho, de chaco también mucha gente. Después se vinieron muchos hermanos bolivianos, gente muy trabajadora. Que en realidad se perdió el objetivo que nosotros teníamos, primeramente. Porque después hubo un trámite así de compra y venta y nosotros habíamos dado el terreno y no le habíamos cobrado absolutamente nada a nadie, era una cosa de ir a vivir y mostrar la necesidad y siempre tratábamos de priorizar a la gente trabajadora para no hacer tipo villa, o tipo de gente de mal vivir. Yo siempre pensé en ese objetivo: que sea un barrio de trabajadores. Para eso me involucre en esa movida.

Lo que te da ser un poco más joven es también la posibilidad de ir y conseguir cosas para los demás es una cosa un poco ingrata a veces, pero muy reconfortante porque ves que se puede llegar a toda la gente y bueno y alguien tiene que hacerlo y alguien que sepa hablar y poder graficarles a los funcionarios la posibilidad de decir bueno esta gente lo necesita estamos acá y era el acompañamiento de la gente que tenía yo. Yel acompañamiento es siempre con la idea de la política y para el bienestar de la gente. Pero en realidad lo que me movía también era el bienestar de la gente que era lo que me inculcaron políticamente a mí. No sería honesto si no lo digo. La universidad siempre estuvo, yo he militado en FULP también. En el principio de lo que era. Y vos me hablabas de Ciencias de la Educación cuando estaba por 6 y nosotros íbamos y hacíamos movidas de la JUP. Digamos que era el origen o el principio de la participación de la universidad en los barrios. Yo he trabajado en Romero, en las margaritas que tenía un comedor ahí, tenía un comedor en Santa Ana, Mabel, tenía otro comedor en lo que es 117 y 76. Nosotros éramos 7 hermanos, y casi todos éramos los más comprometidos, militábamos, tengo una hermana desaparecida por estas cuestiones. Mis padres fueron gente trabajadora, mi mama era italiana y mi padre argentino. Nosotros nacimos casi todos en La Plata, en este barrio (La Loma), acá en mi casa. Mi madre lo mejor, siempre me apoyo en todo, estuvo siempre conmigo hasta último momento. Mi infancia como cualquier pibe de barrio, desde muy chico empecé a militar yo, a los 10 años, vendía el periódico y ya desde chico empecé a trabajar. Es un lindo recuerdo el que tengo de Puente de Fierro por como lo comenzamos, el cariño que me tenía la gente, el cariño que yo le tenía a la gente también. Lo veo en expansión, un lugar de trabajadores, de lo que era en ese entonces a lo que es hoy, hay un cambio en el barrio, hay muchas más casas de material, todo mi sueño de que la gente pudiera hacerse su casa, tener sus lotes, es un poco el pensamiento hecho realidad. Vos si trabajas en algo para que progrese, ves en el tiempo que se da. Yo participe de 23 bis y hasta 28 o 29, por ahí.

Yo en el comienzo note cosas maravillosas de por ejemplo mujeres que trabajaban a la par de un hombre, mujeres albañiles cuando nosotros nos poníamos para hacer una vereda y conseguíamos materiales, y las primeras eran las mujeres. $Y$ vos las ves trabajar y con baldes de piedra y arena y haciendo y llevando, y así hicimos montones de veredas. Yo por la experiencia mía de trabajar, obvio que los hombres trabajaban y también ha pasado de mujeres que podían donar el tiempo para hacer emprendimientos barriales, y no cobraban nada y simplemente era de caminar y bueno. Con respecto a las mujeres siempre he visto más participación, es siempre más la que maneja la cosa, en mi interacción con las organizaciones ya en ese entonces.

Yo pienso que hay que trabajar y estar con la gente, el político tiene que trabajar para la gente. Si vos no trabajas para la gente y no haces bien a la gente entonces no sos 
político, estás haciendo cualquier cosa. Siempre ese es la política, y siempre una idea que es mejorar la calidad de vida de los habitantes de un barrio, quien se mueve por cloacas, quien se mueve por agua. Nosotros tuvimos la experiencia de traer el agua, traer el asfalto, la luz, en un momento habíamos conseguido luz que parecía un estadio de futbol, se veía de la 89. Y los de al lado estaban re calientes, decían “como, estos vinieron ahí, mira la luz que tienen, nosotros no tenemos luz".

Cosas así, pero bueno, a partir de que nosotros nos movilizamos, tenemos participación en todo lo que hacíamos en el barrio, lográbamos cosas. Ninguno podía decir que no. Yo pienso que armar un consejo del barrio está bárbaro, siempre y cuando el objetivo sea el mejoramiento de la calidad de vida de la gente, pero por qué no nos vamos a juntar. Ese es el primer objetivo y la primera consigna porque si vamos a un barrio y no lo mejoramos y no nos movemos para hacer cosas, no se para que vamos. En realidad, siempre me hubiera gustado a mi armar un consejo de nuestra gente, de hecho, nosotros invitamos, funcionó lo que es la primera escuela, el Cebas que venía, el San Juan de Dios que empezó con nosotros. Y nosotros teníamos la posibilidad de vacunar a los chicos, de caminar, de ver todo el tipo de vacunaciones, traer vacunación, atención en el hospital, traer folletos, hacer charlas instructivas sobre distintas temáticas que podían caber en el barrio, transmisión de enfermedades, embarazo precoz, todo ese tipo de cosas que nosotros podíamos mejorar para la gente a su vez no perder de vista roperos comunitarios que habíamos armado, biblioteca, la escuela, siempre para mejorar.

Vos podés llevar muchas cosas al barrio, pero si no educas, si no le das participación en la educación, esa gente queda estancada. Podría simplificar muchas cosas un consejo porque podrían ponerse un objetivo y todos trabajar en ese objetivo, siempre el mismo. La gente después evalúa quien trabaja, quien no trabaja, quien tiene buenas ideas, eso después se ve. Pero mejorar la calidad de vida de los habitantes de un barrio es algo maravilloso que va más allá de la política. Yo no tengo problema en ayudar para armar algo, nosotros tenemos una estructura que queremos en algún momento reciclarla y hacer una cosa, pero cuando tengamos bien claro que grupo es y cómo va a ser. Tenemos un par de cosas en el barrio como para hacer, a mí me gustaba más en educación porque por ahí hace falta en el barrio una buena guardería o un jardín de infantes, porque el de 23 esta superpoblado y mucha gente tiene que caminar o bajar para La Plata para poder darle educación a los chicos, estaría bárbaro poder hacer ahí una buena guardería o un buen jardín de infantes, es un sueño.

Pero bueno, yo si hay voluntades de mejorar la calidad de vida de los vecinos, y uno no puede estar en desacuerdo en esa cuestión. Eso se puede simplificar, si hay mucha gente, muchas organizaciones, por qué no armar una organización del barrio en la cual puedan estar todos los pensamientos. Nosotros teníamos un club acá que estábamos todos de distintos pensamientos, distintas realidades y luchábamos por el barrio, solamente diferíamos en periodo electoral pero siempre con altura y con caballerosidad para encarar alguien que encara las cosas distinto a vos. Pero siempre sin perder el objetivo que es la gente del barrio, el bienestar, mejorar, educación, salud, todo ese tipo de cosas que se pueden lograr a partir de una comunidad organizada. Se podría hacer un consejo del barrio porque en realidad estarían todas las voluntades (Como la antigua Grecia). Sí, no hay nada nuevo bajo el sol, siempre hubo algo, un consejo tribal siempre hubo, siempre que esta la voluntad del bienestar de todos está el consejo que ya viene desde la tribu y desde las cavernas me parece que se juntaban alrededor del fuego y charlaban a ver cómo podían hacer para ir a cazar un búfalo. Pero siempre tiene que haber la voluntad, cuando anteponemos lo personal en lo comunitario se pudre todo, tenemos que pensar en lo comunitario que es bueno porque ahí se van a desarrollar los hijos nuestros, los nietos, el futuro nuestro, de un barrio. Tenemos un barrio con asfalto, con una salita, con un buen jardín de infantes, apuntar a un secundario porque ahí está faltando un secundario y una escuela primaria más. Ya todas esas manzanas tienen para llenar una escuela. 


\section{ENTREVISTA TIPO 2}

Actores vinculados con el mundo académico. Modelo de entrevista a la Arq. Luciana Marsili.

La arquitecta Marsili es especialista docente e investigadores sobre temáticas vinculadas con las urbanizaciones informales, ha dedicado su vida en la universidad a trabajar temas vinculados con la informalidad urbana, los barrios precarios y la participación ciudadana.

\section{1- Preguntas guía: El acceso al suelo y la ocupación informal del territorio}

1. ¿Qué opinión tiene acerca de la problemática del acceso a la tierra y a la vivienda en el Partido de La Plata? ¿Cuáles cree son las causas de la existencia de urbanizaciones informales en el Partido de la Plata puntualmente? ¿A qué cree se debió?

2. ¿Puede determinar quiénes y de manera han intervenido en el proceso de la conformación de las urbanizaciones informales en el partido de la plata?

3. ¿De qué manera cree usted que la aparición de asentamientos informales en la periferia del Partido de La Plata ha transformado el territorio?

4. ¿Podría enumerar las principales problemáticas que existen a su criterio dentro del hábitat informal?

5. ¿Cree que a partir de la toma de tierra y de la ocupación informal del territorio es posible que se produzca un proceso de apropiación entre los sujetos y el territorio?

6. ¿Cree que de esta interacción surgen lugares con carácter simbólico e identitario al interior de los barrios populares?

7. ¿Cuán relevante cree que sea la conformación de redes sociales durante el proceso de ocupación y apropiación territorial en asentamientos informales?

\section{2 - Acerca de la intervención por parte del estado del estado y el papel del mercado inmobiliario}

1. ¿Qué tipos de intervención reconoce por parte del Estado ante la problemática de las urbanizaciones informales a nivel Municipio, Provincia, Nación? 
2. ¿Cómo cree debería el Estado accionar ante las tomas de tierra frente al déficit de vivienda?

3. ¿Cuál es el rol que cumple el mercado informal de suelo y vivienda en la organización territorial puntualmente en el Partido de La Plata?

4. ¿Cómo ha sido su experiencia trabajando en los barrios a través de los proyectos de extensión de la UNLP? ¿A qué conclusiones ha llegado?

5. ¿Cómo cree que debería enfrentarse el problema de la falta de acceso al suelo y a la vivienda? ¿Qué instrumentos deberían aplicarse? ¿Quién es el responsable de realizar los cambios que hacen falta?

\section{ENTREVISTA TIPO 3}

\section{Actores vinculados con el sector público}

En relación con los actores vinculados el sector público se seleccionaron dos tipos de actores que, si bien conocen la gestión desde adentro, también tienen un vínculo y un conocimiento sobre la informalidad urbana. Por un lado, se le realizo una entre vista a Inés Iglesias, directora del Consejo Social de la Universidad Nacional de La Plata, quien lleva adelante una tarea con las organizaciones sociales en los barrios del Partido.

En conjunto con la entrevista se asistió a varias reuniones que el consejo social realiza todos los meses, en las cuales más actores, de organizaciones, académicos y del ámbito del sector estatal participan en mesas de debate, sobre los principales problemas en los barrios y las posibilidades de presentar conjuntamente proyectos e iniciativas para tratar de mejorar la situación, en, el ámbito de la educación, la infraestructura, etc. Esta es una actividad clave, donde los actores interactúan y debaten sobre los principales temas a resolver, por este motivo, la directora del consejo social resulta un gran referente sobre el tema y el manejo que tiene de él.

Una segunda entrevista vinculada con la el sector de la gestión es la entrevista con Pablo González, participante en el relevamiento que llevo a cabo la Secretaria de Tierras, Vivienda e Infraestructura en el marco del Registro público de villas y asentamientos precarios de la provincia de Buenos Aires en el año 2015. Este 
actor resulta un informante clave, no solo por pertenecer y ser un trabajador del estado en la Secretaria de Tierras De La Provincia, parte del Ministerio De Infraestructura y Servicios Públicos, sino por haber participado activamente en el relevamiento barrio a barrio, pudo comentar los pormenores que conlleva llevar adelante por primera vez en la historia un registro oficial de villas y asentamientos, y los planes del sector público estatal frente a esta problemática, una vez obtenidas las cifras y los datos sobre las principales cuestiones en las que intervenir.

\section{Entrevista a Inés Iglesias directora del consejo social de la Universidad Nacional de La Plata.}

La Universidad se propone, mediante el Consejo Social, enriquecer el proceso de retroalimentación entre la Universidad y la Comunidad. Para ello diseñará colectivamente y desde una perspectiva interdisciplinaria y plural, ejes de trabajo estratégicos dirigidos a mejorar integralmente tanto la calidad de vida del conjunto de la población, como la formación universitaria, con el aporte de todos los sectores sociales. El Consejo Social de la Universidad Nacional de La Plata se constituyó a partir del debate de la reforma de estatuto de la universidad en 2008 y por iniciativa de la Secretaría de Extensión, que convoca a diversos sectores a generar el proyecto, es creado el 28 de septiembre de 2010, como órgano asesor del presidente, por el Consejo Superior.

Es un espacio de articulación concreta entre la Universidad y la comunidad Es un espacio de articulación concreta entre la Universidad y la comunidad para dar respuestas a las principales problemáticas sociales de la región. Su agenda de trabajo ha ido creciendo a lo largo de los años, y actualmente cuenta con seis Comisiones permanentes de trabajo que abordan temas diversos como: el acceso a la Tierra y a la Vivienda, la Economía Social y Solidaria, Salud, Niñez y adolescencia, y la Inclusión Educativa.

Tanto la agenda de trabajo anual, como la creación de cada comisión responden a demandas de los diferentes actores que integran el Consejo, que 
plantearon nudos críticos en común sobre los cuales trabajar en el Consejo de la Universidad y en sus organizaciones.

\section{Objetivos / ejes de trabajo del Consejo Social de la UNLP}

- Aportar la visión de la UNLP en temas centrales del debate social en la actualidad.

- Recuperar los aportes de la Comunidad a través de sus diferentes actores, respecto de temas considerados relevantes para la agenda pública y gubernamental en la actualidad.

- Establecer prioridades para orientar las acciones de la Universidad.

- Abordar temáticas en común para el desarrollo de la región (La Plata, Berisso, Ensenada, Magdalena, Brandsen y Punta Indio)

- Contribuir a la implementación de políticas a nivel regional y nacional, a partir de la generación de propuestas desde los diferentes ejes de trabajo planteados

\section{Guía de Preguntas:}

\section{1- Sobre el acceso al suelo y la ocupación informal del territorio.}

Acerca del problema del acceso a la tierra y a la vivienda en el Partido de La Plata

1. ¿Qué opinión le merece la problemática del acceso a la tierra y a la vivienda en el Partido de La Plata?

2. ¿Cuántas urbanizaciones informales identifica actualmente al interior del Partido de La Plata? ¿Qué cantidad de población estima que hay viviendo en la informalidad en la actualidad?

3. ¿Cuál identifica usted como la principal estrategia de acceso al suelo en la periferia del Partido de La Plata?

4. ¿Puede determinar el origen (temporalidad) de las urbanizaciones informales y los contextos en los que han surgido?

5. ¿Puede identificar que actores intervinieron en el proceso de ocupación informal del territorio en los asentamientos de la periferia de La Plata?

6. ¿Puede determinar quiénes y de manera han intervenido en el proceso de la conformación de las urbanizaciones informales en el partido de la plata?

7. ¿Qué rol cumplen las organizaciones sociales antes/ durante y luego de la conformación del asentamiento?

8. ¿Cómo es la dinámica social al interior de los barrios? ¿Existen conflictos? ¿Cuáles? ¿Entre quienes? 


\section{2- Acerca del rol del consejo social / agenda de trabajo en los barrios}

1. ¿Cómo es la vinculación del consejo social con los barrios de la periferia del partido de La Plata?

2. ¿En qué barrios se trabajó desde la creación del consejo en 2010? ¿Con cuales se trabaja actualmente?

3. ¿Qué problemáticas podría identificar en los barrios de la periferia del partido de La Plata?

\section{3- Acerca de la intervención por parte del estado del Estado y el papel del Mercado Inmobiliario}

1. ¿Existe intervención por parte del Estado luego de producidas las tomas de tierra? ¿De qué manera interviene?

2. ¿Cree usted que la existencia de urbanizaciones informales afecta al mercado inmobiliario y de tierras en el partido de La Plata? ¿De qué manera? (Transcripción de audio original de la entrevista).

1. No solo actualmente sino en general la problemática es muy preocupante y tiene que ver con una falta de voluntad de regulación, por acción u omisión los distintos responsables del Estado a lo largo de los años han dejado que sea el mercado quien regule la ocupación del suelo y no la política de hábitat.

Existen experiencias en otros municipios que han decidido planificar, acá se ha decidido no hacerlo y dejar librada la decisión al poder económico, eso lo que va haciendo es que los sectores más pobres, e incluso la clase media con posibilidad de alquilar, pero condenada a alquilar eternamente. Procrear tampoco regulo el tema del suelo, por lo que se terminaron construyendo barrios con la misma lógica que las ocupaciones, bien lejos, sin acceso a servicios, lo cual implica a la gente y al estado un gasto enorme. En los sectores populares es donde más se ve lo que genera, profundiza toda la desigualdad y miseria que ya existe en otros terrenos, pero esta falta de acceso al hábitat es terrible.

La ocupación informal sucede en general sea terreno del estado, que en general son los menos, no es tanto lo fiscal que queda hoy, hay mucho terreno privado. Lo que sucede es que de alguna manera la situaciones que se viven en los barrios sobre todo en momentos de crisis económicas hacen que el hacinamiento, la imposibilidad de seguir pagando un alquiler porque en estos barrios informales también hay alquileres vaya generando una acumulación de situaciones que en algún momento y explota y 
derrama hacia la ocupación de algún terreno en donde en algún porcentaje bastante importante por lo que nosotros hemos podido ver, hay un propietario que está especulando con el valor de esa tierra. Bien sucede que hay propietarios que por ahí heredaron o que cuentan con la propiedad de esa tierra sin posibilidad de generar un emprendimiento, pero para eso también existen herramientas hoy en la legislación.

Hay toda una cuestión que necesita de la intervención en muchos sentidos, para castigar la especulación por un lado o para darle a ese propietario la posibilidad de movilizar el suelo. Lo que pasa es que hay un montón de vacíos que la gente de los barrios de los alrededores identifica y que por ahí pasan años y hasta que se convierten en basurales, desarmaderos de autos, etc. Una serie de cosas que generan que ante esa situación de crisis que viven por el hacinamiento y demás, la gente de esos barrios a veces más organizada, a veces menos, decida ocupar realmente empieza a tratar de construir un barrio con las herramientas que tiene, ahora esa situación de informalidad, el riesgo permanente a ser desalojados el no reconocimiento de ningún derecho por parte del Estado, por no tener la tenencia de la tierra hace que después se les complique muchísimo todo, la tramitación de cualquier cosa porque no pueden tener un certificado de domicilio, el acceso a servicios, obviamente que son súper artesanales porque los van resolviendo ellos mismos, las condiciones de vivienda, la conexión a cloacas, todas cuestiones que impactan en la calidad de vida, desde la salud en adelante.

Obviamente en general, como estas situaciones se van dando cada vez más hacia la periferia, eso también impacta en el acceso a la salud, la educación, al transporte, a todos los servicios que constituyen el hábitat. Obviamente también a la recreación, a los espacios públicos. Es muy difícil, cuando uno ve La Plata piensa "que ciudad maravillosa" porque haces seis cuadras para cualquier lado y tenes una plaza, un parque, tenes espacios verdes, eso se desdibuja completamente en la medida que vos te vas alejando del casco urbano. Y a medida que te vas adentrando en este tipo de barrios más todavía, porque inclusive los propios habitantes de esos lugares intentan preservar espacios que sean colectivos, comunitarios de recreación, pero la necesidad permanente va haciendo que vengan otros vecinos a ocuparlos y ahí se dan peleas de pobres contra pobres.

La ley de acceso justo al hábitat me parece que es una herramienta excelente de recontra avanzada que expresa justamente todas estas experiencias de los sectores populares y las plasma en una legislación que sea capaz de dar respuesta, pero también me parece que estamos a años luz de poder aplicarla correctamente. Hay algunas cuestiones que ya vienen avanzando, pero el espíritu completo de este derecho a la ciudad esta lejísimo hoy de ser algo tangible. Las herramientas existen, son muy 
buenas y están pensadas como herramientas que se van complementando en los distintos niveles, tanto en la provincia como en los municipios. Además, la ley reconoce la participación popular como algo fundamental al momento de la construcción del hábitat, lo que hoy vemos que existe está lejos de eso. Incluso aquellos que se han propuesto implementar algunas de las herramientas lo hacen desde un nivel de fragmentación desde las políticas de estado, es muy difícil que realmente se pueda avanzar en conjunto con todo lo que sería necesario para abordar esta tremenda necesidad.

Las estrategias de acceso al suelo son diversas, hay veces que hay una comunidad que esta hacinada o en una situación de crisis y en donde hay un par de vecinos que dicen hay un terreno que hace ocho años que está en la misma situación "vamos a ocuparlo “. Los vecinos inician ese proceso con las herramientas que tienen, a veces después de ese proceso se acercan organizaciones a ayudar, sobre todo cuando empieza a haber situaciones de desalojo empieza a haber solidaridad activa. Otras veces son organizaciones sociales que planificada mente frente a esa situación, como ya tienen presencia en el barrio ven que ya existe dicen, "Bueno, vamos a ocupar eso". Esos procesos de ocupación son mucho más ordenados, se respeta el tamaño de los lotes, ya lotean ellos mismos, arman las manzanas y tienen definidos los trazados de las calles. Depende muchísimo el grado de organización con la que los vecinos llegas a ocupar.

No podría decir que tipología de urbanización informal predomina en La Plata, me parece que los asentamientos más antiguos tienen esta perspectiva de derrame desorganizado de los barrios hacia la ocupación. Los más nuevos, también de la mano del crecimiento de organizaciones sociales van tomando más la forma de barrios informales. Porque además es más lo que los sectores populares van aprendiendo. En mi experiencia, me adentro en este proceso a partir de 2011, en general es mucho mejor el proceso, más saludable en términos de crecimiento y la posibilidad realmente de construir hábitat con la presencia de organizaciones sociales que sin ella, aun en aquellas ocasiones en que las organizaciones tienen que coexistir.

Las organizaciones que trabajan en el consejo social tienen una madurez muy importante que permita poner por encima la situación de esos vecinos y el poder llegar a una resolución y no su disputa interna en relación a quien conduce ese proceso. Mi experiencia dice que la relación entre las organizaciones no determina el proceso de ocupación. Lo que determina el proceso es la voluntad de todos de avanzar y nosotros hemos intervenido en muchos casos de procesos de relocalización. El desalojo era inminente e imposible llegar a un acuerdo económico con los propietarios de la tierra, por lo general la gente que ocupa dice “Nosotros queremos pagar, no 
queremos que nos regalen, lo que pasa es que no podemos pagar los precios del mercado, necesitamos que nos armen un plan de cuotas, que nos esperen, que nos den cierta flexibilidad" pero en general los propietarios que tienen en la cabeza un desarrollo inmobiliario no quieren saber nada.

La problemática tiene que ver con la ausencia del Estado, por un lado esos terrenos estuvieron vacíos esa cantidad de años, sin alambrar, convertidos en basurales o desarmaderos de autos y el estado nunca intervino para decirle a ese propietario “ mira... esto es un baldío urbano y vos tenes la obligación de movilizar este suelo" eso a partir de la ley 14449 está reglamentado, además hay otro montón de herramientas dentro de las propias ordenanzas municipales y en la reglamentación provincial que permitirían intervenir y hacer. Y por otro lado también falta Estado en esta discusión de los vecinos sobre cómo se construye la ciudad, como hay q ser solidario y como el estado es garante de que eso que está surgiendo no se va a convertir en una villa de emergencia, sino que se va a integrar al barrio que ya existe. Las organizaciones pueden hacer hasta un punto, ese prejuicio social que además muchas veces es alimentado por los medios de comunicación, sobre todo los locales que tienen una postura muy clara respecto de la situación de la tierra y de la propiedad privada como máximo derecho fundamental a garantizar en la historia de la humanidad, ahí falta Estado.

Nuestra experiencia con las organizaciones en los procesos de relocalización cuando no se puede llegar a un acuerdo y hay que relocalizar a las familias, es diametralmente opuesto cuando hay participación de organizaciones sociales que cuando no. Cuando existen las organizaciones acompañando, esos vecinos tienen muchísima más capacidad de organizarse, de gestionar sus propias herramientas, porque por más que el estado tenga la voluntad de llevar la luz, el agua de darles determinados materiales.

Si no hay organización en ese barrio, los primeros tiempos son durísimos, porque el estado tarda, aun teniendo la voluntad y los recursos materiales, tarda muchísimo en llegar y es larguísimo el proceso para los tiempos de la gente. En ese sentido la presencia de las organizaciones ya va teniendo un recorrido porque tiene la experiencia de la construcción de otros barrios, que conocen la zona y los pueden conectar con la cooperativa para llegar a un acuerdo con el tema de la conexión del agua, o los pueden ayudar a charlar con vecinos que ya tienen luz, para que les den luz hasta que estén en condiciones de tener su propio tendido. Esas cosas son fundamentales y hacen a la vida cotidiana y mejoran muchísimo la calidad de vida de estar la organización a no estar, es diametralmente opuesto. Se genera mucho lazo de solidaridad, el proceso es mucho más organizado y más sencillo hacer entender que si tenes la posibilidad de tener 
este lote no lo tenes que vender, no solamente porque no te conviene, sino porque tenes que ser solidario, si vos realmente no lo vas a usar, hay otro compañero que está esperando poder entrar ahí.

Cuando hay organización es algo que se discute, porque tenes delegados porque discuten en asambleas porque tienen todos procesos de organización donde van generando consenso construyendo una lógica que además los va a poder convertir en un barrio después. Si no hay organización es todos contra todos se convierte en una batalla campal, empieza a haber conflictos con el barrio alrededor porque se producen robos y distintas situaciones por las que el consejo social valora muy profundamente el rol de las organizaciones. Y existe organizaciones que a partir de un cierto recorrido y a partir de un cierto desarrollo, y cierta estructuración económica en relación a cooperativas y la posibilidad de gestionar algún recurso y aportar fondos propios, han empezado procesos de comprar inmuebles indivisos, general sus propios loteos y armar barrios. Acá en La Plata, por lo menos hay una organización que lo ha hecho en 2 o3 oportunidades, y que es un ejemplo de que es posible hacerlo porque si una organización con las limitaciones que tiene lo puede hacer, como el estado no va a poder.

Cuando se produce una toma, el poder judicial va directo al derecho de propiedad, muy rara vez mira otra cosa, salvo el juez A. que en general es el que tiene la mirada más social. Dentro de lo que es provincia de Buenos Aires son contados con los dedos de una mano los jueces que siquiera cumplen con la ley en el sentido de notificar al organismo de aplicación de la 14449, que hay un proceso de desalojo en curso. En ese sentido es muy difícil la relación con el poder judicial, después los ejecutivos son variables, depende mucho de quien está en la gestión en ese momento y que concepción tiene. Pero nosotros que hemos pasado ya distintos ejecutivos desde que estamos con el consejo y nos hemos encontrado actores muy comprometidos y actores que consideran que la justicia tiene que ejercer su función y listo, como que no tienen nada más que ver.

Se da que muchos ocupantes son familiares de vecinos de la zona, porque por lo general la gente que toma los terrenos es la misma gente de la zona que sabe que el terreno está vacante y que inclusive tiene algún tipo de registro en términos dominiales de a quién pertenece, de si este medio en el limbo legal. Y después también pasa que, en esas zonas, muchas veces también hay ocupaciones de guante blanco podríamos decir, es decir todo un sistema inmobiliario que se va apropiando de los terrenos vacíos, pero lo hace en términos mucho más "prolijos" se quedan con esas tierras o las alquilan a nombre de... y tampoco hay regulación ahí. Obviamente sin entrar a hablar de lo que sucede en el periurbano con los alquileres de la tierra para 
producir, eso y los barrios cerrados merecen otro capítulo. Hay situaciones irregulares en todos los órdenes, pero hay algunas situaciones irregulares que son aceptadas socialmente, como que están bien porque son parte de las reglas del mercado y otras que no porque las protagonizan los pobres.

El consejo social inicia por demanda de las organizaciones, la primera mesa en la que nos pusimos a armar agenda del consejo estaba sentado el municipio, legisladores, representantes de las provincias, organizaciones sociales, organismos de ciencia y tecnología, representantes de la comunidad universitaria. Nos pusimos a repasar dentro de los temas prioritarios que habían ido surgiendo, en que podíamos intervenir, y ahí levantaron la mano los de las organizaciones y dijeron nosotros queremos traer a la mesa la discusión del acceso a la tierra y a la vivienda, porque nosotros somos los que protagonizamos las tomas de tierra y vivienda, y nadie quiere vivir en esa situación.

Nadie quiere vivir a la intemperie acampando durante meses y meses con el frio, con la lluvia, con los pibes en esa situación, con el riesgo permanente que te vayan a desalojar. Ahora, tampoco nadie nos ofrece una alternativa, nosotros no queremos que nos regalen nada, pero no podemos entrar en este mercado inmobiliario, necesitamos políticas acorde a los compañeros nuestros, a su nivel de ingreso, en un momento en que los sectores populares tenían como cierta posibilidad porque ya había pasado la época más terrible de las ollas populares para resolver que poner sobre la mesa $y$ en ese momento estaban pudiendo pensar bueno como hacer crecer esa familia, el proyecto de vida empezaba a tomar otro rumbo, tenía como más color, ahora el mercado inmobiliario era siempre el mismo.

En ese marco nosotros nos pusimos primero a indagar que políticas públicas existían en ese momento, y ahí es que entramos en contacto con lo que en aquel momento era la comisión nacional de tierras Padre Mujica que estaba a cargo y estuvo después cuando se convirtió en secretario, Rubén Pascolini que es egresado de esta universidad y además con varios actores entre los que estaba Eduardo Reese que en ese momento era subadministrador del instituto de la vivienda. Rubén nos contó en una jornada que armamos que políticas estaba armando la comisión en aquel momento que recorría literalmente la Argentina y Eduardo nos introdujo en el debate de la ley (año 2011). Ahí empezamos un trabajo que tenía como 2 ramas, una de intervenciones puntuales en procesos de regularización convocando a nación y a las distintas áreas de provincia, pero sin la posibilidad que participara el municipio de La Plata por ejemplo porque no había interlocución ahí y después discutiendo políticas públicas, sumándonos a los actores que empujaban el nacimiento de la ley de acceso justo al hábitat. Después intervinimos en procesos que tenían que ver con la reglamentación, 
porque la ley se aprobó en 2012 pero no se reglamentó hasta el 2014, y después de ese proceso nos invitaron como consejo social a integrar el consejo provincial de hábitat, en el que hay representantes por universidades a la UNLP la invitaron por el rol que había tenido el consejo social.

\section{Para cada área el consejo social tiene comisiones de trabajo que son abiertas a} todos aquellos que se quieran sumar a trabajar. Después a medida que las comisiones han ido teniendo su agenda, se van generando como subcomisiones, trabajamos junto con la secretaria de hábitat de nación, antes comisión nacional de tierra, en un curso de 1 año de duración de producción social del hábitat, que dictamos en conjunto docente de la universidad e integrante de la secretaria. De ahí derivo toda una línea que empezamos a discutir cómo consejo social y que después derramo hacia la universidad de que oferta académica teníamos para ese tipo de conocimiento y ahí surgió la posibilidad de generar diplomaturas. Nosotros decidimos a finales de 2015, que a partir de ese momento íbamos a llamar a esos procesos de formación diplomatura y la presidencia de la universidad, en realidad la vice presidencia lo tomo y le pidió a la secretaria académica generar un proyecto de ordenanza para regular la integración de estas diplomaturas. Ahora no solo nosotros como consejo social sino otros espacios de facultades y de la presidencia han presentado propuestas de diplomaturas. Nosotros tenemos aprobada la diplomatura de producción de hábitat y gestión integral del territorio. 


\section{ANEXO 2}

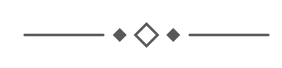

\section{INFORME CENSO \\ PUENTE DE FIERRO}




\section{Informe general censo en el Barrio Puente de Fierro "Trabajo digno,} Identidades, Necesidades y Sueños" Agenda Científica y Mesa de Trabajo Permanente "Puente de Fierro con Inteligencia y Justicia Territorial" - Proyecto de Investigación Orientado y Observatorio Medioambiental La Plata PIO-OMLP.

Entre mayo y septiembre de 2016, producto de once reuniones con los diferentes actores involucrados principalmente en el Comedor Los Chicos del Puente, se listaron 27 necesidades para Puente de Fierro en las que se estaba trabajando y en las que se quiere trabajar para vivir mejor.

\section{Inicio del Censo}

En la cuarta Mesa de Trabajo realizada en noviembre de 2016, surgió como iniciativa de los vecinos una motivación para realizar un censo del barrio Puente de Fierro, haciendo hincapié en algunas macro variables como educación y trabajo, identidades y necesidades. A partir de esta decisión de los vecinos, se diseñó el guión que estructura el censo en conjunto y se trabajó en el mismo durante seis meses, ajustando el contenido del mismo con participación de los vecinos y mediante pruebas piloto.

\section{Ejecución}

El 16 mayo de 2017 se convocó a las 9 hs. a concentrar en una de las organizaciones del barrio para organizar a los encuestadores mediante una pequeña capacitación para el trabajo en terreno. Se contó con la participación de más de 50 estudiantes y docentes de la Escuela de Enfermería del Hospital San Juan de Dios de La Plata, trabajadores sociales de la Municipalidad de La Plata, voluntarios de Universidad Nacional de La Plata, de la ONG Nuevo Ambiente, acompañados de vecinos y referentes del barrio Puente de Fierro y de Altos de San Lorenzo. Para el momento de realizar las encuestas, se formaron grupos de 2 voluntarios acompañados por al menos un vecino a quienes se les asignó una manzana determinada. Se partió de una intersección específica (esquina norte de cada manzana) fijada por los organizadores y a partir de allí se realizó el censo en 
sentido de las agujas del reloj, por cuestiones organizativas. Cada censista, realizó un croquis que contenía todos los hogares (censados y no censados) para contar con información espacial. Luego de esta primera intervención se realizaron entre tres y cuatro encuentros más para completar el censo, debido a que en un solo día no se lograba encuestar más de diez viviendas por la extensión del cuestionario. De esta manera, se visitó alrededor de 4 veces la misma cuadra, completando datos faltantes y corrigiendo los mencionados croquis.

\begin{tabular}{|c|c|}
\hline Total, de manzanas & 45 \\
\hline Total, de hogares & 1077 \\
\hline Hogares censados & 407 \\
\hline Hogares no censados & 670 \\
\hline Total, habitantes & 3922 \\
\hline Personas censadas & 1852 \\
\hline Personas no censadas & 2070 \\
\hline
\end{tabular}

Fuente: Informe general censo en el Barrio Puente de Fierro "Trabajo digno, Identidades, Necesidades y Sueños"

\section{AGENDA CIENTIFICA y MESA DE TRABAJO PERMANENTE "Puente de Fierro con Inteligencia y Justicia Territorial" PIO-OMLP UNLP-CONICET \\ Encuesta y Censo en el Barrio Puente de Fierro, La Plata “TRABAJO DIGNO, IDENTIDADES, SUEÑOS Y NECESIDADES"}

Para cada Unidad Doméstica/Vivienda (encuestar preferentemente al jefe de hogar)

1. Cuántas personas viven?

2. De qué edades? Consignar desde el menor al mayor

3. Domicilio (indicar primera, segunda, tercera casa etc. desde tal esquina)

4. Apellido, nombre y teléfono/tiene whatsupp.

(Indicar que será solo para invitarlos a participar, la información será anónima)

5. Responde cada habitante de la casa: Qué nivel de instrucción tiene (marcar edades en el primer renglón y con una $\mathrm{x}$ donde corresponda)

\begin{tabular}{|l|l|l|l|l|l|l|l|l|l|l|l|}
\hline Edades de cada uno & & & & & & & & & & & \\
\hline Jardín de infantes & & & & & & & & & & & \\
\hline Primaria Incompleta & & & & & & & & & & & \\
\hline Primaria Completa & & & & & & & & & & & \\
\hline Secundaria Incompleta & & & & & & & & & & & \\
\hline Secundaria Completa & & & & & & & & & & & \\
\hline Terciario & & & & & & & & & & & \\
\hline Universitario & & & & & & & & & & & \\
\hline
\end{tabular}


6. Responde cada habitante de la casa: Qué condición laboral tiene (marcar edades en el primer renglón y con una x donde corresponda). "En qué” o "En qué busca trabajo" consignar la edad en cada renglón (entre paréntesis) para no confundir

\begin{tabular}{|l|l|l|l|l|l|l|l|l|}
\hline Edades de cada uno & & & & & & & & En qué: \\
\hline Ocupado & & & & & & & & En qué: \\
\hline Changas & & & & & & & & En qué: \\
\hline Sub ocupado & & & & & & & & En qué: \\
\hline Desocupado & & & & & & & & En qué busca trabajo: \\
\hline Ama de casa / en el hogar & & & & & & & & En qué busca trabajo: \\
\hline
\end{tabular}

7. Responde cada habitante de la casa: ¿Que te gustaría hacer de tu vida? (pregunta abierta y PERSONAL; no se puede responder por parte de quien no está presente)

Integrante del hogar 1

Integrante del hogar 2

Integrante del hogar 3

Integrante del hogar 4

*Si hubiera más integrantes que quieren expresarlo, consignar a continuación, en la carilla en blanco, detrás

8. Responde cada habitante de la casa: Te gustaría hacer el siguiente oficio, capacitación o formación (Calificar cada ítem de 1 a 10: 1 es muy poco, 3 es poco, 5 es más o menos, 7 es bastante, 9 es mucho y 10 es muchísimo) Es PERSONAL la respuesta

Integrante del hogar numero 1: Edad....

\begin{tabular}{|l|l|l|l|}
\hline Albañilería & Panadería & Soldador & Pintura \\
\hline Carpintería & Cocina & Plomería & Yesería, Durlock \\
\hline Enfermería & Chef & Gasista & Otro: \\
\hline Cuidado de adultos /enfermos & Peluquería & Electricista & Otro \\
\hline Repostería & Jardinería & Armado de Bloques & \\
\hline
\end{tabular}

Integrante del hogar numero 2: Edad....

\begin{tabular}{|l|l|l|l|}
\hline Albañilería & Panadería & Soldador & Pintura \\
\hline Carpintería & Cocina & Plomería & Yesería, Durlock \\
\hline Enfermería & Chef & Gasista & Otro: \\
\hline Cuidado de adultos /enfermos & Peluquería & Electricista & Otro \\
\hline Repostería & Jardinería & Armado de Bloques & \\
\hline
\end{tabular}

Integrante del hogar numero 3: Edad....

\begin{tabular}{|l|l|l|l|}
\hline Albañilería & Panadería & Soldador & Pintura \\
\hline Carpintería & Cocina & Plomería & Yesería, Durlock \\
\hline Enfermería & Chef & Gasista & Otro: \\
\hline Cuidado de adultos /enfermos & Peluquería & Electricista & Otro \\
\hline Repostería & Jardinería & Armado de Bloques & \\
\hline
\end{tabular}

*Si hubiera más integrantes completar en hoja a continuación, en la carilla detrás

9. Responde cada habitante de la casa: ¿Haces deportes? ¿Cuál te gustaría hacer? ¿Te gusta el arte?

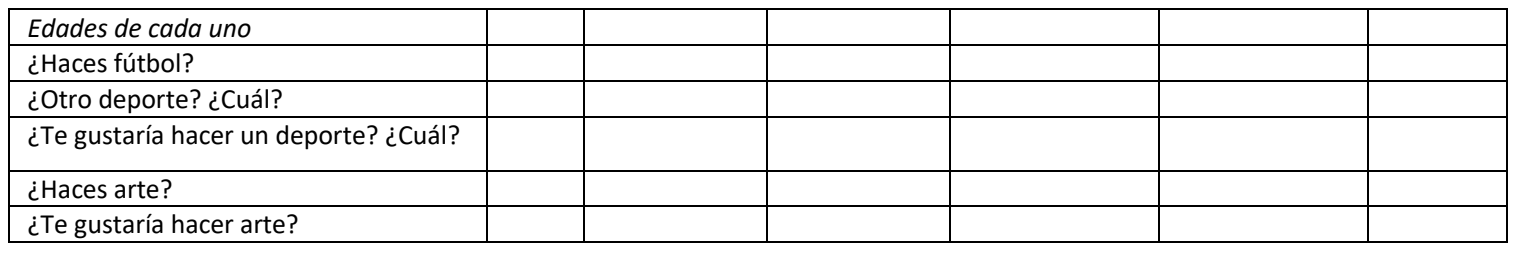


*Arte: puede ser música, murga, teatro, rap, reggaetón, danza, cine, pintura, etc.

Si hubiera más integrantes completar en hoja a continuación, en la carilla detrás

IDENTIDADES: Responde el jefe de hogar (si no está presente, responde otro adulto).

10. En qué lugar nació? (país y ciudad natal)

11. Hace cuánto tiempo vive en el barrio?

12. Inició acciones para regularizar su terreno? Si - No. ¿Cuándo? ¿Con quién?

13. Piensa que el barrio cambió en los últimos cuatro o cinco años? Mejoró - Empeoró - Siempre igual

14. Participa usted en actividades para mejorar el barrio? SI/NO. ¿Dónde? ¿Con qué frecuencia?

15. Con qué palabras identifica el barrio Puente de Fierro?

16. Le gustaría vivir en otro barrio? SI / NO. ¿En cuál?

17. VIVIENDA: Tipo de materiales que constituye la vivienda: Chapa..., Madera..., Mampostería..., otros.... (en orden de importancia)

18. INUNDACION: ¿El 2 de abril de 2013 su casa se inundó? SI/NO. ¿Hasta dónde? Hasta $20 \mathrm{~cm}, 40 \mathrm{~cm}$, $70 \mathrm{~cm}, 1$ metro, $1,5 \mathrm{~m}, 2$ metros. ¿Con qué palabra o frase resume ese día?

19. NECESIDADES. Entre mayo de 2016 y abril de 2017 hicimos siete reuniones de trabajo previas y nueve Mesas de Trabajo referentes y vecinos del barrio. Ellos listaron 27 necesidades para Puente de Fierro en los que están trabajando o en los que quieren trabajar para vivir mejor. ¿Cuáles son las principales necesidades a su juicio? 1 es la primera, 2 es la segunda, y así sucesivamente. Se sugiere listar 10 o más

1) _ TERRENOS (situación dominial). 2)_ MICROS y PARADAS. 3) _ PAVIMENTACION DE CALLES. 4)_CONEXIONES SEGURAS y PANELES ELECTRICOS. 5)_ SEGURIDAD. 6)_CLOACAS. 7)_AGUA CORRIENTE. 8)_CAPACITACION EN OFICIOS. 9)_HUERTAS COMUNITARIAS. 10)_EDUCACION PRIMARIA. 11) COOPERATIVAS DE TRABAJO. 12) INUNDACIONES, ZANJEO y DESAGUES PLUVIALES. 13)_ESPACIOS PUBLICOS y ESPARCIMIENTO. 14)_VEREDAS. 15)_ “NUMERACION BARRIAL" (NOMENCLADORES DE CALLES). 16)_CENTROS DE SALUD. 17)_REFERENTES BARRIALES. 18)_HISTORIA, IDENTIDAD. 19)_RECOLECCION DE RESIDUOS, 20) _ RECICLADO DE BASURA. 21)_SALUD: ACCIONES DE PREVENCION. 22) _ SALUD: ANIMALES (ZOONOSIS) 23) JARDIN MATERNAL. 24)_EDUCACION SECUNDARIA. 25)_EDUCACION: PRE JARDIN y JARDIN. 26) _ “LUZ PUBLICA" (LUMINARIAS). 27)_PRESUPUESTO PARTICIPATIVO. 28) OTRO (Consignar)

- Nombre y apellido del/los encuestadores/es:

- Dia en que fue realizada la encuesta:

\section{Análisis de variable del Censo aplicado a Barrio Puente de Fierro Periodo 2017-2018}

Variable: Regularización del terreno. Del análisis de los datos obtenidos en el censo realizado en el barrio Puente de Fierro, se pudo constatar que la mayoría de los encuestados, un 70\% del total, no ha iniciado acciones para regularizar su situación dominial (Ver tabla 1). 
Tabla 1: ¿Inició acciones para regularizar su terreno?

\begin{tabular}{|c|c|c|c|c|}
\hline \multicolumn{2}{|c|}{} & Frecuencia & Porcentaje & Porcentaje válido \\
\hline \multirow{3}{*}{ Válidos } & $\mathrm{Si}$ & 33 & 28,4 & 29,2 \\
\cline { 2 - 5 } & $\mathrm{No}$ & 80 & 69,0 & 70,8 \\
\cline { 2 - 5 } & Total & 113 & 97,4 & 100,0 \\
\hline \multirow{2}{*}{ Ns/Nc } & & 3 & 2,6 & \\
\hline \multicolumn{2}{|c|}{ Total } & 116 & 100,0 & \\
\hline
\end{tabular}

Fuente: Informe general censo en el Barrio Puente de Fierro

"Trabajo digno, Identidades, Necesidades y Sueños"

Del total de los encuestados que lograron iniciar la regularización de su terreno, se puede ver que un 50\% lo realizó entre el 2007 y el 2015, coincidente con los años de kirchnerismo. En los dos años de la nueva gestión, un 40\% empezó los trámites (ver cuadro 2). Además, manifestaron con quien o quienes realizaron la regularización del terreno, y tal como puede verse en el cuadro 3, muchos recurrieron a vecinos, y centros y organizaciones barriales, pero la mayoría acudió a entidades estatales, entre ellas la municipalidad, provincia, políticos.

Tabla 2: ¿Cuándo inició acciones para regularizar su terreno?

\begin{tabular}{|c|c|c|c|c|}
\hline \multicolumn{1}{|c|}{} & Frecuencia & Porcentaje & Porcentaje válido \\
\hline \multirow{4}{*}{ Válidos } & 1967 & 1 &, 9 & 4,8 \\
\cline { 2 - 5 } & 1997 & 1 &, 9 & 4,8 \\
\cline { 2 - 5 } & 2007 & 1 &, 9 & 4,8 \\
\cline { 2 - 5 } & 2011 & 1 &, 9 & 4,8 \\
\cline { 2 - 5 } & 2012 & 4 & 3,4 & 19,0 \\
\cline { 2 - 5 } & 2014 & 4 & 3,4 & 19,0 \\
\cline { 2 - 5 } & 2015 & 1 &, 9 & 4,8 \\
\cline { 2 - 5 } & 2016 & 4 & 3,4 & 19,0 \\
\cline { 2 - 5 } & 2017 & 4 & 3,4 & 19,0 \\
\cline { 2 - 5 } & Total & 21 & 18,1 & 100,0 \\
\hline
\end{tabular}

Fuente: Informe general censo en el Barrio Puente de Fierro

"Trabajo digno, Identidades, Necesidades y Sueños"

Tabla 3: ¿Con quién inició acciones para regularizar su terreno?

\begin{tabular}{|c|c|c|}
\hline \multicolumn{2}{|c|}{} & Frecuencia \\
\hline \multirow{4}{*}{} & Comedor Falcone & 1 \\
\cline { 2 - 3 } & Copa Los Hermanos & 2 \\
\cline { 2 - 3 } & Delegación & 1 \\
\cline { 2 - 3 } & Municipalidad & 9 \\
\cline { 2 - 3 } & Organizaciones & 2 \\
\cline { 2 - 3 } & Políticos & 2 \\
\cline { 2 - 3 } & Provincia & 1 \\
\cline { 2 - 3 } & Rosa (intermediaria) & 1 \\
\hline
\end{tabular}




\begin{tabular}{|c|c|c|}
\hline & Familiares & 3 \\
\cline { 2 - 3 } & Total & 21 \\
\hline
\end{tabular}

Fuente: Informe general censo en el Barrio Puente de Fierro

"Trabajo digno, Identidades, Necesidades y Sueños"

\section{Variable: Materiales de la vivienda}

Otra variable trabajada fue la correspondiente a los Materiales de la vivienda de los vecinos del barrio, y de su análisis se comprobó que un 50\% de las viviendas están construidas, en su totalidad, con mampostería (ladrillos), y un $35 \%$ fueron realizadas con mampostería y otros materiales como chapa, madera, o ambas.

Tabla 4: Tipo de materiales que constituye la vivienda.

\begin{tabular}{|c|c|c|c|c|}
\hline & & Frecuencia & Porcentaje & Porcentaje válido \\
\hline \multirow{4}{*}{ Válidos } & Mampostería (ladrillos) & 54 & 46,6 & 49,1 \\
\cline { 2 - 5 } & Chapa & 1 &, 9 & 0,9 \\
\cline { 2 - 5 } & Madera & 4 & 3,4 & 3,6 \\
\cline { 2 - 5 } & Mampostería/Chapa & 14 & 12,1 & 12,7 \\
\cline { 2 - 5 } & Mampostería/Madera & 4 & 3,4 & 3,6 \\
\cline { 2 - 5 } & Chapa/Madera & 11 & 9,5 & 10,0 \\
\cline { 2 - 5 } & Mampostería/Chapa/Madera & 20 & 17,2 & 18,2 \\
\cline { 2 - 5 } & Otros & 2 & 1,7 & 1,8 \\
\cline { 2 - 5 } & Total & 6 & 54,8 & 100,0 \\
\hline Ns/Nc & Sistema & 116 & 100,0 & \\
\hline \multicolumn{2}{|c|}{ Total } & "Trabajo digno, Identidades, Necesidades y Sueños" \\
\hline
\end{tabular}

\section{Variable: Inundación}

Se intentó identificar el grado de vulnerabilidad al que estuvieron expuestos los vecinos del barrio censados frente a la importante inundación del 2 de abril del año 2013 experimentada en la ciudad de La Plata y barrios aledaños. A partir de ello, pudimos reconocer que un porcentaje elevado de encuestados se inundaron en ese episodio de riesgo hídrico (ver cuadro 5). Un dato no menor es que entre ese porcentaje de inundados, un 45\% de encuestados se inundó entre 1 metro y 1,70 metros. 
Tabla 5: ¿Su casa se inundó el 2 de abril de 2013?

\begin{tabular}{|c|c|c|c|c|}
\hline \multicolumn{2}{|c|}{} & Frecuencia & Porcentaje & Porcentaje válido \\
\hline \multirow{3}{*}{ Válidos } & $\mathrm{Si}$ & 78 & 67,2 & 74,3 \\
\cline { 2 - 5 } & $\mathrm{No}$ & 27 & 23,3 & 25,7 \\
\cline { 2 - 5 } & Total & 105 & 90,5 & 100,0 \\
\hline \multirow{2}{*}{ Ns/Nc } & Sistema & 11 & 9,5 & \\
\hline \multicolumn{2}{|c|}{ Total } & 116 & 100,0 & \\
\hline
\end{tabular}

Fuente: Informe general censo en el Barrio Puente de Fierro

"Trabajo digno, Identidades, Necesidades y Sueños"

Tabla 6: ¿Hasta dónde se inundó su casa?

\begin{tabular}{|c|c|c|c|}
\hline \multicolumn{1}{|c|}{} & Frecuencia & Porcentaje válido \\
\hline \multirow{4}{*}{ Válidos } & $5-15$ & 6 & 7,8 \\
\cline { 2 - 4 } & $20-30$ & 11 & 14,4 \\
\cline { 2 - 4 } & $40-50$ & 16 & 21,1 \\
\cline { 2 - 4 } & $60-70$ & 5 & 6,6 \\
\cline { 2 - 4 } & $80-90$ & 4 & 5,2 \\
\cline { 2 - 4 } & $100-110$ & 23 & 30,2 \\
\cline { 2 - 4 } & $120-130$ & 3 & 3,9 \\
\cline { 2 - 4 } & $150-170$ & 8 & 10,5 \\
\cline { 2 - 4 } & Total & 76 & 100,0 \\
\hline Ns/Nc & Sistema & 40 & \\
\hline \multicolumn{2}{|c|}{ Total } & 116 & \\
\hline
\end{tabular}

Fuente: Informe general censo en el Barrio Puente de Fierro

"Trabajo digno, Identidades, Necesidades y Sueños"

\section{Variable: Cambios en el barrio}

Se indagó también sobre las percepciones de los vecinos encuestados en torno al barrio. Por un lado, se les preguntó si piensan que hubo cambios en el barrio en los últimos años, y si estos fueron para bien o para mal, o ambos. La mayoría de los encuestados coincidió en que el barrio en cierta medida había mejorado. No obstante, ello, hubo un gran número de vecinos que sostenían que el barrio había empeorado o se mantenía igual hacía años.

Tabla 7: ¿Piensa que el barrio cambió en los últimos años?

\begin{tabular}{|c|c|c|c|c|}
\hline \multicolumn{2}{|c|}{} & Frecuencia & Porcentaje & Porcentaje válido \\
\hline \multirow{4}{*}{ Válidos } & Mejoró & 45 & 8,2 & 40,5 \\
\cline { 2 - 5 } & Empeoró & 13 & 2,4 & 11,7 \\
\cline { 2 - 5 } & Mejoró y empeoró & 32 & 5,9 & 28,8 \\
\cline { 2 - 5 } & Siempre igual & 21 & 3,8 & 18,9 \\
\cline { 2 - 5 } & Total & 111 & 20,3 & 100,0 \\
\hline
\end{tabular}




\begin{tabular}{|c|c|c|c|c|}
\hline Ns/Nc & Sistema & 435 & 79,7 & \\
\hline \multicolumn{2}{|c|}{ Total } & 546 & 100,0 & \\
\hline
\end{tabular}

Fuente: Informe general censo en el Barrio Puente de Fierro

"Trabajo digno, Identidades, Necesidades y Sueños"

A raíz de esta pregunta, surgieron otros interrogantes que merecen ser analizados, en relación a los anhelos de algunos vecinos en torno a vivir en otro barrio. Aunque se visualizaron números muy parejos en cuanto a quienes quieren vivir en otro barrio, y quienes se quieren quedar, se puede destacar que la mayoría, un 54\% de los encuestados decidió permanecer en el barrio. Puede verse de manifiesto el sentido de pertenencia que construyeron los actores en torno a su barrio.

Tabla 8: ¿Le gustaría vivir en otro barrio?

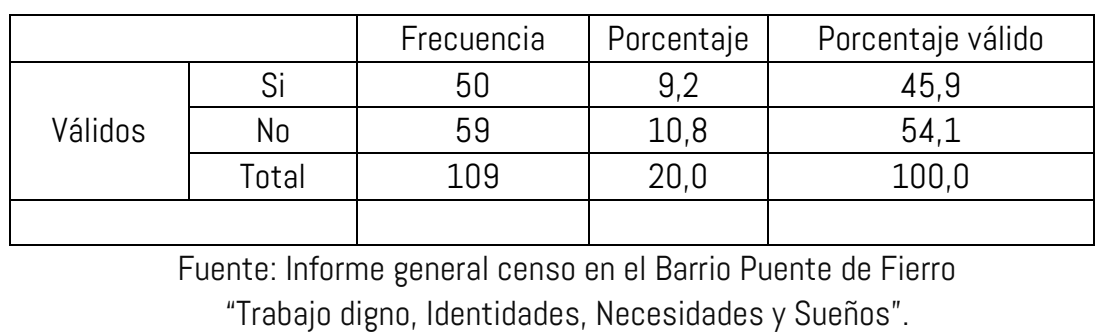

A su vez, ante este panorama, se quiso explorar sobre la participación de los vecinos en actividades que intenten mejorar el barrio. La mayoría de ellos (un 75\%) no tiene participación en ninguna actividad. El porcentaje que resta, manifestaron que tienen una dedicación en los comedores y copas de leche, cooperativas, la iglesia evangélica, y clubes, en su mayoría de forma semanal.

Tabla 9: ¿Participa en actividades para mejorar el barrio?

\begin{tabular}{|c|c|c|c|c|}
\hline \multicolumn{2}{|c|}{} & Frecuencia & Porcentaje & Porcentaje válido \\
\hline \multirow{3}{*}{ Válidos } & $\mathrm{Si}$ & 27 & 4,9 & 24,1 \\
\cline { 2 - 5 } & No & 85 & 15,6 & 75,9 \\
\cline { 2 - 5 } & Total & 112 & 20,5 & 100,0 \\
\hline
\end{tabular}

Fuente: Informe general censo en el Barrio Puente de Fierro

"Trabajo digno, Identidades, Necesidades y Sueños"

Por otro lado, se indagaron en otras percepciones de los vecinos, relacionadas con algunas iniciativas realizadas en el barrio, como la implementación de la vivienda social, y energías renovables, y cuanto les gustaría 
participar. En su mayoría, la población manifestó no tener conocimiento de ninguna de las iniciativas, sin embargo, más de un 50\% de los encuestados demostraron interés en participar.

Tabla 10: ¿Conoce alguna iniciativa de vivienda social?

\begin{tabular}{|c|c|c|c|c|}
\hline \multicolumn{2}{|c|}{} & Frecuencia & Porcentaje & Porcentaje válido \\
\hline \multirow{3}{*}{ Válidos } & $\mathrm{Si}$ & 16 & 2,9 & 14,3 \\
\cline { 2 - 5 } & $\mathrm{No}$ & 96 & 17,6 & 85,7 \\
\cline { 2 - 5 } & Total & 112 & 20,5 & 100,0 \\
\hline
\end{tabular}

Fuente: Informe general censo en el Barrio Puente de Fierro

"Trabajo digno, Identidades, Necesidades y Sueños"

\section{Variable: Centro de salud}

En otra instancia del cuestionario, se indagó sobre la concurrencia de los vecinos al centro de salud del barrio, y se pudo constatar que más de un $50 \%$ de los encuestados asiste al centro médico del barrio. En su mayoría, asisten al centro de salud $\mathrm{N}^{\circ} 42$ y al $\mathrm{N}^{\circ} 8$.

Tabla 11: ¿Concurre al centro de salud del barrio?

\begin{tabular}{|c|c|c|c|c|}
\hline \multicolumn{2}{|c|}{} & Frecuencia & Porcentaje & Porcentaje válido \\
\hline \multirow{3}{*}{ Válidos } & $\mathrm{Si}$ & 61 & 11,2 & 54,5 \\
\cline { 2 - 5 } & No & 51 & 9,3 & 45,5 \\
\cline { 2 - 5 } & Total & 112 & 20,5 & 100,0 \\
\hline
\end{tabular}

Fuente: Informe general censo en el Barrio Puente de Fierro

"Trabajo digno, Identidades, Necesidades y Sueños"

Tabla 12: ¿A qué centro de salud del barrio concurre?

\begin{tabular}{|c|c|c|}
\hline \multicolumn{1}{|c|}{} & Frecuencia \\
\hline \multirow{1}{*}{} & Clínica del niño & 1 \\
\cline { 2 - 3 } & Hospital Gutiérrez & 1 \\
\cline { 2 - 3 } & Hospital de Niños & 1 \\
\cline { 2 - 3 } & Hospital Italiano & 2 \\
\cline { 2 - 3 } & Hospital Rossi & 1 \\
\cline { 2 - 3 } & Hospital San Juan & 2 \\
\cline { 2 - 3 } & Hospital San Martin & 4 \\
\cline { 2 - 3 } & $\mathrm{N}^{\circ} 30$ & 1 \\
\cline { 2 - 3 } $\mathrm{N}^{\circ} 32$ & 1 \\
\hline $\mathrm{N}^{\circ} 41$ & 31 \\
\hline $\mathrm{N}^{\circ} 8$ & 23 \\
\cline { 2 - 3 } & Salita & 1 \\
\cline { 2 - 3 } & Sanatorio Argentino & 1 \\
\cline { 2 - 3 } & Total & 70 \\
\cline { 2 - 3 } & & \\
\cline { 2 - 3 }
\end{tabular}


Fuente: Informe general censo en el Barrio Puente de Fierro

"Trabajo digno, Identidades, Necesidades y Sueños"

Del 1 al 10, ¿cuánto le gustaría participar?

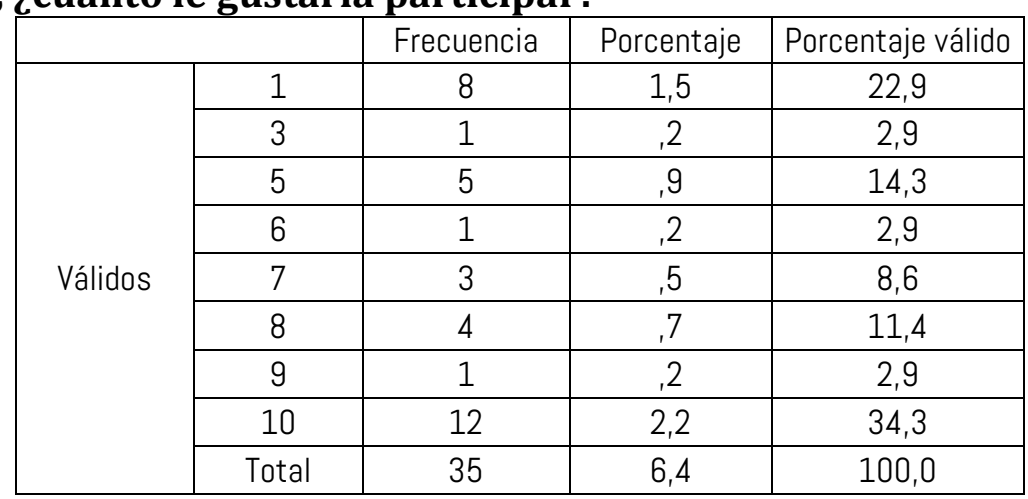

Fuente: Informe general censo en el Barrio Puente de Fierro "Trabajo digno, Identidades, Necesidades y Sueños"

\section{Del 1 al 10, ¿cuánto le gustaría participar?}

\begin{tabular}{|c|c|c|c|c|}
\hline & & Frecuencia & Porcentaje & Porcentaje válido \\
\hline \multirow{7}{*}{ Válidos } & 1 & 13 & 2,4 & 39,4 \\
\hline & 5 & 1 & 2 & 3,0 \\
\hline & 7 & 4 & 7 & 12,1 \\
\hline & 8 & 4 & 7 & 12,1 \\
\hline & 9 & 1 & 2 & 3,0 \\
\hline & 10 & 10 & 1,8 & 30,3 \\
\hline & Total & 33 & 6,0 & 100,0 \\
\hline
\end{tabular}

Fuente: Informe general censo en el Barrio Puente de Fierro "Trabajo digno, Identidades, Necesidades y Sueños" 


\section{ANEXO 3}

CARTOGRAFIA

TEMATICA 


\section{Cartografía - Urbanizaciones Informales del Partido de La Plata}

Todos los mapas fueron realizados en QGIS versión 3.4.6. entre los años 2016 y 2019.

Urbanizaciones informales - Registro público Provincial de villas y asentamientos RPPVAP, 2015. http://190.188.234.6/registro/publico/

Vías principales y secundarias: relevamiento mediante foto satelital 2016 (Google Earth y Google Maps).

Parcelario y manzanas: ARBA www.carto.arba.gov.ar

Límites provinciales, municipales, arroyos y cursos de agua: información obtenida de IGN (2017) www.ign.gob.ar

Cuencas, niveles de peligrosidad e hidrología del Partido tomados de CISAUA 2016.

\begin{tabular}{|c|c|c|c|c|c|}
\hline ID & LOCALIDAD & NOMBRE & TIPO & AÑO ORIGEN & $\begin{array}{c}\text { CANT } \\
\text { FAMILIAS }\end{array}$ \\
\hline 1 & Romero & Malvinas II & Asentamiento informal & 2002 & 273 \\
\hline 2 & Etcheverry & Ferroviario & Villa & 2010 & 133 \\
\hline 3 & Tolosa & La Favelita & Villa & 1983 & 122 \\
\hline 4 & City Bell & Casaca & Villa & 2002 & 20 \\
\hline 5 & Gonnet & La GÃ $f \hat{A}^{1} / 4$ emes & Villa & 1980 & 20 \\
\hline 6 & Gonnet & $8 \& 489$ & Villa & 1980 & 33 \\
\hline 7 & Gorina & La Fabrica & Villa & 1994 & 182 \\
\hline 8 & City Bell & $457 \& 24$ & Villa & 2005 & 6 \\
\hline 9 & Romero & Hijos de Malvinas & Asentamiento informal & 2009 & 110 \\
\hline 10 & Hernández & $514 \& 138$ & Villa & 2001 & 59 \\
\hline 11 & V Elisa & Villa Rica & Asentamiento informal & 2000 & 54 \\
\hline 12 & V Elisa & El Progreso & Asentamiento informal & 2013 & 58 \\
\hline 13 & Arturo Seguí & El Rincón I & Asentamiento informal & 2011 & 58 \\
\hline 14 & V Elisa & La Fortaleza & Asentamiento informal & 2000 & 146 \\
\hline 15 & V Elisa & YPF & Asentamiento informal & 1974 & 38 \\
\hline 16 & Romero & Vieja Estación & Villa & 2012 & 30 \\
\hline 17 & Olmos & El Triangulo & Villa & 2007 & 62 \\
\hline 18 & Arturo Seguí & El Rincón II & Asentamiento informal & 2010 & 57 \\
\hline 19 & Gorina & Colinas del Sol & Asentamiento informal & 2000 & 137 \\
\hline 20 & San Carlos & $153 \& 40$ & Asentamiento informal & 2010 & 80 \\
\hline 21 & San Carlos & La Banda & Asentamiento informal & 2013 & 51 \\
\hline 22 & Arturo Seguí & El Rincón III & Asentamiento informal & 2013 & 10 \\
\hline 23 & Gorina & $28 b \& 482$ & Asentamiento informal & 1987 & 24 \\
\hline 24 & Romero & Las Rosas II & Asentamiento informal & 2013 & 13 \\
\hline 25 & Romero & San Cayetano & Asentamiento informal & 2011 & 220 \\
\hline 26 & Romero & $166 \& 523$ & Asentamiento informal & 2011 & 41 \\
\hline 27 & Romero & Las Rosas C.P.A. & Asentamiento informal & 2012 & 22 \\
\hline 28 & Olmos & Las Casuarinas & Asentamiento informal & 1999 & 124 \\
\hline 29 & Etcheverry & $236 \& 41$ & Asentamiento informal & 2005 & 50 \\
\hline 30 & Romero & $518 \& 162$ & Asentamiento informal & 2011 & 32 \\
\hline 31 & Olmos & Los Rosales & Asentamiento informal & 1985 & 188 \\
\hline 32 & Los Hornos & Las Palmeras & Asentamiento informal & 2009 & 450 \\
\hline 33 & Los Hornos & $52 \& 155$ & Asentamiento informal & 2011 & 29 \\
\hline
\end{tabular}




\begin{tabular}{|c|c|c|c|c|c|}
\hline 34 & Los Hornos & El Triunfo & Asentamiento informal & 1998 & 242 \\
\hline 35 & Los Hornos & $57 \& 155$ & Asentamiento informal & 2000 & 66 \\
\hline 36 & Los Hornos & $155 \& 46$ & Asentamiento informal & 2005 & 39 \\
\hline 37 & Los Hornos & $74 \& 140$ & Asentamiento informal & 2013 & 51 \\
\hline 38 & Los Hornos & Santa Isabel & Asentamiento informal & 2007 & 67 \\
\hline 39 & A de San Lorenzo & Puente de Fierro 2 & Asentamiento informal & 2007 & 220 \\
\hline 40 & Romero & El Bajo & Asentamiento informal & 2009 & 60 \\
\hline 41 & V Elvira & $99 \& 123$ & Asentamiento informal & 1999 & 46 \\
\hline 42 & A de San Lorenzo & $131 \& 83$ & Asentamiento informal & 2007 & 51 \\
\hline 43 & V Elvira & Villa Aburridita & Asentamiento informal & 2001 & 732 \\
\hline 44 & Los Hornos & 2 de abril & Otros & 2013 & 32 \\
\hline 45 & Los Hornos & La Esperanza & Asentamiento informal & 2000 & 200 \\
\hline 46 & Olmos & La Palangana & Otros & 1997 & 141 \\
\hline 47 & City Bell & $456 \& 20$ & Asentamiento informal & decada_1990 & 86 \\
\hline 48 & Romero & Barrio Nuevo & Asentamiento informal & 1980 & 239 \\
\hline 49 & Gonnet & $508 \& 9$ & Villa & decada_1990 & 13 \\
\hline 50 & V Elvira & Aeropuerto & Asentamiento informal & 1998 & 900 \\
\hline 51 & Romero & El Futuro & Asentamiento informal & decada_1990 & 931 \\
\hline 52 & Romero & $167 \& 524$ & Asentamiento informal & decada_1990 & 43 \\
\hline 53 & Romero & Las Rosas & Asentamiento informal & decada_1990 & 666 \\
\hline 54 & Olmos & $155 \& 41$ & Asentamiento informal & decada_1990 & 129 \\
\hline 55 & Los Hornos & $75 \& 142$ & Asentamiento informal & decada_1990 & 135 \\
\hline 56 & V Elvira & Alegre - Villa Alba & Asentamiento informal & 2011 & 70 \\
\hline 57 & V Elvira & Villa Montoro 1 & Villa & 2001 & 40 \\
\hline 58 & A de San Lorenzo & $90 \& 19$ & Villa & 1984 & 100 \\
\hline 59 & A de San Lorenzo & Los Chaques & Villa & 1994 & 15 \\
\hline 60 & V Elvira & $81 \& 13$ & Villa & decada_1990 & 30 \\
\hline 61 & A de San Lorenzo & La Cantera & Villa & 2008 & 295 \\
\hline 62 & V Elvira & $116 \& 77$ & Asentamiento informal & decada_1990 & 30 \\
\hline 63 & V Elvira & Frisón & Villa & 2001 & 100 \\
\hline 64 & Los Hornos & $65 \& 153$ & Otros & decada_1990 & 78 \\
\hline 65 & Tolosa & La Bajada & Asentamiento informal & decada_1980 & 106 \\
\hline 66 & A de San Lorenzo & 26 de Julio & Otros & 1992 & 60 \\
\hline 67 & A de San Lorenzo & $19 \& 77$ & Asentamiento informal & decada_1990 & 68 \\
\hline 68 & V Elvira & Villa Montoro 4 & Asentamiento informal & 2000 & 150 \\
\hline 69 & Romero & Las Margaritas & Villa & 1998 & 60 \\
\hline 70 & V Elvira & Barrio Alegre & Asentamiento informal & 2008 & 200 \\
\hline 71 & V Elvira & Agosti, Carlos & Asentamiento informal & 2007 & 250 \\
\hline 72 & V Elvira & Padre Cajade & Asentamiento informal & 1994 & 60 \\
\hline 73 & V Elvira & $119 \& 604$ & Asentamiento informal & 2000 & 50 \\
\hline 74 & V Elvira & Villa Alba & Asentamiento informal & 1998 & 40 \\
\hline 75 & V Elvira & Joel & Asentamiento informal & 2004 & 900 \\
\hline 76 & Ringuelet & El Mercadito & Asentamiento informal & decada_1990 & 150 \\
\hline 77 & Abasto & Villa San Martin & Asentamiento informal & decada_2000 & 35 \\
\hline 78 & El Peligro & Martin Fierro & Otros & decada_2000 & 60 \\
\hline 79 & El Peligro & Ruta del Sol & Otros & decada_2000 & 200 \\
\hline 80 & A de San Lorenzo & Puente de Fierro 3 & Villa & 2007 & 98 \\
\hline 81 & V Elvira & Villa Montoro 2 & Asentamiento informal & 2002 & 130 \\
\hline 82 & San Lorenzo & La Esperanza (extensión) & Villa & 2006 & 235 \\
\hline
\end{tabular}




\begin{tabular}{|c|c|c|c|c|c|}
\hline 83 & City Bell & Savoia & Otros & 1984 & 321 \\
\hline 84 & & Arroyo Doña Flora \& Calle 38 & Asentamiento informal & 2014 & 160 \\
\hline 85 & San Carlos & 36bis \& 135 & Asentamiento informal & 1996 & 30 \\
\hline 86 & Romero & $161 \& 526$ & Asentamiento informal & 2015 & 55 \\
\hline 87 & City Bell/Gorina & Medalla Milagrosa & Villa & decada_1990 & 135 \\
\hline 88 & & $16 \& 80$ & Asentamiento informal & 90_0_anterior & 225 \\
\hline 89 & Ringuelet & Ciudad Oculta & Otros & 2001 & 48 \\
\hline 90 & Arana & La Aceitera & Asentamiento informal & decada_1990 & 90 \\
\hline 91 & Los Hornos & $136 \& 52$ & Otros & 1980 & 55 \\
\hline 92 & A de San Lorenzo & Los Robles & Asentamiento informal & 2006 & 102 \\
\hline 93 & A de San Lorenzo & Puente de Fierro & Asentamiento informal & 1994 & 921 \\
\hline 94 & Olmos & Retiro & Asentamiento informal & 1996 & 300 \\
\hline 95 & Hernández & Nini & Otros & decada_1990 & 348 \\
\hline 96 & Hernández & Mercosur & Asentamiento informal & 2002 & 325 \\
\hline 97 & Tolosa & Boliviana & Villa & decada_1980 & 60 \\
\hline 98 & Tolosa & La Unión & Asentamiento informal & decada_1990 & 131 \\
\hline 99 & Romero & La Usina & Asentamiento informal & 2005 & 70 \\
\hline 100 & San Carlos & $48 \& 144$ & Asentamiento informal & 1998 & 203 \\
\hline 101 & San Carlos & $40 \& 150$ & Asentamiento informal & decada_1990 & 118 \\
\hline 102 & Romero & Altos del Sol & Asentamiento informal & 1990 & 268 \\
\hline 103 & Abasto & 516 bis \& 220 & Asentamiento informal & 2007 & 165 \\
\hline 104 & Los Hornos & $62 \& 161$ & Asentamiento informal & 1999 & 780 \\
\hline 105 & Los Hornos & 75bis \& 150 & Asentamiento informal & 2000 & 45 \\
\hline 106 & City Bell & El Country & Asentamiento informal & 1974 & 153 \\
\hline 107 & Los Hornos & $152 \& 68$ & Asentamiento informal & decada_1990 & 51 \\
\hline 108 & Los Hornos & $74 \& 153$ & Asentamiento informal & 1998 & 416 \\
\hline 109 & A de San Lorenzo & La Esperanza - La Cantera & Asentamiento informal & 2004 & 547 \\
\hline 110 & A de San Lorenzo & El Ombú & Asentamiento informal & 2006 & 100 \\
\hline 111 & Tolosa & La Bajada II & Villa & 2010 & 27 \\
\hline 112 & V Elvira & Sebastián Sueldo & Asentamiento informal & decada_1990 & 88 \\
\hline 113 & A de San Lorenzo & $29 \& 90$ & Villa & 2003 & 200 \\
\hline 114 & Arturo Seguí & La Victoria & Asentamiento informal & 1991 & 216 \\
\hline 115 & V Elvira & Villa Montoro 3 & Asentamiento informal & 2006 & 124 \\
\hline 116 & Arturo Seguí & $154 \& 413$ & Asentamiento informal & 2013 & 23 \\
\hline 117 & Tolosa & San Luis & Asentamiento informal & decada_1990 & 105 \\
\hline 118 & Gonnet & $3 \& 495$ & Asentamiento informal & decada_1990 & 44 \\
\hline 119 & Romero & Los Pinos & Asentamiento informal & 2010 & 100 \\
\hline 120 & Romero & Malvinas & Otros & 1992 & 635 \\
\hline 121 & Los Hornos & La Vía & Villa & 1984 & 166 \\
\hline 122 & & $526 \& 135$ & Asentamiento informal & 2003 & 40 \\
\hline 123 & Ringuelet & El Gato 2 & Villa & 1984 & 160 \\
\hline 124 & Tolosa & La Laguna (524) & Villa & decada_1990 & 24 \\
\hline 125 & Hernández & $509 \& 134$ & Asentamiento informal & 90_0_anterior & 55 \\
\hline 126 & San Carlos & Toba & Villa & 1995 & 198 \\
\hline 127 & San Carlos & El Olvido & Asentamiento informal & 2001 & 263 \\
\hline 128 & Ringuelet & El Gato 1- El Triangulo & Villa & 1984 & 160 \\
\hline
\end{tabular}




\section{MAPA 1 - TIPOLOGIAS DE URBANIZACIONES INFORMALES}

Fuente: Elaboración propia, con herramienta GIS, 2018 con datos del RPPVAP (2015)

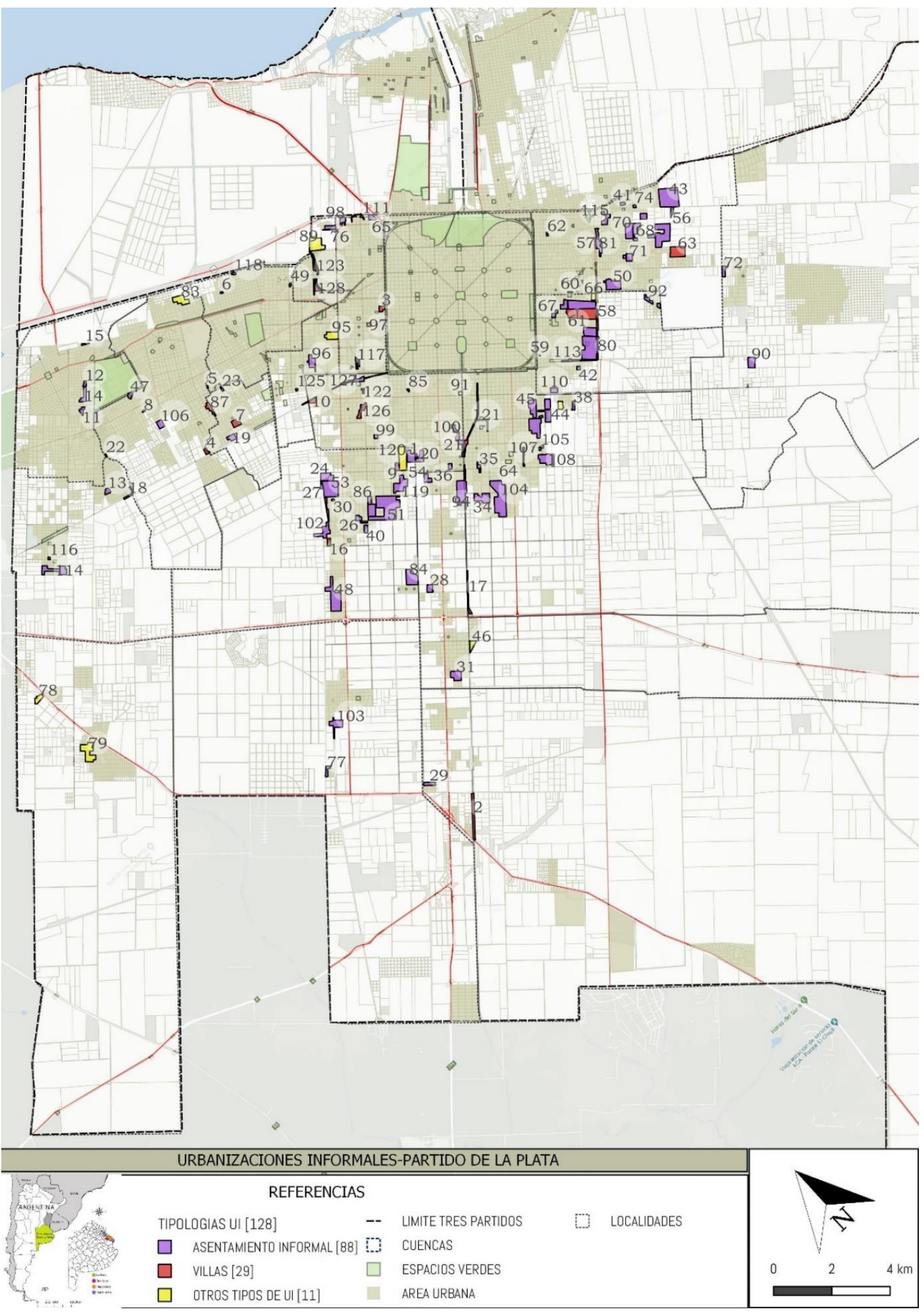




\section{MAPA 2 - NIVELES DE OELIGROSIDAD HIDRICA + URBANIZACIONES INFORMALES}

Fuente: Elaboración propia, con herramienta GIS, 2018 con datos del RPPVAP (2015); CISAUA (2016)

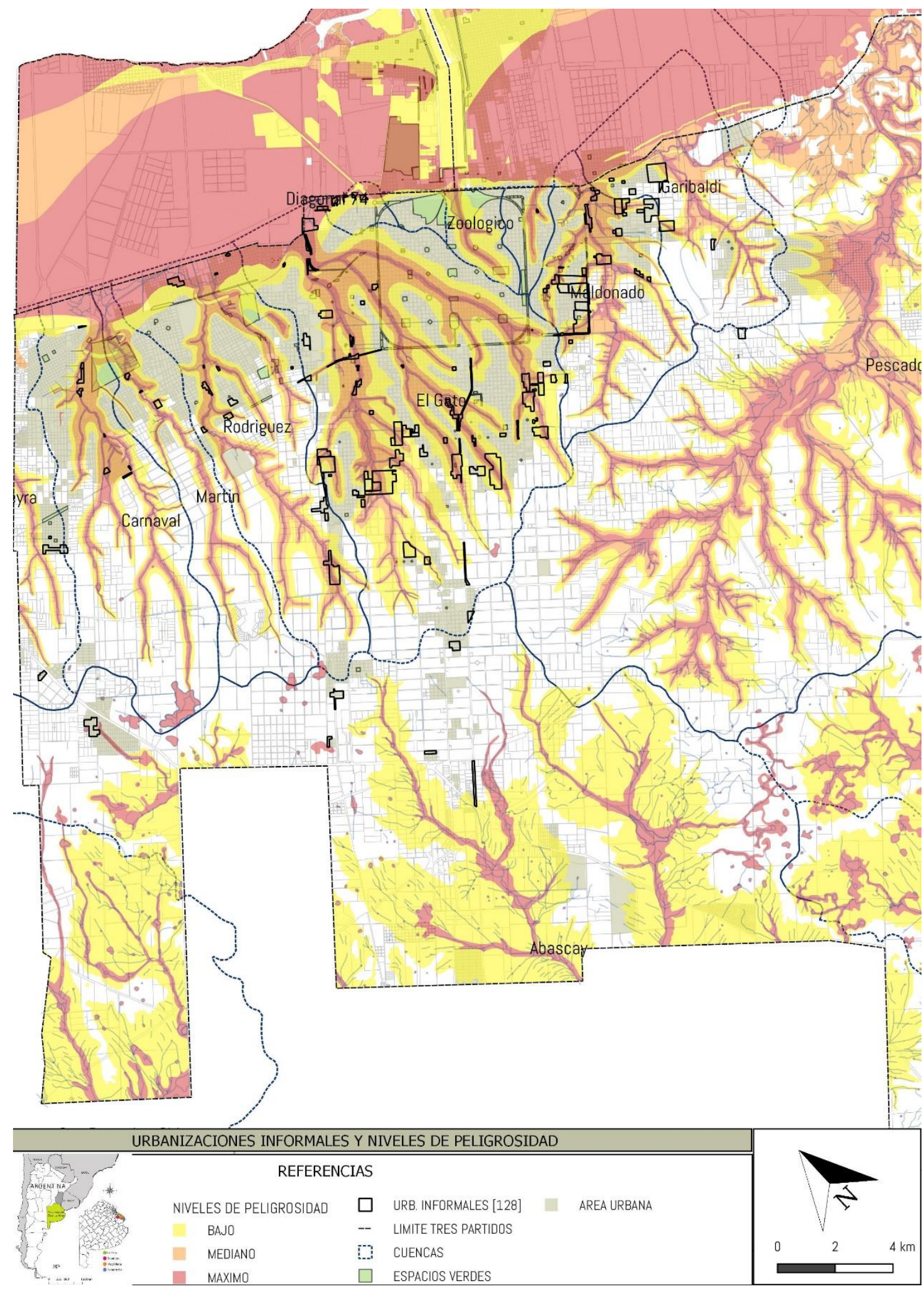




\section{MAPA 3 - DIMENSIÓN TEMPORAL}

Fuente: Elaboración propia, con herramienta GIS, 2018 y datos del RPPVAP (2015)

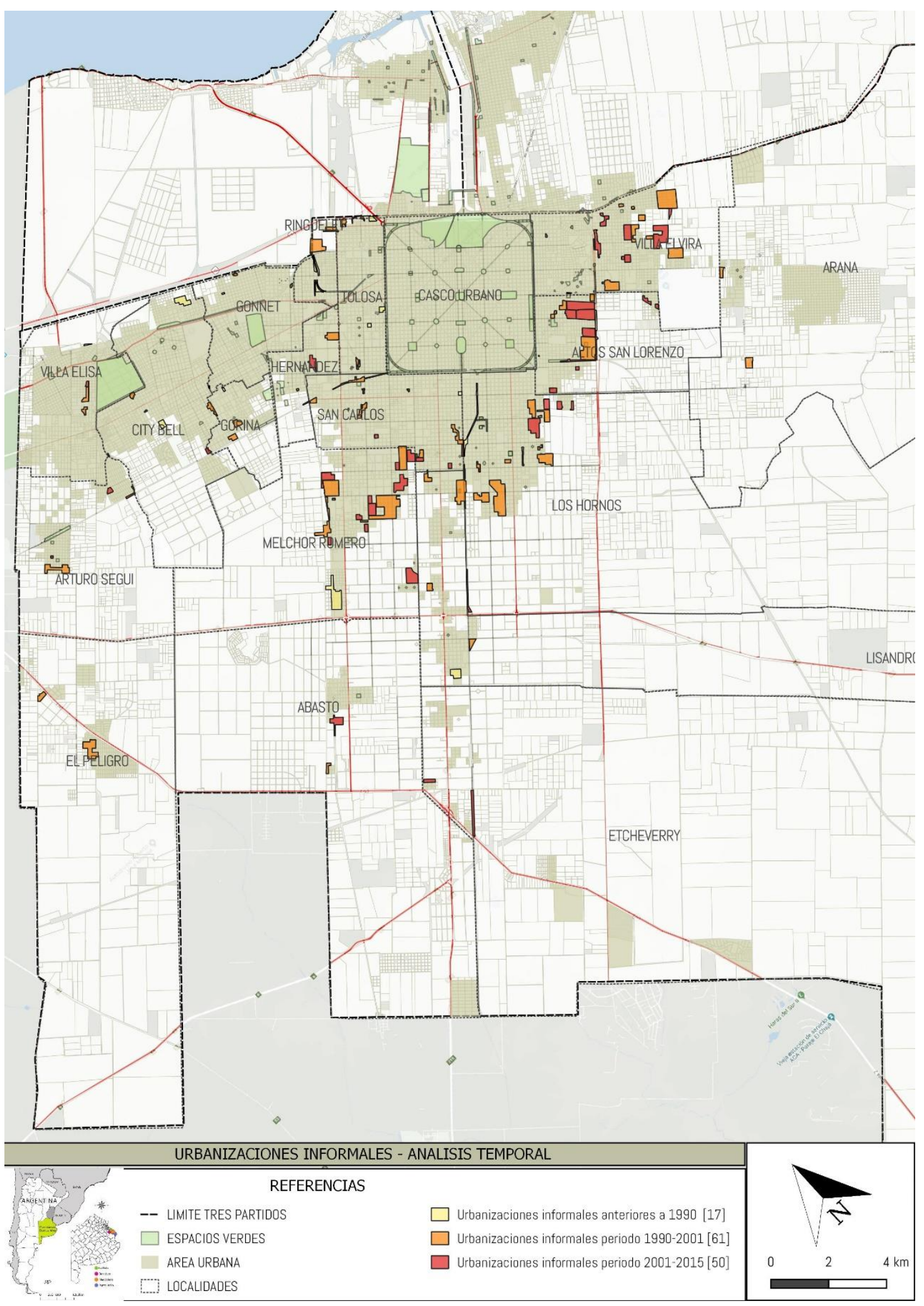


ANEXO 4

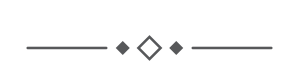

\section{RELEVAMIENTO URBANIZACIONES \\ INFORMALES}




\section{FICHAS RELEVAMIENTO DE URBANIZACIONES INFORMALES POR LOCALIDAD}

\section{URBANIZACIONES INFORMALES EN LA LOCALIDAD DE VILLA ELVIRA}

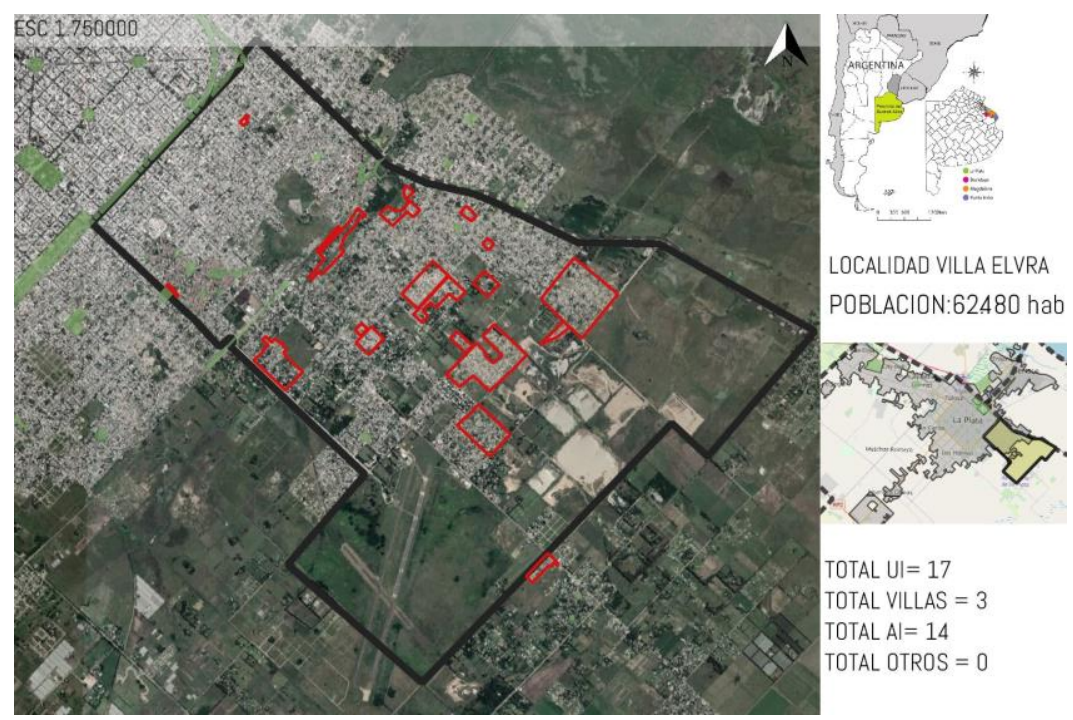

PARTIDO: La Plata

LOCALIDAD: Villa Elvira

NOMBRE OFICIAL: Barrio Alegre

TIPOLOGIA: Asentamiento Informal

AÑO DE ORIGEN: 2008

CANT DE FAMILIAS: 200

SUPERFICIE: $16.1 \mathrm{hc}$

PARTIDO: La Plata

LOCALIDAD: Villa Elvira

NOMBRE OFICIAL: Villa Aburridita

TIPOLOGIA: Asentamiento Informal

AÑO DE ORIGEN: 2001

CANT DE FAMILIAS: 732

SUPERFICIE: 41.9 ho

PARTIDO: La Plata

LOCALIDAD: Villa Elvira

NOMBRE OFICIAL: Villa Montoro IV

TIPOLOGIA: Asentamiento Informal

AÑO DE ORIGEN: 2000

CANT DE FAMILIAS: 156

SUPERFICIE: $10.61 \mathrm{hc}$
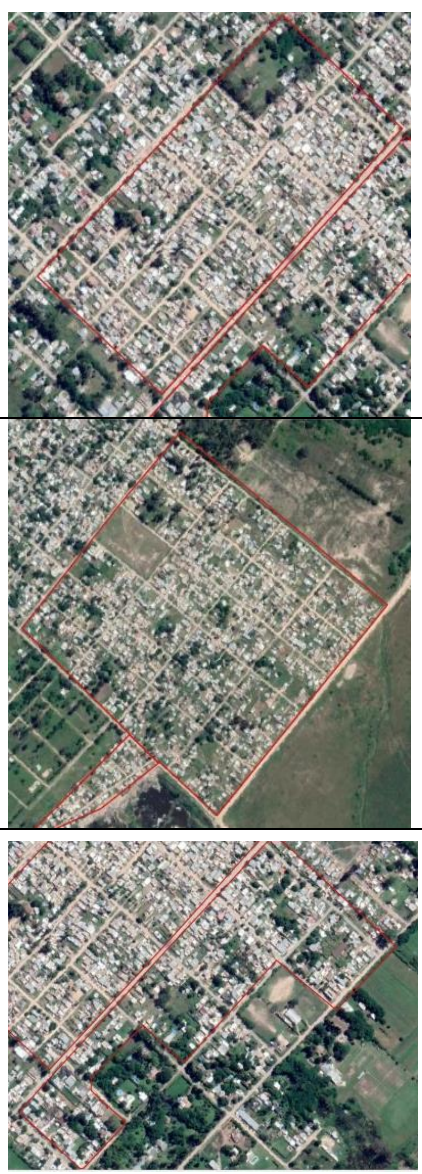
PARTIDO: La Plata

LOCALIDAD: Villa Elvira

NOMBRE OFICIAL: Villa Alegre

TIPOLOGIA: Asentamiento Informal

AÑO DE ORIGEN: 2011

CANT DE FAMILIAS: 70

SUPERFICIE: $2.4 \mathrm{hc}$

PARTIDO: La Plata

LOCALIDAD: Villa Elvira

NOMBRE OFICIAL: $119 \& 604$

TIPOLOGIA: Asentamiento Informal

AÑO DE ORIGEN: 2000

CANT DE FAMILIAS: 50

SUPERFICIE: 4.9 hc

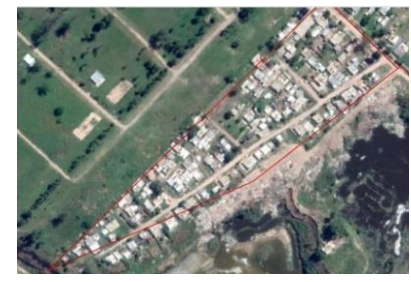

PARTIDO: La Plata

LOCALIDAD: Villa Elvira

NOMBRE OFICIAL: Villa Alba

TIPOLOGIA: Asentamiento Informal

AÑO DE ORIGEN: 1998

CANT DE FAMILIAS: 40

SUPERFICIE: 0.89 hc
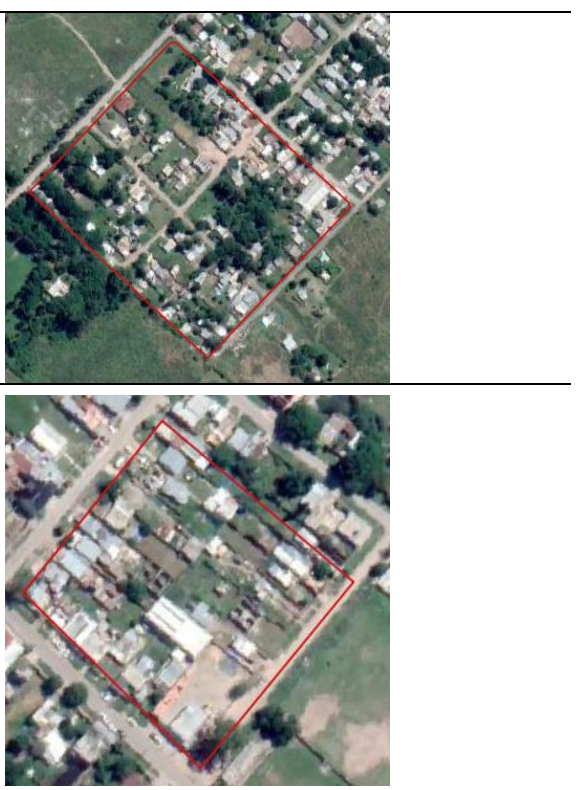

PARTIDO: La Plata

LOCALIDAD: Villa Elvira

NOMBRE OFICIAL: Agosti, Carlos

TIPOLOGIA: Asentamiento Informal

AÑO DE ORIGEN: 2007

CANT DE FAMILIAS: 250

SUPERFICIE: $5.0 \mathrm{hc}$

PARTIDO: La Plata

LOCALIDAD: Villa Elvira

NOMBRE OFICIAL: 99 \& 123

TIPOLOGIA: Asentamiento Informal

AÑO DE ORIGEN: 1999

CANT DE FAMILIAS: 46

SUPERFICIE: 1.5 hc

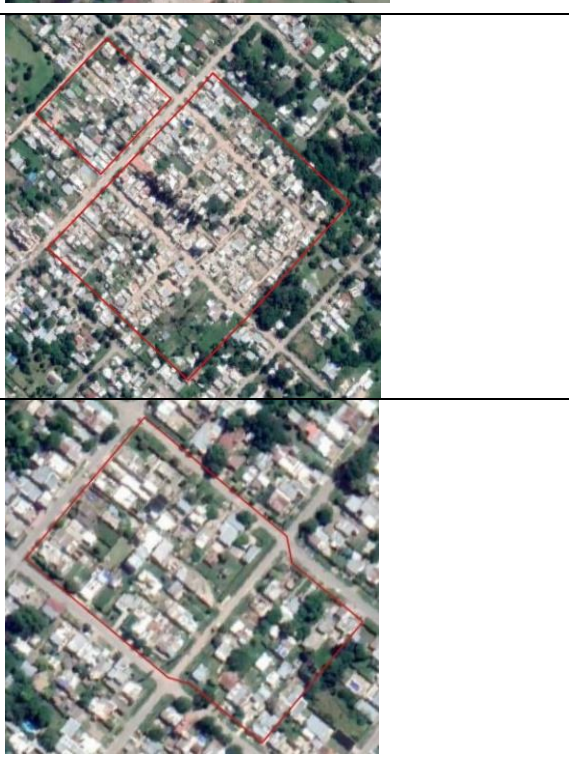

PARTIDO: La Plata

LOCALIDAD: Villa Elvira

NOMBRE OFICIAL: Villa Montoro III

TIPOLOGIA: Asentamiento Informal

AÑO DE ORIGEN: 2006

CANT DE FAMILIAS: 124

SUPERFICIE: $6.3 \mathrm{hc}$

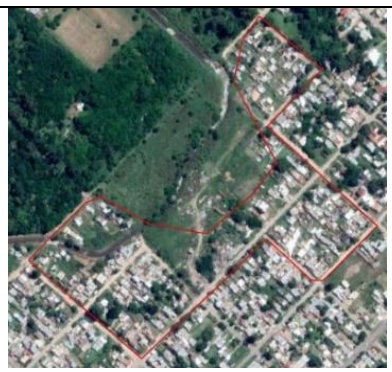


PARTIDO: La Plata

LOCALIDAD: Villa Elvira

NOMBRE OFICIAL: 116 \& 77

TIPOLOGIA: Asentamiento Informal

AÑO DE ORIGEN: Década de 1990

CANT DE FAMILIAS: 30

SUPERFICIE: 0.56 hc

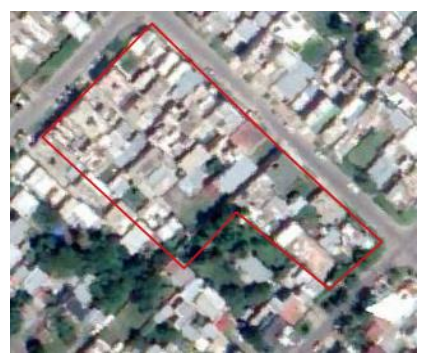

PARTIDO: La Plata

LOCALIDAD: Villa Elvira

NOMBRE OFICIAL: 81 \& 13

TIPOLOGIA: Villa

AÑO DE ORIGEN: Década de 1990

CANT DE FAMILIAS: 30

SUPERFICIE: 0.32 hc

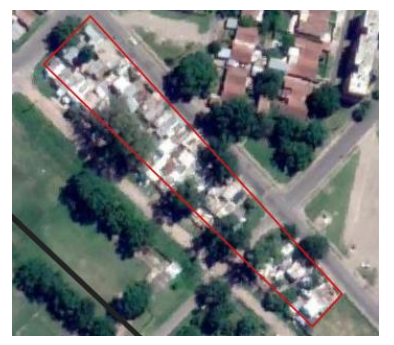

PARTIDO: La Plata

LOCALIDAD: Villa Elvira

NOMBRE OFICIAL: Aeropuerto

TIPOLOGIA: Asentamiento Informal

AÑO DE ORIGEN: 1998

CANT DE FAMILIAS: 900

SUPERFICIE: $16.31 \mathrm{hc}$

PARTIDO: La Plata

LOCALIDAD: Villa Elvira

NOMBRE OFICIAL: frisón

TIPOLOGIA: Villa

AÑO DE ORIGEN: 2001

CANT DE FAMILIAS: 100

SUPERFICIE: $17.6 \mathrm{hc}$
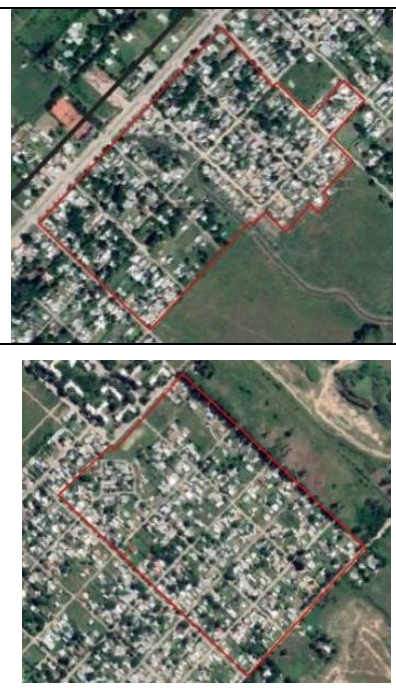

PARTIDO: La Plata

LOCALIDAD: Villa Elvira

NOMBRE OFICIAL: Villa Montoro II

TIPOLOGIA: Asentamiento Informal

AÑO DE ORIGEN: 2002

CANT DE FAMILIAS: 130

SUPERFICIE: $10.47 \mathrm{hc}$

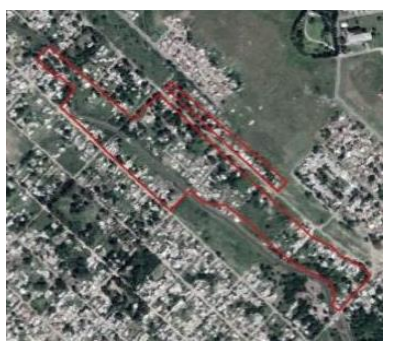

PARTIDO: La Plata

LOCALIDAD: Villa Elvira

NOMBRE OFICIAL: Villa Montoro I

TIPOLOGIA: Villa

AÑO DE ORIGEN: 2001

CANT DE FAMILIAS: 40

SUPERFICIE: $2.5 \mathrm{hc}$

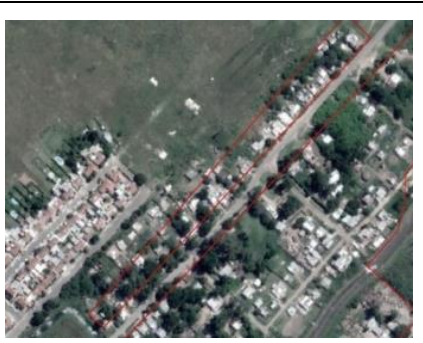


PARTIDO: La Plata

LOCALIDAD: Villa Elvira

NOMBRE OFICIAL: Sebastián Sueldo

TIPOLOGIA: Asentamiento Informal

AÑO DE ORIGEN: Década de 1990

CANT DE FAMILIAS: 88

SUPERFICIE: 2.74 hc

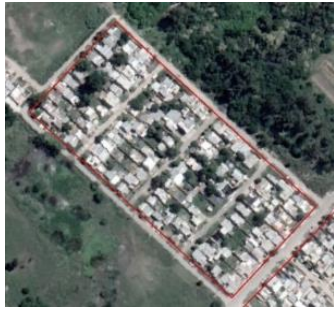

PARTIDO: La Plata

LOCALIDAD: Villa Elvira

NOMBRE OFICIAL: 119 \& 604

TIPOLOGIA: Asentamiento Informal

AÑO DE ORIGEN: 2000

CANT DE FAMILIAS: 50

SUPERFICIE: 4.9 hc

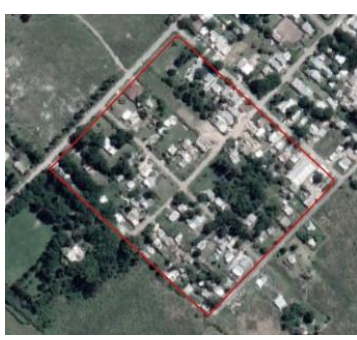

URBANIZACIONES INFORMALES EN LA LOCALIDAD DE ALTOS DE SAN LORENZO

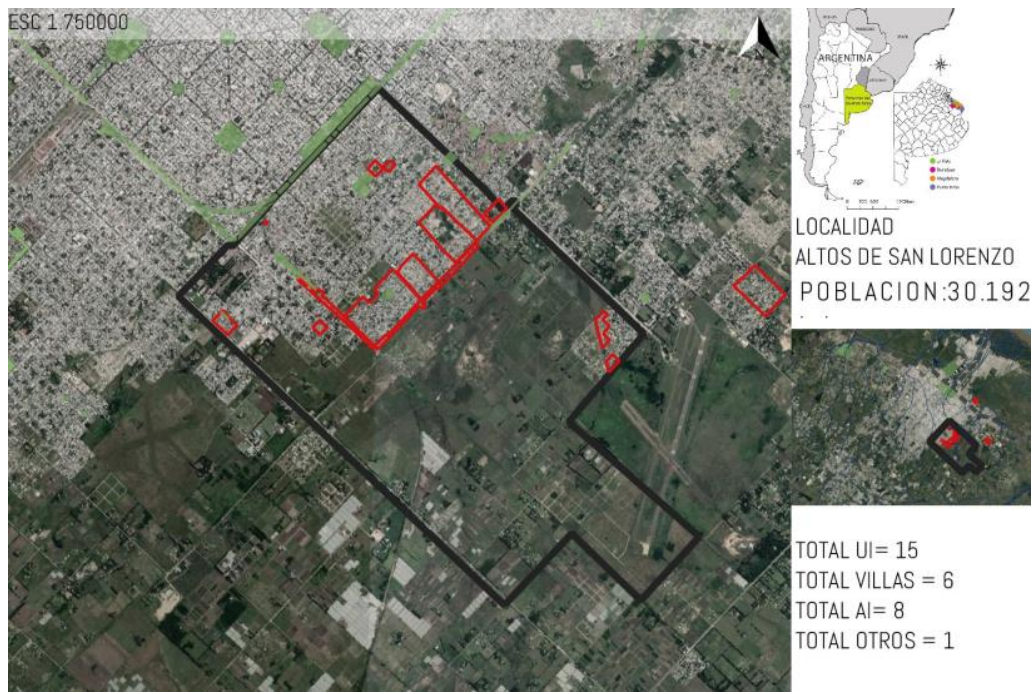

PARTIDO: La Plata

LOCALIDAD: Altos de San Lorenzo

NOMBRE OFICIAL: Puente de Fierro

TIPOLOGIA: Asentamiento Informal

AÑO DE ORIGEN: 1994

CANT DE FAMILIAS: 921

SUPERFICIE: $38.3 \mathrm{hc}$

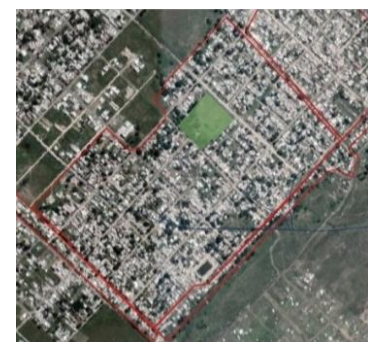


PARTIDO: La Plata

LOCALIDAD: Altos de San Lorenzo

NOMBRE OFICIAL: Puente de Fierro 3

TIPOLOGIA: Villa

AÑO DE ORIGEN: 2007

CANT DE FAMILIAS: 98

SUPERFICIE: 3.7 hc

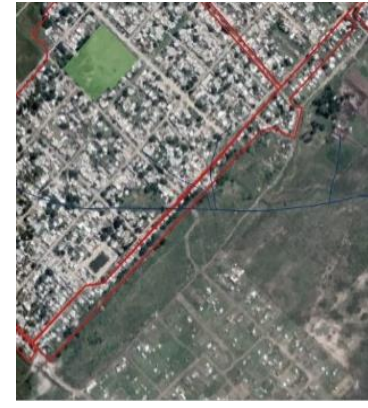

PARTIDO: La Plata

LOCALIDAD: Altos de San Lorenzo

NOMBRE OFICIAL: 29 y 90

TIPOLOGIA: Villa

AÑO DE ORIGEN: 2003

CANT DE FAMILIAS: 200

SUPERFICIE: 5.29 hc

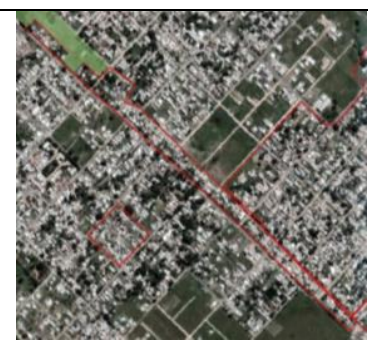

PARTIDO: La Plata

LOCALIDAD: Altos de San Lorenzo

NOMBRE OFICIAL: 131 \& 83

TIPOLOGIA: Villa

AÑO DE ORIGEN: 2007

CANT DE FAMILIAS: 51

SUPERFICIE: 1.4 hc

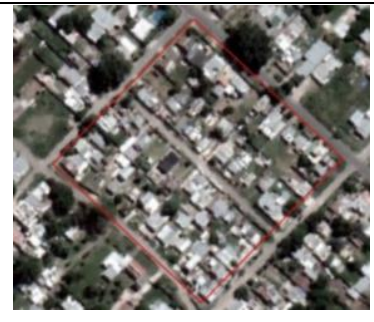

PARTIDO: La Plata

LOCALIDAD: Altos de San Lorenzo

NOMBRE OFICIAL: Puente de Fierro 2

TIPOLOGIA: Asentamiento Informal

AÑO DE ORIGEN: 2007

CANT DE FAMILIAS: 220

SUPERFICIE: $12.8 \mathrm{hc}$

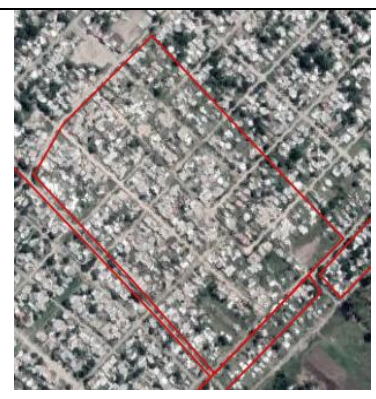

PARTIDO: La Plata

LOCALIDAD: Altos de San Lorenzo

NOMBRE OFICIAL: 90 y 19

TIPOLOGIA: Villa

AÑO DE ORIGEN: 1984

CANT DE FAMILIAS: 100

SUPERFICIE: $3.77 \mathrm{hc}$

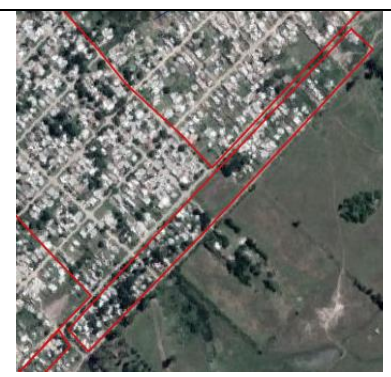

PARTIDO: La Plata

LOCALIDAD: Altos de San Lorenzo

NOMBRE OFICIAL: La Cantera

TIPOLOGIA: Villa

AÑO DE ORIGEN: 2008

CANT DE FAMILIAS: 295

SUPERFICIE: $19.31 \mathrm{hc}$

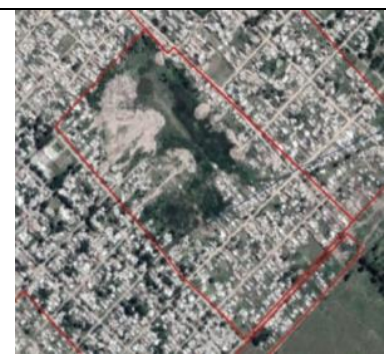


PARTIDO: La Plata

LOCALIDAD: Altos de San Lorenzo

NOMBRE OFICIAL: La Esperanza

TIPOLOGIA: Villa

AÑO DE ORIGEN: 2004

CANT DE FAMILIAS: 547

SUPERFICIE: 40.74 hc

PARTIDO: La Plata

LOCALIDAD: Altos de San Lorenzo

NOMBRE OFICIAL: 26 de julio

TIPOLOGIA: Otros

AÑO DE ORIGEN: 1992

CANT DE FAMILIAS: 60

SUPERFICIE: 3.4 hc

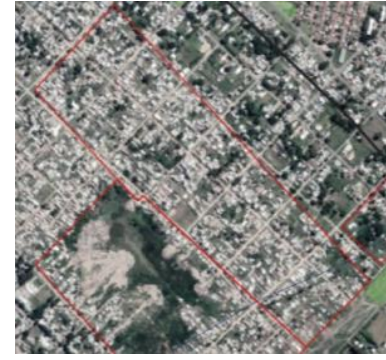

PARTIDO: La Plata

LOCALIDAD: Altos de San Lorenzo

NOMBRE OFICIAL: Los Robles

TIPOLOGIA: Asentamiento Informal

AÑO DE ORIGEN: 2006

CANT DE FAMILIAS: 102

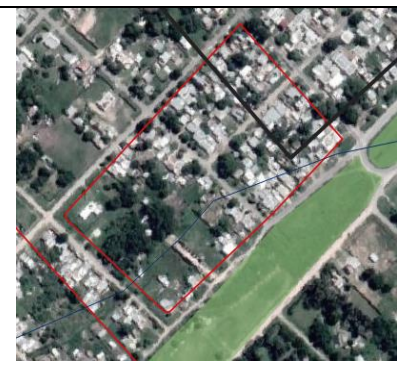

SUPERFICIE: $5.3 \mathrm{hc}$

PARTIDO: La Plata

LOCALIDAD: Altos de San Lorenzo

NOMBRE OFICIAL: Los Chaques

TIPOLOGIA: Villa

AÑO DE ORIGEN: 1994

CANT DE FAMILIAS: 15

SUPERFICIE: 0.8 hc

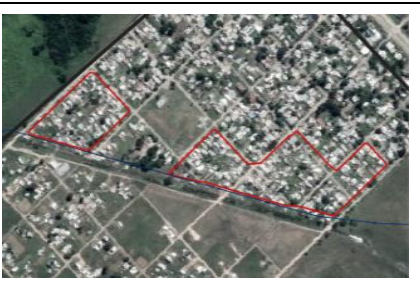

PARTIDO: La Plata

LOCALIDAD: Altos de San Lorenzo

NOMBRE OFICIAL: La Esperanza (extensión)

TIPOLOGIA: Villa

AÑO DE ORIGEN: 2006

CANT DE FAMILIAS: 235

SUPERFICIE: $10.63 \mathrm{hc}$

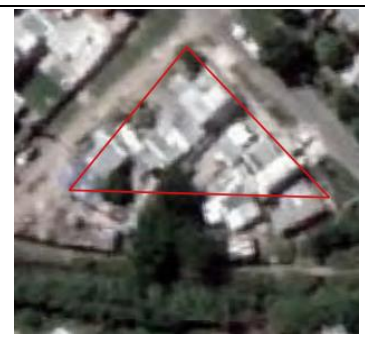

PARTIDO: La Plata

LOCALIDAD: Altos de San Lorenzo

NOMBRE OFICIAL: 16 \& 80

TIPOLOGIA: Asentamiento Informal

AÑO DE ORIGEN: Década del 900 anterior

CANT DE FAMILIAS: 225

SUPERFICIE: 5.7 hc
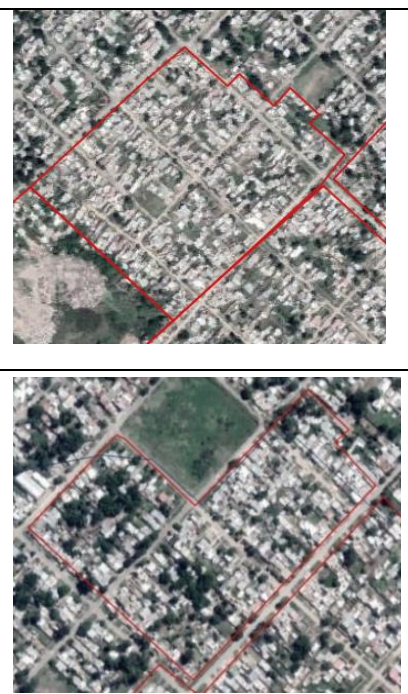
PARTIDO: La Plata

LOCALIDAD: Altos de San Lorenzo

NOMBRE OFICIAL: El Ombú

TIPOLOGIA: Asentamiento Informal

AÑO DE ORIGEN: 2006

CANT DE FAMILIAS: 100

SUPERFICIE: 3.96 hc

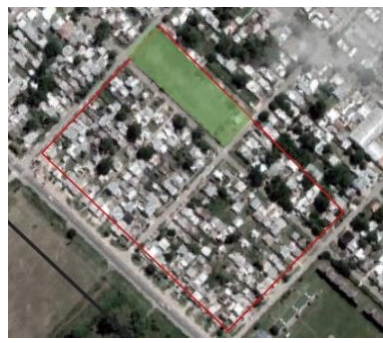

PARTIDO: La Plata

LOCALIDAD: Altos de San Lorenzo

NOMBRE OFICIAL: 19 y 77

TIPOLOGIA: Asentamiento Informal

AÑO DE ORIGEN: Década de 1990

CANT DE FAMILIAS: 68

SUPERFICIE: $2.68 \mathrm{hc}$

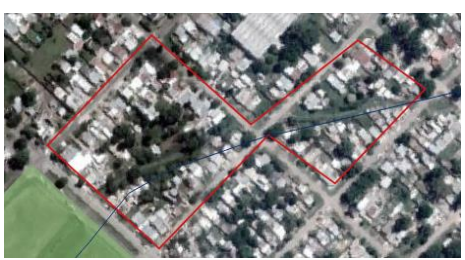

\section{URBANIZACIONES INFORMALES EN LA LOCALIDAD DE LOS HORNOS}

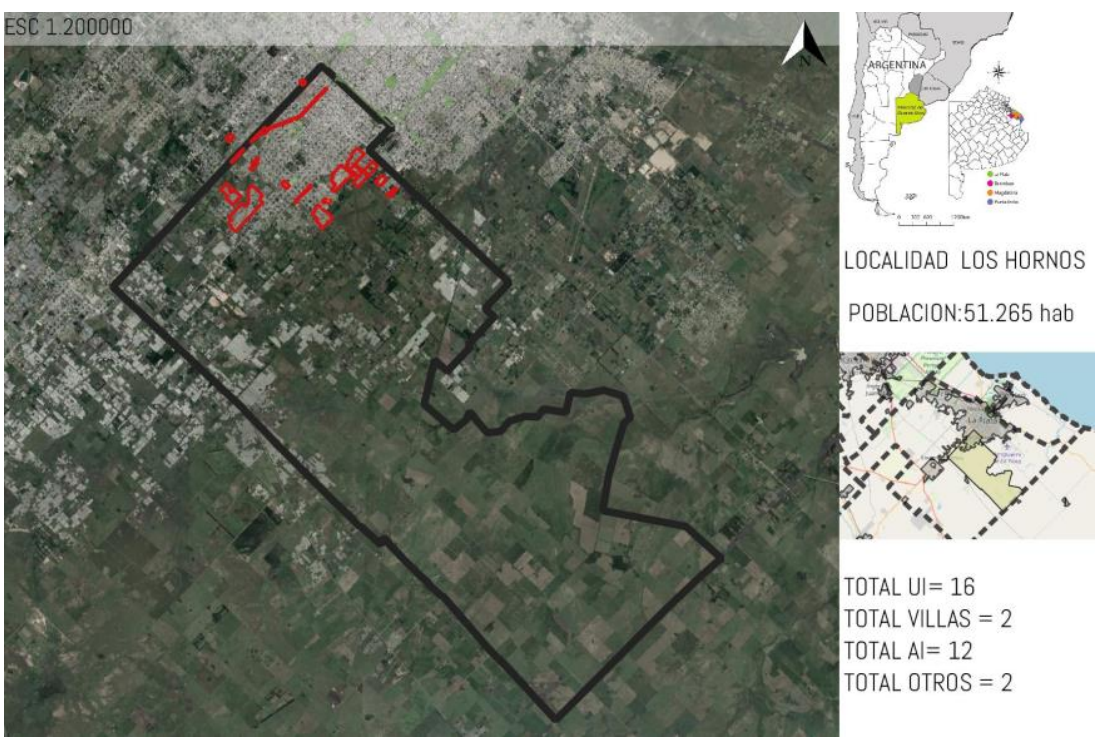

PARTIDO: La Plata

LOCALIDAD: Los Hornos

NOMBRE OFICIAL: La vía

TIPOLOGIA: Villa

AÑO DE ORIGEN: 1984

CANT DE FAMILIAS: 166

SUPERFICIE: $10.8 \mathrm{hc}$

PARTIDO: La Plata

LOCALIDAD: Los Hornos

NOMBRE OFICIAL: 52 \& 125

TIPOLOGIA: Asentamiento Informal

AÑO DE ORIGEN: 2011

CANT DE FAMILIAS: 29

SUPERFICIE: 1.86 hc
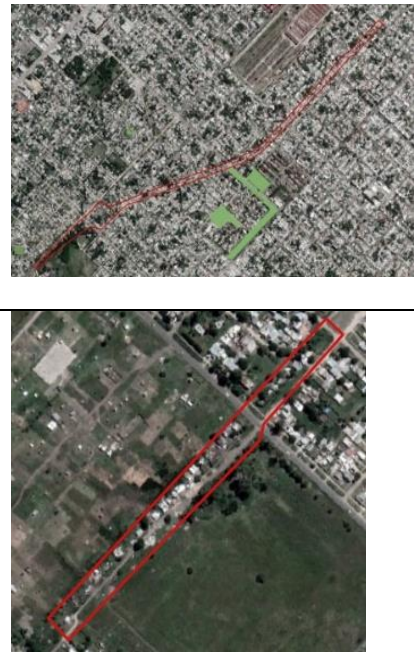
PARTIDO: La Plata

LOCALIDAD: Los Hornos

NOMBRE OFICIAL: 57 \& 155

TIPOLOGIA: Asentamiento Informal

AÑO DE ORIGEN: 2000

CANT DE FAMILIAS: 66

SUPERFICIE: 2.6 hc

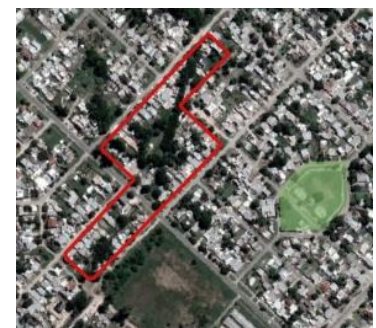

PARTIDO: La Plata

LOCALIDAD: Los Hornos

NOMBRE OFICIAL: El Triunfo

TIPOLOGIA: Asentamiento Informal

AÑO DE ORIGEN: 1998

CANT DE FAMILIAS: 242

SUPERFICIE: $13.8 \mathrm{hc}$

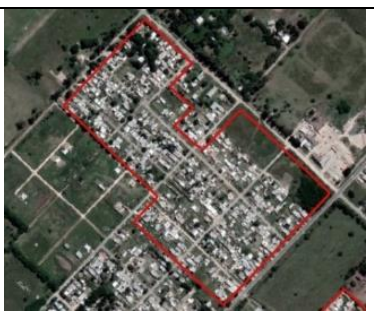

PARTIDO: La Plata

LOCALIDAD: Los Hornos

NOMBRE OFICIAL: 62 \& 161

TIPOLOGIA: Asentamiento Informal

AÑO DE ORIGEN: 1999

CANT DE FAMILIAS: 780

SUPERFICIE: $46.3 \mathrm{hc}$

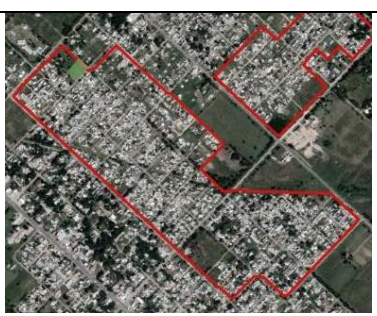

PARTIDO: La Plata
LOCALIDAD: Los Hornos
NOMBRE OFICIAL: 74 \& 153
TIPOLOGIA: Asentamiento Informal
AÑO DE ORIGEN: 1998
CANT DE FAMILIAS: 416
SUPERFICIE: 17.5 hc

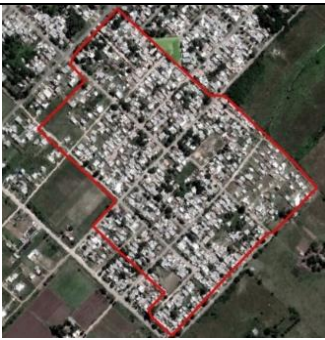

PARTIDO: La Plata

LOCALIDAD: Los Hornos

NOMBRE OFICIAL: 75 bis \& 150

TIPOLOGIA: Asentamiento Informal

AÑO DE ORIGEN: 2000

CANT DE FAMILIAS: 45

SUPERFICIE: $1.2 \mathrm{hc}$

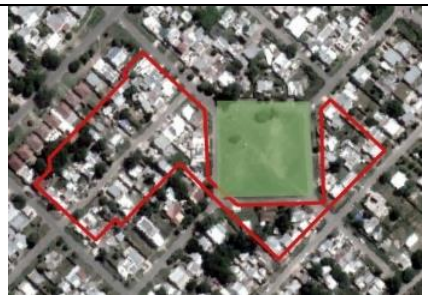

PARTIDO: La Plata

LOCALIDAD: Los Hornos

NOMBRE OFICIAL: Santa Isabel

TIPOLOGIA: Asentamiento Informal

AÑO DE ORIGEN: 2007

CANT DE FAMILIAS: 67

SUPERFICIE: $2.4 \mathrm{hc}$

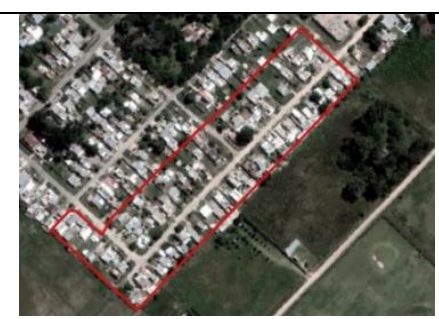


PARTIDO: La Plata

LOCALIDAD: Los Hornos

NOMBRE OFICIAL: 2 de abril

TIPOLOGIA: OtrOS

AÑO DE ORIGEN: 2013

CANT DE FAMILIAS: 32

SUPERFICIE: $4.6 \mathrm{hc}$

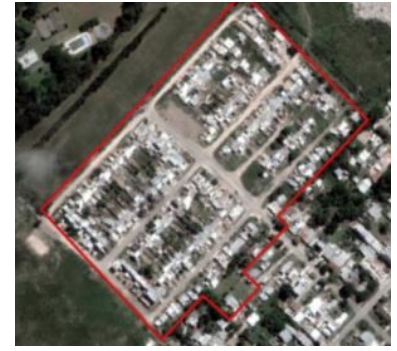

PARTIDO: La Plata

LOCALIDAD: Los Hornos

NOMBRE OFICIAL: 75 \& 142

TIPOLOGIA: Asentamiento Informal

AÑO DE ORIGEN: Década de 1990

CANT DE FAMILIAS: 135

SUPERFICIE: $9.8 \mathrm{hc}$

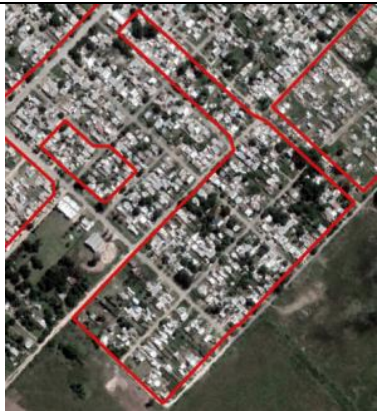

PARTIDO: La Plata

LOCALIDAD: Los Hornos

NOMBRE OFICIAL: 74 \& 140

TIPOLOGIA: Asentamiento Informal

AÑO DE ORIGEN: 2013

CANT DE FAMILIAS: 51

SUPERFICIE: $6.5 \mathrm{hc}$

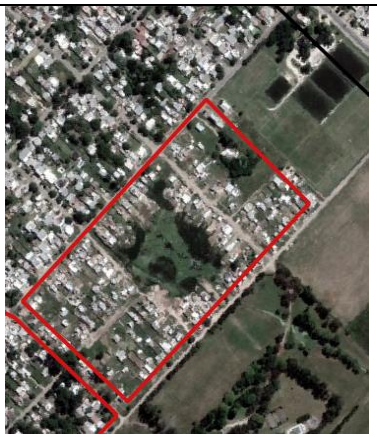

PARTIDO: La Plata

LOCALIDAD: Los Hornos

NOMBRE OFICIAL: 152 \& 68

TIPOLOGIA: Asentamiento Informal

AÑO DE ORIGEN: Década 1990

CANT DE FAMILIAS: 51

SUPERFICIE: $2.4 \mathrm{hc}$

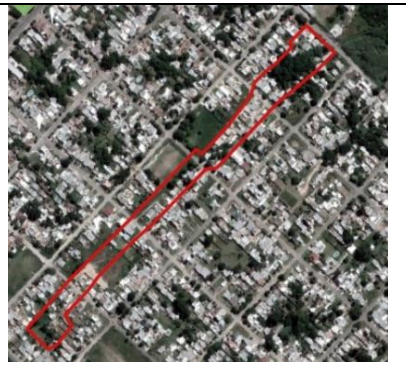

PARTIDO: La Plata

LOCALIDAD: Los Hornos

NOMBRE OFICIAL: Las Palmeras

TIPOLOGIA: Asentamiento Informal

AÑO DE ORIGEN: 2009

CANT DE FAMILIAS: 450

SUPERFICIE: 20.8 hc

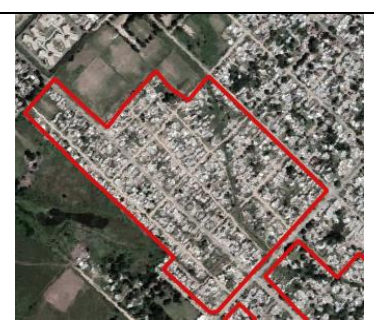

PARTIDO: La Plata

LOCALIDAD: Los Hornos

NOMBRE OFICIAL: La Esperanza

TIPOLOGIA: Asentamiento Informal

AÑO DE ORIGEN: 2000

CANT DE FAMILIAS: 200

SUPERFICIE: 13 hc

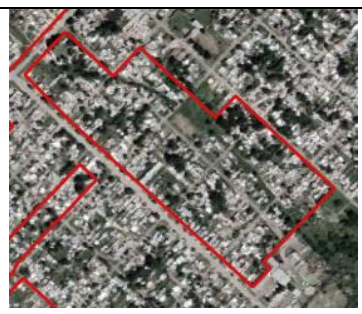

Pá g i n a 331 
PARTIDO: La Plata

LOCALIDAD: Los Hornos

NOMBRE OFICIAL: 65 \& 153

TIPOLOGIA: OtrOS

AÑO DE ORIGEN: Decada de 1990

CANT DE FAMILIAS: 78

SUPERFICIE: 2.4 hc

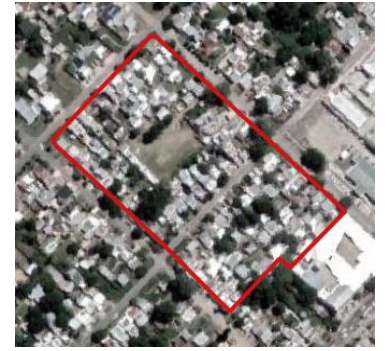

PARTIDO: La Plata

LOCALIDAD: Los Hornos

NOMBRE OFICIAL: El Triangulo

TIPOLOGIA: Villa

AÑO DE ORIGEN: 2007

CANT DE FAMILIAS: 62

SUPERFICIE: $5.91 \mathrm{hc}$

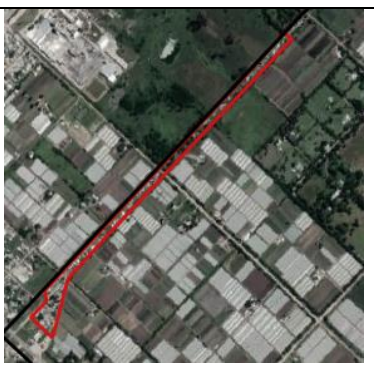

URBANIZACIONES INFORMALES EN LA LOCALIDAD DE SAN CARLOS

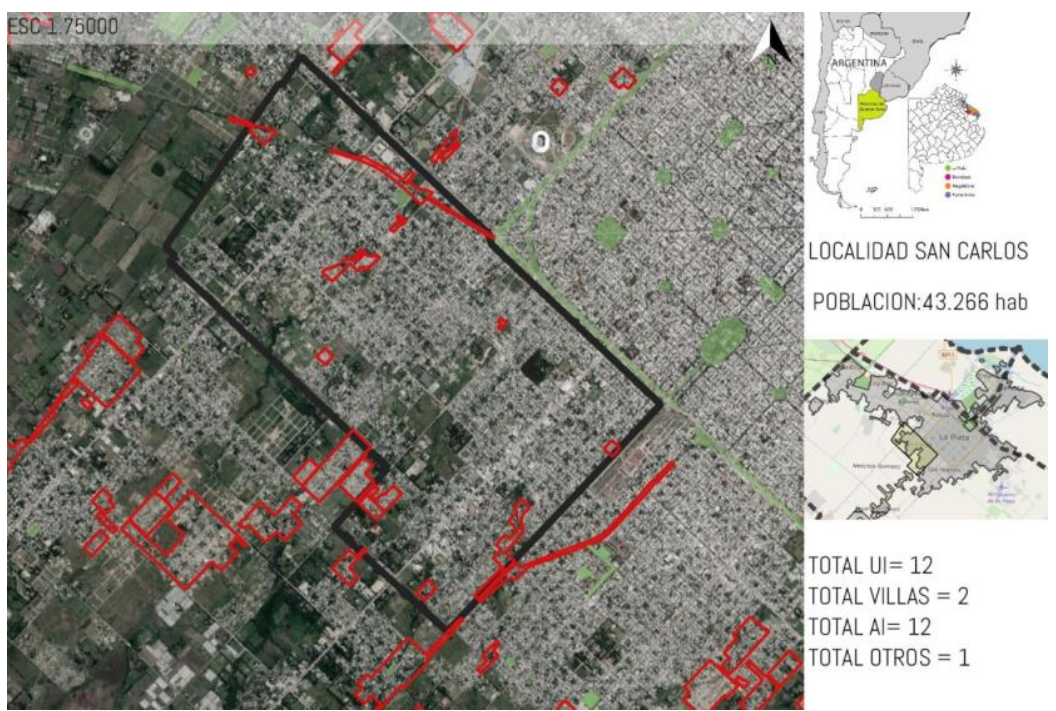

PARTIDO: La Plata

LOCALIDAD: San Carlos

NOMBRE OFICIAL: 136 \& 62

TIPOLOGIA: Otros

AÑO DE ORIGEN: 1980

CANT DE FAMILIAS: 55

SUPERFICIE: 1.44 ho

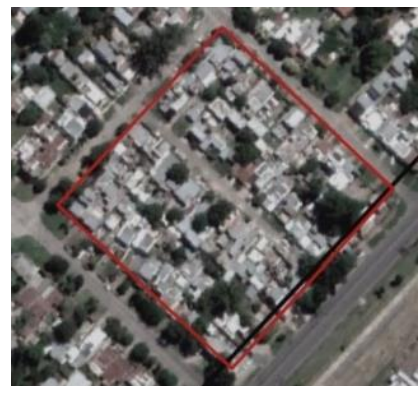


PARTIDO: La Plata

LOCALIDAD: San Carlos

NOMBRE OFICIAL: 48 \& 144

TIPOLOGIA: Asentamiento Informal

AÑO DE ORIGEN: 1998

CANT DE FAMILIAS: 203

SUPERFICIE: $8.7 \mathrm{hc}$

PARTIDO: La Plata

LOCALIDAD: San Carlos

NOMBRE OFICIAL: La Banda

TIPOLOGIA: Asentamiento Informal

AÑO DE ORIGEN: 2013

CANT DE FAMILIAS: 51

SUPERFICIE: 2 hc

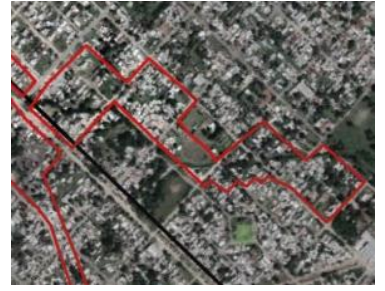

PARTIDO: La Plata

LOCALIDAD: San Carlos

NOMBRE OFICIAL: 115 \& 46

TIPOLOGIA: Asentamiento Informal

AÑO DE ORIGEN: 2005

CANT DE FAMILIAS: 39

SUPERFICIE: $2.3 \mathrm{hc}$
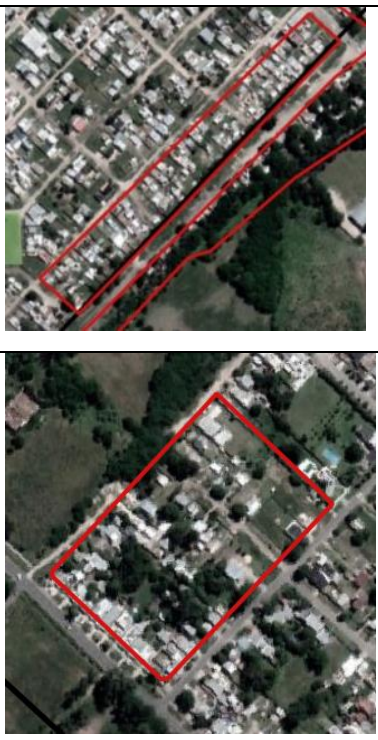

PARTIDO: La Plata

LOCALIDAD: San Carlos

NOMBRE OFICIAL: 153 \& 40

TIPOLOGIA: Asentamiento Informal

AÑO DE ORIGEN: 2010

CANT DE FAMILIAS: 80

SUPERFICIE: $3.3 \mathrm{hc}$

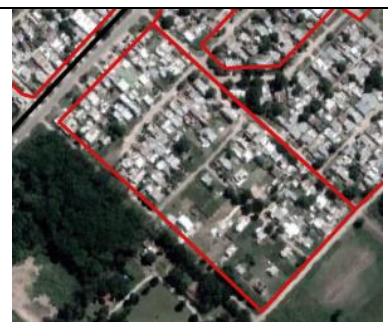

PARTIDO: La Plata

LOCALIDAD: San Carlos

NOMBRE OFICIAL: 40 \& 150

TIPOLOGIA: Asentamiento Informal

AÑO DE ORIGEN: Década de 1990

CANT DE FAMILIAS: 118

SUPERFICIE: $4.5 \mathrm{hc}$

PARTIDO: La Plata

LOCALIDAD: San Carlos

NOMBRE OFICIAL: La Usina

TIPOLOGIA: Asentamiento Informal

AÑO DE ORIGEN: 2005

CANT DE FAMILIAS: 70

SUPERFICIE: $4.61 \mathrm{hc}$

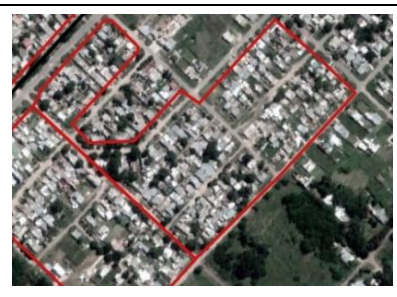

PARTIDO: La Plata

LOCALIDAD: San Carlos

NOMBRE OFICIAL: Toba

TIPOLOGIA: Villa

AÑO DE ORIGEN: 1995

CANT DE FAMILIAS: 198
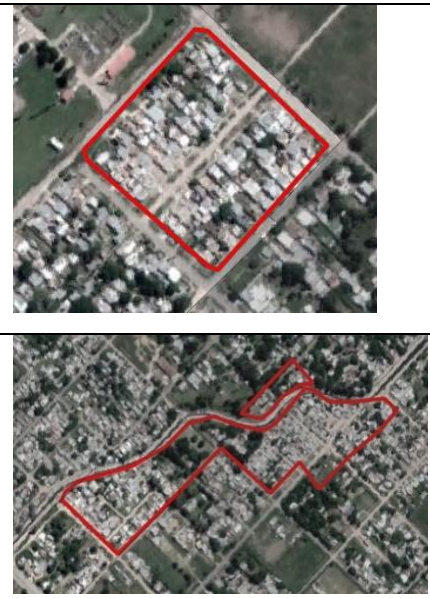

Pá g in a 333 
SUPERFICIE: $6.53 \mathrm{hc}$

PARTIDO: La Plata

LOCALIDAD: San Carlos

NOMBRE OFICIAL: 526 \& 135

TIPOLOGIA: Asentamiento Informal

AÑO DE ORIGEN: 2003

CANT DE FAMILIAS: 40

SUPERFICIE: $0.930 \mathrm{hc}$

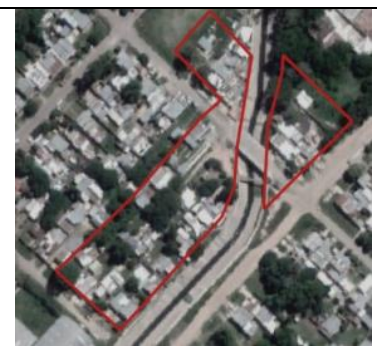

PARTIDO: La Plata

LOCALIDAD: San Carlos

NOMBRE OFICIAL: El Olvido

TIPOLOGIA: Asentamiento Informal

AÑO DE ORIGEN: 2001

CANT DE FAMILIAS: 263

SUPERFICIE: $9.16 \mathrm{hc}$

PARTIDO: La Plata

LOCALIDAD: San Carlos

NOMBRE OFICIAL: 36 bis \& 135

TIPOLOGIA: Asentamiento Informal

AÑO DE ORIGEN: 1996

CANT DE FAMILIAS: 30

SUPERFICIE: 0.56 hc
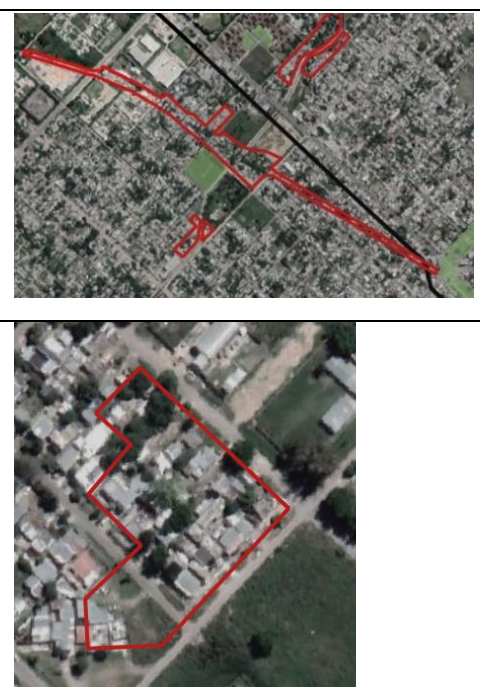

PARTIDO: La Plata

LOCALIDAD: San Carlos

NOMBRE OFICIAL: 514 \& 138

TIPOLOGIA: Villa

AÑO DE ORIGEN: 2001

CANT DE FAMILIAS: 59

SUPERFICIE: $3.9 \mathrm{hc}$

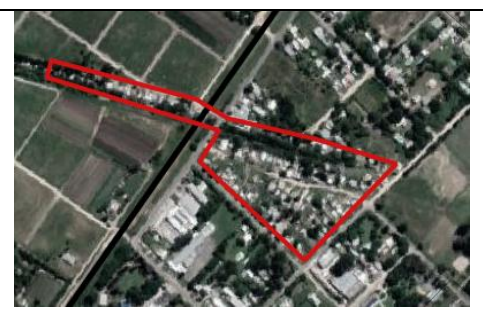

\section{URBANIZACIONES INFORMALES EN LA LOCALIDAD DE OLMOS}

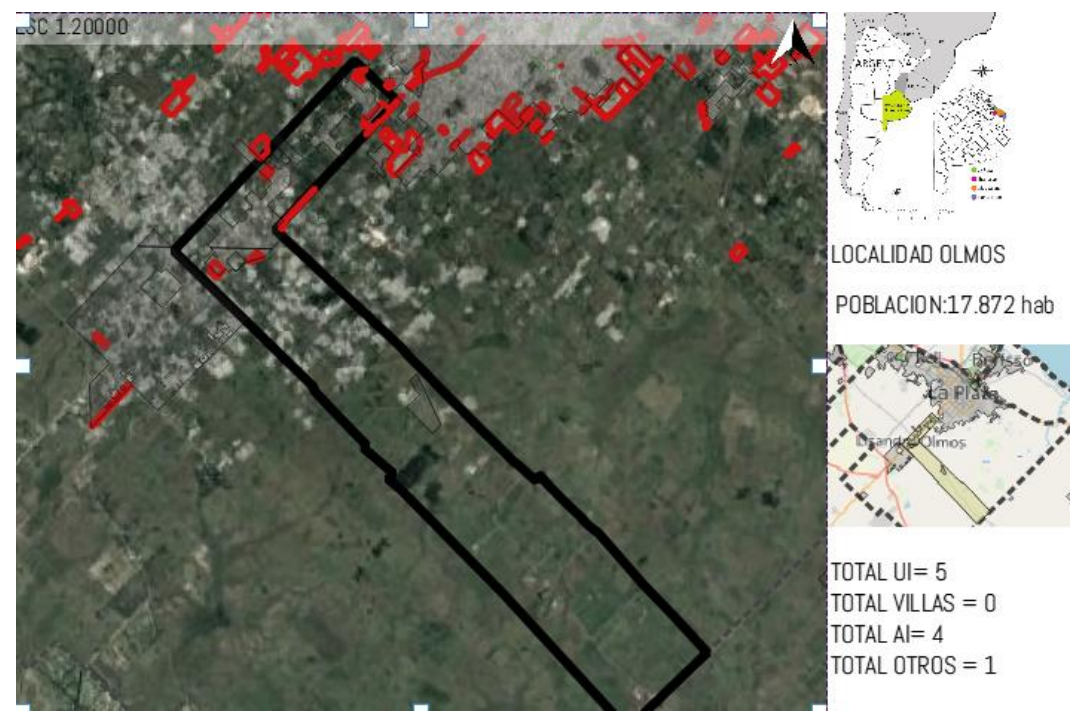


PARTIDO: La Plata

LOCALIDAD: OImOS

NOMBRE OFICIAL: Retiro

TIPOLOGIA: Asentamiento Informal

AÑO DE ORIGEN: 1996

CANT DE FAMILIAS: 300

SUPERFICIE: 26.3 hc

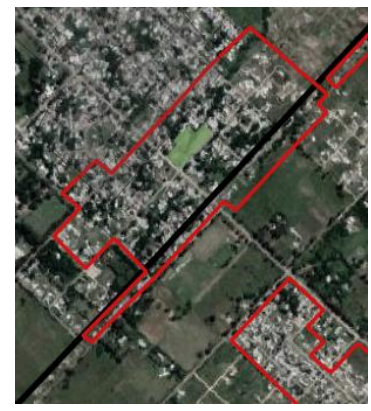

PARTIDO: La Plata

LOCALIDAD: OImOS

NOMBRE OFICIAL: 155 \& 41

TIPOLOGIA: Asentamiento Informal

AÑO DE ORIGEN: Decada de 1990

CANT DE FAMILIAS: 129

SUPERFICIE: 5.67 hc

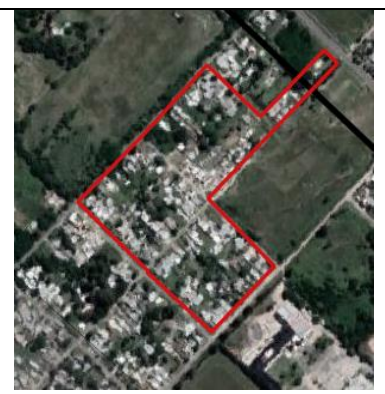

PARTIDO: La Plata

LOCALIDAD: OImos

NOMBRE OFICIAL: Las Casuarinas

TIPOLOGIA: Asentamiento Informal

AÑO DE ORIGEN: Decada de 1999

CANT DE FAMILIAS: 124

SUPERFICIE: 5 hc

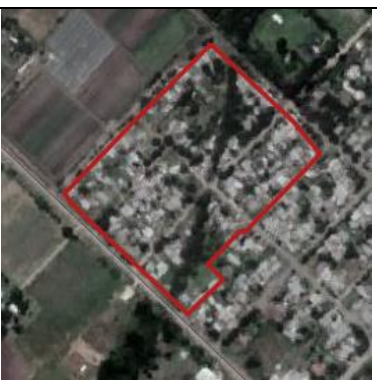

PARTIDO: La Plata

LOCALIDAD: OImos

NOMBRE OFICIAL: La Palangana

TIPOLOGIA: Otros

AÑO DE ORIGEN: 1997

CANT DE FAMILIAS:141

SUPERFICIE: 4.9 hc

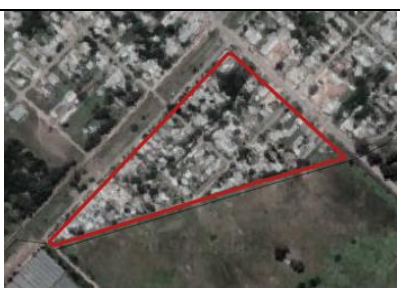

PARTIDO: La Plata

LOCALIDAD: OImos

NOMBRE OFICIAL: Los Rosales

TIPOLOGIA: Asentamiento Informal

AÑO DE ORIGEN: 1985

CANT DE FAMILIAS: 188

SUPERFICIE: 10.4 hc

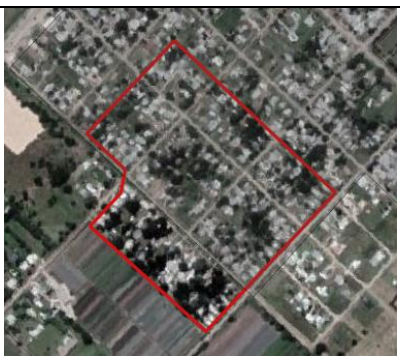




\section{URBANIZACIONES INFORMALES EN LA LOCALIDAD DE ROMERO}

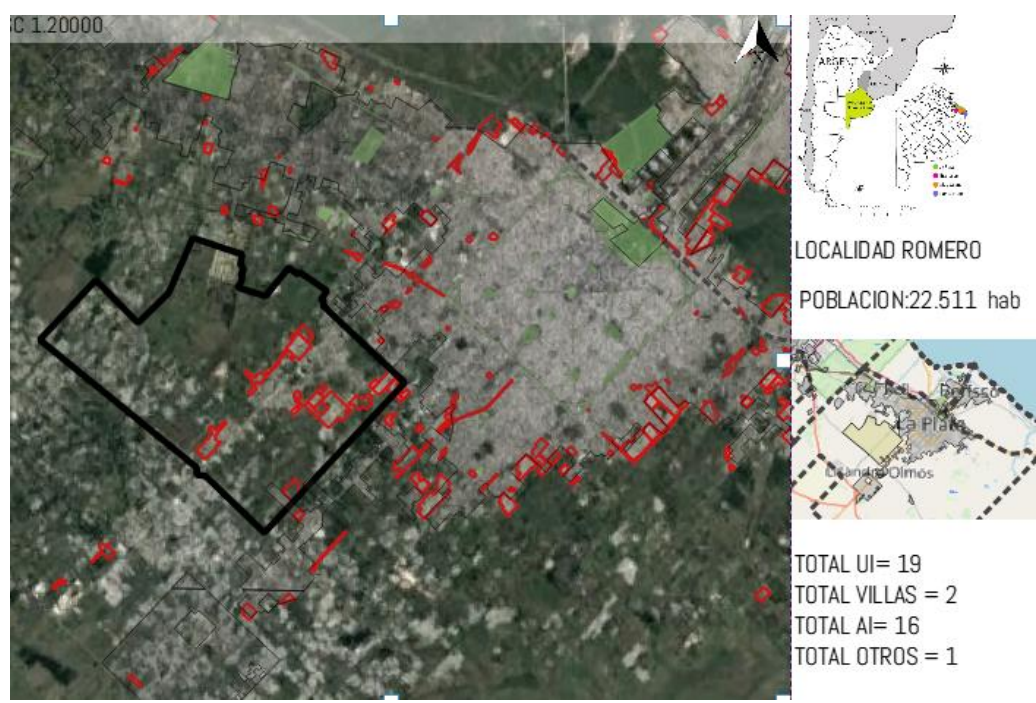

PARTIDO: La Plata

LOCALIDAD: Romero

NOMBRE OFICIAL: Malvinas II

TIPOLOGIA: Asentamiento Informal

AÑO DE ORIGEN: 2002

CANT DE FAMILIAS: 273

SUPERFICIE: $9.1 \mathrm{hc}$

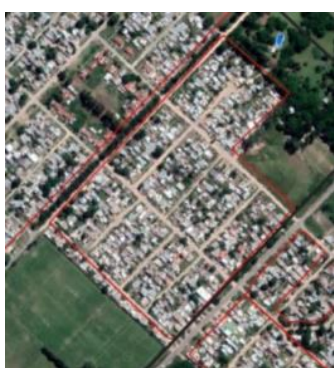

PARTIDO: La Plata

LOCALIDAD: Romero

NOMBRE OFICIAL: Malvinas

TIPOLOGIA: Otros

AÑO DE ORIGEN: 1992

CANT DE FAMILIAS: 635

SUPERFICIE: $21.1 \mathrm{hc}$

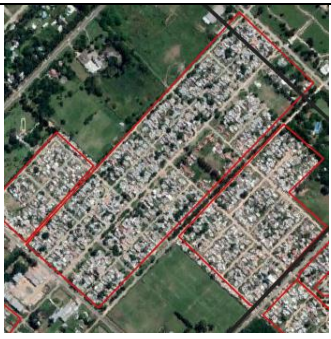

PARTIDO: La Plata

LOCALIDAD: Romero

NOMBRE OFICIAL: Hijos de Malvinas

TIPOLOGIA: Asentamiento Informal

AÑO DE ORIGEN: 2009

CANT DE FAMILIAS: 110

SUPERFICIE: 3.77 ho

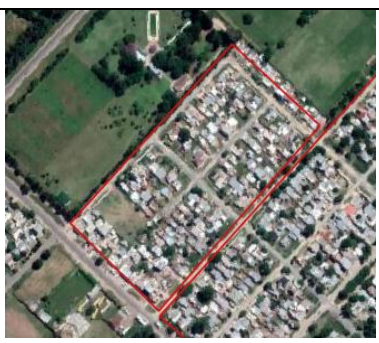

PARTIDO: La Plata

LOCALIDAD: Romero

NOMBRE OFICIAL: Los Pinos

TIPOLOGIA: Asentamiento Informal

AÑO DE ORIGEN: 2010

CANT DE FAMILIAS: 100

SUPERFICIE: $16.9 \mathrm{hc}$

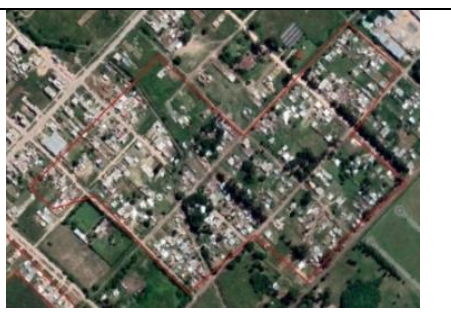


PARTIDO: La Plata

LOCALIDAD: Romero

NOMBRE OFICIAL: El futuro

TIPOLOGIA: Asentamiento Informal

AÑO DE ORIGEN: Década de 1990

CANT DE FAMILIAS: 931

SUPERFICIE: $54.6 \mathrm{hc}$

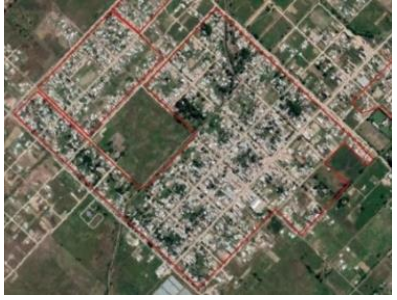

PARTIDO: La Plata

LOCALIDAD: Romero

NOMBRE OFICIAL: San Cayetano

TIPOLOGIA: Asentamiento Informal

AÑO DE ORIGEN: 2011

CANT DE FAMILIAS: 220

SUPERFICIE: 10.7 hc

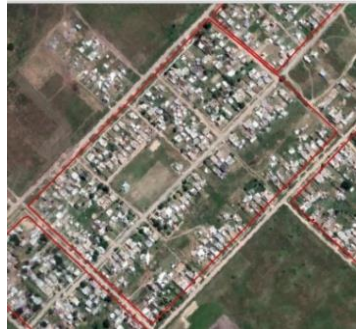

PARTIDO: La Plata

LOCALIDAD: Romero

NOMBRE OFICIAL: 161 \& 526

TIPOLOGIA: Asentamiento Informal

AÑO DE ORIGEN: 2015

CANT DE FAMILIAS: 55

SUPERFICIE: 3.5 hc

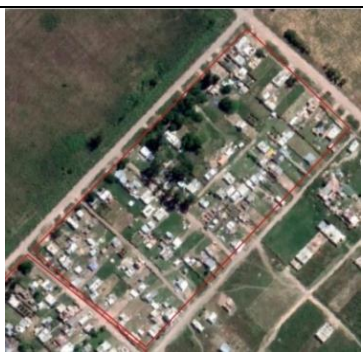

PARTIDO: La Plata

LOCALIDAD: Romero

NOMBRE OFICIAL: EI Bajo

TIPOLOGIA: Asentamiento Informal

AÑO DE ORIGEN: 2009

CANT DE FAMILIAS: 60

SUPERFICIE: 3.1 hc

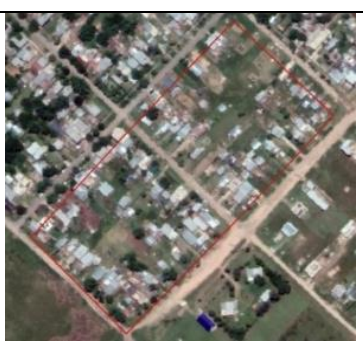

PARTIDO: La Plata

LOCALIDAD: Romero

NOMBRE OFICIAL: 167 \& 524

TIPOLOGIA: Asentamiento Informal

AÑO DE ORIGEN: Decada de 1990

CANT DE FAMILIAS: 43

SUPERFICIE: $1.6 \mathrm{hc}$

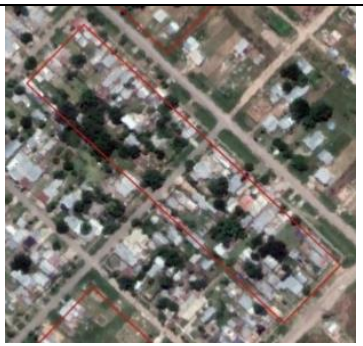

PARTIDO: La Plata

LOCALIDAD: Romero

NOMBRE OFICIAL: 166 \& 523

TIPOLOGIA: Asentamiento Informal

AÑO DE ORIGEN: 2011

CANT DE FAMILIAS: 41

SUPERFICIE: 3.3 hc

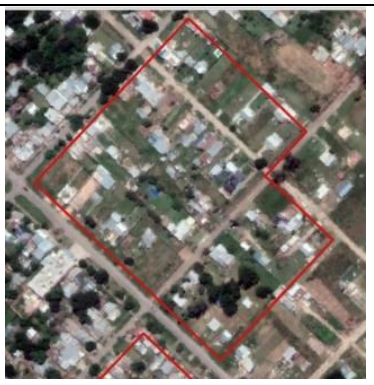


PARTIDO: La Plata

LOCALIDAD: Romero

NOMBRE OFICIAL: Arroyo Doña Flora

TIPOLOGIA: Asentamiento Informal

AÑO DE ORIGEN: 2014

CANT DE FAMILIAS: 160

SUPERFICIE: 18.1 hc

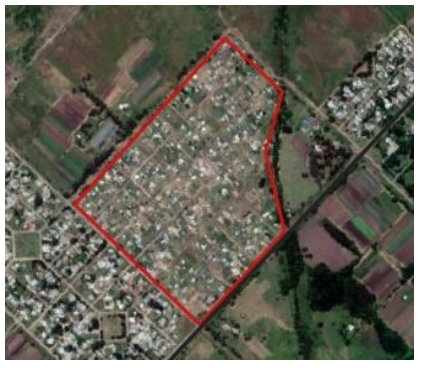

PARTIDO: La Plata

LOCALIDAD: Romero

NOMBRE OFICIAL: Barrio Nuevo

TIPOLOGIA: Asentamiento Informal

AÑO DE ORIGEN: 1980

CANT DE FAMILIAS: 239

SUPERFICIE: 29.7 hc

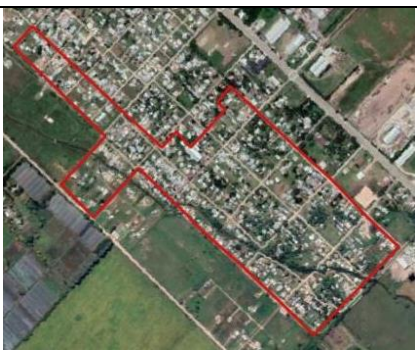

PARTIDO: La Plata

LOCALIDAD: Romero

NOMBRE OFICIAL: Vieja estación

TIPOLOGIA: Villa

AÑO DE ORIGEN: 2012

CANT DE FAMILIAS: 30

SUPERFICIE: 2.8 hc

PARTIDO: La Plata

LOCALIDAD: Romero

NOMBRE OFICIAL: Altos del Sol

TIPOLOGIA: Asentamiento Informal

AÑO DE ORIGEN: 1990

CANT DE FAMILIAS: 268

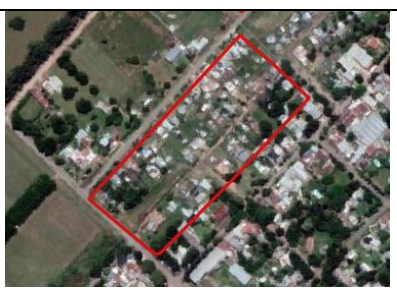

SUPERFICIE: $12.03 \mathrm{hc}$

PARTIDO: La Plata

LOCALIDAD: Romero

NOMBRE OFICIAL: Las Margaritas

TIPOLOGIA: Villa

AÑO DE ORIGEN: 1998

CANT DE FAMILIAS: 60

SUPERFICIE: 3.9 hc
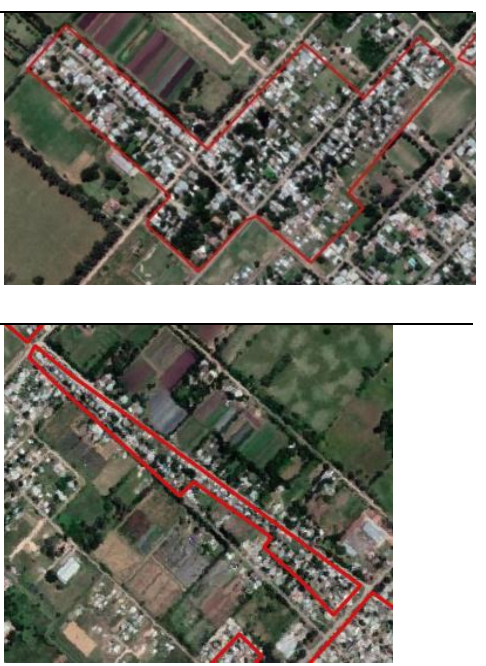

PARTIDO: La Plata

LOCALIDAD: Romero

NOMBRE OFICIAL: 518 \& 162

TIPOLOGIA: Asentamiento Informal

AÑO DE ORIGEN: 2011

CANT DE FAMILIAS: 32

SUPERFICIE: 0.6 hc

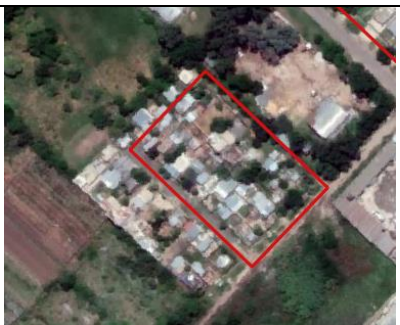


PARTIDO: La Plata

LOCALIDAD: Romero

NOMBRE OFICIAL: Las Rosas

TIPOLOGIA: Asentamiento Informal

AÑO DE ORIGEN: Decada de 1990

CANT DE FAMILIAS: 666

SUPERFICIE: 28.4 hc

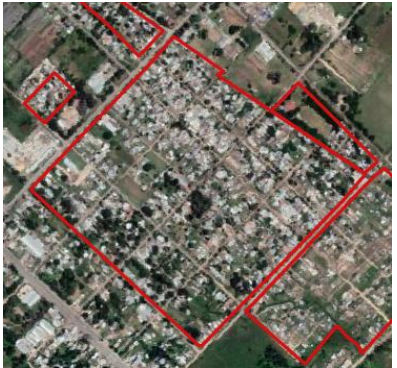

PARTIDO: La Plata

LOCALIDAD: Romero

NOMBRE OFICIAL: Las Rosas CPA

TIPOLOGIA: Asentamiento Informal

AÑO DE ORIGEN: 2012

CANT DE FAMILIAS: 22

SUPERFICIE: 1.7 hc

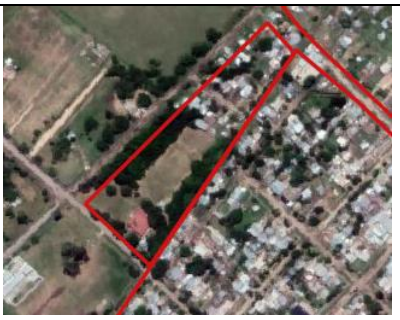

PARTIDO: La Plata

LOCALIDAD: Romero

NOMBRE OFICIAL: Las Rosas II

TIPOLOGIA: Asentamiento Informal

AÑO DE ORIGEN: 2013

CANT DE FAMILIAS: 13

SUPERFICIE: $10.91 \mathrm{hc}$

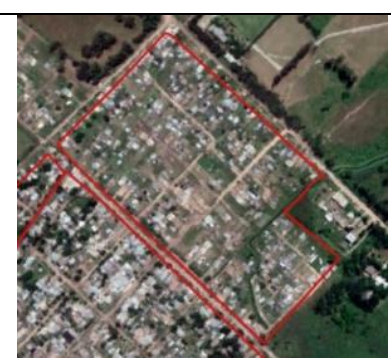

\section{URBANIZACIONES INFORMALES EN LA LOCALIDAD DE ABASTO}

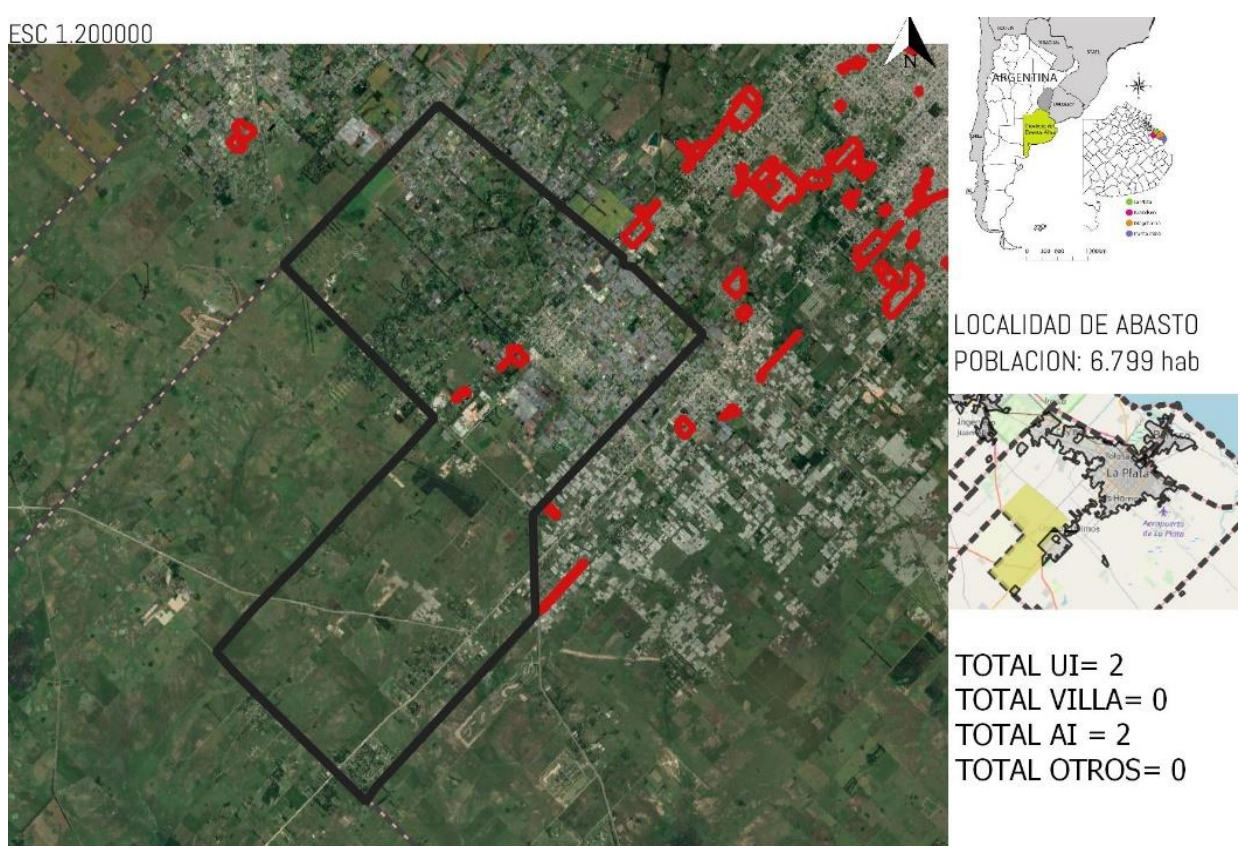


PARTIDO: La Plata

LOCALIDAD: Abasto

NOMBRE OFICIAL: 516 bis \& 220

TIPOLOGIA: Asentamiento Informal

AÑO DE ORIGEN: 2007

CANT DE FAMILIAS: 165

SUPERFICIE: $12.12 \mathrm{hc}$

PARTIDO: La Plata

LOCALIDAD: Abasto

NOMBRE OFICIAL: Villa San Martin

TIPOLOGIA: Asentamiento Informal

AÑO DE ORIGEN: Decada del 2000

CANT DE FAMILIAS: 35

SUPERFICIE: $3.42 \mathrm{hc}$

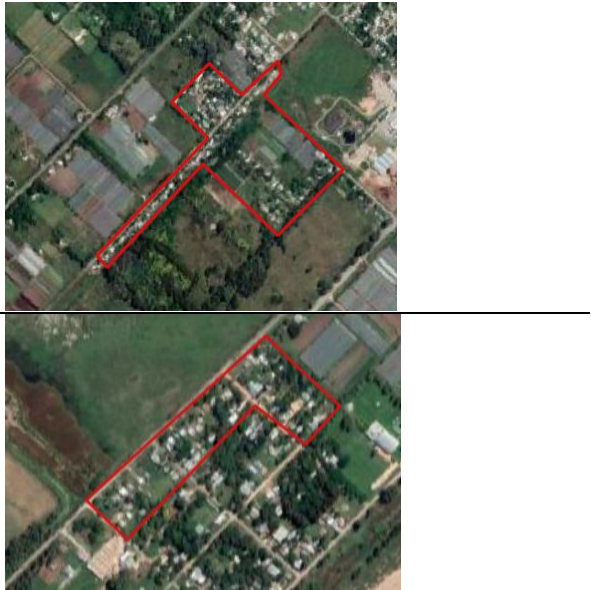

\section{URBANIZACIONES INFORMALES EN LA LOCALIDAD DE EL PELIGRO}

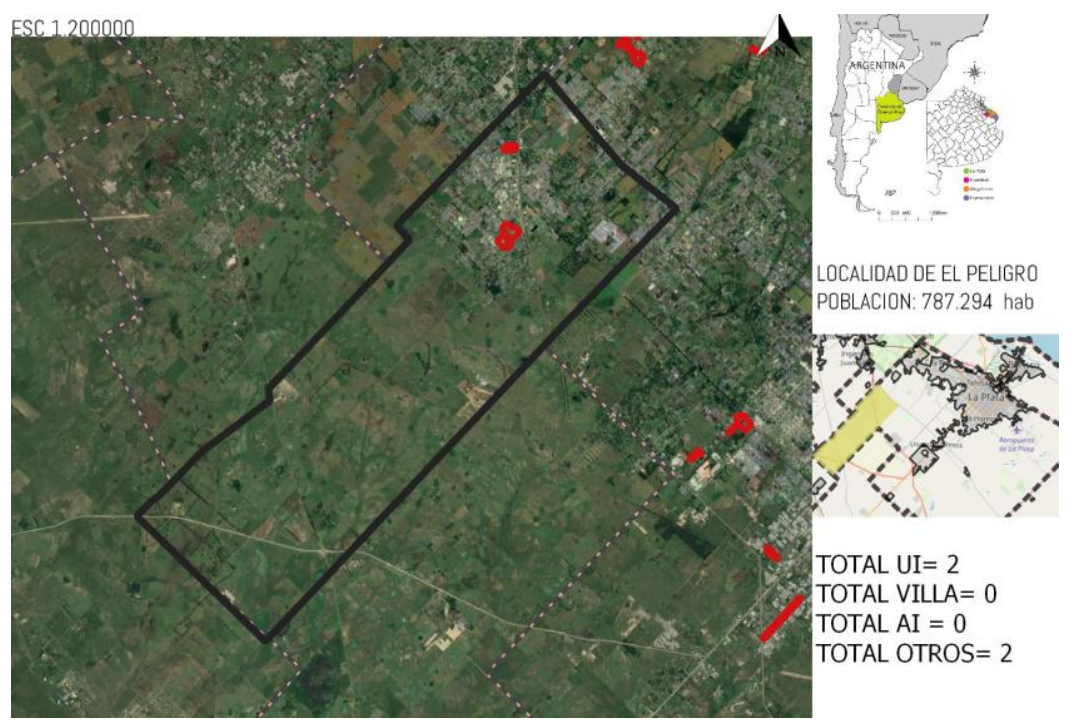

PARTIDO: La Plata

LOCALIDAD: El Peligro

NOMBRE OFICIAL: Martin Fierro

TIPOLOGIA: OtrOS

AÑO DE ORIGEN: Decada del 2000

CANT DE FAMILIAS: 60

SUPERFICIE: 5.38 hc

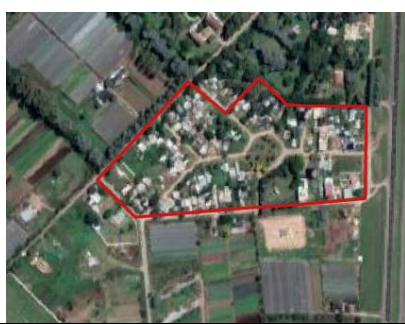

PARTIDO: La Plata

LOCALIDAD: EI Peligro

NOMBRE OFICIAL: Ruta del Sol

TIPOLOGIA: OtrOS

AÑO DE ORIGEN: Decada del 2000

CANT DE FAMILIAS: 200

SUPERFICIE: $21.2 \mathrm{hc}$

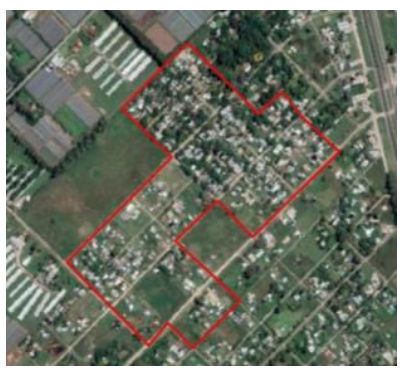




\section{URBANIZACIONES INFORMALES EN LA LOCALIDAD DE ARTURO SEGUI}

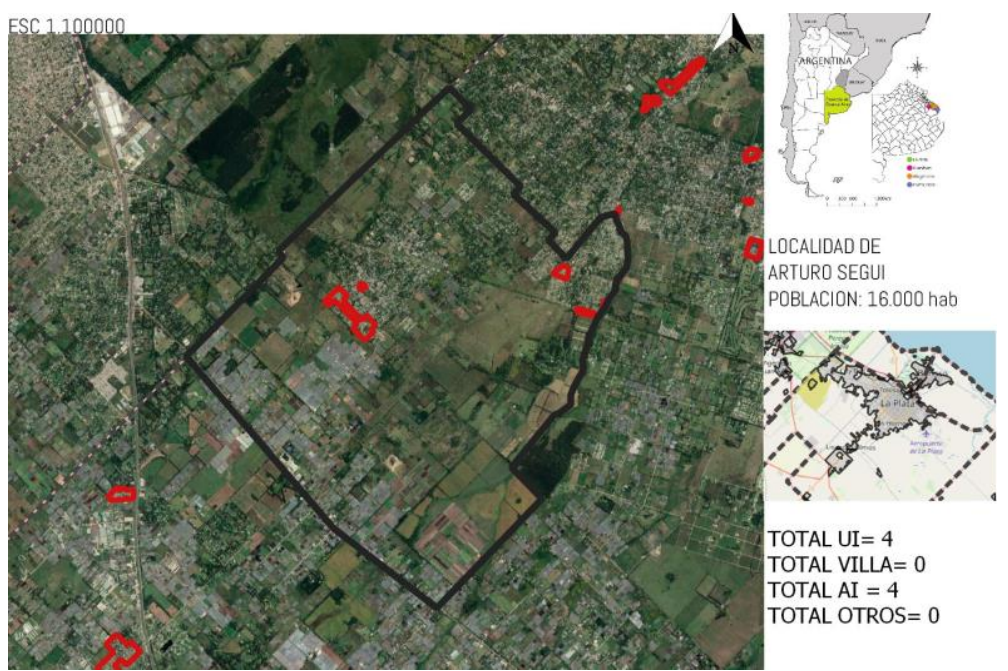

PARTIDO: La Plata

LOCALIDAD: Arturo Seguí

NOMBRE OFICIAL: EI Rincón II

TIPOLOGIA: Asentamiento Informal

AÑO DE ORIGEN: Decada del 2010

CANT DE FAMILIAS: 57

SUPERFICIE: 2.5 hc

PARTIDO: La Plata

LOCALIDAD: Arturo Seguí

NOMBRE OFICIAL: EI Rincón I

TIPOLOGIA: Asentamiento Informal

AÑO DE ORIGEN: 2011

CANT DE FAMILIAS: 58

SUPERFICIE: 2.9 hc

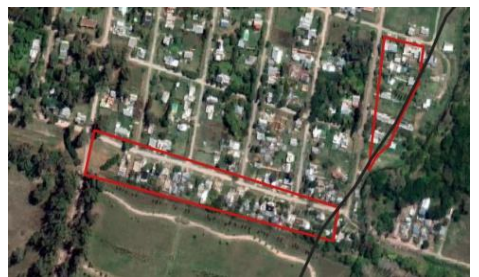

PARTIDO: La Plata

LOCALIDAD: Arturo Seguí

NOMBRE OFICIAL: La Victoria

TIPOLOGIA: Asentamiento Informal

AÑO DE ORIGEN: 1991

CANT DE FAMILIAS: 216

SUPERFICIE: 15 hc
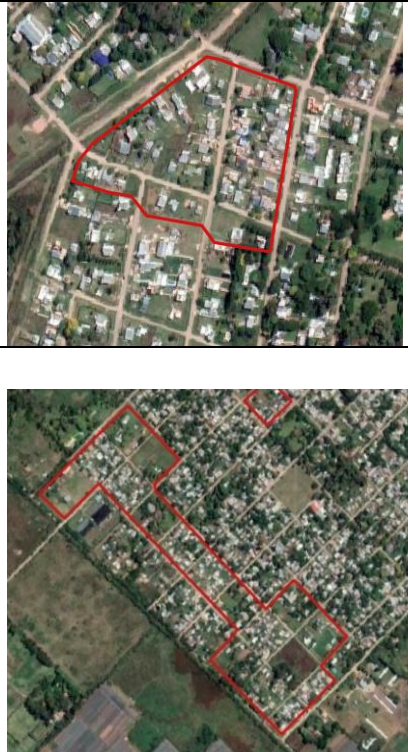

PARTIDO: La Plata

LOCALIDAD: Arturo Seguí

NOMBRE OFICIAL: 154 \& 413

TIPOLOGIA: Asentamiento Informal

AÑO DE ORIGEN: 2013

CANT DE FAMILIAS: 23

SUPERFICIE: 0.7 hc

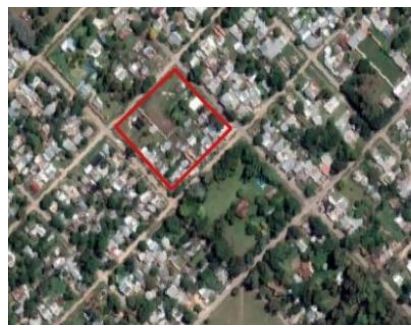

P á g i n a 341 


\section{URBANIZACIONES INFORMALES EN LA LOCALIDAD DE VILLA ELISA}

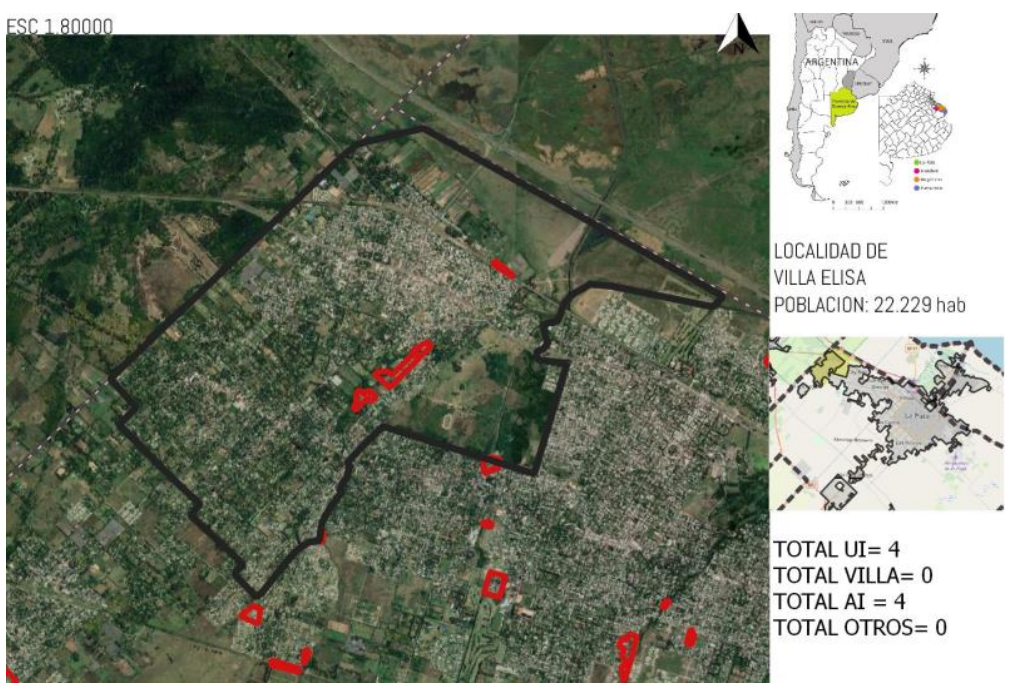

PARTIDO: La Plata

LOCALIDAD: Villa Elisa

NOMBRE OFICIAL: Villa Rica

TIPOLOGIA: Asentamiento Informal

AÑO DE ORIGEN: 2000

CANT DE FAMILIAS: 54

SUPERFICIE: 2.8 hc

\section{PARTIDO: La Plata}

LOCALIDAD: Villa Elisa

NOMBRE OFICIAL: La Fortaleza

TIPOLOGIA: Asentamiento Informal

AÑO DE ORIGEN: 2000

CANT DE FAMILIAS: 146

SUPERFICIE: 5.8 hc

PARTIDO: La Plata

LOCALIDAD: Villa Elisa

NOMBRE OFICIAL: EI Progreso

TIPOLOGIA: Asentamiento Informal

AÑO DE ORIGEN: 2013

CANT DE FAMILIAS: 58

SUPERFICIE: $1.6 \mathrm{hc}$

PARTIDO: La Plata

LOCALIDAD: Villa Elisa

NOMBRE OFICIAL: YPF

TIPOLOGIA: Asentamiento Informal

AÑO DE ORIGEN: 1974

CANT DE FAMILIAS: 38

SUPERFICIE: 0.9 hc
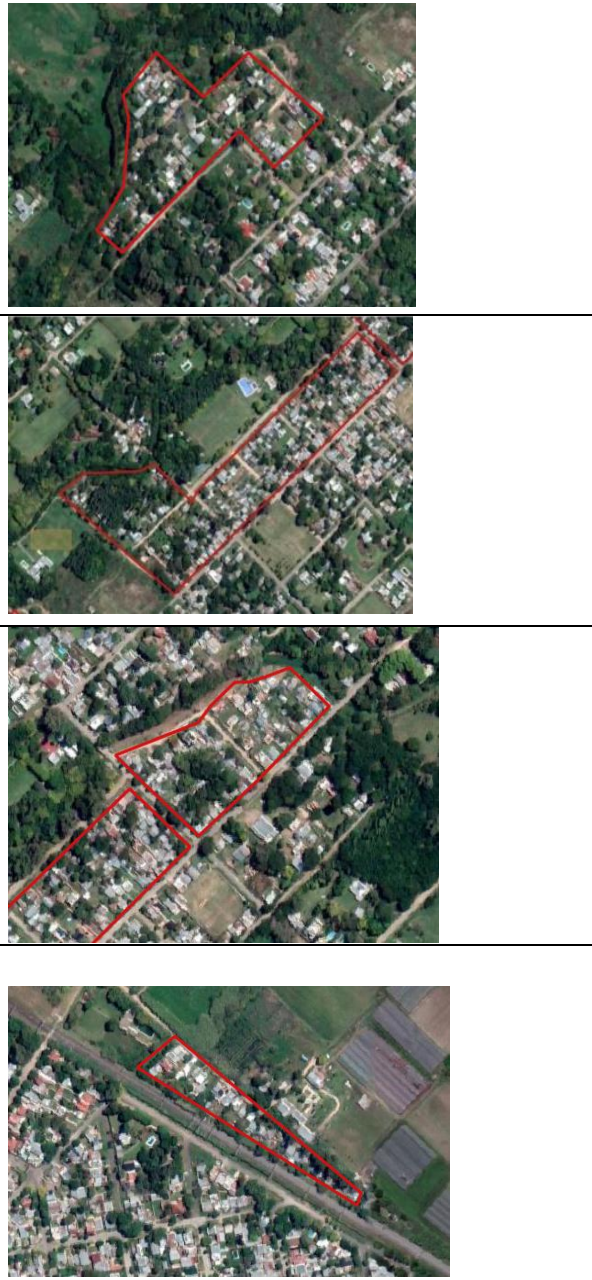


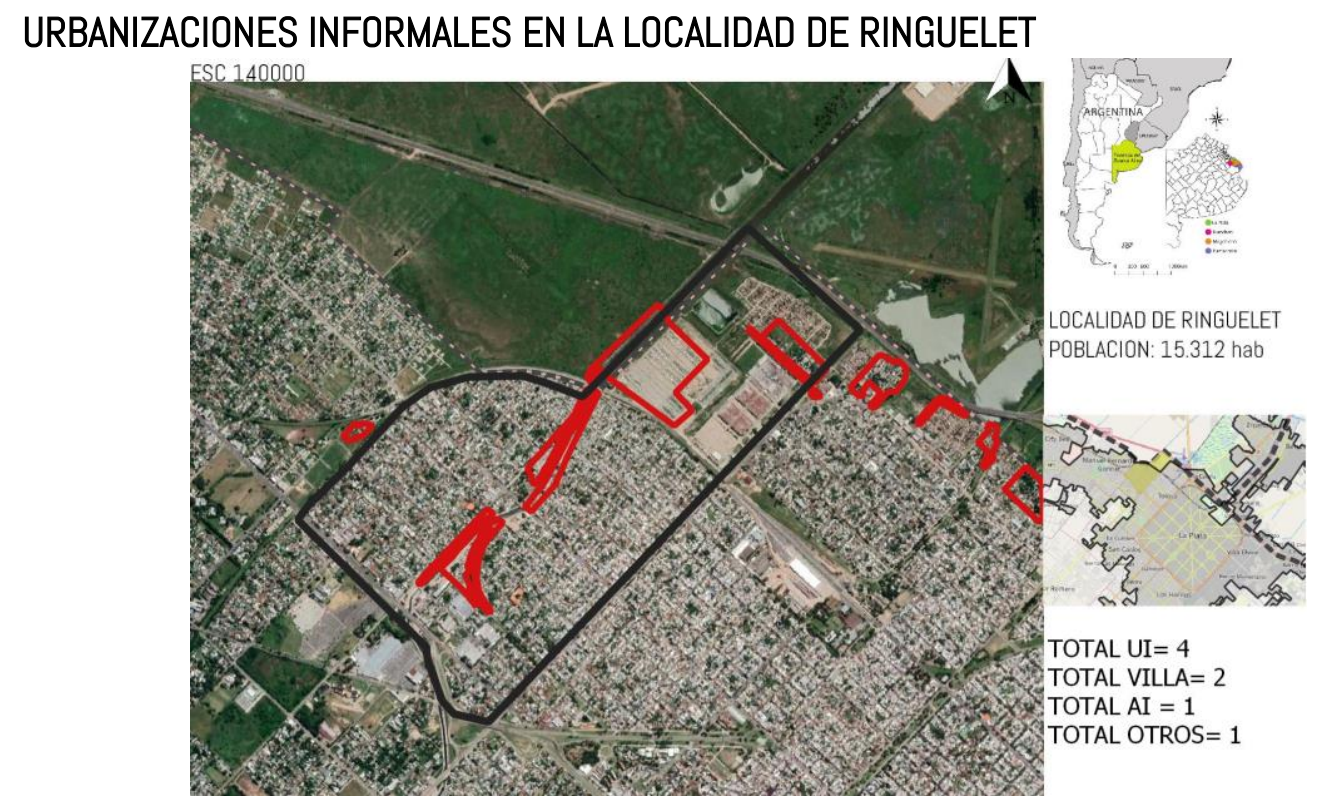

PARTIDO: La Plata

LOCALIDAD: Ringuelet

NOMBRE OFICIAL: EI Gato- Triangulo

TIPOLOGIA: Villa

AÑO DE ORIGEN: 1984

CANT DE FAMILIAS: 160

SUPERFICIE: $5.5 \mathrm{hc}$

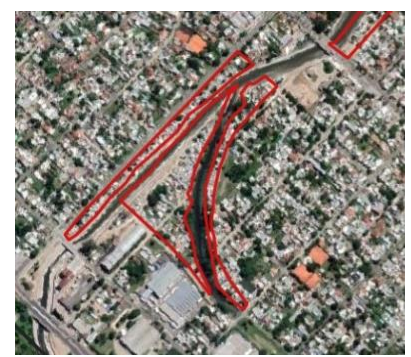

PARTIDO: La Plata

LOCALIDAD: Ringuelet

NOMBRE OFICIAL: EI Gato II

TIPOLOGIA: Villa

AÑO DE ORIGEN: 1984

CANT DE FAMILIAS: 160

SUPERFICIE: $5.3 \mathrm{hc}$

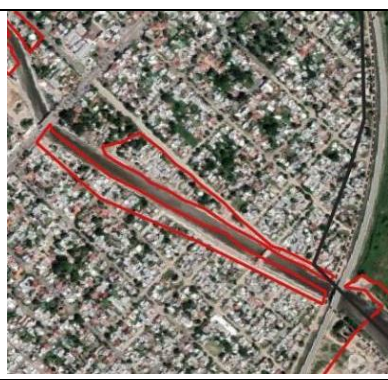

PARTIDO: La Plata

LOCALIDAD: Ringuelet

NOMBRE OFICIAL: Ciudad oculta

TIPOLOGIA: Otros

AÑO DE ORIGEN: 2001

CANT DE FAMILIAS: 48

SUPERFICIE: $19.53 \mathrm{hc}$

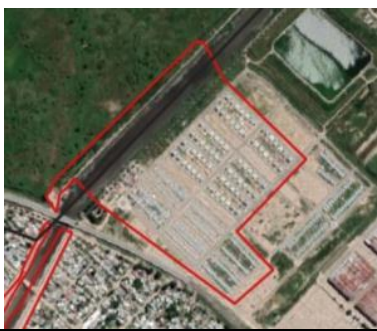

PARTIDO: La Plata

LOCALIDAD: Ringuelet

NOMBRE OFICIAL: El Mercadito

TIPOLOGIA: Asentamiento Informal

AÑO DE ORIGEN: Decada de 1990

CANT DE FAMILIAS: 150

SUPERFICIE: $5.13 \mathrm{hc}$

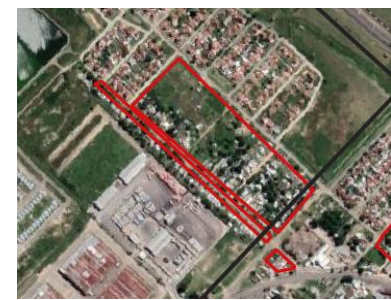




\section{URBANIZACIONES INFORMALES EN LA LOCALIDAD DE TOLOSA}

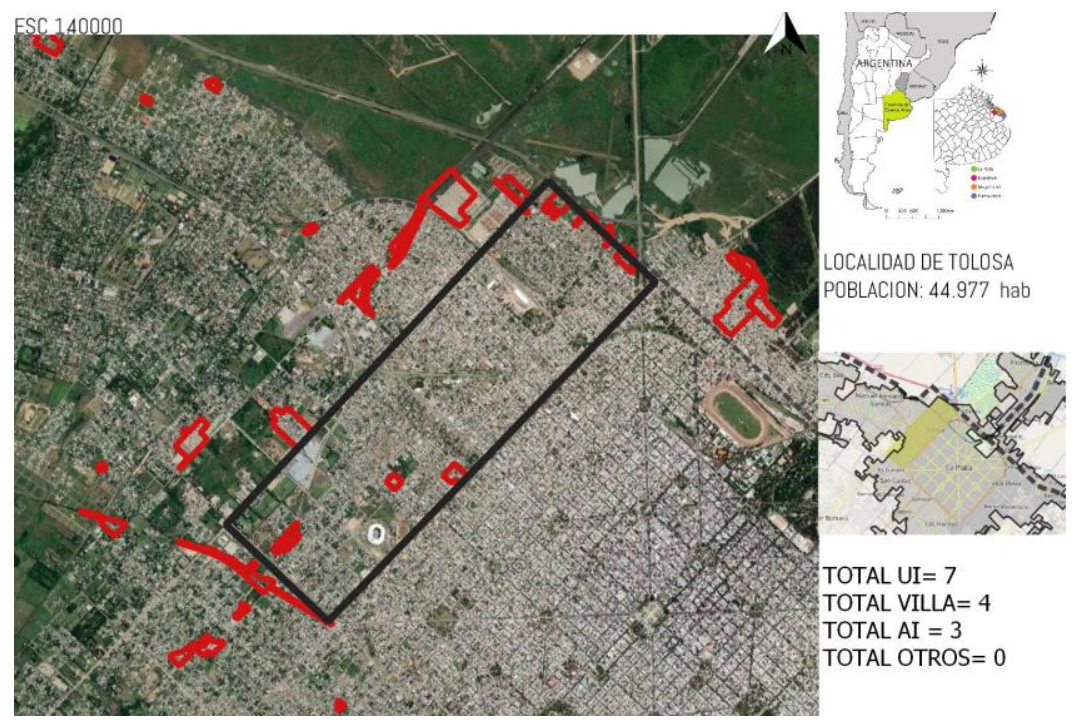

PARTIDO: La Plata

LOCALIDAD: Tolosa

NOMBRE OFICIAL: San Luis

TIPOLOGIA: Asentamiento Informal

AÑO DE ORIGEN: Decada de 1990

CANT DE FAMILIAS: 105

SUPERFICIE: 3.44 hc

PARTIDO: La Plata

LOCALIDAD: Tolosa

NOMBRE OFICIAL: boliviana

TIPOLOGIA: Villa

AÑO DE ORIGEN: Decada de 1980

CANT DE FAMILIAS: 60

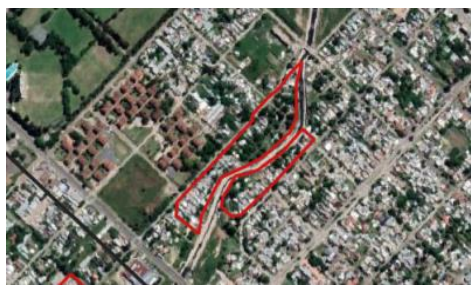

SUPERFICIE: $1.6 \mathrm{hc}$

PARTIDO: La Plata

LOCALIDAD: Tolosa

NOMBRE OFICIAL: La Favelita

TIPOLOGIA: Villa

AÑO DE ORIGEN: 1983

CANT DE FAMILIAS: 122

SUPERFICIE: 3.3 hc

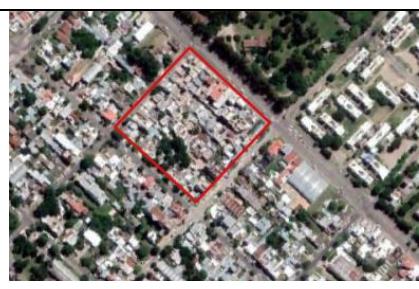

PARTIDO: La Plata

LOCALIDAD: Tolosa

NOMBRE OFICIAL: La Bajada

TIPOLOGIA: Asentamiento Informal

AÑO DE ORIGEN: Decada de 1980

CANT DE FAMILIAS: 106

SUPERFICIE: 3.4 hc
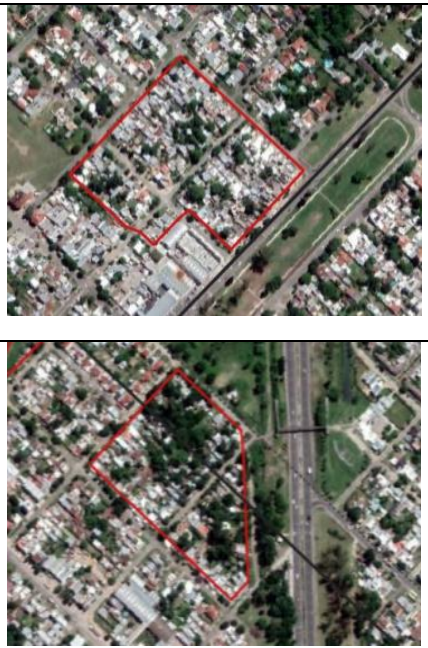
PARTIDO: La Plata

LOCALIDAD: Tolosa

NOMBRE OFICIAL: La Bajada II

TIPOLOGIA: Villa

AÑO DE ORIGEN: 2010

CANT DE FAMILIAS: 27

SUPERFICIE: 1.16 hc

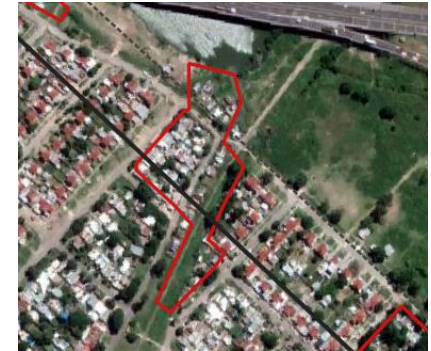

PARTIDO: La Plata

LOCALIDAD: Tolosa

NOMBRE OFICIAL: La Laguna (524)

TIPOLOGIA: Villa

AÑO DE ORIGEN: Decada de 1990

CANT DE FAMILIAS: 24

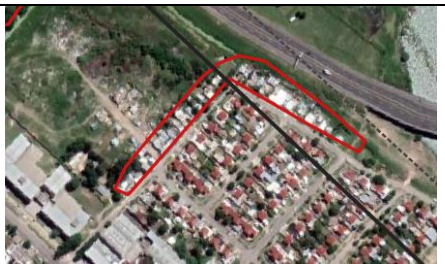

SUPERFICIE: 0.81hc

PARTIDO: La Plata

LOCALIDAD: Tolosa

NOMBRE OFICIAL: La Unión

TIPOLOGIA: Asentamiento Informal

AÑO DE ORIGEN: Decada de 1990

CANT DE FAMILIAS: 131

SUPERFICIE: $4.1 \mathrm{hc}$

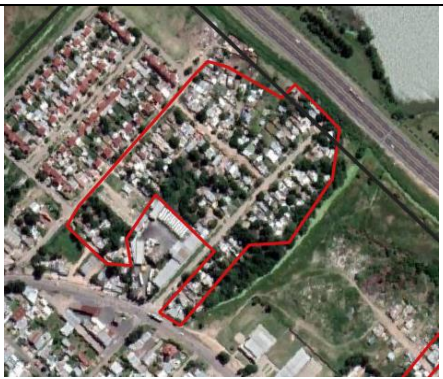

URBANIZACIONES INFORMALES EN LA LOCALIDAD DE HERNANDEZ

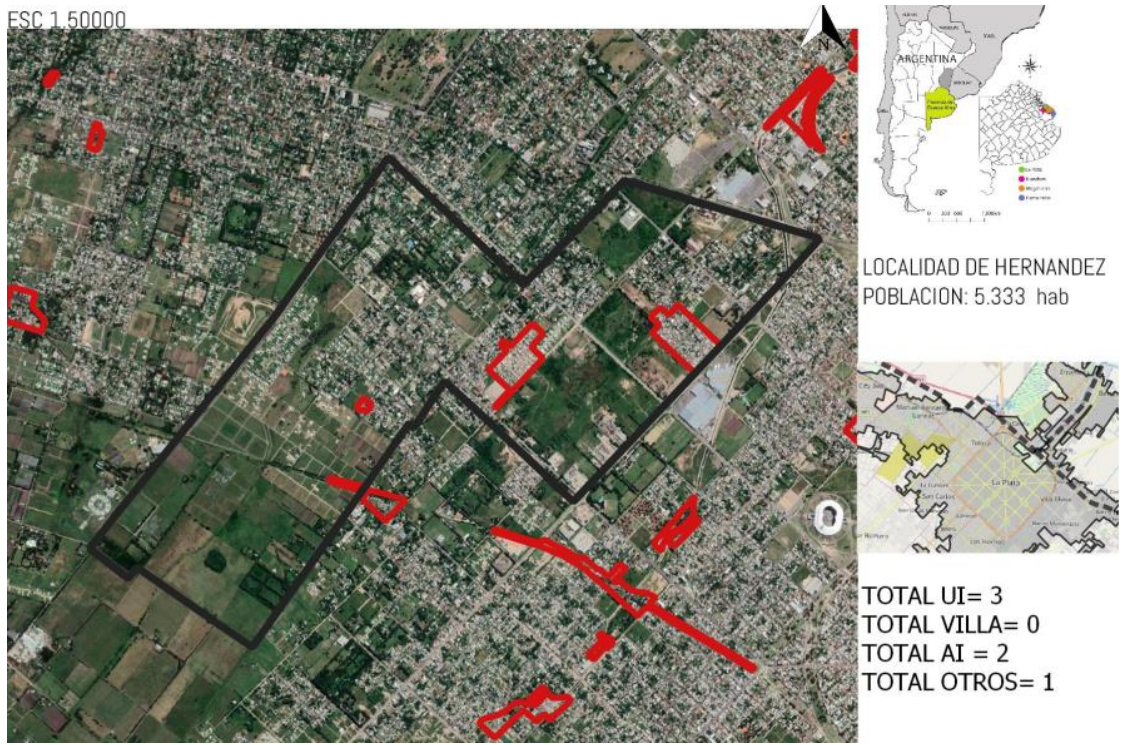

PARTIDO: La Plata

LOCALIDAD: Hernández

NOMBRE OFICIAL: Nini

TIPOLOGIA: Otros

AÑO DE ORIGEN: Decada de 1990

CANT DE FAMILIAS: 348

SUPERFICIE: $11 \mathrm{hc}$

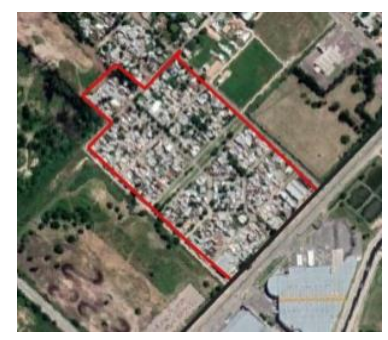


PARTIDO: La Plata

LOCALIDAD: Hernández

NOMBRE OFICIAL: Mercosur

TIPOLOGIA: Asentamiento Informal

AÑO DE ORIGEN: 2002

CANT DE FAMILIAS: 325

SUPERFICIE: 8.39 hc

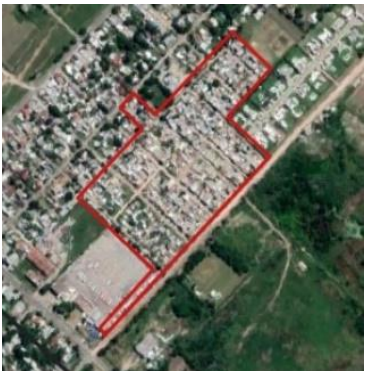

PARTIDO: La Plata

LOCALIDAD: Hernández

NOMBRE OFICIAL: 509 \& 134

TIPOLOGIA: Asentamiento Informal

AÑO DE ORIGEN: 1990 o anterior

CANT DE FAMILIAS: 55

SUPERFICIE: 0.52 hc

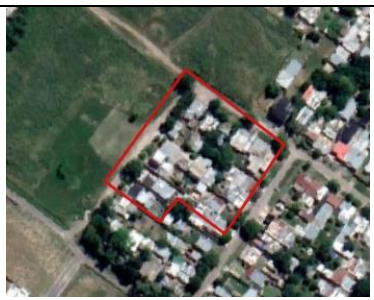

\section{URBANIZACIONES INFORMALES EN LA LOCALIDAD DE CITY BELL}

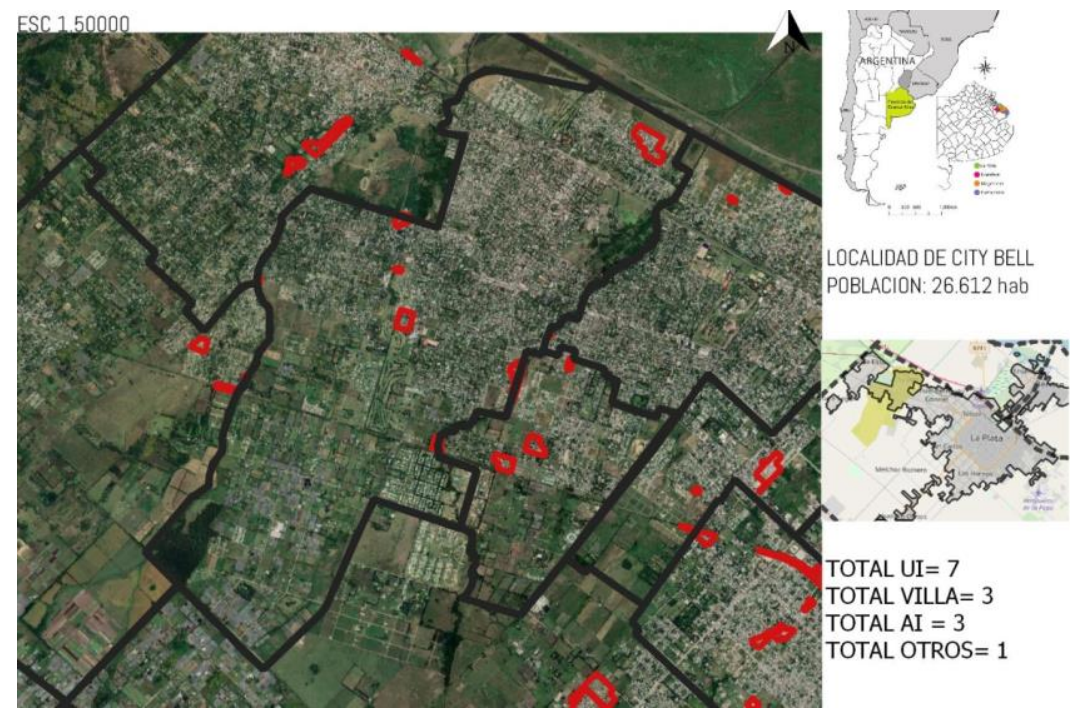

PARTIDO: La Plata

LOCALIDAD: City Bell

NOMBRE OFICIAL: Savoia

TIPOLOGIA: Otros

AÑO DE ORIGEN: 1984

CANT DE FAMILIAS: 321

SUPERFICIE: 7.74 hc

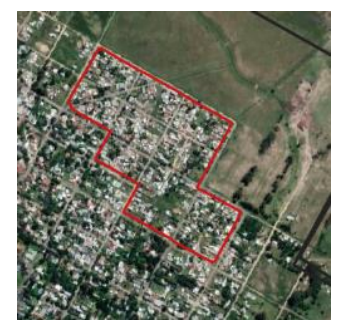

PARTIDO: La Plata

LOCALIDAD: City Bell

NOMBRE OFICIAL: 456 \& 20

TIPOLOGIA: Asentamiento Informal

AÑO DE ORIGEN: Decada de 1990

CANT DE FAMILIAS: 86

SUPERFICIE: 2.63 hc

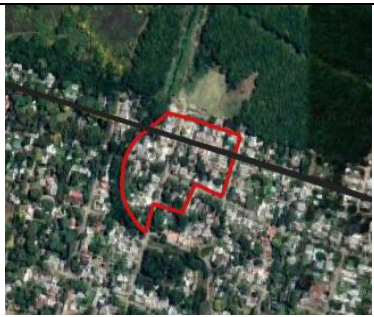


PARTIDO: La Plata

LOCALIDAD: City Bell

NOMBRE OFICIAL: 457 \& 24

TIPOLOGIA: Villa

AÑO DE ORIGEN: 2005

CANT DE FAMILIAS: 6

SUPERFICIE: $0.45 \mathrm{hc}$

PARTIDO: La Plata

LOCALIDAD: City Bell

NOMBRE OFICIAL: El Rincón III

TIPOLOGIA: Asentamiento Informal

AÑO DE ORIGEN: 2013

CANT DE FAMILIAS: 10

SUPERFICIE: $0.33 \mathrm{hc}$

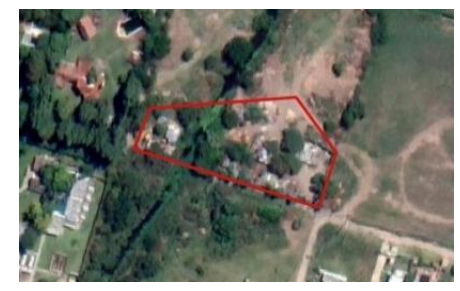

PARTIDO: La Plata

LOCALIDAD: City Bell

NOMBRE OFICIAL: Casaca

TIPOLOGIA: Villa

AÑO DE ORIGEN: 2002

CANT DE FAMILIAS: 20

SUPERFICIE: $3.42 \mathrm{hc}$

PARTIDO: La Plata

LOCALIDAD: City Bell

NOMBRE OFICIAL: Medalla Milagrosa

TIPOLOGIA: Villa

AÑO DE ORIGEN: Decada de 1990

CANT DE FAMILIAS: 135

SUPERFICIE: $3.91 \mathrm{hc}$

PARTIDO: La Plata

LOCALIDAD: City Bell

NOMBRE OFICIAL: EI Country

TIPOLOGIA: Asentamiento Informal

AÑO DE ORIGEN:1974

CANT DE FAMILIAS: 153

SUPERFICIE: 5.12 hc
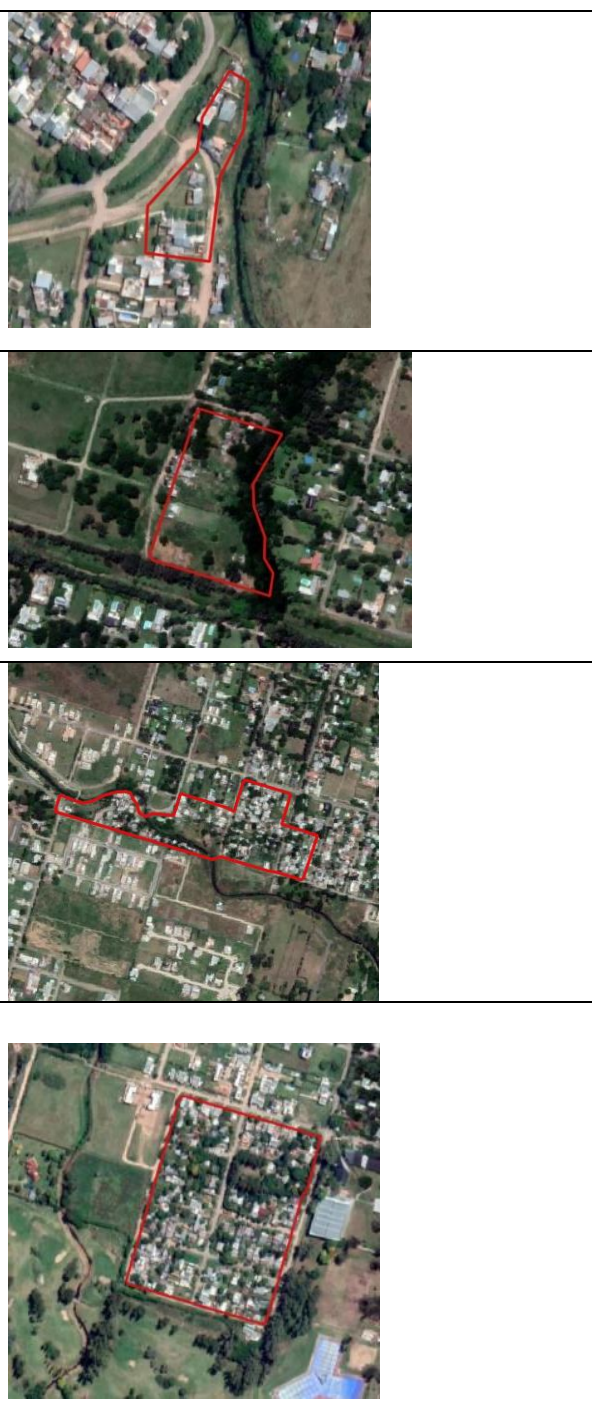


\section{URBANIZACIONES INFORMALES EN LA LOCALIDAD DE GONNET}

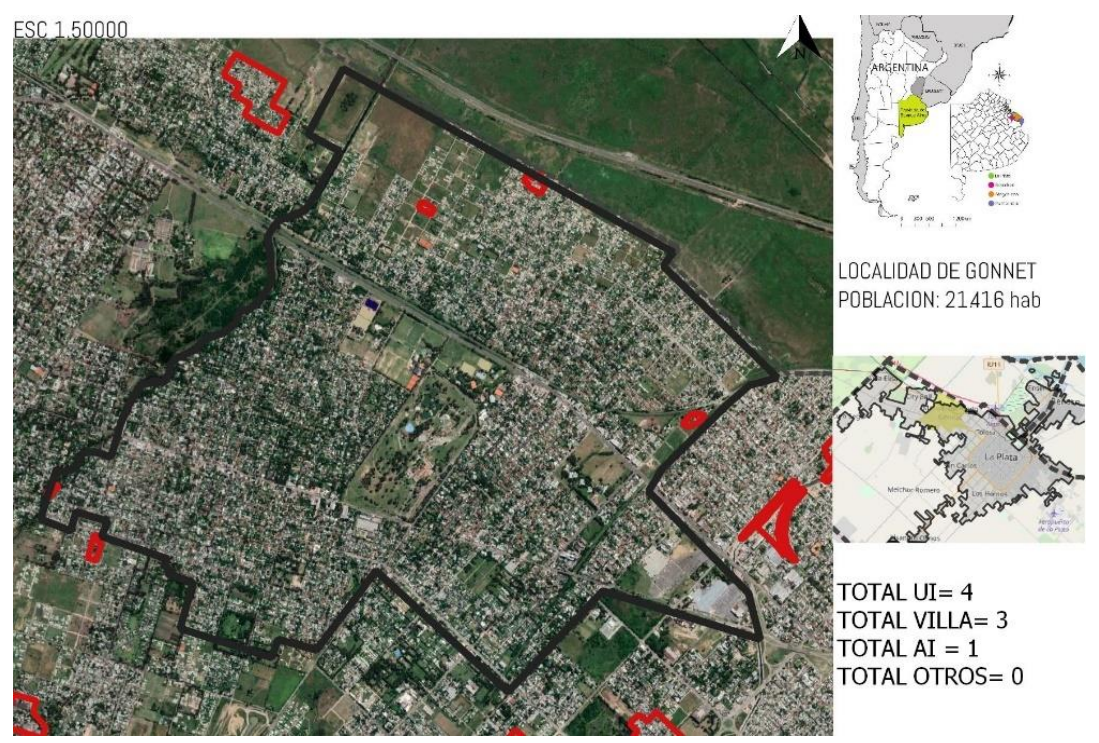

PARTIDO: La Plata

LOCALIDAD: Gonnet

NOMBRE OFICIAL: 508 \& 9

TIPOLOGIA: Villa

AÑO DE ORIGEN: Decada de 1990

CANT DE FAMILIAS: 13

SUPERFICIE: $1.19 \mathrm{hc}$

PARTIDO: La Plata

LOCALIDAD: Gonnet

NOMBRE OFICIAL: 3 \& 495

TIPOLOGIA: Asentamiento Informal

AÑO DE ORIGEN: Decada de 1990

CANT DE FAMILIAS: 44

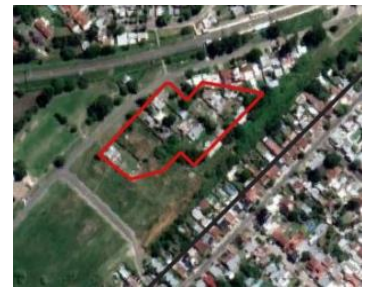

SUPERFICIE: $1.1 \mathrm{hc}$

PARTIDO: La Plata

LOCALIDAD: Gonnet

NOMBRE OFICIAL: 8 \& 489

TIPOLOGIA: Villa

AÑO DE ORIGEN:1980

CANT DE FAMILIAS: 33

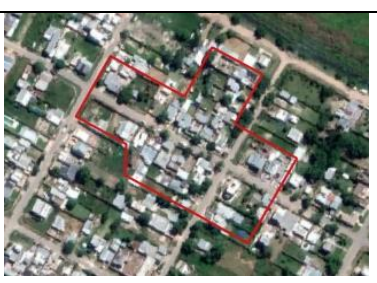

SUPERFICIE: $0.51 \mathrm{hc}$

PARTIDO: La Plata

LOCALIDAD: Gonnet

NOMBRE OFICIAL: La Güemes

TIPOLOGIA: Villa

AÑO DE ORIGEN:1980

CANT DE FAMILIAS: 20

SUPERFICIE: 0.34 hc
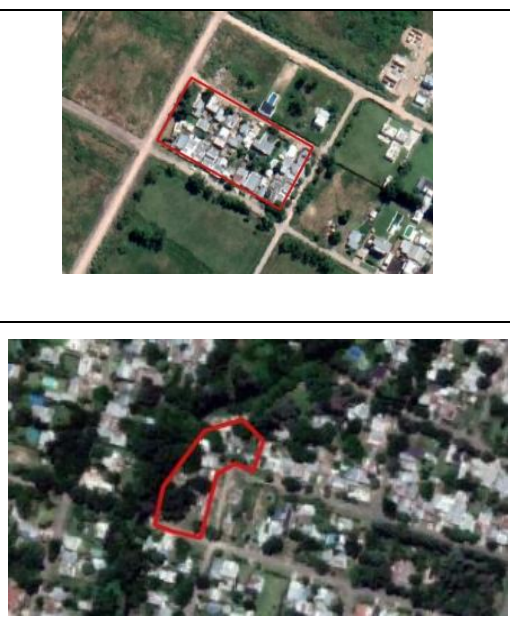


\section{URBANIZACIONES INFORMALES EN LA LOCALIDAD DE GORINA}

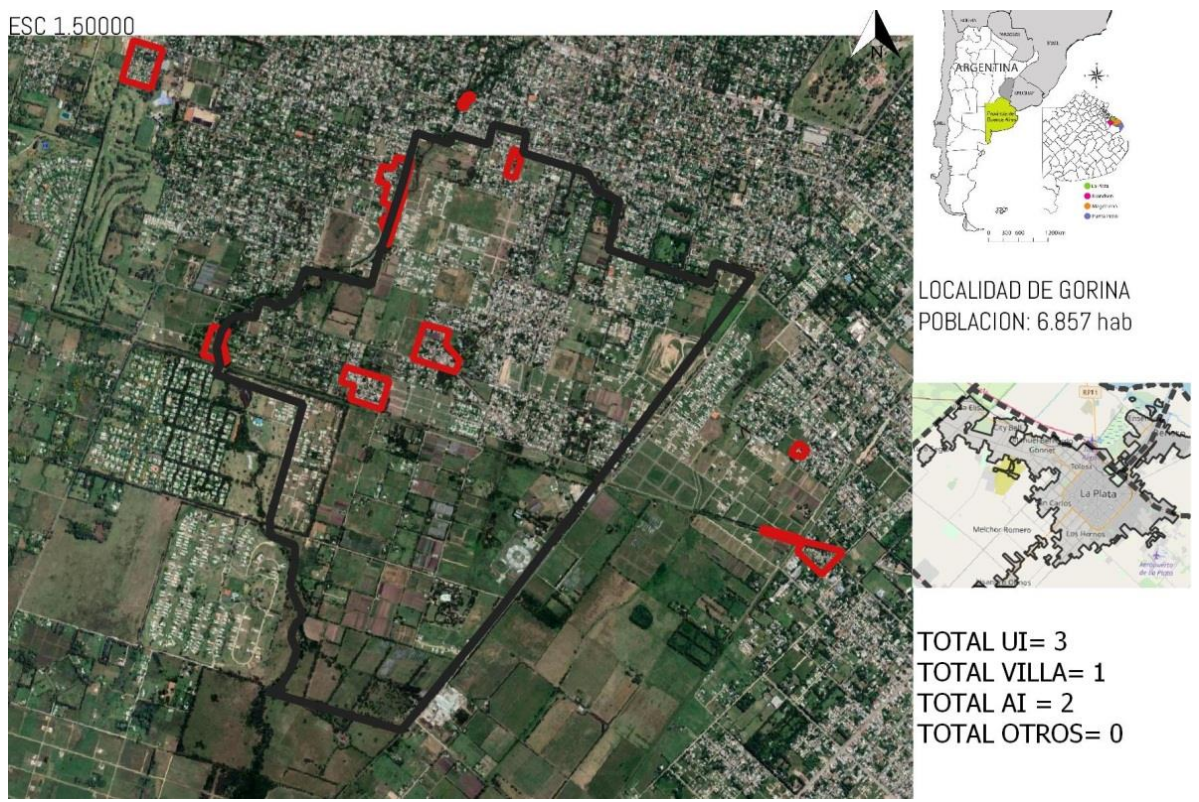

PARTIDO: La Plata

LOCALIDAD: Gorina

NOMBRE OFICIAL: Colinas del Sol

TIPOLOGIA: Asentamiento Informal

AÑO DE ORIGEN: 2000

CANT DE FAMILIAS: 137

SUPERFICIE: $4.68 \mathrm{hc}$

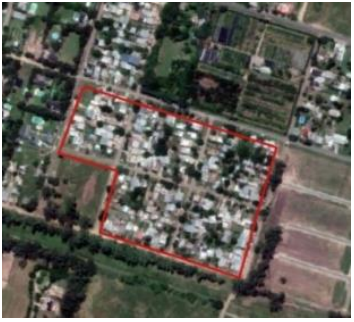

PARTIDO: La Plata

LOCALIDAD: Gorina

NOMBRE OFICIAL: La Fabrica

TIPOLOGIA: Villa

AÑO DE ORIGEN:1994

CANT DE FAMILIAS: 182

SUPERFICIE: 5.27 hc

PARTIDO: La Plata

LOCALIDAD: Gorina

NOMBRE OFICIAL: 28 bis y 482

TIPOLOGIA: Asentamiento Informal

AÑO DE ORIGEN:1987

CANT DE FAMILIAS: 24

SUPERFICIE: 1 hc
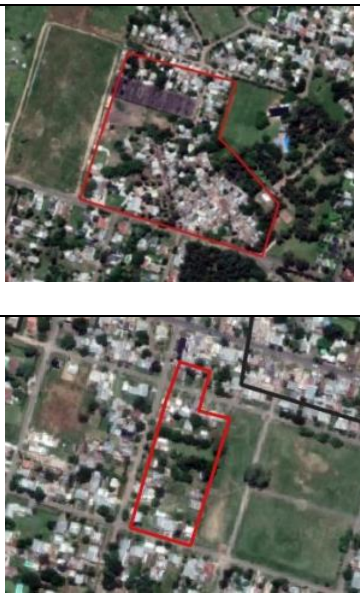


\section{URBANIZACIONES INFORMALES EN LA LOCALIDAD DE ETCHEVERRY}

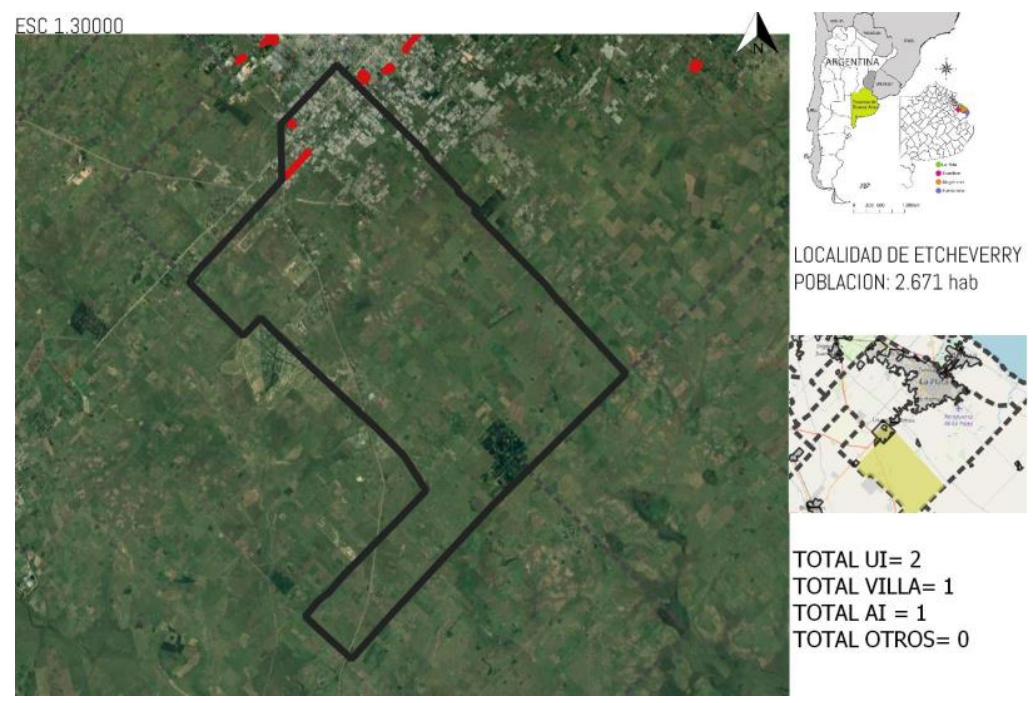

PARTIDO: La Plata

LOCALIDAD: Etcheverry

NOMBRE OFICIAL: Ferroviario

TIPOLOGIA: Villa

AÑO DE ORIGEN:2010

CANT DE FAMILIAS: 133

SUPERFICIE: 11.6 hc

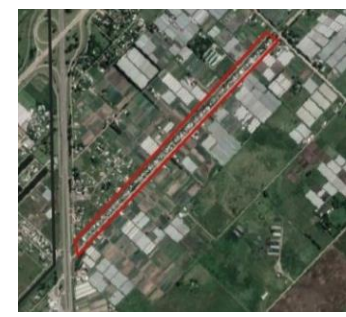

PARTIDO: La Plata

LOCALIDAD: Etcheverry

NOMBRE OFICIAL: 236 \& 41

TIPOLOGIA: Asentamiento Informal

AÑO DE ORIGEN:2005

CANT DE FAMILIAS: 50

SUPERFICIE: 4.3 hc

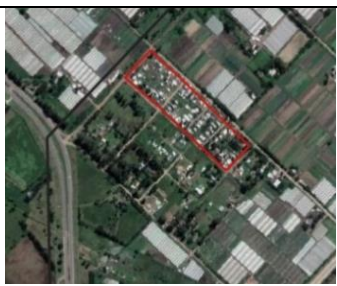

